Florida International University FIU Digital Commons

$1-5-2008$

\title{
Investigating the origin of PM2.5 in Baltimore using highly time-resolved organic molecular markers measured during the Baltimore PM-supersite
}

Anna R. Bernardo-Bricker

Florida International University

DOI: $10.25148 /$ etd.FI14051123

Follow this and additional works at: https://digitalcommons.fiu.edu/etd

Part of the Civil Engineering Commons

\section{Recommended Citation}

Bernardo-Bricker, Anna R., "Investigating the origin of PM2.5 in Baltimore using highly time-resolved organic molecular markers measured during the Baltimore PM-supersite" (2008). FIU Electronic Theses and Dissertations. 1652.

https://digitalcommons.fiu.edu/etd/1652 
FLORIDA INTERNATIONAL UNIVERSITY

Miami, Florida

INVESTIGATING THE ORIGIN OF PM2.5 IN BALTIMORE

USING HIGHLY TIME-RESOLVED ORGANIC MOLECULAR MARKERS

MEASURED DURING THE BALTIMORE PM-SUPERSITE

A dissertation submitted in partial fulfillment of the

requirements for the degree of

DOCTOR OF PHILOSOPHY

in

CIVIL ENGINEERING

by

Anna R. Bernardo-Bricker 
To: Interim Dean Amir Mirmiran

College of Engineering and Computing

This dissertation, written by Anna R. Bernardo-Bricker, and entitled Investigating the Origin of PM 2.5 in Baltimore using Highly Time-Resolved Organic Molecular Markers Measured during the Baltimore PM-Supersite, having been approved in respect to style and intellectual content, is referred to you for judgment.

We have read this dissertation and recommend that it be approved.

Berrin l'ansel

Fernando Miralles-Wilhelm

Wolfgang W. Rogge, Major Professor

Date of Defense: June 5, 2008

The dissertation of Anna R. Bernardo-Bricker is approved.

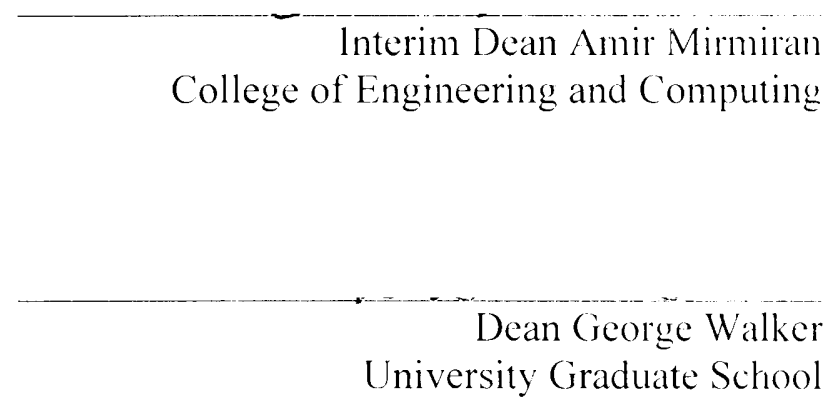

Florida International University. 2008 
(C) Copyright 2008 by Anna R. Bernardo-Bricker All rights reserved. 


\section{DEDICATION}

To my parents Grazia and Simone Bernardo, in memoriam 


\section{ACKNOWLEDGMENTS}

First of all, I would like to express my earnest gratitude to my advisor, Dr. Wolfgang F. Rogge. This work would not be possible without his generous support. I most sincerely thank him for the great opportunity he has given me to participate in two significant research endeavors such as the Pittsburg Air Quality Study and the Baltimore PM-Supersite. I am also thankful for allowing me through the last six years ample space to both learn and develop my capabilities as a research scientist, for always challenging me to do my best. I am thankful for his guidance, mentorship, hands-on help in the lab, and useful discussions throughout my doctoral studies.

I thankfully acknowledge the contribution from the many individuals who were involved in the field sampling campaigns. To Dr. John Ondov and David Harrison from the University of Maryland, for managing the collection of hundreds of samples of ambient fine particles at the Baltimore-PM supersite from May 2002 to February 2003. Dr. Allen Robinson and Dr. R. Subramanian from Carnegie Mellon University conducted the sampling in the Squirrel Hill Tunnel in Pittsburgh, PA in November 2002. These samples were analyzed and investigated as part of the research presented here. I am also thankful to Andrew Grieshop (Andy) from Carnegie Mellon for kindly answering and clarifying all sorts of sampling related questions for nearly four years.

I appreciate the help of Dr. Orhan Sevimoglu. During his years as a graduate student in our lab, Orhan committed many long days to helping prepare the sampling media and to extract the hundreds of samples. 
I am grateful to my committee members, Dr. Berrin Tansel, Dr. Fernando Miralles-Wilhelm, and Dr. Rudolf Jaffe for dedicating their time to serve on my thesis committee and for their helpful suggestions.

I wish to thank Dr. Amir Mirmiran for his assistance in securing much needed financial help through Teaching Assistantships that supported me from 2004 to 2006. Thanks also to Dr. Berrin Tansel and Dr. Hector Fuentes for taking the time to write letters of recommendation in thoughtful support of my application for the Dissertation Year Fellowship. It would have been hardly possible for me to complete the Ph.D program without the generous financial support provided by Florida International University through the Dissertation Year Fellowship.

I wish to thank my family. My husband Ken and my children Rebecca and George provided the unconditional love and unwavering encouragement to support me in many ways along these arduous years to accomplish my goal.

I would like to thankfully acknowledge the funding sources that supported the research projects. The Baltimore supersite was supported by the United States Environmental Protection Agency through cooperative agreement number R-82806301. The Squirrel Hill Tunnel study was conducted as part of the Pittsburgh Air Quality Study, which was supported by US Environmental Protection Agency under contract R82806101 and the US Department of Energy National Energy Technology Laboratory under contract DE-FC26-01NT41017. 
ABSTRACT OF THE DISSERTATION

INVESTIGATING THE ORIGIN OF PM2.5 IN BALTIMORE

USING HIGHLY TIME-RESOLVED ORGANIC MOLECULAR MARKERS

MEASURED DURING THE BALTIMORE PM-SUPERSITE

by

Anna R. Bernardo-Bricker

Florida International University, 2008

Miami, Florida

Professor Wolfgang F. Rogge, Major Professor

The detailed organic composition of atmospheric fine particles with an aerodynamic diameter smaller than or equal to 2.5 micrometers (PM 2.5) is an integral part of the knowledge needed in order to fully characterize its sources and transformation in the environment. For the study presented here, samples were collected at 3-hour intervals. This high time resolution allows gaining unique insights on the influence of short- and long-range transport phenomena, and dynamic atmospheric processes. A specially designed sequential sampler was deployed at the 2002-2003 Baltimore PMSupersite to collect PM2.5 samples at a 3-hourly resolution for extended periods of consecutive days, during both summer and winter seasons. Established solvent-extraction and GC-MS techniques were used to extract and analyze the organic compounds in 119 samples from each season. Over 100 individual compounds were quantified in each sample. For primary organics, averaging the diurnal ambient concentrations over the sampled periods revealed ambient patterns that relate to diurnal emission patterns of major source classes. Several short-term releases of pollutants from local sources were 
detected, and local meteorological data was used to pinpoint possible source regions. Biogenic secondary organic compounds were detected as well, and possible mechanisms of formation were evaluated. The relationships between the observed continuous variations of the concentrations of selected organic markers and both the on-site meteorological measurements conducted parallel to the PM2.5 sampling, and the synoptic patterns of weather and wind conditions were also examined. Several one-to-two days episodes were identified from the sequential variation of the concentration observed for specific marker compounds and markers ratios. The influence of the meteorological events on the concentrations of the organic compounds during selected episodes was discussed. It was observed that during the summer, under conditions of pervasive influence of air masses originated from the west/northwest, some organic species displayed characteristics consistent with the measured PM2.5 being strongly influenced by the aged nature of these long-traveling background parcels. During the winter, intrusions from more regional air masses originating from the south and the southwest were more important. 
1.1 Background on Analytical Measurements for Characterization of Organic Compounds in Fine Particles

Scope of the Dissertation 5

References

EMISSION FACTORS OF ORGANIC COMPOUNDS IN PM2.5

FROM HEAVY DUTY DIESEL AND LIGHT-DUTY GASOLINE VEHICLES DERIVED FROM MEASUREMENTS IN THE SQUIRREL HILL TUNNEL, PITTSBURGH, PA

Introduction

Sampling Procedure 22

Sampling Media Preparation, and Samples Storage and Transportation Procedures

Fossil Fuel and Lubricating Oil Markers ....................................... 32

Particle Bound Combustion Products: Organic Acids and Polycyclic Aromatic Hydrocarbons ….................................. 34

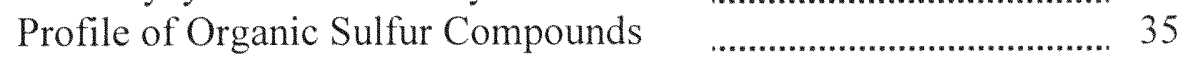

Tire Wear Marker: Benzothiazole _.................................................. 44

Emission Profiles for Heavy-duty Diesel and

Light-duty Gasoline Vehicles......

Comparison to Results from Other Studies …….................................. 50

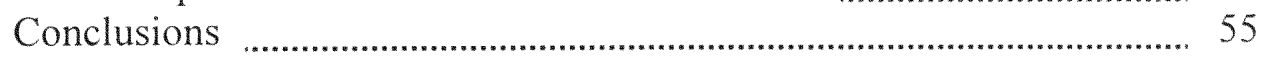

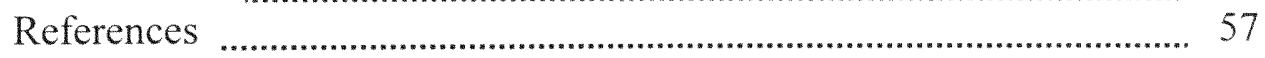

THREE-HOURLY AND SUMMER/WINTER VARIATIONS

IN ATMOSPHERIC CONCENTRATIONS OF ORGANIC COMPOUNDS IN PM2.5 MEASURED DURING THE

BALTIMORE PM-SUPERSITE 

INFLUENCING PM2.5 IN BALTIMORE IDENTIFIED FROM HIGHLY TIME-RESOLVED

ORGANIC CHARACTERIZATION DATA ….................................... 146

Sample Extraction and Gas Chromatography/Mass Spectrometry (GC/MS) Analysis Procedures

Distribution Pattern of n-Alkanes with Predominance of even-over-odd Homologues 
Biomass Burning, 20-21 July, and Associated Long-range Influence Association of the Variations of in the Minimum Daily Levels of Organic Compounds and the Origin of Transported Air

Parcels

4.3.4.3 Association of the Variations in the Daily Cycles of Biogenic Secondary Reaction Products and the Origin and Characteristics of the Background Air

4.4 Conclusions 
TABLE

1.1 Urban Sources of Fine Particulate Matter that have been Characterized for Organic Compounds

2.1 Traffic and Chemical Information during the three Sampling Periods Conducted in the Squirrel Hill Tunnel

2.2 Organic Profiles $(\mu \mathrm{g} / \mathrm{kg}$ fuel) for LDVs and HDDVs Derived from Measurements in the Squirrel Hill Tunnel

3.1 Correlation Parameters, $\mathrm{R}^{2}$, slope and intercept, for the Linear Fitting of the three-hourly Concentrations of Sum of particle-phase PAHs vs Hopanes for each summer and winter sampling day

4.1 Correlation Parameters, $\mathrm{R}^{2}$, slope and intercept, for the Linear Fitting of the three-hourly Concentrations of Nopinone vs Relative Humidity for each summer and winter sampling day 


\section{LIST OF FIGURES}

FIGURE

PAGE

1.1 Geographical distribution of areas in the United States that exceed the National Ambient Air Quaility Standard (NAAQS) for PM 2.5. Areas indicated exceeded the 1997 standards with designated 2001-2003 data

2.1 Scatter plots of the emission factors of organic compounds measured in individual samples (y-axis) vs. the global average emission factor from all Squirrel Hill Tunnel samples ( $\mathrm{x}$-axis)

2.2 Bar graphs comparing the emission factors of three organic sulfur compounds with selected target species displaying similar emission trends: dibenzothiophene and sum of PAHs from phenanthrene to pyrene $(a, b)$, 4-methyldibenzothiophene and sum of n-alkylcyclohexanes C17 - C20 (c,d), benzo[b]naphtho[2,1-d]thiophene and sum of PAHs from benzo[b]fluorene to coronene $(\mathrm{g}, \mathrm{h})$. Also compared, pattern of the sum of n-alkylcyclohexanes $\mathrm{C} 21-\mathrm{C} 25$ and sum of hopanes $(\mathrm{e}, \mathrm{f})$

2.3 Scatter plots of the emission factors of organic sulfur compounds vs. the HDDV fuel fraction

2.4 Scatter plots of the emission factors of 4-methyldibenzothiophene vs. those of individual n-alkylcyclohexanes measured in the Squirrel Hill Tunnel

2.5 Total traffic volume and corresponding emission factors of benzothiazole measured in the Squirrel Hill Tunnel

2.6 Comparison of the emission factors of organic compounds associated to PM2.5 measured in several tunnel studies in the U.S. reporting a similarly comprehensive characterization: Squirrel Hill Tunnel, PA, Washburn Tunnel, TX, Van Nuys Tunnel, CA, and Caldecott Tunnel, CA

2.7 Emission factors of selected species measured in this study as a function of the fuel-fraction of HDDVs. Best-fit linear regression line is shown. Comparison to emission factors reported in the literature for dynamometer experiments and fleet segregated calculations from measurements conducted in the Caldecott Tunnel

3.1 Time series of the summer and winter three-hourly concentrations of PM2.5 mass ( $\mathrm{a}, \mathrm{c}$ ) and the bulk chemical properties elemental carbon, $\mathrm{EC}$, and organic carbon, OC (b, d) 
3.2 Three-hourly variations of the concentrations of selected groups of n-alkanes during summer and winter, respectively: sum of n-alkanes (C19-C25) $(a, b)$, and sum of odd n-alkanes $(\mathrm{C} 27, \mathrm{C} 29, \mathrm{C} 31, \mathrm{C} 33, \mathrm{C} 35)(\mathrm{c}, \mathrm{d})$

3.3 Time series of the distribution of the seven most abundant $n$-alkanoic acids in three-hourly ambient samples from the summer (a) and winter (b) sampling campaigns

3.4 Three-hourly summer and winter diurnal variations of the concentrations of $\mathrm{n}$-hexadecanoic acid (C16, palmitic) (a, b), and n-octadecanoic acid (C18, stearic acid) (c, d)

3.5 Three-hourly diurnal variations of the sum of the concentrations of high molecular weight even n-alkanoic acids (C24,C26,C28,C30,C32) during summer (a, b) and winter (c)

3.6 Scatter plots of the three-hourly concentrations of the unsaturated n-alkenoic acid palmitoleic (C16:1), oleic (C18:1) and linoleic acid (C18:2).

Best-fit line and linear correlation factor are shown

3.7 Three-hourly summer and winter diurnal variations of the concentrations of unsaturated fatty acids: cis-9-hexadecenoic acid (C16:1, palmitoleic, a, b), cis-9-octadecenoic acid (C18:1, oleic, c, d) and, cis,cis-9,12-octadecadienoic acid $(\mathrm{C} 18: 2$, linoleic, $\mathrm{e}, \mathrm{f})$

3.8 Time-series of the three-hourly ratios of unsaturated:saturated fatty acids concentrations during summer and winter, respectively: oleic:stearic $(\mathrm{C} 18: 1$ to $\mathrm{C} 18, \mathrm{~b}, \mathrm{e})$, palmitoleic:palmitic $(\mathrm{C} 16: 1$ to $\mathrm{C} 16: 0, \mathrm{c}, \mathrm{f})$, and corresponding solar radiation data $(a, d)$

3.9 Three-hourly summer and winter diurnal variations of the sum of the concentrations of the n-alkylcyclohexanes homologues C19-C25 (a,b), and the sum of hopanes $(\mathrm{c}, \mathrm{d})$

3.10 Scatter plots of the three-hourly concentrations of the fossil fuel derived n-alkanes (sum of homologues C19 to C25), n-alkylcyclohexanes (sum of homologues $\mathrm{C} 22$ to $\mathrm{C} 25$ ) and hopanes. Best-fit line and linear correlation factor are shown

3.11 Time series of the three-hourly abundances of $17 \alpha(\mathrm{H}) 21 \beta(\mathrm{H}) 22,29,30$ trisnorhopane, $17 \alpha(\mathrm{H}) 21 \beta(\mathrm{H})$-29-norhopane, $17 \alpha(\mathrm{H}) 21 \beta(\mathrm{H})$-hopane relative to the total sum of hopanes, for the winter (b) and summer (c) data. The abundance of these species in the six samples from the Squirrel Hill Tunnel is shown in (a) 
3.12 Time series of the winter three-hourly concentrations of levoglucosan (b) and of the ambient temperature (a)

3.13 Three-hourly summer and winter variations of the concentrations of markers of wood burning: levoglucosan (a, b), dehydroabietic acid (c, d), and syringaldehyde $(e, f)$. Episodic days excluded from graphs: 24-25-November and 20-21-July

3.14 Time-series of the summer and winter three-hourly concentrations of dehydroabietic acid (DAA a, c) and of the ratio of concentrations of dehydroabieric acid: levoglucosan (DAA/Levo b, d)

3.15 Time-series of the summer and winter three-hourly contributions of emissions from wood burning to ambient organic carbon (OC). Calculations based on the use of levoglucosan as organic molecular source tracer

3.16 Three-hourly summer and winter diurnal variations of the concentrations of oxy-PAHs: 9,10-anthracenedione (anthraquinone: a, b), 7H-benz[de]anthracen7-one (benzanthrone: c, d), and benz[a]anthracene-7,12-dione (benzo[a]anthracenedione: $\mathrm{e}, \mathrm{f}$ )

3.17 Time-series of the summer and winter three-hourly contributions of emissions from natural gas burning appliances to ambient organic carbon (OC). Calculations based on the use of benzo[a]anthracenedione as molecular source tracer

3.18 Three-hourly summer and winter diurnal variations of the concentrations of low-molecular-weight PAHs: anthracene $(a, b)$, fluoranthene $(c, d)$ and pyrene $(\mathrm{e}, \mathrm{f})$

3.19 Three-hourly summer and winter diurnal variations of the concentrations of high-molecular-weight PAHs: sum of chrysene and triphenylene $(a, b)$, benzo[a]pyrene $(\mathrm{c}, \mathrm{d})$ and sum of the particle phase PAHs from benzo[b]fluoranthene to coronene $(\mathrm{e}, \mathrm{f})$

3.20 Time-series of the three-hourly concentration ratios of anthracene:fluoranthene ([Anth]:[Fluo]) and benzo[a]pyrene:benzo[b]pyrene ([BaP]:[BeP]) during summer (a) and winter (b)

3.21 Three-hourly summer and winter diurnal variations of the concentrations of selected aliphatic- and aromatic-dicarboxylic acids. Summer data presented as line plot for individual days (a-i); Winter data presented as vertical points plots with overlaid boxplots $(\mathrm{j}-\mathrm{m})$ 
3.22 Three-hourly summer and winter diurnal variations of the concentrations of phytone and nopinone

3.23 Scatter plots showing the associations of the daily averaged concentrations of nopinone vs. those of nitrogen oxide $\left(\mathrm{NO}_{2}\right)(\mathrm{a}, \mathrm{c})$ and ozone $\left(\mathrm{O}_{3}\right)(\mathrm{b}, \mathrm{d})$ in summer and winter, respectively

3.24 Three-hourly summer (a) and winter (b) diurnal variations of the concentrations of norpinonic acid

3.25 Scatter plots showing the associations of the daily averaged concentrations of cis-pinonic acid vs, those of nitrogen oxide $\left(\mathrm{NO}_{2}\right)\left(\mathrm{a}, \mathrm{c}\right.$, ) and ozone $\left(\mathrm{O}_{3}\right)$ $(b, d)$ in summer and winter, respectively. The slope of the trend shown is given

3.26 Three-hourly summer (a) and winter (b) diurnal variations of the concentrations of cholesterol

3.27 Time-series of the summer and winter three-hourly contributions of emissions from meat cooking operations to ambient organic carbon (OC). Calculations based on the use cholesterol as molecular source tracer

3.28 Three-hourly summer (a) and winter (b) diurnal variations of the concentrations of $\beta$-sitosterol

3.29 Three-hourly summer (a) and winter (b) diurnal variations of the concentrations of tobacco smoke branched n-alkanes markers. Sum of iso-C31, antiso-C32 and iso-C33

4.1 Map of Baltimore showing the location of the sampling site. In circles, the largest concentrations of general manufacturing areas: near the site, Canton; to the south, Curtis Bay

4.2 Three-hourly averages of temperature, relative humidity and wind speed measured throughout the summer $(\mathrm{a}-\mathrm{c})$ and winter $(\mathrm{d}-\mathrm{f})$ campaigns at the Ponca Street sampling site during the Baltimore-PM Supersite 2002-2003. Averages were composed from 5-min data

4.3 Diagram summarizing the evolving geographical regimes of background air throughout the days of the summer sampling campaign, according to backward air mass trajectories performed using the NOAAS's Hysplit software 
4.4 Diagram summarizing the evolving geographical regimes of background air throughout the days of the winter sampling campaign, according to backward air mass trajectories performed using the NOAAS's Hysplit software

4.5 Map of the U.S. northeastern region and the Great Lakes showing sketches of the central path of the various regimes of air masses arriving at the Ponca Street sampling site, according to backward trajectories calculations performed using the NOAA's Hysplit software

4.6 Distribution of n-alkanes in sample 21:00 8-August 2002 and wind direction/speed frequency for this time period

4.7 Time-series of the three-hourly concentrations of selected molecular markers for burning of plastic materials in waste incinerators and open-burning conditions, and ratio of even to odd high molecular weight n-alkanes (range $\mathrm{C} 26-\mathrm{C} 33$ ) in summer $(\mathrm{a}, \mathrm{b})$ and winter $(\mathrm{c}, \mathrm{d})$ samples

4.8 Time-series of the three-hourly summer (c) and winter ( $\mathrm{f}$ ) concentrations of tris(2,4-di-tertbutylphenyl)phosphate (tbPO4), a molecular markers for open burning of plastic materials and corresponding wind speed $(a, d)$ and direction $(b, e)$

4.9 Distribution of n-alkanes in three different samples: 18:00 25-November and 00:00 26-November 2002, and 06:00 23-February 2003. Wind direction/speed frequency for each sample is shown

4.10 Time-series of the 3-hourly concentrations of the vehicular biomarker, Sum of Hopanes, and of NOx and NO measured in summer $(a, b)$ and winter $(\mathrm{c}, \mathrm{d})$ samples. Wind direction/speed frequency plots for the samples marked with a number are given in Figure 4.11. Expanded analysis of sample marked with $(*)$ is given in Figure 4.12

4.11 Wind direction/speed frequency plots for selected samples marked in Figure 4.10. The wind speed scale and calm winds projection applies to all frequency plots. Numbers (1) through (6) refer to numbers in Figure 4.10

4.12 Three-hourly concentrations of the petroleum biomarkers, Sum of hopanes, and of the gas species NOx and NO. Expanded section from Figure 4.10 asterisk $\left(^{*}\right)$, showing from 21:00 19-November to 21:00 21-November. Wind direction/speed frequency plots shown for 20-November samples starting at 03:00 and 06:00 
4.13 Three-hourly concentrations of biomass burning organic markers compounds measured in the PM2.5 sampled on 6-August 2002

4.14 Three-hourly concentrations of biogenic-derived organic high molecular weight n-alkanes (b) and n-alkanoic acids (d), terrestrial plant biomarker $\alpha$-amyrin and plant steroid $\beta$-sitosterol (b) measured in the PM2.5 sampled on 6-August 2002. Three-hourly wind distributions of 5-min wind speed measurements for that day shown in (a)

4.15 Three-hourly concentrations of n-alkenoic acids (a-c) abundant in the fine particles emitted from cooking operations, and of the animal sterol cholesterol (d), a marker for meat cooking, measured in the PM2.5 sampled on 6-August 2002

4.16 Three-hourly concentrations of the petroleum biomarkers, hopanes (b) and the sum of particle-phase-PAHs (c) measured in the PM2.5 sampled on 6-August 2002. Also shown is the pattern of vehicular flow calculated from the counts at the Baltimore Harbour Tunnel toll plaza for that day (a), and the wind direction/speed frequency plot for the day

4.17 Three-hourly concentrations of anthropogenic n-alkanes (b) and n-alkanoic acids (c) measured in the PM2.5 sampled on 6-August 2002. Also shown, 3-hourly averages of PM 2.5 mass (a) averaged from 30-min measurements for this day

4.18 Three-hourly concentrations of aliphatic and aromatic dicarboxylic acids (butanedioic (succinic, a), pentanedioic (glutaric, b), hexanedioic (adipic, c), 1,2-benzenedicarboxylic (phthalic, d), 1,4-benzenedicarboxylic (terephthalic, e), and 4-methyl-1,2 benzenedicarboxylic (4-methylphthalic, f), and of secondary oxidation products measured in the PM2.5 sampled on 6-August 2002

4.19 Three-hourly concentrations of wood burning markers levoglucosan (a) and syringaldehyde (b), the plant sterol $\beta$-sitosterol and the pentacyclic triterpenic terrestrial plant biomarker $\alpha$-amyrin (c), measured in the PM2.5 sampled on 24- and 25-November 2002

4.20 Three-hourly concentrations of unsaturated n-alkenoic acids (C16:1, C18:1, C18:2) and n-octadecanoic acid (stearic, c) measured in the PM2.5 sampled on 24- and 25-November 2002

4.21 Three-hourly concentrations of selected markers of anthropogenic activity measured in the PM2.5 sampled on 24- and 25-November 2002 
4.22 Three-hourly concentrations of n-alkanoic acids in the ranges $\mathrm{C} 10-\mathrm{C} 20$ and $\mathrm{C} 21-\mathrm{C} 32$ measured in the PM2.5 sampled on 24- and 25-November 2002

4.23 Scatter plots of the three-hourly concentrations of PAHs

(Sum from benzo[b]fluoranthene to coronene) vs. (a) levoglucosan,

(b) the low-molecular weight n-alkanoic acids (C10-C20),

(c) the high-molecular weight n-alkanoic acids (C21-32), measured in the PM2.5 sampled on 24- and 25-November 2002

4.24 Time series of the three-hourly concentrations of levoglucosan (a) and the aliphatic dicarboxylic acids butanedioic (succinic, b), pentanedioic (glutaric, c), hexanedioic (adipic, d), and nonanedioic (azelaic, e) measured in the PM2.5 sampled during November 2002

4.25 Time series of the three-hourly concentrations of levoglucosan (a) and the aromatic dicarboxylic acids acids 1,2-benzenedicarboxylic (phthalic, b), 1,4-benzenedicarboxylic (terephthalic, c), and 1,3-benzenedicarboxylic (isophthalic, d) measured in the PM2.5 sampled during November 2002 .....

4.26 Time series of the three-hourly concentrations of levoglucosan (a) and the secondary biogenic reaction products nopinone (b), norpinonic acid (c), cis-pinonic acid (d) measured in the PM2.5 sampled during November 2002

4.27 Time series of the three-hourly winter and summer concentrations of reactive gases nitrogen oxides (NOx: a, d) and ozone (b, e) and of the secondary biogenic reaction product cis-pinonic acid $(\mathrm{c}, \mathrm{f})$

4.28 Three-hourly concentrations of organic markers of biomass burning measured in the PM2.5 sampled on 20- and 21-July 2002

4.29 Three-hourly concentrations of biogenic-derived organic high molecular weight n-alkanes (a) and n-alkanoic acids (b), and plant steroid $\beta$-sitosterol (c) measured in the PM2.5 sampled on 20- and 21-July 2002

4.30 Time series of the three-hourly concentrations of the wood burning marker levoglucosan and of the fraction of even alkanoic acids to odd n-alkanes calculated as [Sum n-alkanoic acids (C24, C26, C28, C30, C32)]/ [Sum n-alkanes (C27, C29, C31, C33, C35)]

4.31 Concentration distributions patterns of n-Alkanoic acids (C13 to $\mathrm{C} 32$ ): a) most frequently observed pattern, shown as average of samples from 09:00 19-July to 03:00 20-July, and b) uncharacteristic pattern observed from 06:00 20-July until 21:00 22-July 
4.32 Emission factors distribution patterns of n-Alkanoic acids (C13 to C32) reported in the literature for various prescribed and simulated open burning of biomass. MHFF, mixed hardwood forest foliage litter; FPSP, Florida palmetto/slash pine; WGLP, wiregrass/longleaf pine

4.33 Hysplit trajectories map (a) and calculated intrusion diagram (b) of the trajectory labeled \#1 followed in the individual runs of four consecutive days (from 19 to 22 July)

4.34 Three-hourly concentrations of organic compounds abundant in the particle-phase emissions form cooking operations, cis,cis-9,12-octadecadienoic acid (linoleic acid, a), 9-hexadecenoic acid (palmitoleic, b), and cis-9-octadecenoic acid (oleic, c), and the animal sterol cholesterol (d), measured in the PM2.5 sampled on 20- and 21-July 2002

4.35 Three-hourly concentrations of select organic markers of fossil fuel, n-alkanes (a), and n-alkylcyclohexanes (b), the petroleum biomarkers hopanes (c), and the combustion-derived particle-phase PAHs (d), measured in the PM2.5 sampled on 20- and 21-July 2002 at the Ponca Street site during the Baltimore PM-Supersite

4.36 Time series of the three-hourly concentrations of levoglucosan (a) and the aliphatic dicarboxylic acids butanedioic (succinic, b), pentanedioic (glutaric, c), hexanedioic (adipic, d), and nonanedioic (azelaic, e) measured in the PM2.5 sampled during July and August 2002

4.37 Time series of the three-hourly concentrations of levoglucosan (a) and the aromatic dicarboxylic acids 1,2-benzenedicarboxylic (phthalic, b), 1,4-benzenedicarboxylic (terephthalic, c), and 1,3-benzenedicarboxylic (isophthalic, d) measured in the PM2.5 sampled during July and August 2002

4.38 Diagram of the evolving geographical regimes of background air throughout the days of the summer sampling campaign (a), the 3-hourly concentrations of PM 2.5 mass (b), and the daily minimum concentration (background level) OC-basis of selected organic molecular markers (c-e)

4.39 Time-series of the three-hourly ratios of the n-alkylcyclohexanes ([nonadecylcyclohexane] $+[$ eicosylcyclohexane])/([heptadecylcyclohexane] + [octadecylcyclohexane]) during summer (a) and winter (b)

4.40 Diagram of the evolving geographical regimes of background air throughout the November sampling days (a), the 3-hourly concentrations of PM 2.5 mass (b), and the daily minimum concentration (background level) OC-basis of selected organic molecular markers (c-e) 
4.41 Daily minimum concentration on a OC-basis (daily-MIN) of selected biogenic (a) and anthropogenic (b, c) organic molecular markers during the summer 2002 sampling campaign

4.42 Time series of the three-hourly summer (a) and winter (b) concentrations of nopinone and relative humidity

4.43 Scatter plots showing the associations of the daily averaged concentrations of nopinone vs, those of ozone $\left(\mathrm{O}_{3}\right)(\mathrm{a}, \mathrm{c})$ and the ambient relative humidity $(b, d)$ in summer and winter, respectively

4.44 Diagram of the evolving geographical regimes of background air throughout the winter sampling campaign (a), the three-hourly ratio benzo[a]pyrene/benzo[e]pyrene (b), and concentrations of nopinone (c) and cis-pinonic acid (d)

4.45 Back-trajectories of air parcels ending at the Ponca Street sampling site on 9-November and 14-November at 05:00 UTC. Computed using the NOAA-Hysplit model

4.46 Diagram of the evolving geographical regimes of background air throughout the summer sampling campaign (a), the three-hourly concentrations of ozone $\left(\mathrm{O}_{3}, b\right)$, and the secondary biogenic reaction products nopinone (c) and cis-pinonic acid (d)

4.47 Time series of the three-hourly summer (a) and winter (c) concentrations of levoglucosan and the corresponding three-hourly ratios of [cis-pinonic acid]/[nopinone] 


\section{CHAPTER 1}

\section{INTRODUCTION}

Fine airborne particulate matter with an aerodynamic diameter smaller than $2.5 \mu \mathrm{m}$ (PM2.5) has long been recognized as an important contributor to problems of regional haze (e.g., Eldering and Cass, 1996); moreover, based on a review of the scientific evidence on its risks to human health (e.g., HEI, 1995) the U.S. Environmental Protection Agency (EPA) revised the National Ambient Air Quality Standard (NAAQS) to include, beginning in 1997, a standard for PM2.5 in addition to the existing standard for PM10.

Airborne particulate matter, also known as aerosol matter, is a complex mixture of inorganic and organic constituents. These particles are emitted directly from a number of primary biogenic and anthropogenic sources, and it can also be formed in the atmosphere via atmospheric reactions that produce so called secondary organic aerosol (SOA). The composition of PM2.5 includes a large number of inorganic and organic species. Major chemical components of airborne particles include sulfates, nitrates, ammonium, sodium chloride, minerals, soot or black carbon, and organic matter. The organic fraction is highly complex in itself. It is estimated that the organic fraction can contain thousands of individual compounds, often at very low concentrations which makes their quantification a challenging effort. Consequently, even today, at best only $10-20 \%$ of the detailed nature of the organic mass is typically reported. Yet, detailed organic characterization of ambient PM2.5 provides information which is essential to the understanding of its emission sources, health effects, and the atmospheric dynamics and chemical transformations involving its components. Ultimately, this understanding is expected to support the development of suitable strategies for its control. 


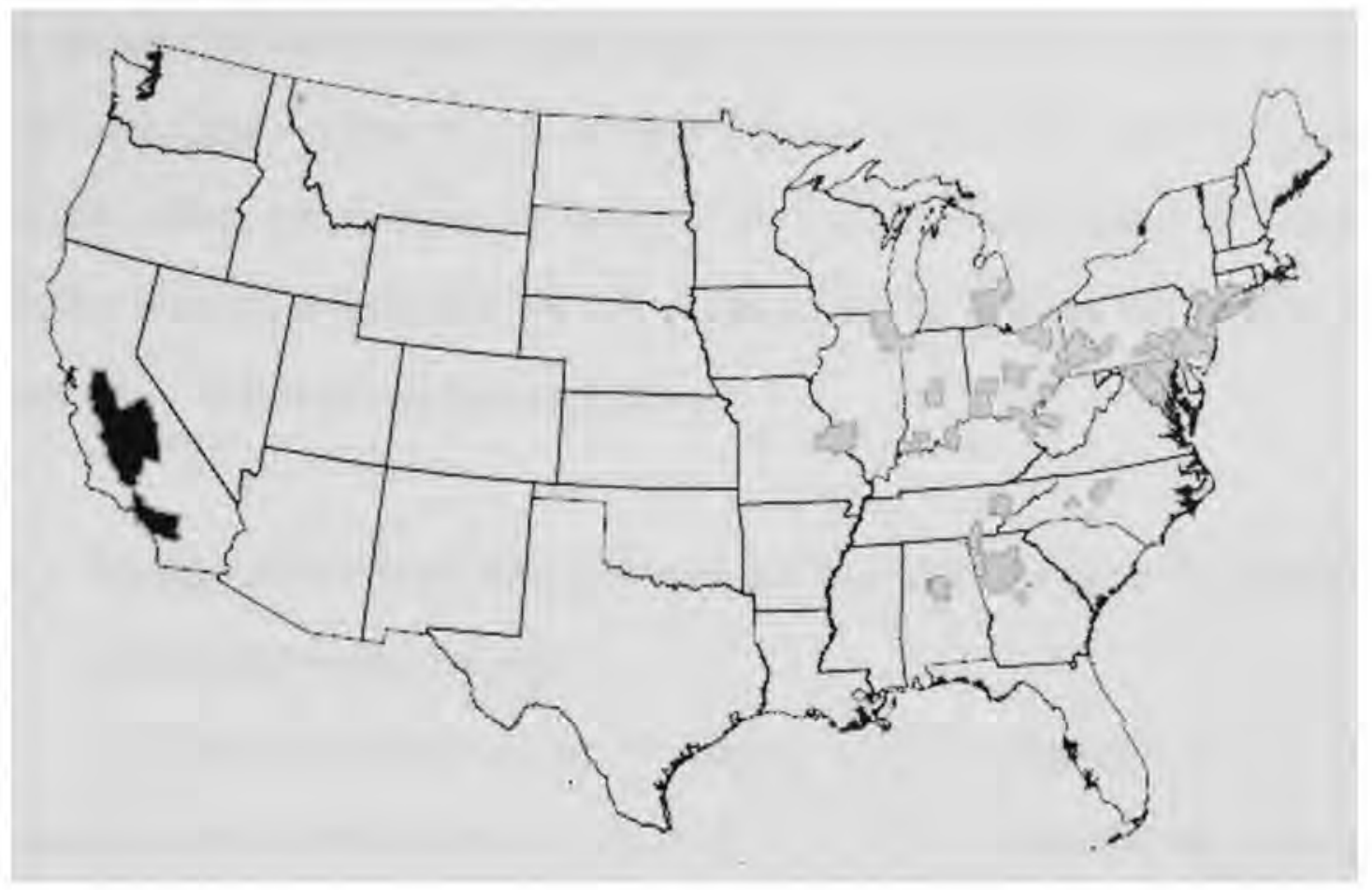

- Violated annual NAAQS $\left(15.0 \mu \mathrm{g} / \mathrm{m}^{3}\right)$ and 24-hour NAAQS $\left(65 \mu \mathrm{g} / \mathrm{m}^{3}\right)$ [2 areas]

$\square$ Violated annual NAAQS $\left(15.0 \mu \mathrm{g} / \mathrm{m}^{3}\right)$ [37 areas]

Figure 1.1: Geographical distribution of areas in the United States that exceed the National Ambient Air Quaility Standard (NAAQS) for PM 2.5. Areas indicated exceeded the 1997 standards with designated 2001-2003 data. Reference: http://www.epa.gov/particles/pdfs/20061025_graphsmaps.pdf

The regional distribution of the PM2.5 pollution problem in the U.S. is illustrated in Figure 1.1. Two distinct geographic regions exceed the levels designated in the NAAQS standard: the eastern United States, and the South Coast and San Joaquin Valley areas in California. While the individual organic compounds associated with PM2.5 have been characterized for different urban sites in the west of the U.S., much less is known for the eastern states. The Baltimore PM Supersite project is one of seven special study areas established under the U.S. EPA-Supersites program with the goal to pursue a 
concentrated effort to investigate the air quality related to fine particulate matter specific to the mid-Atlantic region. As part of the Baltimore PM Supersite, a PM2.5 organic speciation study was designed to determine the ambient concentrations of organic compounds during prolonged periods in both summer 2002 and winter 2002-2003 at an exceptionally high three-hour time-resolution.

\subsection{Background on Analytical Measurements for Characterization of Organic Compounds in Fine Particles}

Analytical procedures have been developed to solvent-extract and measure the concentration of individual organic compounds in the complex mixtures of fine particles samples from ambient and major emission sources. During the past decade, most major primary sources of organic fine particulate matter have been characterized and emission factors have been reported for hundreds of individual organic compounds. Table 1.1 provides a summary of the literature references for these sources characterization studies.

Research field studies to examine the abundance and seasonal variations of the organic molecular species associated to PM2.5 have been conducted at best with 24-hour sampling period and often for a frequency of only every fifth to sixth day. Several research studies have been conducted in California (Rogge et al., 1993a; Schauer et al., 1996; Rinehart et al., 2006). Analogous studies based on 24-hour samples have also been carried out for southeastern states (Zheng et al., 2002) and for Texas (Fraser et al., 2002; Yue et al., 2004a,b), and more recently for Pittsburgh, PA as part of the Pittsburgh Air Quality Study (PAQS) (Robinson et al., 2006 a-c, Subramanian et al., 2007). 
Table 1.1: Urban Sources of Fine Particulate Matter that have been Characterized for Organic Compounds

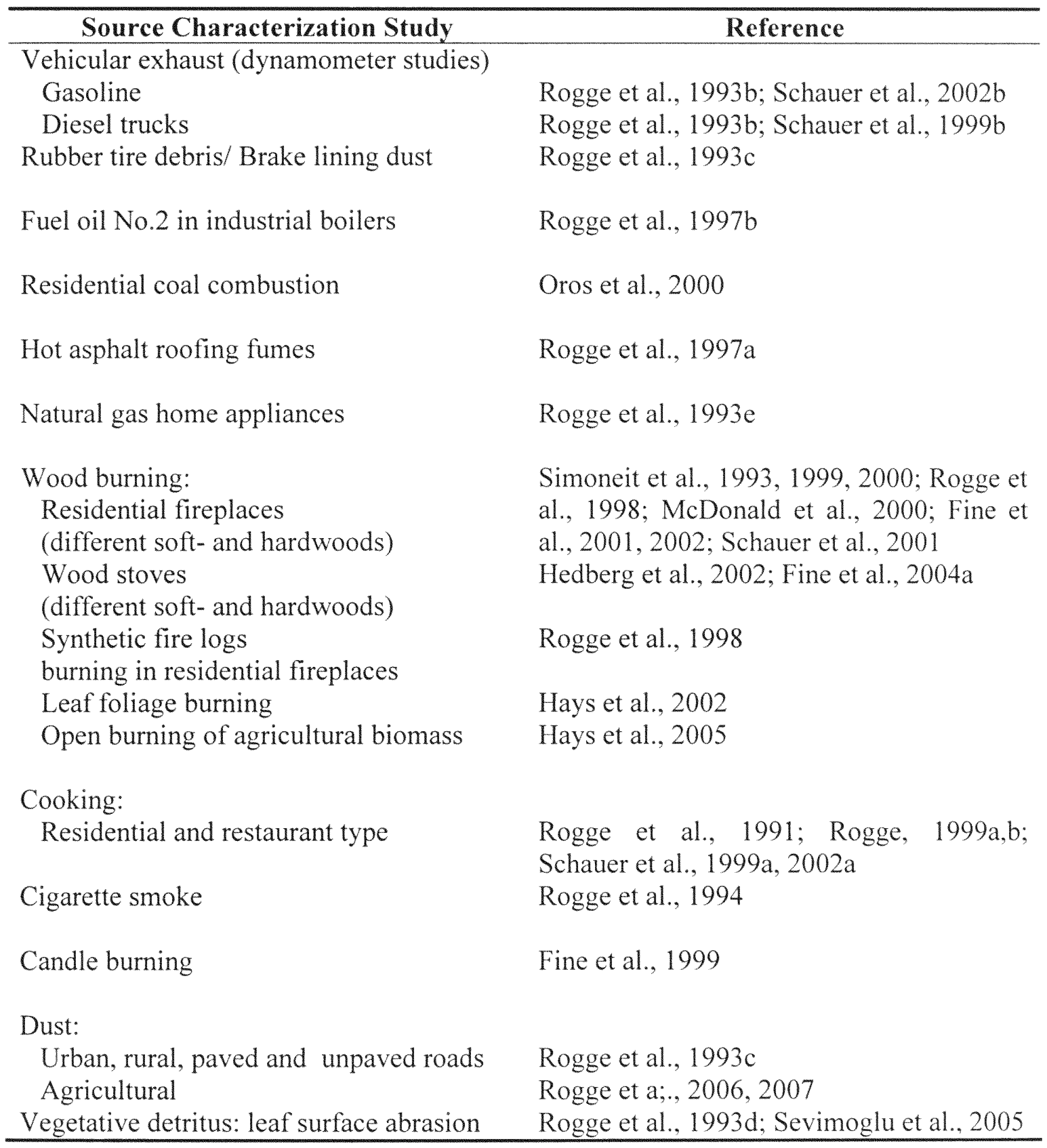

Analyzing the patterns of diurnal variations of the concentrations of organic compounds associated to PM2.5 provides the dual opportunity to better distinguish the contribution from primary sources as well as to identify the prevailing atmospheric 
conditions that lead to the formation of SOA. Diurnal variations of selected organic compounds has so far been conducted only for the west coast in Los Angeles (Fine et al. 2004b, Ning et al., 2007) and the Fraser Valley, Canada (Cheng et al., 2004, 2006) using composited diurnal samples and sampling over fairly short time periods.

\subsection{Scope of the Dissertation}

The results from two distinct datasets are presented and analyzed in this dissertation; both aimed at gaining or refining knowledge that is specific to understanding the characteristics of the organic matter component of the atmospheric PM2.5 in the Northeastern United States. The first of these sets was generated as part of the source characterization phase of the Pittsburgh Air Quality Study (PAQS), and the second as part of the Baltimore PM-Supersite. Following is a brief explanation of the purpose and important findings for each chapter.

Chapter 2, "Emission Factors of Organic Compounds in PM2.5 from Heavyduty Diesel and Light-duty Gasoline Vehicles derived from measurements in the Squirrel Hill Tunnel, Pittsburgh, PA", describes the sampling campaign conducted as part of the PAQS in the Squirrel Hill Tunnel in Pittsburgh, PA during November 2002, with the objective to develop an organic profile of the emissions from vehicular sources representative of the Northeastern U.S. region. Emissions from vehicular sources are an important category of particulate air pollution in the urban areas from this region; however, limited information is available about the organic composition of the exhaust emitted from local fleet of vehicles. Receptor models have been widely used to apportion ambient measurements of PM2.5 to their sources by incorporating organic profiles. 
Results from these approaches are very sensitive to the source profiles used; therefore, development of locally representative profiles is necessary in order to fine-tune apportionment predictions. These profiles are mainly developed from either dynamometer studies on a selected number of vehicles, or via on-road measurements which are typically conducted in tunnels, in which case the sampling from a large and locally representative fleet of vehicles can be achieved.

Emission factors for 73 organic compounds in samples from on-road vehicular traffic measured in the Squirrel Hill Tunnel, PA, are reported here for three distinct sampling periods: an early morning/high-truck (EM), a rush-hour/low speed (RH), and a mid-day period (MD). Furthermore, the emission factors of the measured species over the different traffic compositions sampled (fractions of diesel-powered trucks between $3 \%$ and $13 \%$ ) vary sufficiently so that it is possible to calculate separate organic profiles for gasoline-powered light-duty vehicles (LDVs) and diesel-powered heavy-duty vehicles (HDDVs) by applying linear regression.

The profiles of the petroleum biomarkers hopanes and steranes are very consistent for all three sampling periods; in contrast, larger variability is observed for the PAHs profiles. Considering all traffic situations, results indicate that the emission of organic markers of fuel and lubricating oil, i.e., n-alkanes, n-alkylcyclohexanes and hopanes are strongly associated to the fuel-based fraction of HDDVs in the fleet. Likewise, HDDVs are also more associated with larger emissions of the low-molecular weight polyaromatic hydrocarbons (lmw-PAHs), including phenathrene, anthracene, cyclopentaphenanthrene, fluoranthene and pyrene, while LDVs are more associated to the emissions of benzo[g,h,i]perylene and coronene. The rest of the PAHs measured, 
benzo[b]fluoranthene, benzo[k]fluoranthene, benzo[j]fluoranthene, benzo[e]pyrene, benzo[a]pyrene, perylene, indeno[c,d]pyrene and dibenzo[a,h]anthracene, appear to be equally contributed by both types of vehicles.

Based on benzothiazole, a marker for tire wear, the larger contribution appears to be associated with hindered traffic flow such as that occurring during transient/creep driving conditions.

The associations found between the n-alkylcyclohexanes and the organic sulfur compounds 4-methyl- and 4,6-dimethyldibenzothiophene imply a larger contribution of diesel fuel to the measured emission factors of the lower molecular weight nalkylcyclohexanes (C17-C20). Lastly, the association found between the emission factors of hmw-PAHs and benzo[b]naphtho[2,1-d]thiophene, an indicator of the pyrolysis of sulfur-containing fuels, imply that vehicles with no after-burning treatment emit exceedingly large amounts of hmw-PAHs, benzo[b]fluoranthene, benzo[k]fluoranthene, benzo[j]fluoranthene, benzo[e]pyrene, benzo[a]pyrene, perylene, indeno[c,d]pyrene, benzo[g,h,i]perylene, dibenzo[a,h]anthracene and coronene.

In addition, a detailed comparison of the results from this study with profiles developed from dynamometer and roadway tunnels studies in other regions of the U.S. allows drawing one important implication. Variability in the composition of engine emissions appears to be a stronger function of the differences in engine type, performance and operation, than it is of those of fuel and lubricating oil.

Chapter 3, "Three-hourly and Summer/Winter Variations in Atmospheric Concentrations of Organic Compounds in PM2.5 Measured during the Baltimore PM-Supersite", describes in detail the especially designed sampling system and 
evaluates the complete summer and winter data sets of organic compounds assembled from the measurements conducted during the Baltimore PM-Supersite. The primary goal of this chapter is to examine the 3-hourly variations of concentrations of individual organic compounds and compare the levels and patterns observed during the two seasonal periods sampled, summer 2002 and summer/winter 2002/2003. A simple graphic procedure is used in order to display global aspects of the data sets in a meaningful way that simplifies identifying compound's seasonal abundance, effect of point-sources, and grouping of episodes.

The 3-hourly variation of concentrations summary plots of the four series of organic markers for primary emissions from fossil fuel burning sources, i.e., sum of the n-alkanes in the range C19-C25, n-alkylcyclohexanes, hopanes, and particle-phase PAHs, display very similar patterns in both seasons, strongly suggesting that these are determined by common sources. Evaluations of the data reveal that they are predominantly influenced by emissions from vehicular exhaust in both seasons. However, generally larger concentrations levels of these species during the winter compared to the summer indicate that several of these compounds are subject to seasonal dynamic differences.

During the winter, the 3-hourly samples from Baltimore display a highly consistent diurnal cycle for the ratio of benzo[a]pyrene $(\mathrm{BaP})$ to benzo[e]pyrene $(\mathrm{BeP})$. Based on previous literature knowledge, the concurrence of the minimum ratio with the time of maximum solar radiation, together with the evenness of the pattern throughout the time-series can be interpreted as being consistent with photochemical loss as the dominant degradation path for $\mathrm{BaP}$. In contrast, during the summer, the ratio is 
appreciably lower and more variable indicating that degradation occurs at a faster rate and is influenced by other factors.

Significantly larger nighttime concentration of odd carbon-number n-alkanes (range C27-C35), even carbon-number n-alkanoic acids (range C24-C32) together with the source specific organic markers for wood burning, levoglucosan, dehydroabietic acid and syringyl-moiety phenols, on 24-26-November 2002 and 21-February 2003 indicate that the emission of those compounds are associated to appreciable larger nighttime contribution on those days. Using levoglucosan as a tracer for wood smoke is possible to estimate the contribution of wood burning to the ambient levels of organic carbon (OC). These calculations indicate that $20-35 \%$ of the ambient OC measured during those events comes from wood burning. Contribution for all other days of the winter sampling campaign is of the order of $5-10 \%$. Analogous estimates indicate that during the summer the contribution of fine particles form biomass burning is approximately $0.5 \%$, while this fraction rose to $1-4 \%$ throughout 20-21-July, a period displaying characteristics consistent with the influence of smoke from long-range and regional biomass burning.

In urban aerosols, the organic unsaturated acids n-hexadecenoic acid (C16:1, palmitoleic), n-octadecenoic acid (C18:1, oleic) and n-octadecadienoic acid (C18:2, linoleic) are dominated by emissions from cooking operations. Further, the ratios of the unsaturated to the saturated homologues, n-hexadecanoic acid (C16) and n-octadecanoic acid (C18), is taken as an indication of the relative processing/aging of the atmospheric aerosol. On a 3-hourly basis, the palmitoleic:palmitic ratios display similarly low values during summer and winter, median $0.1 \pm 0.1$. On the other hand, during the winter, the ratio oleic:stearic are between 0.8 and 2.2 and display a very strong diurnal pattern 
consisting of sharp midday decay of the ratio value. This minimum value concurs with the maximum diurnal solar radiation indicating that photochemical degradation of oleic acid is observed on a diurnal basis, analogous to the result indicated for $\mathrm{BaP}: \mathrm{BeP}$. During the summer, the ratio oleic:stearic values are in the range 0.1 to 1 ; the same order of magnitude and following a similar trend as the palmitoleic:palmitic ratio. Consequently, it can be concluded that that oleic and palmitoleic acids are subject to different diurnal atmospheric dynamics.

Among the dicarboxylic organic acids analyzed, the diurnal trends observed here indicate the ambient concentrations of 4-methylphthalic acid are solely determined by secondary formation in the local atmosphere via a photochemical-driven mechanism; thus supporting the notion that this compound may serve as an active indicator of secondary anthropogenic aerosol formation.

Chapter 4, "Short- and Long-range Atmospheric Events Influencing PM 2.5 in Baltimore Identified from Highly time-resolved Organic Characterization Data", specifically examines the relationships of the observed continuous variations of the concentrations of organic markers as well as PM2.5 mass and the reactive species Ozone $\left(\mathrm{O}_{3}\right)$ and nitrous oxides $\left(\mathrm{NO}_{2}\right.$, NOx $)$ with the on-site meteorological measurements conducted parallel to the PM2.5 sampling and the synoptic patterns of weather and wind conditions. The synoptic trajectories of air masses were computed using the NOAA Hysplit software running 3-day backward trajectories to identify major region sources of transported air masses that contributed to the background air on different days. Data from the end-point files generated by the software was reduced and analyzed to build diagrams 
that permit to easily display the progression of the influencing air parcel regimes and give a comparative view of their interaction with the local atmosphere ("intrusion").

Measurements encompass two distinct influencing meteorological scenarios. Days during which a local sea breeze circulation is observed in the diurnal wind direction data, and others during which the local wind direction experiences no diurnal change. The latter, concur with periods during which the prevalent direction of the long-range winds is from the west, northwest, north or south, and the local wind is persistently aligned with that direction for periods of one to three days. The periods identified as being under a strong west/northwesterly influence are 09:00 17-July to 09:00 19-July, 5-August and 7November. Under northerly are 00:00 6-August to 06:00 9-August, and under southerly are 09:00 21-July to 21:00 22-July, 10-12-August, 8-9-November, and 12:00 14November to 12:00 15-November.

This study shows that, during the summer, under conditions of pervasive westerly/northwesterly influence the data displays a number of characteristics consistent with the PM2.5 being strongly influenced by the aged/processed nature of the background air masses. These characteristic include larger concentrations and percent proportions of the lower-molecular weight n-alkanoic acids, particularly n-nonanoic acid, dicarboxylic acids particularly azelaic and phthalic acid. In addition, a significant change is observed of both the percent proportions of hopanes and the relationship of hopanes to n-alkylcyclohexanes typical of vehicular emissions and which characterizes all other periods, even though the sampling site was located within less than one kilometer from a major highway. 
The prevalent regime of influence during the November portion of the winter sampling campaign is from the south/southwest. These trajectories generally travel shorter distances; i.e., they are more "regional". The southern regime is observed to be associated with appreciably larger concentrations of the secondary biogenic reaction products nopinone, cis-pinonic acid and norpinonic acid. During the summer, the air masses originating from the south are seen more associated with the transport of fine particles from biomass burning and during this type of influence an appreciable enhancement of the measured concentrations of daytime cis-pinonic acid is observed. Because a similar enhancement is noted in two cases during the winter (24-25-November and 21-February, 2003) which can specifically be isolated to be influenced by local emissions and display a large contribution from wood burning (approximately $30 \%$ of the OC) it can be concluded that it is possible that such enhancement be associated to the presence of wood soot, as has been hypothesized from data derived from chamber experiments reported in the research literature.

The major implications from the above results are two fold: During the summer, long-range transport can be important under the influence of the long-range westerly regimes. During the winter, intrusions from more "regional" air masses are more important. Specific evidence of transport under the southerly regimes is given by the presence of secondary biogenic reaction products. This is also supported by the knowledge that areas from West Virginia and Virginia are densely forested. 
Chow, J. C., Watson, J. G., Lowenthal, D. H., Chen, L.-W. A., Zielinska, B., Rinehart. L. R., Magliano, K. L., 2006. Evaluation of organic markers for chemical mass balance source apportionment at the Fresno Supersite. Atmospheric Chemistry and Physics Discussions 6, 10,341-10,372.

Cheng, Y., Li, S.-M., Leithead, A., Brickell, P.C., Leaitch, W.R., 2004. Characterizations of cis-pinonic acid and n-fatty acids on fine aerosols in the Lower Fraser Valley during Pacific 2001 Air Quality Study. Atmospheric Environment 38 (34), 5789 5800 .

Cheng, Y., Li, S.-M., Leithead, A., Brook, J.R., 2006. Spatial and diurnal distributions of n-alkanes and n-alkan-2-ones on PM2.5 aerosols in the Lower Fraser Valley, Canada. Atmospheric Environment 40 (15), 2706-2720.

Coulter, C.T., 2004. EPA-CMB8.2 Users Manual EPA-452/R-04-01. Air Quality Modeling Group Emissions, Monitoring and Analysis Division, Office of Air Quality Planning and Standards, Research Triangle Park, NC 27711.

Eldering, A., Cass, G. R., 1996. Source-oriented model for air pollutant effects on visibility. Journal of Geophysical Research 101, 19342-19369.

Fine, P.M., Cass, G.R., Simoneit, B.R.T., 1999. Characterization of fine particle emissions from burning church candles. Environmental Science and Technology 33 (14), 2352-2362.

Fine, P.M., Cass, G.R., Simoneit, B.R.T., 2001. Chemical characterization of fine particle emissions from fireplace combustion of woods grown in the northeastern United States. Environmental Science and Technology 35 (13), 2665-2675.

Fine, P.M., Cass, G.R., Simoneit, B.R.T., 2002. Chemical characterization of fine particle emissions from the fireplace combustion of woods grown in the southern United States. Environmental Science and Technology 36 (7), 1442-1451.

Fine, P.M., Cass, G.R., Simoneit, B.R.T., 2004a. Chemical characterization of fine particle emissions from the wood stove combustion of prevalent United States tree species, Environmental Engineering Science 21(6), 705-721.

Fine, P.M, Chakrabarti, B., Krudysz, M., Schauer, J.J., Sioutas, C., 2004b. Diurnal variations of individual organic compound constituents of ultrafine and accumulation mode particulate matter in the Los Angeles basin. Environmental Science and Technology 38 (5), 1296-1304. 
Fraser, M.P, Yue, Z.W., Tropp, R.J., Kohl, S.D., Chow, J.C., 2002. Molecular composition of organic fine particulate matter in Houston, TX. Atmospheric Environment 36 (38), 5751-5758.

Fraser, M.P., Yue, Z.W, Buzcu, B., 2003. Source apportionment of fine particulate matter in Houston, TX, using organic molecular markers, Atmospheric Environment, $37(15), 2117-2123$.

Hays, M.D., Geron, C.D., Linna, K.J., Smith, N.D., Schauer, J.J., 2002. Speciation of gas-phase and fine particle emissions from burning of foliar fuels, Environmental Science and Technology 36 (11), 2281-2297.

Hays, M.D., Fine, P.M., Geron, C.D., Kleeman, M.J., Gullett, B.K., 2005. Open burning of agricultural biomass: Physical and chemical properties of particle-phase emissions, Atmospheric Envirnoment 39(36), 6747-6764.

Hedberg, E., Kristensson, A., Ohlsson, M., Johansson, C., Johansson, P.A., Swietlicki, E., Vesely, V., Wideqvist, U., Westerholm, R., 2002. Chemical and physical characterization of emissions from birch wood combustion in a wood stove. Atmospheric Environment 36 (30), 4823-4837.

HEI (Health Effects Institute). 1995. Special Report - Particulate Air Pollution and Daily Mortality: The Phase I Report of the Particle Epidemiology Evaluation Project. Phase I.A: Replication and Validation of Selected Studies. Health Effect Institute: Cambridge, MA.

McDonald, J.D., Zielinska, B., Fujita, E.M., Sagebiel, J.C., Chow, J.C., Watson, J.G., 2000. Fine particle and gaseous emission rates from residential wood combustion, Environmental Science and Technology 34 (11), 2080-2091, 2000.

Ning, Z., Geller, M.D., Moore, K.F., Sheesley, R., Schauer, J.J., Sioutas, C., 2007. Daily variation in chemical characteristics of urban ultrafine aerosols and inference of their sources. Environmental Science and Technology 41 (17), 6000-6006.

Oros, D.R., Simoneit, B.R.T., 2000. Identification and emission rates of molecular tracers in coal smoke particulate matter, Fuel 79 (5), 515-536.

Rinehart, L.R., Fujita, E.M., Chow, J.C., Magliano, K., Zielinska, B., 2006. Spatial distribution of PM2.5 associated organic compounds in central California. Atmospheric Environment 40 (2), 290-303.

Robinson, A. L., Subramanian, R., Donahue, N. M., Bernardo-Bricker, A., Rogge, W. F., 2006a. Source apportionment of molecular markers and organic aerosol. 1. Polycyclic aromatic hydrocarbons and methodology for data visualization. Environmental Science and Technology 40(24), 7803-7810. 
Robinson, A. L., Subramanian, R., Donahue, N. M., Bernardo-Bricker, A., Rogge, W. F., 2006b. Source apportionment of molecular markers and organic aerosol. 2. Biomass smoke. Environmental Science and Technology 40(24), 7811-7819.

Robinson, A. L., Subramanian, R., Donahue, N. M., Bernardo-Bricker, A., Rogge, W. F., 2006c. Source apportionment of molecular markers and organic aerosol. 3. Food cooking emissions. Environmental Science and Technology 40(24), 7820-7827.

Rogge, W.F., Hildemann, L.M., Mazurek, M.A., Cass, G.R., Simoneit, B.R.T., 1991. Sources of fine organic aerosol, 1. Charbroilers and meat cooking operations, Environmental Science and Technology 25 (6), 1112-1125.

Rogge, W.F., Hildemann, L.M., Mazurek, M.A., Cass, G.R., Simoneit, B.R.T., 1993a. Quantification of urban organic aerosols at a molecular level, Identification, abundance and seasonal variation. Atmospheric Environment 27A, 1309-1330.

Rogge, W.F., Hildemann, L.M., Mazurek, M.A., Cass, G.R., Simoneit, B.R.T., 1993b. Sources of fine organic aerosol. 2. Noncatalyst and catalyst-equipped automobiles and heavy-duty diesel trucks, Environmental Science and Technology 27(4), 636651 .

Rogge, W.F., Hildemann, L.M., Mazurek, M.A., Cass, G.R., Simoneit, B.R.T., 1993c. Sources of fine organic aerosol. 3. Road dust, tire debris, and organometallic brake lining dust, roads as sources and sinks, Environmental Science and Technology $27(9), 1892-1904$.

Rogge, W.F., Hildemann, L.M., Mazurek, M.A., Cass, G.R., Simoneit, B.R.T., 1993d. Sources of fine organic aerosol. 4. Particulate abrasion products from leaf surfaces of urban plants, Environmental Science and Technology 27(13), 2700-2711.

Rogge, W.F., Hildemann, L.M., Mazurek, M.A., Cass, G.R., Simoneit, B.R.T., 1993e. Sources of fine organic aerosol. 5. Natural gas home appliances, Environmental Science and Technology 27(13), 2736-2744.

Rogge, W.F., Hildemann, L.M., Mazurek, M.A., Cass, G.R., Simoneit, B.R.T., 1994. Sources of fine organic aerosol, 6. Cigarette smoke in the urban atmosphere. Environmental Science and Technology 28 (7), 1375-1388.

Rogge, W.F., Hildemann, L.M., Mazurek, M.A., Cass, G.R., Simoneit, B.R.T., 1996. Mathematical modeling of atmospheric fine particle-associated primary organic compound concentrations, Journal of Geophysical Research 101, D14, 19, 37919,394 . 
Rogge, W.F., Hildemann, L.M., Mazurek, M.A., Cass, G.R., Simoneit, B.R.T., 1997a. Sources of fine organic aerosol, 7. Hot asphalt roofing tar pot fumes. Environmental Science and Technology 31 (10), 2726-2730.

Rogge, W.F., Hildemann, L.M., Mazurek, M.A., Cass, G.R., Simoneit, B.R.T., 1997b. Sources of fine organic aerosol, 8. Boilers burning No. 2 distillate fuel oil. Environmental Science and Technology 31 (10), 2731-2737.

Rogge, W.F., Hildemann, L.M., Mazurek, M.A., Cass, G.R., Simoneit, B.R.T., 1998. Sources of fine organic aerosol, 9. Pine, oak, and synthetic log combustion in residential fireplaces. Environmental Science and Technology 32 (1), 13-22.

Rogge, W.F., 1999a. Investigating indoor air quality by using a dynamic and modular source testing approach for indoor cooking, Final Rep., 335 pp., Center for Indoor Air Quality Research (CIAR).

Rogge, W.F., 1999b. Emissions of heterocyclic aromatic amines from residential cooking, Final Rep., 111 pp., American Lung Association of Florida.

Rogge, W.F., Medeiros, P.M., Simoneit, B.R.T., 2007. Organic marker compounds in surface soils of crop fields from the San Joaquin Valley fugitive dust characterization study. Atmospheric Environment, 41 (37), 8183-8204.

Rogge, WF, Medeiros, PM, Simoneit, BRT. , 2006. Organic marker compounds for surface soil and fugitive dust from open lot dairies and cattle feedlots." Atmospheric Environment, 40 (1), 27-49.

Schauer, J.J., Rogge, W.F., Hildemann, L.M., Mazurek, M.A., Cass, G.R., Simoneit, B.R.T. 1996. Source apportionment of airborne particulate matter using organic compounds as tracers. Atmospheric Environment 30 (22), 3837-3855.

Schauer, J.J., Kleeman, M.J., Cass, G.R., Simoneit, B.R.T., 1999a. Measurement of emissions from air pollution sources. 1. C1-C29 Organic compounds from meat charbroiling. Environmental Science and Technology 33 (10), 1566-1577.

Schauer, J.J., Kleeman, M.J., Cass, G.R., Simoneit, B.R.T., 1999b. Measurement of emissions from air pollution sources. 2. C1-C29 Organic compounds from medium duty diesel trucks. Environmental Science and Technology 33 (10), 1578-1587.

Schauer, J.J., Cass, G.R., 2000. Source apportionment of wintertime gas-phase and particle-phase air pollutants using organic compounds as tracers. Environmental Science and Technology 34 (9), 1821-1832. 
Schauer, J.J., Kleeman, M.J., Cass, G.R., Simoneit, B.R.T., 2001. Measurement of emissions from air pollution sources. 3. C1-C29 Organic compounds from fireplace combustion of wood. Environmental Science and Technology 35 (9), 1716-1728.

Schauer, J.J., Kleeman, M.J., Cass, G.R, Simoneit, B.R.T. 2002a. Measurement of emissions from air pollution sources. 4. C1-C27 Organic compounds from cooking with seed oils. Environmental Science and Technology 36 (4), 567-575.

Schauer, J.J., Kleeman, M.J., Cass, G.R, Simoneit, B.R.T. 2002b. Measurement of emissions from air pollution sources. 5. C1-C32 Organic compounds from gasolinepowered motor vehicles. Environmental Science and Technology 36 (6), 11691180.

Schwartz, J., Neas, L. M., 2000. Fine particles are more strongly associated than coarse particles with acute respiratory health effects in school children. Epidemiology 11, $6-10$.

Sevimoglu, O., Rogge, W.F., Bernardo-Bricker, A., Robinson, A., Subramanian, R., 2005. Fine particulate abrasion products from leaf surfaces of urban plants: Comparison between Los Angeles and Pittsburgh. Specialty Conference: Particulate Matter, Supersites Program and Related Studies, Atlanta, GA, February 7-11.

Simoneit, B.R.T., Rogge, W.F., Mazurek, M.A., Standley, L.M., Hildemann, L.M., Cass, G.R., 1993. Lignin pyrolysis products, lignans and resin acids as specific tracers of plant classes in emissions from biomass combustion. Environmental Science and Technology 27 (12), 2533-2541.

Simoneit, B.R.T, Schauer, J.J., Nolte, J.J., Oros, D.R., Elias, V.O., Fraser, M.P., Rogge, W.F., Cass., G.R., 1999. Levoglucosan, a tracer for cellulose in biomass burning and atmospheric particles. Atmospheric Environment 33 (2), 173-182.

Simoneit, B.R.T., Rogge, W.F., Lang, Q., Jaffé, R., 2000. Molecular characterization of smoke from campfire burning of pine wood (Pinus elliottii), Chemosphere. Global Change Science 2, 101-105.

Subramanian, R., Donahue, N. M., Bernardo-Bricker, A., Rogge, W. F., Robinson, A. L., 2007. Insights into the primary-secondary and regional-local contributions to organic aerosol and PM2.5 mass in Pittsburgh, Pennsylvania. Atmospheric Environment 41(35), 7414-7433.

Watson, J.G., Cooper, J.A., Huntzicker, J.J., 1984. The effective variance weighting for least squares calculations applied to the mass balance receptor model. Atmospheric Environment 18(7), 1347-1355. 
Yue, Z. W., Fraser, M.P., 2004a. Characterization of nonpolar organic fine particulate matter in Houston, Texas. Aerosol Science and Technology 38 (S1), 60-67.

Yue, Z. W., Fraser, M.P. 2004b. Polar organic compounds measured in fine particulate matter during TexAQS 2000. Atmospheric Environment 38 (20), 3253-3261.

Zheng, M., Cass, G.R., Schauer, J.J., Edgerton, E.S., 2002. Source apportionment of PM2.5 in the southeastern United States using solvent-extractable organic compounds as tracers. Environmental Science and Technology 36 (11), 2361-2371. 


\section{CHAPTER 2}

\section{EMISSION FACTORS OF ORGANIC COMPOUNDS IN PM2.5 FROM HEAVY- \\ DUTY DIESEL AND LIGHT-DUTY GASOLINE VEHICLES DERIVED FROM MEASUREMENTS IN THE SQUIRREL HILL TUNNEL, PITTSBURGH, PA}

(Bernardo-Bricker, A., Rogge, W.F., Robinson, A.L., Subramanian, R., Donahue. N.M, Atmospheric Environment, in preparation)

\subsection{Introduction}

Epidemiologic studies have suggested that exposure to ambient levels of particulate matter with an aerodynamic diameter smaller than $2.5 \mu \mathrm{m}$ (PM2.5), rather than coarse particles, are more closely associated with mortality and adverse cardiorespiratory effects (e.g., Dockery et al, 1993; Pope et al., 2002, 2004; Laden et al., 2006). These findings have motivated ample research aimed at both identifying the important components and characteristics of PM2.5 responsible for the health effects (e.g., Dellinger et al., 2001; Li et al., 2003; Seagrave et al., 2006) as well as to accurately characterize the various sources contributing to the ambient concentrations of these fine particles in the local atmosphere.

Motor vehicles powered by internal combustion engines are considered to contribute a major portion of the primary PM2.5 to the ambient air in different urban areas throughout the United States. Almost all primary particles emitted with the exhaust from fossil fuel powered vehicles and a variable amount of the particles generated from tire and break abrasion are smaller than $2.5 \mu \mathrm{m}$ in aerodynamic diameter (Garg et al., 2000, Lough et al., 2005, Dahl et al., 2006). Receptor models have been typically used to 
estimate the specific contribution of different source types to the ambient PM2.5 concentrations. These receptor oriented apportionment techniques require suitable source profiles and ambient data of a site of interest. The apportionment of the ambient pollutant concentrations back to their sources strongly depends on the quality of the emissions inventory for the area selected to perform source/receptor reconciliation. Moreover, incorporating source profiles of organic compounds associated to PM2.5 in receptor modeling has been shown to both improve the distinction between gasoline and diesel emissions and allow a more accurate estimate of other sources (Schauer et al., 1996; Chow et al., 2002; Chow et al., 2006).

Several distinct sampling approaches have been used in order to develop sources profiles for motor vehicles exhaust. The predominant methodology consists of using a dilution sampling system attached to a vehicle's exhaust while being tested on a dynamometer using the U.S. Federal Test Procedure protocols (US-FTP) to simulate different vehicle operating conditions. Emission factors of the organic compounds present in the gas- and particle-phase exhaust from gasoline- and diesel-powered vehicles have been developed using data from dynamometer-based emission testing (e.g. Rogge et al., 1993a; Lowenthal et al., 1994; Schauer et al., 1999, 2002; Fraser et al., 2002; Zielinska et al., 2004a,b; Fujita et al., 2007; Riddle et al., 2007a, 2007b). Dynamometer testing offers the advantage of precision, since all experimental variables as are known. However, FTP testing is costly and can only be performed for a limited number of vehicles. Furthermore, fuels differ not only from season to season, but also from location to location. Moreover, real-life driving cycles are often different from the driving modes simulated by the FTP. Consequently, on-road emission factors for the major exhaust 
constituents have been found to differ from those measured when testing according to the FTP (Kirchestetter et al., 1996; Gillies et al., 2001).

On-road emission factors can be derived from sampling in roadway tunnels based on a balance of the carbon content in the fuel vs. the exhaust. This method offers the advantage of sampling emissions from a large fleet operated under real-life conditions. Even prior to the EPA's 1997 National Ambient Air Quality Standard (NAAQS) for PM2.5 tunnel studies had been conducted, for example, in the Fort McHenry, MD and Tuscarora Mountain, PA in order to determine the emission factors for the major exhausts' gaseous pollutants, carbon monoxide $(\mathrm{CO})$, carbon dioxide $\left(\mathrm{CO}_{2}\right)$, nitrogen oxides (NO, NOx) and nonmethane hydrocarbons (NMHCs) (Pierson et al., 1996), as well as to derive profiles of the gas-phase and semi-volatile organic compounds (SVOCs) (Zielinska et al., 1996). Further, Gertler and co-workers (2001) carried out measurements in the Tuscarora Mountain Tunnel in order to characterize the particle size distributions and particles mass emission rates. Similarly, several types of on-road emission studies in the Caldecott Tunnel, CA have been regularly conducted in order to keep updated inventories for the specific geographic area. Measurements in the Caldecott Tunnel have included emission factors for gas pollutants and volatile organic compounds (VOCs) (e.g.., Kirchstetter et al., 1996), continuous gas and particle measurements as well as mass and chemical characterization of PM2.5 for elemental carbon (EC) and organic carbon (OC) (Kirchstetter et al., 1999), emission profiles of polyaromatic hydrocarbons (PAHs) in PM2.5 (Miguel et al., 1998; Marr et al. 1999), and more recently, particles mass concentrations, size distributions, and estimated emission factors for trace metals (Geller et al., 2005), and for a suite of organic compounds in the fine and accumulation 
modes (Phuleria et al., 2006). Organic compounds in the gas- and particle-phase have also been measured in the Van Nuys Tunnel, CA by Fraser et al. $(1998,1999)$. In Texas, measurements have been carried out in the Washburn Tunnel to estimate the emission factors for metals, PM2.5 mass and associated organic compounds (Chellam et al., 2005).

As part of the "Pittsburgh Air Quality Study" (PAQS) measurement campaigns were conducted in the Squirrel Hill Tunnel, PA in order to derive local emission factors for a suite of pollutants. The complex chemistry of gasoline and diesel is further complicated by evolving federal set standards, and a range of state regulatory requirements. Most of the dynamometer and tunnel studies conducted to generate organic profiles have taken place in California, where gasoline specifications, for example, are more astringent than those of other states. The objective of this paper is to present the first detailed profile and emission factors of organic compounds associated to the PM2.5 emitted from vehicular fleets typical of the Pittsburgh region. Further, we also assess the distinguishing signatures observed in the samples corresponding to the traffic hours exhibiting a higher proportion of diesel-powered vehicles, and develop separate organic profiles for light-duty vehicles (LDV) and heavy-duty-diesel vehicles (HDDV). Emission factors are compared to those measured in major dynamometer testing as well as those derived from measurements in other tunnels in the U.S.

\subsection{Experimental Methods}

\subsubsection{Sampling Sites and Program}

The PM2.5 samples for organic profiles were collected in the Squirrel Hill Tunnel, which is located on the eastern side of the city of Pittsburgh. This 4,225 ft long 
twin-bore tunnel is a major east-west access road on Intersate-376 allowing light- and heavy-duty vehicles traffic. Squirrel Hill Tunnel has two one-way lanes in each bore and it follows a constant 2.5 percent grade rising from east to west. Sampling took place in the tunnel's west-bound bore during selected time periods; early morning (EM) from 00:00 to 06:00, rush hour (RH) from 07:00-09:00, and mid-day (MD) 10:00-16:30. Supporting traffic and chemical data has been reported elsewhere (Grieshop et al., 2006); here Table 2.1 presents the values of these parameters measured nearly concurrent to the

Table 2.1: Traffic and Chemical Information during the Three Sampling Periods Conducted in the Squirrel Hill Tunnel

\begin{tabular}{|c|c|c|c|c|c|c|}
\hline $\begin{array}{l}\text { Date and } \\
\text { Start Sample Time }\end{array}$ & $\begin{array}{c}\text { 18-Nov-02 } \\
0: 00 \\
\end{array}$ & $\begin{array}{c}\text { 19-Nov-02 } \\
0: 00\end{array}$ & $\begin{array}{c}12-\text { Nov }-02 \\
6: 35\end{array}$ & $\begin{array}{c}13-\text { Nov- } 02 \\
6: 35 \\
\end{array}$ & $\begin{array}{c}20-\text { Nov-02 } \\
6: 30 \\
\end{array}$ & $\begin{array}{c}21-\text { Nov- } 02 \\
10: 00\end{array}$ \\
\hline Elapsed Time (hours) & 5.8 & 5.8 & 2.5 & 2.4 & 3.2 & 6.4 \\
\hline Period Identification & \multicolumn{2}{|c|}{$\begin{array}{c}\text { High-Truck } \\
\text { (Early Morning) }\end{array}$} & \multicolumn{3}{|c|}{$\begin{array}{l}\text { Low-Speed } \\
\text { (Rush Hour) }\end{array}$} & $\begin{array}{l}\text { High-Speed } \\
\text { (Midday) }\end{array}$ \\
\hline Name & EMI & EM2 & RH1 & $\mathrm{RH} 2$ & $\mathrm{RH} 3$ & MD \\
\hline Total Vehicle Count & 5,664 & 5,536 & 9,141 & 9,384 & 12,423 & 20,488 \\
\hline $\begin{array}{l}\text { Traffic Volume } \\
\text { (vehicles/hour) }\end{array}$ & 970 & 950 & 3,671 & 3,894 & 3,931 & 3,206 \\
\hline $\begin{array}{l}\text { Average Speed } \\
\text { (miles/hour) }\end{array}$ & 56 & 58 & 31 & 32 & 35 & 51 \\
\hline \multicolumn{7}{|l|}{$\begin{array}{l}\text { Average Truck } \\
\text { Fraction }\end{array}$} \\
\hline vehicle basis $^{1}$ & 0.10 & 0.13 & 0.04 & 0.04 & 0.03 & 0.07 \\
\hline fuel basis ${ }^{2}$ & 0.28 & 0.31 & 0.13 & 0.12 & 0.11 & 0.21 \\
\hline $\mathrm{EC}(\mathrm{mg} / \mathrm{Kg}$ fuel $)$ & 157 & N/A & 97 & 80 & $\mathrm{~N} / \mathrm{A}$ & 89 \\
\hline $\mathrm{OC}(\mathrm{mg} / \mathrm{Kg}$ fuel $)$ & 130 & N/A & 55 & 59 & $\mathrm{~N} / \mathrm{A}$ & 54 \\
\hline $\mathrm{NOx}(\mathrm{g} \mathrm{NO} / \mathrm{Kg}$ fuel $)$ & 20 & 17 & 8 & 8 & 8 & 11 \\
\hline PM2.5 (mg/Kg fuel) & 266 & 256 & 167 & 140 & 212 & 243 \\
\hline
\end{tabular}


sampling of PM2.5 for organic speciation. Based on visual inspection, the fleet composition was divided in two categories, assuming that the larger vehicles including tractors, trucks and the few observed city buses were primarily heavy-duty diesel vehicles (HDDV), while smaller vehicles including family vans, sports utility vehicles and automobiles, were light duty vehicles (LDV) primarily powered by gasoline.

Parallel to the tunnel study, five 24-hour ambient PM2.5 samples were collected; three at the PAQS central site (on the grounds of Schenley Park, Pittsburgh) and two on the roof of the Business Building at Carnegie Mellon University. Field blanks for both the tunnel and the ambient locations were also analyzed as part of the quality control process.

\subsubsection{Sampling Procedure}

The sampling systems were set up above the ceiling of the tunnel at approximately 5 meters above the road and approximately 50 meters from the exit-end of the tunnel. The PM2.5 samples were collected using a Tisch Environmental, Inc. Model TE-1000 PUF sampler equipped with an URG cyclone (URG-2000-30AE, URG Corp.) to remove particles with an aerodynamic diameter larger than $2.5 \mu \mathrm{m}$, and it was operated at $145 \mathrm{lpm}$. Ambient samples were collected by using the same type of PM2.5 sampling equipment. Samples were collected on quartz fiber filters (102 $\mathrm{mm}$ diameter, Pall Lifesciences, Tissuquartz 2500 QAT-UP) followed by a polyurethane foam (PUF) plug $(7.5 \mathrm{~cm}$ diameter $\times 7.5 \mathrm{~cm}$ long, Tisch Environmental, Inc. TE-1010) installed downstream of the filter to trap SVOCs. 


\subsubsection{Sampling Media Preparation, and Samples Storage and Transportation Procedures}

Prior to sampling, quartz fiber filters were annealed at $550{ }^{\circ} \mathrm{C}$ for 4 hours to remove possible organic contaminants. PUF plugs were solvent cleaned following a 5cycle procedure of about $4 \mathrm{~min}$ each, using a solvent mixture of methylene chloride:acetone:hexane $(2: 4: 4)$ for the first four cycles and methylene chloride for the last. Cleaning was achieved by placing each PUF into a glass or stainless steel beaker, adding the cleaning solvent until $1 / 3$ to $1 / 2$ of the plug was immersed, and following a mechanical compression cleaning technique by using a glass or stainless steel plunger to press and depress the PUF plugs up and down. After the last cleaning cycle, PUFs were dried under mild vacuum in a desiccator and stored in cleaned glass jars with solvent rinsed Teflon-lined lids. The glass jars were first cleaned with water and solvent free detergent (Fisher), followed by rinsing three times with tap water and two more times with deionized water. Next the glass jars were rinsed with acetone and after drying, they were annealed in a muffle at $550{ }^{\circ} \mathrm{C}$ for 4 hours. All sample media handling was conducted using solvent rinsed stainless steel tweezers. All the solvents used in the procedure were Fisher GC-Resolv grade or equivalent Burdick\&Jackson.

After sampling, solvent rinsed tweezers were used to fold the sampled quartz fiber filter in such a manner that the collected particulate matter remained on the inside fold. The folded filter was carefully wrapped in a piece of annealed aluminum foil. Each set of quartz fiber filter and PUF plug was stored airtight in the same glass jar that originally contained the clean PUF plug, and was transported back to the lab in a cooler. In the Pittsburgh lab, the glass jars containing the samples were stored in freezers set a temperature of less than $-21{ }^{\circ} \mathrm{C}$ until they were shipped to Florida International 
University (FIU), Miami, FL. Sample shipment was conducted by securely placing jars in a cooler that contained dry ice and shipped overnight to FIU. Upon arrival at FIU the temperature in the cooler was measured, and sample jars were immediately inspected, catalogued and stored in freezers at less than $-21^{\circ} \mathrm{C}$ until analysis.

\subsubsection{Sample Extraction Protocol}

All glassware used for sample extraction was annealed at $550{ }^{\circ} \mathrm{C}$ for at least 4 hours. All fittings and transfer lines were made of TFE or PTFE Teflon and solvent rinsed before and after usage. All glassware rinses, standard solution preparation and extraction work were performed using solvents Fisher GC-Resolv grade.

Prior to extraction, each filter was spiked with a known amount of an internal standard suite consisting of seven perdeuterated n-alkanes (Chiron AS, Norway): C12, C16, C20, C24, C28, C32, C36. Filters were extracted using four 10-min cycles of mild ultrasonic agitation in a temperature controlled bath $\left(25^{\circ} \mathrm{C}\right)$. For each cycle, $30 \mathrm{ml}$ of fresh methylene chloride were used; the extracts were filtered and combined into a single flask using a Step-Saver Filtration System (Fisher Scientific). PUF plugs were extracted three times using a custom designed Repeated Compression Extraction Apparatus (RCEA) that consists of a thick walled glass cylinder equipped with PTFE valves system and a glass plunger. For the first time, a $60-\mathrm{ml}$ aliquot of methylene chloride was used, 40-ml aliquots were used for the second and third extractions. After extraction, filter and PUF extracts were combined and the total extract reduced to a volume of $2-3 \mathrm{ml}$ by rotary evaporation. The total extract was reduced further by a stream of high purity $\mathrm{N}_{2}$ to a final volume of typically $200-300 \mu \mathrm{L}$. This reduced extract was then reacted with freshly 
produced diazomethane to convert organic acids to their methyl ester analogues and acidic hydroxyl compounds to their methoxy analogues. Derivatized sample extracts were stored in a freezer at less than $-21^{\circ} \mathrm{C}$ until GC/MS analysis. Field blanks and lab blanks were processed analogously.

\subsubsection{Gas Chromatography/Mass Spectrometry (GC/MS) Analysis}

Analysis of all samples including derivatized and underivatized portions were carried out on a Gas Chromatograph (GC) model HP-6890 coupled to a Mass-Spectra Detector (MSD) model HP-5973 (Agilent Technologies). The GC was operated in the splitless mode and was equipped with a capillary column DB-5MS (J\&W $30 \mathrm{~m} \times 0.25 \mathrm{~mm}$ i.d. $x 0.25 \mu \mathrm{m}$ film thickness). Temperature programming of the $\mathrm{GC}$ consisted of the following steps: isothermal at $60^{\circ} \mathrm{C}$ for $2 \mathrm{~min}$, temperature ramp of $6^{\circ} \mathrm{C} / \mathrm{min}$ up to $300^{\circ} \mathrm{C}$, and isothermal hold for $18 \mathrm{~min}$. The injector temperature was set at $300{ }^{\circ} \mathrm{C}$ and the GC/MS interface temperature at $285^{\circ} \mathrm{C}$. Helium was used as carrier gas with a flow rate of $1.2 \mathrm{ml} / \mathrm{min}$. The injected sample volume was $1 \mu \mathrm{l}$. Sample injection was accomplished with a HP-Automatic Liquid Sampler HP-G1513-90100 (Agilent Technologies) in the pulse mode at 25 psi for the first minute. The MSD was operated in the electron impact mode at $70 \mathrm{eV}$ electron energy, scan range 50-550 amu. The GC/MS data was acquired and processed using a Agilent ChemStation.

\subsubsection{Compound Identification and Quantification}

The target list of compounds for analysis and quantification comprised 140 organic species. Each target compound was identified in the ambient and the tunnel 
samples by comparison with the retention time and mass fragmentation pattern of 124 authentic standards. Whenever standards were unavailable, identification was based on comparison of their mass fragmentation pattern with that of the NIST and Wiley mass spectral libraries.

Area counts for each identified peak were converted to mass units using a relative response factor (RRF) calculated for each compound and correcting for the recovery of the appropriate internal standard to account for any losses incurred throughout the sample extraction procedure. The individual RRFs were determined from the GC/MS analysis of authentic standard of the target compounds containing 1-phenyldodecane as an internal standard for quantification. Whenever an authentic standard was not available for a given target, the RRF of a closely related specie was used. The precision of each individual compound concentration was calculated based on replicate GC/MS analysis of selected samples. The calculated precision of measurement for individual compounds range from $1 \%$ to $21 \%$, with $90 \%$ of the targets exhibit precisions between $1 \%$ and $10 \%$.

\subsubsection{Quality Assurance/Quality Control (QA/QC)}

Assurance of analytical quality and control of the procedures were determined through the use of laboratory blanks and field blanks. Field blanks consisted of a sampling media pair of quartz filter and PUF which had undergone the same handling preparation and procedures as those of regular samples, including placement into the sampler and shipment. All compounds quantified in the samples were blank corrected. Targets that were found in the blanks were generally present in amounts equivalent to less than $1 \%$ of their mass measured in either ambient or tunnel samples. 


\subsection{Results and Discussion}

The pollutant composition of a primary source is typically reported as emission factors; in the case of vehicular exhaust these are defined as the emitted mass of a given compound or specie per unit of either distance traveled $(\mathrm{km})$ or fuel consumed $(\mathrm{kg}$ fuel). The fuel-basis is appropriate for tunnel studies because the measured amount of carboncontaining emission products $\left(\mathrm{CO}_{2}, \mathrm{CO}, \mathrm{EC}\right.$ and $\left.\mathrm{OC}\right)$ can be directly related to the amount of carbon present in the fuel consumed, via a carbon-mass balance (e.g., Fraser et al., 1998).

The concentrations of the organic compounds measured in the Squirrel Hill Tunnel were background-corrected by subtracting their respective ambient levels. These corrected tunnel concentrations (in units of $\mathrm{ng} / \mathrm{m}^{3}$ ) were converted to fuel-based emission factors ( $\mu \mathrm{g} / \mathrm{kg}$ fuel) by multiplying the corrected concentrations of each compound by a conversion factor $\left(C_{f}\right)$ which was calculated using the following equation:

$$
C f=\frac{0.87 \times f_{H D}+0.85 \times\left(1-f_{H D}\right)}{\left.\llbracket\left[\mathrm{CO}_{2}\right]_{h C}+[C O]_{h c}\right]}\left[\frac{M W_{C O_{2}}}{M W_{C}}\right]
$$

Where constants and variables have the following meaning: carbon weight fraction of diesel ( $\mathrm{g}$ of $\mathrm{C} / \mathrm{kg}$ of fuel)

0.85 carbon weight fraction gasoline ( $\mathrm{g}$ of $\mathrm{C} / \mathrm{kg}$ of fuel)

$f_{H D} \quad$ fraction of traffic identified as heavy-duty diesel vehicles 


$\begin{array}{ll}{\left[\mathrm{CO}_{2}\right]_{b c}} & \text { background-corrected concentration of } \mathrm{CO} 2\left(\mathrm{in} \mathrm{g} / \mathrm{m}^{3}\right) \\ {[\mathrm{CO}]_{b c}} & \text { background-corrected concentration of } \mathrm{CO}\left(\mathrm{in} \mathrm{g} / \mathrm{m}^{3}\right) \\ M W_{\mathrm{CO}_{2}} & \text { molecular weight of } \mathrm{CO}_{2}(44 \mathrm{~g} / \mathrm{g} \mathrm{mol}) \\ M W_{C} & \text { molecular weight of } \mathrm{C}(12 \mathrm{~g} / \mathrm{g} \mathrm{mol})\end{array}$

More than 100 individual organic compounds were targeted, 73 were identified and quantified in the tunnel air. The background corrected fuel-based emission factors for these compounds are provided in Appendix A (Table A.1). The 73 compounds reported here were measured inside the tunnel at levels that were significantly larger than their corresponding background concentration; $93 \%$ of the compounds were measured in concentrations that were 3 to 28 times larger than the average-plus-two standard deviation of their concentration in the background air.

A summary of the dataset structure can be gathered from Figure 2.1; here each graph represents a family of organic compounds and each scatter plot represents the chemical profile observed in individual samples plotted versus the global average profile of all six samples, which is assigned in the x-axis. Trend lines are fitted to two separate averages: the solid line is the linear trend for the average of EM1, EM2 and MD (average HDDV fuel-fraction $0.25 \pm 0.05$; average speed $54 \pm 4 \mathrm{mph}$ ) and the dash line for the average of RH1, RH2 and RH3 (average HDDV fuel-fraction $0.12 \pm 0.01$; average speed $33 \pm 2 \mathrm{mph}$ ). These lines are included to facilitate the view of the profiles, and the $\mathrm{R}^{2}$ values are given to point out the consistency of the data set. For simplicity, the group of the first five-PAHs including phenanthrene (Phen), anthracene (Anth), 


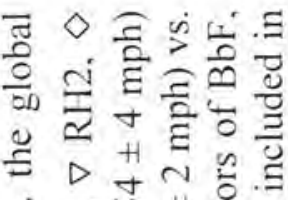

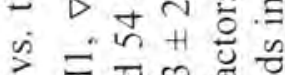

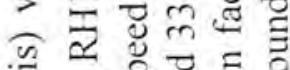

के के छ

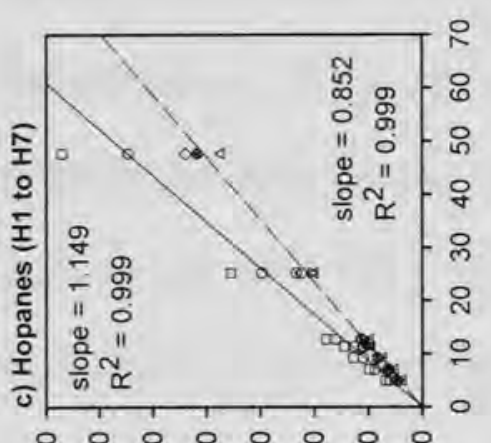

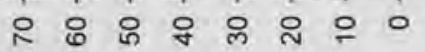
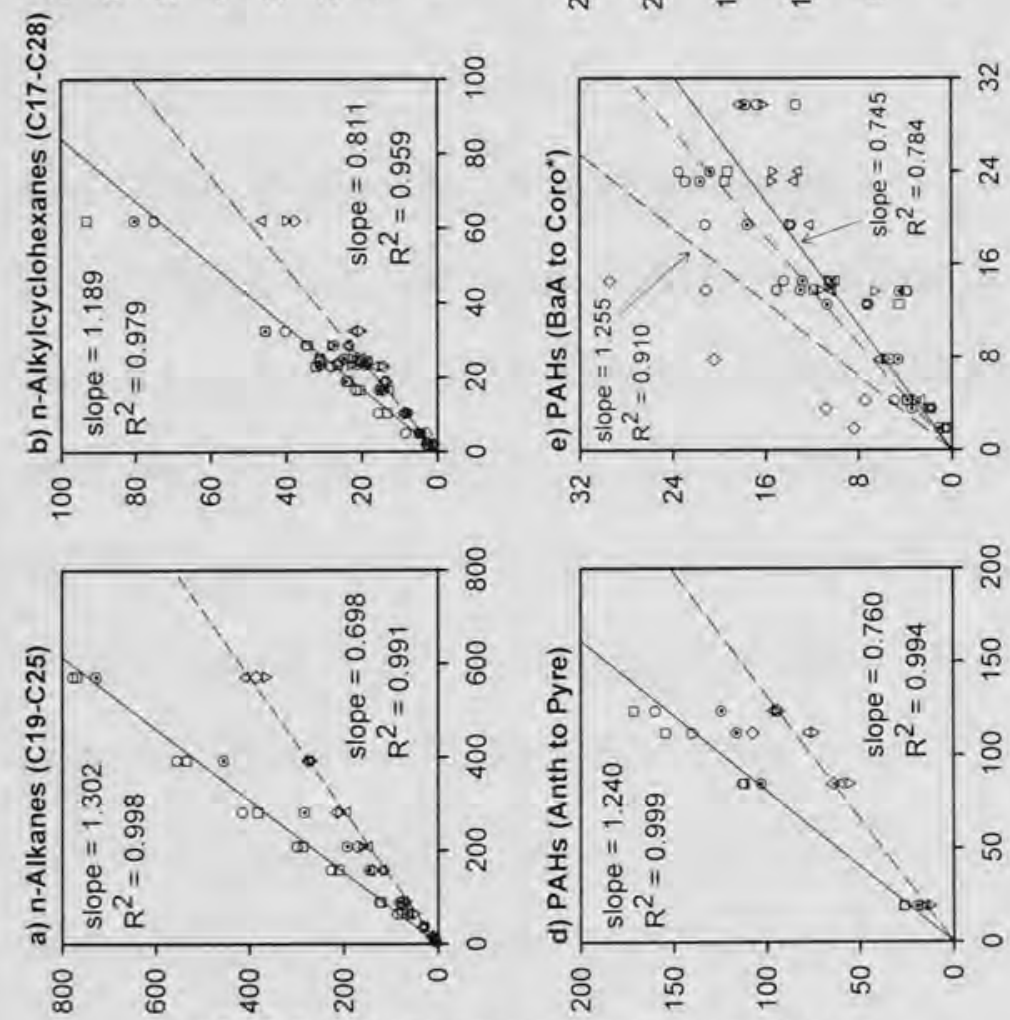

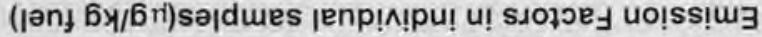
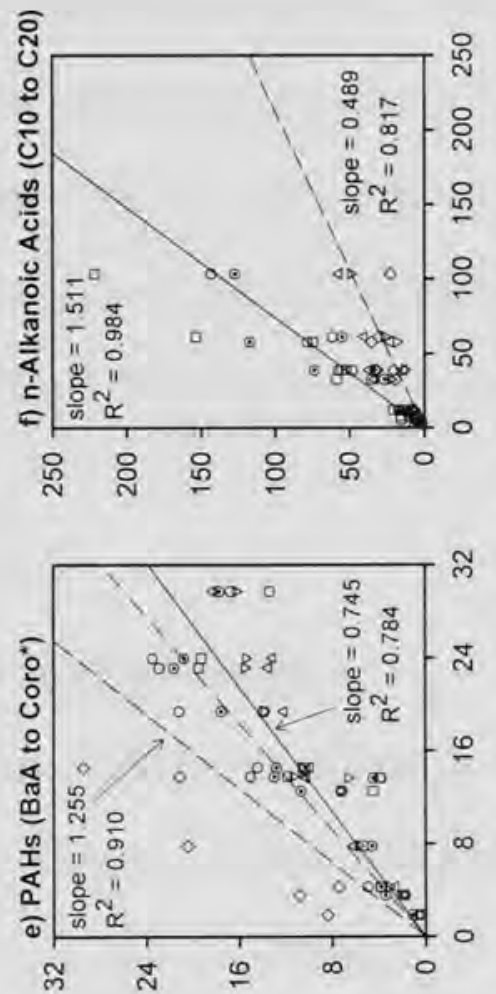

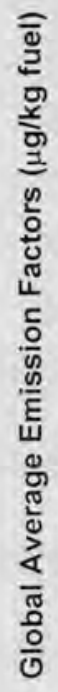

.


cyclopentaphenanthrene (Cyphen), fluoranthene (Fluo) and pyrene (Pyre) will be referred to as lower molecular weight PAHs (lmw-PAHs) and that of the twelve PAHs including benzo[a]anthracene $(\mathrm{BaA})$, chrysene/triphenylene $(\mathrm{Ch} / \mathrm{Tr})$, benzo[b]fluoranthene $(\mathrm{BbF})$, benzo[k]fluoranthene $(\mathrm{BkF})$, benzo[j]fluoranthene $(\mathrm{BjF})$, benzo[e]pyrene $(\mathrm{BeP})$, benzo[a]pyrene (BaP), perylene (Pery), indeno[c,d]pyrene (IcdP), benzo[g,h,i]perylene (BghiP), dibenzo[a,h]anthracene (DahA) and coronene (Coro) will be referred to as higher molecular weight PAHs (hmw-PAHs). In the following sections, the molecular composition of the tunnel samples will be discussed based on the context provided by this figure.

\subsubsection{Fossil Fuel and Lubricating Oil Markers}

The exhaust from internal combustion engines includes compounds from two distinct sources, the products of the incomplete combustion of fuel or the burning of lubricating oil constituents plus the direct volatilization of components in the unburned fuel and the lubricating oil. The presence of the petroleum biomarkers hopanes and steranes in the fine particles exhausted from motor vehicles are source-specific organic molecular markers for lubricating oil (Rogge et al., 1993a; Schauer et al, 2002). The presence of the homologues series of n-alkanes and n-alkylcyclohexanes can be ascribed to diesel fuel and lubricating oils as explained by Rogge et al (1993a) based on the following basic premises.

The distillate petroleum fractions that make up gasoline and diesel fuels have distinctly different boiling point ranges, less than $220^{\circ} \mathrm{C}$, and between $280^{\circ} \mathrm{C}$ and $360^{\circ} \mathrm{C}$ respectively; furthermore, lubricating oil bases are produced from the distillate fraction 
with a boiling point between $400^{\circ} \mathrm{C}$ and $550^{\circ} \mathrm{C}$. In addition, lubricating oil bases are subject to dewaxing processes in order to eliminate the straight chain n-alkanes; however, these bases still contain alkylated naphtenic moieties including n-alkylcyclohexanes. Consequently, n-alkycyclohexanes measured in the particle-phase exhaust from gasolinepowered vehicles originate from lubricating oil with no contribution from unburned fuel. On the other hand, particle-phase n-alkanes and n-alkylcyclohexanes in the exhaust from diesel-powered vehicles derive mainly from lubricating oil with possible contribution in the range $19 \leq \mathrm{C} \leq 21$ from unburned diesel fuel.

Figure 2.1 a-c shows that for n-alkanes, n-alkylcyclohexanes and hopanes the slope representing the samples EM1, EM2 and MD are consistently higher than the ones representing the RH samples by a factor of approximately 1.6. Given that the fuel-based fraction of HDDVs during the EM and MD periods is larger than that of the RH periods by a factor of $2-3$, the consistently larger slope suggests that the factor that dominates the measured emission of fine particles associated to lubricating oil is the fraction of HDDVs in the fleet.

Considering all six samples, the ratio of the sum of the n-alkanes homologues in the range $24 \leq \mathrm{C} \leq 26$ to that of the sum of homologues $20 \leq \mathrm{C} \leq 22$ is $0.21 \pm 0.02$. This value is closer to the one reported in the literature for fine particle emissions from heavy duty diesel trucks $(0.26 \pm 0.05$ in Shah et al., 2005; 0.35 in Rogge et al., 1993b) and medium duty diesel trucks (0.54 in Schauer et al., 1999); in contrast, the corresponding ratios for gasoline-powered vehicles with or without catalytic converter have been reported to be appreciably higher $(1.0 \pm 0.1$ in Rogge et al., $1993 \mathrm{~b}$ and $2.7 \pm 0.1$ in Schauer et al., 2002. Analogously, the tunnel samples yield a value of $0.96 \pm 0.20$ for the ratio of the sum of the 
n-alkylcyclohexanes homologues $\mathrm{C} 19$ through $\mathrm{C} 21$ to that of the sum of $\mathrm{C} 23$ through

C25. The lower-molecular weight n-alkylcyclohexanes homologues in the range of $\mathrm{C} 17$ to $\mathrm{C} 20$ have been identified in diesel (Schauer et al., 2002) but not in gasoline (Schauer et al., 2002); therefore, in previous tunnel studies (Fraser et al., 1998) they have been associated with their presence in diesel fuel. The similarities found between our results and those reported in the literature, along with the larger slope observed in Figure $2.1 \mathrm{a}, \mathrm{b}$ for the average of the combined EM and MD samples (solid line) may be interpreted as an indication of the relative enrichment of n-alkanes and n-alkylcyclohexanes due to the contribution of diesel fuel and lubricating oil in the sampling periods with the larger fractions of HDDVs.

\subsubsection{Particle Bound Combustion Products: Organic Acids and Polycyclic}

\section{Aromatic Hydrocarbons}

An appreciably larger slope of the profile of n-alkanoic acids is observed for the average of samples EM1, EM2 and MD (Figure 2.1.f) compared to those of the RH period (ratio of 3.1). Analogously to the previous section, because the fuel-based fraction of HDDVs during the EM and MD periods is larger than that of the RH periods by a factor of 2-3, then it appears that the emissions of n-alkanoic acids as a class are also overall influenced by the fraction of HDDVs in the fleet.

The larger slope observed for the lmw-PAHs, in a similar pattern as that observed for the fossil fuel and lubricating oil markers, also indicate that the emission factors measured for these compounds depends predominantly on the fraction of HDDVs. In contrast, a larger variability is observed in the set of hmw-PAHs and; furthermore, when 
all three RH samples are included, the slope of the line representing these samples is actually larger than the one for the EM1, EM2 and MD. The emission factors of individual hmw-PAHs in sample RH3 are larger than the average plus two times the standard deviation of $\mathrm{RH} 1$ and $\mathrm{RH} 2$; excluding this sample essentially erases the difference between the two trend lines. This is shown in Figure 2.1 e by a dash-point line.

The major difference between the profile of organic compounds observed in RH3 and that of the other samples is the much larger emission factors of the hmw-PAHs. A similar result is also found in the measurements reported from a study conducted in the Washburn Tunnel, TX (Chellam et al, 2005). Analysis of the proportion of individual compounds in our target list in each sample shows only two differences in the profile of sample RH3 compared to all others. Firstly, the proportion of lmw-PAHs is much lower; that is, while the ratio of $1 \mathrm{mw}-\mathrm{PAHs}$ to hmw-PAHs is 1.6 in sample RH3, it displays values in the range of 5 to 11 (average $7.6 \pm 2.3$ ) in the other samples. Secondly, the emission factor of the benzo[b]naphtho[2,1-d]thiophene is remarkably larger in sample RH3. The possible meaning of the association between the larger emission factors of hmw-PAHs and benzo[b]naphtho[2,1-d]thiophene in sample RH3 is explored in section

\subsection{3.}

\subsubsection{Profile of Organic Sulfur Compounds}

Organic sulfur compounds are not typically included in the lists of species analyzed in the fine particle exhausted from motor vehicles. However, these can be useful in helping differentiate among the possible sources contributing to the fine particle emitted from diesel- and gasoline-powered vehicles. Four compounds were targeted in 
this study, dibenzothiophene, 4-methyldibenzothiophene, 4,6-dimethyldibenzothiophene and benzo[b]naphtho[2,1-d]thiophene. Data obtained for these compounds are summarized in the two figures described below.

Figure 2.2 shows the patterns of similarities identified between the emission factors of the organic sulfur compounds and other target markers measured in the six tunnel samples. The emission pattern of dibenzothiophene through all driving conditions is very similar to that of the Imw-PAHs (Figure $2.2 \mathrm{a}, \mathrm{b}$ ). The pattern of 4methyldibenzothiophene as well as 4,6-dimethyldibenzothiophene closely follow that of the n-alkylcyclohexanes from $\mathrm{C} 17$ to $\mathrm{C} 20$, as shown in Figure $2.2 \mathrm{c}$, d for the former. On the other hand, the pattern of the remaining n-alkylcyclohexanes homologues is more similar to that of the sum of hopanes (Figure 2.2 e,f). Similarities are also observed between the patterns of benzo[b]naphtho[2,1-d]thiophene and individual hmw-PAHs, from benzo[b]fluoranthene to coronene, as shown here for the sum in Figure $2.2 \mathrm{~g}$,h. This last association is particularly relevant since, as indicated in section 2.3.2, out of the three samples acquired during the RH period the major difference between the profile of organic compounds observed in RH3 and that of the other two samples is solely the much larger emission factors of the hmw-PAHs.

In Figure 2.3 the emission factors of the four organic sulfur compounds in the six tunnel samples are plotted vs. the HDDV fuel-fraction; it can be seen that the first three compounds are well associated with the HDDV fuel-fraction, while the factors of benzo[b]naphtho[2,1-d]thiophene do not display the same type of fit. The linear correlation factor, $\mathrm{R}^{2}$, for dibenzothiophene, 4-methyldibenzothiophene and 4,6dimethyldibenzothiophene are, respectively, 0.59, 0.69 and 0.79 . Likewise, the ratios of 

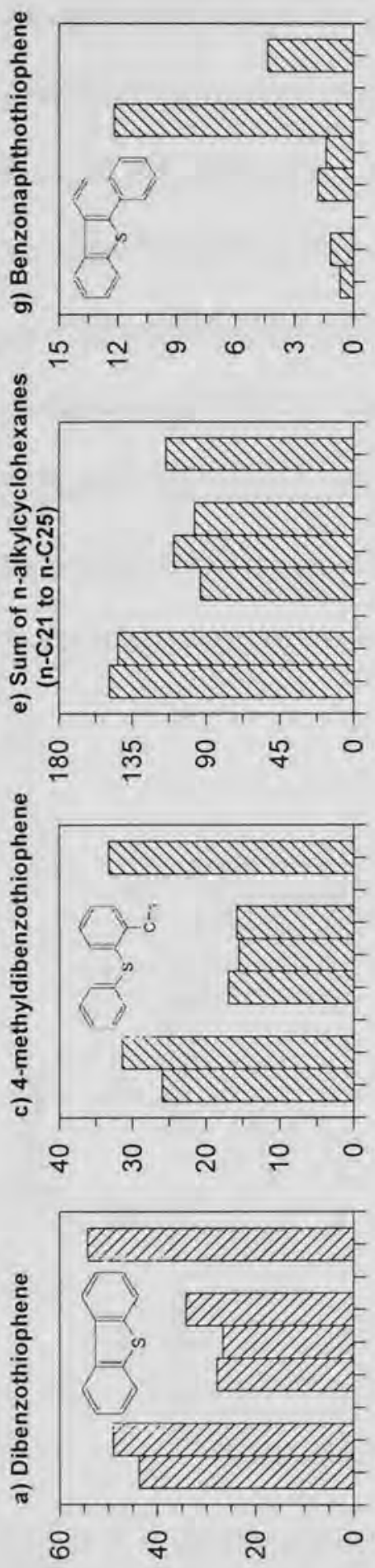

|ən\} $6 y / 6$ ri

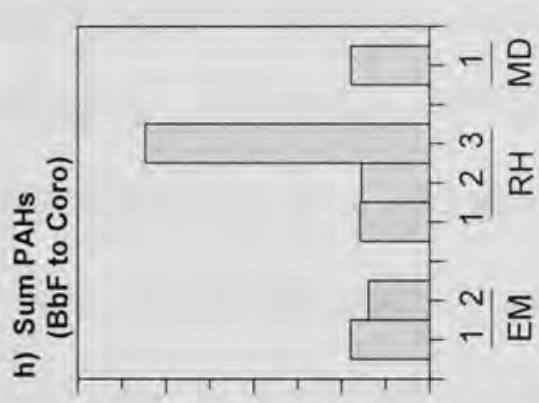

ㅇํㅇ ㅇํㅇ
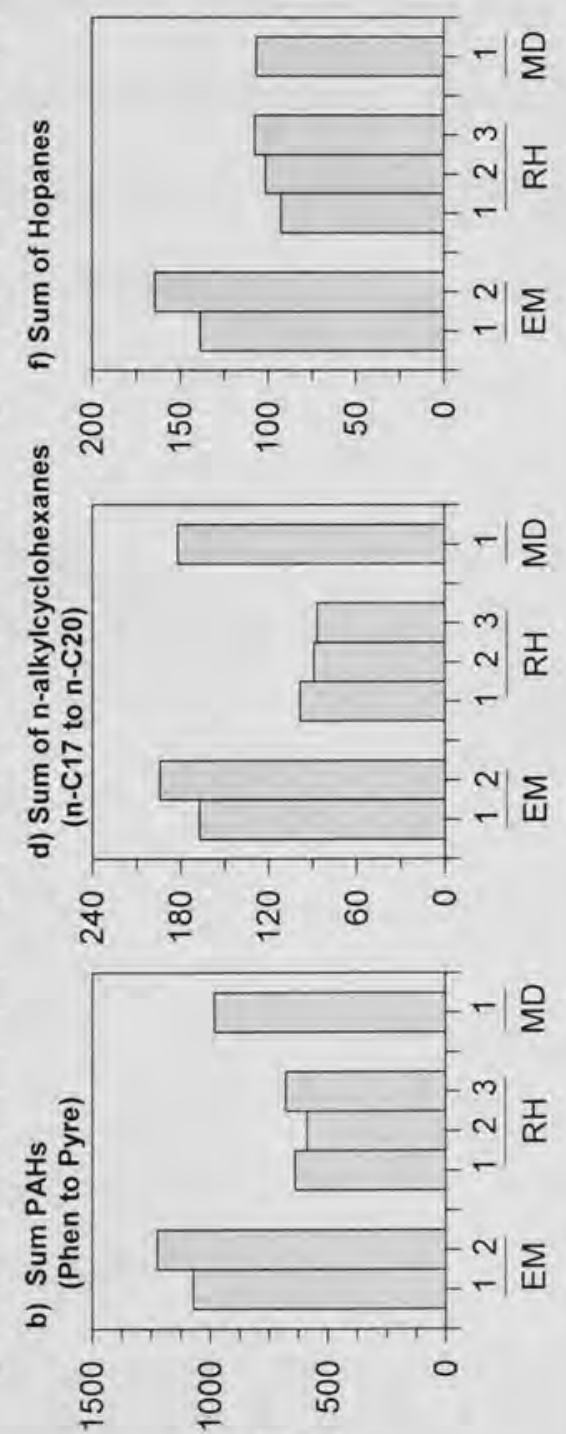

Iəny $6 y / 6 r i$
ปิ่

¿

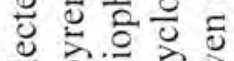

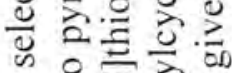

웧ㅇ

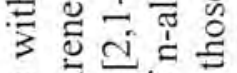

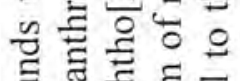

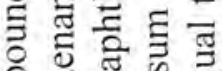

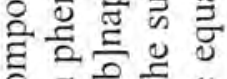

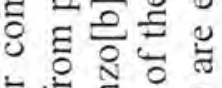

导焉总

के

.

엔 유류

ธฏU ฐ

\& क

至

$\div \stackrel{0}{0} \stackrel{0}{0}$

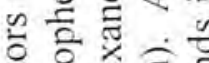

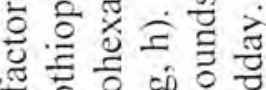

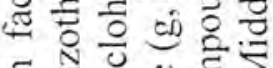

ప స્心

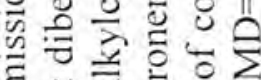

छ 元苛

(u)

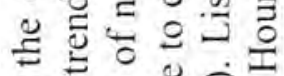

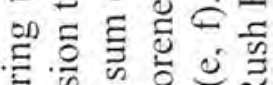

त) क $0 \cong 2$

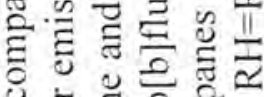

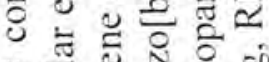

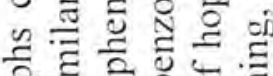

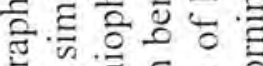
का

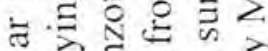

๑

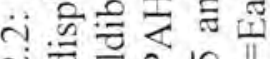
그의 ڤั

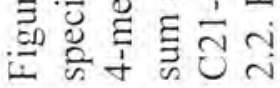


the slope to the intercept are, in that order, 5, 9 and 14 . It is also noted that the relative change in the magnitude of the slopes for the three species is smaller than that of the intercept; that is, while the changes in the magnitude of the slope are approximately $35 \%$ those of the intercept are in the order of $80 \%$. In a linear association of emission factors vs. HDDV fuel fraction is implicit that the intercept relates to the "zero-diesel" or gasoline contribution and the slope is a measure of the degree of influence from emissions of HDDVs. Therefore, the measurements suggest that the fuel fraction of HDDVs in the fleet has a consistent and dominant influence in the measured factors of all three species while emissions from gasoline vehicles only have a relative larger influence on the measured factors of dibenzothiophene.

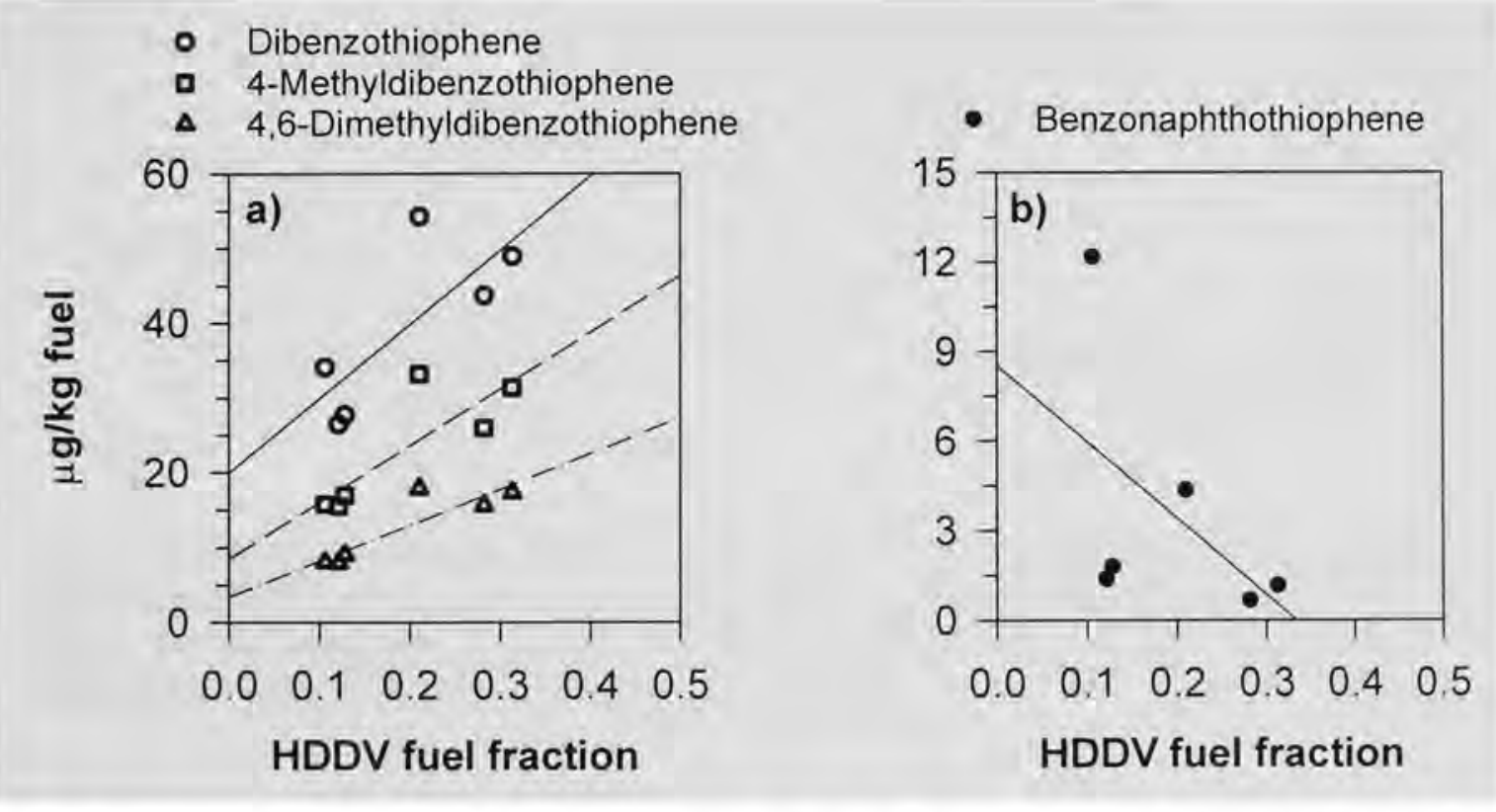

Figure 2.3: Scatter plots of the emission factors of organic sulfur compounds vs, the HDDV fuel fraction. In (a), ratio of slope to intercept, respectively, for dibenzothiophene, 4-methyldibenzothiophene and 4,6-dimethyldibenzothiophene equal to 5,9 and 14 . 
Based on the premise that the source of hopanes is lubricating oil, the similarity of the patterns of hopanes and the n-alkylcyclohexanes homologues with $\mathrm{C} \geq 21$ (Figure 2.2 e,f) indicate that these are predominantly contributed by lubricating oil. The similarity of the patterns of the n-alkylcyclohexanes homologues with $17 \geq \mathrm{C} \geq 20$ and the methyl/dimethyldibenzothiophene (shown in Figure $2.2 \mathrm{c}, \mathrm{d}$ for methyl-) together with the information from Figure 2.3 help to substantiate that the homologues with $17 \geq \mathrm{C} \geq 20$ are contributed by diesel fuel.
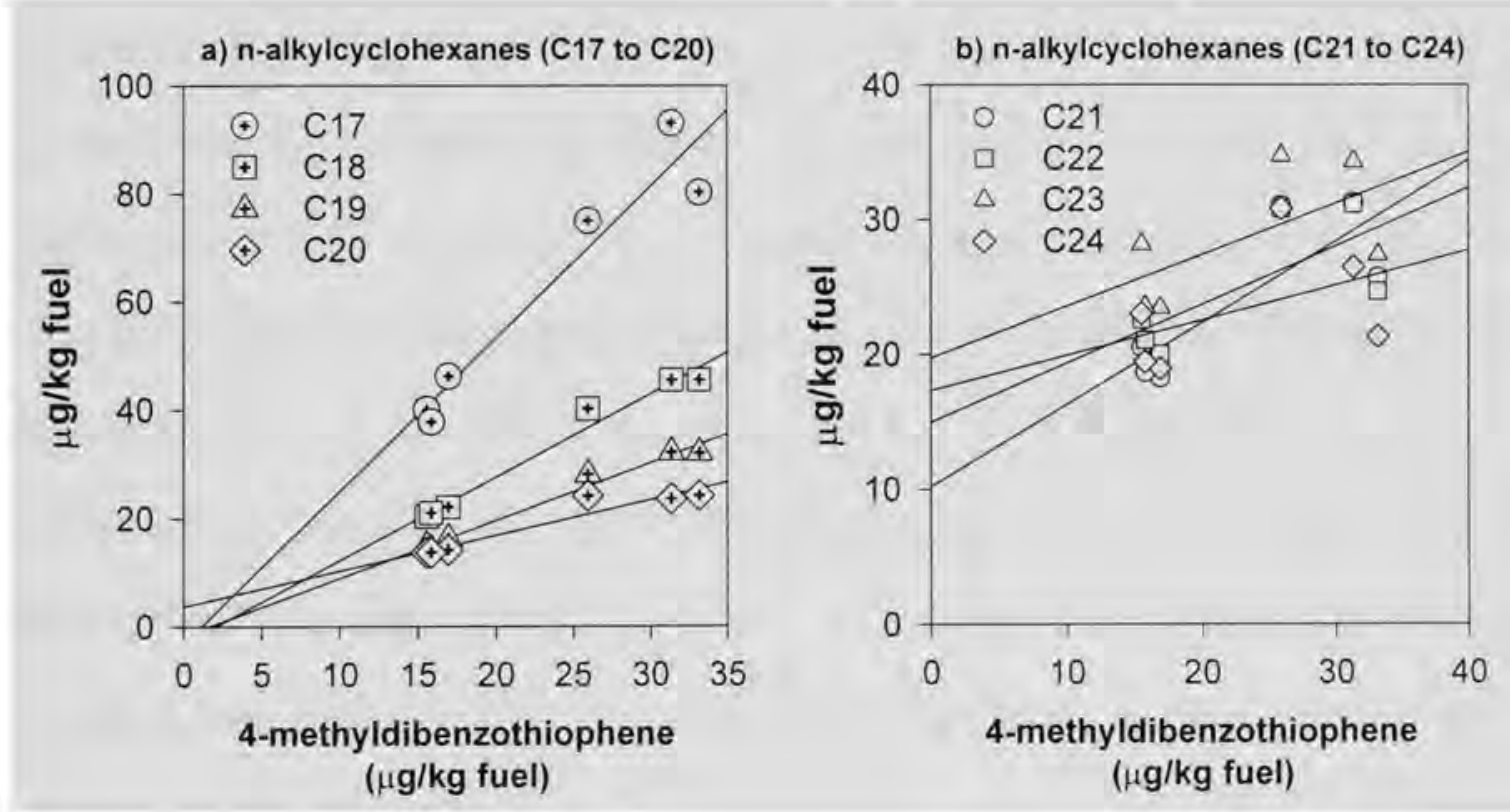

Figure 2.4: Scatter plots of the emission factors of 4-methyldibenzothiophene vs. those of individual $n$-alkylcyclohexanes measured in the Squirrel Hill Tunnel. $\mathrm{R}^{2}$ ranges and slopes for homologues in increasing order of carbon number are, respectively: (a) $0.978>R^{2}>0.910 ; 2.82,1.55,1.06$, and 0.66 , (b) $0.671>R^{2}>0.211 ; 0.61,0.44,0.33,0.26$.

In addition, correlations of the emission factors of individual n-alkylcyclohexanes homologues with 4,6-dimethyldibenzothiophene are shown in Figure 2.4. The $\mathrm{R}^{2}$ for homologues $\mathrm{C} 17-\mathrm{C} 20$ (Figure $2.4 \mathrm{a}$ ) is remarkably high, $0.98 \pm 0.02$, with a nearly zero 
intercept for all four lines, and a steadily decreasing slope from $\mathrm{C} 17$ to $\mathrm{C} 20$. On the other hand, the correlation of the emission factors of each of the subsequent five homologues, $\mathrm{C} 21$ to $\mathrm{C} 25$, with the corresponding 4,6-dimethyldibenzothiophene displays a similar slope and, most importantly, the intercept is greater than zero (Figure $2.4 \mathrm{~b}$ ). Altogether these results support the conclusion presented in section 2.3 .1 based solely on the comparison of data from this study with that available from the literature.

In order to interpret the remaining associations observed for dibenzothiophene and benzo[b]naphtho[2,1-d]thiophene, some basic premises about the origin of these compounds must first be established. Normal commercial diesel and gasoline fuels sold in the Pittsburgh area at the time of the study were nominally less than 500 and 300 ppmw, respectively. Organic sulfur is present in gasoline mainly in the form of thiophene, alkyl-thiophenes, benzothiophene, and methyl-/dimethyl-benzothiophene, all gas-phase associated compounds. The semi-volatiles dibenzothiophene and its methyland dimethyl- derivatives are relatively abundant in diesel fuel, even in ultra-low sulfur diesel (Schade and Anderson, 2006). Furthermore, the specificity of these organic sulfur compounds in gasoline and diesel has also been confirmed for local, Pennsylvania, samples of the fuels (Ma et al., 2002); explicitly, gas chromatography with flame photometric detection analysis in their study indicates that dibenzothiophene and its methyl- dimethyl- and trimethyl- derivatives are present in diesel but not in gasoline.

Previous dynamometer studies by Schauer and collaborators have reported the emission of dibenzothiophene in the fine particle emissions from vehicular exhausts at the following rates: $4.74 \mu \mathrm{g} / \mathrm{kg}$ for emissions from diesel-powered (1999), and 2.67 $\mu \mathrm{g} / \mathrm{kg}$ fuel and $143.6 \mu \mathrm{g} / \mathrm{kg}$ respectively for emissions from catalyst-equipped and 
noncatalyst equipped gasoline-powered vehicles (2002). That is, the relative contribution of dibenzothiophene from the three types of vehicles has a pattern noncatalyst:catalyst:diesel equal to $54: 1: 1.8$, indicating a disproportionately larger input from noncatalyst equipped gasoline vehicles. Since dibenzothiophene is not present in gasoline fuel itself, the implications are that if this compound is observed in the exhaust from HDDVs it may be indicative of directly volatilized diesel fuel; in contrast, if observed in exhaust from gasoline-powered vehicles it must have other sources. Some possibilities are chemical transformation involving sulfur compounds present in gasoline or lubricating oil.

The particle-phase compound benzo[b]naphtho[2,1-d]thiophene has been identified in the exhaust from diesel and gasoline engines. Data obtained from dynamometer measurements has been reported for in-use gasoline-powered vehicles (Norbeck et al., 1998), light-duty and heavy-duty diesel-powered vehicles (Zielinska et al., 1998), light-/medium-duty diesel-powered and gasoline-powered vehicles (Zielinska et al., 2004b), two-stroke vehicles powered by gasoline (Mayer et al., 1999), and experimental tests using a diesel generator (Liang et al., 2006). The trends among the published results indicate that emission factors of this compound are highly variable for both types of engines. Among gasoline vehicles, the dynamometer tests performed by Norbeck et al. (1988) yield an average emission factor, for the 25 vehicles tested, of 0.70 $\mu \mathrm{g} / \mathrm{kg}$ fuel (range $0-2.8 \mu \mathrm{g} / \mathrm{kg}$ fuel) and factors were found to be two to three times larger (1.4 to $8.4 \mu \mathrm{g} / \mathrm{kg}$ fuel) for the older vehicles in the fleet, those using carburetor and equipped with oxidation catalyst emission control. In the Zielinska et al., 2004b study the emission factor of this compound for gasoline-powered vehicles emitting visible "white 
smoke" (vehicles that may burn lubricating oil) is reported as $195 \mu \mathrm{g} / \mathrm{kg}$ fuel, for normaland high-emitter diesel-powered vehicles the emission factors are $38 \mu \mathrm{g} / \mathrm{kg}$ fuel and 1.2 $\mu \mathrm{g} / \mathrm{kg}$ fuel, respectively, and for "black smokers" (vehicles that burn excess fuel or "fuelrich" mixture) and normal emitter gasoline-powered vehicles $6 \mu \mathrm{g} / \mathrm{kg}$ fuel and $13.3 \mu \mathrm{g} / \mathrm{kg}$ fuel, respectively. That is, a pattern "white smoker" gasoline:"black smoker" gasoline:normal gasoline:diesel:high-emitter diesel equal to 15:0.4:1:3:0.1.

Recently Liang et al. (2006) investigated the composition of the fine particles emitted from a diesel-powered generator at various engine operating conditions and fuel sulfur contents. In their study, benzo[b]naphtho[2,1-d]thiophene was detected in the fine particles emitted by the diesel-powered generator operating under different load conditions but it was not detected in samples of fresh diesel with nominal sulfur contents of 400 ppmw and 2000 ppmw used for the experiments. Therefore, the authors concluded that this compound is generated during the combustion process.

Laboratory experiments conducted by Winkler et al., (2002) with the objective to investigate the products of the gas-phase pyrolysis and related reactions that can occur during combustion of various organic-sulfur compounds support the notion that the benzo[b]naphtho[2,1-d]thiophene measured in the aerosol from vehicular exhaust is from pyrolytic origin. In addition, their findings also offer plausible explanations for the origin of dibenzothiophene in the exhausted particles. Results from their study show that above $800^{\circ} \mathrm{C}$ the gas-phase pyrolysis of thiophene produces benzothiophene (29\%) and dibenzothiophene (11\%), and the pyrolysis of benzothiophene produces benzo[b]naphtho[2,1-d]thiophene (11\%); furthermore, authors also observed an increased thermal stability in the order dibenzothiophene $>$ benzothiophene $>$ thiophene. That is, 
while only $12 \%$ of unreacted thiophene was found in the pyrolysate, the ureacted proportions of benzothiophene and dibenzothiophene were found to be $56 \%$ and $86 \%$ respectively. This information support the conclusion that the dibenzothiophene measured in the emissions from diesel-powered vehicles is associated to unburned fuel while that form gasoline-powered vehicles is associated to burned fuel. Consequently, it can be concluded that the similarity of patterns shown in Figure 2.2 a,b reflects that, throughout all driving situations, larger emissions of the $1 \mathrm{mw}-\mathrm{PAH}$ are more associated to diesel fuel.

The sampling information presented in Table 2.1 indicates that about 11 and 231 additional HDDVs and gasoline vehicles, respectively, were sampled in RH2 compared to RH1. In contrast, sample RH3 was representative of approximately 20 to 30 fewer HDDVs but sampled approximately 3,000 additional gasoline vehicles traveling at the lower speed and more transient conditions of the "rush hour" sampling period. The measured emission factor of hopanes, dibenzothiophene and the methyl/dimethyldibenzothiophene for RH1, RH2 and RH3 are very similar. Likewise, the ratio of 4-methyldibenzothiophene and 4,6-dimethyldibenzothiophene to dibenzothiophene is very similar throughout all six samples displaying variations of $11 \%$ and $14 \%$ respectively; corresponding ratios are $0.6 \pm 0.1$ and $0.32 \pm 0.04$. On the other hand, the ratio of benzo[b]naphtho[2,1-d]thiophene to dibenzothiophene displays a greater variation; dibenzo[b]naphtho[2,1-d]thiophene represents only $2-8 \%$ of the emission of dibenzothiophene in all samples except in sample RH3 when it increases to $36 \%$. If the much larger emission factor of dibenzo[b]naphtho[2,1-d]thiophene in sample RH3 would be associated to burning of gasoline, for example, one would also expect to observe the 
effect on a larger emission of dibenzothiophene particularly since 3,000 more cars are sampled during RH3 than RH1 or RH2. Furthermore, there is no evidence of more fuel consumption during the RH3 sampling period compared to the other two. Figure $2.3 \mathrm{~b}$ indicates that any combination of samples reflects a negative slope; that is, the largest impact on this specie is likely to be caused by gasoline-powered cars. According to the previous literature results presented above, a plausible explanation is that the notably larger emission factor of dibenzo[b]naphtho[2,1-d]thiophene in sample RH3 is associated to gasoline vehicles that are passing lubrication oil. This would also explain the larger emission factors of the hmw-PAHs in this sample, as it has been reported that the lubricating oil in gasoline vehicles, but not diesel-powerd vehicles, absorbs and concentrates particle-phase PAHs that are formed during combustion (Zielinska et al., 2004b) which are then partly reflected in the emissions. Lastly, these reasons are also supported by findings that lubrication oil and fuel make separate and distinct contributions to particulate matter from motor vehicles (Kleeman et al., 2008).

\subsubsection{Tire Wear Marker: Benzothiazole}

The organic compounds that are measured in the PM 2.5 samples collected inside a tunnel environment reflect both direct primary emissions from the vehicles' exhausts and non-exhaust emissions. The latter may include species that originate from the wear of tires and brakes as well as the re-suspension of road dust. Benzothiazole is one of the degradation products of the accelerators used in the vulcanization process of tire manufacturing. Rogge et al. (1993b) detected this compound in the particles from tire wear and in the PM2.5 from re-suspended road dust from Pasadena, CA. Benzothiazole 
has also been detected in residential, highway and road dusts from Narraganset, RI (Reddy et al., 1997). In the Reddy et al. study (1997), benzothiazole was identified in radiator antifreeze liquid; however, it was concluded that the major source of benzothiazole in the road dust was from leaching of rubber material. Therefore, benzothiazole measured in the tunnel environment is expected to be originated from particles of rubber tires or the re-suspension of road dust containing tire debris.

Benzothiazole comprises from $3 \%$ to $19 \%$ of the total emission of identified compounds in each tunnel sample. The largest emissions were measured during the RH period. Tire wear particles are generated during the rolling shear of the tire tread against the road surface (Rogge et al., 1993b); therefore, if tire wear alone would be the determinant factor of the measured benzothiazole, one would expect, to some extent, proportionality with the number of vehicles sampled. Figure 2.5 shows the emission factors of benzothiazole measured in each sample with the corresponding traffic volume flow in vehicles/h. It can be seen that an increase of over three-fold in the vehicles/hour sampled during MD compared to EM does not have a significant effect on the emission factor of benzothiazole (average emission for EM period $202 \pm 64 \mathrm{ug} / \mathrm{kg}$ fuel; MD 255 $\mathrm{ug} / \mathrm{kg}$ fuel). Rather, the largest increase is observed in the samples from the RH period. The average speed during the rush hour was 31-35 miles/hour, indicating more braking compared to the other two periods, when the average speed was 51-58 miles/hour. These results suggest that hindered traffic flow such as that occurring during transient/creep driving conditions has a large impact on the measured amount of benzothiazole. Further evidence is provided by the similarity of the emission pattern of benzothiazole through the three driving periods to that reported by Grieshop et al (2006) for the metals 
associated to brake-wear, $\mathrm{Ba}, \mathrm{Cu}$ and $\mathrm{Sb}$; that is, the emission of these metals was also observed to be significantly higher only during the RH period.

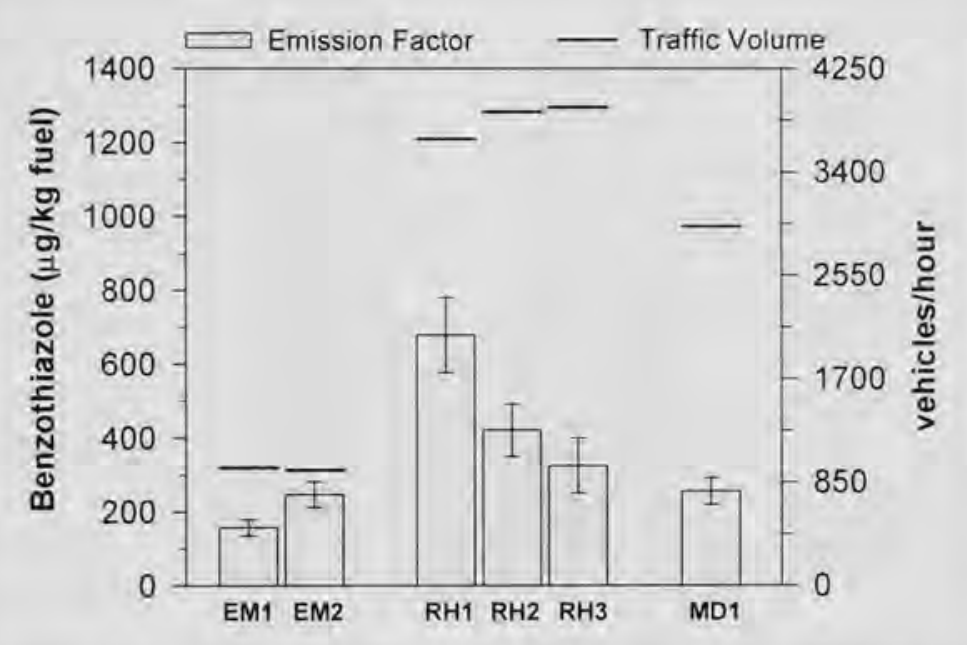

Figure 2.5: Total traffic volume and corresponding emission factors of benzothiazole measured in the Squirrel Hill Tunnel.

\subsubsection{Emission Profiles for Heavy-duty Diesel and Light-duty Gasoline Vehicles}

One of the objectives of this study was to derive organic profiles for LDVs and HDDVs. The fraction of HDDVs in the fleet during the sampling campaign ranges from $3 \%$ to $13 \%$ by number count and from $11 \%$ to $31 \%$ fuel-based. A strong linear association is observed between the emission of individual organic compounds and the fuel-based fraction of HDDVs suggesting that profiles for LDVs and HDDVs can be segregated using linear regression model. Previous studies have used this method to derive emission factors for the major exhaust's gas pollutants (Pierson et al., 1996) and for VOCs (Zielinska et al., 1996). As explained in the previous sections, practically all compounds including the lmw-PAHs follow a proportionally increasing emission factor 
Table 2.2: Organic Profiles $(\mu \mathrm{g} / \mathrm{kg}$ fuel) for LDVs and HDDVs Derived from Measurements in the Squirrel Hill Tunnel

\begin{tabular}{|c|c|c|c|c|}
\hline Compounds ${ }^{1}$ & LDV & HDDV & $\begin{array}{c}R^{2} \\
\left(\text { see Note }{ }^{2}\right)\end{array}$ & $\begin{array}{c}\text { Compound } \\
\text { ID }^{4}\end{array}$ \\
\hline \multicolumn{5}{|l|}{ n-Alkanes } \\
\hline Nonadecane & $150 \pm 54.6$ & $2,332 \pm 391$ & 0.8988 & a \\
\hline Eicosane & $103 \pm 28.3$ & $1,603 \pm 185$ & 0.9494 & a \\
\hline Heneicosane & $83.1 \pm 20.4$ & $1,115 \pm 161$ & 0.9231 & a \\
\hline Docosane & $73.6 \pm 16.9$ & $775 \pm 137$ & 0.8892 & a \\
\hline Tricosane & $63.2 \pm 14.6$ & $558 \pm 119$ & 0.8438 & a \\
\hline Tetracosane & $37.9 \pm 5.9$ & $306 \pm 51.3$ & 0.8762 & a \\
\hline Pentacosane & $38.1 \pm 5.6$ & $179 \pm 39.1$ & 0.8392 & a \\
\hline Hexacosane & $17.4 \pm 3.3$ & $117 \pm 25.8$ & 0.8365 & a \\
\hline Heptacosane & $2.1 \pm 1.6$ & $76.5 \pm 13.6$ & 0.8884 & a \\
\hline Octacosane & $2.6 \pm 1.2$ & $53.4 \pm 8.01$ & 0.9173 & a \\
\hline Nonacosane & $3.8 \pm 1.7$ & $33.0 \pm 10.2$ & 0.6669 & a \\
\hline Triacontane & $2.2 \pm 1.6$ & $22.3 \pm 11.1$ & 0.4699 & a \\
\hline \multicolumn{5}{|l|}{ n-Alkylcyclohexanes } \\
\hline Undecylcyclohexane & $13.6 \pm 5.2$ & $265 \pm 40.1$ & 0.8907 & $\mathrm{~b}$ \\
\hline Dodecylcyclohexane & $7.9 \pm 3.7$ & $135 \pm 32.7$ & 0.8097 & a \\
\hline Tridecylcyclohexane & $5.9 \pm 2.6$ & $94.0 \pm 22.7$ & 0.8110 & $b$ \\
\hline Tetradecylcyclohexane & $7.9 \pm 2.1$ & $64.9 \pm 14.5$ & 0.8338 & $b$ \\
\hline Pentadecylcyclohexane & $11.4 \pm 1.3$ & $77.6 \pm 7.1$ & 0.9675 & $b$ \\
\hline Hexadecylcyclohexane & $14.8 \pm 1.5$ & $67.8 \pm 8.9$ & 0.9358 & a \\
\hline Heptadecylcyclohexane & $18.7 \pm 2.2$ & $69.9 \pm 16.0$ & 0.8271 & a \\
\hline Octadecylcyclohexane & $15.2 \pm 2.8$ & $57.2 \pm 20.4$ & 0.6629 & $b$ \\
\hline Nonadecylcyclohexane & $9.5 \pm 1.6$ & $46.0 \pm 10.8$ & 0.8196 & a \\
\hline Eicosylcyclohexane & $4.5 \pm 1.6$ & $35.0 \pm 11.8$ & 0.6877 & b \\
\hline Heneicosylcyclohexane & $2.4 \pm 1.2$ & $15.8 \pm 9.0$ & 0.4317 & $b$ \\
\hline Docosylcyclohexane & $0.87 \pm 0.40$ & $7.1 \pm 2.3$ & 0.6075 & $b$ \\
\hline \multicolumn{5}{|l|}{ Hopanes } \\
\hline $\begin{array}{l}17 \alpha(\mathrm{H})-22,29,30 \text {-trisnorhopane } \\
\text { (H1) }\end{array}$ & $7.9 \pm 0.5$ & $26.2 \pm 6.9$ & 0.7835 & a \\
\hline $17 \alpha(\mathrm{H}), 21 \mathrm{~b}(\mathrm{H})-29$-norhopane $(\mathrm{H} 2)$ & $26.8 \pm 4.2$ & $135 \pm 38.8$ & 0.7484 & b \\
\hline $17 \alpha(H), 21 \beta(H)$-hopane $(H 3)$ & $12.8 \pm 1.49$ & $77.0 \pm 13.5$ & 0.8638 & a \\
\hline $\begin{array}{l}22-\mathrm{S}, 17 \alpha(\mathrm{H}), 21 \beta(\mathrm{H})-30- \\
\text { homohopane }(\mathrm{H} 4)\end{array}$ & $6.1 \pm 0.9$ & $40.8 \pm 7.7$ & 0.8629 & c \\
\hline $\begin{array}{l}22-\mathrm{R}, 17 \alpha(\mathrm{H}), 21 \beta(\mathrm{H})-30- \\
\text { homohopane }(\mathrm{H} 5)\end{array}$ & $4.96 \pm 0.56$ & $27.0 \pm 5.3$ & 0.8381 & $\mathrm{c}$ \\
\hline $\begin{array}{l}22-\mathrm{S}, 17 \alpha(\mathrm{H}), 21 \beta(\mathrm{H})-30- \\
\text { bishomohopane }(\mathrm{H} 6)\end{array}$ & $3.44 \pm 0.34$ & $22.3 \pm 3.5$ & 0.8580 & c \\
\hline $\begin{array}{l}22-\mathrm{R}, 17 \alpha(\mathrm{H}), 21 \beta(\mathrm{H})-30- \\
\text { bishomohopane }(\mathrm{H} 7)\end{array}$ & $2.72 \pm 0.42$ & $14.5 \pm 4.0$ & 0.7617 & $\mathrm{c}$ \\
\hline
\end{tabular}

Table continues in next page 
Table 2.2: continuation

\begin{tabular}{|c|c|c|c|c|}
\hline Compounds ${ }^{1}$ & LDV & HDDV & $\begin{array}{c}\mathrm{R}^{2} \\
\left(\text { see Note } \text { Not }^{2}\right) \\
\end{array}$ & $\begin{array}{c}\text { Compound } \\
1 \mathrm{D}^{4}\end{array}$ \\
\hline \multicolumn{5}{|l|}{ Steranes } \\
\hline $20 \mathrm{R}-5 \alpha(\mathrm{H}), 14 \beta(\mathrm{H}), 17 \beta(\mathrm{H})-$ & & & & \\
\hline Cholestane (S1) & $7.4 \pm 0.7$ & $26.3 \pm 5.1$ & 0.8712 & a \\
\hline $20 \mathrm{~S}-5 \alpha(\mathrm{H}), 14 \beta(\mathrm{H}), 17 \beta(\mathrm{H})$ & & & & \\
\hline Cholestane (S2) & $5.0 \pm 0.7$ & $21.3 \pm 5.9$ & 0.7631 & $b$ \\
\hline $20 \mathrm{R}-5 \alpha(\mathrm{H}), 14 \beta(\mathrm{H}), 17 \beta(\mathrm{H})$ & & & & \\
\hline Ergostane (S4) & $5.3 \pm 0.5$ & $28.6 \pm 3.7$ & 0.9389 & $b$ \\
\hline $20 \mathrm{~S}-5 \alpha(\mathrm{H}), 14 \beta(\mathrm{H}), 17 \beta(\mathrm{H})$ & & & & \\
\hline Ergostane (S5) & $4.1 \pm 0.2$ & $15.5 \pm 1.5$ & 0.9656 & $b$ \\
\hline $20 \mathrm{R}-5 \alpha(\mathrm{H}), 14 \beta(\mathrm{H}), 17 \beta(\mathrm{H})$ & & & & \\
\hline Sitostane (S6) & $9.3 \pm 1.2$ & $45.1 \pm 10.0$ & 0.8347 & $\mathrm{~b}$ \\
\hline $20 \mathrm{~S}-5 \alpha(\mathrm{H}), 14 \beta(\mathrm{H}), 17 \beta(\mathrm{H})-$ & & & & \\
\hline Sitostane (S7) & $6.7 \pm 1.0$ & $47.0 \pm 8.5$ & 0.8528 & b \\
\hline \multicolumn{5}{|l|}{$\mathrm{PAHs}^{3}$} \\
\hline Phenanthrene (Phen) & $145 \pm 67.1$ & $2,069 \pm 333$ & 0.9280 & a \\
\hline Anthracene (Anth) & $23.4 \pm 13.3$ & $334 \pm 63.6$ & 0.9021 & a \\
\hline Cyclopentaphenanthrene (Cyphen) & $4.5 \pm 1.3$ & $76.8 \pm 6.2$ & 0.9808 & a \\
\hline Fluoranthene (Fluo) & $25.9 \pm 3.2$ & $438 \pm 15.3$ & 0.9963 & a \\
\hline Pyrene (Pyre) & $44.4 \pm 4.2$ & $449 \pm 20.6$ & 0.9937 & a \\
\hline Benzo[a]anthracene $(\mathrm{BaA})$ & $10.4 \pm 3.5$ & $48.2 \pm 21.2$ & 0.6325 & a \\
\hline Chrysene/Triphenylene $(\mathrm{Ch} / \mathrm{Tr})$ & $11.0 \pm 1.7$ & $47.0 \pm 21.4$ & 0.6156 & $\mathrm{a}$ \\
\hline Benzo[b]fluoranthene (BbF) & $11.1 \pm 2.1$ & $33.0 \pm 31.0$ & 0.2751 & a \\
\hline Benzo[k]fluoranthene (BkF) & $6.4 \pm 0.8$ & $1.2 \pm 1.0$ & 0.4025 & a \\
\hline Benzo[j]fluoranthene (BjF) & $1.9 \pm 0.7$ & $10.1 \pm 4.2$ & 0.6554 & a \\
\hline Benzo[e]pyrene $(\mathrm{BeP})$ & $9.6 \pm 1.9$ & $22.3 \pm 16.1$ & 0.3904 & $\mathrm{a}$ \\
\hline Benzo[a]pyrene (BaP) & $9.6 \pm 1.2$ & $19.3 \pm-14.3$ & 0.1949 & a \\
\hline Perylene (Pery) & $1.98 \pm 0.03$ & $0.0 \pm 0.03$ & 0.0086 & a \\
\hline Indeno[1,2,3-cd]pyrene (IcdP) & $9.4 \pm 2.5$ & $0.0 \pm 0.5$ & 0.1505 & a \\
\hline Benzo[g,h,i]perylene (BghiP) & $19.4 \pm 2.1$ & $0.0 \pm 0.6$ & 0.4234 & a \\
\hline Dibenzo[a,h]anthracene (DahA) & $0.77 \pm 0.19$ & $0.0 \pm 0.8$ & 0.0860 & a \\
\hline Coronene (Coro) & $11.2 \pm 2.6$ & $0.00 \pm 0.57$ & 0.6712 & a \\
\hline \multicolumn{5}{|l|}{ oxy-PAHs } \\
\hline 9-Fluorenone (9-Fluo) & $45.8 \pm 10.7$ & $467 \pm 80.6$ & 0.8934 & a \\
\hline 9,10 -Anthracenedione $(9,10-$ Anth $)$ & $15.9 \pm 3.39$ & $192 \pm 23.0$ & 0.9455 & a \\
\hline $\begin{array}{l}\text { 7H-Benz[de]anthracen-7-one } \\
(7 \mathrm{H}-\mathrm{BdeA})\end{array}$ & $7.1 \pm 0.2$ & $36.2 \pm 4.66$ & 0.8207 & a \\
\hline $\begin{array}{l}\text { Benz[a]anthracen-7,12-dione } \\
(\mathrm{BaA}-7,12 \mathrm{O})\end{array}$ & nd & nd & & a \\
\hline 7,8-Benzoquinoline (7,8Bqui) & $1.5 \pm 0.3$ & $5.6 \pm 1.6$ & 0.8207 & b \\
\hline \multicolumn{5}{|l|}{ Dicarboxylic acids } \\
\hline $\begin{array}{l}\text { 1,3-benzenedicarboxylic acid- } \\
\text { (Isophthalic Acid) }\end{array}$ & $0.94 \pm 0.50$ & $9.3 \pm 2.5$ & 0.736 & a \\
\hline
\end{tabular}

Table continues in next page 
Table 2.2: continuation

\begin{tabular}{|c|c|c|c|c|}
\hline Compounds ${ }^{1}$ & LDV & HDDV & $\begin{array}{c}\mathrm{R}^{2} \\
\left(\text { see } \text { Note }^{2} \text { ) }\right.\end{array}$ & $\begin{array}{c}\text { Compound } \\
\text { ID }^{4}\end{array}$ \\
\hline \multicolumn{5}{|l|}{ n-Alkanoic acids } \\
\hline Decanoic Acid & $7.6 \pm 7.6$ & $137 \pm 49.1$ & 0.6615 & a \\
\hline Undecanoic Acid & $21.2 \pm 4.8$ & $113 \pm 28.0$ & 0.8019 & a \\
\hline Dodecanoic Acid & \pm & $302 \pm 156$ & 0.4788 & a \\
\hline Tridecanoic Acid & $5.9 \pm 2.1$ & $37.1 \pm 15.6$ & 0.5760 & a \\
\hline Tetradecanoic Acid & ns & $229 \pm 87.6$ & 0.6303 & a \\
\hline Pentadecanoic Acid & ns & $65.5 \pm 6.3$ & 0.9647 & $\mathrm{a}$ \\
\hline Hexadecanoic Acid & ns & $759 \pm 66.4$ & 0.9372 & a \\
\hline Heptadecanoic Acid & ns & $46.1 \pm 5.71$ & 0.8870 & a \\
\hline Octadecanoic Acid & ns & $420 \pm 111$ & 0.6970 & a \\
\hline Nonadecanoic Acid & ns & $18.5 \pm 3.7$ & 0.7901 & a \\
\hline Eicosanoic Acid & ns & $45.3 \pm 11.1$ & 0.7265 & a \\
\hline Heneicosanoic Acid & $\mathrm{ns}$ & $26.2 \pm 9.2$ & 0.5757 & a \\
\hline \multicolumn{5}{|l|}{ Organic sulfur compounds } \\
\hline Dibenzothiophene (DbT) & $20.0 \pm 6.0$ & $119 \pm 34.4$ & 0.5900 & a \\
\hline \multirow{3}{*}{$\begin{array}{l}\text { 4-methyldibenzothiophene (mDbT) } \\
\text { 4,6-dimethyldibenzothiophene } \\
\text { (dmDbT) } \\
\text { Benzo[b]naphtho[2,1-d]thiophene } \\
\text { (BbNT) }\end{array}$} & $8.5 \pm 5.0$ & $84.2 \pm 27.9$ & 0.6941 & b \\
\hline & $3.4 \pm 2.4$ & $51.1 \pm 13.3$ & 0.7870 & b \\
\hline & $8.5 \pm 4.5$ & $0.0 \pm 21.0$ & 0.2661 & b \\
\hline \multicolumn{5}{|l|}{ Other } \\
\hline 1-naphthalenecarboxaldehyde & $50.4 \pm 6.4$ & $200 \pm 40.4$ & 0.8558 & $\mathrm{~b}$ \\
\hline 2-naphthalenecarboxaldehyde & $72.4 \pm 3.4$ & $219 \pm 23.6$ & 0.9955 & $\mathrm{~b}$ \\
\hline
\end{tabular}

1 Abbreviations given in parenthesis

${ }^{2}$ Split for all individual compounds with the exception of PAHs was calculated using the values from all six available samples.

${ }^{3}$ For these compounds, calculations were performed using five samples; i.e., excluding RH3.

${ }^{4}$ Compound identification: a, authentic standard verification and quantification; $b$, MSspectrum verification and quantified using authentic standard with similar structure, polarity, and volatility; c, NIST sample-spectrum verification and quantified using authentic standard with similar structure.

nd $=$ not detected

ns $=$ not a significant source

with increasing fuel-fraction of HDDVs including data from all six samples. In addition, excluding sample RH3 to calculate segregated contribution of the hmw-PAHs improves 
the correlation but it does not significantly change the trend. Fleet-segregated emission factors obtained by linear regression are presented in Table 2.2 .

\subsubsection{Comparison to Results from Other Studies}

For the majority of the organic compounds measured in this study, our data indicates that the most noticeable effect on the aggregate emissions measured in the tunnel are those that reflect primarily the fraction of diesel-powered vehicles, assuming that all heavy-duty vehicles are diesel-powered and the remaining vehicles in the fleet are gasoline-powered. The major exception are the hmw-PAHs and the combustion derived organic-sulfur compound dibenzo[b]naphtho[2,1-d]thiophene. Even these, appear to be associated to causes that are transient in nature rather than revealing a relationship to parameters of the fleet driving mode per se, such as for example vehicle speed.

Previous studies which report emission factors for a suite of organic compounds similarly comprehensive to that described here have only been conducted for three roadway tunnels in the U.S, the Van Nuys Tunnel, CA (Fraser et al., 1998), the Washburn Tunnel, TX (Chellam et al., 2005), and the most recent emission measurements in the Caldecott Tunnel, CA (Phuleria et al., 2006). Comparison of data measured in the Squirrel Hill Tunnel to that from these three previous tunnel studies is presented in Figure 2.6. In order to maintain consistency, all needed conversions to achieve common units of emission factors $(\mu \mathrm{g} / \mathrm{kg}$ fuel) were performed considering average fleet fuel consumption values for LDVs and HDDVs of 12 and 47 liters $/ 100 \mathrm{~km}$ respectively (Pierson et al., 1996), together with the corresponding reported values of fleet compositions and background-corrected $\mathrm{CO}_{2}$ and $\mathrm{CO}$ in each of the studies. The 
fleet consumption values used are considered to be still valid during the studied period (Grieshop et al., 2006).

Figure 2.6 shows that the emission factors measured in the Squirrel Hill Tunnel are, for all species considered, within the range of the values published for the Washburn Tunnel, TX and the Caldecott Tunnel, CA. On the other hand, the values from the Van Nuys Tunnel, CA are appreciable larger than the others. The largest differences are observed for hopanes, particularly $17 \alpha(\mathrm{H}), 21 \beta(\mathrm{H})$-29-norhopane and $17 \alpha(\mathrm{H}), 21 \beta(\mathrm{H})$ hopane (H1, H2, Figure 2.6 a), n-alkanes (Figure $2.6 \mathrm{f}$ ) and the Imw-PAHs (Figure $2.6 \mathrm{~b}$ ), while smaller differences are observed for the hmw-PAHs (Figure $2.6 \mathrm{c}$,e) with the exception of benzo[g,h,i]perylene (BghiP, Figure $2.6 \mathrm{~d}$ ). The larger emission factors of the lower n-alkylcyclohexanes homologues C17-C22 (Figure $2.6 \mathrm{~h}$ ) measured in the Van Nuys tunnel is surprising. The sampling in the Washburn tunnel was conducted on quartz filter only while in the Squirrel Hill a backup PUF was used in addition; for this reason, the larger emission factors of the n-alkanes C 20-C22 measured in the Squirrel Hill compared to those in Washburn could be explained by evaporative losses from the filter; however, for the same reason it emphasizes the preponderance of the lower molecular weight n-alkylcyclohexanes homologues measured in the Washburn Tunnel, even when sampling on quartz filter only. Measurements in the Van Nuys Tunnel were conduced in 1993; therefore, it is possible that the higher emissions could in part be explained by the advancements in technology or fuel specifications. However, it is important to highlight once again that while larger differences are observed in some of the organic compounds, other, particularly the hmw-PAHs have not changed as much by comparison, with the exception of the benzo[g,h,i]perylene. 


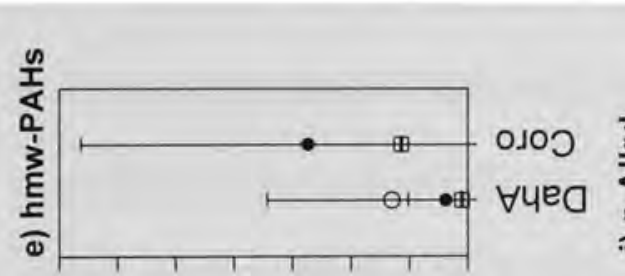

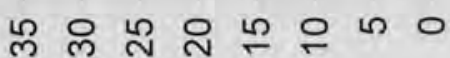

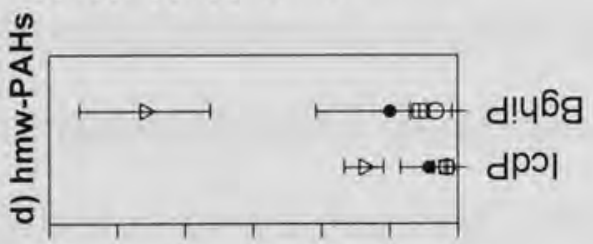

윰 용 \&
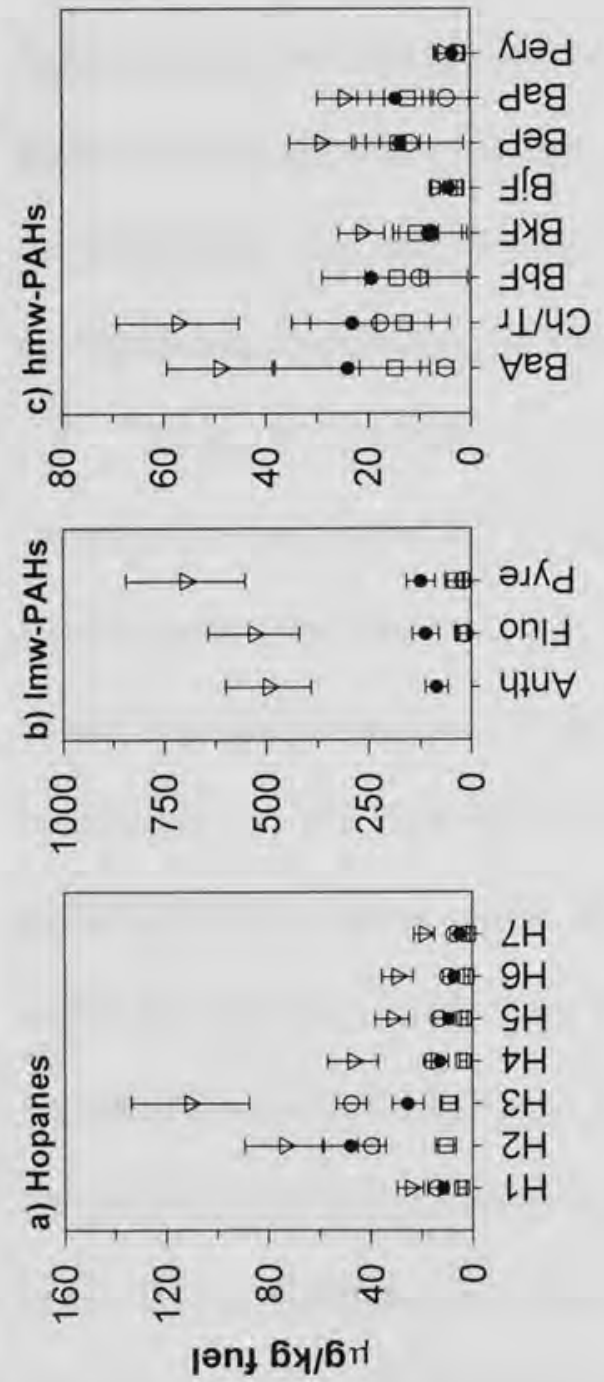
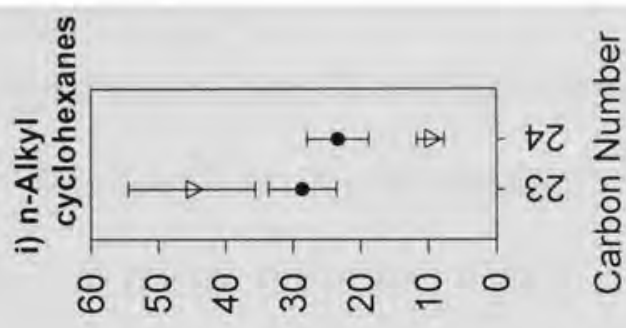

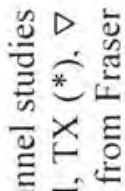

$\leqq \dot{\Xi}$

可

¿ $=\frac{1}{0}$

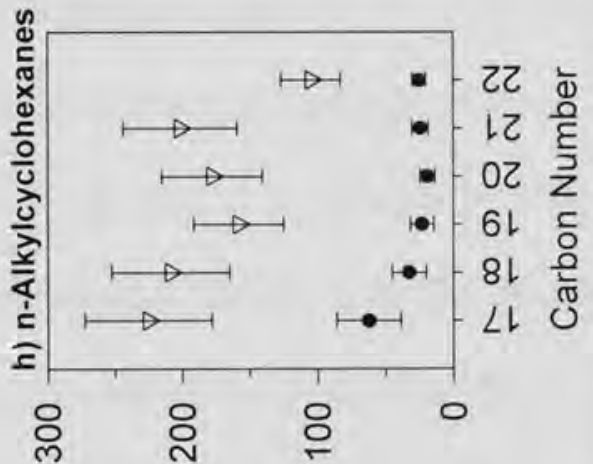

¿

व

药》

व $0 \equiv$

E $<F$

账

$\sum_{0}^{\infty} \overrightarrow{0}$

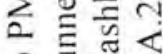

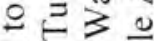

氖总

.

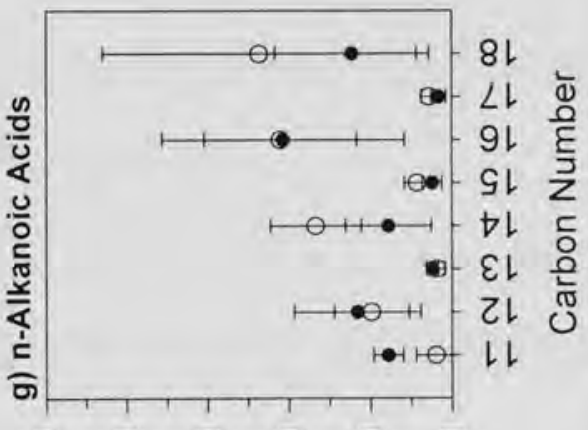

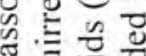

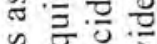

ป

○. 음

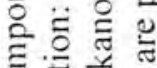

氖兰嵒

O

氜*

का 뜐

$\div$ บ

0

융ㅇㅇㅇㅇ 응 导导主

흘 总

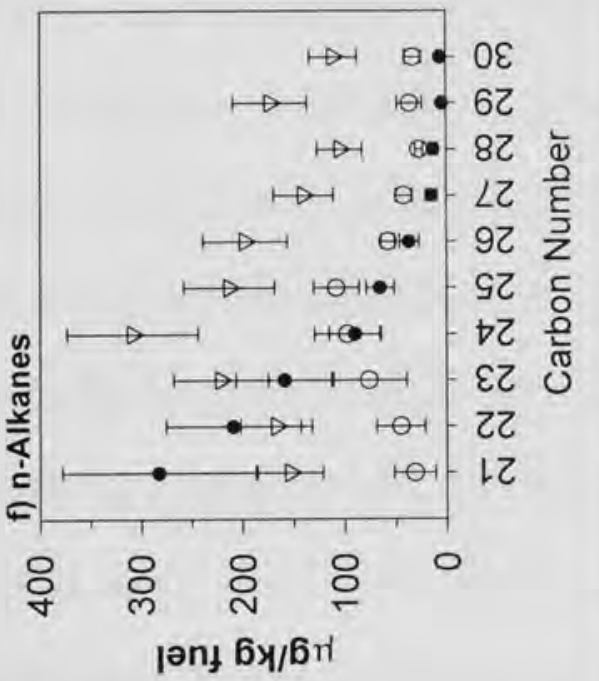


Separate LDVs- and HDDVs- emission factors of organic compounds associated to fine particles derived from measurements conducted in roadway tunnels has only been reported for the Caldecott Tunnel. This tunnel has the advantage of having one of its three bores restricted to LDV traffic only during selected diurnal periods; therefore, the approach followed there consists of conducting measurements during the diurnal period of maximum HDDV fraction (about 4\%) in the truck-influenced bore, and during the period of peak LDVs traffic volume in the bore not allowed to HDDVs. Then, the emission factors for the LDDVs are calculated directly from the measurements in the light-duty-only bore using a carbon balance approach analogous to the one described here for the Squirrel Hill Tunnel in the introduction to section 2.3, and the emission factors for the HDDVs are calculated by subtracting the apportioned contribution of LDVS from the measurements conducted in the truck-influenced bore.

Figure 2.7 presents a comparison of the emission factors of selected organic compounds separated for LDVs and HDVs as determined in the Squirrel Hill Tunnel with those derived from three separate studies conducted in the Caldecott Tunnel as well as values reported from dynamometer testing. Lack of consistency in the list of targeted compounds in the different studies complicates comparison; nonetheless, several meaningful observations can be identified. To begin with, our results are well distributed within the spread of literature values on both sides, the LDDVs and the HDDVs. This is very important to consider, particularly for the two hmw-PAHs benzo[g,h,i]perylene and coronene (Figures $2.7 \mathrm{~g}, \mathrm{~h}$ ) which appear to be emitted predominantely by LDVs (Rogge et al., 1993a; Zielinska et al., 2004; Riddle etl al., 2007 a,b; Fujita et al., 2007). Next, there is consistency of the emission factors of more than one organic compound derived 

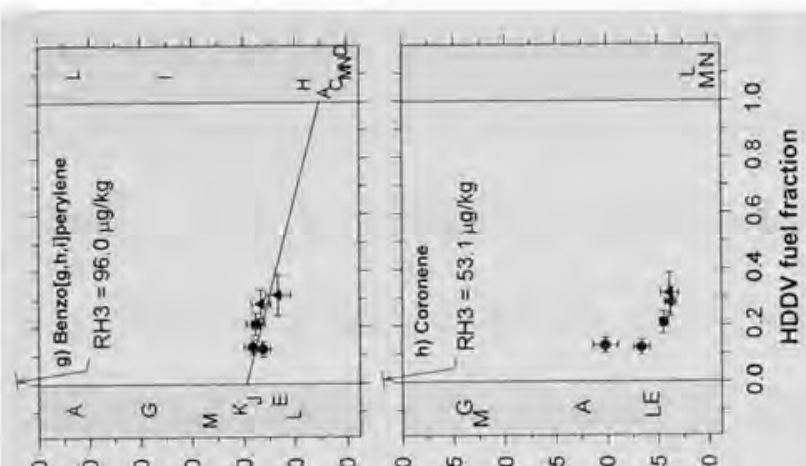

용요 응

ำ ㄴำㅇำ
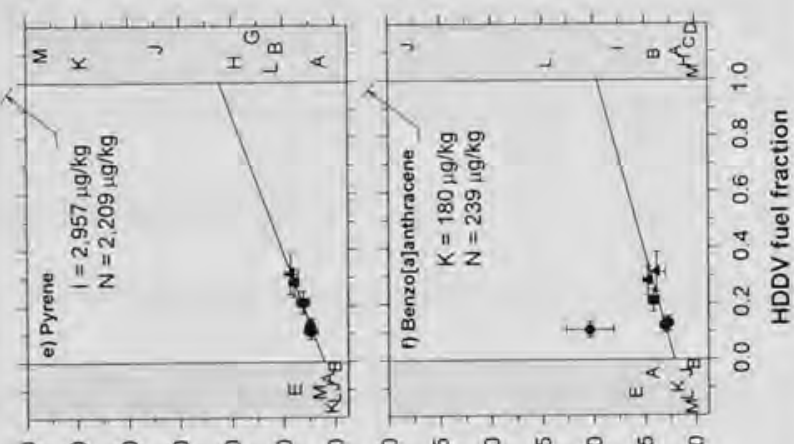

\&
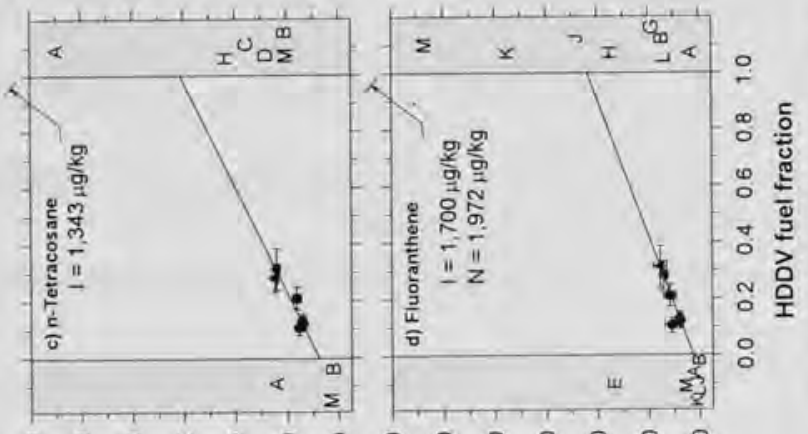

응 \& \& \& 8

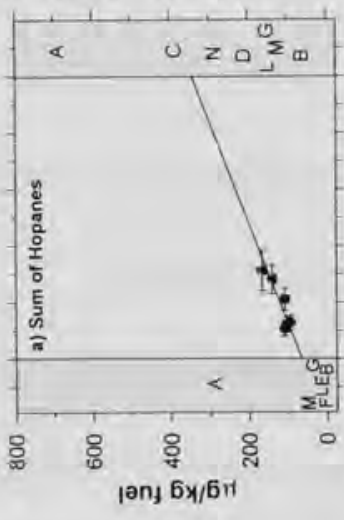

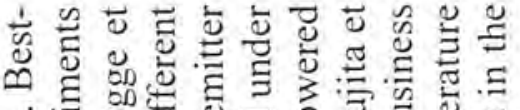

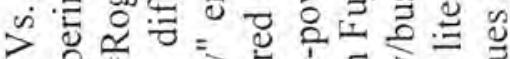

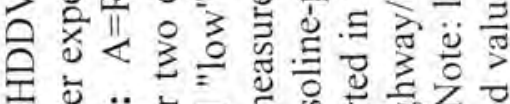

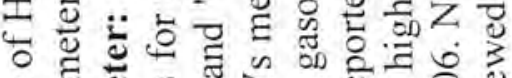

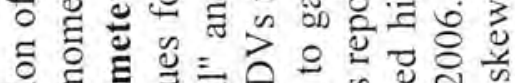

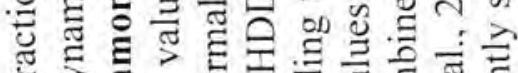

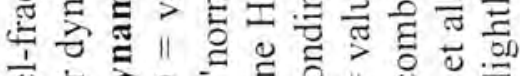

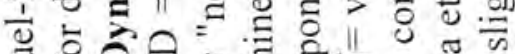

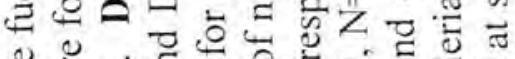

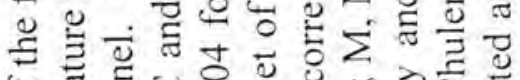

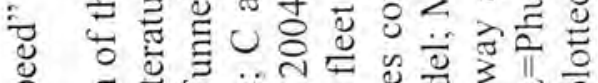
कू

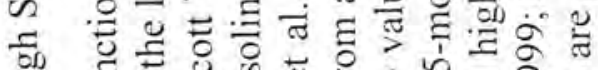

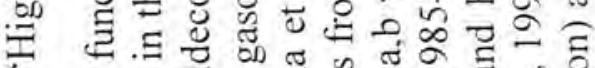

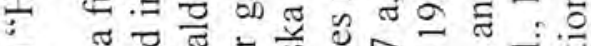

-

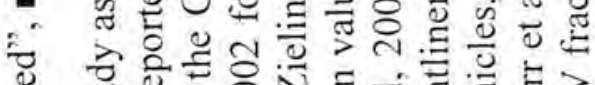

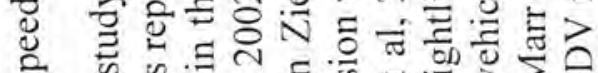
क के

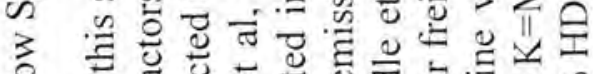

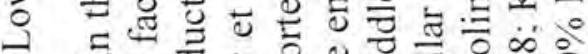

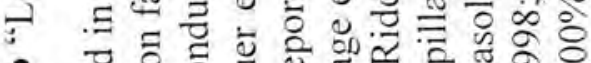

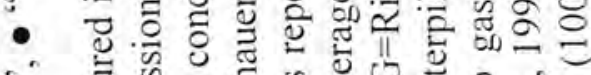

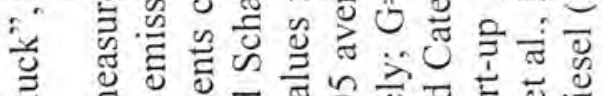

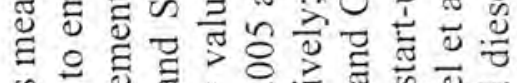
के Ð

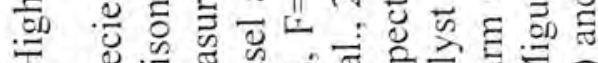

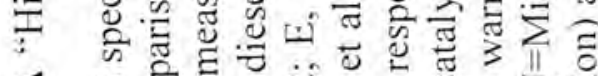

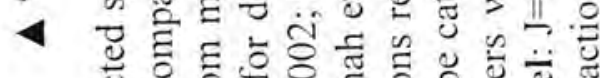

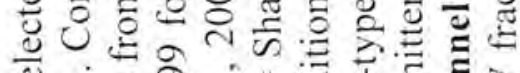

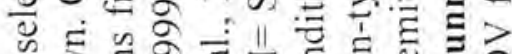
फ

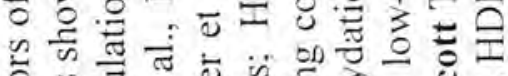
क क त

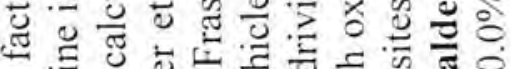

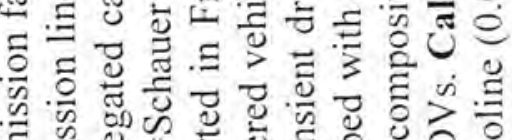

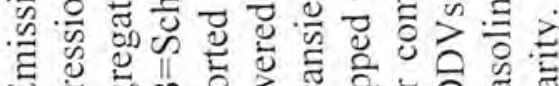
理 ․ㅓㄴ

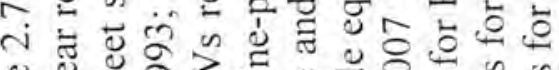

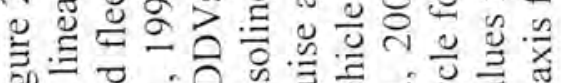

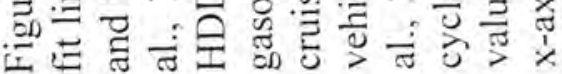


here for HDDVs with those measured in the Caldecott Tunnel. For example, hopanes, fluoranthene and pyrene are relatively equally close to those reported for the Caldecott Tunnel (letters J, K, and L on Figures $2.7 \mathrm{a}, \mathrm{d}, \mathrm{e}$ ). Other examples of similar consistencies include: extrapolated values for the three species n-tetracosane, fluoranthene and pyrene (Figures $2.7 \mathrm{c}, \mathrm{d}, \mathrm{e}$ ) are closest to the same dynamometer study (Shah et al., 2005), and the HDDVs emission factor for the sum of hopanes (Figures 2.7 a) along with fluoranthene and pyrene (Figures $2.7 \mathrm{c}, \mathrm{d}, \mathrm{e}$ ) are close to those reported by Riddle et al ( $2007 \mathrm{~b}$ ). This coherence lends confidence to the values derived here assuming a linear extrapolation of the measured values.

The emission factors measured in the Squirrel Hill Tunnel were found to fit the overall trend of data obtained from other studies including both measurements conducted during the summertime in roadway tunnels from other regions of the U.SA., California and Texas, as well as dynamometer studies performed on in-use vehicles from western states where fuel quality specifications, for example, are different that those in place in Pennsylvanya. The overall quality of this fit suggests that variability in the composition of engine emissions appears to be a stronger function of the differences in engine type, performance and operation, than it is of those of fuel and lubricating oil.

\subsection{Conclusions}

The profiles of the petroleum biomarkers hopanes and steranes are very consistent for all three sampling periods; in contrast, larger variability is observed for the PAHs profiles. Considering all traffic situations, results indicate that the emission of organic markers of fuel and lubricating oil, i.e., n-alkanes, n-alkylcyclohexanes and hopanes are 
strongly associated to the fuel-based fraction of HDDVs in the fleet. Likewise, HDDVS are also more associated with larger emissions of the lmw-PAHs phenathrene, anthracene, cyclopentaphenanthrene, fluoranthene and pyrene, while the hmw-PAHs benzo[g,h,i]perylene and coronene are more associated to LDVs. The rest of the PAHs measured, benzo[b]fluoranthene, benzo[k]fluoranthene, benzo[j]fluoranthene, benzo[e]pyrene, benzo[a]pyrene, perylene, indeno[c,d]pyrene and dibenzo[a,h]anthracene, appear to be equally contributed by both types of vehicles.

Based on benzothiazole, a marker for tire wear, the larger contribution appears to be associated with hindered traffic flow such as that occurring during transient/creep driving conditions.

The associations found between the n-alkylcyclohexanes and the organic sulfur compounds 4-methyl- and 4,6-dimethyldibenzothiophene imply a larger contribution of diesel fuel to the measured emission factors of the lower molecular weight nalkylcyclohexanes. Lastly, the association found between the emission factors of hmwPAHs and benzo[b]naphtho[2,1-d]thiophene, an indicator of the pyrolysis of sulfurcontaining fuels, imply that vehicles with no after-burning treatment emit exceedingly large amounts of hmw-PAHs, benzo[b]fluoranthene, benzo[k]fluoranthene, benzo[j]fluoranthene, benzo[e]pyrene, benzo[a]pyrene, perylene, indeno[c,d]pyrene, benzo[g,h,i]perylene, dibenzo[a,h]anthracene and coronene. 
Chellam, S.,P., Kulkarni, P., Fraser, M.P., 2005. Emissions of organic compounds and trace metals in fine particulate matter from motor vehicles. A tunnel study in Houston, Texas. Journal of the Air and Waste Management Association 55 (1), $60-72$.

Chow, J.C., Watson, J.G., 2002. Review of PM2.5 and PM10 apportionment for fossil fuel combustion and other sources by the chemical mass balance receptor model. Energy and Fuels 16(2), 222-260.

Chow, J. C., Watson, J. G., Lowenthal, D. H., Chen, L.-W. A., Zielinska, B., Rinehart, L. R., Magliano, K. L., 2006. Evaluation of organic markers for chemical mass balance source apportionment at the Fresno Supersite. Atmospheric Chemistry and Physics Discussions 6, 10,341-10,372.

Dahl, A., Gharibi, A., Swietlicki, E., Gudmundsson, A., Bohgard, M., Ljungman, A.M. Blomqvist, G., Gustafsson, M., 2006. Traffic generated emissions of ultrafine particles from pavement - tire interface. Atmospheric Environment 40 (7), 13141323.

Dellinger, B., Pryor, W.A., Cueto, R., Squadrito, G.L., Hegde, V., Deutsch, W.A., 2001. Role of free radicals in the toxicity of airborne fine particulate matter. Chemical Research in Toxicology 14 (10), $1371-1377$.

Dockery, D.W., Pope, C.A., III, Xu, X., Spengler, J.D., Ware, J.H., Fay, M.E., Ferris, B.G., Speizer, F.A., 1993. An Association between air pollution and mortality in six U.S. cities, New England Journal of Medicine 329, 1753-1759.

Fraser, M.P., Cass, G.R., Simoneit, B.R.T., 1998. Gas-phase and particle-phase organic compounds emitted from motor vehicle traffic in a Los Angeles roadway tunnel. Environmental Science and Technology 32 (14), 2051-2060.

Fraser, M.P., Cass, G.R., Simoneit, B.R.T., 1999. Particulate organic compounds emitted from motor vehicle exhaust and in the urban atmosphere. Atmospheric Environment 33 (17), 2715-2724.

Fraser, M., Lakshmanan, K., 2002. Variation in composition of fine particulate emissions from heavy-duty diesel vehicles. Journal of Geophysical Research 107 (D21), 8346-8352.

Fujita, E. M., Zielinska, B., Campbell, D., Arnott, W. P., Sagebiel, J. C., Mazzoleni, L., Chow, J. C., Crews, W., Snow, R., Clark, N., Wayne W. S., Lawson, D.R., 2007. Variations in speciated emissions from spark-ignition and compression-ignition 
motor vehicles in California's South Coast Air Basin. Journal of the Air and Waste Management Association, 57, 705-720.

Garg, B.D., Cadle, S.H., Mulawa, P.A., Groblicki, P.J., Laroo, C., Parr, G.A., 2000. Brake wear particulate matter emissions. Environmental Science and Technology 34 (21), 4463-4469.

Geller, M.D., Sardar, S.B., Phuleria, H., Fine, P.M., Sioutas, C., 2005. Measurements of particle number and mass concentrations and size distributions in a tunnel environment. Environmental Science and Technology 39 (22), 8653-8663.

Gertler, A.W., Abu-Allaban, M., Coulombe, W., Gillies, J.A., Pierson, W.R., Rogers, C. F., Sagebiel, J.C., Tarnay, L., Cahill, T.A., 2001. Measurements of mobile source particulate emissions in a highway tunnel. International Journal of Vehicle Design 27 (1-4), 87-93.

Gillies, J.A., Gertler, A.W., Sagebiel, J.C., Dippel, W.A., 2001. On-road particulate matter PM2.5 and PM10 emission factors in the Sepulveda Tunnel, Los Angeles, California. Environmental Science and Technology 35 (6), 1054-1063.

Grieshop, A.P., Lipsky, E.M., Pekney, N.J., Takahama, S., Robinson, A.L., 2006. Fine particle emission factors from vehicles in a highway tunnel: Effects of fleet composition and season. Atmospheric Environment 40 (S2), S287-S298.

Kirchstetter, T.W., Singer, B.C., Harley, R.A., Kendall, G.R., Chan. W., 1996. Impact of oxygenated gasoline use on California light-duty vehicle emissions. Environmental Science and Technology 30 (2), 661-670.

Kirchstetter, T.W., Harley, R.A., Kreisberg, N.M., Stolzenburg, M.R., Hering, S.V., 1999. On-Road measurement of fine particle and nitrogen oxide emissions from light- and heavy-duty motor vehicles. Atmospheric Environment 33 (18), 2955 2968.

Kleeman, M. J., Riddle, S. G., Robert, M. A., Jakober, C. A., 2008. Lubricating oil and fuel contributions to particulate matter emissions from light-duty gasoline and heavy-duty diesel vehicles. Environmental Science and Technology 42(1), 235242.

Laden, F., Schwartz, J., Speizer, F.E., Dockery, D.W,, 2006. Reduction in fine particulate air pollution and mortality: Extended follow-up of the Harvard Six Cities study. American Journal of Respiratory Critical Care Medicine 173, 667-672.

Li, N., Sioutas, C., Cho, A., Schmitz, D., Misra, C., Sempf, J., Wang, M. Y., Oberley, T., Froines, J., Nel, A., 2003. Ultrafine particulate pollutants induce oxidative stress and mitochondrial damage. Environmental Health Perspective 111, 455-460. 
Liang, F.Y., Lu, M.M., Birch, M.E., Keener, T.C., Liu, Z., 2006. Determination of polycyclic aromatic sulfur heterocycles in diesel particulate matter and diesel fuel by gas chromatography with atomic emission detection. Journal of Chromatography A, 1114 (1), 145-153.

Lough, G. C., Schauer, J. J., Park, J. S., Shafer, M. M., DeMinter, J, T., Weinstein, J. P., 2005. Emissions of metals associated with motor vehicle roadways. Environmental Science and Technology 39 (3), 826-836

Lowenthal, D. H., Zielinska, B., Chow, J. C., Watson, J. G., Gautam, M., Ferguson, D. H., Neuroth, G. R., Stevens, K. D., 1994. Characterization of heavy-duty diesel vehicle emissions. Atmospheric Environment 28 (4), 731-743.

Ma, X.L., Sun, L., Song, C.S., 2002. A new approach to deep desulfurization of gasoline, diesel fuel and jet fuel by selective adsorption for ultra-clean fuels and for fuel cell applications. Catalysis Today, 77 (1-2), 107-116.

Marr, L. C., Kirchstetter, T. W., Harley, R. A., Miguel, A. H., Hering, S. V., Hammond, S. K., 1999. Characterization of polycyclic aromatic hydrocarbons in motor vehicle fuels and exhaust emissions. Environmental Science and Technology 33(18), 3091-3099.

Mayer, A., Wyser, M., Matter, U., Czerwinski, J., Stadler, E., Wolfensberger, U., Mattrel, P., Huthwohl, G., Schindler, A., 1999. Best Available Technology for Emission Reduction of Small $4 \mathrm{~s}$ SI Engines. Proceeding of the SAE Small Engine Technology Conference. Document Number: 1999-01-3338.

Miguel, A. H.; Kirchstetter, T. W.; Harley, R. A.; Hering, S. V., 1998. On-Road Emissions of particulate polycyclic aromatic hydrocarbons and black carbon from gasoline and diesel vehicles. Environmental Science and Technology 32(4), 450455.

Norbeck, J. M., Durbin, T. D., Truex, T. J., 1998. Characterization of particulate emissions from gasoline fueled vehicles. Report no. 98-VE-RT85-006-FR. Center for Environmental Research and Technology, College of Engineering, University of California.

Phuleria, H.C., Geller, M.D., Fine, P.M., Sioutas, C., 2006. Size-Resolved emissions of organic tracers from light- and heavy-duty vehicles measured in a california roadway tunnel. Environmental Science and Technology 40 (13), 4109-4118.

Pierson, W.R., Gertler, A.W., Robinson, N.F., Sagebiel, J.C., Zielinska, B., Bishop, G.A., Stedman, D.H., Zweidinger R.B., Ray, W.D., 1996. Real-World automotive emissions-summary of studies in the Fort McHenry and Tuscarora Mountain tunnels. Atmospheric Environment 30 (12), 2233-2256. 
Pope, C. A. I., Burnett, R. T., Thun, M. J., Calle, E. E., Krewski, D., Ito, K., Thurston, G. D., 2002. Lung cancer, cardiopulmonary mortality, and long-term exposure to fine particulate air pollution. Journal of the American Medical Association 287 (9), 1132-1141.

Pope, C.A., III, Burnett, R.T., Thurston, G.D., Thun, M.J., Calle, E.E., Krewski, D., Godleski, J.J., 2004. Cardiovascular mortality and long-term exposure to particulate air pollution: Epidemiological evidence of general pathophysiological pathways of disease, Circulation 109, 71-77.

Reddy, C. M.; Quinn, J. G., 1997. Environmental chemistry of benzothiazoles derived from rubber. Environmental Science and Technology 31(10), 2847-2853.

Riddle, S. G., Robert, M. A., Jakober, C. A., Hannigan, M. P., Kleeman, M. J., 2007a. Size Distribution of Trace Organic Species Emitted from Light-Duty Gasoline Vehicles. Environmental Science and Technology 41(21), 7464-7471.

Riddle, S. G., Robert, M. A., Jakober, C. A., Hannigan, M. P., Kleeman, M. J., $2007 \mathrm{~b}$. Size Distribution of Trace Organic Species Emitted from Heavy-Duty Diesel Vehicles. Environmental Science and Technology 41(6), 1962-1969.

Rogge, W.F., Hildemann, L.M., Mazurek, M.A., Cass, G.R., Simoneit, B.R.T., 1993 a. Sources of fine organic aerosol .2. Noncatalyst and catalyst-equipped automobiles and heavy-duty diesel trucks. Environmental Science and Technology 27 (4), 636651.

Rogge, W.F., Hildeman, L.M., Mazurek, M.A. and Cass, G.R., 1993b. Sources of fine organic aerosol. 3. Road dust, tire debris, and organometallic brake lining dust: Roads as sources and sinks. Environmental Science and Technology 27(9), 18921904

Schade, T., Andersson, J.T., 2006, Speciation of Alkylated Dibenzothiophenes in a Deeply Desulfurized Diesel Fuel. Energy and Fuels 20, 1614-1620.

Schauer, J. J., Rogge, W. F., Hildemann, L., M., Mazurek, M. A., Cass, G. R., 1996. Source apportionment of airborne particulate matter using organic compounds as tracers. Atmospheric Environment 30 (22), 3837-3855.

Schauer, J. J., Kleeman, M. J., Cass, G. R., Simoneit, B. R. T., 1999. Measurement of emissions from air pollution sources. 2. C1-C29 Organic compounds from medium duty diesel trucks. Environmental Science and Technology 33(10), 15781587. 
Schauer, J. J., Kleeman, M. J., Cass, G. R., Simoneit, B. R. T., 2002. Measurement of emissions from air pollution sources. 5. C1-C32 Organic compounds from gasoline-powered motor vehicles. Environmental Science and Technology 36(6), 1169-1180.

Seagrave, J., McDonald, J.D., Bedrick, E., Edgerton, E.S., Gigliotti, A.P., Jansen, J.J., Ke, L., Naeher, L.P., Seilkop, S.K., Zheng, M.Z., Mauderly, J.L., 2006. Lung toxicity of ambient particulate matter from Southeastern U.S. sites with different contributing sources: Relationships between composition and effects. Environmental Health Perspectives 114 (9), 1387-1393.

Shah, S.D., Ogunyoku, T.A., Miller, J.W., Cocker, D.R., 2005. On-Road emission rates of PAH and n-alkane compounds from heavy-duty diesel vehicles. Environmental Science and Technology 39 (14), 5276-5284.

Winkler, J.K., Karow, W., Rademacher, P., 2002. Gas-phase pyrolysis of heterocyclic compounds, part 1 and 2: flow pyrolysis and annulation reactions of some sulfur heterocycles: thiophene, benzo[b]thiophene, and dibenzothiophene. A productoriented study. Journal of Analytical and Applied Pyrolysis 62 (1), 123-141.

Zielinska, B., Sagebiel, J.C., Harshfield, G., Gertler, A.W., and Pierson, W.R., 1996. Volatile organic compounds up to $\mathrm{C} 20$ emitted from motor vehicles; measurement methods. Atmospheric Environment 30(12), 2269-2286.

Zielinska, B., McDonald, J.D., Hayes, T., Chow,J.C., Fujita, E.M., Watson, J.G., 1998. Northern Front Range Air Quality Study. Volume B: Source measurements. Prepared for Colorado State University, Fort Collins, CO, Desert Research Institute, Reno, NV.

Zielinska, B., Sagebiel, J., Arnott, W.P., Rogers, C.F., Kelly, K.E., Wagner, D.A., Lighty, J.S., Sarofim, A.F., Palmer, G., 2004a. Phase and size distribution of polycyclic aromatic hydrocarbons in diesel and gasoline vehicle emissions. Environmental Science and Technology 38(9), 2557-2567.

Zielinska, B., Sagebiel, J., McDonald, J.D., Whitney, K., Lawson, D.R., 2004b. Emission rates and comparative chemical composition from selected In-Use diesel and gasoline-fueled vehicles. Journal of the Air and Waste Management Association 54(9), 1138-1150. 


\section{CHAPTER 3}

THREE-HOURLY AND SUMMER/WINTER VARIATIONS IN ATMOSPHERIC

CONCENTRATIONS OF ORGANIC COMPOUNDS IN PM2.5 MEASURED

DURING THE BALTIMORE PM-SUPERSITE

(Bernardo-Bricker, A., Rogge, W.F., Ondov, J.M., manuscript in preparation)

\subsection{Introduction}

Fine particles (PM2.5) are an important contributor to problems of regional haze and have been associated to adverse respiratory and cardiovascular health effects (Dockery et al., 1993; Schwarz et al., 2002; Pope et al., 2002, 2004; Laden et al., 2006). Organic compounds constitute an important fraction of PM2.5 in the atmosphere of urban areas (e.g., Turpin et al., 2000) and knowledge of its composition is needed in order to help complete the bigger picture and properly evaluate its implications for human health and its role in global atmospheric changes such as cloud nucleation properties and temperature.

Over the last 15 years, the organic composition of urban aerosols has been studied for various densely populated urban areas in the U.S. using 24-hour sampling of PM2.5. As a result, a good understanding has been gained of the seasonal characteristics of organic aerosol for those areas. For example, southern and central California (Rogge et al., 1993a; Rinehart et al., 2006), southeastern U.S. states (Zheng et al., 2002), Texas (Fraser et al., 2002; Yue et al., 2004a, 2004b). A comprehensively detailed characterization of organic compounds associated to PM2.5, unprecedented for the eastern USA, was recently accomplished using 24-hour measurements acquired during 
the Pittsburgh Air Quality Study 2001-2002 for more than one year cycle (Robinson et al., 2006 a-c; Subramanian et al., 2007).

In order to improve understanding of the sources and dynamic process involving fine particles in atmospheric air it is necessary reducing the sampling frequency as close as possible to being representative of the timescales of the inputs and process. Ideally, samples should be acquired at an hourly resolution; however, practical limitations are imposed by the detection limit of the analytical method used. Well established analytical methods have been developed to accomplish the detailed characterization of the composition of the organic aerosol. These methods consist of solvent extraction of the organic compounds associated to PM2.5 followed by analysis via gas chromatography/mass spectrometry techniques in order to identify and quantify the organic species. The sampling frequency is constrained by the minimum amount of sample necessary in order to carry out these procedures together with the flow capabilities of the sampling system. Due to these constraints, until now the diurnal variations of selected organic compounds has only been explored to a limited extent and only for locations in the western states, particularly California.

The first of these studies was conducted by sampling over a 4-hour averaging time every six hours at four urban locations in California in order to track the variations of concentrations of organic compounds during a select two-day photochemical smog episode on September 8-9, 1993 (Fraser et al., 1996, 1997, 1998, 2003a). A second study also conducted in California analyzed the organic compounds in size-segregated samples, fine and accumulation modes, collected at two urban sites during a one-week sampling campaign in summer (2002, 26-30-August) and winter (2003-13-17-January). Only three 
daily samples of 3.5 hours each were collected, and the samples were composited by replacing in the sampler the filter for the appropriate daily time interval such that only one weekly sample was created for each time interval and size range at each site; interpretation of results relied on the validity that the meteorological conditions were shown to be relatively consistent for each time period (Fine et al, 2004a). Similarly composited diurnal size-segregated sampling, coarse, accumulation and ultrafine, was also conducted during the Southern California Particle Center and Supersite in the summer of 2006 (Ning et al., 2007). Diurnal, 12-hr sampling, of PM2.5 for organic speciation was also part of the Pacific 2001 Air Quality Study; there samples were collected for a two week period in the Lower Fraser Valley, Canada (Cheng et al., 2004, 2006).

The PM2.5 organic characterization study conducted as part of the Baltimore PMSupersite is unique in several ways. Firstly, a sampler was specifically designed in order to perform consistent and reliable acquisition of samples at a 3-hourly frequency for a sufficiently long consecutive stretch of time, two to three weeks, during two distinct seasonal periods, summer 2002 fall/winter 2002-2003. In addition, a comprehensive set of meteorological and chemical information was also attained concurrently to the samples for organic characterization; the availability of this information provides the opportunity to study the organic characterization data under different meteorological regimens as well as assisting in elucidating dynamical atmospheric processes.

The primary goal of this paper is to describe and examine the major seasonal differences in the 3-hourly variations of concentrations of individual organic compounds within the perspective of the day-to-day concentration changes. In order to be able to 
represent the entire data set in a configuration that facilitates this, when appropriate, vertical point plots that include all individual measurements available for each of the 3 hourly periods were created using Sigma Plot (version 8.0; SPSS Inc.). Data displayed in this fashion also simplifies identifying compound's seasonal abundance, effect of pointsources, and grouping of episodes.

\subsection{Experimental Methods}

\subsubsection{Sampling Location, Sampler and Samples Description}

PM2.5 samples for the organic molecular speciation study were collected at the Ponca Street site in downtown Baltimore (Latitude: $39.289^{\circ}$, Longitude: $-76.554^{\circ}$ ). Approximately 100 meters to the west of the sampling site (angular direction $170^{\circ}-240^{\circ}$ ) there is a Maryland Transit Administration bus maintenance facility. To the east (angular direction $40^{\circ}-50^{\circ}$ ) are two interstate highways (I-95 and I-895).

In order to collect in three hours sufficient amount of PM2.5 to be extracted and analyzed via solvent-extraction followed by gas chromatography/mass spectrometry (GC/MS) a new sampling system had to be designed and tested. A schematic representation of the sampling system is given as Appendix B (Figure B.1). This system is comprised of five separate sampling channels connected to one PM2.5 inlet operated in a sequential mode. The sampling channels and sampling media holders were set up inside a trailer. In order to remove particles with an aerodynamic diameter larger than $2.5 \mu \mathrm{m}$, the sampler was equipped with a Marple PM2.5 inlet impactor that protruded about $2 \mathrm{~m}$ above the trailer roof. The system was operated at a nominal flow rate of $600 \mathrm{lpm}$. Samples were collected on quartz fiber filters (125 mm diameter, Pall Gelman Science. 
Tissuquartz 2500 QAT-UP) followed by a polyurethane foam (PUF) plug (111 mm diameter x $5 \mathrm{~cm}$ long, foam type 2715/C30 Sobie Upholstery Supply Co., Miami, FL) installed downstream of the filter to trap semi-volatile organic compounds (SVOCs). A breakthrough experiment was conducted to examine the use of 1,2 and 3 PUFs for varying sampling times of three, four and five-hour. Analysis of the data showed that for a sampling time of three hours, approximately $85-95 \%$ of the n-alkanes with vapor pressures lower than $3.25 \times 10^{-4}(\mathrm{C} \geq 19)$ were retained within the one filter/one PUF arrangement.

Sampling took place during the summer of 2002 and fall 2002-winter 2003 as follows: A total of 216 three-hour samples (including 29 blanks) were collected through 14 days in July (July 14- 27) and 12 days in August (August 1-12), and a total of 237 three-hour samples (including 31 blanks) were collected through 24 days in November (November 4-27), 3 days in December (Dec 6-8) and 4 days in February 2003 (February 21-24). However, due to resources limitations only 119 each from the summer and from the fall/winter sampling campaigns were selected for analysis. Samples for analysis were selected taking into consideration, among other factors, the availability of complete sets of measurements of other variables measured concurrently at the sampling site.

Results presented here are based on the analysis of 119 three-hourly samples each from continuous days during two distinct seasonal periods as follows. Summer: 1722-July, 24-July, 5-12-August, 2002. Fall/Winter: 7-9-November, 14-16-November, 1922-November, 24-26-November, 2002 and 21-24-February 2003. For simplicity, from now on the colder sampling period will be refered to as "winter". Brief gaps in the continuity of sampling were due to interruptions during rainy days at the sampling site. 


\subsubsection{Sample Media Preparation, Storage and Transportation}

Prior to sampling, sampling media was prepared in the laboratory at Florida International University (FIU) and then shipped to the University of Maryland (UM). A batch of quartz fiber filters was placed in a glass Petri dish wrapped in aluminum foil and annealed at $550^{\circ} \mathrm{C}$ for 4 hours to remove possible organic contaminants. PUF plugs were solvent cleaned individually following a 7 -cycle procedure of about 5 min each, using in each cycle $150 \mathrm{ml}$ of the following solvent sequence: one cycle with ethanol, two cycles with acetone, two cycles with hexane, and two cycles with methylene chloride. Cleaning was achieved by placing each PUF in a specially designed Repeated Compression Extraction Apparatus (RCEA) that consists of a thick walled glass cylinder equipped with PTFE valves system and a glass plunger. The PUF was placed in the RCEA, the cleaning solvent was added, and the plunger was used to press and depress the PUF plug up and down. After the last cleaning cycle, PUFs were dried under vacuum in a desiccator and then transferred to an individual clean glass jar with Teflon-lined lid. Prior, the glass jars were solvent cleaned three times each with methanol, methylene chloride and acetone. All sample media handling was conducted using solvent rinsed stainless steel tweezers. All the solvents used in the procedure were Fisher GC-Resolv grade or equivalent Burdick \& Jackson, and before use these were tested for contaminant levels.

After sampling, solvent rinsed tweezers were used to fold the sampled quartz fiber filter in such a manner that the collected particulate matter remained on the inside fold. The folded filter was carefully wrapped in a piece of annealed aluminum foil. Each set of quartz fiber filter and PUF plug was stored airtight in the same glass jar that originally contained the unused PUF plug, and was transported back to the lab in a cooler. In the 
Maryland lab, the glass jars containing the samples were stored in freezers at less than $-21{ }^{\circ} \mathrm{C}$ until they were shipped to Miami, FL. Sample shipment was conducted by securely placing jars in a cooler that contained dry ice, ice packs and paper for insulation, and shipped overnight. Upon arrival at FIU the temperature in the cooler was measured, and sample jars were immediately inspected, catalogued and stored in freezers at less than $-21{ }^{\circ} \mathrm{C}$ until ready for extraction procedure.

\subsubsection{Sample Extraction Protocol}

All glassware used for samples extraction was annealed at $550{ }^{\circ} \mathrm{C}$ for at least 4 hours. All fittings and transfer lines were made of TFE or PTFE Teflon and solvent rinsed before and after usage. All glassware rinses, standard solution preparation and extraction work, were performed using solvents Fisher GC-Resolv grade.

Immediately before solvent extraction, each filter was spiked with a known amount of an internal standard suite consisting of seven perdeuterated n-alkanes (Chiron AS, Norway): C12, C16, C20, C24, C28, C32, C36. The amount of the internal standard mix spiked into the sample is proportional to the amount of the organic carbon (OC) present in the given sample. Filters were extracted using four 10-min cycles of mild ultrasonic agitation in a temperature controlled bath $\left(25^{\circ} \mathrm{C}\right)$. Aliquots of $30 \mathrm{ml}$ of fresh methylene chloride were used for each cycle. After each agitation the extracts were filtered and combined into a single flask using a Step-Saver Filtration System (Fisher Scientific). Each PUF plug was also spiked with an aliquot of the internal standard suite followed by extraction. PUFs were subjected to a three-cycle extraction using the RCEA. 
For the first cycle, a $60-\mathrm{ml}$ aliquot of methylene chloride was used; $40-\mathrm{ml}$ aliquots were used for the second and third extractions.

After extraction, the volume of each extract was reduced to a volume of $2-3 \mathrm{ml}$ by rotary evaporation followed by a gentle solvent evaporation with a stream of high purity $\mathrm{N}_{2}$ to a final volume of typically $100-150 \mu$ l. Filter and PUF extracts were stored and analyzed separately. Next, each reduced extract was reacted with diazomethane to convert organic acids to their methyl ester analogues and acidic hydroxyl compounds to their methoxy analogues. Derivatized sample extracts were stored in a freezer at less than $-21^{\circ} \mathrm{C}$ until analysis by $\mathrm{GC} / \mathrm{MS}$.

\subsubsection{Gas Chromatography/Mass Spectrometry (GC/MS) Analysis}

Analysis of all derivatized samples was carried out on a Gas Chromatographer (GC) model HP-6890 interfaced with a Mass-Spectra Detector (MSD) model HP-5973 (Agilent Technologies). The injected sample volume was $1 \mu$. Sample injection was accomplished with a HP-Automatic Liquid Sampler HP-G1513-90100 (Agilent Technologies) operated in the splitless mode at 25 psi for the first minute. Temperature of the injector was set to $300^{\circ} \mathrm{C}$. A capillary column DB-5MS (J\&W $30 \mathrm{~m} \times 0.25 \mathrm{~mm}$ i.d. $\mathrm{x}$ $0.25 \mu \mathrm{m}$ film thickness) was used for separations. Temperature programming of the GC column consisted of the following steps: isothermal at $60^{\circ} \mathrm{C}$ for $2 \mathrm{~min}$, temperature ramp of $6{ }^{\circ} \mathrm{C} / \mathrm{min}$ up to $300^{\circ} \mathrm{C}$, and isothermal hold for $18 \mathrm{~min}$. The GC/MS interface temperature was set to $285^{\circ} \mathrm{C}$. Helium was used as carrier gas with a flow rate of 1.2 $\mathrm{ml} / \mathrm{min}$. The MSD was operated in the electron impact mode at $70 \mathrm{eV}$ electron energy set on a scan range of 50 to $550 \mathrm{amu}$. 


\subsubsection{Compound Identification and Quantification}

The GC/MS data was acquired and processed using a Agilent ChemStation. A total of 111 compounds, selected for analysis from a target list, were identified in the ambient PM2.5 samples by comparison with the retention time and mass fragmentation pattern of authentic standards. Standards were available for 96 of the targets; whenever standards were unavailable, identification was based on comparison of their mass fragmentation pattern with that of the National Institute of Standards and Technology (NIST-NBS75K) and Wiley mass spectral libraries.

Area counts for each identified peak were converted to mass units using a relative response factor (RRF) for each compound and correcting for the recovery of the appropriate internal standard to account for any losses incurred throughout the sample extraction procedure. The individual RRFs were determined from the GC/MS analysis of authentic standards containing 1-phenyldodecane as an internal standard. The precision of each individual compound concentration was calculated based on replicate analysis of randomly selected samples. A total of 73 filter extracts and 49 filter extracts were subject to duplicate GC/MS analysis. The total relative precision $(p)$ of a compound from an $n$ number of duplicate analyses was computed by using the equation:

$$
p=\sqrt{\frac{\sum s^{2}}{n}} \quad \text { Equation } 3.1
$$

where

$$
s=\frac{1}{\sqrt{2}} \times \frac{\left|C_{1}-C_{2}\right|}{\frac{C_{1}+C_{2}}{2}}
$$


Here $C_{1}$ and $C_{2}$ are the concentration of the target in each of the two duplicate analyses measurements of the same sample. Final error of the measurements accounted for these relative precisions corrected by the standard deviation (SD) of each of the RRFs obtained for authentic standards. For the compounds for which authentic standard were not available, the RRFs and measurement uncertainty were assumed to be identical to those of the available standard compounds with similar chemical structures, polarities, and molecular weights. Errors were found to vary from $1 \%$ to $25 \%$ with median value of $15 \%$.

\subsubsection{Quality Assurance/Quality Control (QA/QC)}

Assurance of analytical quality and control of the procedures were determined through the use of laboratory blanks and field blanks. Field blanks consisted of a sampling media pair of quartz filter and PUF which had undergone the same handling preparation and procedures as those of regular samples, including placement into the sampler and shipment. All compounds quantified in the samples were blank corrected. Masses of those targets found in the blanks were no more than $1 \%$ of their mass measured in ambient samples.

\subsection{Results and Discussion}

\subsubsection{Characteristics of the PM2.5 during the Studied Periods}

The 3-hourly measurements of PM2.5 approached or exceeded the 24-hrs NAAQS limit of $35 \mu \mathrm{g} / \mathrm{m}^{3}$ on seven days in the summer and three days in the fall. These days were respectively, 18-21-July (overall average $40.7 \mu \mathrm{g} / \mathrm{m}^{3} \pm 12.1 \mu \mathrm{g} / \mathrm{m}^{3}$ ), 5-, 11 - 
and 12- August (overall average $26.3 \mu \mathrm{g} / \mathrm{m}^{3} \pm 12.5 \mu \mathrm{g} / \mathrm{m}^{3}$ ), 19-20-November (overall average $\left.31.7 \mu \mathrm{g} / \mathrm{m}^{3} \pm 1.6 \mu \mathrm{g} / \mathrm{m}^{3}\right)$, and 25 -November $\left(36.0 \mu \mathrm{g} / \mathrm{m}^{3} \pm 6.4 \mu \mathrm{g} / \mathrm{m}^{3}\right)$.

During the summer, the OC-fraction of PM2.5 is in the range of $7 \%$ to $75 \%$ with a median of $23 \%$; during the winter, the range is $14 \%$ to $68 \%$ with a median proportion of $34 \%$. The sum of the identified organic compounds corresponds, respectively, to $2-29 \%$ (median $8 \%$ ) and $3-15 \%$ (median $5 \%$ ) of the summer and winter OC. Targeted compounds include straight chain and branched-alkanes, n-alkylcyclohexanes, n-alkanoic acids, n-alkenoic acids, dicarboxylic aliphatic and aromatic acids, resin acids, sterols, hopanes, steranes, polyaromatic hydrocarbons (PAHs), oxygenated polycyclic aromatic (oxy-PAHs), sugars, secondary oxidation products and others. The most abundant compound classes in the samples from the summer period are n-alkanoic acids, n-alkanes and PAHs; on average these represent $45 \%, 24 \%$ and $14 \%$, respectively, of the total concentration of identified compounds. In the winter samples, the most abundant compounds are n-alkanes, n-alkanoic acids, PAHs and levoglucosan, respectively representing $30 \%, 29 \%, 11 \%$ and $8 \%$ of the total identified.

While elemental carbon (EC) is considered of primary origin, the organic compounds fraction (OC) can be either directly emitted from primary sources or formed in the atmosphere (secondary). As shown in Figure $3.1 \mathrm{~d}$, during the winter, the 3-hourly concentrations of OC follow very closely the same trend as EC, suggesting that the measured $\mathrm{OC}$ is strongly influenced by primary emissions. Linear regression of the 3hourly concentrations of $\mathrm{OC}(\mathrm{y})$ vs $\mathrm{EC}(\mathrm{x})$ yield an $\mathrm{R}^{2}=0.8253$, for a line with slope $3.07 \pm$ 0.15 and intercept $1.48 \pm 0.35$. In contrast, as can be inferred from Figure $3.1 \mathrm{~b}$, during the summer, the 3-hourly concentrations of EC and OC are poorly correlated $\left(\mathrm{R}^{2}=0.036\right)$. 
In particular, disproportionately large concentrations of $\mathrm{OC}$ are observed throughout July and during 10-12-August. Therefore, from the bulk chemical characteristics of PM2.5, EC and OC, it is possible to infer that the winter samples and the summer samples from days 22-, 24-July and 7-9-August display a relatively more "primary" nature in contrast to the comparatively more pronounced "secondary" nature 17-21-July, and 5-, 10-12August.

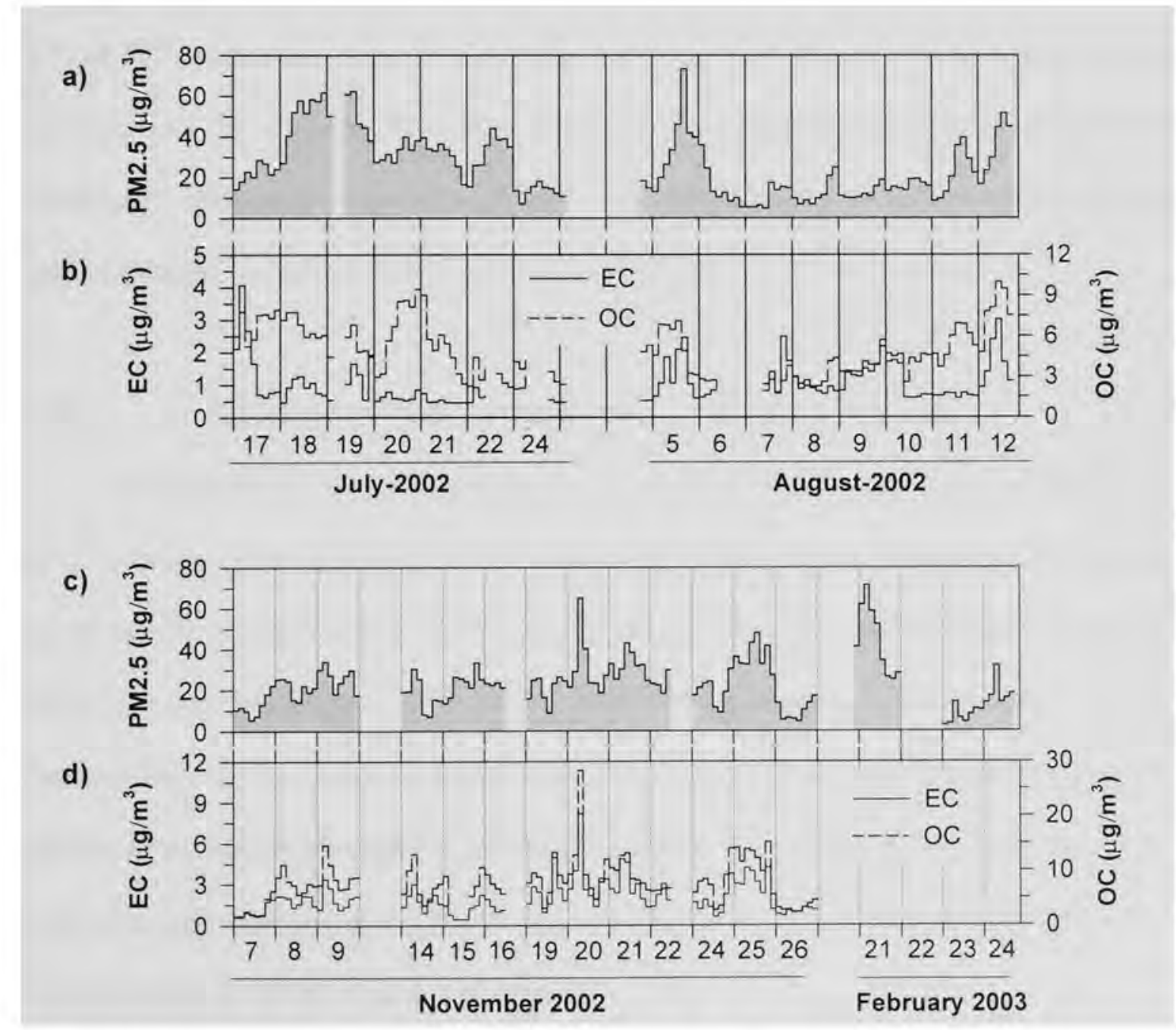

Figure 3.1: Time series of the summer and winter three-hourly concentrations of PM2.5 mass $(\mathrm{a}, \mathrm{c})$ and the bulk chemical properties elemental carbon, EC, and organic carbon, $\mathrm{OC}(\mathrm{b}, \mathrm{d})$. 


\subsubsection{Diurnal and Seasonal Variations of the Ambient Concentrations of Organic}

\section{Compounds}

In order to be able to represent the entire data set in a configuration that allows examination of the diurnal patterns within the perspective of the daily variations of concentrations, whenever appropriate vertical point plots that include all individual measurements available for each of the 3 -hourly periods sampled, 15 to 17 points, were created using Sigma Plot (version 8.0; SPSS Inc.). Boxplots, with standard boundaries at $5^{\text {th }}$ and $95^{\text {th }}$ percentiles, were overlaid with the purpose of helping to readily distinguish the spread of the data for each 3-hourly period. Data displayed in this way simplifies visualizing abundance, patterns, episodes and the influence of point-sources while maintaining the variations observed in the time-series.

\subsubsection{Homologous Series of n-Alkanes}

In the ambient PM2.5 from Baltimore, n-alkanes from $\mathrm{C} 19$ to $\mathrm{C} 33$ were identified in all samples. The concentration of homologues in the range C19 to C25 comprises approximately $85-90 \%$ of the total series in both seasons. Most samples show no carbon preference for homologues with $\mathrm{C}<25$ and a distinguishable predominance of the concentration of the odd-homologues for $\mathrm{C}>24$. This distribution reflects the typical pattern of an urban atmosphere primarily impacted by fossil-fuel hydrocarbons with small amounts of superimposed lipids from the leaves' waxes of terrestrial higher plants (Simoneit B.R.T., 1984; Rogge et al, 1993d).

The n-alkanes carbon preference index ${ }^{1}, \mathrm{CPI}_{\text {odd }}$, are in the range of 1 to 2 for $92 \%$ and $97 \%$ of the summer and winter samples, respectively. The median value of $\mathrm{CPI}_{\mathrm{odd}}$ is 
the same in both seasons, 1.2 . These values indicate that the analyzed samples are mainly influenced by anthropogenic emissions and the similarity of the median in both seasons implies a nearly constant input of biogenic background in both seasonal periods. About $6 \%$ of summer and $3 \%$ of winter samples with a value $\mathrm{CPI}_{\text {odd }}<1$ (evenings of 7-8 and 8-9August, and of 25 -November) show a distribution with a strong predominance of evento-odd n-alkanes homologues. This type of pattern is not commonly observed in atmospheric particles; therefore, efforts are made to elucidate its likely source. This issue is discussed in detail in section 4.3.3.1. Values of $\mathrm{CPI}_{\text {ood }}>2$ were observed in seven samples: four samples from 6-August and three from 23-February, indicating that these samples reflect a comparatively larger influence of higher-plants biogenic input. A graph of the $\mathrm{CPI}_{\text {odd }}$ for the summer and winter time-series is provided in Appendix B (Figure B.4).

Figure 3.2 shows the summary plots os the 3 -hourly concentrations for two groups of n-alkanes: C19-C25, derived mainly from fossil fuel combustion, particularly petroleum derived hydrocarbons, and odd $\mathrm{C} 27-\mathrm{C} 35$, dominated by the contribution of the waxes from the abrasion of leaves from higher plants. The median concentrations of the fossil fuel derived $n$-alkanes are $25-50 \%$ larger during the winter; however, the 3 -hourly concentrations show a greater spread during the summer. The median concentrations of the biogenic higher-plant derived n-alkanes are about $25 \%$ larger in the winter compared to the summer; however, the concentration values show an appreciable larger day-to-day variability during the winter. Event days that can be distinguished from the summary plots

${ }^{1} \mathrm{CPI}: \quad$ n-alkanes $=\sum$ Odd $[\mathrm{C} 25-\mathrm{C} 33] / 2$ Even[C24-C32];

n-alkanoic acids $=\sum$ Even[C24-C32]/Odd[C23-C31]; Ref: Simoneit, 1982 
of fossil-fuel derived n-alkanes include the evening of 8-August, and the mornings of 20November and 21-February; similarly, the odd-n-alkanes were measured in notably larger concentrations from the evening of 24-November and throughout 25-November.
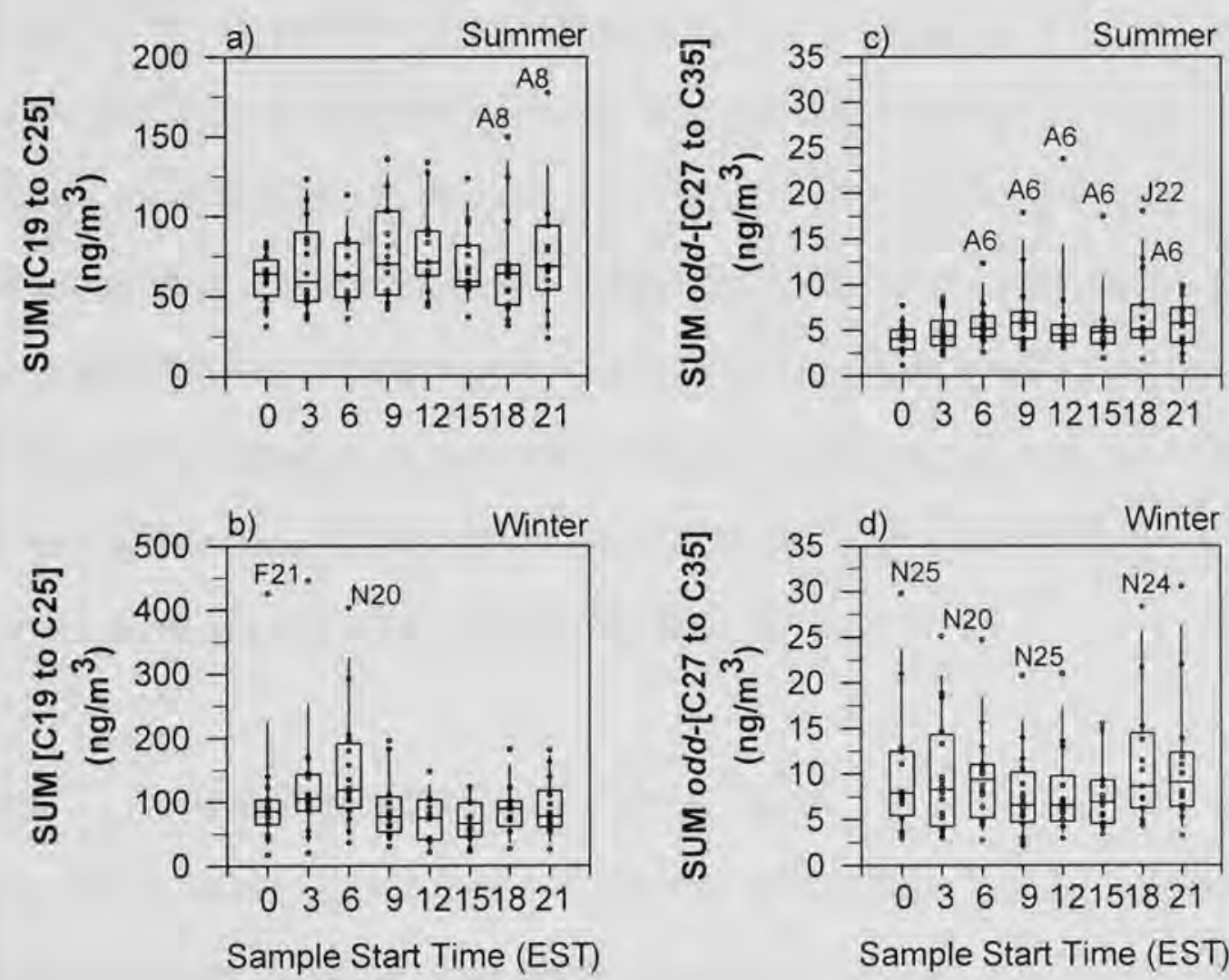

Sample Start Time (EST)

Figure 3.2: Three-hourly variations of the concentrations of selected groups of n-alkanes during summer and winter, respectively: sum of n-alkanes (C19-C25) (a, b), and sum of odd n-alkanes $(\mathrm{C} 27, \mathrm{C} 29, \mathrm{C} 31, \mathrm{C} 33, \mathrm{C} 35)(\mathrm{c}, \mathrm{d})$. Numbers in graphs are the days of the corresponding month: $\mathrm{J}=\mathrm{July}, \mathrm{A}=$ August in summer, and $\mathrm{N}=$ November and $\mathrm{F}=\mathrm{February}$ in winter.

A pronounced and distinctive diurnal variation is observed on 6-August for the odd high molecular weight $n$-alkanes, consisting of increasing concentrations during the 
morning hours and peaking at mid-day. Inspection of the surface wind data measured at the sampling site (see Appendix B, Figure B.7) indicates that on most of the summer sampling days the maxima mid-day wind speed was in the range of $3-5 \mathrm{~m} / \mathrm{s}$; on the other hand, on 6-August this maxima reached a value of $7-9 \mathrm{~m} / \mathrm{s}$ and the $5-\mathrm{min}$ wind direction measurements indicate rapid shifts within $50^{\circ}$ of due north. The strong similarity of the patterns of the concentration of odd-alkanes (Figure $3.2 \mathrm{c}$ ) and the wind speed suggest that on this day the prominent increase of concentration and the observed diurnal variation of the biogenic n-alkanes were dominated by the effect of wind shear. Sudden changes in wind direction and speed increase the likelihood of waxes being removed from leaves either by rubbing against each other or due to the abrasion caused by wind blown particles (Rogge et al., 1993d). The median concentrations of biogenic n-alkanes are not significantly different in the winter than in the summer; however, the 3-hourly distributions displayed a noticeably larger spread in the winter.

\subsubsection{Homologous Series of n-Alkanoic Acids}

Short-chain n-alkanoic acids $(<\mathrm{C} 20)$ occur in most living organisms; however, in the fine particles of urban atmospheres considerable amounts are introduced from anthropogenic activities. Approximately $50 \%$ of the organic compounds that are identified in the fine particles emitted from the exhaust of cooking operations, catalytic equipped gasoline-powered and heavy duty diesel-powered vehicles, consist of shortchain n-alkanoic acids (Rogge et al.1993b). The homologues n-hexadecanoic (palmitic) and n-octadecanoic (stearic) acids are among the most abundant organic compounds in the emissions from cooking operations (Rogge et al., 1991). Burning of coal and biomass 
also generates considerable amounts of the short-chain n-alkanoic acids; though, unlike emissions from cooking and vehicular exhaust, homologues of chain length C20 and above are also present in important amounts in the profiles of biomass burning (Oros et al., 2001a,b, 2006) and low-rank coals such as lignite and brown burned at low temperatures (Oros and Simoneit, 2000). Since coal is used by regulated sources such as power plants for generation of electricity, and is no longer used in the northeast of the U.S. for space heating, the predominant inputs of n-alkanoic acids to the aerosol in the urban atmosphere are expected to be vehicular and cooking operation sources, and to a more variable extent, from biomass or wood burning.

Nearly half of the concentration of identified compounds in the PM2.5 from both seasons is comprised of n-alkanoic acids. Although these derive from a myriad of biogenic and anthropogenic sources, and some may even partially be of secondary origin, analysis of their distributions can yield important information about their sources. Straight-chain n-alkanoic acids, determined as methyl esters, range from C9 to C32 in all samples from Baltimore. Approximately $70-85 \%$ of the total abundance is comprised of seven species. The median proportional contributions of $\mathrm{C} 8: \mathrm{C} 9: \mathrm{C} 10: \mathrm{C} 12: \mathrm{C} 14: \mathrm{C} 16: \mathrm{C} 18$ in the summer and winter samples are, respectively, 16:33:10:6:4:9:5 and $9: 11: 5: 4: 3: 24: 14$

Figure 3.3 shows the percent proportion of the seven most abundant n-alkanoic acids in each of the 3-hourly samples for the time-series of both seasons. These graphs indicate that the proportion of homologues $\mathrm{C} 10, \mathrm{C} 12$ and $\mathrm{C} 14$ are very similar in both seasons. However, more distinct differences are observed for C8, and particularly, C9, C16 and C18. The proportion of homologue C9 (black circles) is generally lower during 
ஆั
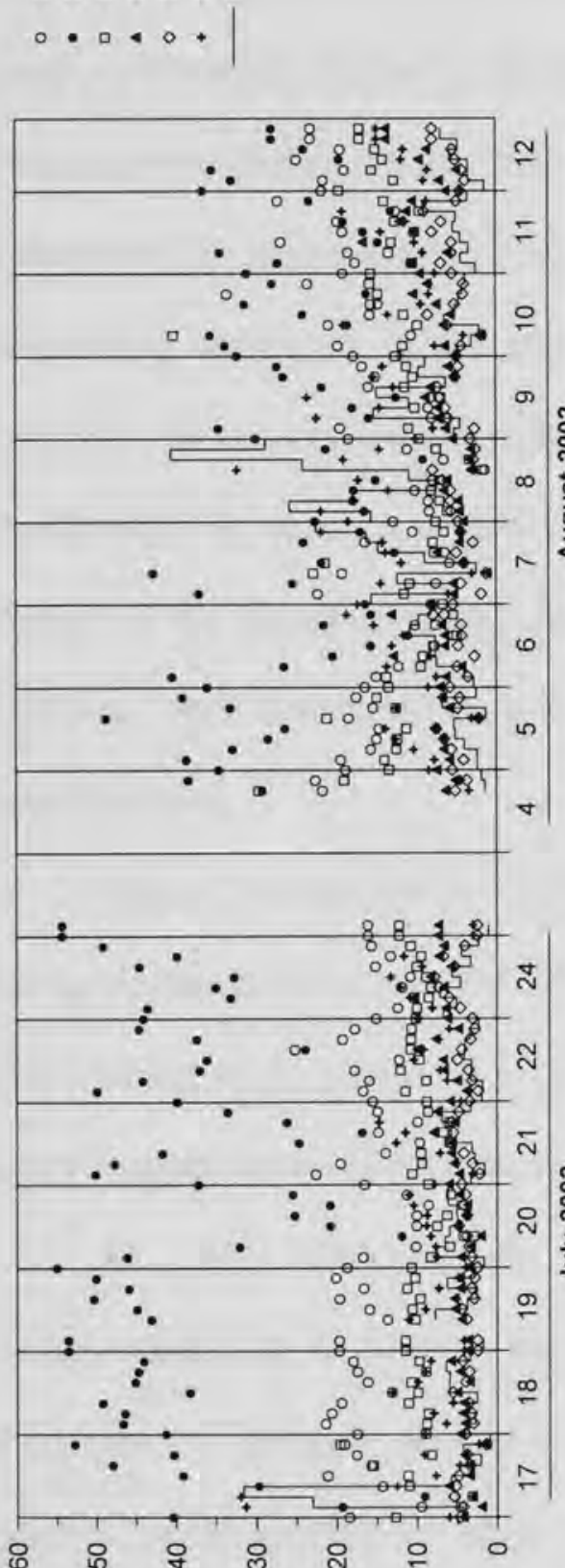

әэuepunq $\forall$ p! $\forall$ ग!०uex| $\forall-u \%$

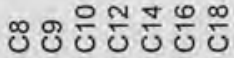
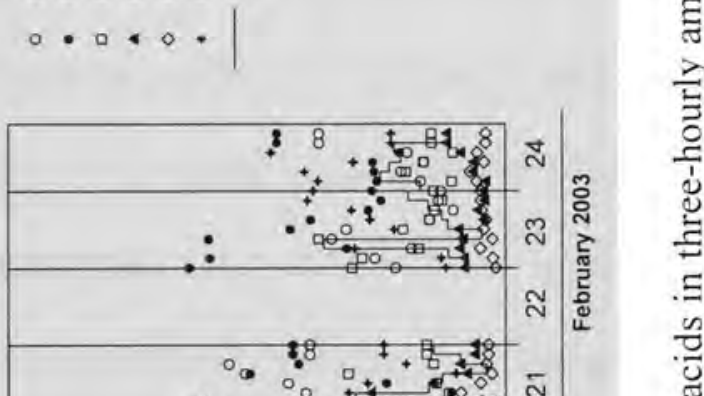

ปั่

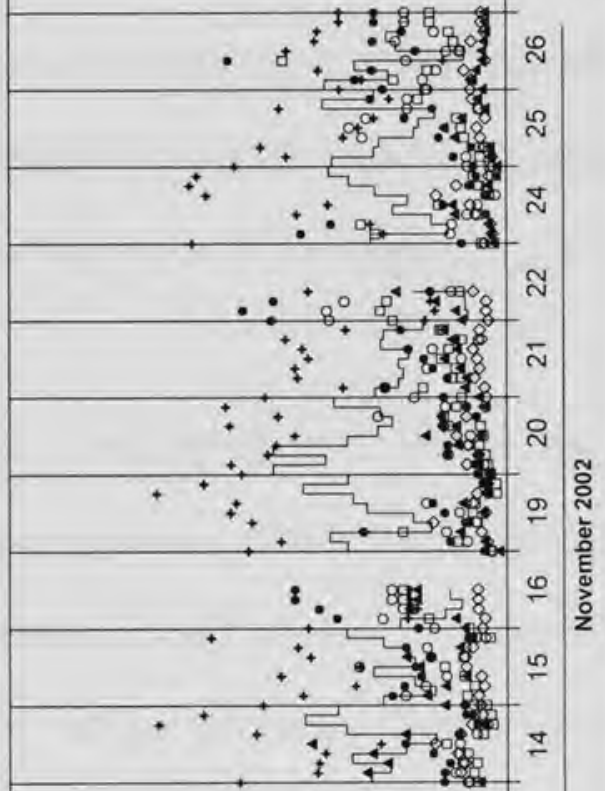

2 
the winter compared to the summer but most significant are the larger 3-hourly proportions throughout specific summer days compared to others; namely, the proportion in samples from 18-19-July, 22-, 24-July and 5-August is approximately double than in samples 6-9-August. Secondly, the proportion of palmitic (+ sign) and stearic (line) acids are much lower during the summer. A consistently larger contribution of n-nonanoic acid during specific summer days is significant because it may point to a change in the contributing sources or in the atmospheric dynamics such as, for example, different formation or removal mechanisms associated to distinct summer episodes. This consideration is based on the knowledge that $n$-nonanoic acid has been identified as a product of the photodegradation of oleic acid (9-octadecenoic acid) (Kawamura and Ikushima, 1993) and therefore, it may be indicative of the degree of processing of the organic aerosol.

Figure 3.4 sumarize the variations of concentrations of palmitic and stearic acids during the two seasons sampled. The concentrations of both species are approximately double in the winter compared to the summer. The $\mathrm{R}^{2}$ of the linear correlation of the 3 hourly concentrations of palmitic vs. stearic acid in summer and winter are, respectively, 0.612 and 0.874 . Considering the variety of sources that emit these compounds, this correspondence, at a 3-hourly level, suggests that their ambient concentrations are dominated by common sources or dynamics. A pattern of diurnal variation is not observed in the summer for either specie and in the winter a mild pattern is apparent consisting of lower concentrations at midday. The ratio of maximum to minimum concentrations range from 3 to 49 ( 49 for 24-November, see Figure 3.4.d), with a median value of 7 . 
a)

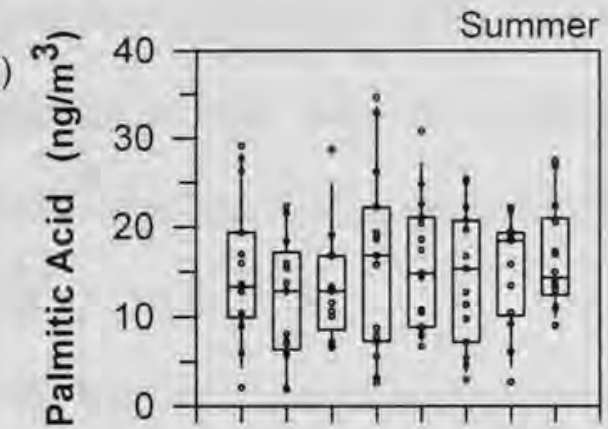

c)

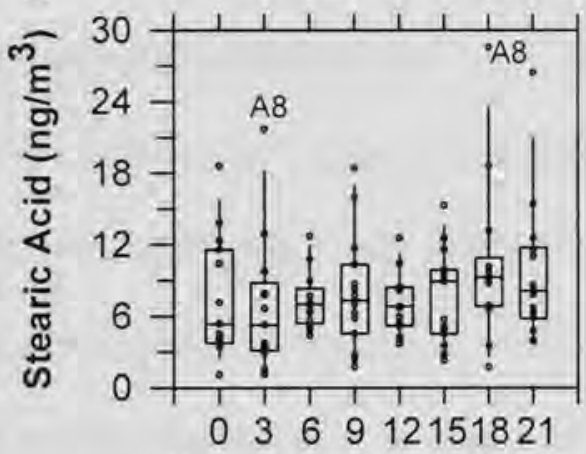

Sample Start Time (EST) b)

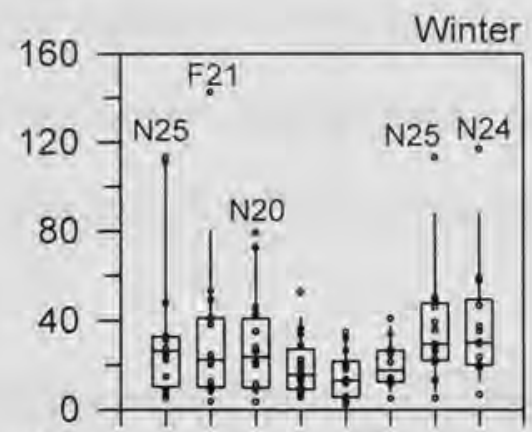

d)

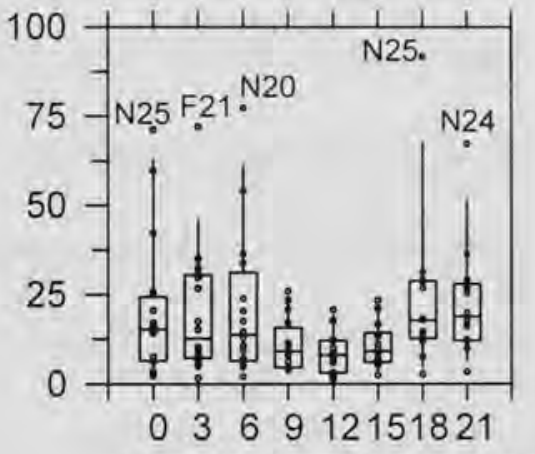

Sample Start Time (EST)

Figure 3.4: Three-hourly summer and winter diurnal variations of the concentrations of nhexadecanoic acid (C16, palmitic) (a, b), and n-octadecanoic acid (C18, stearic acid) (c, d). Numbers in graphs are the days of the corresponding month: $J=J u l y, A=A u g u s t ~ i n$ summer, and $\mathrm{N}=$ November and $\mathrm{F}=\mathrm{February}$ in winter.

The average percent fraction of the long-chain fatty acids (C21-C32) to the total n-alkanoic acids is approximately $9 \% \pm 8 \%$ in the summer and $17 \% \pm 7 \%$ in the winter. $\mathrm{CPI}_{\text {even }}$ (C24-C32) average $4.9 \pm 1.4$ and $4.7 \pm 0.5$ during the summer and winter, respectively (graphs provided in Appendix B. Figure B.4). Significantly larger $\mathrm{CPI}_{\text {even }}$ values, between 8 and 10, are observed during the 6-August event described section 3.3.2.1 for the odd-carbon number high molecular weight n-alkanes; furthermore, the distribution of n-alkanoic acids for this day's set of samples displays the typical pattern of the long-chain fatty acids that has been reported for green vegetative detritus (Rogge et al., 1993d, Sevimoglu et al., 2005), with very strong predominance of the even numbered 
homologues and a maximum at C28. Likewise, the summary plots displaying the sum of the concentrations of even carbon-number high molecular weight n-alkanoic acids in the range C24-C32 (Figure 3.5 b) also show the significantly higher concentrations observed at midday of 6-August.

The concentrations of the even-carbon higher molecular weight n-alkanoic acids homologues display a significantly larger concentration in most of the samples from the July period compared to August, particularly during the 20-21-July episode discussed in section 4.3.4.1. In August, a mild diurnal variation is apparent, with larger concentrations during the day (a dome-like shape in Figure 3.5 b). In contrast, the opposite trend is observed during the winter when the minimum concentrations are observed at midday similarly to those described for palmitic and steraic acid; however, here the ratio between the maximum and the minimum concentration for each day ranges from 1 to 5 with a median value of 3 .

A bowlike diurnal pattern with a minimum around midday is often interpreted, particularly during the winter, as an indication of a pollutant continuous emission from many sources, combined with a shallower mixing layer at night and enhanced convective dispersion during the day as the height of the mixing layer increases due to the land surface heating. Mixing height data derived from LIDAR measurements conducted during the Baltimore PM Supersite (Ondov et al., 2006) indicate that the mixing height typically displayed a steady increase in the morning hours to reach sustained maximum values between the sampling hours 12:00 and 15:00. These maximum averaged 1,825 $\mathrm{m}$ $\pm 365 \mathrm{~m}$, followed by a continuous decrease reaching the lowest values, approximately $650 \mathrm{~m} \pm 130 \mathrm{~m}$, at about 15:00 hour. This means that for any species only on days when 
the nighttime maximum to daytime minimum concentration ratios is observed to be larger than 3-4 there is an indication of net larger nighttime emission. Significantly larger maximum to minimum concentrations observed for n-alkanes (Figure 3.2) and n-alkanoic acids (Figure 3.4) on 24-26-November and February (out of scale) indicate that the emission of those compounds were associated to larger nighttime sources contribution on these days.
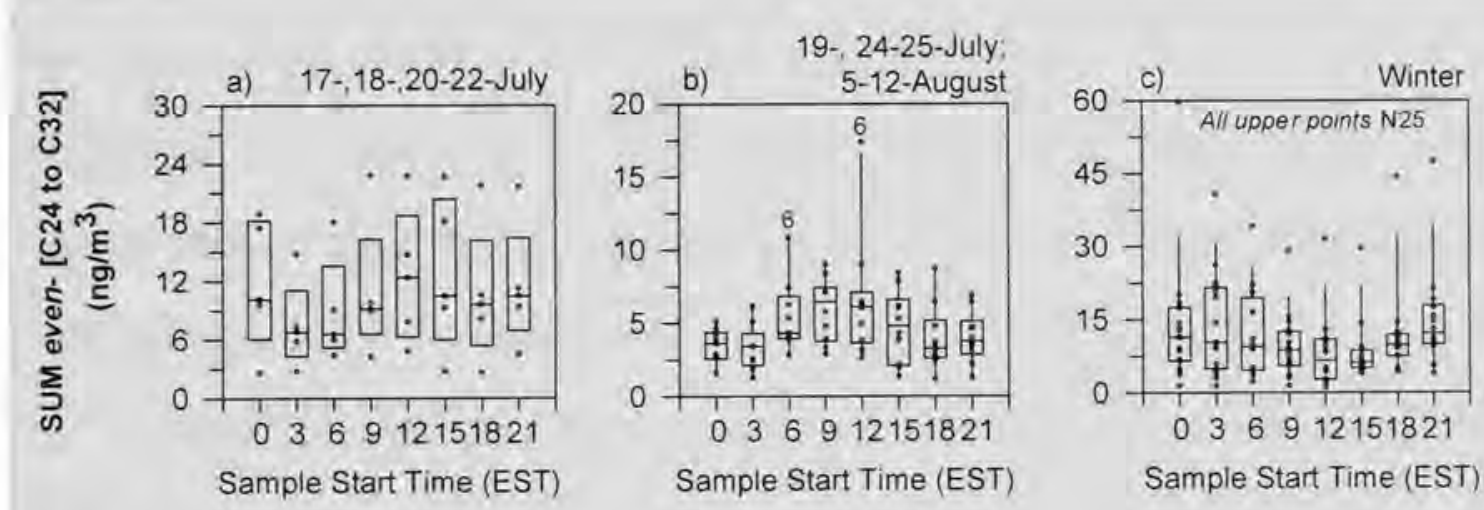

Figure 3.5: Three-hourly diurnal variations of the sum of the concentrations of high molecular weight even n-alkanoic acids (C24,C26,C28,C30,C32) during summer (a, b) and winter (c). Numbers in graphs are the days of the corresponding month: J=July, $\mathrm{A}=$ August in summer, and $\mathrm{N}=$ November and $\mathrm{F}=\mathrm{February}$ in winter.

\subsubsection{Unsaturated n-Alkenoic Acids}

In this study we quantified two mono-unsaturated fatty acids, 9-hexadecenoic acid (palmitoleic) and cis-9-octadecenoic acid (oleic), and one bi-unsaturated, cis,cis-9,12octadecadienoic acid (linoleic). Palmitoleic acid has been reported in the composition of the fine particle emissions exhausted from meat cooking operations (Rogge et al., 1991, Schauer et al., 1999a) and cooking with seed oils (Schauer et al.. 2002b). In all but one of 
these sources (Rogge et al., 1991) all three alkenoic acids are reported, and the relative amount of oleic acid is always the largest by nearly one order of magnitude. The target alkenoic acids have also been found in the emissions from burning of wood under open burning conditions (Hays et al, 2002, 2005; Lee et al, 2005), fireplaces (Fine et al., 2001, 2002 ) and woodstoves (Fine et al, 2004b). In addition, oleic and linoleic have also been identified in the fine particulate matter from cigarette smoking (Rogge et al., 1994), leaf surface abrasion (Rogge et al., 1993d), urban, rural, paved and unpaved road dusts and tire wear debris (Rogge et al. 1993c), re-suspended fine particles from various agricultural soils (Rogge et al, 2007), and hot asphalt roofing fumes (Rogge et al., 1997a). Trace amounts of oleic acid have been detected in the fine particles exhausted from gasoline- and diesel-operated motor vehicles (Rogge 1993b) as well.

Palmitoleic and oleic acids are present in all the summer and winter samples from Baltimore; however their abundances are dissimilar in important ways. Figure 3.6 illustrates that while the concentrations of palmitoleic acid are found at similar levels in samples from both seasons, those of oleic and linoleic acids are, respectively, 6 and 30 times larger during the winter compared to the summer. In addition, on a 3-hourly basis the concentrations of oleic and linoleic acid are exceptionally well correlated in the winter (Figure $3.6 \mathrm{~d}$ ), and while those of palmitoleic and oleic display a consistent correlation during the summer (slope of 1.2, Figure 3.6 a) no such uniform structure is observed in the winter (Figure $3.6 \mathrm{c}$ ).

Unlike the n-alkanes and n-alkanoic acids, these unsaturated species display sharp diurnal variations. The brevity of the peaks is an indication of the labile nature of unsaturated fatty acids which is also apparent in the strong seasonal dependence of the 
concentrations. However, the similar concentration levels of oleic and palmitoleic acid in the summer samples is puzzling. According to published organic profiles for major urban sources of fine particles (Table 1.1), cooking operations yield the largest emission factors of palmitic, stearic, palmitoleic and oleic acids (see Appendix B, Figure B.5), and for

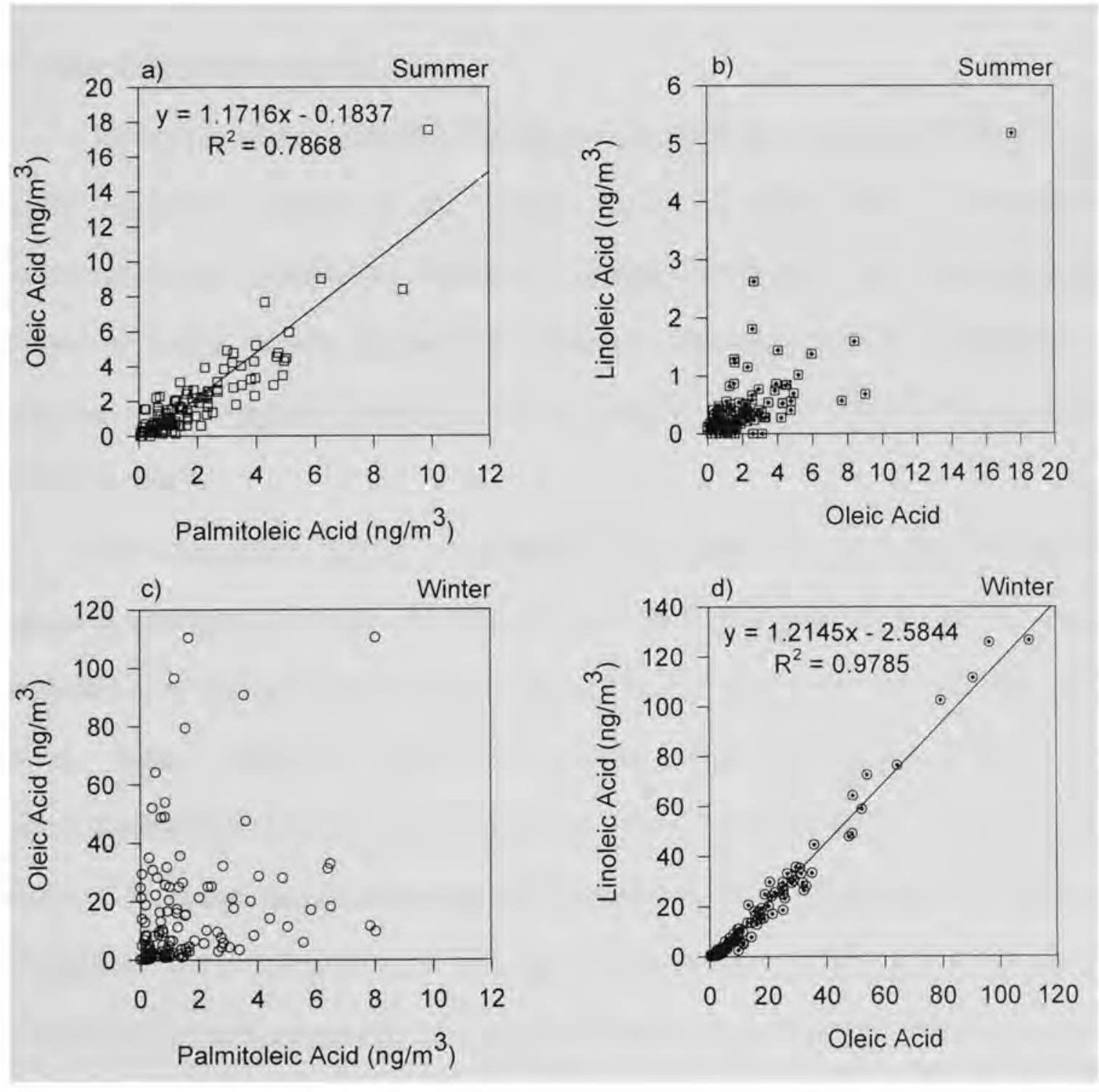

Figure 3.6: Scatter plots of the three-hourly concentrations of the unsaturated n-alkenoic acid palmitoleic (C16:1), oleic (C18:1) and linoleic acid (C18:2). Best-fit line and linear correlation factor are shown. 
these sources the ratio of oleic:palmitoleic acids span from 11 to 175 . These ratio values are observed daily during the winter, with the highest values occurring during the night and the early morning. In contrast, during the summer these peak ratios are much lower, from 3 to 7, and they are observed only in six samples; as indicated in Figure 3.6a, the average ratio is only 1.17 . These ambient concentration ratios near one imply either that there are unknown sources of palmitoleic acid or that oleic acid is preferentially depleted in a time scale of less than three hours.

During the winter, the diurnal changes of concentration of oleic and linoleic are highly regular, in contrast to the summer. Figure 3.7 shows that the minimum concentrations are consistently observed on samples 09:00 and 12:00. This diurnal pattern of strong daytime depletion is consistent with photochemical degradation, proposed as an important mechanism for the removal of oleic acid (Kawamura and Ikushima, 1993).

The atmospheric stability of unsaturated fatty acids is low compared to their saturated analogues; therefore, the ratio of the unsaturated:saturated acids has been suggested as an indicative of the degree of processing or "aging" of the aerosol (Simoneit et al., 1988). Figure 3.8 shows the 3-hourly ratios oleic:stearic (b, e) and palmitoleic:palmitic (c,f) for the summer and winter data, respectively. The median values of the palmitoleic:palmitic ratio are low and very similar in summer and winter, respectively $0.08 \pm 0.09$ and $0.13 \pm 0.11$. On the other hand, the peak values of the ratio oleic:stearic are between 0.8 and 2.2 during the winter, and are observed during the night in all days except 21 -November whereas during the summer, the ratio is appreciably lower and more so during the July sampling days. In terms of aging, these graphs allow to 


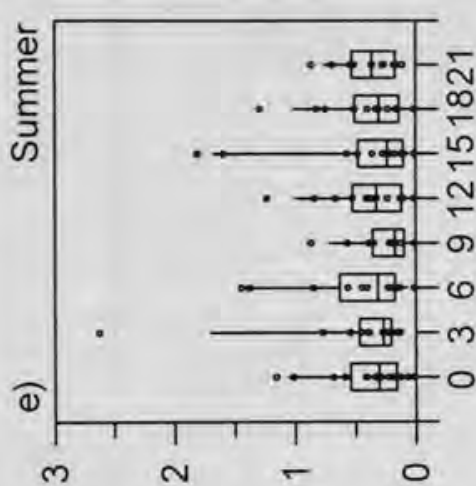

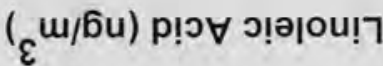

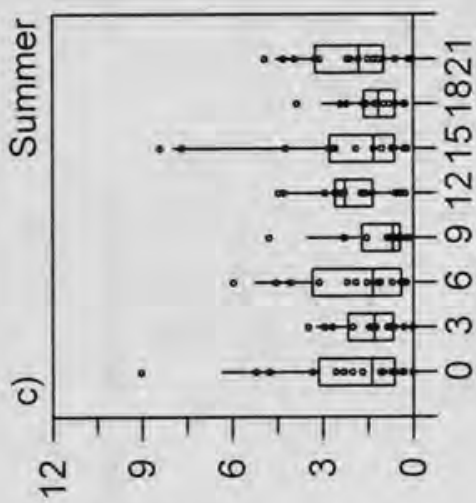

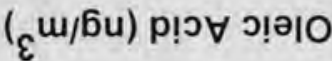

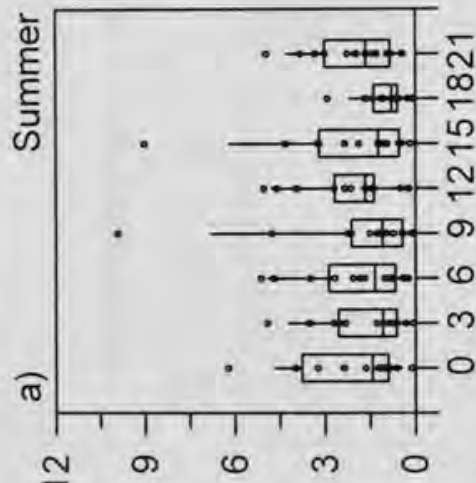

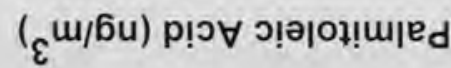

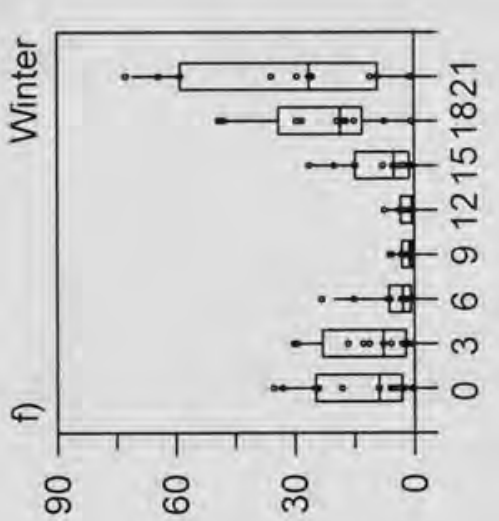

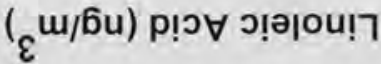

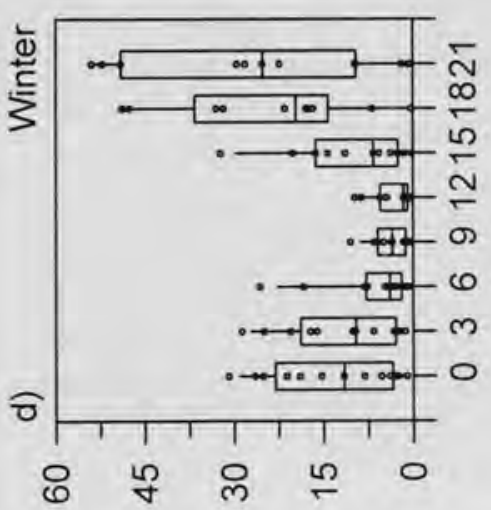

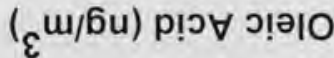

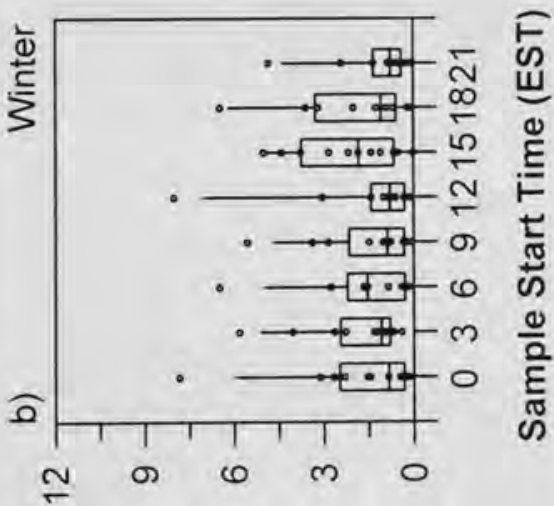

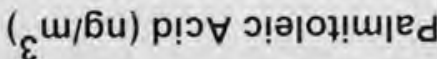

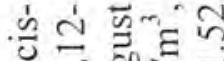
$\ddot{\theta}$ i

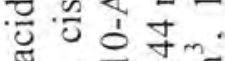

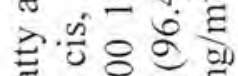
च $\dot{\vec{g}} \dot{0} 0$

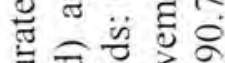

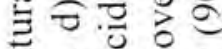

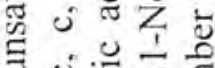

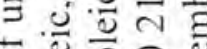
능 $\vdots \ldots \ddot{\sigma} z$

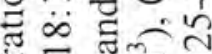
氜. E 诃 잉

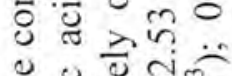

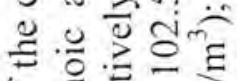
क ज्य की पै क्ष

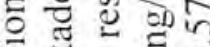
营 $>$ is 0 . तु क क ज

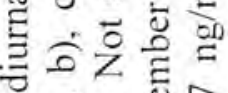
私宁于

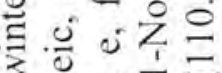
는

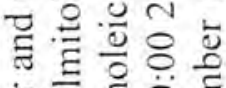
ப. ह$\exists \ddot{\infty} \Xi$

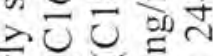
긍ㅇㅇ ग 可

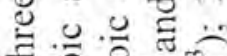
F 긍 को की ते 플 $=$

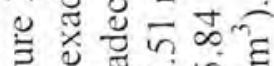

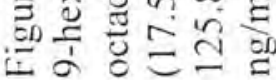



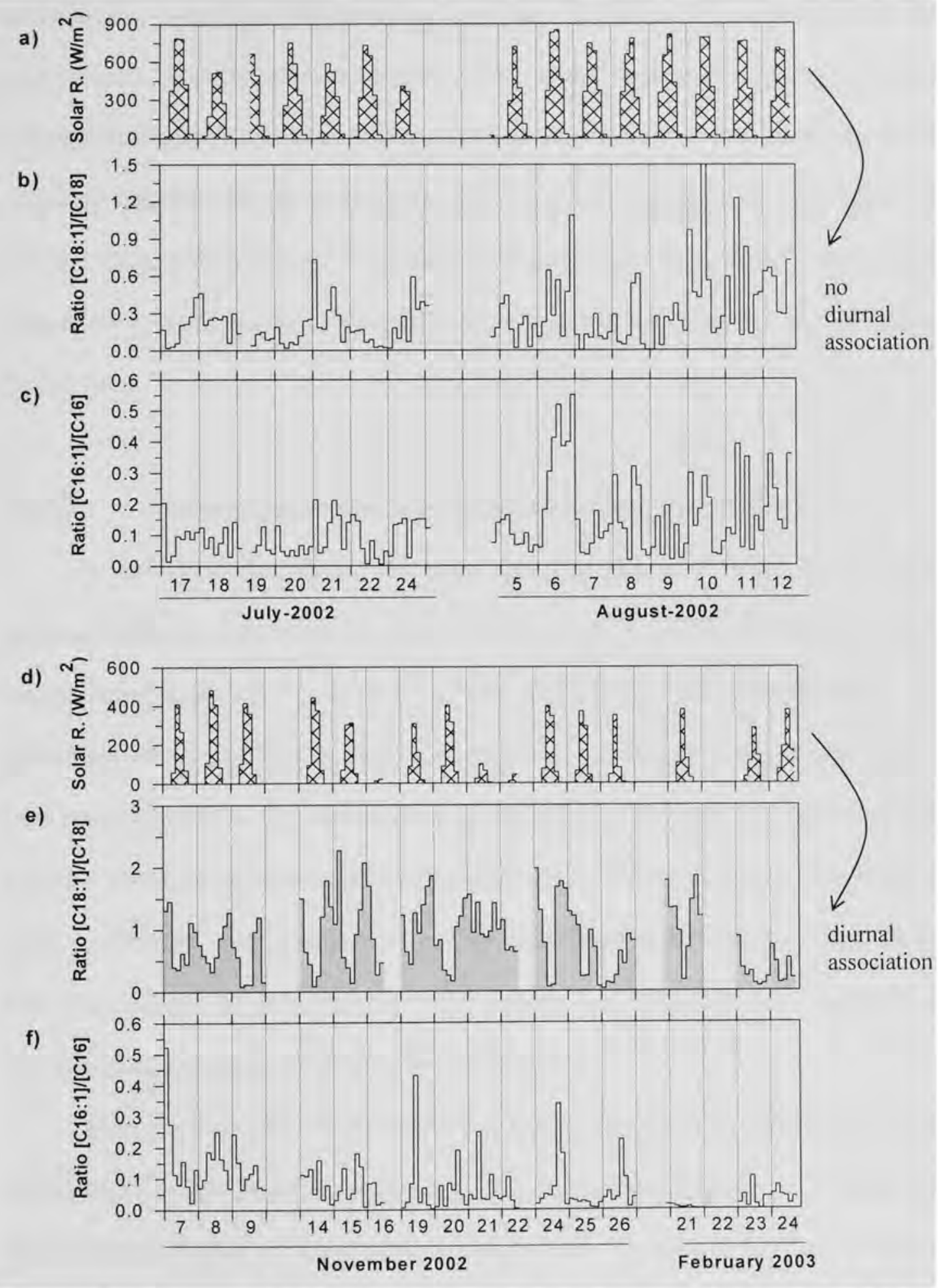

Figure 3.8: Time-series of the three-hourly ratios of unsaturated:saturated fatty acids concentrations during summer and winter, respectively: oleic:stearic (C18:1 to C18, b, e), palmitoleic:palmitic $(\mathrm{C} 16: 1$ to $\mathrm{C} 16: 0, \mathrm{c}, \mathrm{f})$, and corresponding solar radiation data $(\mathrm{a}, \mathrm{d})$. 
conclude that overall the July sampling days were influenced by a comparatively more aged aerosol. However, most importantly, these results support the conclusion that oleic and palmitoleic are subject to different diurnal atmospheric dynamics. Given the high regularity observed for the plot of ratio [C18:1]/[C18] during the winter (Figure $3.8 \mathrm{e}$ ) and the sharp midday decay of the ratio coinciding with the maximum solar radiation (Figure 3.8 a), these results are indicative of photochemical degradation of oleic acid on a diurnal basis.

\subsubsection{Homologous Series of n-Alkylcyclohexanes and Hopanes}

In the urban atmosphere, the most prevalent source of cyclic alkanes is from petroleum-derived anthropogenic inputs (Hostettler et al., 2002). The lower molecular weight homologues, $\mathrm{C} 17$ to $\mathrm{C} 20$, have been identified in diesel fuel (Schauer et al., 1999b) but not in gasoline (Schauer et al., 2002c). Homologues in the range C19 to C25 have been identified in the particle-phase of the exhaust from both non-catalyst equipped gasoline- and diesel-powered vehicles (Schauer et al., $1999 \mathrm{~b}$ and 2002c). The series of nalkylcyclohexanes ranging from $\mathrm{C} 17$ to $\mathrm{C} 28$ were found in all samples from Baltimore. The predominant homologous in both seasons are $17 \leq \mathrm{C} \leq 21$; the sum of their concentrations represents $60-80 \%$ of the series total.

Eight hopanes were identified in the PM2.5 samples from Baltimore, including $18 \alpha(\mathrm{H}) 21 \beta(\mathrm{H})-22,29,30$-trisnorneohopane, $\quad 17 \alpha(\mathrm{H}) 21 \beta(\mathrm{H})$-hopane, $\quad 17 \alpha(\mathrm{H}) 21 \beta(\mathrm{H})-$ 22,29,30-trisnorhopane, $17 \alpha(\mathrm{H}) 21 \beta(\mathrm{H})-29$-norhopane, 22-(S and $\mathrm{R}) 17 \alpha(\mathrm{H}), 21 \beta(\mathrm{H})-30-$

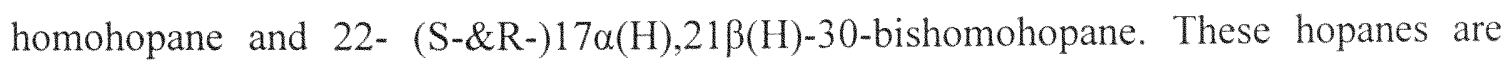
considered petroleum biomarkers unique to fossil fuel combustion. Of the major urban 
sources for which organic profiles have been developed, hopanes are biomarkers for the emissions that result from the burning of petroleum derived fuels including vehicular emissions and emissions from fuel oil boilers (Rogge et al., 1997b) and coal (Oros and Simoneit, 2000). In Baltimore, the predominant species in both seasons are $17 \alpha(\mathrm{H}), 21 \beta(\mathrm{H})-29-$ norhopane (norhopane) and $17 \alpha(\mathrm{H}), 21 \beta(\mathrm{H})$-hopane (hopane) representing about $50 \%$ of the series total.

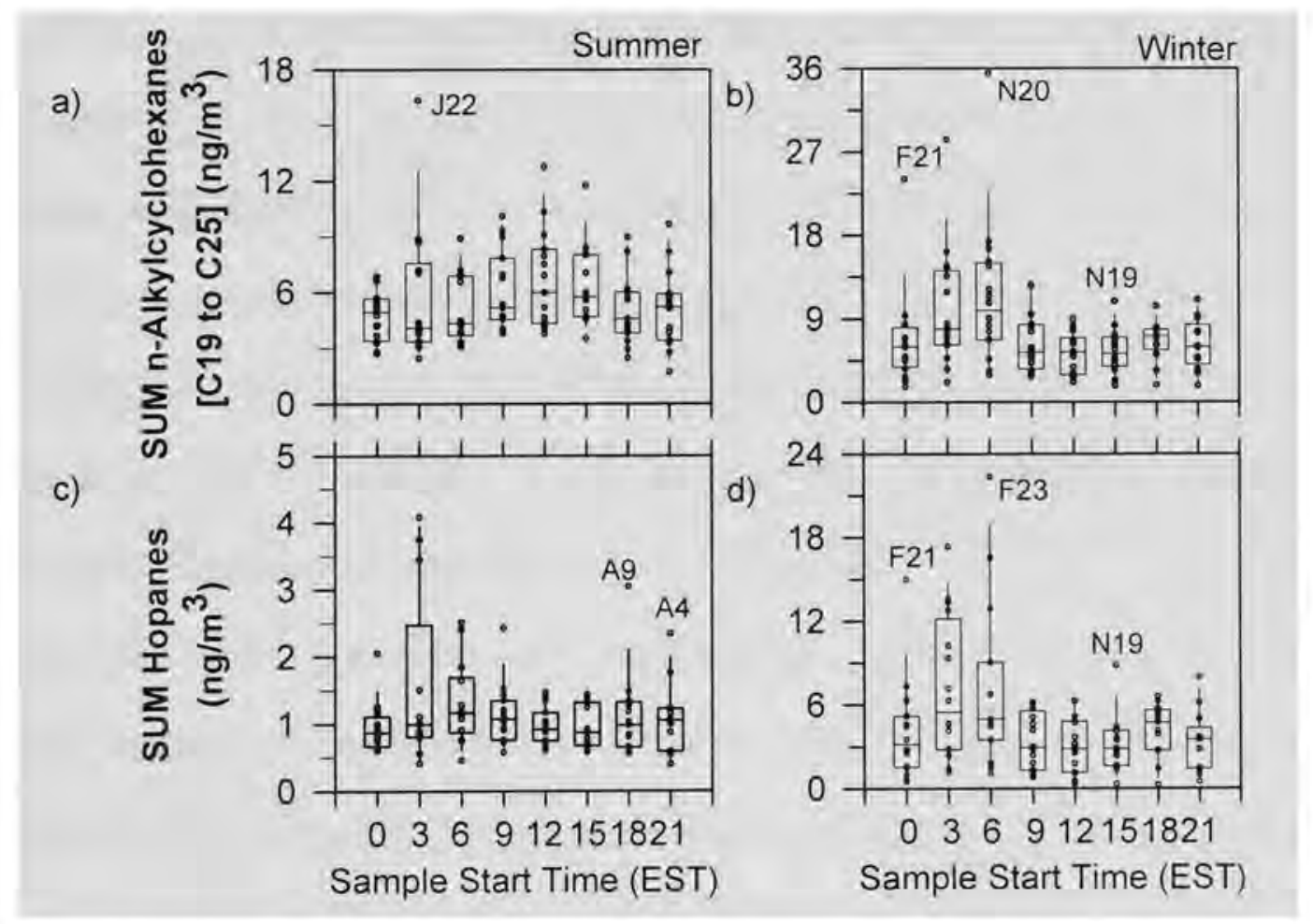

Figure 3.9: Three-hourly summer and winter diurnal variations of the sum of the concentrations of the n-alkylcyclohexanes homologues C19-C25 (a, b), and the sum of hopanes (c, d). Numbers in graphs are the days of the corresponding month: J=July, $\mathrm{A}=$ August in summer, and $\mathrm{N}=$ November and $\mathrm{F}=\mathrm{February}$ in winter. Values not shown for hopanes: 03:00 22-Jul: $11.89 \mathrm{ng} / \mathrm{m}^{3}, 06: 0020-\mathrm{Nov}: 34.11 \mathrm{ng} / \mathrm{m}^{3}$.

Summary plots of the 3-hourly concentrations of n-alkylcyclohexanes and hopanes are shown in Figure 3.9. During the winter, a mild diurnal trend is observed for 
both compound families consisting of larger concentrations during the morning hours 03:00 and 06:00, and relatively even the remaining of the day. The correlation of the $3-$ hourly concentrations of the fossil-fuel derived n-alkanes (C19-C25), nalkylcyclohexanes (C22-C25) and hopanes (sum of 8 hopanes identified) are shown in Figure 3.10 .

The linear trend shown in Figure 3.10c for the summer data is calculated excluding the three black-filled square data points. These points correspond to samples fom the evening of days 7- and 8-August when the "excess" of n-alkanes is associated to emissions from plastic burning (Chapter 4, section 4.3.3.1). Excluding these three points, the correlation between the fossil fuel derived n-alkanes and n-alkylcyclohexanes is similar to that observed in the winter (Figure 3.10 a). The 3 -hourly concentrations of the n-alkylcyclohexanes $22 \leq \mathrm{C} \leq 25$ are exceedingly well correlated with those of hopane during the winter (Figure 3.10b), suggesting that the measured concentrations of hopanes are largely dominated by vehicular emissions associated to lubricating oil (Chapter 2). On the other hand, a hopanes:n-alkylcyclohexanes ratio similar to that observed in winter is only observed in a handful of the summer samples. The linear fit for this group of samples is given in Figure $3.10 \mathrm{~d}$ (data points represented by dotted diamonds). None of the samples falling on this line were collected during daylight hours; i.e, 09:00, 12:00, 15:00 or 18:00. That is, the highest possible slope in the association of alkylcyclohexanes vs. hopanes is observed at times 00:00, 03:00, 06:00 or 21:00; furthermore, from the month of July, only data from day $17^{\text {th }}$ yields a ratio described by this line.

Since the concentrations of hopanes are larger during the winter, one presumption is that the markers' larger concentrations are due to increased emissions. Al- 

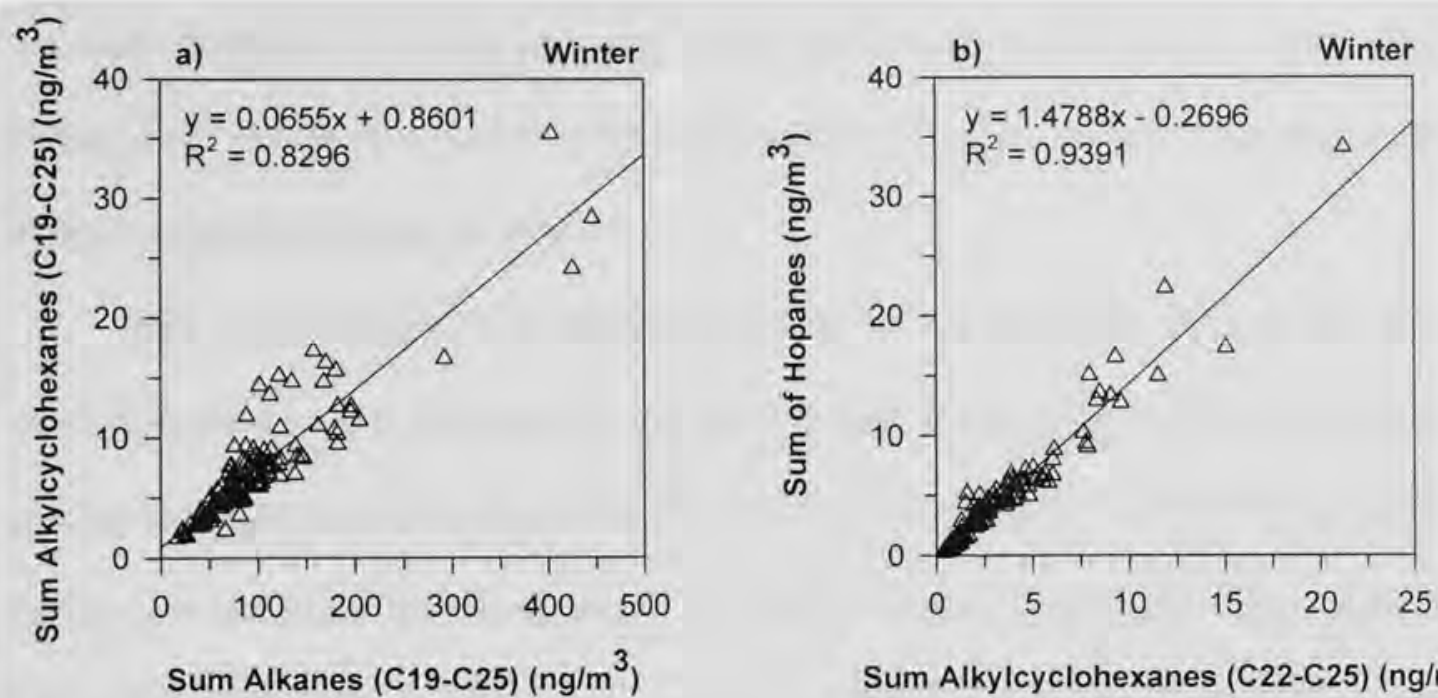

Sum Alkylcyclohexanes (C22-C25) $\left(\mathrm{ng} / \mathrm{m}^{3}\right)$
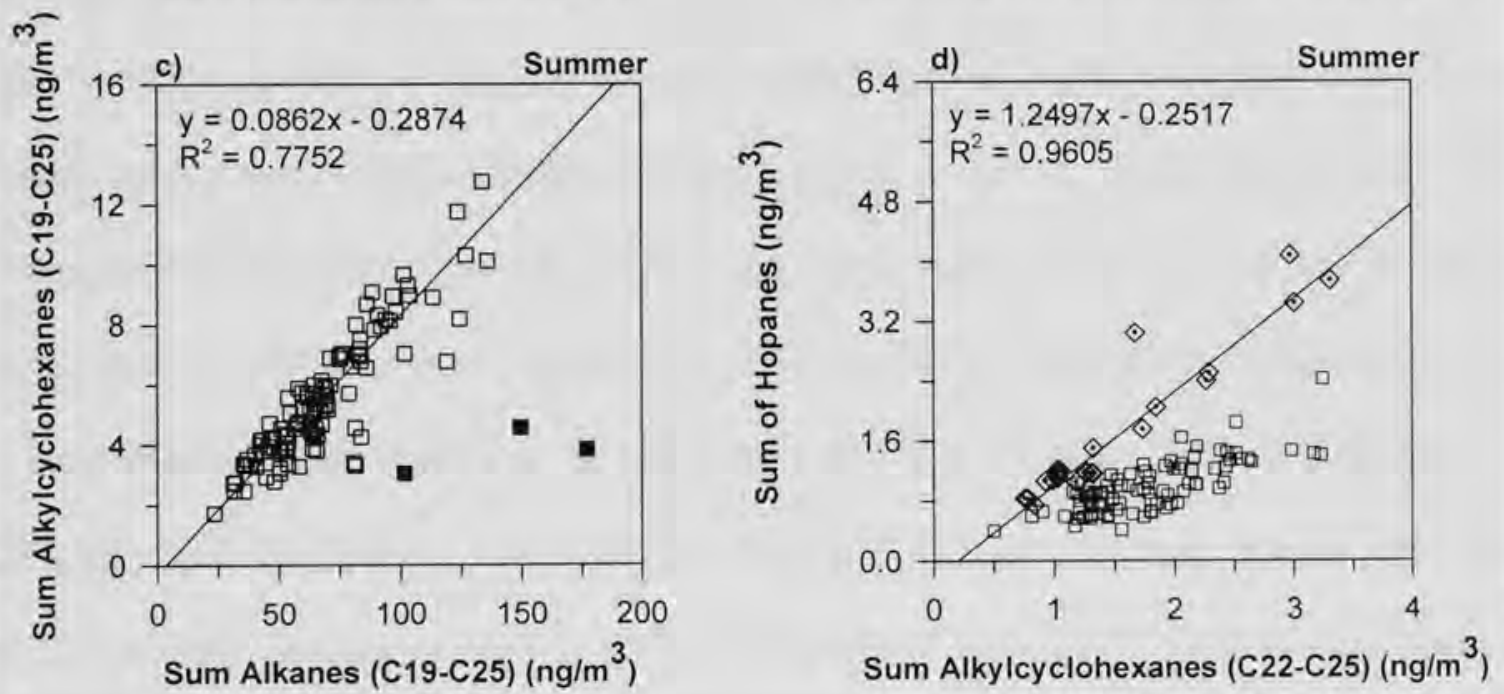

Figure 3.10: Scatter plots of the three-hourly concentrations of the fossil fuel derived nalkanes (sum of homologues C19 to C25), n-alkylcyclohexanes (sum of homologues C22 to $\mathrm{C} 25$ ) and hopanes. Best-fit line and linear correlation factor are shown. Fitting line in graph (c) calculated excluding the three encircled points, in graph (d) only for data points represented by a dotted diamond.

though it is likely that an increase in the combustion of petroleum-derived fuels such as fuel-oils may occur in the winter to satisfy space heating needs, and that this may in part explain the larger concentrations observed in this season, the essence of the results 
displayed in Figure 3.10 suggest that the observed seasonal differences in concentrations (Figure 3.9) are likely to reflect different dynamics in place during the summer rather than a larger input during the winter.

The 28 possible inter-correlations between the 3 -hourly ambient concentrations of all eight hopanes were analyzed for the summer and winter data. During the winter, all species are highly associated with linear correlation factors, $R^{2}$, of $0.99 \pm 0.01$ whereas during the summer, the associations are more variable with some days exhibiting $0.60 \leq R^{2} \leq 0.85$ and others $R^{2}<0.4$. The summer variability is readily illustrated in a plot of the percent proportion of each of the eight hopanes in the 3-hourly samples. The timeseries progression for each season is shown in Figure 3.11. The relative abundance of all hopanes remains remarkably consistent in all winter samples (shown only for the first three most abundant hopanes: Figure $3.11 \mathrm{~b}$ ); furthermore, the observed proportions are nearly identical to those observed for on-road vehicular traffic in the Squirrel Hill Tunnel (Figure 3.11 a). During the summer (Figure $3.11 \mathrm{c}$ ), only the proportions of $17 \alpha(\mathrm{H}), 21 \beta(\mathrm{H})$-hopane as well as those of homohopanes and bishomohopanes isomer pairs (only hopane shown here) stay relatively constant throughout all samples; on the other hand, the relative abundances of the other three hopanes are more variable. It is noteworthy that proportions of the hopanes reach the winter levels (which are similar to the vehicular levels) on a transient basis in select samples: early morning of 17-July, 03:00 22-July and 06:00 24-July, 03:00 5-August, and on a more continuous basis in samples from 6-9-August. Thus far we have noted that the distribution of the n-alkanoic acids indicate a different makeup of the aerosol during most of July compared to August. Therefore, it is possible that the dissimilar proportions of hopanes observed during this 
a)

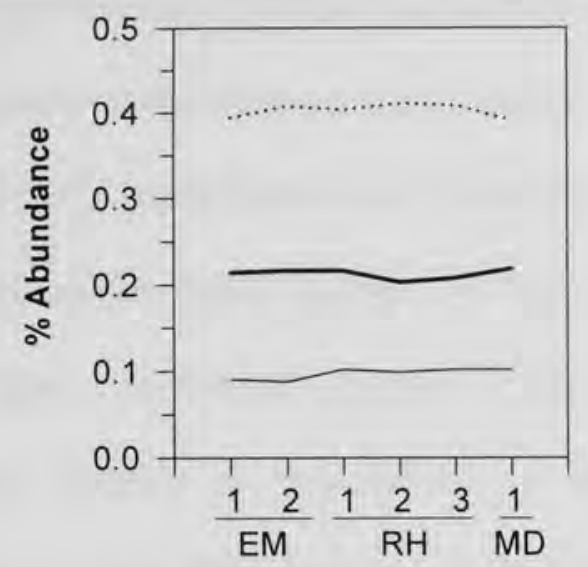

b)

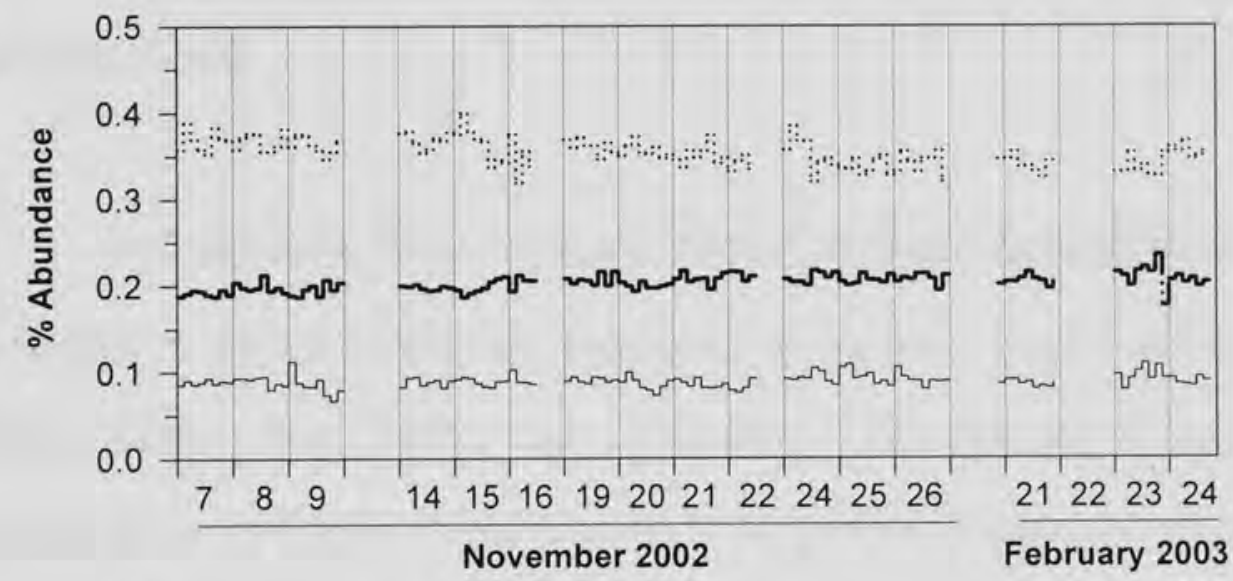

c)

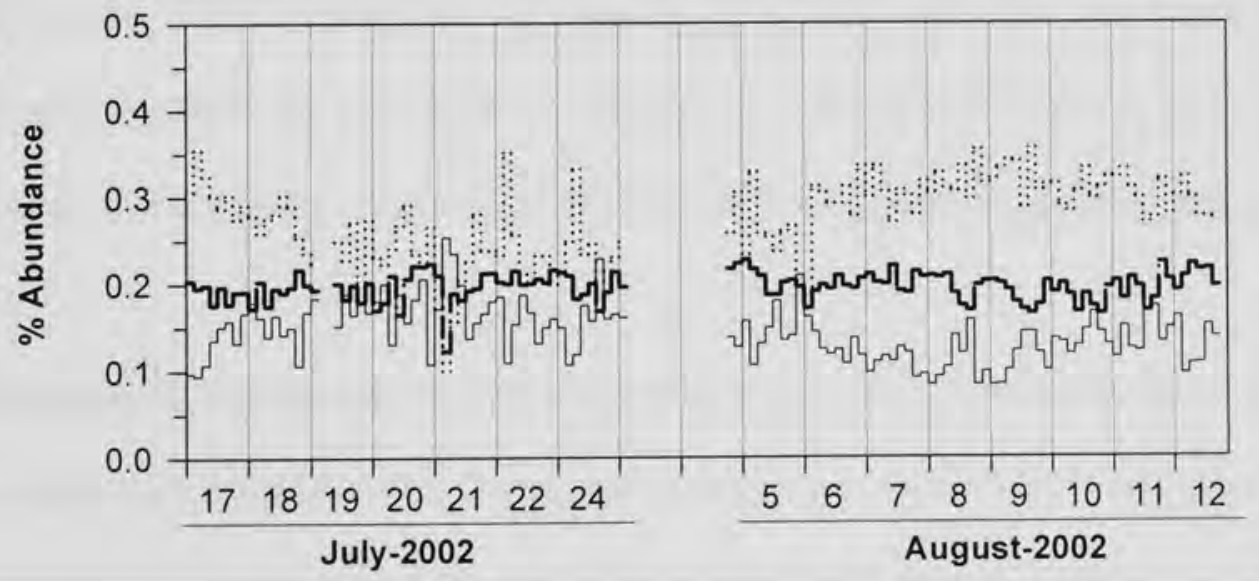

Figure 3.11: Time series of the three-hourly abundances of $17 \alpha(\mathrm{H}) 21 \beta(\mathrm{H}) 22,29,30$ trisnorhopane, $17 \alpha(\mathrm{H}) 21 \beta(\mathrm{H})-29$-norhopane, $17 \alpha(\mathrm{H}) 21 \beta(\mathrm{H})$-hopane relative to the total sum of hopanes, for the winter (b) and summer (c) data. The abundance of these species in the six samples from the Squirrel Hill Tunnel is shown in (a). 
sampling period may be associated to such difference. For example, it has been suggested that generally lower summer-than-winter concentrations of hopanes in 24-hour samples throughout the northeastern and southeastern U.S. may in part be evidence of aging of particulate matter (Robinson et al,, 2006d), where presumably hopanes are oxidized via a heterogeneous mechanism involving hydroxyl radicals (Rudich et al., 2007), as well as dynamical aspects of partitioning of semi-volatile organic compounds including differences in the characteristics of dilution associated to the nature of background air (Donahue, et al., 2006).

\subsubsection{Levoglucosan, Resin Acids and Phenols: Biomass Burning Tracers}

Cellulose is the most abundant component of biomass. Upon combustion at temperatures higher than $300^{\circ} \mathrm{C}$, the compound 1,6-anhydro-b-d-glucopyranose (levoglucosan) is formed as the major product of the thermal breakdown of cellulose (Simoneit et al., 1999). Because of its large emission rates $(40-1200 \mathrm{mg} / \mathrm{kg}$ of wood burned) and because of its apparent atmospheric stability (Fraser et al., 2000), levoglucosan is regarded as a generic indicator of the burning of anything containing cellulose.

Resin acids are introduced into atmospheric particles directly distilled from the source wood that contains them, generally referred as softwoods; these are coneproducing trees that have resinous ducts through trunk and branches which keeps them evergreen. Trees that loose their leaves, generally referred as hardwoods, do not produce resin acids. Both softwood and hardwood trees contain lignin, a polymeric substance that holds the cellulose fibers together and is made up of guaiacyl- and syringyl- building 
block units; however because the proportional composition of these units differs in both types of woods, so does the composition in the smoke produced from their burning. As a result, identification of products from the thermal breakdown of syringyl-moieties, particularly syringic acid, in samples of ambient fine particulate matter is a strong indication of burning of hardwoods (Simoneit et al., 2004).

In this study we looked for nine biomass burning tracers; levoglucosan, five resin acids (pimaric acid, sandaracopimaric acid, isopimaric acid, dehydroabietic acid, and 7 oxodehydroabietic acid), and three syringyl-moieties compounds (syringaldehyde, acetosyringone and syringic acid).

During the winter, all nine biomass burning tracers were found in all samples although within a wide range of concentrations. Our observations appear consistent with the expected increase in the usage of wood burning for space heating during the winter (Houck et al., 2006). Figure 3.12 show that the magnitude of the concentration of levoglucosan follows more or less an opposite trend to that of the ambient temperatures. Concentrations increase from 7-November to 21 -February while overnight ambient temperatures almost steadily drop from $10{ }^{\circ} \mathrm{C}$ to $0^{\circ} \mathrm{C}$. There are also other aspects to consider, including weekend effect and atmospheric conditions. For example, overnight temperatures were similar on Wednesday 20-November and on Sunday 24-November; however, it is more likely that residential fireplaces are used during weekends. Also, Fri 21-February temperatures were still below zero after the unprecedented President's Day blizzard that swept through the area on 15-17-February and wind speeds were shallow ( 0 $3 \mathrm{~m} / \mathrm{s}$ ) compared to Sunday $23-$ November at a briskly $6 \mathrm{~m} / \mathrm{s}$. 
a)

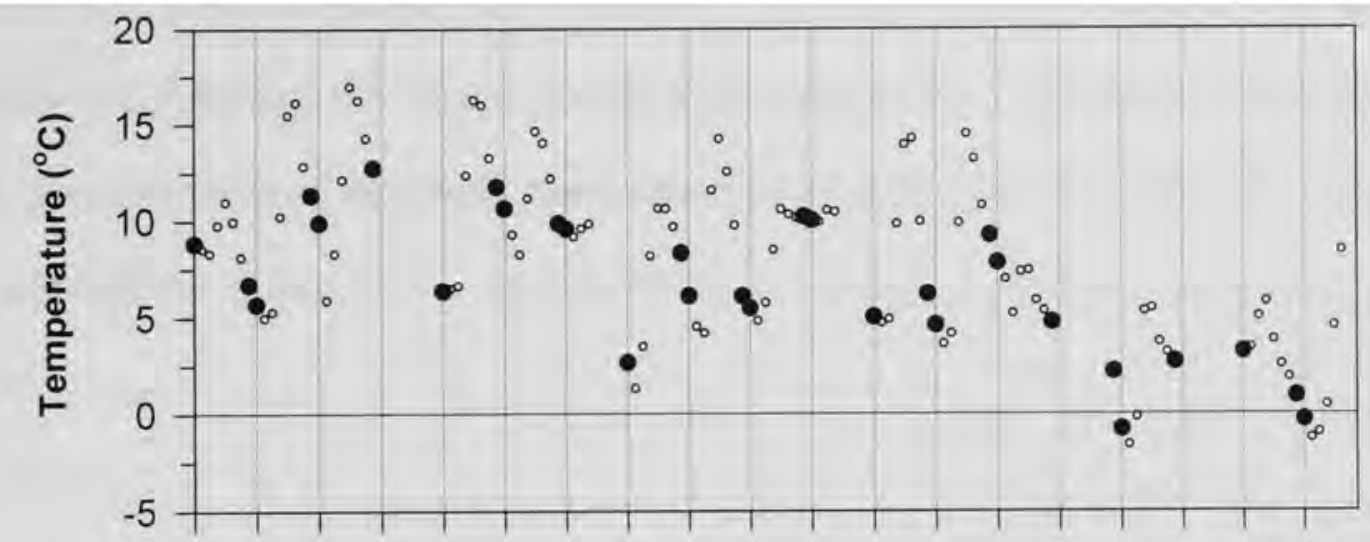

b)

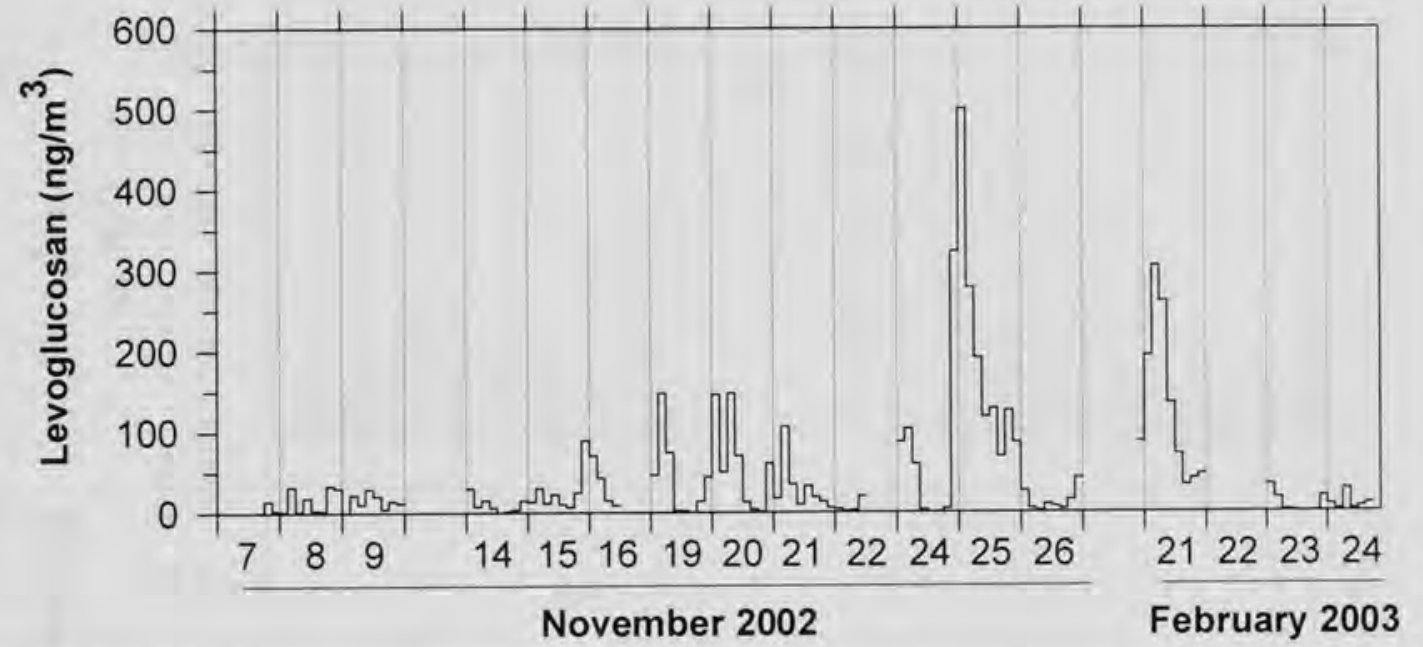

Figure 3.12: Time series of the winter three-hourly concentrations of levoglucosan (b) and of the ambient temperature (a). Darker circles in (a) highlight the values for the 0:00 and 21:00 (overnight) samples.

Linear inter-correlations among the 3-hourly winter concentrations of the nine compounds were investigated and all $\mathrm{R}^{2}$ values were found to be between 0.5 and 0.9 . Among the three syringic-moieties the highest $R^{2}$ is found between syringaldehyde and acetosyringone $\left(R^{2}=0.937\right)$, and a somewhat lower value $\left(R^{2}=0.636 \pm 0.004\right)$ for syringic acid with either of them. On the other hand, the correlation of levoglucosan with either syringaldehyde or acetosysiringone yields a $\mathrm{R}^{2}=0.685 \pm 0.026$ while that of levoglucosan with syringic acid is 0.852 . This better fit is driven by the nine high concentration 
samples from 24-26-November and 21-February. Syringic acid is specifically indicative of hardwood; therefore, this finding implies increased proportion of hardwood burning in those days. This is consistent with survey data indicating that $75-90 \%$ of the fuel used in the Mid-Atlantic States for the purpose of space heating is hardwood (Houck et al., 2006).

a)

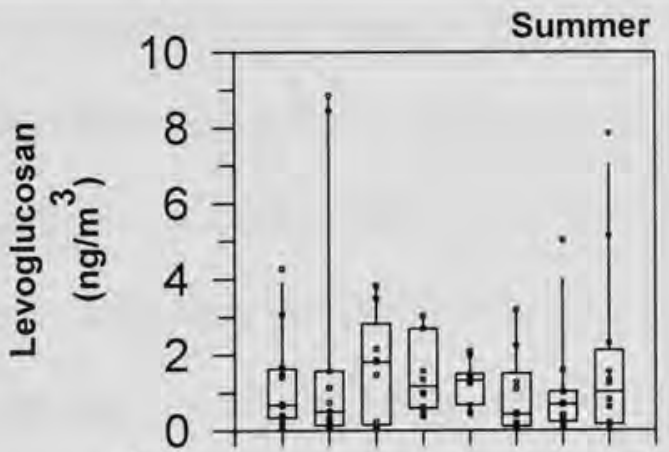

c)

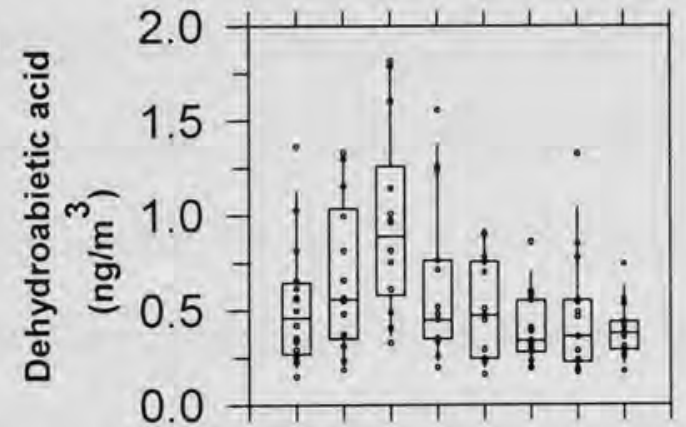

e)

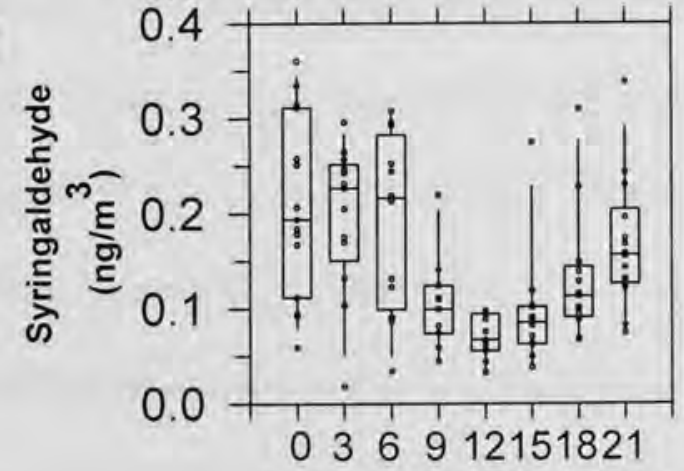

Sample Start Time (EST) b)

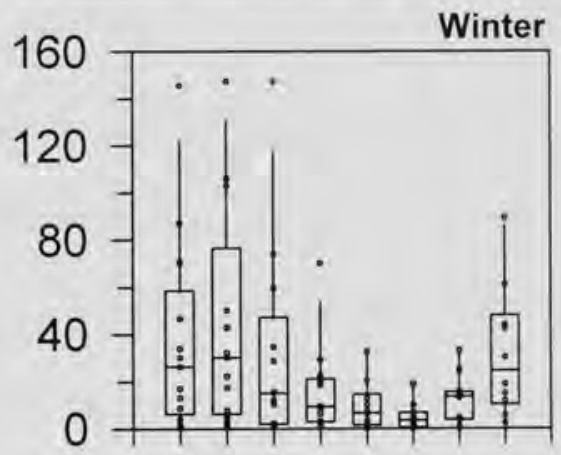

d)

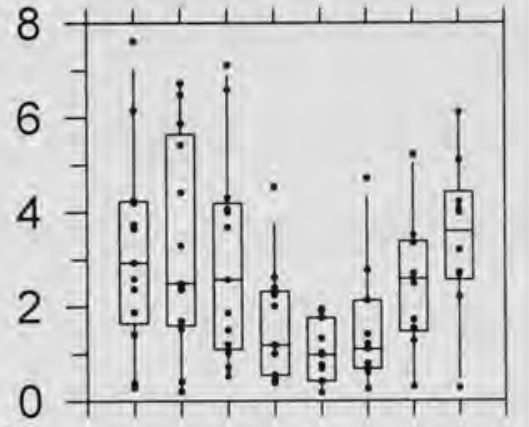

f)

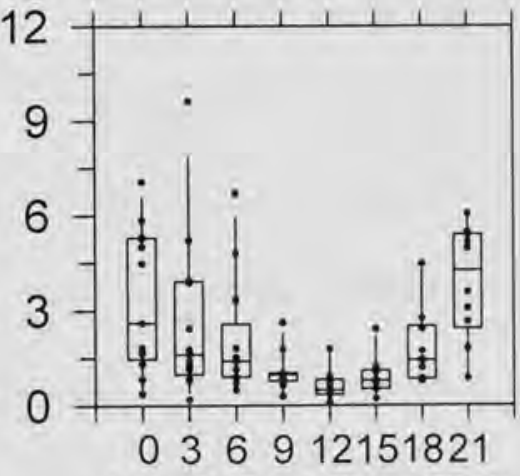

Sample Start Time (EST)

Figure 3.13: Three-hourly summer and winter variations of the concentrations of markers of wood burning: levoglucosan $(\mathrm{a}, \mathrm{b})$, dehydroabietic acid $(\mathrm{c}, \mathrm{d})$, and syringaldehyde (e, f). Episodic days excluded from graphs: 24-25-November and 20-21-July. 
Figure 3.13 shows the summary plots, excluding events from 24 and 25 November in winter, and 20-July in summer, for levoglucosan, dehydroabietic acid and syringaldehyde, the only syringic-moiety compound found above detection limit in the summer samples. Two important aspects revealed in these graphs include the seasonal abundance and the correlation among the markers. The median line of the diurnal concentrations of levoglucosan and syringaldehyde indicate that their levels are approximately ten times larger during the winter; on the other hand, the concentrations of dehydroabietic acid are only approximately three times larger in the winter compared to the summer. The second aspect refers to the inter-associations among the markers. The patterns of the three markers are in synchrony during the winter and dissonance during the summer. As indicated in the previous paragraph, the analysis of the linear intercorrelations of 3-hourly winter concentrations are high, suggesting that they reflect common sources and appear to be dominated by wood burning for space heating. This activity implies the use of a relatively uniform "woodfuel" in contrast to the very different and highly variable set of inputs that could influence and dominate at various times the summer concentrations, including burning of biomass from agricultural and forest management practices and wild forest fires, as well as the contribution from unregulated sources such as outdoor wood boilers, which during the summer time could be used, for example, to heat water for domestic use, pools, etc. For this reason, the lack of uniformity in the trends of the markers during the summer is not surprising.

Levoglucosan was identified in 103 of the 119 summer samples analyzed but was found in concentrations above $1 \mathrm{ng} / \mathrm{m}^{3}$ only in a handful. Concentrations are appreciably larger through the episode of 20-21-July which is explained in detail in section 4.3.3.1. 
Both dehydroabietic acid and syringaldehyde exhibit regular diurnal patterns (Figure 3.13 $b, c)$; yet, these are not congruent. The pattern observed for syringaldehyde consists of larger concentrations in the nigh-time/early morning with a ratio of maximum to minimum concentrations in the range of 3 to 10 , median value of 4 ; this suggests that both a regular emission input at those times of day and a highly persistent cycling background level of woodsmoke particles may explain the observed pattern. The diurnal range and median of the maximum to minimum concentrations of dehydroabietic acid are similar to those observed for syringaldehyde; however, the peak concentrations are shifted towards daytime hours, most frequently during the morning.

Linear inter-correlations among the 3-hourly concentrations of the six species identified in the summer samples were also investigated. The only significant associations were found among the primary resin acids, pimaric, sandaracopimaric and dehydroabietic acid, with $\mathrm{R}^{2}=0.42 \pm 0.06$. Considering the low concentration levels of the first two resins, these associations are quite good. Resin acids are specific indicators of directly volatilized diterpenoids from resinous trees or materials; therefore, their presence, particularly that of the relatively more labile pimaric and sandaracopimaric acids helps to confirm fresh input volatilized from resinous material.

Hardwood trees do not produce resin acids; therefore, the presence of these species in atmospheric aerosols are regarded as molecular tracer for combustion of softwoods, the major specie being dehydroabietic acid (Simoneit and Mazurek, 1982; Standley and Simoneit, 1994; Rogge et al., 1998). Data from several organic characterization studies of the particle emissions from a variety of softwoods and mixed hard/soft woods burned under several conditions, from open burning to wood-stoves and 


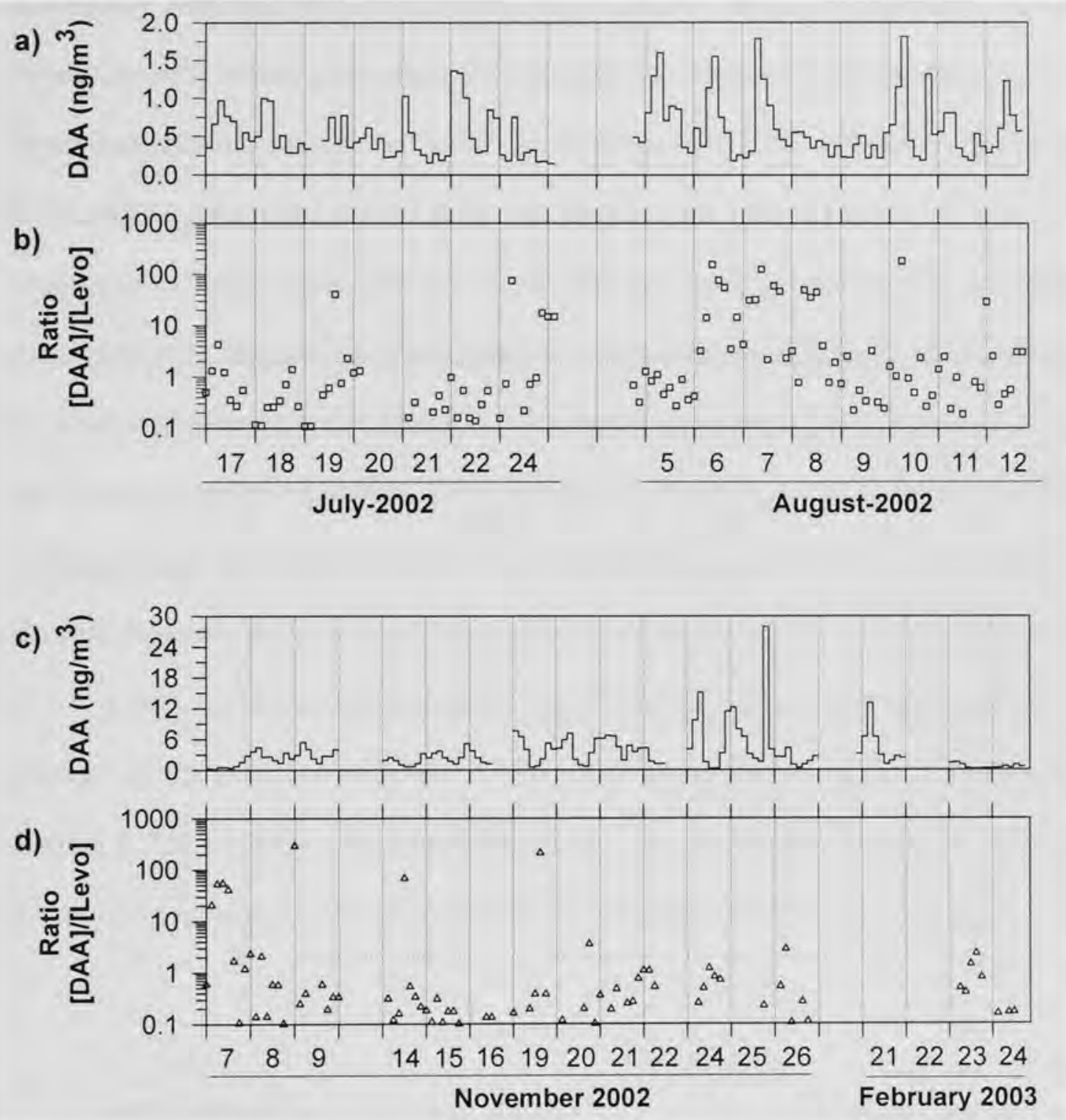

Figure 3.14: Time-series of the summer and winter three-hourly concentrations of dehydroabietic acid (DAA a, c) and of the ratio of concentrations of dehydroabieric acid: levoglucosan (DAA/Levo b, d).

for space-heating (Schauer et al., 2001; Fine et al, 2001 and 2002; Hays et al., 2002 and 2005; Lee et al, 2005), show that the ratios of dehydroabietic acid to levoglucosan can range from $5 \times 10^{-4}$ to 1.3 . For the majority of the 3-hourly samples from Baltimore, 
specifically $89 \%$ and $70 \%$ of the winter and summer samples, respectively, the ratio values are well within this range. The average ratio values for those fractions of the winter and summer samples are $0.24 \pm 0.29$ (range 0.01-1.42) and $0.47 \pm 0.38$ (range $0.02-1.40$ ), respectively. However, seven samples from the winter and 19 from the summer yield ratio values between 15 and 300, as shown in Figure 3.14. The lack of correspondingly large signal of levoglucosan suggests that these samples were influenced by sources of dehydroabietic acid other than the burning of biomass containing it. There are several possible industrial processes which utilize resinous materials as input, including paper and pulp mills, paint and varnish industries, etc. This may explain why the dehydroabietic peaks do not all correspond to wind blowing from the same direction.

Lastly, source specific tracers such as levoglucosan allow a straightforward estimate of the source contribution. This is possible by comparing the OC-normalized fraction of the marker, in this case levoglucosan, in each ambient sample to that in the source using Equation 3.3 to compute the \% of Ambient OC from wood burning:

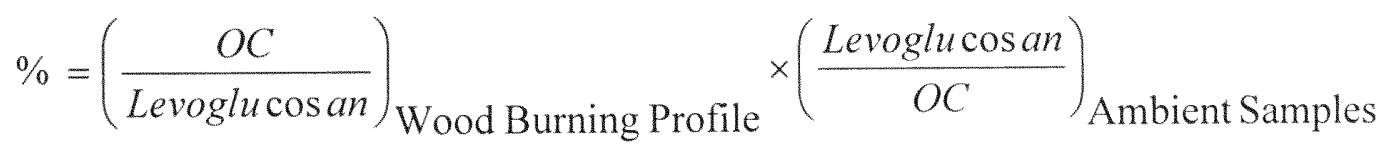

Equation 3.3

For example, over $90 \%$ of the detailed organic profile of fine particles from prescribed burning reported by Lee et al, (2005) is comprised of levoglucosan. Using the published emission factor $(94.75 \pm 40.25 \mathrm{mg}$ levoglucosan $/ \mathrm{g}$ OC) it is possible to 
estimate that during the two summer sampling weeks in Baltimore, biomass burning contributed from 0.1 to $3 \%$ of the OC. The median value for the two weeks was $0.3 \%$; however, during the 20-21-July episode this input increased to 1-3\%. This ten-fold increase from a minor event highlights the impact that wood burning can have on atmospheric levels of fine particles. By comparison, using the average emission factor of levoglucosan published by Fine et al. (2001) for the burning in fireplaces of wood grown in the northeastern U.S. it can be calculated that the contribution of wood burning to OC during November 2002 was in average $5 \pm 6 \%$ of the OC but it reached 3 -hourly contribution values of $10-35 \%$ during the $24-25$-November event, which represents approximately $4-10 \%$ of the PM 2.5. Figure 3.15 presents the 3 - hourly contributions of wood burning to ambient $\mathrm{OC}$, based on levoglucosan, in both seasons sampled.

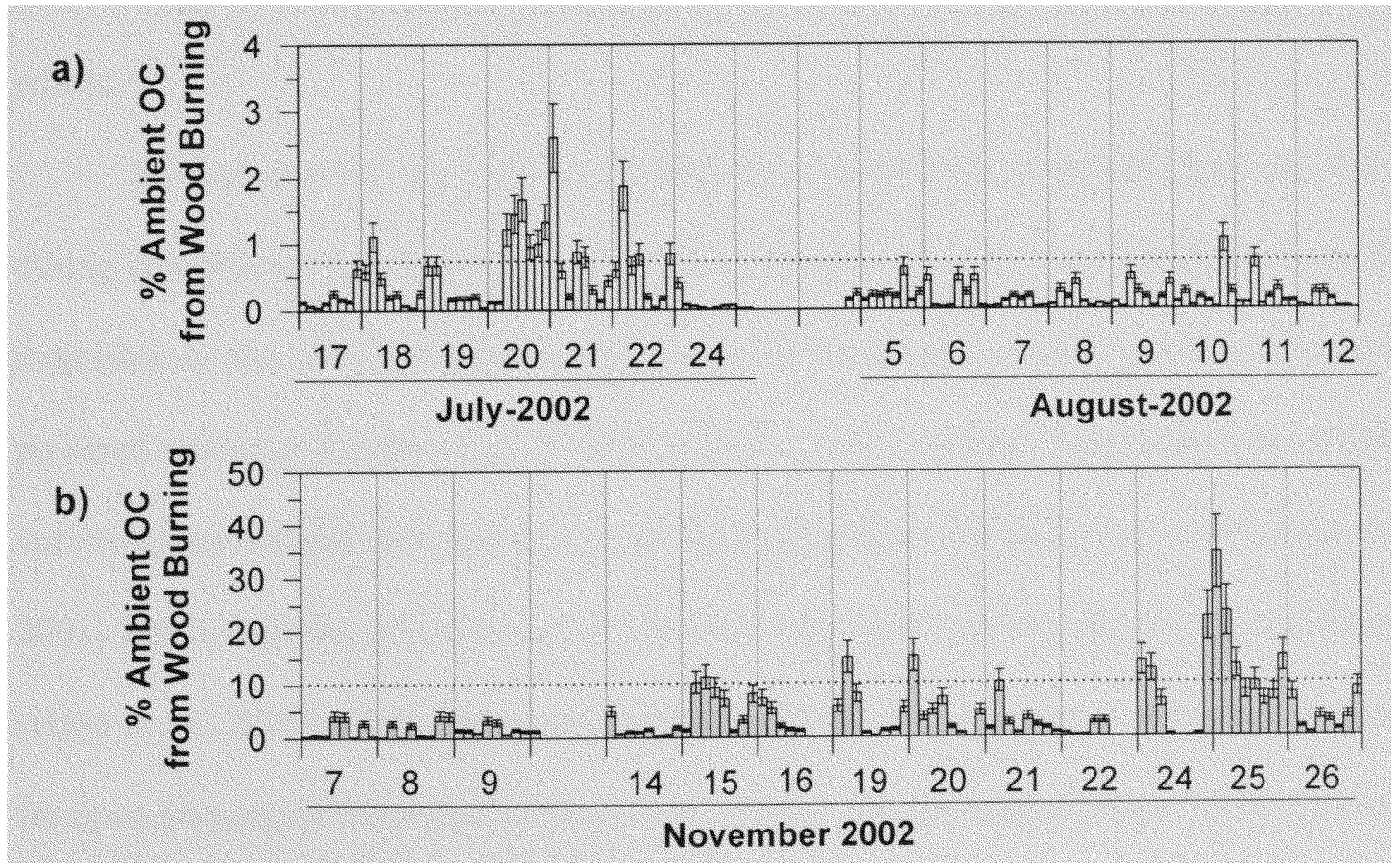

Figure 3.15: Time-series of the summer and winter three-hourly contributions of emissions from wood burning to ambient organic carbon (OC). Calculations based on the use of levoglucosan as organic molecular source tracer. 
Four oxygenated polyaromatic hydrocarbons (oxy-PAHs) were identified in the samples from Baltimore, 9-fluorenone (9-Fluo, fluorenone), 9,10-anthracenedione (9,10Anth, anthraquinone), 7H-benz[de]anthracen-7-one (7H-BdeA, benzanthrone), benz[a]anthracene-7,12-dione (BaA-7,12O, benzo[a]anthracenedione). The most abundant species are 9-Fluo and 9,10-Anth, comprising $99 \%$ and $91 \%$ of the total in summer and winter respectively. The overall median concentration of 9-Fluo is approximately the same in the summer and winter (overall 3-hourly median: summer= $3.3 \mathrm{ng} / \mathrm{m}^{3}$, winter $\left.=3.8 \mathrm{ng} / \mathrm{m}^{3}\right)$; on the other hand, concentrations of 9,10-Anth are lower in the winter samples (overall 3-hourly-median: summer, $3.0 \mathrm{ng} / \mathrm{m}^{3}$ and winter, 1.2 $\mathrm{ng} / \mathrm{m}^{3}$ ). Median concentrations of $7 \mathrm{H}-\mathrm{BdeA}$ and BaA-7,12O are, respectively, $0.05 \mathrm{ng} / \mathrm{m}^{3}$ and $0.03 \mathrm{ng} / \mathrm{m}^{3}$ during the summer, and much larger, $0.32 \mathrm{ng} / \mathrm{m}^{3}$ and $0.10 \mathrm{ng} / \mathrm{m}^{3}$, in the winter.

Several studies have indicated that the compounds analyzed here are formed during combustion processes. For example, 9-Fluo, 9,10-Anth, and 7H-BdeA have been identified in the fine particles emitted from the exhaust of both gasoline and dieselpowered vehicles (Rogge et al., 1993b; Schauer, et al., 2002c; Zielinska et al., 2004), a variety of hardwoods and softwoods burned in fireplaces (Rogge et al., 1993; Fine et al., 2001, 2002), woodstoves (Fine et al., 2004b), and open burning of agricultural biomass (Hays et al., 2005). Only emission factors of 9-Fluo are reported in the organic profiles for open burning of foliar fuels (Hays, et al., 2002). The compound BaA-7,12O has been identified in the fine particles emitted by gas-fired home appliances (Rogge 1993e). 
Summary plots of the species quantified here are presented in Figure 3.16. For simplicity, common names of the species will be used for the following discussion. The pattern of anthraquinone shows a closer similarity to that the other two species during the winter than the summer (Figure $3.16 \mathrm{~b}$ vs. d, f, and a vs. c, e). This translates in correlation factors, $\mathrm{R}^{2}$, of $0.67-0.73$ and $0.10-0.31$ for the correlation of the 3-hourly concentrations of anthraquinone with those of the other two species during summer and winter, respectively. The species benzanthrone and benz[a]anthracenedione are found only in the filter in samples from both seasons; on the other hand, approximately $44 \% \pm$ $30 \%$ of fluorenone and $4 \% \pm 5 \%$ of anthraquinone are found in the PUF in the samples from the summer. This proportion changes significantly in the winter samples where $8.4 \% \pm 7.4 \%$ of fluorenone is in the PUF while anthraquinone is found only in the filter. Consequently, the improved correlation of anthraquinone with the other two particlephase oxy-PAHs during the winter is likely more significantly associated to atmospheric dynamical changes rather than changes in seasonal emission sources.

An appreciably larger increase in the winter to summer concentrations is observed for benzanthrone (Figure $3.16 \mathrm{~d}$ vs. c) than for benz[a]anthracenedione (Figure $3.16 \mathrm{f}$ vs. e). This result is consistent with the information from literature sources profile indicating that benz[a]anthracenedione is only found in the emissions from natural gas, whereas benzanthrone is found in the particles emitted from natural gas and wood smoke. The use of natural gas is likely to increase during the winter to satisfy space heating needs. Using benz[a]anthracenedione as a molecular tracer for natural gas burning it is possible to estimate the contribution of this source category to ambient $O C$ by means of an equation analogous to Equation 3.3 to compare the OC-normalized 3-hourly 


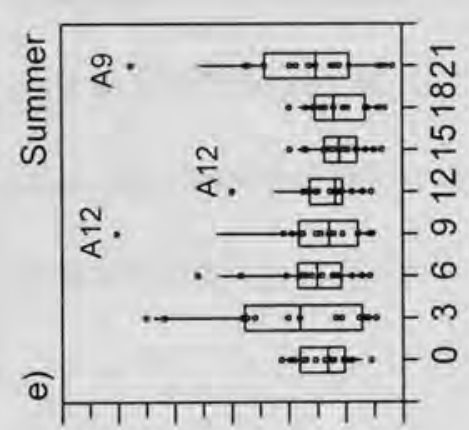

당응 웅 ( $(w / 6 u)$ әиоำәиәэеมчนи[е]zuәg

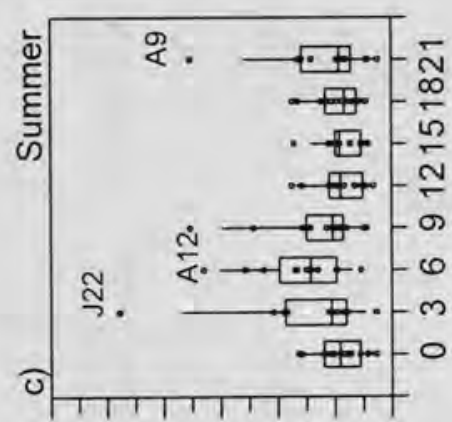
융 ్ㅠㅇ 공 응웅 ( $\varepsilon$ w/6u) әиолчұนеzuәg

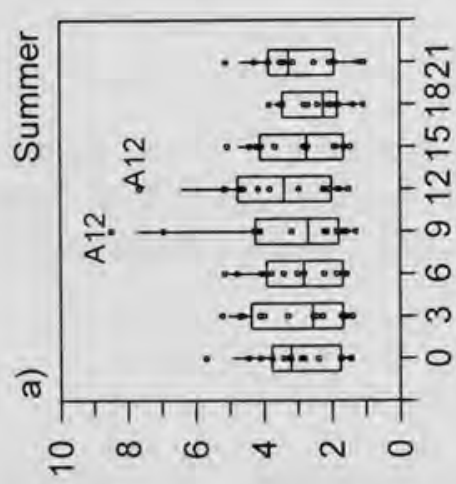

$$
\text { ( } \varepsilon \text { u/bu) }
$$

әuоu!̣besчұu $\forall$

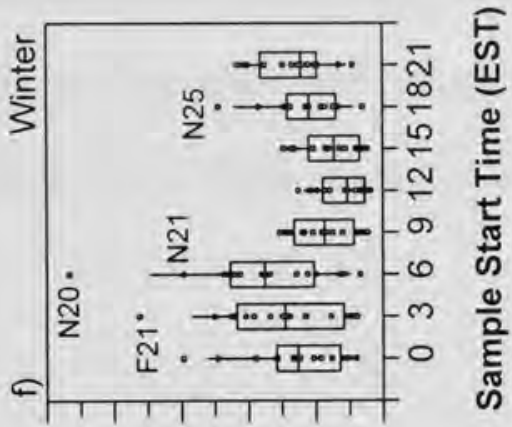

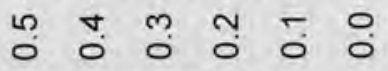

( $\varepsilon / \mathrm{w} / 6 \mathrm{u})$

\section{әио!рәиәэедчวน[e]zuәg}

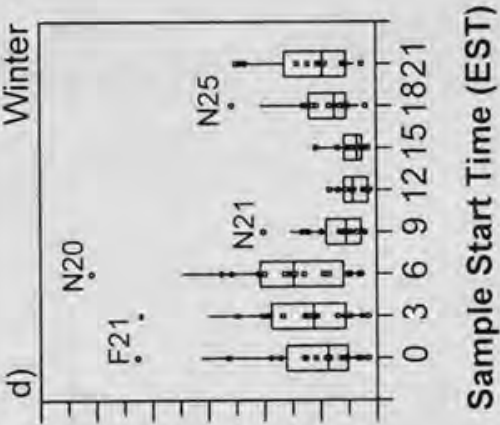

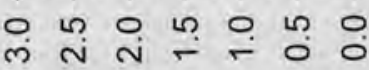

( $\varepsilon$ w/6u)

әиодчวuеzuәg

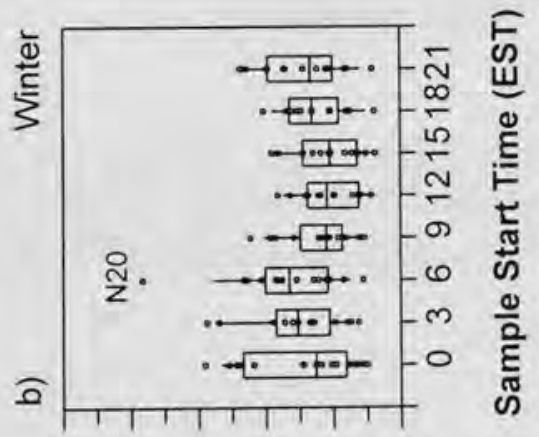

( $\varepsilon$ w/6u)

әuоu!nbesчұu $\forall$
م่

的要

昙蓄

更

ชิ

\%

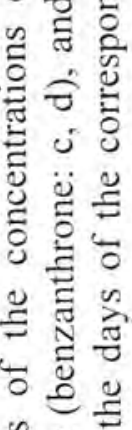

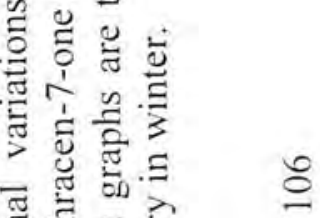

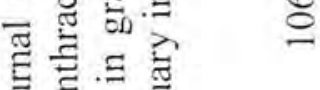

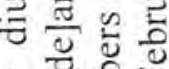

पे $\frac{}{\mathrm{N}}$ III

赔至

3 臬至

栗的

Oิن

品

ํํㄹ을

हิ

준큰

퓰 त

空志

즈 त

E

$\therefore$ 을

0 .

m

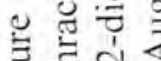

品

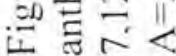


ambient ratios of benz[a]anthracenedione to the source ratio. The reported OC-based emission factor of benz[a]anthracenedione from sources that burn natural gas is 5.8584 $\mu \mathrm{g} / \mathrm{mg}$ OC (Rogge et al,, 1993 e). The calculated estimated fraction of this sources' category contribution to ambient $\mathrm{OC}$ in both seasons sampled is less than $1 \%$, as presented in Figure 3.17.

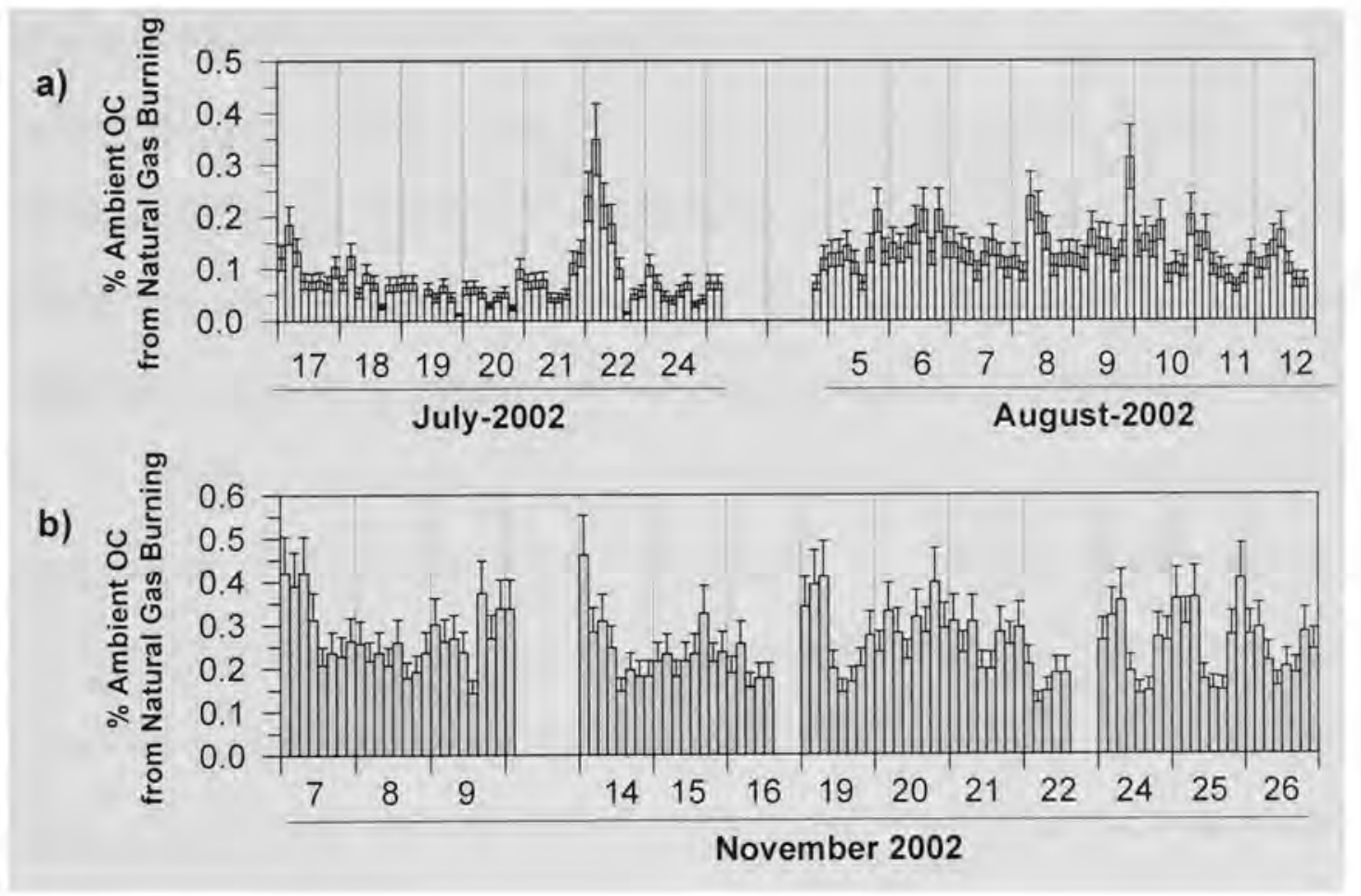

Figure 3.17: Time-series of the summer and winter three-hourly contributions of emissions from natural gas burning appliances to ambient organic carbon (OC). Calculations based on the use of benz[a]anthracenedione as molecular source tracer.

\subsubsection{Polycyclic Aromatic Hydrocarbons}

Polycyclic aromatic hydrocarbons (PAHs) are produced during the incomplete combustion of any organic matter. Rogge and collaborators have characterized the PAHs 
profiles in all major urban combustion sources (Rogge et al, 1991, 1993 a,b,d,e 1997 a,b, 1998), cigarette smoke (Rogge et al., 1994), and road dust (Rogge et al, 1993 c).

Seventeen polycyclic aromatic hydrocarbons (PAH) are identified in this study. In decreasing order of vapor pressure these include phenanthrene (Phen), anthracene (Anth), 4H-cyclopentaphenanthrene (Cyphen), fluoranthene (Fluo), pyrene (Pyre), chrysene/triphenylene $(\mathrm{Ch} / \mathrm{Tr})$, benzo[a]anthracene $(\mathrm{BaA})$, benzo[b]fluoranthene $(\mathrm{BbF})$, benzo[k]fluoranthene $(\mathrm{BkF})$, benzo[j]fluoranthene $(\mathrm{BjF})$, benzo[e]pyrene $(\mathrm{BeP})$, benzo[a]pyrene (BaP), perylene (Pery), indeno[1,2,3-cd]pyrene (IcdP), benzo[g,h,i]perylene (BghiP), dibenzo[a,h]anthracene (DahA) and coronene (Coro). PAHs from benzo[b]fluoranthene to coronene were only found in the filters in samples from both seasons; from hereafter we will refer to this group as particle-phase PAHs.

The most abundant PAHs in the Baltimore samples is Phen, representing approximately $70 \% \pm 4 \%$ and $62 \pm 4 \%$ of the group's total summer and winter concentrations, respectively. Excluding Phen, the two most abundant PAHs in samples from both seasons are Fluo and Pyre followed by Anth and Cyphen. PAHs from $\mathrm{Ch} / \mathrm{Tr}$ to Coro comprise $6 \%$ and $31 \%$ of the total group in summer and winter samples, respectively. The typical pattern of combustion PAHs is observed for this group, with predominantly higher concentrations for $\mathrm{BaA}, \mathrm{Ch} / \mathrm{Tr}, \mathrm{BbF}, \mathrm{BeP}, \mathrm{BaP}, \mathrm{IcdP}, \mathrm{BghiP}$ and Coro and lower for BkF, Pery and DahA.

Summary plots of the diurnal variations of PAHs are presented in Figures 3.18 and 3.19. These figures show that during the winter the 3 -hourly concentrations of all PAHs are uniformly spread, and display a mild diurnal trend consisting of larger concentrations in the morning. However, excluding 21-February, the ratio of the daily 


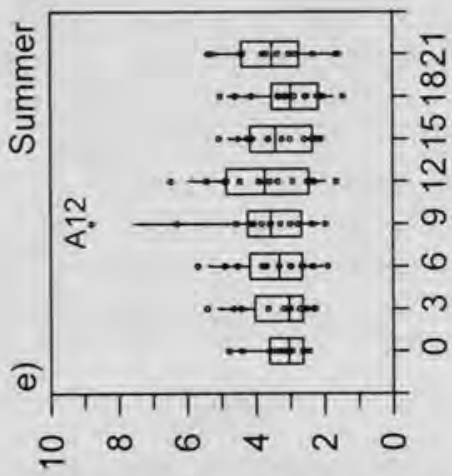

$(\varepsilon w / 6 u)$ әиәл $\kappa_{d}$

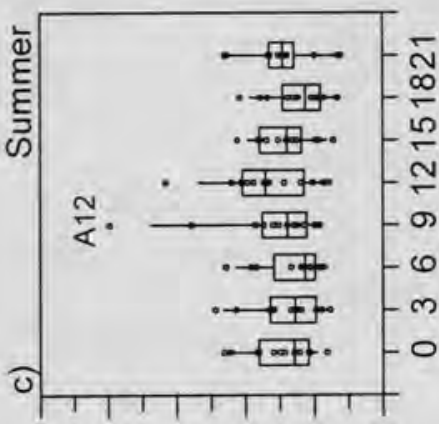

ผ ำ 은

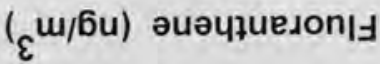

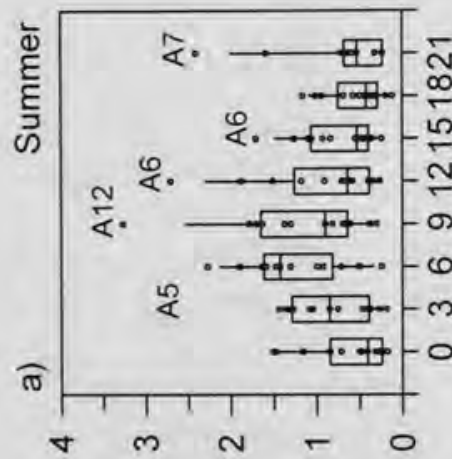

( $\varepsilon$ w/6u) әиәэедчди

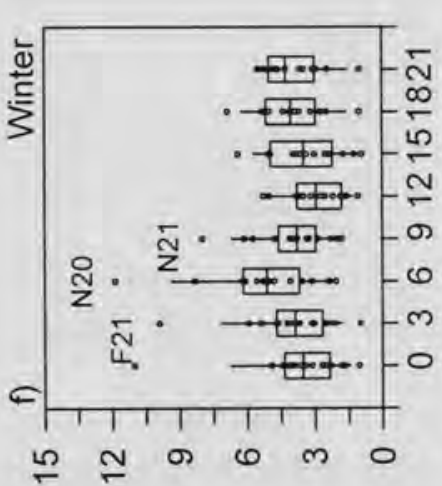

$(\varepsilon w / 6 u)$ әиәлК $\kappa_{d}$

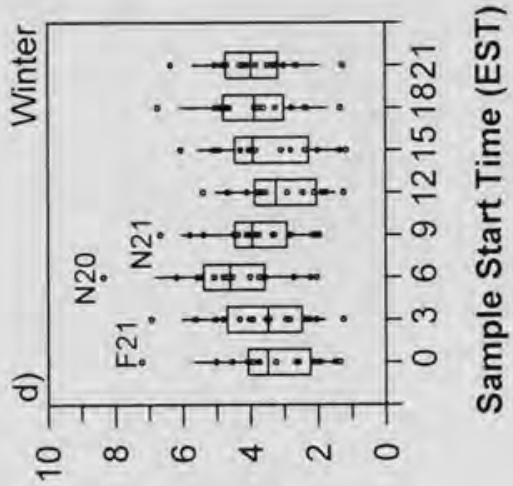

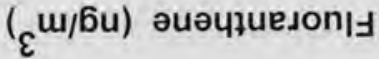

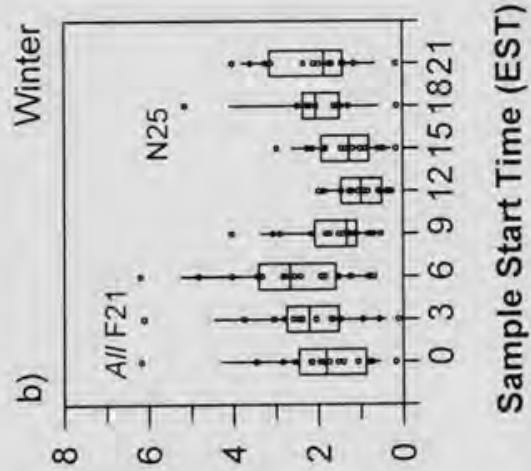

( $\varepsilon$ m/6u) әиәэедчри

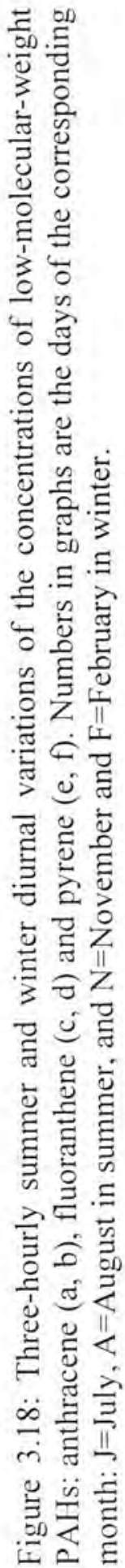




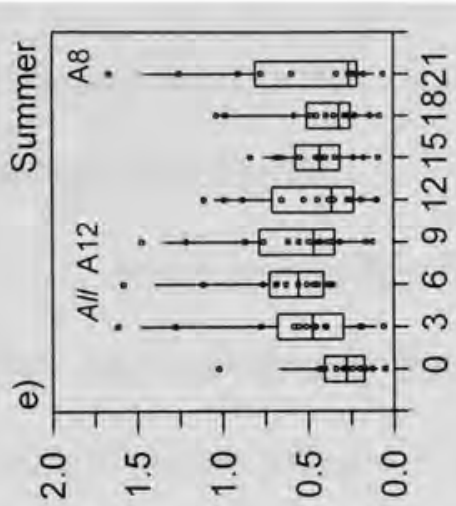

$\left(\varepsilon_{\varepsilon} \mathrm{w} / 6 \mathrm{u}\right)$

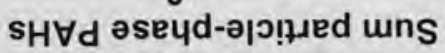

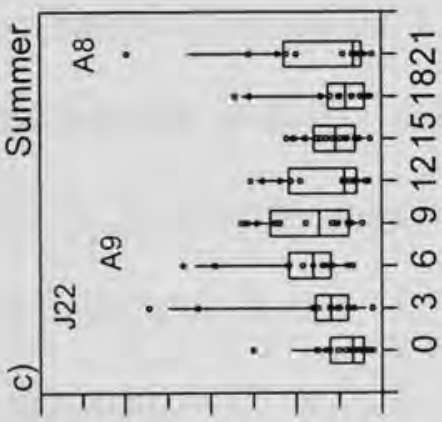

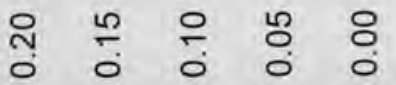
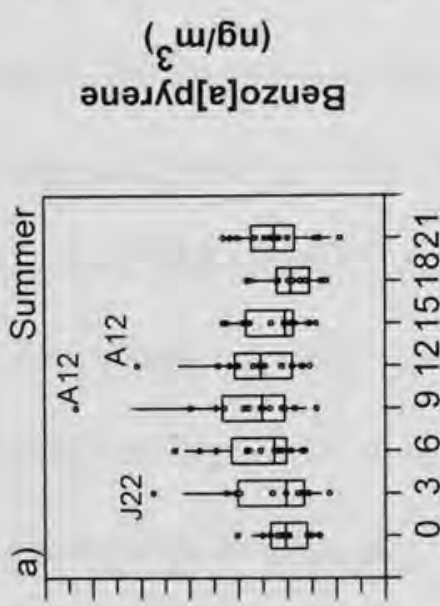

N

$$
\text { ( } \varepsilon^{m / 6 u)}
$$

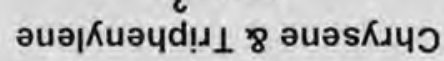

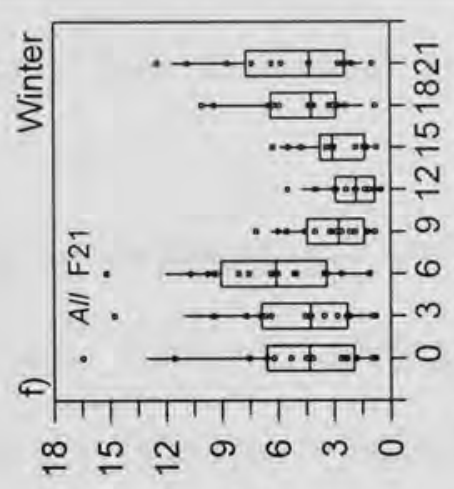

\section{$(\varepsilon \omega / 6 u)$}

\section{sH $\forall d$ oseud әэ!̣मed uns}

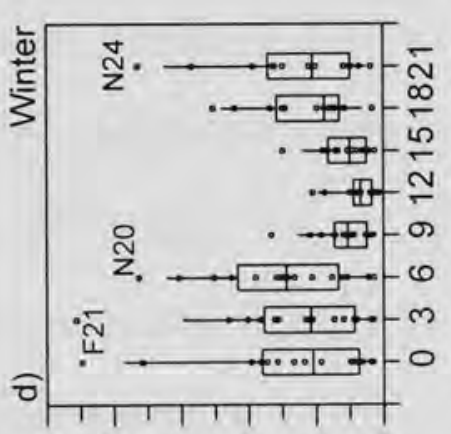

䍃

$$
\text { กิ }
$$

$(\varepsilon w / 6 u)$

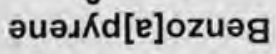

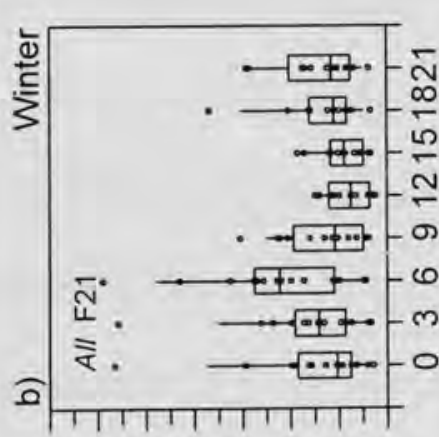

n 0 n 0 n 0 n 0 no

लं $\sim$ N -00

$(\varepsilon m / 6 u)$

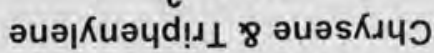

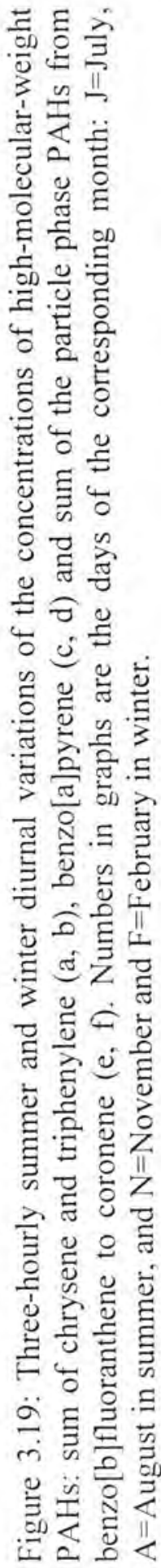


maximum to minimum concentrations is close to a value of 3 , suggesting that the measurements reflect emissions from distributed sources coupled with diurnal atmospheric dilution.

Some interesting aspects of the dynamics of PAHs are revealed by comparing their seasonal concentrations levels. The winter concentrations of Anth are larger than those observed during the summer (Figure $3.18 \mathrm{a}, \mathrm{b}$ ); however, the opposite is observed for Fluo (Figure $3.18 \mathrm{c}, \mathrm{d}$ ). The concentrations of Pyr and Cyphen are similar in both seasons (Figure 3.18 e, f). The remaining PAHs display a larger 3-hourly median concentration during the winter, by a factor of 3 to 11 compared to the summer. The smallest ratio of winter to summer median concentrations is observed for $\mathrm{Ch} / \mathrm{Tr}$ (Figure $3.19 \mathrm{a}, \mathrm{b}$ ) and the largest for $\mathrm{BaP}$ (Figure $3.19 \mathrm{c}, \mathrm{d}$ ); all others display a ratio of approximately $7 \pm 1$. Looking across in Figure 3.18, an association between the concentrations of Anth, Fluo, and Pyr is apparent during the winter; however, during the summer, this is limited only to Fluo and Pyr. In terms of linear correlations, during the winter, the 3-hourly concentrations of Fluo vs. Pyr are associated with $R^{2}=0.893$ and a nearly null intercept. The other two correlations; i.e., Anth vs. either Fluo or Pyr, yield a similar $\mathrm{R}^{2}$ and slope but a positive intercept, implying a faster loss of Anth. The summer 3-hourly concentrations of Fluo and Pyr are larger than those of Anth, and their overall correlation is poor $\left(\mathrm{R}^{2}=0.17\right.$ and 0.37$)$. The larger ratio of Fluo to Anth observed in the summer implies a notably faster decay of Anth in the summer compared to the winter. This result is consistent with previous measurements indicating that the relative reaction rate of gas-phase hydroxyl radicals and ozone with Anth is an order of magnitude faster than with Phen and Fluo (Atkins et al., 1994). 
The 3-hourly concentration ratios $\mathrm{BaP}$ to $\mathrm{BeP}$ and $\mathrm{Anth}$ to Fluo are presented in Figure 3.20. During the winter, the Anh to Fluo ratios average $0.47 \pm 0.19$ while during the summer the value is lower, at $0.12 \pm 0.09$. For the $\mathrm{BaP}$ to $\mathrm{BeP}$ ratios, the average values for winter and summer are, respectively, $0.86 \pm 0.22$ and $0.45 \pm 0.16$. Photodegradation of $\mathrm{BaP}$ from particles occurs at a faster rate than $\mathrm{BeP}$; therefore, the ratio $\mathrm{BaP} / \mathrm{BeP}$ has often been used as an indication of relative aging of particles (Nielsen, 1988; Simoneit et al., 1991). Figure $3.20 \mathrm{~b}$ shows that during the winter, the maximum to

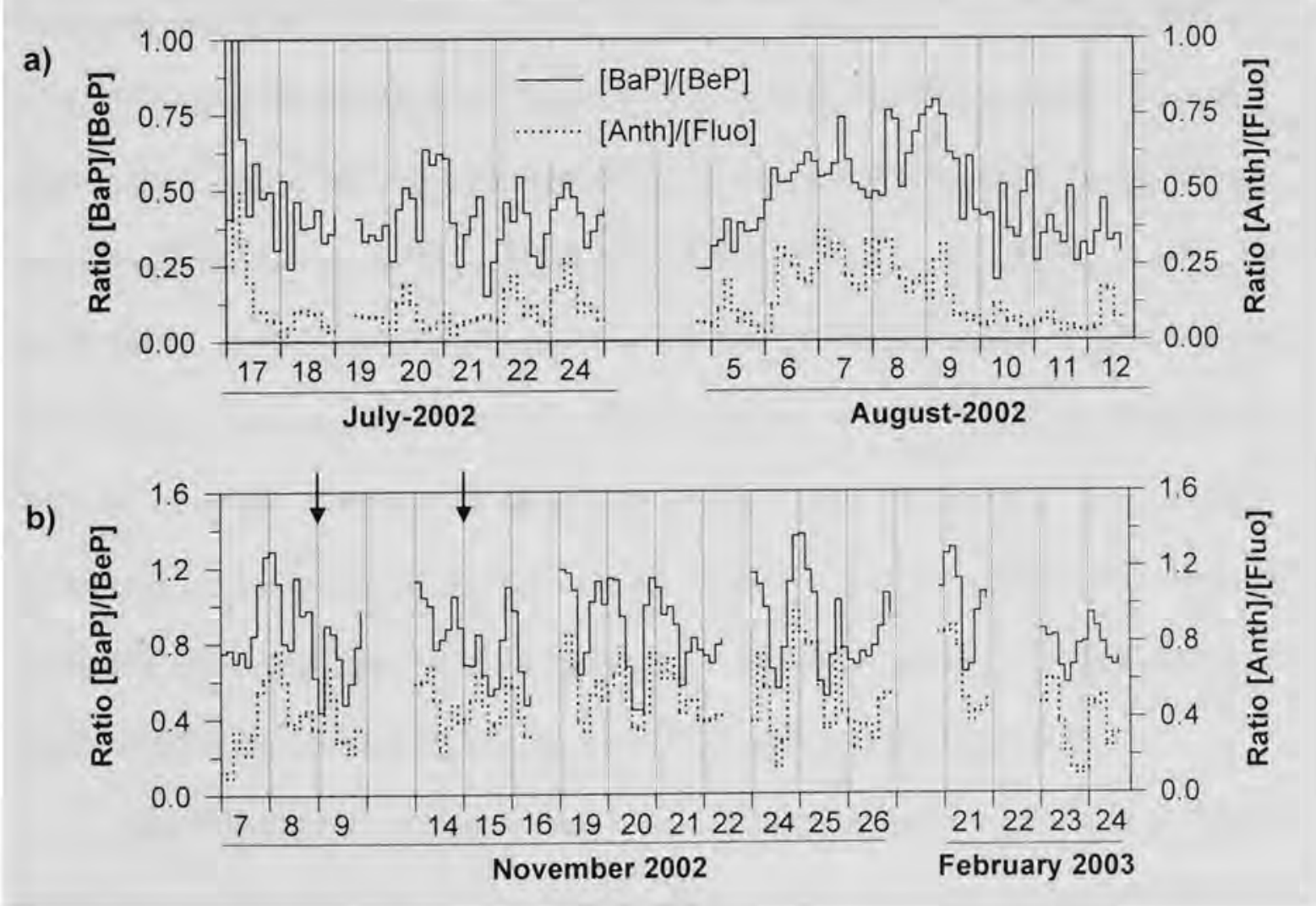

Figure 3.20: Time-series of the three-hourly concentration ratios of anthracene:fluoranthene ([Anth]:[Fluo]) and benzo[a]pyrene:benzo[b]pyrene $([\mathrm{BaP}]:[\mathrm{BeP}])$ during summer (a) and winter (b). 
minimum concentration diurnal ratio is often close or above unity, indicating fresh emissions; furthermore, the ratios follow a consistent diurnal cycle with minimum values observed at midday, with the exception of two cases, 8-November and 14-November, when two minimum values are observed per day: one of the overnight (marked with arrows in Figure 3.20 b). In contrast, during the summer, the ratio is more variable and, with the possible exception of 8-August, it displays no regular diurnal pattern (Figure 3.20 a). The trends observed for the Anth:Fluo ratio are similar to those described for $\mathrm{BaP}: \mathrm{BeP}$. These results indicate that during the winter, most samples were primarily influenced by fresh local emissions and suggests photochemical degradation as an important mechanism for the loss of the PAHs on a daily basis. On 8-9-November and 14-15-November the influence of overnight transport from upwind locations is possible. During the summer, the only sustained period influenced by a relatively fresher aerosol, as indicated by the comparatively higher values of both ratios, is 6-9-August. Despite the lower values, on the remaining summer days the ratios displayed cycles of variations that still suggest a dynamic influence. The only exception is 17-19-July and 5-August; the lack of variation observed on these days suggest that the samples were strongly influenced by the quality of background air rather than local emissions, with the sole exception of the first three samples from day 17-July which appear to be impacted by a fresh nearby plume as indicated by the remarkably high values of both ratios.

The influence of vehicular emissions on the measured levels of particle phase PAHs can be evaluated through the quality of the association of the PAHs with hopanes. Table 3.1 presents the values of the linear correlation parameters found for the summer and the winter data. During most days, in both seasons, the data points are well correlated 
in a consistent manner with a similar slope. The intercept is null or negative in all summer days suggesting that the measured levels of PAHs are dominated by emissions from vehicular sources. In contrast, this is not the case in the winter, implying that although the measured concentrations are dependent on vehicular activity there can be other important contributions. According to the available literature that provides data of detailed organic characterization of sources, in addition to the collective emission from motor vehicles, particularly those lacking catalytic exhaust treatment devices or with mal-

Table 3.1: Correlation Parameters, $\mathrm{R}^{2}$, slope and intercept, for the Linear Fitting of the three-hourly Concentrations of Sum of particle-phase PAHs vs Hopanes for each summer and winter sampling day.

\begin{tabular}{|c|c|c|c|c|c|c|c|}
\hline Date & $\mathrm{R}^{2}$ & Slope & Intercept & & $\mathrm{R}^{2}$ & Slope & Intercept \\
\hline & & & & $7-\mathrm{Nov}-02$ & 0.82 & 1.37 & -0.22 \\
\hline & & & & $8-\mathrm{Nov}-02$ & 0.54 & 0.62 & 1.14 \\
\hline 17-Jul-02 & 0.83 & 0.81 & -0.67 & $9-\mathrm{Nov}-02$ & 0.38 & 0.38 & 2.34 \\
\hline 18-Jul-02 & 0.02 & 0.31 & 0.19 & 14-Nov-02 & 0.52 & 0.26 & 1.70 \\
\hline 19-JuI-02 & 0.49 & 0.38 & -0.04 & 15-Nov-02 & 0.02 & 0.06 & 3.59 \\
\hline 20-JuI-02 & 0.32 & 0.52 & -0.07 & 16-Nov-02 & 0.73 & 1.70 & -0.88 \\
\hline 21-Jul-02 & 0.02 & 0.06 & 0.19 & 19-Nov-02 & 0.17 & 0.50 & 2.87 \\
\hline 22-Jul-02 & 0.60 & 0.29 & -0.06 & $20-$ Nov- 02 & 0.68 & 0.33 & 4.76 \\
\hline 24-JuI-02 & 0.94 & 0.47 & -0.20 & 21-Nov-02 & 0.92 & 1.03 & 0.67 \\
\hline 5-Aug-02 & 0.19 & 0.09 & 0.31 & 22-Nov-02 & 0.09 & 0.06 & 2.33 \\
\hline 6-Aug-02 & 0.82 & 0.72 & -0.12 & 24-Nov-02 & 0.63 & 1.46 & -0.20 \\
\hline 7-Aug-02 & 0.68 & 1.12 & -0.45 & $25-$ Nov -02 & 0.32 & 1.13 & 0.94 \\
\hline 8-Aug-02 & 0.07 & 0.14 & 0.59 & 26-Nov-02 & 0.07 & 0.48 & 0.76 \\
\hline 9-Aug-02 & 0.66 & 0.61 & 0.30 & 21-Feb-03 & 0.94 & 0.87 & 1.61 \\
\hline 10-Aug-02 & 0.58 & 0.59 & 0.01 & 23-Feb-03 & 0.94 & 0.88 & 0.47 \\
\hline $11-A u g-02$ & 0.13 & -0.31 & 0.71 & 24-Feb-03 & 0.46 & 0.23 & 2.09 \\
\hline $\begin{array}{l}\text { Average } \\
\text { Standard }\end{array}$ & 0.66 & 0.61 & -0.14 & $\begin{array}{l}\text { Average } \\
\text { Standard }\end{array}$ & 0.66 & 0.86 & 1.20 \\
\hline Deviation & 0.19 & 0.25 & 0.28 & Deviation & 0.22 & 0.50 & 1.49 \\
\hline
\end{tabular}


functioning units, another potential source that could become an important combined input of these particle phase PAHs is the burning of any material for production of heat during the winter, including wood burning in fireplaces and stoves, and burning of debris, particularly that containing plastic material.

\subsubsection{Aliphatic and Aromatic Dicarboxylic Acids}

Four aliphatic dicarboxylic acids were identified in the samples from this study; butanedioic (succinic), pentanedioic (glutaric), hexanedioic (adipic) and nonanedioic (azelaic) acids. In addition, our target list also includes four aromatic dicarboxylic acids compounds, 1,2-benzenedicarboxylic (phthalic), 1,4-benzenedicarboxylic (terephthalic), 1,3-benzenedicarboxylic (isophthalic), and 4-methyl-1,2-benzenedicarboxylic (4methylphthalic).

The aliphatic succinic, glutaric and adipic acids have been identified in the particles emitted from several types of cooking operations (Rogge et al., 1993, Schauer et al., 1999a, Schauer et al, 2002b). They have also bee observed in the fine particles generated from wood and biomass burning; for example, succinic and glutaric acids (Rogge et al, 1998), and adipic and azealic acids (Fine et al, 2001) have been reported in the organic compounds profiles of the fine particles emitted from the burning of wood in residential fireplaces, the series of dicarboxylic acids from $\mathrm{C} 4$ to $\mathrm{C} 10$ have been reported for the burning of various mixes of foliar fuel under open burning conditions (Hays 2002).

Dicarboxylic acids can also originate from secondary heterogeneous or homogeneous atmospheric reactions. One important piece of information that 3 -hourly 
resolved concentrations may provide is whether primary emissions or secondary processes control the observed concentrations of specific species under particular conditions. The following discussion of specific compounds is centered on this aspect.

All the aliphatic dicarboxylic acids were not found in all of the samples analyzed. Furthermore, glutaric acid was the only aliphatic dicarboxylic to be consistently found in all the winter samples. During the winter, the diurnal variations of concentration were more continuous in nature while in the summer they displayed a more discrete character; that is, the specie was present at specific times and completely absent at others. Consequently, the winter patterns can be summarized using boxplots (Figure 3.21, j-m); on the other hand, the summer patterns cannot be summarized in this fashion. Instead, these are presented in a different format (Figure $3.21 \mathrm{a}-\mathrm{i}$ ).

As indicated above, glutaric acid was identified in all the samples from the winter and, except for specific events, in concentrations clearly above that of the other aliphatic dicarboxylic. Background and peak concentrations are of the order of $0.3 \mathrm{ng} / \mathrm{m}^{3}$ and $2-5$ $\mathrm{ng} / \mathrm{m}^{3}$, respectively, and the variation of 3-hourly concentrations displays a very regular pattern (Figure $3.21 \mathrm{j}$ ). The peak concentrations, particularly the large values, were observed in the early morning and the evening hours. This diurnal trend is similar to that observed for the wood burning markers (Figure $3.13 \mathrm{~b}, \mathrm{~d}, \mathrm{f}$ ); however, the linear correspondence between the concentrations of glutaric acid and that of the individual wood burning markers on a 3 -hourly basis is poor; only in a couple of instances, 19November and 21-February, the peaks of wood burning markers and glutaric acid clearly coincide in several continuous samples. On the other hand, correlations between the sum of the daily concentrations of glutaric acid and those of individual wood burning markers 
show consistency and a modest association, $\mathrm{R}^{2}=0.3-0.4$. During the summer, glutaric acid was detected in concentrations above $1 \mathrm{ng} / \mathrm{m}^{3}$ only during the wood burning episode of 20-21-July (Figure 3.21 a), and peak concentrations coincided with those of the wood burning markers in some of the samples from this event. Otherwise, summer concentrations were below $0.1 \mathrm{ng} / \mathrm{m}^{3}$ and only one time was a clear peak observed at noon of 11 -August (Figure $3.21 \mathrm{~b}$ ). These results suggest that the concentrations of glutaric acid in fine particles appear to be more prevalent in the presence of wood smoke. However, the results also indicate that the ambient concentrations of glutaric acid may be subject to complex formation and depletion dynamics.

During the summer, the observations for succinic and azealic acids are very similar to those described for glutaric. Figure $3.21(b, f, k)$ shows the summer and winter concentrations of azealic as an example. Excluding event situations related to wood smoke, during the summer, the concentrations levels of azelaic acid were $0.1 \mathrm{ng} / \mathrm{m}^{3}$ to $0.3 \mathrm{ng} / \mathrm{m}^{3}$. In contrast; during the winter, excluding two event situations $(25-$ November and 21 -February), concentrations were of the order of $0.1 \mathrm{ng} / \mathrm{m}^{3}-0.4 \mathrm{ng} / \mathrm{m}^{3}$ and do not display a clear diurnal pattern.

Phthalic acid is the most abundant aromatic dicarboxylic acid in the samples from both winter and summer; it represents approximately $90 \%$ of the total amount of the group in each sample. Phthalic and terephtlalic acids were identified in all samples; on the other hand, isophtalic was only identified in $37 \%$ and $76 \%$ of the summer and winter samples respectively. Methyl-phthalic acid was only detected in the samples from August. The most remarkable variation of concentration observed for phthalic acid during the summer is by far that observed in the background levels in going from 19- to 20-July. 


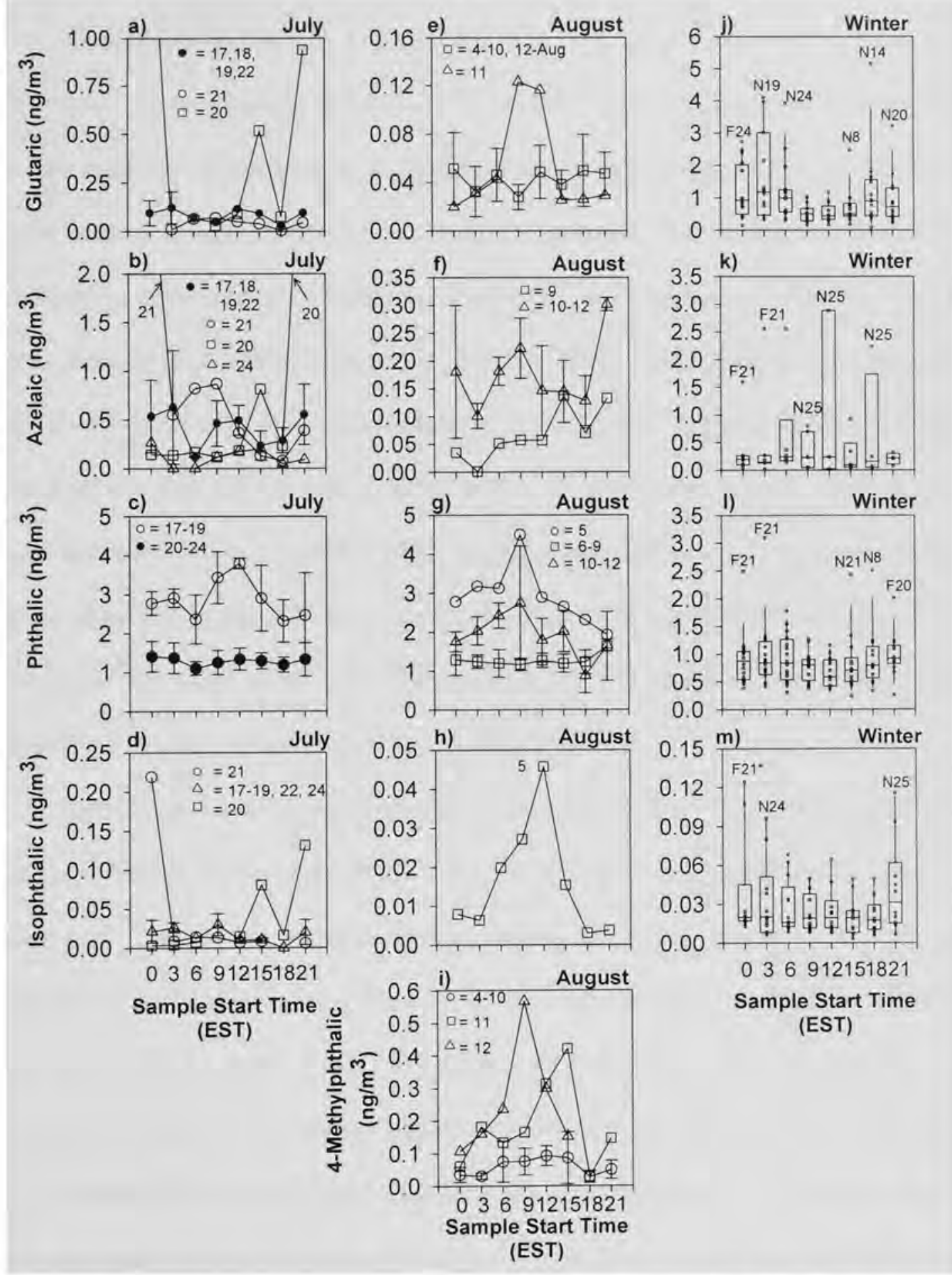

Figure 3.21: Three-hourly summer and winter diurnal variations of the concentrations of selected aliphatic- and aromatic-dicarboxylic acids. Summer data presented as line plot for individual days (a-i); Winter data presented as vertical points plots with overlaid boxplots $(\mathrm{j}-\mathrm{m})$. In winter graphs $\mathrm{N}=$ November and $\mathrm{F}=\mathrm{February}$. 
As noted in Figure $3.21 \mathrm{c}$, during the three days 17-19-July, peak concentrations of $\sim 1 \mathrm{ng} / \mathrm{m}^{3}$ above a background level of $\sim 2.5 \mathrm{ng} / \mathrm{m}^{3}$ were consistently observed at midday. However the background level sharply drops by approximately half on 19-July. A similar pattern is also observed in August as shown in Figure 3.21 g. In contrast, excluding the sharp rise on event days (8-November and 21-February; Figure 3.211 ), the winter concentrations and diurnal pattern are very regular, cycling between a background level of $\sim 0.5 \mathrm{ng} / \mathrm{m}^{3}$ at mid-day and maximum of $\sim 1.5 \mathrm{ng} / \mathrm{m}^{3}$ observed at the onset and at the end of the day (00:00 and 121:00 samples). These results suggest that during the winter, the concentrations of phthalic acid appear dominated by multiple local continuous sources while during the summer, other formation in the atmosphere may also be a factor to consider and, furthermore, the distinct variations in background levels suggest that long-range transport may be important on some days.

Interestingly, 4-methylphthalic acid was found in each of the samples from the 412-August period, but in none of the other summer or winter samples. As shown in Figure 3.21 i, the 3-hourly concentrations display a very clear diurnal variation with sharp increases observed during daytime. Furthermore, a trend of gradually increasing concentrations from day 5- to day 12-August is also observed. This compound has been suggested as marker of secondary particle formation (Fine et al., 2004a). The diurnal trends observed here clearly support the idea that 4-methylphthalic acid is formed in the local atmosphere via a photochemical-driven mechanism; in addition, the results also suggest that a heterogeneous system may be at place. The kinetics of heterogeneous reaction systems strongly depend on the characteristics of the substrate. The overall 
characteristics of July, particularly 20-22-July, reflect a dominance of fine particles from biomass smoke; since 4-methylphthalic acid was also not detected in the winter samples, it is possible that its formation may be hindered or not favored in an atmosphere enriched with fine particles from biomass burning. In addition, because its formation appears to be driven by sun light (peaks clearly at mid-day), it is very likely that during the winter the concentrations would be below the detection limit possible with our analytical procedure for the 3-hourly samples.

\subsubsection{Secondary Biogenic Compounds}

In this study we focused our attention on one branched unsaturated ketone 6,10,14-trimethyl-2-pentadecanone (phytone), and three terpene oxidation products, nopinone, cis-pinonic acid and norpinonic acid. Phytone has been proposed as the major product of the thermal alteration of phytol, the isoprenoidyl side chain of chlorophyll (Simoneit et al., 1988). Nopinone has been clearly identified as a product of the oxidation of $\beta$-pinene. It has been found in numerous studies (Jaoui et al, 2003 and references therein) to be a major product of the gas-phase reaction of $\beta$-pinene with either hydroxyl radicals $(\cdot \mathrm{OH})$ or ozone $\left(\mathrm{O}_{3}\right)$; because of its high vapor pressure equilibrium constant it partitions onto pre-existing organic particles. Cis-pinonic and norpinonic acids have been identified in the particle phase products of ozonolysis of both $\beta$ - and $\alpha$-pinene (Yu et al., 1999). Cis-pinonic acid has been identified as the major particle-phase product of the reaction of $\alpha$-pinene in presence of sunlight with either $\mathrm{O}_{3}$ (Kamens et al., 1999) or with NOx (Kamens et al., 2001). 
During the summer, a mild but very regular pattern was observed in the 3 -hourly variations of the concentrations of phytone as shown in Figure 3.22 a. The ratio of daily maximum to minimum concentration is $2.0 \pm 0.7$, a relatively larger value of 3.6 is only observed on 21-July. The smooth rolling pattern of the diurnal graph is consistent with continuous production/emission and depletion of the compound, together with dilution according to changes in the diurnal mixing height. As illustrated in Figure $3.22 \mathrm{~b}$, a similar pattern is observed during November; however, it suggests an accumulation-like trend. On three separate periods, 7-9-November, 14-16-November and 19-21-November, the concentrations of phytone gradually increased, almost linearly, from $1.4 \pm 0.2 \mathrm{ng} / \mathrm{m}^{3}$ to $7 \pm 2 \mathrm{ng} / \mathrm{m}^{3}$ for the first two days, followed by a sudden decrease beginning at the early hours of the morning (00:00 and 03:00) on the third day. In February concentrations were low, on the order of $0.4 \mathrm{ng} / \mathrm{m}^{3}$ to $3 \mathrm{ng} / \mathrm{m}^{3}$.

During the summer, the variations of concentrations observed for nopinone are very similar to those of phytone. However, the minimum/maximum gaps are steeper (Figure $3.22 \mathrm{c}$ ). Among other things, this result implies that the net production rate per each day exceeds that of depletion. Here, we examine the associations of the observed concentrations of nopinone with that of the reactive gases $\mathrm{NOx}, \mathrm{NO}_{2}$ and $\mathrm{O}_{3}$ data measured at Baltimore concurrently with the samples for organic analysis. No correlations were found on a 3-hourly basis. This result is not unexpected; firstly, both oxidizers are involved in a myriad of atmospheric processes, and secondly, because the biogenic products species considered are produced in the gas phase and then partition to the particle phase it is possible that other factors such as temperature and humidity may 

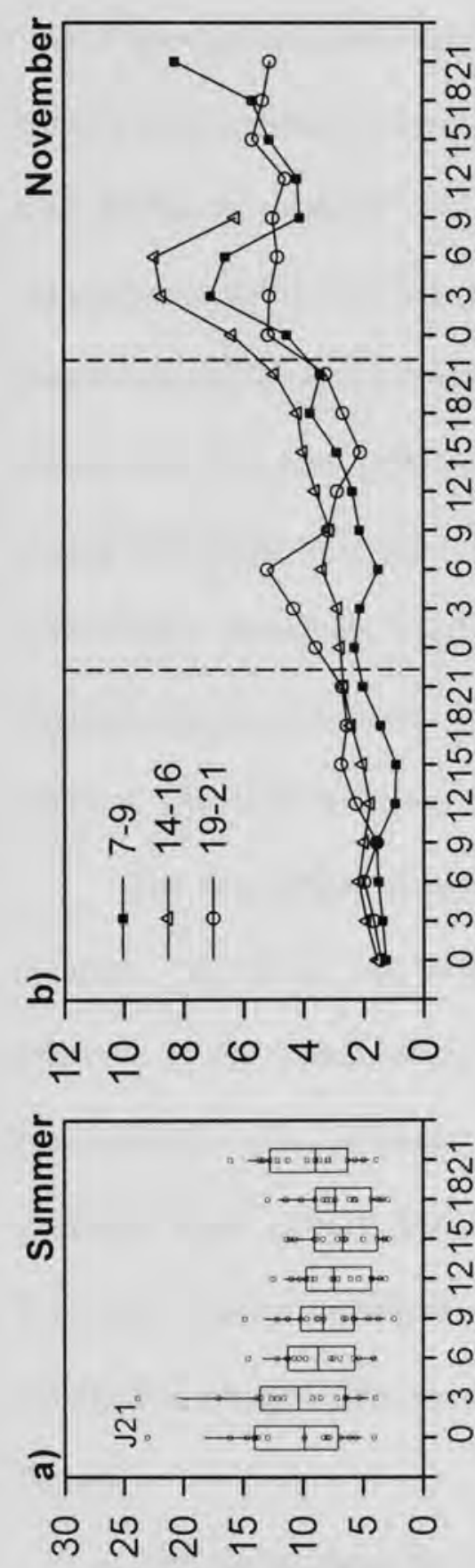

( $\varepsilon^{m / 6 u) ~ ә u о т k u d ~}$
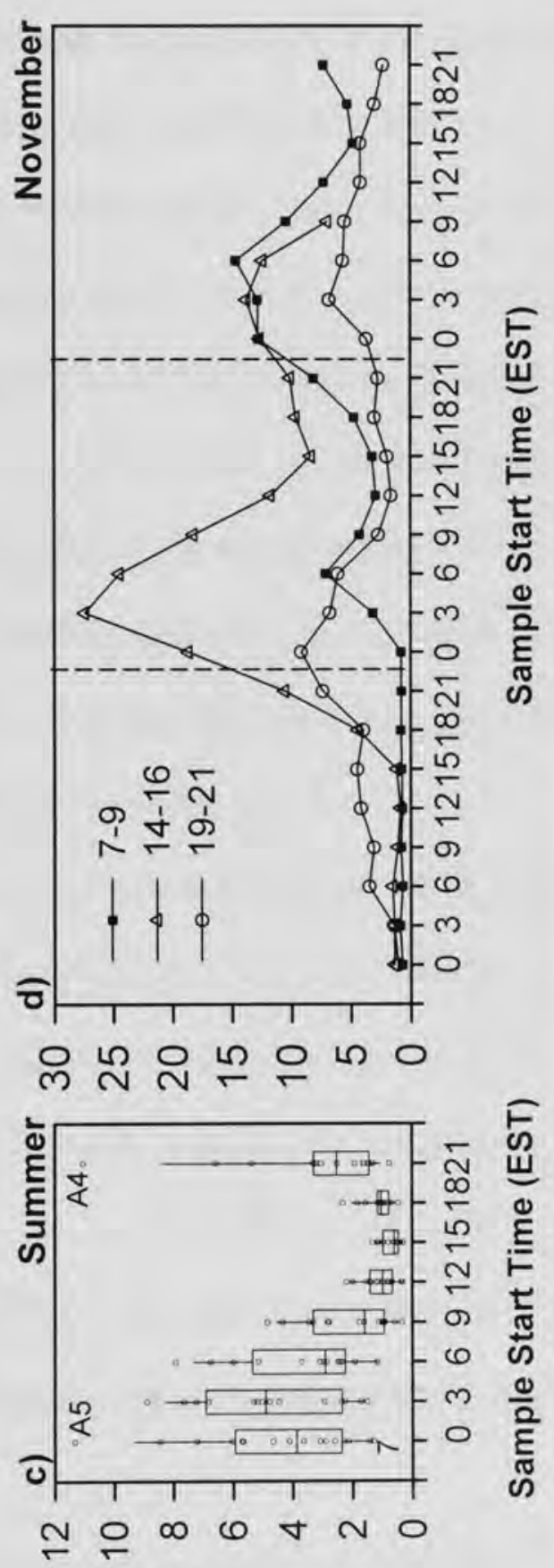

$\left.{ }_{\varepsilon} m / 6 u\right)$ әuоu!doN

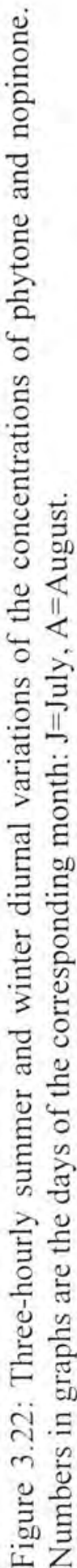


play a role in determining the time of day when the maxima is observed. The results of the correlations of the daily average concentrations of these species are shown in Figure 3.23. Winter gas data was only available for the November sampling days. These graphs indicate that a positive association is seen with $\mathrm{NOx}$ and $\mathrm{NO}_{2}$ (only $\mathrm{NO}_{2}$ shown here) both during the summer and the winter. On the other hand, during the winter, the association with $\mathrm{O}_{3}$ is mildly negative; that is, if at all, higher concentrations of $\mathrm{O}_{3}$ are associated with lower concentrations of nopinone. In fact, on three days (9-, 15-, and 16November), the concentrations of $\mathrm{O}_{3}$ are minimum, yet the concentrations of nopine are among the largest observed. Given that in the two periods 7-9-November and 14-16November a concurrent trend of steadily increasing concentration is also observed for phytone, (Figure $3.22 \mathrm{~b}, \mathrm{~d}$ ), it is possible that these days were influenced by transported material. This issue is further explored in section 4.3.4.3.

The association of nopinone and ozone during the summer appears to be more complex. Two trends can be distinguished; in July the relationship is similar to the one observed in the winter while in August the concentrations of nopinone increase with increasing $\mathrm{O}_{3}$ concentrations. These results suggest that the production of nopinone is generally more closely associated to the availability of $\mathrm{NOx} / \mathrm{NO}_{2}$, either in daylight involving NOx or nighttime involving $\mathrm{NO}_{3}$, than it is to that of $\mathrm{O}_{3}$. Furthermore, the results also suggest that the association with $\mathrm{O}_{3}$ may depend more strongly on other factors.

The trends observed for cis-pinonic acid are very similar to those of norpinonic acid. The most abundant specie, particularly in the winter, is cis-pinonic acid. Correlations of the 3-hourly concentrations of cis-pinonic vs. norpinonic acids yield values 

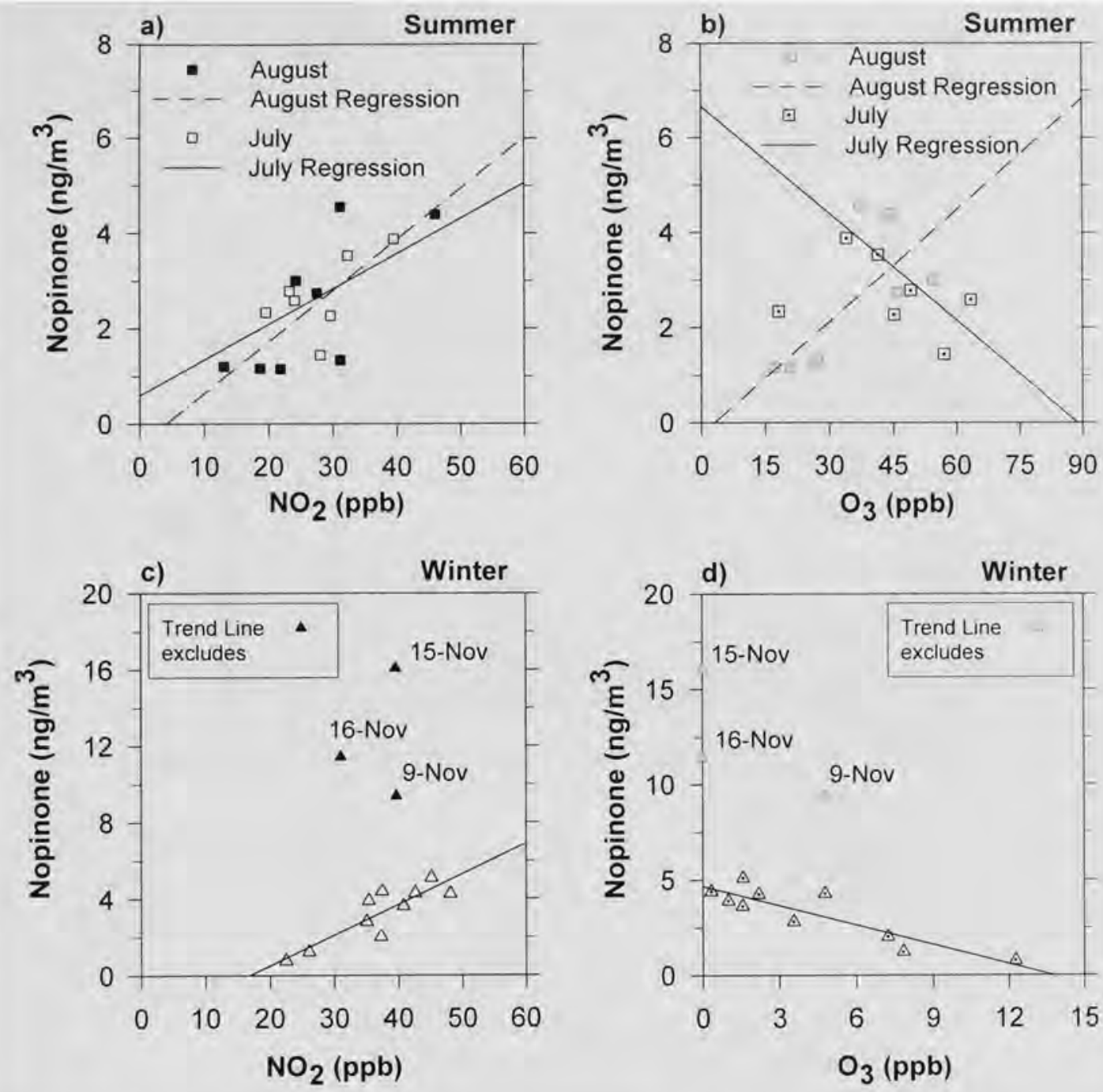

Figure 3.23: Scatter plots showing the associations of the daily averaged concentrations of nopinone vs. those of nitrogen oxide $\left(\mathrm{NO}_{2}\right)(\mathrm{a}, \mathrm{c})$ and ozone $\left(\mathrm{O}_{3}\right)(\mathrm{b}, \mathrm{d})$ in summer and winter, respectively.

of $\mathrm{R}^{2}$ of 0.73 and 0.80 for summer and winter, respectively. For the summer data, the association improves if the daily averages (or the daily sum) concentration of the two species are correlated rather than the 3 -hourly concentrations $\left(\mathrm{R}^{2}=0.91\right)$. Here, only the diurnal variations of the less abundant specie, norpinonic acid, will be illustrated and discussed. Trends for cis-pinonic acid are identical. 


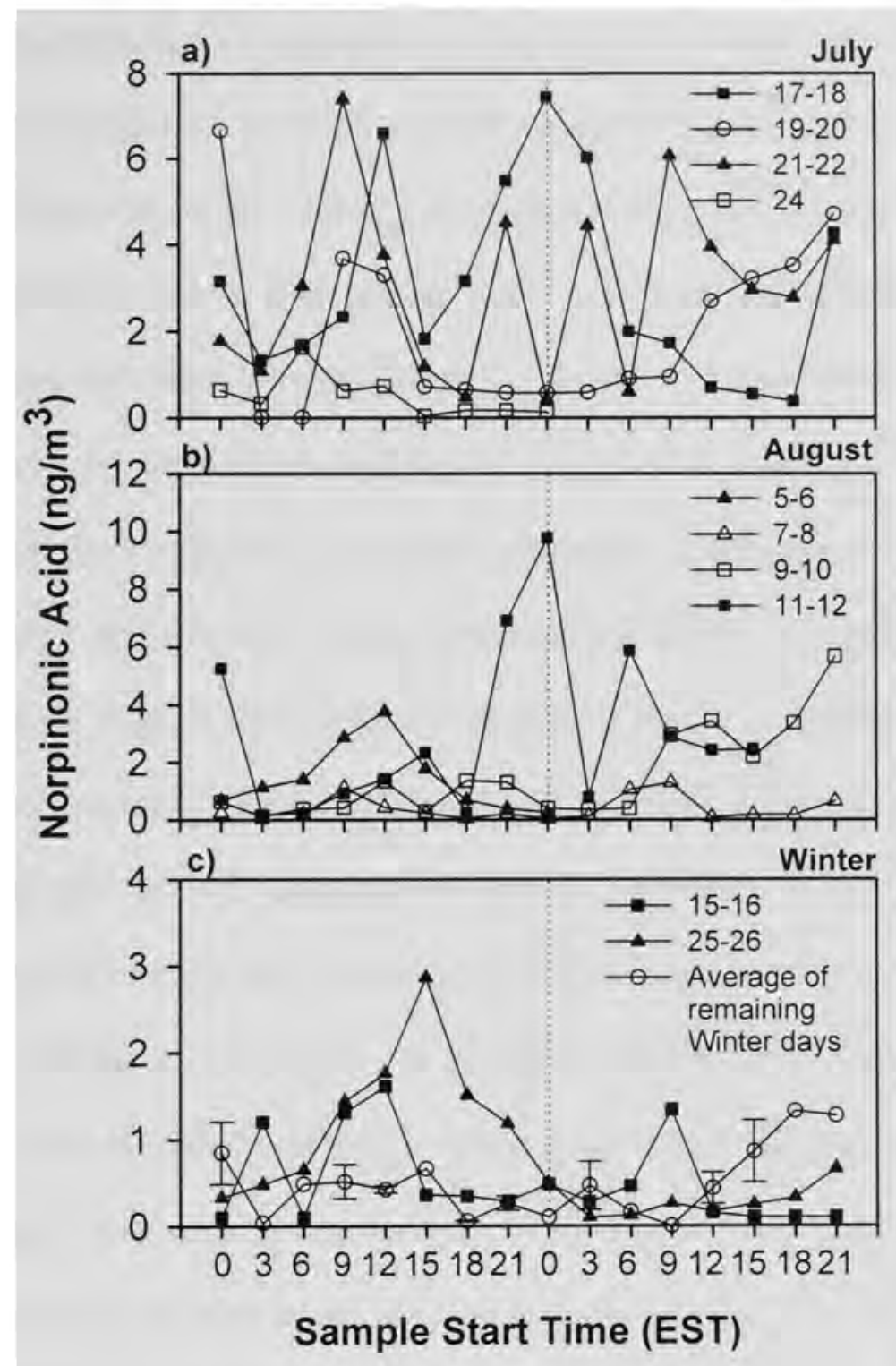

Figure 3.24: Three-hourly summer (a) and winter (b) diurnal variations of the concentrations of norpinonic acid.

In contrast to the gradual change that characterizes the diurnal patterns of phytone and nopinone, those of norpinonic and cis-pinonic acids show more abrupt changes in concentration both during the summer and winter days. For example, the summary of the 
variations of concentration of norpinonic acid are shown in Figure 3.24. Gradual diurnal changes of concentration as those observed for nopinone appear more consistent with a process happening continuously with the limiting-step being the equilibrium of nopinone between gas/particle phases, and as the day's temperature increases desorption is followed by rapid depletion of the compound by reaction in the gas phase. In contrast, the sudden changes of concentrations and the less regular pattern observed for norpinonic and cis-pinonic acid suggests a different chemistry. Furthermore, the differences observed between the July and August concentration levels, as it was the case with dicarboxylic acids, suggest that formation in heterogeneous or multiple phase process may be involved, as these depend on the specific characteristics of the substrate particles.

A correlation analysis analogous to the one presented above for nopinone was conducted using the average daily concentrations of cis-pinonic acid vs. $\mathrm{NO}_{2}$ and $\mathrm{O}_{3}$. The results, shown in Figure 3.25, suggest that during the summer, production paths involving both oxidants may be equally important whereas association with $\mathrm{O}_{3}$ is less important during the winter. Two additional aspects are noteworthy from these graphs. During the summer, a positive association between cis-pinonic acid and $\mathrm{NO}_{2}$ is observed in all days; however, in some days the levels of cis-pinonic appear clearly above the trend line. During the winter, for most days the trend of both nopinone and cis-pinonic acid vs. the oxidants $\mathrm{NO}_{2}$ and $\mathrm{O}_{3}$ are similar (Figure 3.23 and Figure 3.25), with the exception of 25November; on this day, while the measured concentration of nopinone is within the trend, that of cis-pinonic acid is larger. This result suggests that the ambient concentrations of nopinone and cis-pinonic (and norpinonic) acid were subject to different dynamics on this day. These conditions are further explored in section 4.3.4.3. 

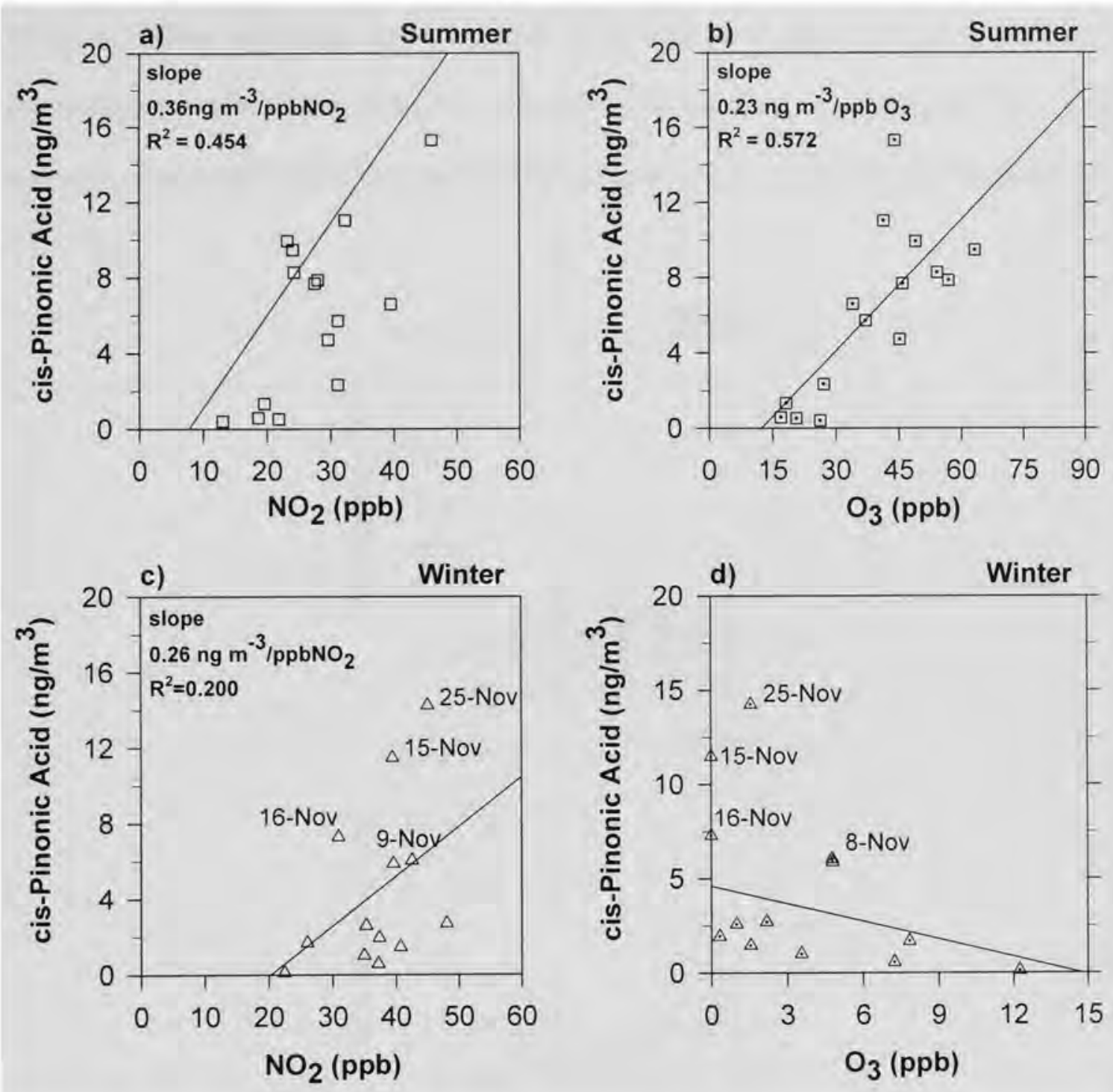

Figure 3.25: Scatter plots showing the associations of the daily averaged concentrations of cis-pinonic acid vs. those of nitrogen oxide $\left(\mathrm{NO}_{2}\right)\left(\mathrm{a}, \mathrm{c}\right.$, ) and ozone $\left(\mathrm{O}_{3}\right)(\mathrm{b}, \mathrm{d})$ in summer and winter, respectively. The slope of the trend shown is given.

\subsubsection{Cholesterol}

Cholesterol is an animal sterol, or steroid alcohol. Rogge and collaborators (1991) detected this compound in the particle-phase emissions from cooking meat and suggested that the main route for injection of cholesterol into atmospheric particles is via steam- 
stripping. Other studies have also reported cholesterol in the fine particles emitted from the grilling of meat (Schauer et al., 1999a) and chicken (Mc Donald et al, 2003). This compound has been detected in ambient fine particles and it has been used as a molecular
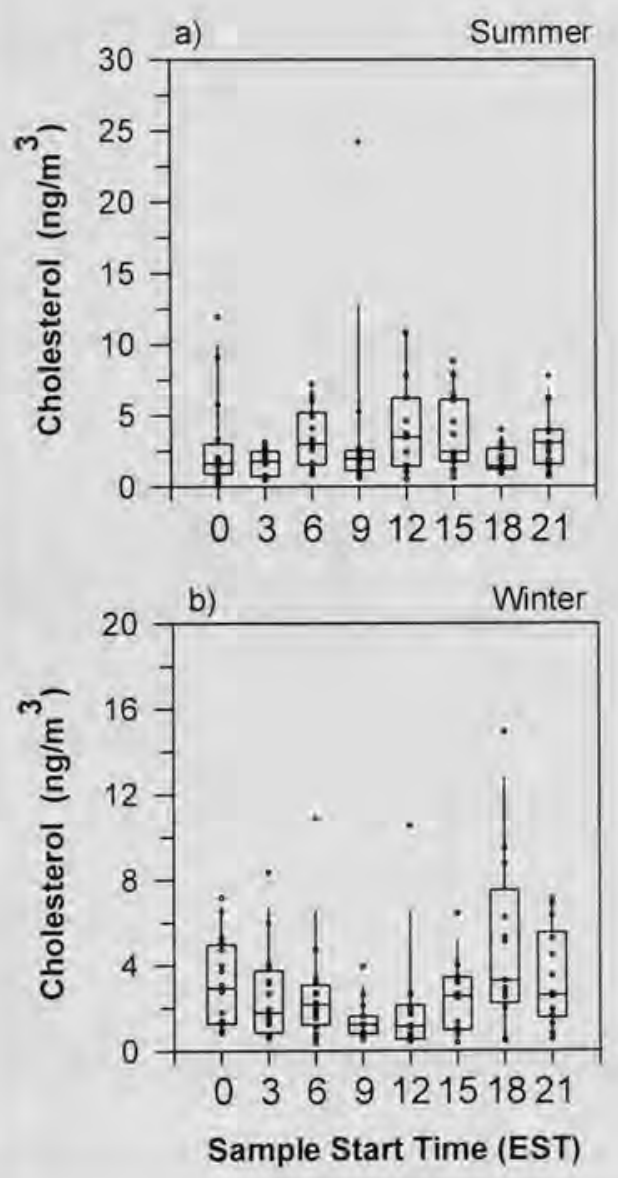

Figure 3.26: Three-hourly summer (a) and winter (b) diurnal variations of the concentrations of cholesterol.

tracer to apportion urban emissions from meat cooking operations in several areas in the U.S. (Schauer et al., 1996; Zheng et al., 2002; Fraser et al., 2003b).

The patterns we observe for cholesterol are summarized in Figure 3.26. Firstly, there is to note that the summer and winter concentration levels are very similar. The 
seasonal patterns of variations are equivalent to those described here for the unsaturated n-alkenoic acids, particularly oleic acid. During the summer, discrete peaks are often observed during the day. On the other hand; during the winter, peak concentrations were observed both as discrete peaks and as $2-3$ time period continuous highs, especially in the evening or early morning; this may be partly due to poorer atmospheric dispersion conditions during winter.

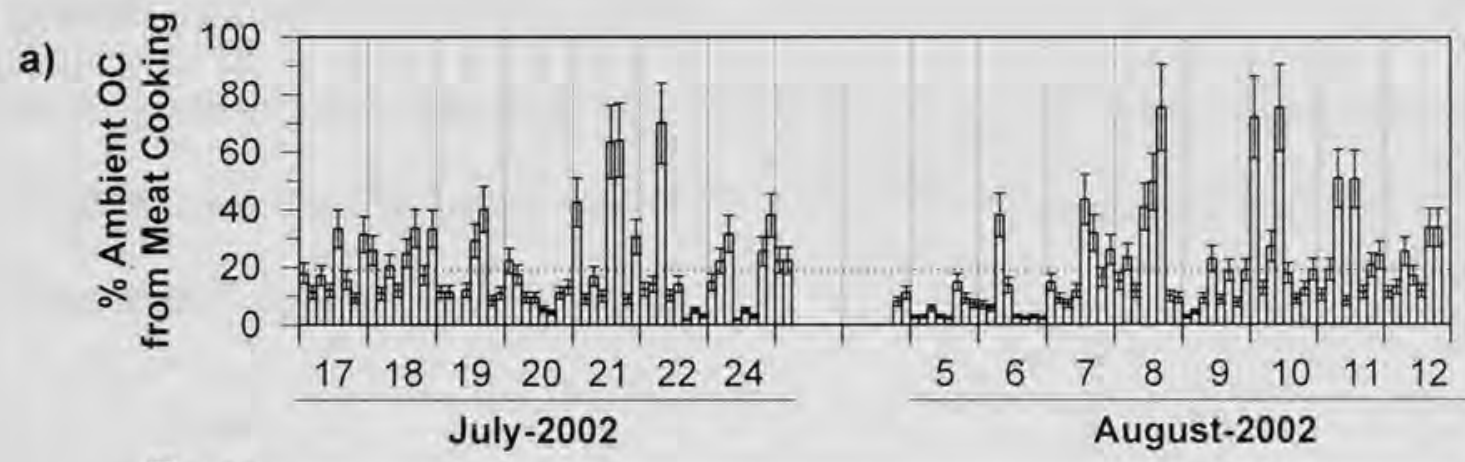

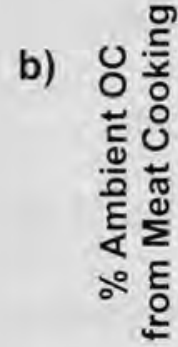

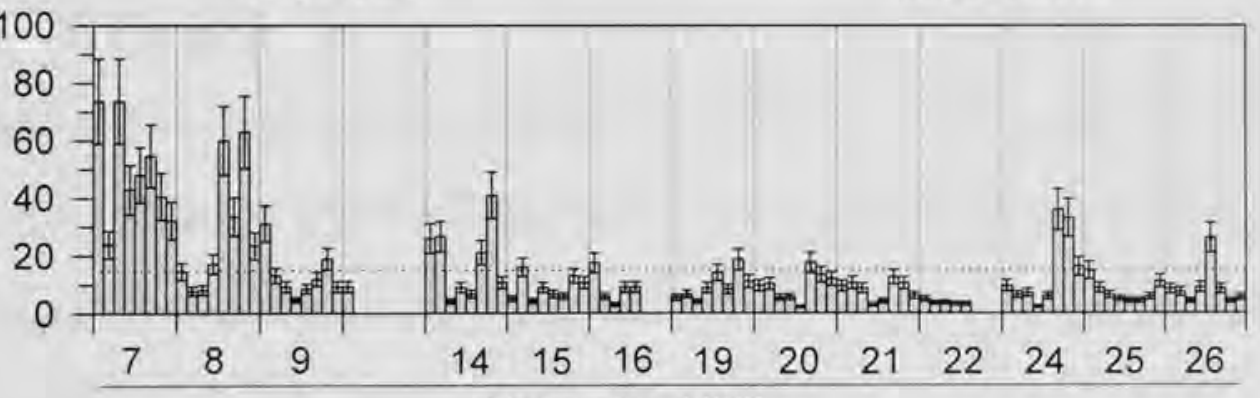

November 2002

Figure 3.27: Time-series of the summer and winter three-hourly contributions of emissions from meat cooking operations to ambient organic carbon (OC), Calculations based on the use cholesterol as molecular source tracer.

Taking cholesterol as a molecular marker for cooking of meat, it is possible to use the average cholesterol:OC ratio from published sources profiles in order to estimate the contribution of meat cooking to ambient OC by using the analogous method to that 
presented in previous sections for wood and natural gas burning. The average ratio, including emissions from meat frying and charbroiling (Rogge et al., 1991; Schauer et al., 1999 a) and residential fish cooking (Rogge, 2000), is $0.32 \pm 0.15$. The distribution of the 3-hourly summer and winter ambient fractions of cholesterol:OC indicate that on average $25 \% \pm 10 \%$ of the ambient OC in Baltimore is contributed by meat cooking sources. This value is close to the range reported in the literature, $19 \% \pm 10 \%$, for the apportionment of this source, using cholesterol as molecular tracer, in other urban cities in the USA (Schauer et al, 1996; Fraser et al., 2003 b, Zheng et al., 2002). As shown in Figure 3.27, for some samples the calculated contribution is not only well above the average, but close to $100 \%$. This suggests that there are other transient unaccounted sources of cholesterol in the aerosol measured in Baltimore.

\subsubsection{1 $\quad \beta$-Sitosterol}

$\beta$-sitosterol is a plant sterol; therefore, its presence is evidence of the input of fresh vegetative detritus. In addition, it has been used as a confirmatory biomarker for biomass burning (Simoneit et al., 1999), and more recently it has been identified in resuspended particles from agricultural soils (Rogge et al., 2007).

The 3-hourly diurnal variations of concentrations observed for $\beta$-sitosterol are shown in Figure 3.28. The strikingly larger concentrations observed during the winter may be reflective of a larger degradation rate of this compound in the summer atmospheric conditions. The winter pattern reflects the similarity of the trends of the 3 hourly concentrations of $\beta$-sitosterol to those of the biomass burning markers (Figure 3.13). In July, it is identified in concentrations above background levels on 17-July and 
22-July helping to confirm burning of biomass. In August, concentrations were markedly elevated on day $6^{\text {th }}$ supporting the conclusion that the pattern of biogenic input observed on that day for higher plant derived n-alkanes (Figure $3.2 \mathrm{c}$ ) and n-alkanoic acids (Figure $3.5 \mathrm{~b})$ is influenced by biogenic input.
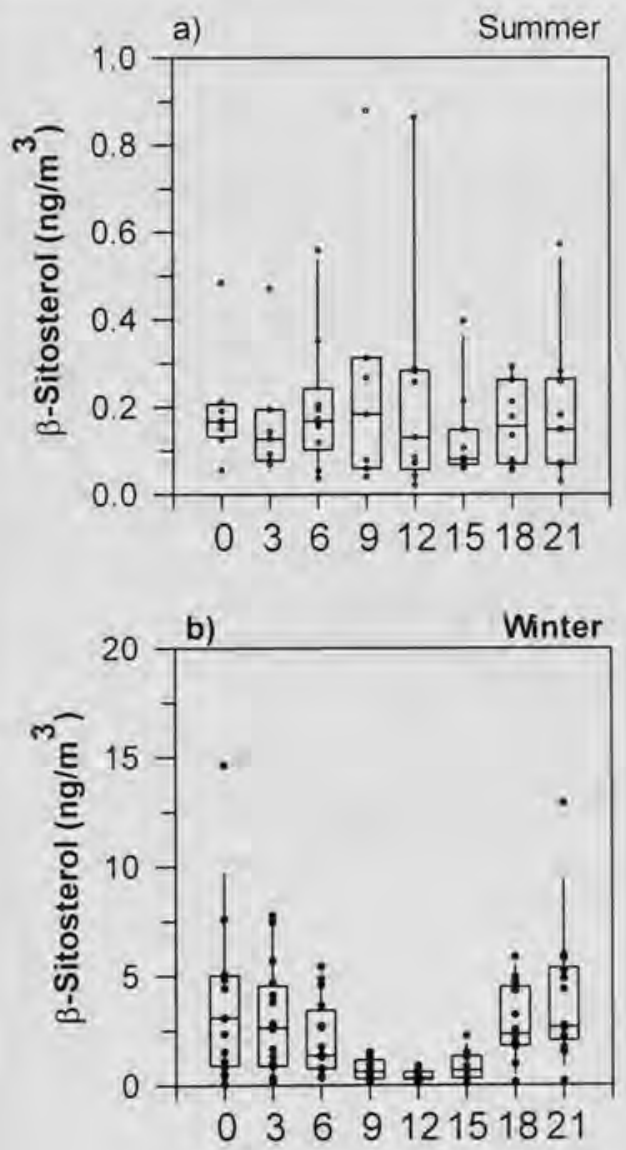

Sample Start Time (EST)

Figure 3.28: Three-hourly summer (a) and winter (b) diurnal variations of the concentrations of $\beta$-sitosterol.

\subsubsection{2 iso-antiso Alkanes}

The particle-phase of the smoke from cigarette and tobacco burning has been investigated by several researchers (Rogge et al., 1994; Kavouras et al., 1998; Bi et al., 
2005). Their findings have shown that the characteristic pattern of normal and branched iso- and antiso- alkanes from $\mathrm{C} 27$ to $\mathrm{C} 33$ found in the tobacco leaves is preserved in the particles produced from burning cigarettes. Therefore, these compounds have been suggested as tracers of environmental tobacco smoke.
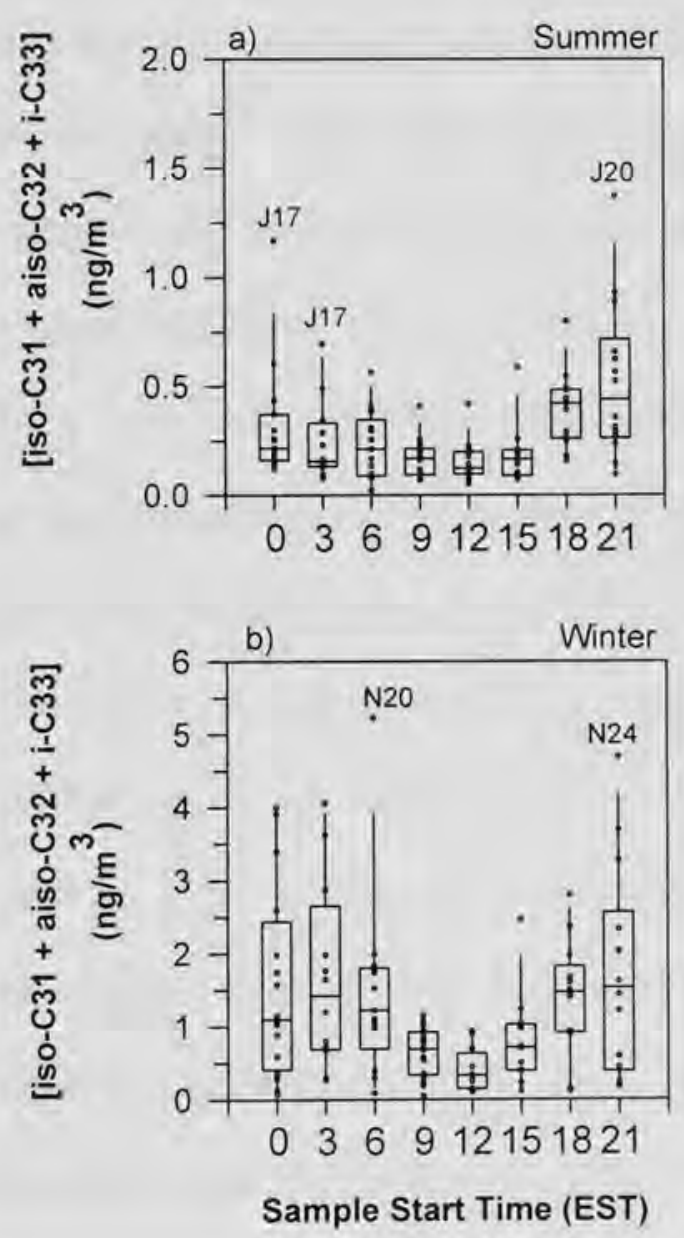

Figure 3.29: Three-hourly summer (a) and winter (b) diurnal variations of the concentrations of tobacco smoke branched n-alkanes markers. Sum of iso-C31, antiso$\mathrm{C} 32$ and iso-C33. Numbers in graphs are the days of the corresponding month: $\mathrm{J}=\mathrm{July}$, $\mathrm{A}=$ August in summer, and $\mathrm{N}=$ November and $\mathrm{F}=$ February in winter. 
Three iso- and anteiso- branched alkanes were identified in this study, isohentriacontane (iso-C31), anteiso-dotriacontane (aiso-C32), and iso-titriacontane (iso$\mathrm{C} 33)$. Both iso-C31 and aiso-C32 were found in all samples analyzed. Isomer iso-C33 was near detection limit in the "peak" samples and; consequently, below detection limit in all other. As shown in Figure 3.29, the variations of their 3-hourly concentrations fall into a clear diurnal pattern in both seasons. Peak concentrations are observed in the mornings and the evening but tend to be larger in the latter. Is also important to notice that they start the increasing trend at 12:00; before the time of maximum atmospheric dilutions (15:00). This indicates that net emissions are higher at those times. In addition, excluding very high values, the ratio values of maximum to minimum diurnal concentrations during the summer and winter respectively are 2 to 9 (median 4 ) and 2 to 8 (median 6). These results are consistent to those reported in a recent study conducted to examine daily smoking patterns among a group of representative smokers (Chandra et al., 2007), indicating that the pattern is characterized by a morning high/daily dip/evening incline approximately at 07:00-9:00/09:00-17:00-17:00-23:00.

During the summer, the higher values on Saturday 20-July and Friday-Sunday 810-August (on the upper stem in Figure 3.29 a) may reasonably indicate more frequency of smoking during weekend days. Without history from the previous day, the high concentrations observed at the onset 17-July from 00:00 to 03:00 are more difficult to wholly explain. This example illustrates the importance of the highresolution/continuous measurements in fine-tuning the determination of sources and processes. During the winter, the disproportionately larger concentration on the evening of 24-November can be explained by poor dispersion, when conditions of photochemical 
smog prevailed; low wind speed, high solar radiation, as it was explained in section 3.2.6. The concentrations during the winter are larger than during the summer. The atmospheric stability of these high molecular weight branched alkanes has not been investigated. If we assume that these markers are uniquely tracers of tobacco smoke and use the published source profile (Rogge et. al, 1994), the estimated contribution of cigarette smoke to OC would be $0.35 \pm 0.31 \%$ in the summer and $0.95 \pm 0.61 \%$ in the winter. The appreciably difference in contributions for this source suggest either unnacounted sources of the markers in the winter or that they subject to greater losses in the summer.

\subsection{Conclusions}

The most abundant compound classes in the samples from the summer period are n-alkanoic acids, n-alkanes and PAHs; on average these represent $45 \%, 24 \%$ and $14 \%$, respectively, of the total concentration of identified compounds. In the winter samples, the most abundant compounds are n-alkanes, n-alkanoic acids, PAHs and levoglucosan, respectively representing $30 \%, 29 \%, 11 \%$ and $8 \%$ of the total identified. The n-alkanes carbon preference index, $\mathrm{CPI}_{\mathrm{odd}}$, for majority of the summer and winter samples are in the range of 1 to 2 with a median value of 1.2 , indicating that they are mainly influenced by anthropogenic emissions with a nearly constant input of biogenic background in both seasonal periods. About $6 \%$ of summer and $3 \%$ of winter samples display a value $\mathrm{CPI}_{\text {odd }}<1$ (evenings of 7-8 and 8-9-August, and of 25-November), the distribution of $\mathrm{n}$ alkanes in these samples display a strong predominance of even-to-odd n-alkanes 
homologues reflecting the influence of combustion sources not typically documented for the atmospheric aerosol measured in urban atmospheres throughout the U.S.

Evaluations of the data reveal that 3-hourly variation of concentrations of the four series of organic markers for primary emissions from fossil fuel burning sources, i.e., sum of the n-alkanes in the range $\mathrm{C} 19-\mathrm{C} 25$, n-alkylcyclohexanes, hopanes, and particlephase PAHs, are predominantly influenced by emissions from vehicular exhaust in both seasons. However, generally larger concentrations levels of these species during the summer compared to the winter indicate that several of these compounds are subject to seasonal dynamic differences.

During the winter, the 3-hourly samples from Baltimore display a highly consistent diurnal cycle for the ratio of benzo[a]pyrene $(\mathrm{BaP})$ to benzo[e]pyrene $(\mathrm{BeP})$. The ratio values fall in the range of 0.8 to 1.2 and the minimum is consistenly observed at midday. The concurrence of the minimum ratio with the time of maximum solar radiation, together with the evenness of the pattern throughout the time-series can be interpreted as being consistent with photochemical loss as the dominant degradation path for $\mathrm{BaP}$ during the winter. The only exceptions are noted on 8-November and 14November, when two minimum ratios are observed, one of them overnight, suggesting that transported aerosol may be a factor to consider on these days. In contrast, during the summer, the ratio is lower and more variable indicating that degradation occurs at a faster rate and is influenced by other factors.

Significantly larger nighttime concentration of odd carbon-number n-alkanes (range C27-C35), even carbon-number n-alkanoic acids (range C24-C32) together with the source specific organic markers for wood burning, levoglucosan, dehydroabietic acid 
and syringyl-moiety phenols, on 24-26-November 2002 and 21-23-February 2003 indicate that the emission of those compounds were associated to appreciable larger nighttime contribution on those days. Using levoglucosan as a tracer for wood smoke is possible to estimate the contribution of wood burning to the ambient levels organic carbon (OC). These calculations indicate that $20-35 \%$ of the ambient OC measured during those events is from wood burning. Contribution for all other days of the winter sampling campaign is of the order of $5-10 \%$. Analogous estimates indicate that during the summer the contribution of fine particles form biomass burning is approximately $0.5 \%$, while this fraction rose to $1-4 \%$ throughout $20-21-J u l y$, a period displaying characteristics consistent with the influence of regional biomass burning.

On a 3-hourly basis, the palmitoleic:palmitic concentration ratios display similarly low values during summer and winter, median $0.1 \pm 0.1$. On the other hand, during the winter, the ratio oleic:stearic are between 0.8 and 2.2 and display a very strong diurnal pattern consisting of sharp midday decay of the ratio value. This minimum value concurs with the maximum diurnal solar radiation indicating that photochemical degradation of oleic acid is observed on a diurnal basis, analogous to the conclusion indicated for $\mathrm{BaP}: \mathrm{BeP}$. During the summer, the ratio oleic:stearic values are in the range 0.1 to 1 ; the same order of magnitude and following a similar trend as the palmitoleic:palmitic ratio. Consequently, it can be concluded that that oleic and palmitoleic acids are subject to different diurnal atmospheric dynamics.

Assuming cholesterol as tracer for cooking of meat, it can be estimated that $25 \%$ $\pm 10 \%$ of the ambient $\mathrm{OC}$ in Baltimore is contributed by meat cooking sources. For some of the 3-hourly samples the calculated contribution is not only well above the average, 
but close to $100 \%$ suggesting that there are other transient unaccounted sources of cholesterol in the aerosol measured in Baltimore.

Among the dicarboxylic organic acids analyzed, the diurnal trends observed here indicate the ambient concentrations of 4-methylphthalic acid are solely determined by secondary formation in the local atmosphere via a photochemical-driven mechanism; thus supporting the notion that this compound may serve as an active indicator of secondary anthropogenic aerosol formation.

The data indicates that the production of nopinone may be generally more closely associated to the availability of $\mathrm{NOx} / \mathrm{NO}_{2}$, either in daylight involving $\mathrm{NOx}$ or nighttime involving $\mathrm{NO}_{3}$, than it is to that of $\mathrm{O}_{3}$. The results also suggest that the association with $\mathrm{O}_{3}$ during the summer may depend more strongly on other factors. Similarly, the diurnal patterns of cis-pinonic and norpinonic acid display a stronger association with the $\mathrm{NOx} / \mathrm{NO}_{2}$ system. On some specific days during the winter, 8-9-November and 15-16November, the measured concentrations of all three compounds are larger than predicted by the trend observed between their concentration and that of the reactive gases NOx (or $\mathrm{NO}_{2}$ ) and $\mathrm{O}_{3}$ during the remaining days. This results also supports the inference from the $\mathrm{BaP}: \mathrm{BeP}$ ratio that transported aerosol may be a factor to consider on these days. 
Bi, X., Sheng, G., Feng, Y., Fu, J., Xie, J., 2005. Gas- and particulate-phase specific tracer and toxic organic compounds in environmental tobacco smoke. Chemosphere 61 (10), 1512-1522.

Chandra, S., Scharf, D., Shiffman, S., Dang, Q., Shadel, W.G., 2007. Daily smoking patterns, their determinants, and implications for quitting, Experimental and Clinical Psychopharmacology 15(1), 67-80.

Cheng, Y., Li, S.-M., Leithead, A., Brickell, P.C., Leaitch, W.R., 2004. Characterizations of cis-pinonic acid and n-fatty acids on fine aerosols in the Lower Fraser Valley during Pacific 2001 Air Quality Study. Atmospheric Environment 38 (34), 5789 5800 .

Cheng, Y., Li, S.-M., Leithead, A., Brook, J.R., 2006. Spatial and diurnal distributions of n-alkanes and n-alkan-2-ones on PM2.5 aerosols in the Lower Fraser Valley, Canada. Atmospheric Environment 40 (15), 2706-2720.

Dockery, D.W., Pope, C.A., III, Xu, X., Spengler, J.D., Ware, J.H., Fay, M.E., Ferris, B.G., Speizer, F.A., 1993. An Association between air pollution and mortality in six U.S. cities, New England Journal of Medicine 329, 1753-1759.

Donahue, N.M., Robinson, A.L., Stanier, C.O., Pandis, S.N., 2006. Coupled partitioning, dilution and chemical aging of semivolatile organics, Environmental Science and Technology 40 (8), 2635-2643.

Fine, P. M., Cass, G. R., Simoneit, B. R. T., 2001. Chemical characterization of fine particle emissions from fireplace combustion of woods grown in the northeastern United States. Environmental Science and Technology 35 (13), 2665-2675.

Fine, P. M., Cass, G. R., Simoneit, B. R. T., 2002. Chemical characterization of fine particle emissions from the fireplace combustion of woods grown in the southern United States. Environmental Science and Technology 36 (7), 1442-1451.

Fine, P. M., Chakrabarti B, Krudysz, Schauer J, Sioutas C., 2004a. Diurnal variations of individual organic compound constituents of ultrafine and accumulation mode particulate matter in the Los Angeles basin. Environmental Science and Technology, 38 (5), 1296-1304.

Fine, P. M., Cass, G. R., Simoneit, B. R. T., 2004b. Chemical characterization of fine particle emissions from the wood stove combustion of prevalent United States tree species. Environ. Engineering Science 21 (6), 705-721 
Fraser, M.P., Lakshmanan, K., 2000. Using Levoglucosan as a molecular marker for the long-range transport of biomass combustion aerosols. Environmental Science and Technology $34(21), 4560-4564$.

Fraser, M. P., Grosjean, D., Grosjean, E., Rasmussen, R. A., Cass, G. R., 1996. Air quality model evaluation data for organics. 1. Bulk chemical composition and gas/particle distribution factors. Environmental Science and Technology 30(5), 1731-1743.

Fraser, M. P., Cass, G. R., Simoneit, B. R. T., Rasmussen, R. A., 1997. Air quality model evaluation data for organics. 4. C2-C36 Non-aromatic hydrocarbons. Environmental Science and Technology 31(8), 2356-2367.

Fraser, M. P., Cass, G. R., Simoneit, B. R. T., Rasmussen, R. A., 1998. Air quality model evaluation data for organics. 5. C6-C22 Nonpolar and semipolar aromatic compounds. Environmental Science and Technology 32(12), 1760-1770.

Fraser, M.P, Yue, Z.W., Tropp, R.J., Kohl, S.D., Chow, J.C., 2002. Molecular composition of organic fine particulate matter in Houston, TX. Atmospheric Environment $36(38), 5751-5758$.

Fraser, M. P., Cass, G. R., Simoneit, B. R. T., 2003a. Air quality model evaluation data for organics. 6. C3-C24 Organic acids. Environmental Science and Technology $37(3), 446-453$.

Fraser, M.P, Yue Z.W., Buzcu, B., 2003b. Source apportionment of fine particulate matter in Houston, TX, using organic molecular markers. Atmospheric Environment 37 (15), 2117-2123.

Hays, M. D., Geron, C. D., Linna, K. J., Smith, N. D., Schauer, J. J., 2002. Speciation of gas-phase and fine particle emissions from burning of foliar fuels. Environmental Science and Technology 36 (11), 2281-2295.

Hays, M. D., Fine, P. B., Geron, C. D., Kleeman, M. J., Gullett, B. K., 2005. Open burning of agricultural biomass: Physical and chemical properties of particlephase emissions. Atmospheric Environment 39 (36), 6747-6764.

Hostettler, F.D., Kvenvolden, K.A., 2002. Alkylcyclohexanes in environmental geochemistry. Environmental Forensic 3(3-4), 293-301.

Houck, J.E., Eagle, B.N., 2006. Control Analyses and Documentation for Residential Wood Combustion in the MANE-VU Region, Control Analyses and Documentation for Residential Wood Combustion in the MANE-VU Region Final Report, prepared for the Mid-Atlantic Regional Air Management Association. 
Jaoui, M., Kamens, R.M., 2003. Mass balance of gaseous and particulate products from $\beta$-Pinene $/ \mathrm{O}_{3} / \mathrm{Air}$ in the absence of light and $\beta$-Pinene/NOx/Air in the presence of natural sunlight. Journal of Atmospheric Chemistry 45 (2), 101-141.

Kamens, R., Jang, M., Chien, C.-J., Leach, K., 1999. Aerosol formation from the reaction of $\alpha$-Pinene and ozone using a gas-phase kinetics-aerosol partitioning model. Environmental Science and Technology 33(9), 1430-1438.

Kamens, R. M., Jaoui, M., 2001. Modeling Aerosol Formation from $\alpha$-Pinene + NOx in the Presence of natural sunlight using gas-phase kinetics and gas-particle partitioning theory. Environmental Science and Technology 35(7), 1394-1405.

Kavouras, I.G., Stratigakis, N., Stephanou, E.G., 1988. Iso- and anteiso-alkanes: Specific tracers of environmental tobacco smoke in indoor and outdoor particle-size distributed urban aerosols. Environmental Science and Technology 32 (10), 13691377.

Kawamura, K., Ikushima, K., 1993. Seasonal changes in the distribution of dicarboxylic acids in the urban atmosphere. Environmental Science and Technoogy 27(10), 2227-2235.

Laden, F., Schwartz, J., Speizer, F.E., Dockery, D.W., 2006. Reduction in fine particulate air pollution and mortality: Extended follow-up of the Harvard Six Cities study. American Journal of Respiratory Critical Care Medicine 173, 667-672.

Lee, S., Baumann, K., Schauer, J.J., Sheesley, R.J., Naeher, L.P., Meinardi, S., Blake, D.R., Edgerton, E.S., Russell, A.G., Clements M., 2005. Gaseous and particulate emissions from prescribed burning in Georgia, Environmental Science and Technology 39 (23), 9049-9056.

Nielsen, T., 1988. The decay of benzo(a)pyrene and cyclopenteno(c,d)pyrene in the atmosphere. Atmospheric Environment 22, 2249-2254.

Ning, Z., Geller, M.D., Moore, K.F., Sheesley, R., Schauer, J.J., Sioutas, C., 2007. Daily variation in chemical characteristics of urban ultrafine aerosols and inference of their sources. Environmental Science and Technology 41 (17), 6000-6006.

Ondov, J.M., Buckley, T.J., Hopke, P.K., Ogulei, D., Parlanged, M.B.,Rogge, W.F., Squibb, K.S., Johnston, M.V., Wexler, A.S., 2006. Baltimore Supersite: Highly time- and size-resolved concentrations of urban PM2.5 and its constituents for resolution of sources and immune responses. Atmospheric Environment 40, S224-S237. 
Oros, D.R., Simoneit, B.R.T., 2000. Identification and emission rates of molecular tracers in coal smoke particulate matter. Fuel 79 (5), 515-536.

Oros, D.R., Simoneit, B.R.T., 2001a. Identification and emission factors of molecular tracers in organic aerosols from biomass burning Part 1. Temperate climate conifers. Applied Geochemistry 16(13), 1513-1544.

Oros, D.R., Simoneit, B.R.T., 2001b. Identification and emission factors of molecular tracers in organic aerosols from biomass burning Part 2. Deciduous trees. Applied Geochemistry 16 (13), 1545-1565.

Oros, D.R., bin Abas, M.R., Omar, N.Y.M.J., Rahman, N.A., Simoneit, B.R.T., 2006. Identification and emission factors of molecular tracers in organic aerosols from biomass burning: Part 3. Grasses. Applied Geochemistry 21 (6), 919-940.

Pope, C. A. I., Burnett, R. T., Thun, M. J., Calle, E. E., Krewski, D., Ito, K., Thurston, G. D., 2002. Lung cancer, cardiopulmonary mortality, and long-term exposure to fine particulate air pollution. Journal of the American Medical Association 287 (9), 1132-1141.

Pope, C.A., III, Burnett, R.T., Thurston, G.D., Thun, M.J., Calle, E.E., Krewski, D., Godleski, J.J., 2004. Cardiovascular mortality and long-term exposure to particulate air pollution: Epidemiological evidence of general pathophysiological pathways of disease, Circulation 109, 71-77.

Rinehart, L.R., Fujita, E.M., Chow, J.C., Magliano, K., Zielinska, B., 2006. Spatial distribution of PM2.5 associated organic compounds in central California. Atmospheric Environment 40 (2), 2990-303.

Robinson, A. L., Subramanian, R., Donahue, N. M., Bernardo-Bricker, A., Rogge, W. F., 2006a. Source apportionment of molecular markers and organic aerosol-1. Polycyclic aromatic hydrocarbons and methodology for data visualization. Environmental Science and Technology 40(24), 7803-7810.

Robinson, A. L., Subramanian, R., Donahue, N. M., Bernardo-Bricker, A., Rogge, W. F., 2006b. Source apportionment of molecular markers and organic aerosol. 2. Biomass smoke. Environmental Science and Technology 40(24), 7811-7819.

Robinson, A. L., Subramanian, R., Donahue, N. M., Bernardo-Bricker, A., Rogge, W. F., $2006 \mathrm{c}$. Source apportionment of molecular markers and organic aerosol. 3. Food cooking emissions.Environmental Science and Technology 40(24), 7820-7827.

Robinson, A.L., Donahue, N.M., Rogge, W.F., 2006d. Photochemical oxidation and changes in molecular composition of organic aerosol in the regional context. Journal of Geophysical Reaserch-Atmospheres 111, D03302. 
Rogge, W.F., Hildemann, L.M., Mazurek, M.A., Cass, G.R., Simoneit, B.R.T., 1991. Sources of fine organic aerosol. 1. Charbroilers and meat cooking operations. Environmental Science and Technology 25 (6), 1112-1125.

Rogge W. F., Mazurek M. A., Hildemann L. M., Cass G. R. and Simoneit B. R. T., 1993a. Quantification of urban organic aerosols at a molecular level: identification, abundance and seasonal variation. Atmospheric Environment 27A, 1309-1330.

Rogge, W.F., Hildemann, L.M., Mazurek, M.A., Cass, G.R., Simoneit, B.R.T., 1993b. Sources of fine organic aerosol. 2. Noncatalyst and catalyst-equipped automobiles and heavy-duty diesel trucks. Environmental Science and Technology 27(4), 636651 .

Rogge, W.F., Hildemann, L.M., Mazurek, M.A., Cass, G.R., Simoneit, B.R.T., 1993c. Sources of fine organic aerosol. 3. Road dust, tire debris, and organometallic brake lining dust: roads as sources and sinks. Environmental Science and Technology 27(9), 1892-1904.

Rogge, W.F., Hildemann, L.M., Mazurek, M.A., Cass, G.R., Simoneit, B.R.T., 1993d. Sources of fine organic aerosol. 4. Particulate abrasion products from leaf surfaces of urban plants. Environmental Science and Technology 27(13), 27002711.

Rogge, W.F., Hildemann, L.M., Mazurek, M.A., Cass, G.R., Simoneit, B.R.T., 1993e. Sources of fine organic aerosol. 5. Natural gas home appliances. Environmental Science and Technology 27(13), 2736-2744.

Rogge, W.F., Hildemann, L.M., Mazurek, M.A., Cass, G.R., Simoneit, B.R.T., 1994. Sources of fine organic aerosol. 6. Cigarette smoke in the urban atmosphere. Environmental Science and Technology 28(7), 1375-1388.

Rogge, W.F., Hildemann, L.M., Mazurek, M.A., Cass, G.R., Simoneit, B.R.T., 1997 a. Sources of fine organic aerosol. 7. Hot asphalt roofing tar pot fumes. Environmental Science and Technology 31(10), 2726-2730.

Rogge, W.F., Hildemann, L.M., Mazurek, M.A., Cass, G.R., Simoneit, B.R.T., 1997b. Sources of fine organic aerosol. 8. Boilers burning No. 2 distillate fuel oil. Environmental Science and Technology 31(10), 2731-2737.

Rogge, W.F., Hildemann, L.M., Mazurek, M.A., Cass, G.R., Simoneit, B.R.T., 1998. Sources of fine organic aerosol. 9. Pine, oak, and synthetic log combustion in residential fireplaces. Environmental Science and Technology 32(1), 13-22. 
Rogge, W. F., 2000. Investigating Indoor Air Quality by using a Dynamic and Modular Source Testing Approach for Indoor Cooking, Final Report to the Center for Indoor Air Research (CIAR).

Rogge, W.F., Medeiros. P.M., Simoneit, B.R.T., 2007. Organic marker compounds in surface soils of crop fields from the San Joaquin Valley fugitive dust characterization study. Atmospheric Environment 41 (37), 8183-8204.

Rudich, Y., Donahue, N.M., Mentel, T.F., 2007. Aging of organic aerosol: bridging the gap between laboratory and field studies. Annual Review of Physical Chemistry $58,321-52$

Schauer, J.J., Rogge, W.F., Hildemann, L.M., Mazurek, M.A., Cass, G.R., Simoneit, B.R.T., 1996. Source apportionment of airborne particulate matter using organic compounds as tracers. Atmospheric Environment 30 (22), 3837-3855.

Schauer, J. J.; Kleeman, M. J.; Cass, G. R.; Simoneit, B. R. T., 1999a. Measurement of emissions from air pollution sources. 1. C-1 through C-29 organic compounds from meat charbroiling. Environmental Science and Technology 33 (10), 15661577 .

Schauer, J. J., Kleeman, M. J., Cass, G. R., Simoneit, B. R. T., 1999b. Measurement of emissions from air pollution sources. 2. C1-C29 Organic compounds from medium duty diesel trucks. Environmental Science and Technology 33(10), 15781587.

Schauer, J. J.; Kleeman, M. J.; Cass, G. R.; Simoneit, B. R. T., 2002a. Measurement of Emissions from Air Pollution Sources. 3. C1-C29 Organic Compounds from Fireplace Combustion of Wood. Environmental Science and Technology 35 (9), $1716-1728$.

Schauer, J. J.; Kleeman, M. J.; Cass, G. R.; Simoneit. B. R. T., 2002b. Measurement of emissions from air pollution sources, 4. C-1-C-27 organic compounds from cooking with seed oils. Environmental Science and Technology 36 (4), 567-575.

Schauer, J. J., Kleeman, M. J., Cass, G. R., Simoneit, B. R. T., 2002c. Measurement of emissions from air pollution sources. 5. Cl-C32 Organic compounds from gasoline-powered motor vehicles. Environmental Science and Technology 36(6), 1169-1180.

Schwartz, J., Laden, F., Zanobetti, A. 2002. The Concentration-Response relation between PM2.5 and daily deaths. Environmental Health Perspectives 110 (10), 1025-1029. 
Sevimoglu, O., Rogge, W.F., Bernardo-Bricker, A., Robinson, A., Subramanian, R., 2005. Fine Particulate Abrasion Products from Leaf Surfaces of Urban Plants:. Comparison between Pittsburgh and Los Angeles. 12PD-26. Poster at American Association for Aerosol Research. February 7-11, Atlanta, GA.

Simoneit, B.R.T., Mazurek, M.A., 1982. Organic matter of the troposphere. II. Natural background of lipid matter in aerosols over the rural western United States. Atmospheric Environment 16,2139-2159.

Simoneit, B.R.T., 1984. Organic matter of the troposphere III. Characterization and source of petroleum and pyrogenic residues in aerosols over the western United States. Atmospheric Environment 18, 51-67.

Simoneit, B. R. T., Cox, R. E., Standley, L. J., 1988. Organic matter of the troposphere. IV. Lipids in Harmattan aerosol in Nigeria. Atmospheric Environment 22, 9831004.

Simoneit, B.R.T., Sheng, G., Chen, X., Fu, J., Zhang, J., Xu, Y., 1991. Molecular marker study of extractable organic matter in aerosols from urban areas of China. Atmospheric Environment 25A, 2111-2129.

Simoneit, B.R.T., Schauer, J.J., Nolte, C.G., Oros D.R., Elias V.O., Fraser M.P., Rogge W.F., Cass G.R., 1999. Levoglucosan, a tracer for cellulose in biomass burning and atmospheric particles. Atmospheric Environment 33 (2), 173-182.

Simoneit, B.R.T., Kobayashi, M., Mochida, M., Tsubonuma, N., Kawamura, K., Lee, M., Komazaki, N., 2004. Composition and major sources of organic compounds of aerosol particulate matter sampled during the ACE-Asia campaign. Journal of Geophysical Research 109, D19S10.

Standley, L.J., Simoneit, B.R.T., 1994. Resin diterpenoids as tracers for biomass combustion aerosols. Journal of Atmospheric Chemistry 18, 1-15.

Subramanian, R., Donahue, N. M., Bernardo-Bricker, A., Rogge, W. F., Robinson, A. L., 2007. Insights into the primary-secondary and regional-local contributions to organic aerosol and PM2.5 mass in Pittsburgh, Pennsylvania. Atmospheric Environment 41(35), 7414-7433.

Turpin B.J., Saxena P., Andrews E., 2000. Measuring and simulating particulate organics in the atmosphere: problems and prospects. Atmospheric Environment 34 (18), 2983-3013.

Yu, J., Cocker, D.R.I., Griffin, R.J., Flagan, R.C., Seinfeld, J.H., 1999. Gas-phase ozone oxidation of monoterpenes: gaseous and particulate products. Journal of Atmospheric Chemistry 34, 207-258. 
Yue, Z. W., Fraser, M.P., 2004a. Characterization of nonpolar organic fine particulate matter in Houston, Texas. Aerosol Science and Technology 38 (S1), 60-67.

Yue, Z. W., Fraser, M.P., 2004b. Polar organic compounds measured in fine particulate matter during TexAQS 2000. Atmospheric Environment 38 (20), 3253-3261.

Zheng, M., Cass, G.R., Schauer, J.J., Edgerton, E.S., 2002. Source apportionment of PM2.5 in the southeastern United States using solvent-extractable organic compounds as tracers. Environmental Science and Technology 36, 11, 2361-2371.

Zielinska, B., Sagebiel, J., McDonald, J.D., Whitney, K., Lawson, D.R. 2004. Emission Rates and Comparative Chemical Composition from Selected In-Use Diesel and Gasoline-Fueled Vehicles, Journal of the Air and Waste Management Association $54,1138-1150$. 


\section{CHAPTER 4}

\section{SHORT- AND LONG-RANGE ATMOSPHERIC EVENTS INFLUENCING PM2.5 IN BALTIMORE IDENTIFIED FROM HIGHLY TIME-RESOLVED ORGANIC CHARACTERIZATION DATA}

(Bernardo-Bricker, A., Rogge, W.F., Ondov, J.M., manuscript in preparation)

\subsection{Introduction}

The dynamic nature of the atmosphere greatly complicates management of local air quality. The local levels of fine particulate matter pollution (PM2.5) are not only influenced by the short-range sources but they are also known to be a function of regional emissions, meteorological conditions, and even prevalent synoptic air circulation flows.

Baltimore is a $240 \mathrm{~km}^{2}$ urban industrial deepwater port city in the northeast of the U.S., influenced by a large number of local sources. Most of its industry is concentrated in the $125 \mathrm{~km}^{2}$ area from the center of the city, and immediately adjacent to populous neighborhoods. This area's local point sources alone comprise more than 40 industrial facilities (Ondov et al., 2006). The city is also influenced by the emissions of large volumes of vehicles; the three major toll facilities, Ft. McHenry, Harbor Tunnel, and Francis Scott Key Bridge, record counting 30,000 heavy diesel vehicles and 300,000 spark-engine vehicles per day. In addition, urban emissions generated in Washington, DC are a mere 50 to $90 \mathrm{~km}$ southwest of Baltimore along the Potomac River; furthermore, analysis of chemical characterization of PM2.5 and trace gases data has suggested that regional transport can contribute $40-70 \%$ of the local levels of PM2.5 (Chen et al., 2002). 
Within the context of the Baltimore PM-Supersite, conducting an intensive field study to acquire a large set of PM2.5 samples at an unprecedented 3-hourly resolution and perform a highly detailed organic characterization of such samples had the fundamental objective to utilize the research quality data in order to gain specific understanding of short- and long-range phenomena. During a two-week period in JulyAugust 2002, three-week period in November 2002 and a three-day period in February 2003, samples of PM2.5 for organic speciation were collected every three hours on a nearly continuous basis. A total of 238 samples were extracted and analyzed by using advanced solvent-extraction and GC-MS techniques. Over 100 individual compounds including molecular source tracers were identified in each sample. Previous studies have examined the diurnal variations of some organic compounds in ambient PM2.5 in areas such as Los Angeles, CA (Fine et al. 2004a, Ning et al., 2007) and the Fraser Valley, Canada (Cheng et al., 2004, 2006). However, the data sets of organic characterization of PM2.5 from the Baltimore study allow a unique comprehensive mapping of the organic composition and dynamics of fine particles for an urban area in the U.S.

This chapter specifically examines the relationships between the observed diurnal variations of the concentrations of selected organic markers and both the on-site meteorological measurements conducted parallel to the PM2.5 sampling and the synoptic patterns of weather and wind conditions. Several events and episodes can be distinctly identified and explained from the sequential variation of concentration observed for specific organic marker compounds and markers ratios. The association between meteorological events and the concentrations of the organic compounds during selected events and episodes is discussed. Backtrajectories of air parcels are also performed for 
each day of the study in order to identify the geographical regions that provided influx of background air for each day. Using numerical information of air parcel height and depth of the mixing layer at each point of the daily trajectories, a diagram of the intrusion of air masses from different directions is built in order to evaluate the association between different source regions of background air and the observed organic characteristics.

\subsection{Experimental Methods}

The dataset used in this study is derived from the detailed organic characterization analysis of PM2.5 samples collected as part of the Baltimore-PM Supersite 2002-2003 campaigns. The sampling system and procedures, and the analytical sample extraction and analysis protocols have been described in great detail in Chapter 3 (sections 3.2.1 to 3.2.4). Important information is briefly summarized in sections $4.2 .1-4.2 .4$.

\subsubsection{Sampling Location, Sampler and Samples Description}

The PM2.5 samples for the organic molecular speciation study were collected at the Ponca Street site in downtown Baltimore (Latitude: $39.2891^{\circ}$, Longitude: $-76.5546^{\circ}$ ). A map of Baltimore showing the location of the sampling site is shown in Figure 4.1. Located within 100 meters west of the sampling site (angular direction $170^{\circ}-240^{\circ}$ ) there is a Maryland Transit Administration bus maintenance facility. To the east (angular direction $40^{\circ}-50^{\circ}$ ) are two interstate highways (I-95 and I-895).

A sampling system was designed to collect sequentially eight samples per day at a 3-hour interval. The sampling inlet was equipped with a Marple PM2.5 impactor to remove particles with an aerodynamic diameter larger than $2.5 \mu \mathrm{m}$. The system was run 
at a nominal flow rate of $600 \mathrm{lpm}$, and samples were collected on a substrate set consisting of one quartz filter followed by one polyurethane foam (PUF) plug installed downstream of the filter to trap semi-volatile organic compounds. Quartz fiber filters Tissuquartz 2500 QAT-UP, $125 \mathrm{~mm}$ diameter, were purchased from Pall Gelman Science. PUF plugs acquired from Sobie Upholstery Supply Co, consisted of foam type $2715 / \mathrm{C} 30$ custom cut to a size of $111 \mathrm{~mm}$ diameter $\times 5 \mathrm{~cm}$ long.

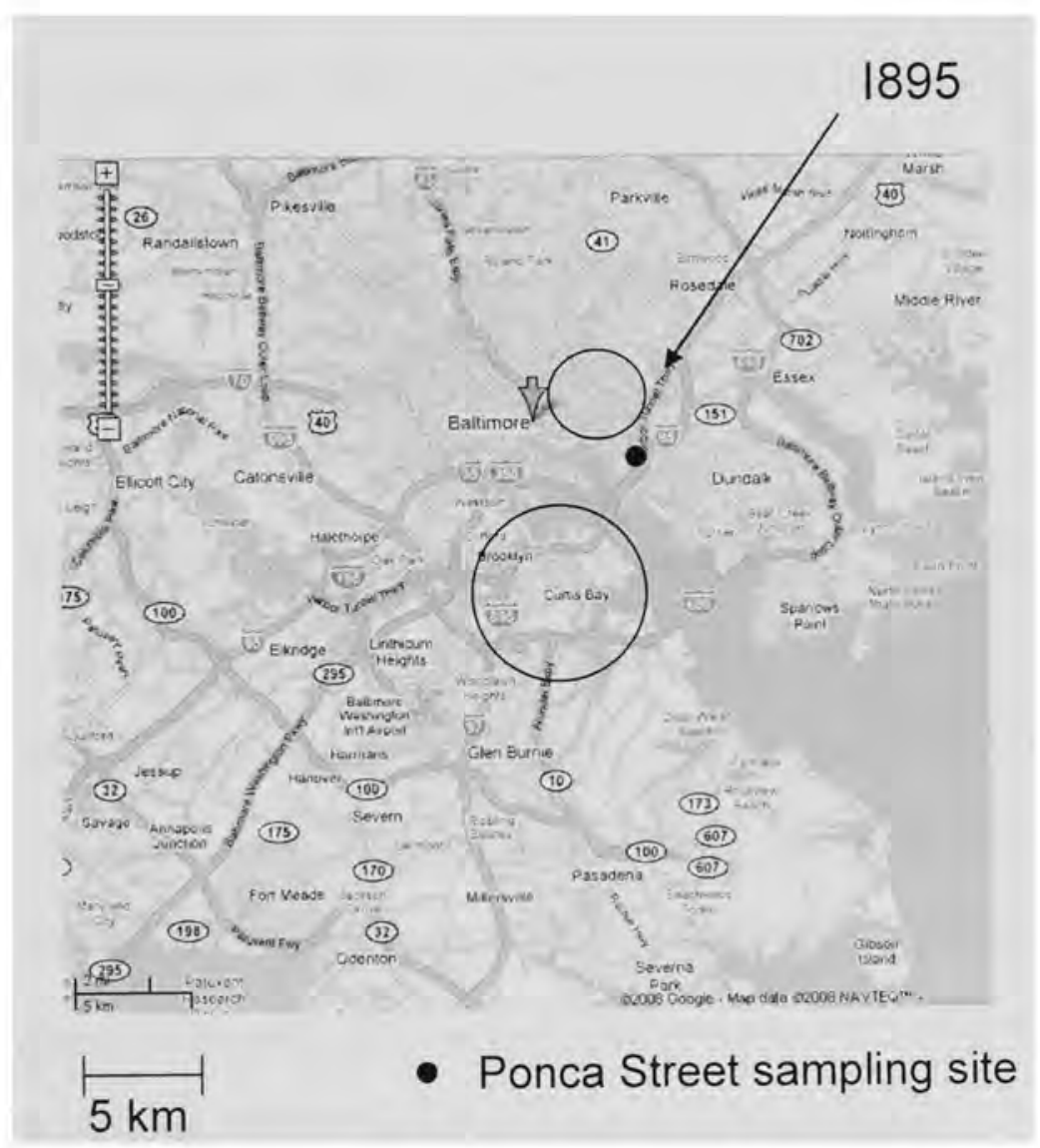

Figure 4.1: Map of Baltimore showing the location of the sampling site. In circles, the largest concentrations of general manufacturing areas: near the site, Canton; to the south, Curtis Bay.

A total 119 samples from each of the two seasons were analyzed for over 100 organic compounds. The summer samples comprise the following days from the year 
2002: 17-22-July, 24-July, and 5-12-August. The winter samples comprise: 7-10-, 14-16-, 19-22-, and 24-26-November-2002, and 21-23-February 2003.

\subsubsection{Sample Extraction and Gas Chromatography/Mass Spectrometry (GC/MS) Analysis Procedures}

Immediately before solvent extraction each filter was spiked with a known amount of an internal standard suite consisting of seven perdeuterated n-alkanes (Chiron AS, Norway): C12, C16, C20, C24, C28, C32, C36. Filters were extracted with methylene chloride using mild ultrasonic agitation. Each PUF plug was also spiked with an aliquot of the internal standard suite followed by a three-cycle extraction with methylene chloride using specially designed Repeated Compression Extraction Apparatus (RCEA).

After extraction, the volume of each of the filter and PUF extracts were separately reduced to a volume of $2-3 \mathrm{ml}$ by rotary evaporation followed by a gentle solvent evaporation with a stream of high purity $\mathrm{N}_{2}$ to a final volume of typically $100-150 \mu \mathrm{L}$. Filter and PUF extracts were stored and analyzed separately. Next, each reduced extract was reacted with diazomethane to convert organic acids to their methyl ester analogues and acidic hydroxyl compounds to their methoxyl analogues. Derivatized sample extracts were stored in a freezer at less than $-21{ }^{\circ} \mathrm{C}$ until analysis by $\mathrm{GC} / \mathrm{MS}$.

Analysis of all derivatized samples was carried out on a Gas Chromatographer (GC) model HP-6890 interfaced with a Mass-Spectra Detector (MSD) model HP-5973 (Agilent Technologies). A capillary column DB-5MS (J\&W $30 \mathrm{~m} \times 0.25 \mathrm{~mm}$ i.d. $\mathrm{x}$ $0.25 \mu \mathrm{m}$ film thickness) was used for separations. Temperature programming of the GC 
column consisted of the following steps: isothermal at $60^{\circ} \mathrm{C}$ for $2 \mathrm{~min}$, temperature ramp of $6{ }^{\circ} \mathrm{C} / \mathrm{min}$ up to $300^{\circ} \mathrm{C}$, and isothermal hold for $18 \mathrm{~min}$. The GC/MS interface temperature was set to $285^{\circ} \mathrm{C}$. Helium was used as carrier gas with a flow rate of 1.2 $\mathrm{ml} / \mathrm{min}$. The MSD was operated in the electron impact mode at $70 \mathrm{eV}$ electron energy set on a scan range of 50 to $550 \mathrm{amu}$.

\subsubsection{Compound Identification and Quantification}

The GC/MS data was acquired and processed using a Agilent ChemStation. Compounds were identified in the ambient PM2.5 samples by comparison with the retention time and mass fragmentation pattern of authentic standards. Whenever standards were unavailable, identification was based on comparison of their mass fragmentation pattern with that of the National Institute of Standards and Technology (NIST-NBS75K) and Wiley mass spectral libraries.

Area counts for each identified peak were converted to mass units using a relative response factor (RRF) for each compound and correcting for the recovery of the appropriate internal standard to account for any losses incurred throughout the sample extraction procedure. Errors were found to vary from $1 \%$ to $25 \%$ with a median value of $15 \%$.

\subsubsection{Quality Assurance/Quality Control (QA/QC)}

Assurance of analytical quality and control of the procedures were determined through the use of laboratory blanks and field blanks. Field blanks consisted of a sampling media pair of quartz filter and PUF which had undergone the same handling 
preparation and procedures as those of regular samples, including placement into the sampler and shipment. All compounds quantified in the samples were blank corrected. Masses of those targets found in the blanks were no more than $1 \%$ of their mass measured in ambient samples.

\subsection{Results and Discussion}

In the following discussion, short-range changes refer to "events" which can be inferred with certainty that were caused by sources nearby and are influenced by the local meteorological conditions; some of these events are transient in nature others are not. In the context of air pollution the word "episode" typically refers to time periods during which pollution standards are exceeded, or pollutant level is significantly above the "normal" or "background". Each day, the aerosol of urban atmospheres is influenced by the uninterrupted influx of anthropogenic generated emissions; therefore, it is difficult to define in absolute terms a "background" concentration level of a given organic compound, particularly because these also depend on the chemical lifetime of the given species and the various scales of motion within the atmosphere. Acquiring eight samples of PM2.5 per day gives the unique opportunity to determine the variations in the minimum concentration of each of the organic compounds on sequential days. By evaluating the changes of these minimum daily levels, it is possible to discern possible associations with the large-scale winds.

Firstly, a summary of the local and the large-scale essential meteorological information is presented, and then, specific observations than can be distinguished as short-range, or being more strongly affected by long-range causes will be examined. 


\subsubsection{Local Meteorological Data}

Meteorological variables such as temperature, relative humidity, solar radiation, mean wind speed and direction were measured at the sampling site at a 5 -min resolution concurrently to the samples of PM2.5 for organic characterization. Figure 4.2 shows the summary 3-hourly averages for each variable, temperature (a, d), relative humidity (b, e), and wind speed $(\mathrm{c}, \mathrm{f})$, for the summer and winter periods studied, respectively. This figure shows that humidity and temperature are generally higher in July compared to August. Specific trends can also be identified for each of these two periods. For example, during 6-12 August both temperature and relative humidity display increasing trends; on the other hand, the July cycles for these two variables show nearly opposite trends; i.e., while the temperature cycles gradually decrease an average $6^{\circ} \mathrm{C}$, the relative humidity cycles gradually increase from $43 \%$ (17-July) to $82 \%$ (24-July). During the summer, these combined features are typically observed with moving cold fronts. Daily weather maps which are available from NOAA archives (NOAA), confirm that on day 18-July (Appendix C) a strong high pressure was located above the Great Lakes area while a broad low pressure was located over the mid-Atlantic area; low pressures persisted up to 20-July. On this day a cold front line is over Maryland. A similar cold front is also observed on day 5-August.

The temperature and relative humidity cycles for 9-12-August are different from those described for July; both variables display an increase, from $25^{\circ} \mathrm{C}$ to $29^{\circ} \mathrm{C}$ and from $48 \%$ to $58 \%$ respectively. This pattern is consistent with favorable conditions for summer stagnation buildup. 


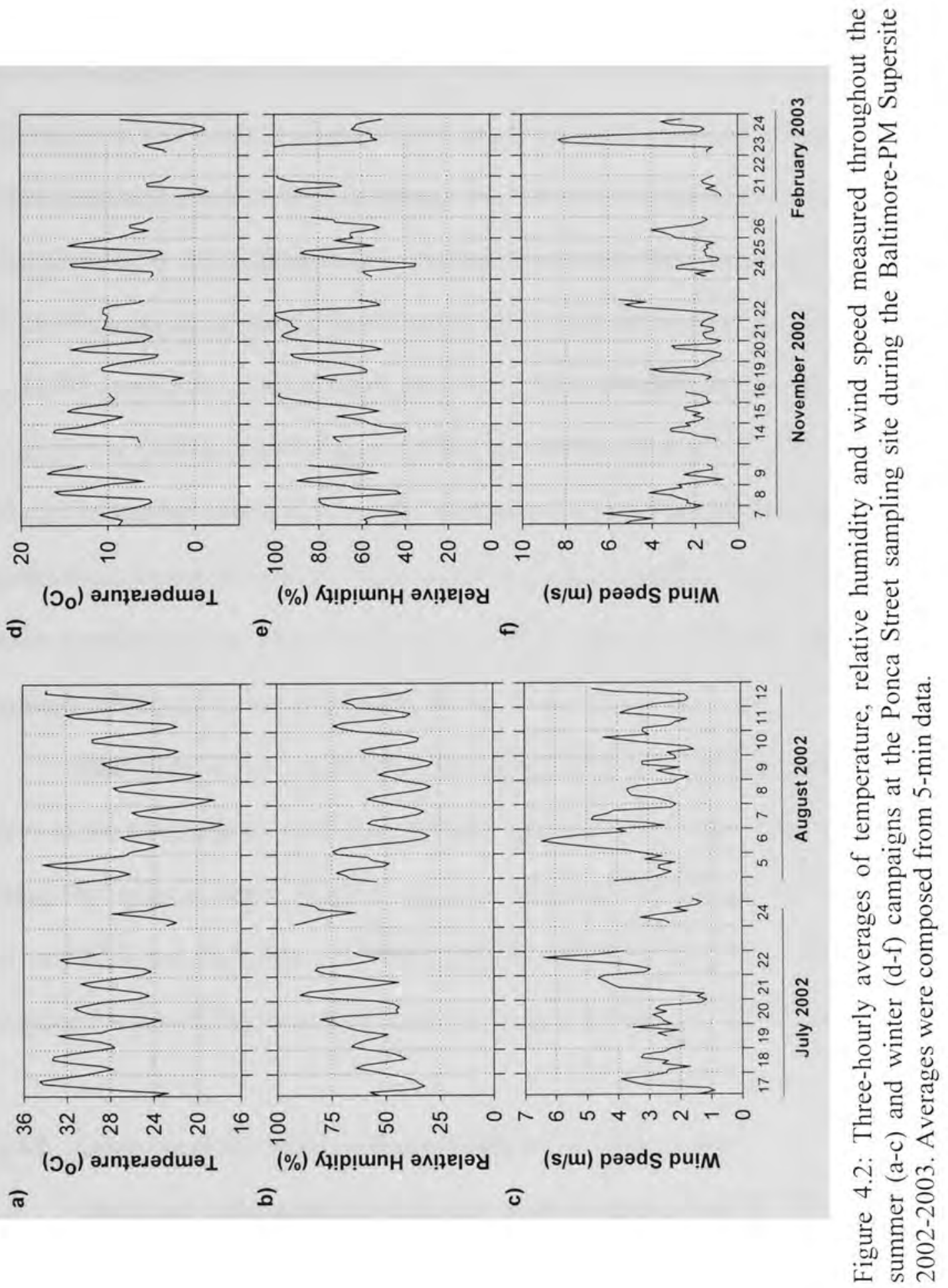


The summarized 3-hourly wind data is included in Figure $4.2(\mathrm{c}, \mathrm{f})$ to illustrate the few days in which the local wind speed was clearly higher, 21-22-July and 6-7-August during the summer, and 22-November, 23-February in the winter. Complete surface wind direction and speed data at original 5-min resolution (Appendix B) indicates that a typical wind direction pattern of bay sea "breeze" was observed on several days. This pattern is characterized by wind direction from the northeast at time 00:00, then gradually shifting clockwise to reach, on most days, the southeast or south direction by sampling time 09:00 or 12:00. During the summer, this pattern was observed clearly only on day 17-, but also on days 21-, 24-July, and 9-August; during the winter, on days 19-, and partly on days 22-, 25-November and in February. In order for a local air flow pattern of bay sea breeze to develop, is required that no strong weather system is present. Therefore, on the days when circulation is not observed, it can be assumed that the local wind pattern was more strongly influenced by the larger scale winds.

Brief gaps in the continuity of sampling were due to interruptions during rainy days at the sampling site and only once for preventive maintenance (03:00, 06:00 19July). During the summer campaign, about $10 \mathrm{~mm} / \mathrm{h}$ of rain was recorded on the evening of July $23 \mathrm{rd}$ and light rain $(0.5 \mathrm{~mm} / \mathrm{h})$ on the evening of July 24 th. Winter sampling stopped due to very light rains $(0.1 \mathrm{~mm} / \mathrm{h})$ through November $11,12,16$, and 17 .

\subsubsection{Long-range Air Masses: Hysplit Backward Trajectories}

Backward trajectories for each day of the sampling periods were computed in order to identify the origin and pathways of the air parcels arriving at the sampling site. These simulations were performed using the HYbrid Single-Particle Lagrangian 
Integrated Trajectory (Hysplit-4) model developed at the National Oceanic and Atmospheric Administration-Air Resources Laboratory (NOOA-ARL) (Draxler, 1994), Runs were carried out using the model archived wind field EDAS data.

Multiple trajectories were calculated ending at several heights, $50-2000 \mathrm{~m}$, at the sampling location. In addition, a variable number of trajectories over a period of 72 hours ending at different times of a given day were also calculated, and some were computed backward and forward to check accuracy of source location. Results were very consistent, which greatly increases the confidence in the predicted sources regions. In addition, these exercises proved that for most days, particularly those of the month of July bestscenario situations: unchanging path for the last 24-hour and under a high pressure system, as we shall see later, essentially it does not matter how many trajectories or at what height they end. For uniformity, the final set of daily trajectories for analysis was computed ending at $500 \mathrm{~m}$ as recommended by Kleiman et al. $(2000,2002)$ for trajectory analysis of potential source regions affecting air quality in the mid-Atlantic states of the U.S. A recommendation based on optimization analysis, as at lower altitudes trajectories would be interfered by surface features.

In order to display in a simple format the succession of the different regimes affecting contiguous days, and to give a comparative view of their interaction with the local atmosphere, an "intrusion" diagram was built for each season. The procedure followed to build these diagrams is explained in detail in Appendix C. Here, definitions and important details are summarized. Each backward trajectory run yields a map and a numeric file named the "endpoints file". This includes information of height of the air mass and depth of the mixed layer at each point of the trajectory. Intrusion was calculated 
by subtracting the depth of the mixed layer from the height of the air mass at each point of the trajectory. The notion is that if the result is a positive number this means that the mass passed over the point but did not interact with the local atmosphere; on the other hand negative numbers results indicate intrusion of the air mass into the local atmosphere. The final intrusion diagrams for the summer and the winter sampling periods are presented in Figures 4.3 and Figure 4.4, respectively. Figure 4.5 shows the trajectories paths sketched on a U.S. map for easy reference to the geographic regions.

Figure 4.3 indicates that the month of July was largely dominated by air masses originated from the west. It is noteworthy that the "northwest" trajectory in this diagram refers to a long and persistent path. For example, for the first sampling day, 17-July, Hysplit predicts a bundle of trajectories, originating three days earlier from the Great Lakes area and traveling on a consistent path from the northwest through Michigan, Ohio and the middle of Pennsylvania for three-four days prior to reaching the sampling site. This is known, because the same trajectory appeared in the runs of the successive three days with very little change in the path. Along the way, a "west" trajectory follows for the first three days; afterwards the west regime is still present, but other parcels also arrive from the "south" and the "east". The "eastern-mixed" refers to a path shown to originate in New Hampshire, move outward over the ocean and enter Maryland from the south. The air masses originating from the western side which persistently traveled the long distances $(\sim 1,200 \mathrm{~km})$ on a consistent path are likely to display relatively greater characteristics of processed/aged aerosol.

The "northwest" trajectory is not seen in August, only the "west" ones are observed at the beginning and at the end of the sampling period. The "longer" traveling 


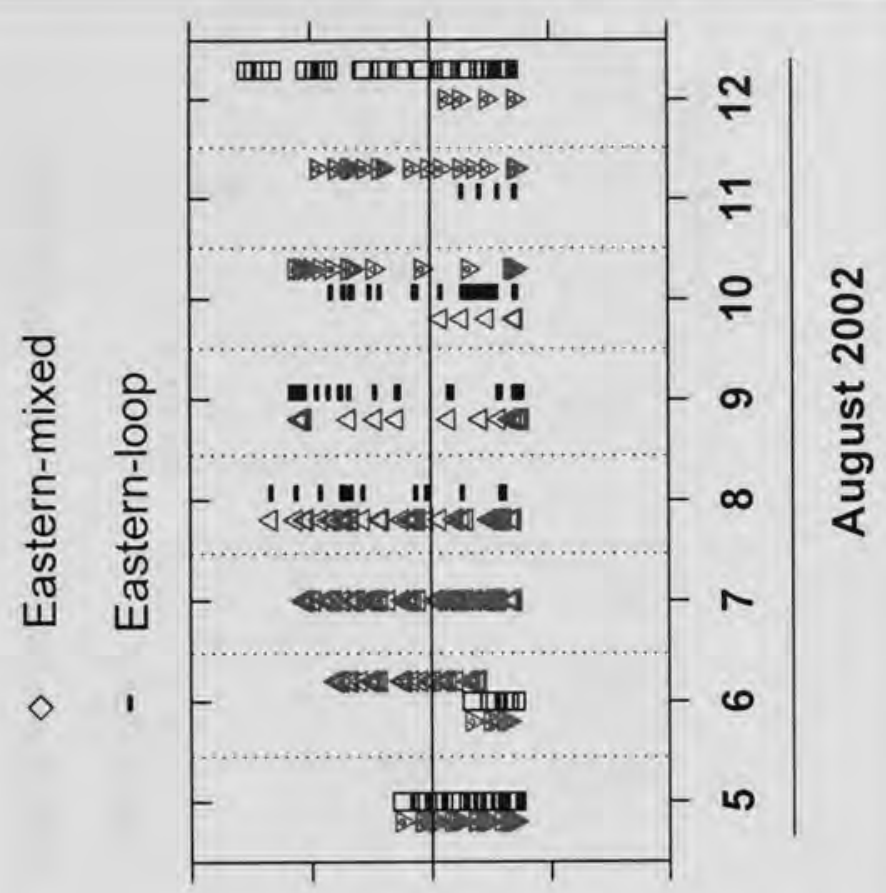

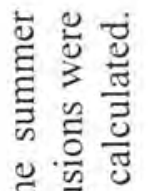

$\stackrel{5}{2}$

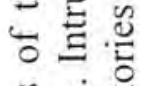

事

元要

I 8

클

엘체

至 is

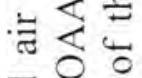

믈

范号

䒕 吾

पँ

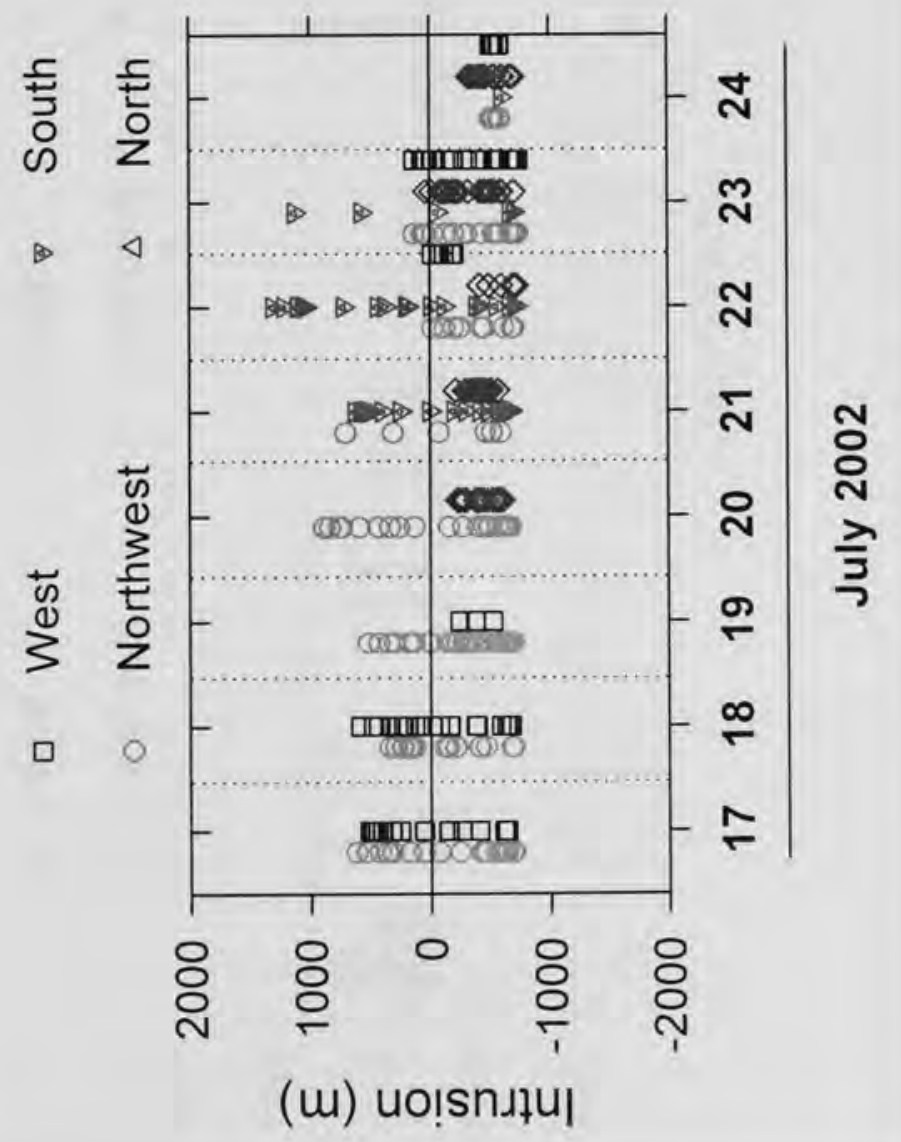

ญ ह

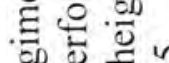

का एँ

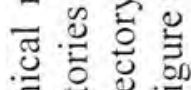

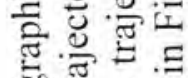

का एँ

क्ष

का हू ह

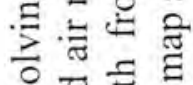

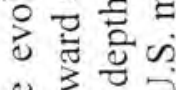

는

on $\frac{\pi}{0} \cdot \Xi$

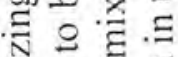

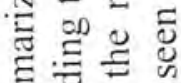

ఏ잉

ฮ

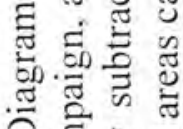

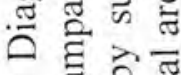

ㄱ. तु

भ 00 귤

플

$\exists$ 글

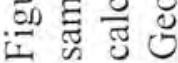



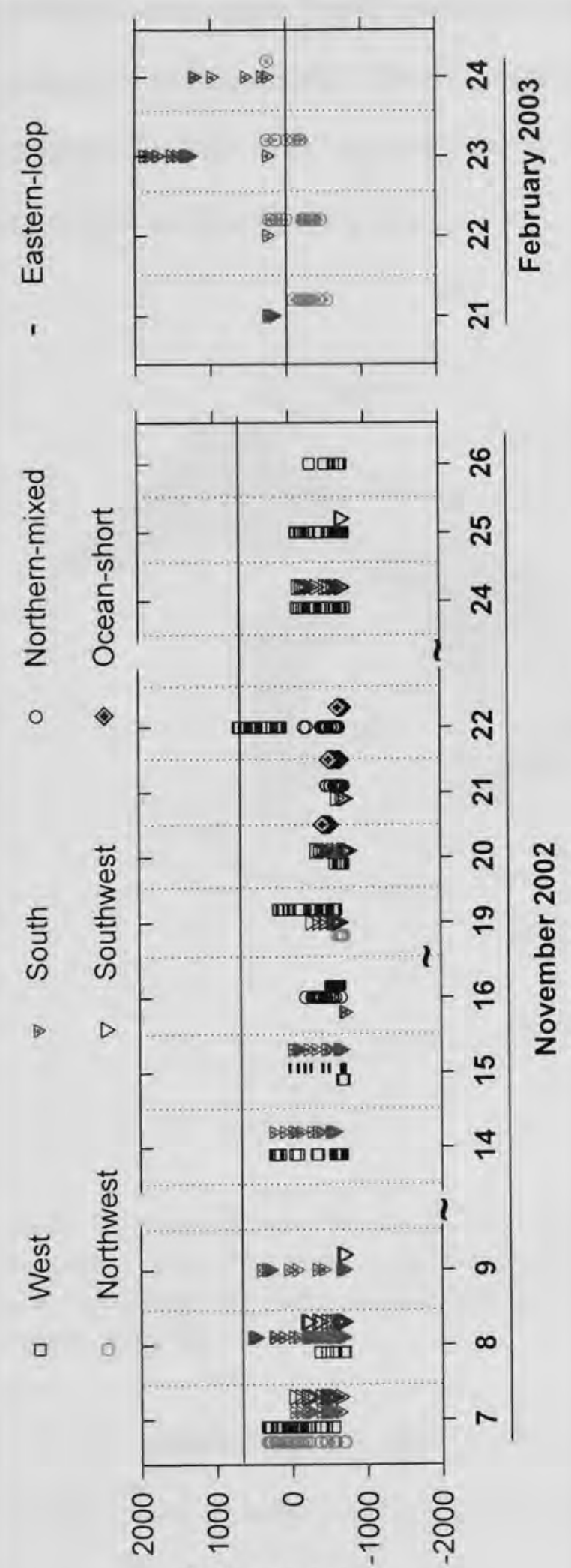

(u) uo!̣snıu|

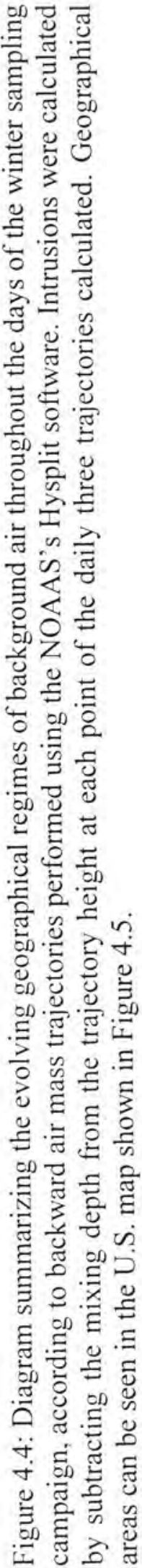


parcels are those on the "north" path from Canada and through the relatively less polluted eastern side of Pennsylvania. The other influencing parcels for this period of the summer campaign travel are more "regional"; that is, by comparison, they travel shorter distances of the order of $200-400 \mathrm{~km}$ or less.

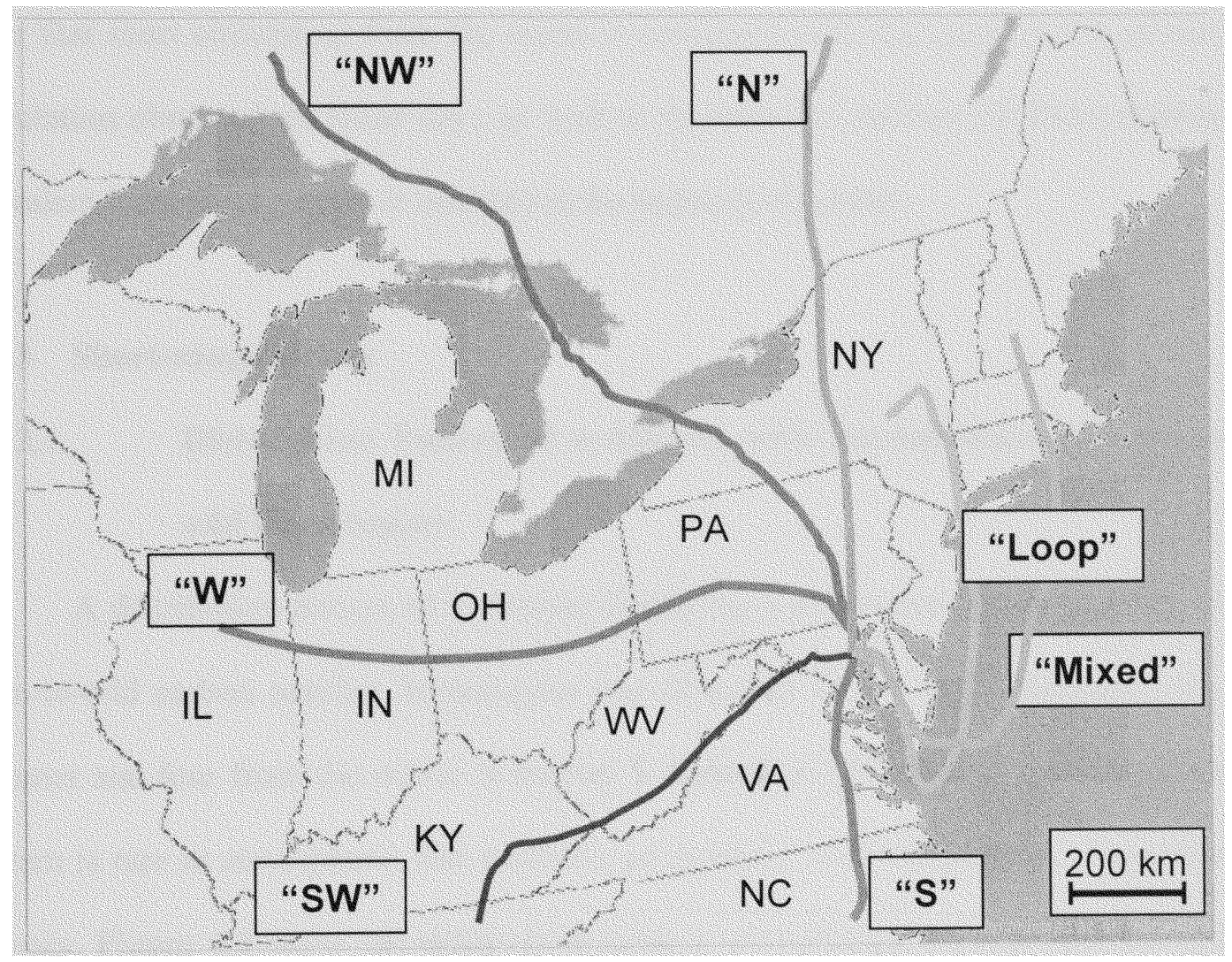

Figure 4.5: Map of the U.S. northeastern region and the Great Lakes showing sketches of the central path of the various regimes of air masses arriving at the Ponca Street sampling site, according to backward trajectories calculations performed using the NOAA's Hysplit software.

In contrast to the summer, the winter diagram (Figure 4.4) shows an appreciable smaller spread of vertical points for the trajectories, with the exception of the beginning of November. The spread of the vertical points is determined by the spread of the 
intrusion values. Less spread is simply related to the lower mixing height during wintertime and the consequent hindered vertical motion. The numbers indicate two things: strong intrusion is possible in the wintertime and paths are shorter. The prevalent local wind direction (graphs available in Appendix B) indicate that the near surface-wind pattern was aligned with the long-range winds mainly between 7- and 15-November, after that short circulation from the ocean is consistent with the local pattern of sea bay circulation observed on those days as well as in February, and on 25-26-November the prevalent local wind pattern is oriented in the opposite direction.

\subsubsection{Short-range Events}

\subsubsection{Distribution Pattern of n-Alkanes with Predominance of even-over- odd Homologues}

A distribution pattern of $n$-alkanes displaying a pronounced predominance of the even-to-odd carbon number homologues was observed in ten of the samples from the summer and four from the winter (Chapter 3, section 3.3.2.1). This type of distribution pattern is rare in atmospheric fine particles, particularly with the absence of branched nalkanes. Figure 4.6 show the distribution pattern of n-alkanes for one selected sample together with the wind direction/speed frequency plot corresponding to the 3-hourly period during which the sample was acquired.

In the literature we only find one reporting of a similar pattern. Simoneit et al. (2005) have characterized the organic emission profile of smoke particles (PM 10) sampled from the open-fire combustion of new polyethylene plastic bags as well as several roadside and landfills test samples containing polyethylene plastic bags. Their 
study found that the GC/MS of the extracts from polyethylene plastic bags displayed only even-carbon n-alkanes in the range $\mathrm{C} 16-\mathrm{C} 40$, and the spectra of the smoke produced from the burning of the plastic bags consisted of n-alkanes series from $\mathrm{C} 20$ to $\mathrm{C} 40$ with a strong predominance of the even-carbon-number homologues. Further, the even-to-odd predominance was also observed in the smoke from the open burning of road side and landfill trash. Authors theorize that the prevalence of even- number n-alkanes in the chromatograms of the smoke from open-burning of refuse containing the plastic can be explained as originating from stripping or direct volatilization from the plastic material.

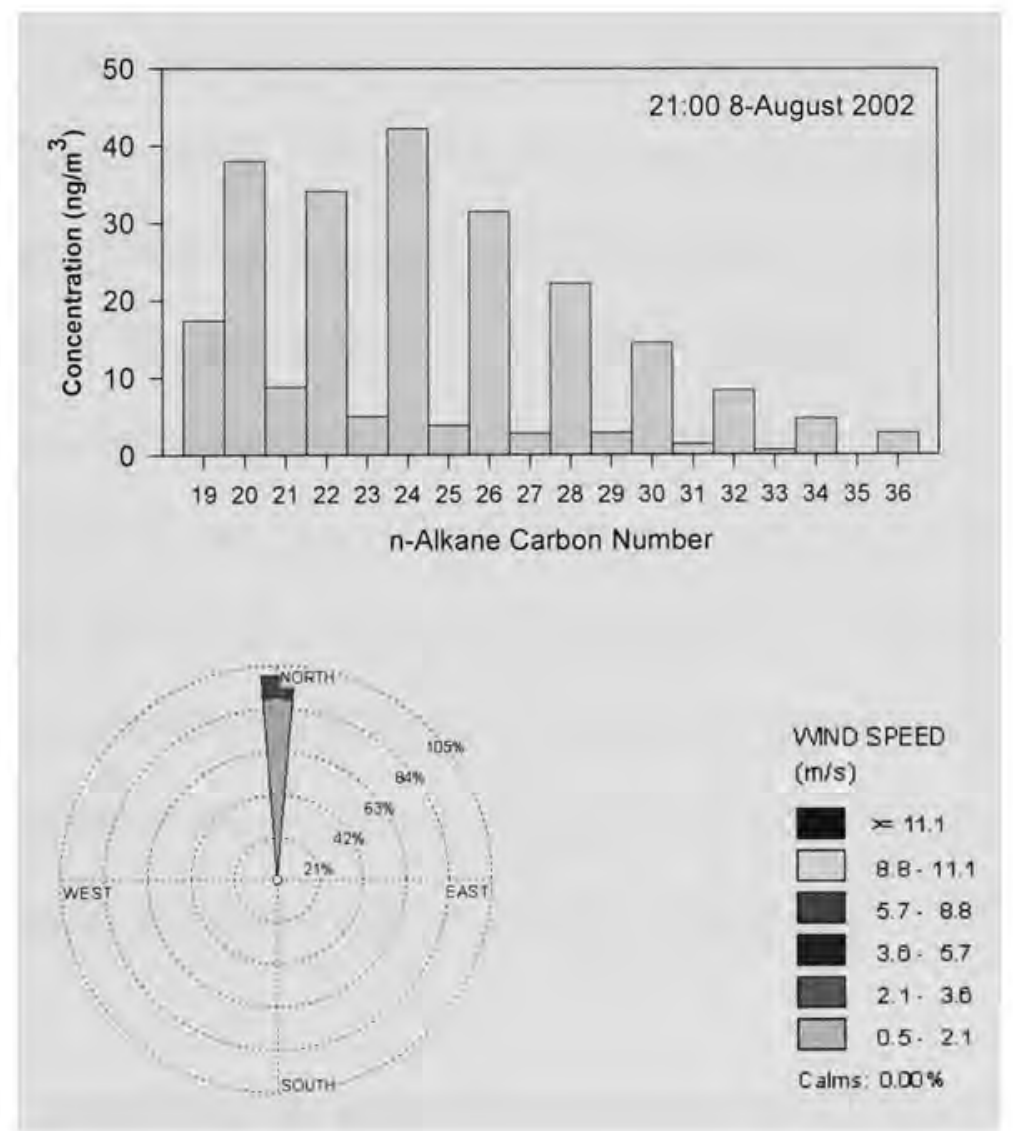

Figure 4.6: Distribution of n-alkanes in sample 21:00 8-August 2002 and wind direction/speed frequency for this time period. 
That is, pyrolysis of polyethylene produces random depolymerization generating both odd-and even-carbon n-alkanes and this mixture is "diluted" by emissions from the direct volatilization of polyethylene which, as indicated above, is enriched in even homologues that can be observed up to $\mathrm{C} 40$ by GC/MS. In addition, smoke samples were found to be characterized by considerable amounts of tris(2,4-di-tertbutylphenyl) phosphate (tbPO4), an oxidation product of the anti-oxidant Irgafos 168 (tris(2,4-di-tertbutylphenyl)phosphite), and the presence of 1,3,5-triphenylbenzene (TPB), a PAH compound that had already been previously observed in the exhaust of incinerators burning plastic materials (Tong et al., 1984).

In order to test the hypothesis that episodes displaying a marked even-to-odd nalkanes predominance pattern in the Baltimore ambient samples may be associated to events of burning of refuse containing polyethylene materials, we searched and quantified the organic markers TPB and tbPO4 in each of the 238 Baltimore samples. Due to the unavailability of authentic standards for these compounds, the species were located in the chromatograms based on their reported kovatz index (Simoneit et al., 2005). For positive identification the mass spectra fragmentation pattern for 1,3,5-triphenylbenzene was compared to that of the Wiley and NBS75K mass spectral libraries, while for tbPO4 the pattern was compared to the one given in Simoneit et al. (2005). Response factors were assumed to be equal to those of indeno[c,d]pyrene and coronene, for TPB and tbPO4 respectively.

Figure 4.7 shows the time series of the concentrations of TPB and tbPO4, as well as the ratio of the concentration of the even-to-odd carbon number n-alkanes. The compound TPB was identified in all the samples (Figure $4.7 \mathrm{a}, \mathrm{c}$ ). The concentrations in 
a)

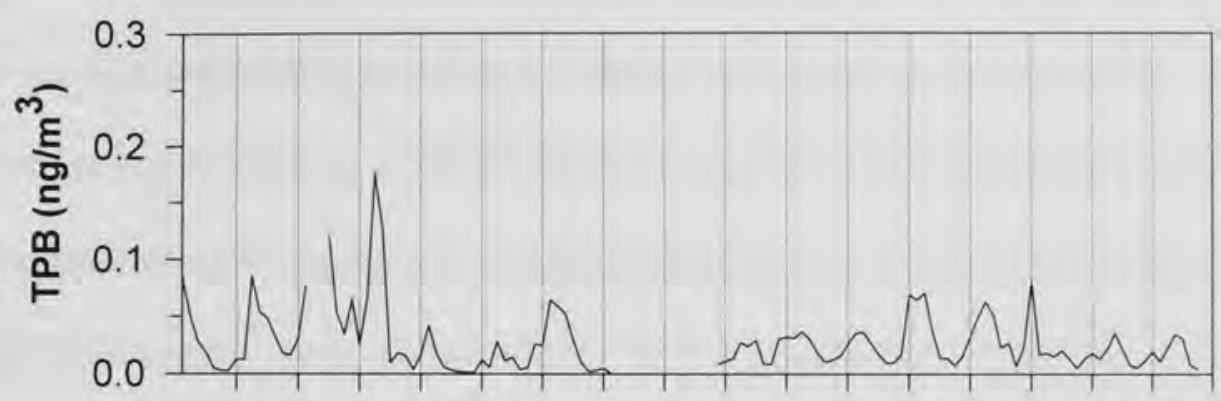

b)

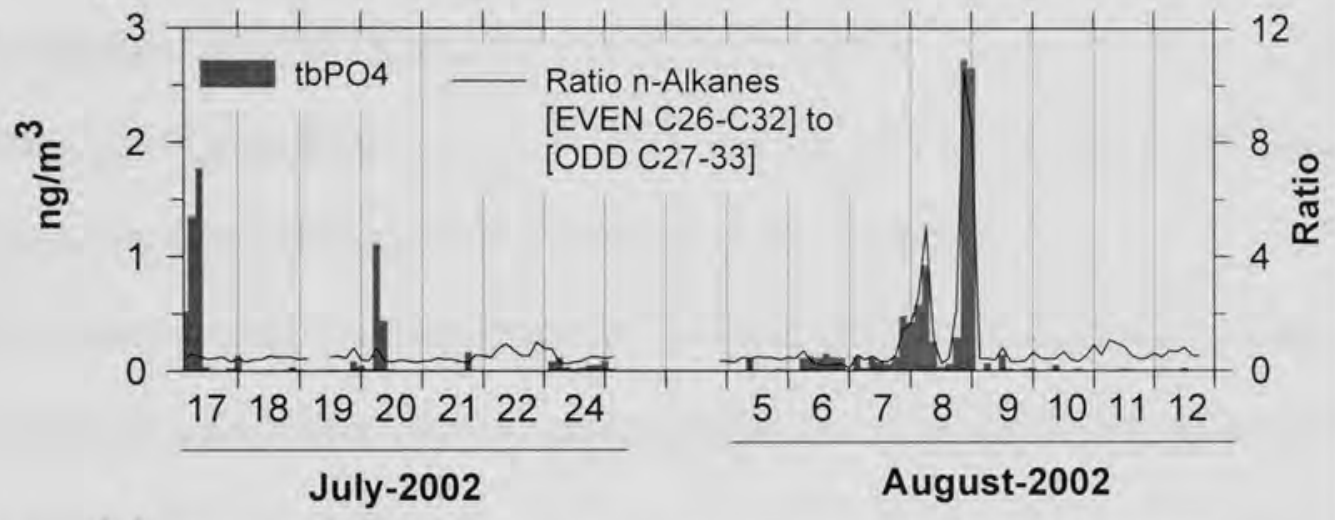

c)

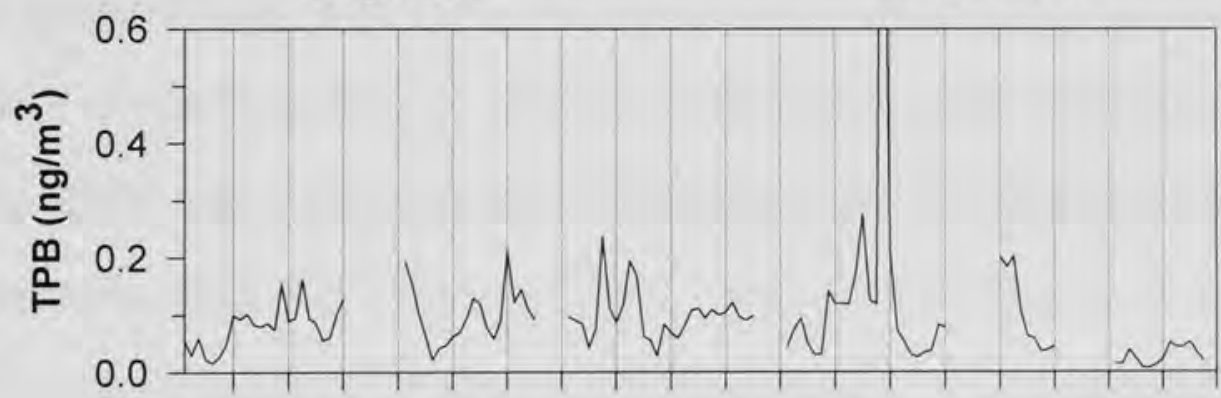

d)

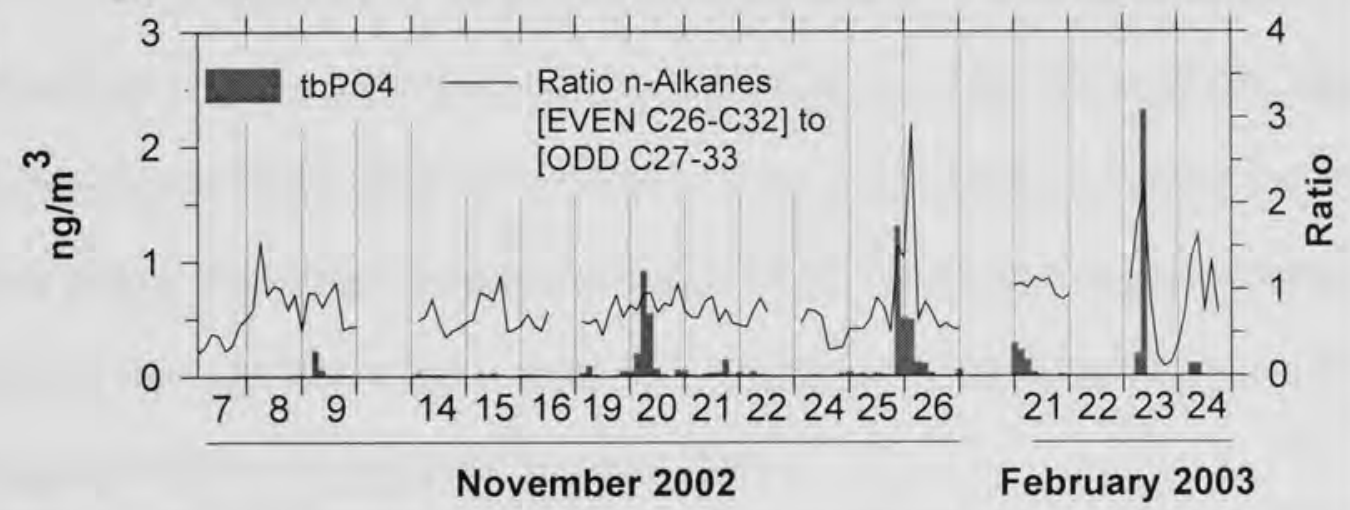

Figure 4.7: Time-series of the three-hourly concentrations of selected molecular markers for burning of plastic materials in waste incinerators and open-burning conditions, and ratio of even to odd high molecular weight n-alkanes (range C26-C33) in summer $(\mathrm{a}, \mathrm{b})$ and winter (c,d) samples. TPB=1,3,5-Triphenylbenzene, tbPO4=tris $(2,4-\mathrm{di}-$ tertbutylphenyl)phosphate. 
the winter samples are approximately two times larger than in the summer. The 3 -hourly variations show a remarkably consistent diurnal cycle, particularly during the summer, with maximum concentrations at 03:00 and minimum at 15:00. On the other hand, the tbPO4 was detected at levels close to detection limit in most samples with the exception of sporadic high concentration peaks in four different occasions $\left(1.1 \mathrm{ng} / \mathrm{m}^{3}\right.$ to $\left.2.7 \mathrm{ng} / \mathrm{m}^{3}\right)$ during the summer, and three during the winter $\left(0.92 \mathrm{ng} / \mathrm{m}^{3}\right.$ to $\left.2.3 \mathrm{ng} / \mathrm{m}^{3}\right)$. The lack of overall association between the trends of TPB and tbPO4 was at first unexpected; however, based on premises found in the literature is not a surprising result.

The literature work available about the characterization of semivolatile products of the pyrolysis of polyethylene plastics, indicate that TPB can be specifically associated to burning of polyethylene under closed conditions. For example, the work by Tong et al., (1984) which specifically describe fly ashes from municipal incinerator and most recently Font et al., (2004) studying the pyrolysis of polyethylene in a laboratory scale furnace, report identifying TPB. The compound tbPO4 is the oxidation product of a plastic antioxidant additive tris(2,4-di-tert-butylphenyl)phosphate (Irgafos 168) specifically used in the production of plastic and rubber material (Wright et al,, 1996). Observation of the plastic antioxidant oxidation product tbPO4 and of the particle-phase n-alkanes with a distribution pattern displaying strong predominance of the even-carbon homologues has been reported only for the open burning of polyethylene plastic and mixed trash containing polyethylene material (Simoneit et al., 2005).

In striking contrast to open burning, burning in a reactor or incinerator takes place under conditions of high turbulence and stable/controlled high temperatures; therefore, the aerosol produced under these burning conditions is not expected to either present 
tbPO4 nor to display a carbon-number preference for the distribution of n-alkanes. These two features would only be present in the aerosol produced under open burning conditions. As explained above, the pyrolysis of polyethylene produces random incision of the starting polymer; hence the predominance of even-number carbon n-alkanes in the smoke is imprinted by the stripping/volatilization of the plastic's oligomer units.

Therefore, the first conclusions that can be made from our results is that for most of the summer and winter data, the highly regular diurnal variations of TPB concentrations suggest a pattern which is consistent with regular input from distributed incinerator sources regularly burning inputs containing plastic polyethylene materials. There are dozens of such facilities in Baltimore, located from $20 \mathrm{~km}$ to $100 \mathrm{~km}$ from the sampling site, including municipal waste-to-energy facilities and medical waste incineration. In contrast, the intermittent variation of concentrations observed for tbPO4 is indicative of event situations or plumes corresponding to open burning of plastic containing material/wastes.

All the observations of tbPO4 in the summer and the winter are associated with wind blowing from the north direction. The signals are never seen when the local wind blows from the south. This is shown in Figure 4.8 (expanded version in Appendix C, Figures C.21 and C.22). Sometimes the signal of the tbPO4 is observed but the distribution of the n-alkanes does not display a strong predominance of the even-number carbon homologues. Assuming that the n-alkane pattern and the tbPO4 are both associated to the same source, a plausible explanation is that the tbPO4 is more sensitive than the detection of the n-alkane pattern and; furthermore, the peculiar distribution of the $\mathrm{n}$-alkanes is an indication of the specific presence of unburned plastic oligomers; that is, 
a)

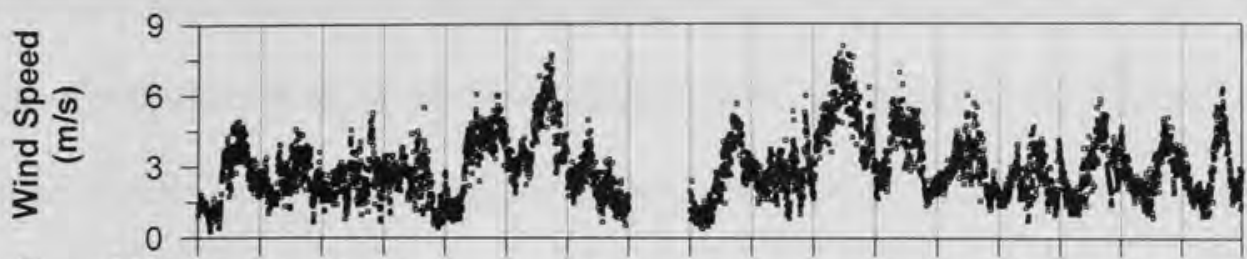

b)

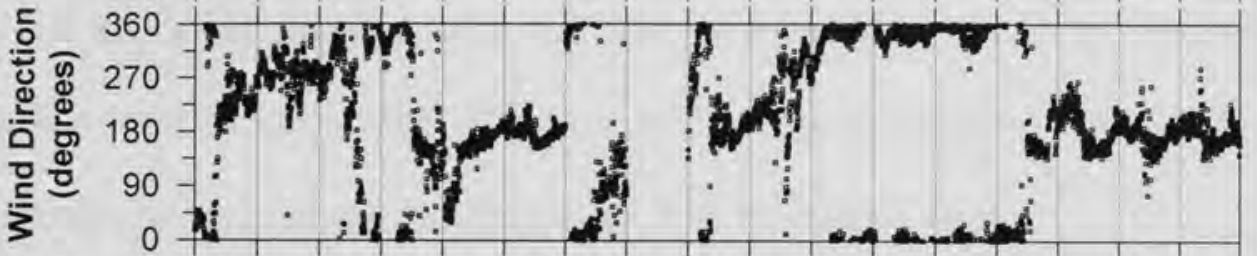

c)

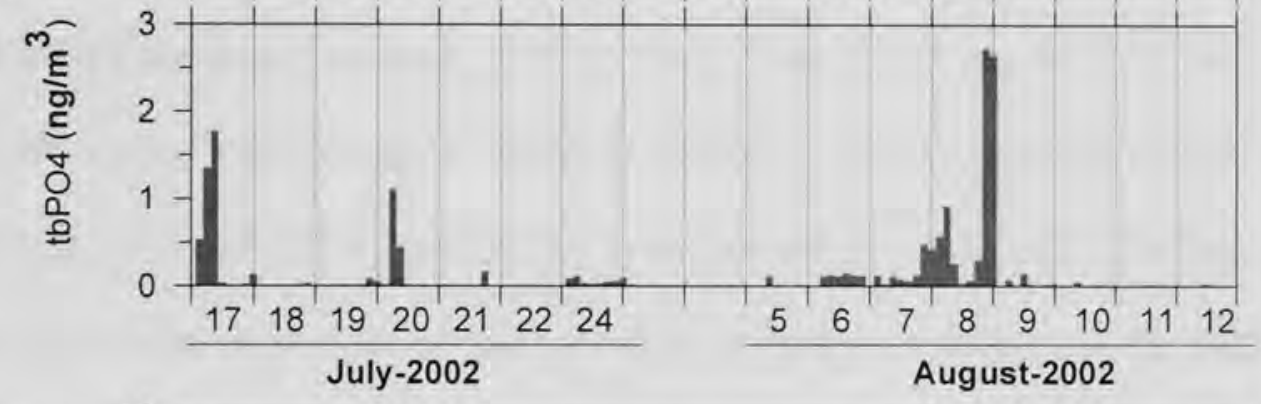

d)

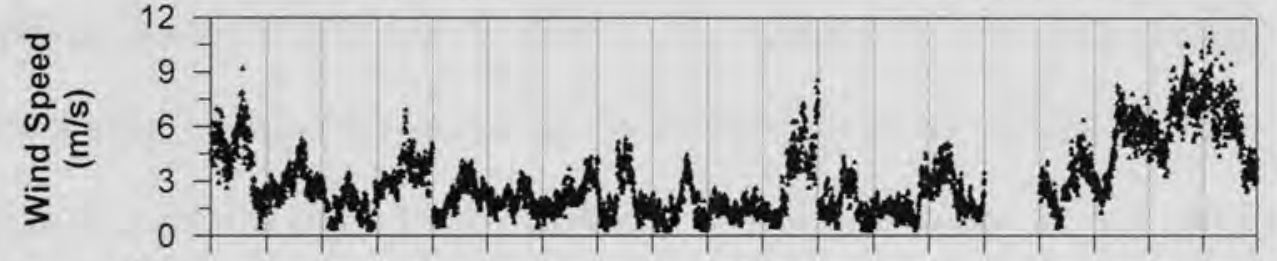

e)

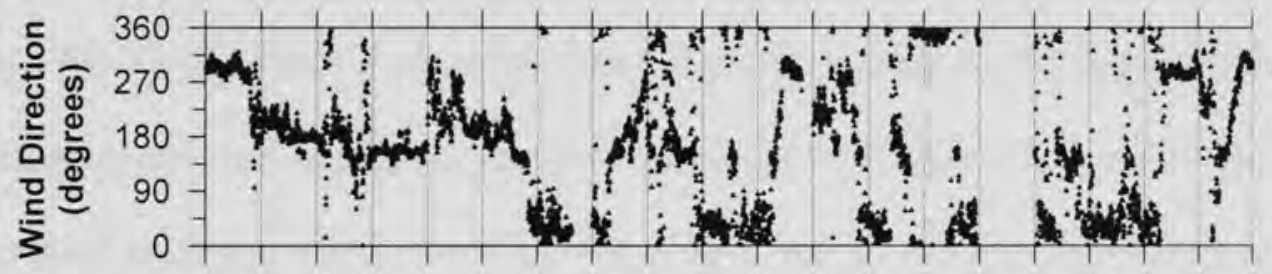

f)

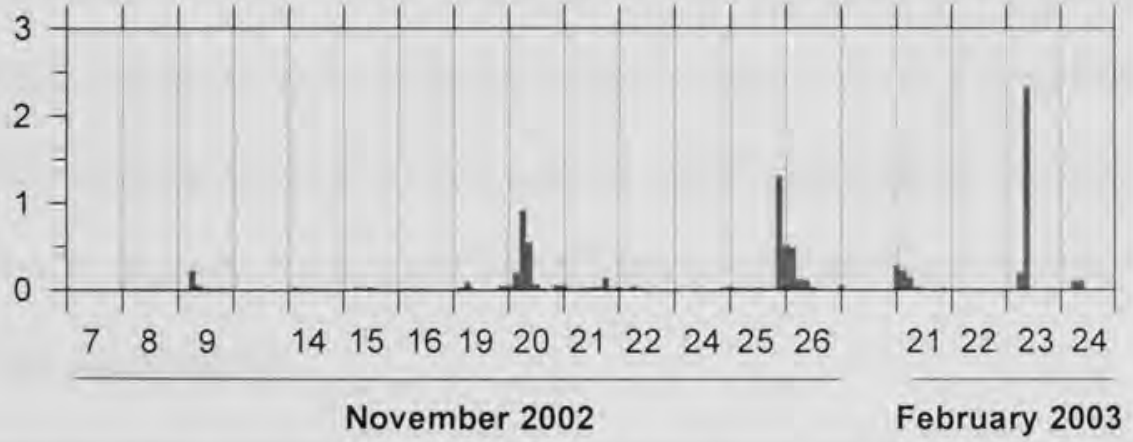

Figure 4.8: Time-series of the three-hourly summer (c) and winter (f) concentrations of tris(2,4-di-tertbutylphenyl)phosphate (tbPO4), a molecular markers for open burning of plastic materials and corresponding wind speed (a, d) and direction $(b, e)$. 
if the volatilized fraction is minor, then the pattern would be masked by the prevalence of the opposite distribution pattern of the n-alkanes from the biogenic background. The strength of the signals and the uniformity of pattern observed in the evenings of 7 - and 8August can be explained based on the combination of constant northerly wind influx from 03:00 6-August through 09:00 9-August, and the poorer dispersion caused by the low wind speeds $(2-3 \mathrm{~m} / \mathrm{s})$ on the evening of day 7-August and 8-August.

Interesting scenarios are seen on 06:00 23-February 2003 and 25-26-November 2002; a closer view of these events is shown in Figure 4.9. On 23-February (Figure 4.9 c), wind speeds were high $(-5-6 \mathrm{~m} / \mathrm{s})$ and the wind changed direction fast; therefore, it is likely that only a draft was sampled yet the signal of tbPO4 is strong and the ratio of even-to-odd n-alkanes (C26-C33) is fairly large (Figure $4.7 \mathrm{~d}$ ) even though the distribution pattern of the n-alkanes is not so strong (Figure $4.9 \mathrm{c}$ ), possibly due to a combination of short waft and a larger fraction of waxes from plants on the background of that day. The usual odd-to-even predominance in the patterns of the high molecular weight n-alkanes emerges rapidly in the next two samples (Figure $4.9 \mathrm{c}$, inset). On the night of 25-26-November, within just three hours, the strength of the n-alkanes pattern is also seen to evidently change in two contiguous samples (Figure $4.9 \mathrm{a}$, b). It becomes unambiguous that the peculiar n-alkane pattern and the tbPO4 signal peaks, whether the effect from the same or separate sources, are specifically associated with wind blowing from the north of the sampling site.

The strongly localized and relative frequent observations of the organic markers, tbPO4 and even-predominant n-alkanes, suggest that they are not caused by a random event, and instead, they may be associated to rather regularly occurring activities. Some 
a)
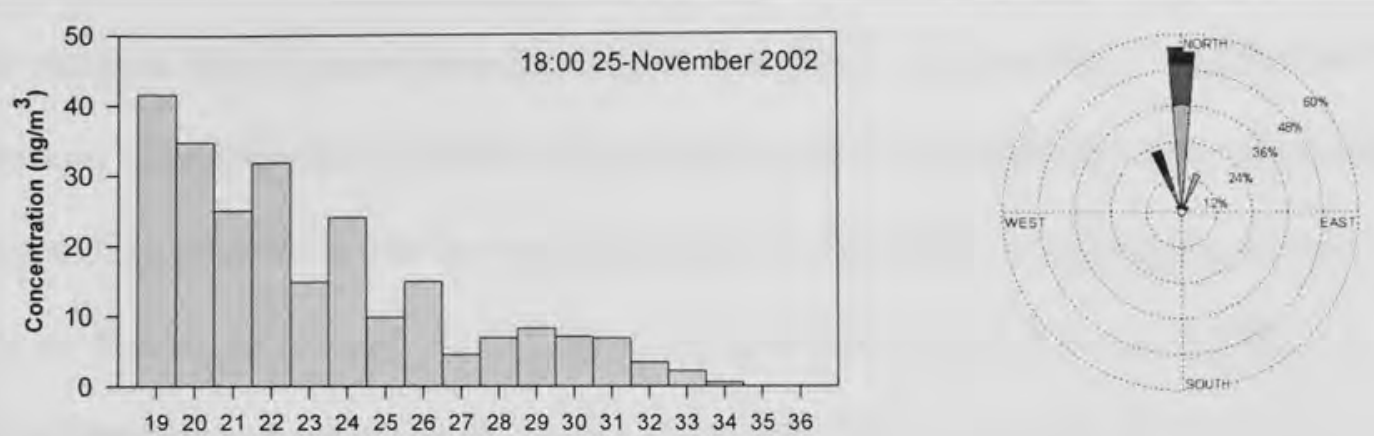

b)
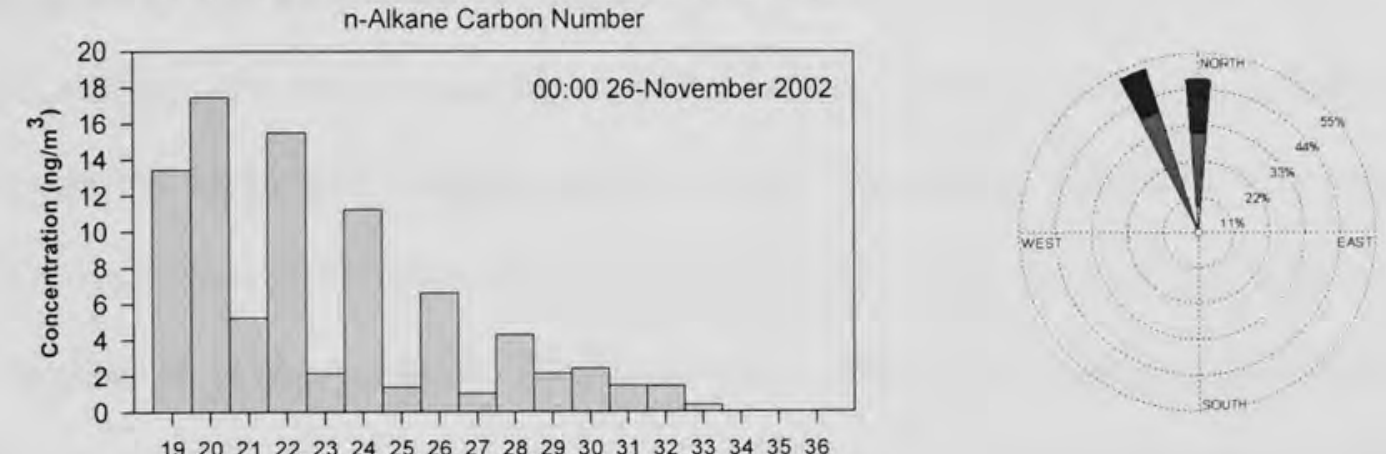

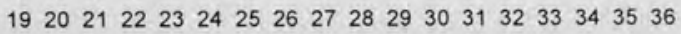
n-Alkane Carbon Number

c)
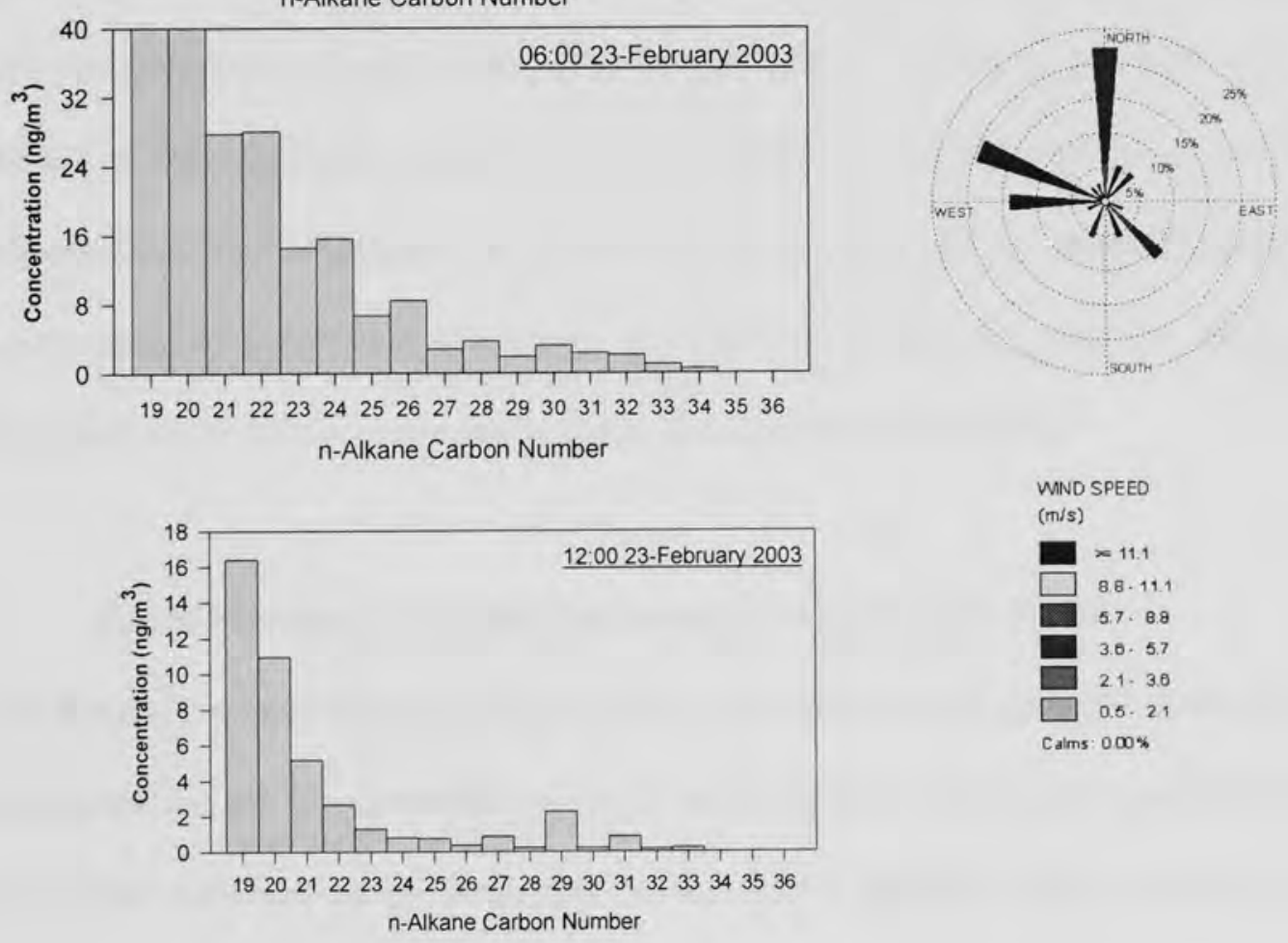

Figure 4.9: Distribution of n-alkanes in three different samples: 18:00 25-November and 00:00 26-November 2002, and 06:00 23-February 2003. Wind direction/speed frequency for each sample is shown. 
possible sources may include open burning at dumpsites, or burning of agricultural polyethylene. The latter is a possibility for several reasons. The majority of the farmland in Maryland is located in the north-central part of the State including the northern sections of Baltimore County. According to the Maryland Department of Agriculture, agricultural activities account for the largest single land-use in Maryland, with 2,100,000 acres, or roughly $33 \%$ of total land area used for farming. The ubiquitous use of plastics also covers the agriculture industry where the term "agricultural plastics" refers to a variety of types used for different purposes. Agricultural activities frequently result in the open burning of plastic materials (Lemieux et al., 2004). Low density polyethylene (LDPE and LLDPE) film is typically used to package or wrap silage and hay, to make bunker silo and greenhouse covers, bale wrap, mulch film, and other applications that require the use of flexible plastic material. For these reasons, is possible that the markers may be associated to such widespread activities. Studies aimed at precise characterization of this source category are needed in order to establish their quantitative effect on levels of PM2.5 as well as the levels of specific organic species associated with it.

\subsubsection{Early Morning Vehicular Emissions Events, 03:00 to 06:00}

The 3-hourly concentrations of hopanes exceeded the average plus two times the standard deviation of all the measured values in each season's set a few times. These occurrences were observed more frequently in the 03:00 samples. Figure $4.10(\mathrm{a}, \mathrm{c})$ illustrate this observation. The wind direction/speed frequency plots for the samples marked in Figure 4.10 are presented in Figure 4.11. These plots show that in four cases (1-4, Figure 4.10), the 03:00 measurements were strongly associated to wind blowing 
from a narrow span of directions in the southwest quadrant of the windrose (22-July, 5August, 12-August, 14-November). On the other hand, for 17-July and 9-August the wind roses $(5,6$ Figure 4.10$)$ indicate that the wind blew mostly from the north.

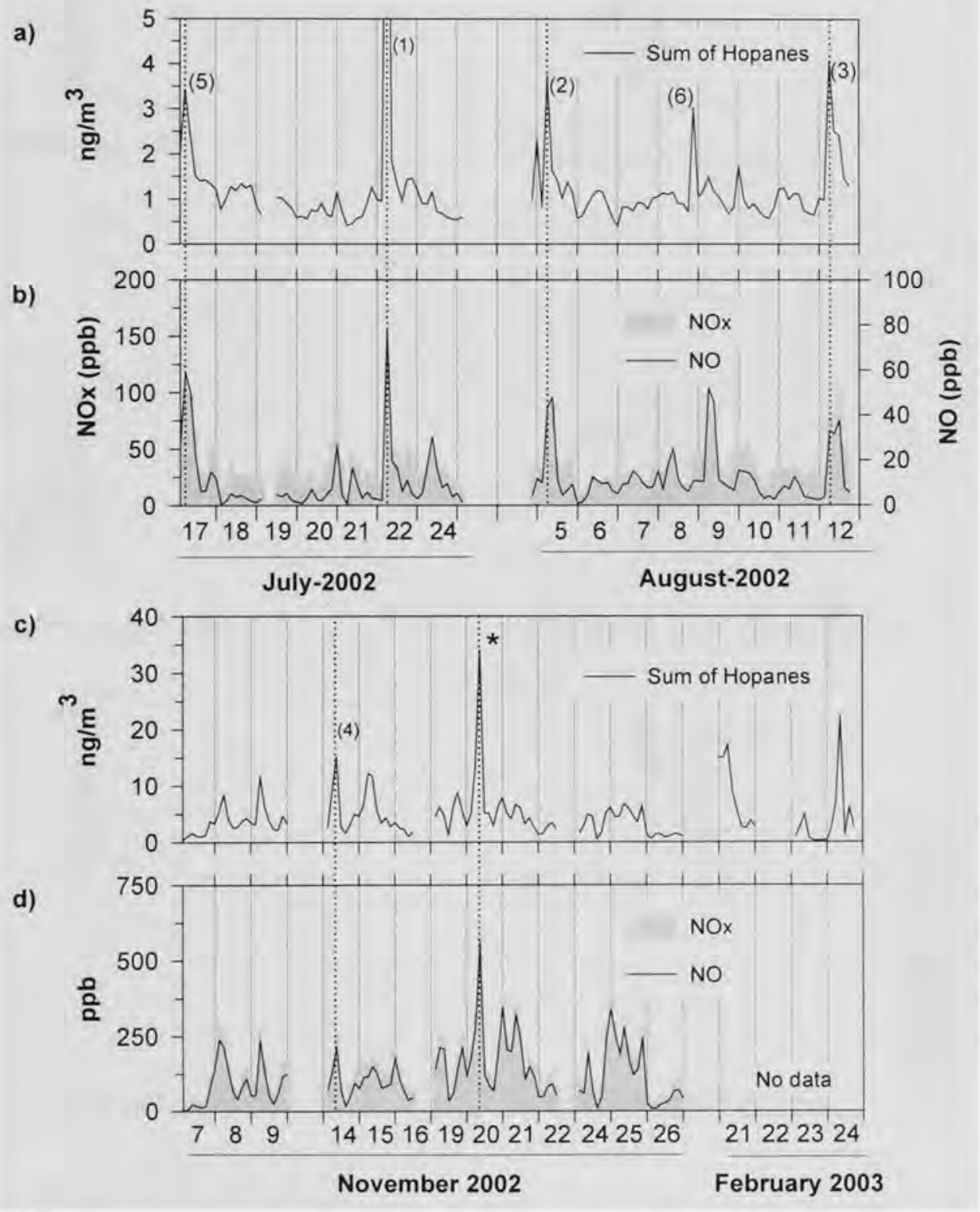

Figure 4.10: Time-series of the 3-hourly concentrations of the vehicular biomarker, Sum of Hopanes, and of NOx and NO measured in summer $(a, b)$ and winter (c,d) samples. Wind direction/speed frequency plots for the samples marked with a number are given in Figure 4.11. Expanded analysis of sample marked with $(*)$ is given in Figure 4.12. 


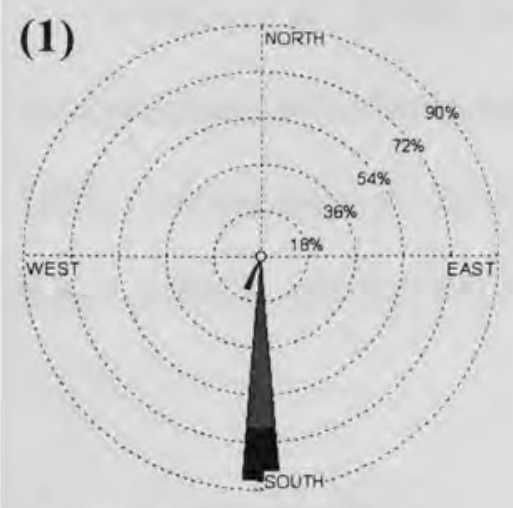

03:00-06:00 22-July 2002

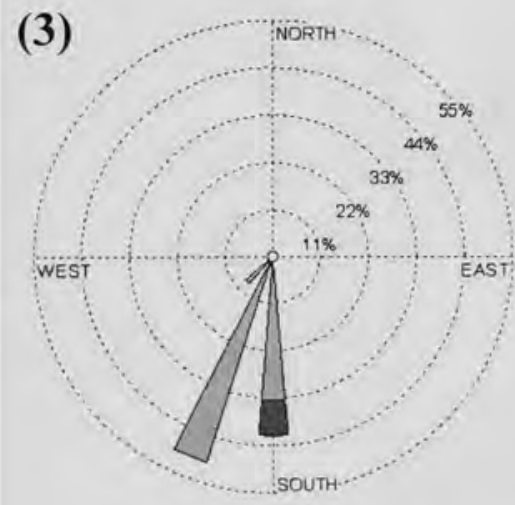

\section{3:00-06:00 12-August 2002}

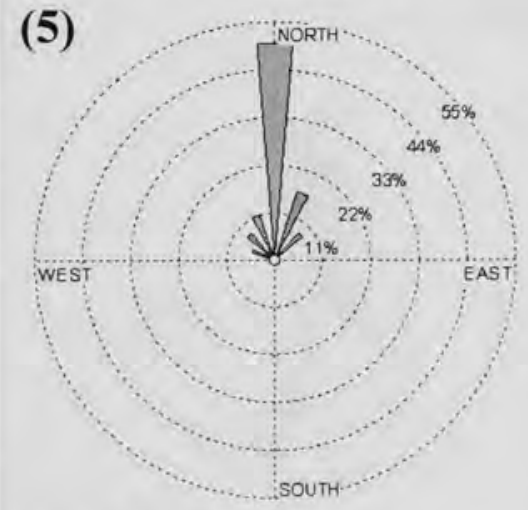

03:00-06:00 17-July 2002
(2)

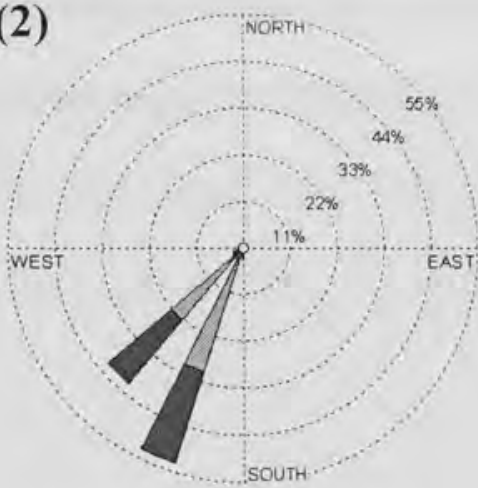

03:00-06:00 5-August 2002

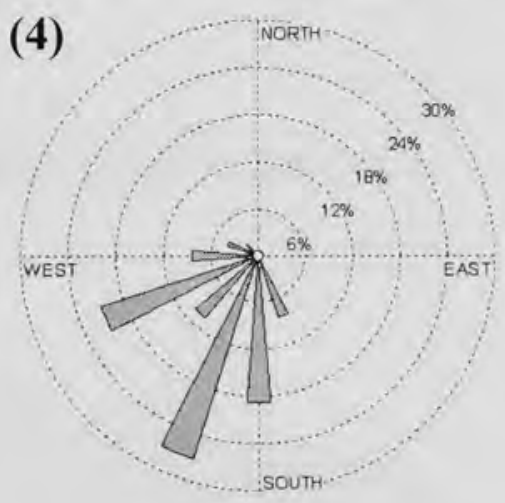

03:00-06:00 14-November 2002

(6)

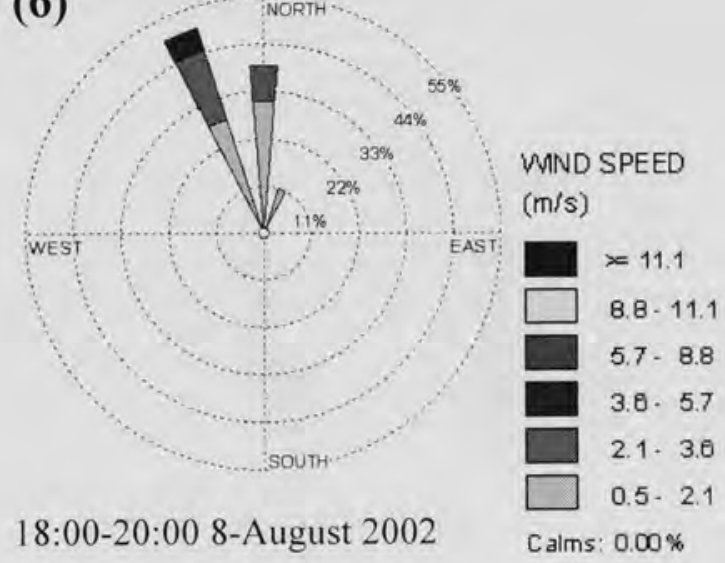

Figure 4.11: Wind direction/speed frequency plots for selected samples marked in Figure 4.10. The wind speed scale and calm winds projection applies to all frequency plots. Numbers (1) through (6) refer to numbers in Figure 4.10. 
Park et al. (2005) recently reported observing a short-term variation in their measurements of ambient nitrate at the Ponca street supersite location during the year 2002; concentration of nitrate and NOx were high when winds blew from the directions $0-60^{\circ}(\mathrm{I}-895 \mathrm{~N})$ and $150-220^{\circ}$ (MTA bus depot). Included in Figure 4.10 are the NOx and

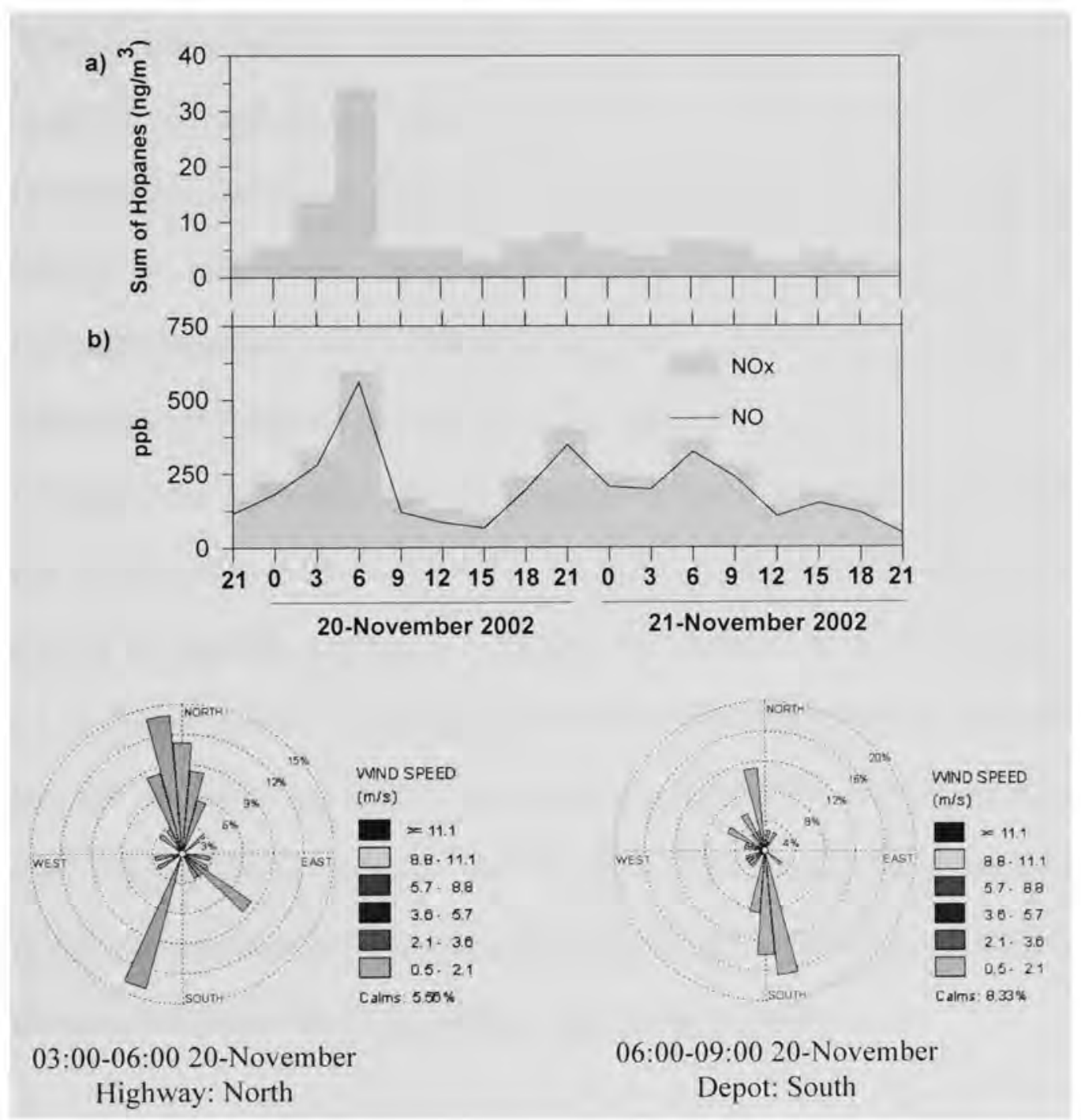

Figure 4.12: Three-hourly concentrations of the petroleum biomarkers, Sum of hopanes, and of the gas species NOx and NO. Expanded section from Figure 4.10 asterisk $\left(^{*}\right)$, showing from 21:00 19-November to 21:00 21-November. Wind direction/speed frequency plots shown for 20-November samples starting at 03:00 and 06:00. I895 location $0-60^{\circ}$; MTA bus depot $150-220^{\circ}$. 
NO data measured at the Ponca Street site concurrently with the samples of PM2.5 for organic characterization (summer, Figure $4.10 \mathrm{~b}$; winter, Figure $4.10 \mathrm{~d}$ ). It can be seen that all except one of the samples with high hopanes concentration also exhibits elevated concentrations of NOx and NO. Consequently, a strong influence by emission from the bus depot is a reasonable explanation for the high concentrations of hopanes observed in those specific 03:00 samples. The samples 03:00 17-July and 18:00 8-August, are associated with the north wind direction (Figure 4.10, 5, 6). Given the pattern of wind direction frequency, association of the high hopane concentration with traffic traveling on the highway is very likely. Interestingly, as shown in Figure 4.12 , the wind direction/speed frequencies on 20-November suggest that both the depot and the highway could have impacted the sampling site on that morning.

Finally, it is noteworthy that the samples with peak concentration of hopanes discussed in this section (Figure 4.10) display the percent proportion of hopanes which is characteristic of vehicular sources, as explained in section 3.3.2.4 and illustrated in Figure 3.11. Figure 3.11 indicates that these samples are transient points in the midst of all others that do not reflect the distinctive percent proportion of vehicular emissions. This result suggests that the intrusion and frequency of the regional background during most of July has a prominent influence on the characteristics of the measured PM2.5 and this influence is only override by the effect of nearby intense plumes.

\subsubsection{First Evidence of Local Diurnal Patterns: 6-August 2002}

The meteorological information presented in sections 4.3 .1 and 4.3 .2 indicates that the conditions prevalent on 6-August are as follows. A cold front had passed on the 
previous day, and the 7AM weather map (NOAA) for day $6^{\text {th }}$ shows Maryland on the back of the front. Hysplit runs show the northerly flow (lines " $N$ " in Figure 4.5) just beginning. With the exception of the first two sampling periods of the day, local winds were from the north and the wind speeds minimum/maximum were fairly high, $3-4 \mathrm{~m} / \mathrm{s}$ and $5-7 \mathrm{~m} / \mathrm{s}$, respectively.

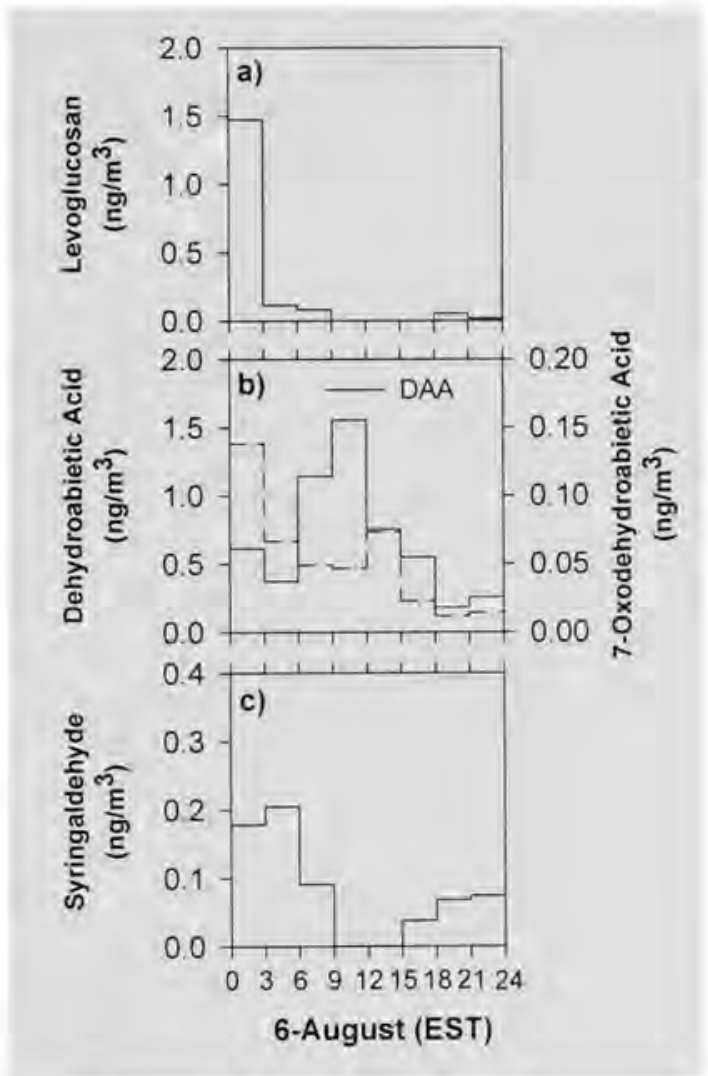

Figure 4.13: Three-hourly concentrations of biomass burning organic markers compounds measured in the PM2.5 sampled on 6-August 2002.

The diurnal variations of the biomass burning markers for this day, shown in Figure 4.13, indicate a low background level, with the exception of the residual signal of levoglucosan from the previous day, Otherwise, large daytime peaks of dehydroabietic 
acid were observed often during the summer, and based on the analysis of the overall dataset given in section 3.3.2.5, they appear unrelated to biomass smoke. Instead, it is possible that such transient signals originate from the emissions of other non-combustion sources of resin acids; for example, processes that use resinous trees for production of pulp and paper.

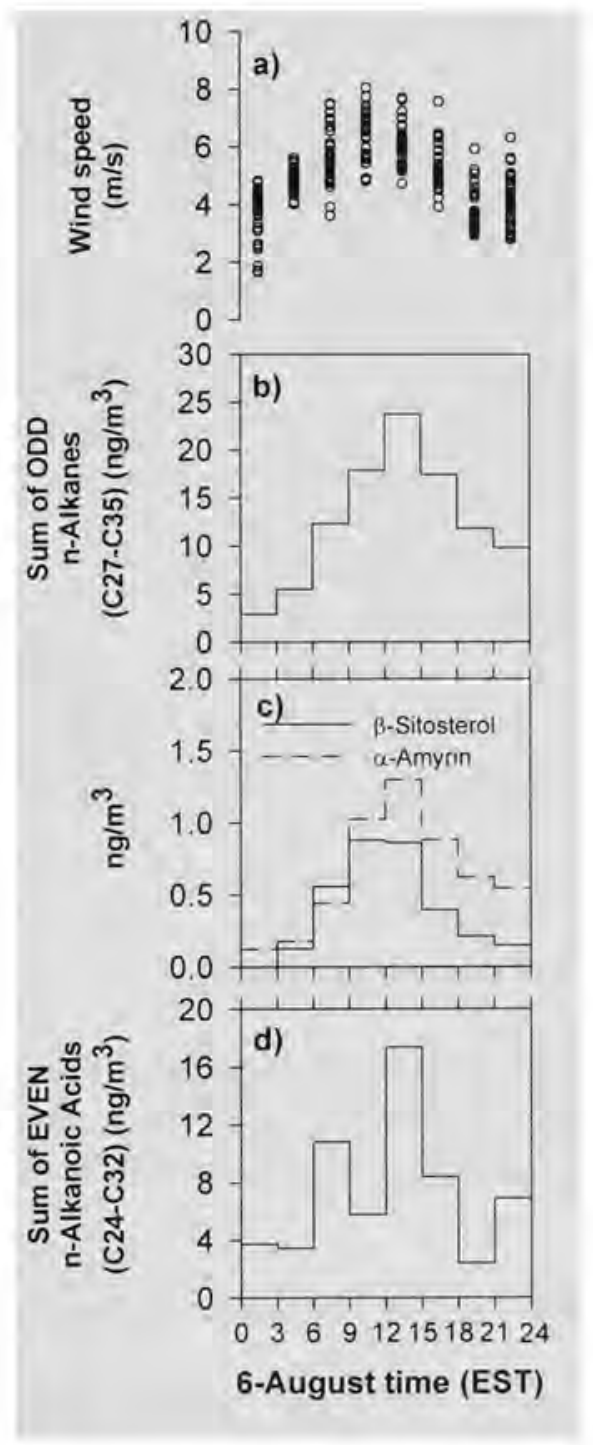

Figure 4.14: Three-hourly concentrations of biogenic-derived organic high molecular weight n-alkanes (b) and n-alkanoic acids (d), terrestrial plant biomarker $\alpha$-amyrin and plant steroid $\beta$-sitosterol (b) measured in the PM2.5 sampled on 6-August 2002. Threehourly wind distributions of 5-min wind speed measurements for that day shown in (a). 


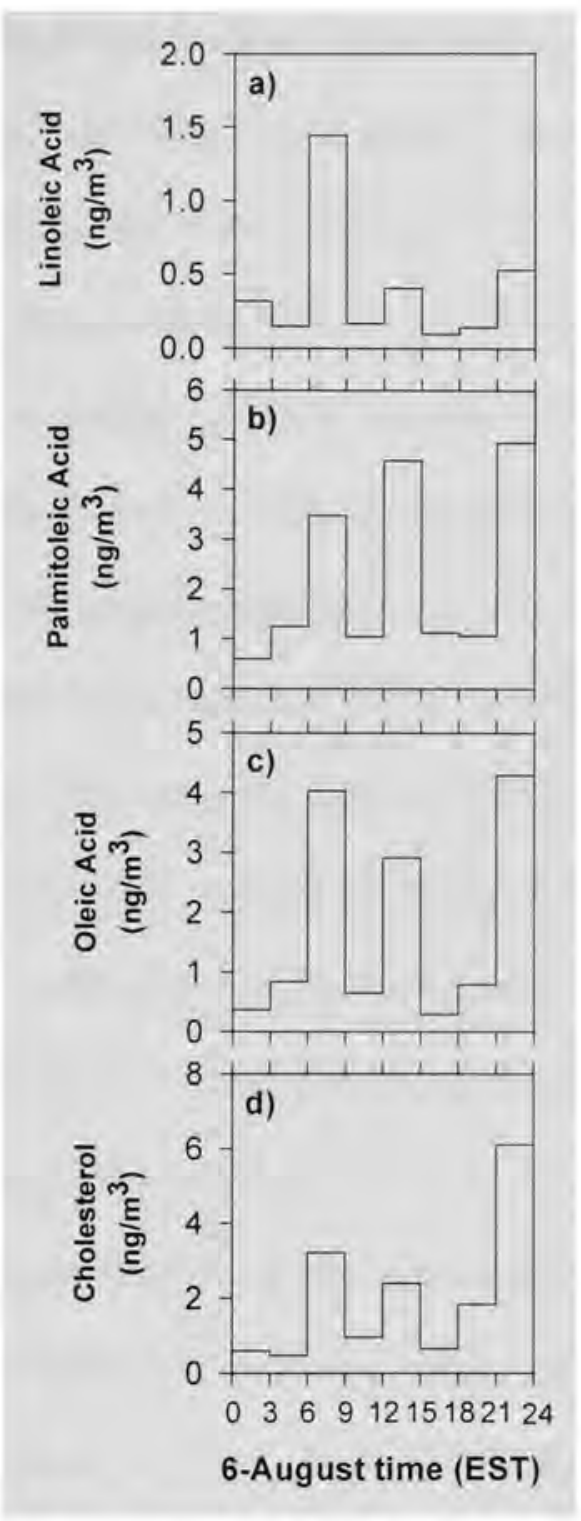

Figure 4.15: Three-hourly concentrations of n-alkenoic acids (a-c) abundant in the fine particles emitted from cooking operations, and of the animal sterol cholesterol (d), a marker for meat cooking, measured in the PM2.5 sampled on 6-August 2002.

The biogenic contribution from terrestrial higher plants is indicated by the distinct distribution pattern of the high molecular weight odd-to-even predominance of n-alkanes (C27-C35) and even-to-odd predominance of the n-alkanoic acids (C24-C32) homologues in the chromatogram of each of the 3-hourly samples. Evidence of fresh 
vegetative input is provided by the presence of the pentacyclic triterpenoid $\alpha$-amyrin, a characteristic biomarker of terrestrial higher plants (Simoneit et al., 2004), and $\beta$ sitosterol, a confirmatory marker for input of vegetation. As shown in Figure 4.14 b,c, the 3-hourly concentrations of these markers follow very closely the same trend of the high molecular weight odd-carbon n-alkanes (linear correlation, $\mathrm{R}^{2}=0.78 \pm 0.03$ ). In addition, all three follow the same diurnal pattern of the wind speed for this day (Figure 4.14 a).

In contrast, the diurnal pattern of the sum of even-carbon number high molecular weight n-alkanoic acids is somewhat different (Figure $4.14 \mathrm{~d}$ ). The observed ratio of [odd n-alkanes]:[even n-alkanoic acids] ranges from 0.8 to 5.0 (average $2 \pm 1$ ). Reported ratio values for dead and green leaf abrasion products (Rogge et al., $1993 \mathrm{c}$ ) and re-suspension of urban road dust (Rogge et al., 1993 b) are, respectively, 3, 15 and 1.2. Therefore, the variability can be explained by the varying contribution of mostly re-suspension of dust, along with fresh and dead vegetative detritus.

The variations of concentrations of the cooking markers, shown in Figure 4.15, display three peaks in the diurnal periods during which one would expect the increased activity from cooking operations to occur, during breakfast, lunch and dinner times. In addition the pattern's shape also illustrates the relatively short-life of particles generated by this source category.

The closeness of the highway and the high consistency of the wind direction and speed patterns for this day, suggest that it is possible that a steady vehicular plume impacted the site. Figure 4.16 shows the 3 -hourly variations of the concentrations of the petroleum biomarkers hopanes and of the particle-phase PAHs, together with the hourly counts of total vehicles and heavy-duty vehicles recorded at the Baltimore Harbor plaza, 
incoming traffic to I895. The patterns of the biomarkers follow trend a very similar to the vehicular flow, particularly that of the vehicles with 3-or-more axles. On the other hand, the pattern of particle-phase PAHs is more similar to the 2-axles vehicular flow, suggesting that the latter may have a greater influence.

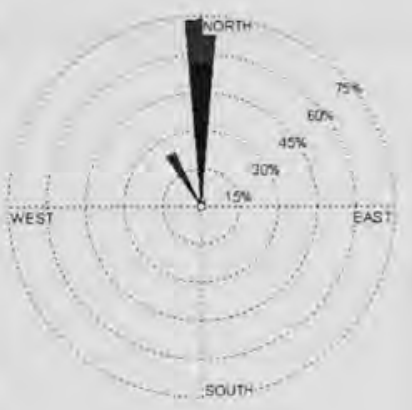

WIND SPEED $(\mathrm{m} / \mathrm{s})$

$\square=11$

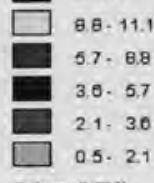

Calms: $0.00 \%$

6-August 2002

Times 09:00 to 24:00
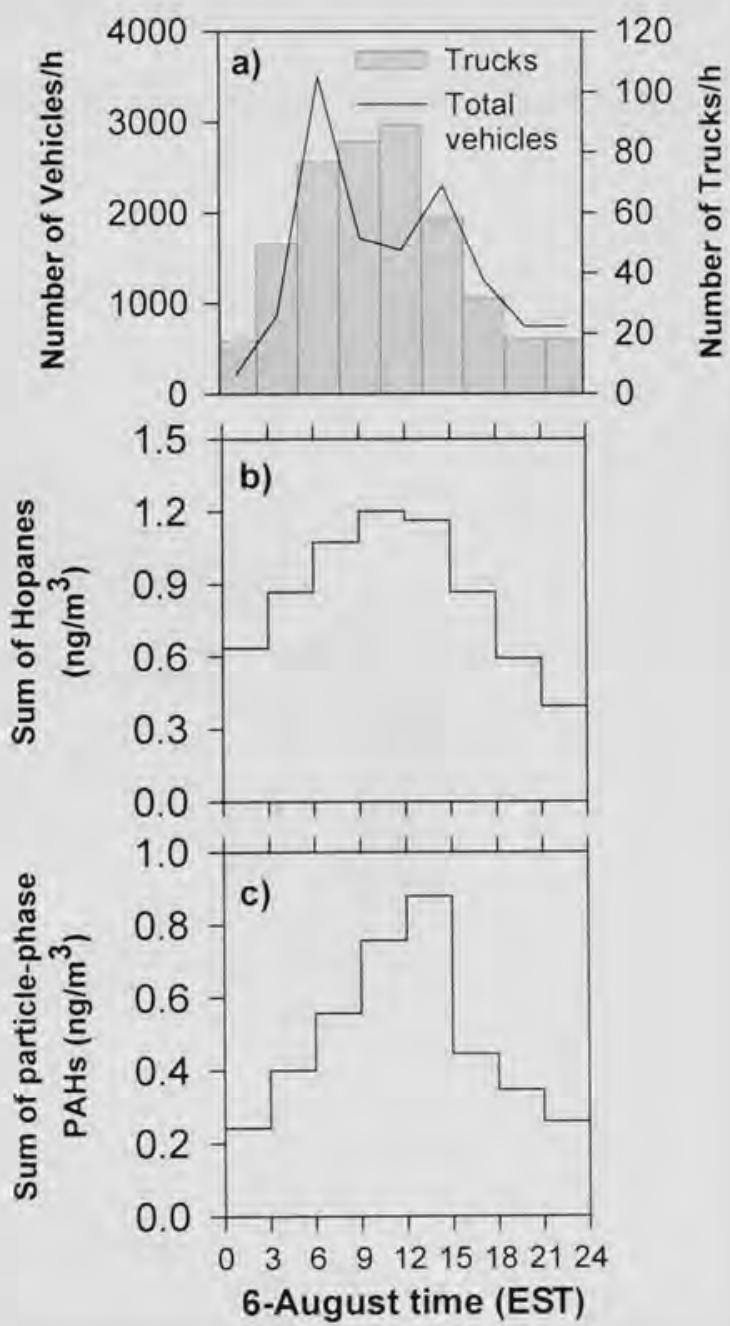

Figure 4.16: Three-hourly concentrations of the petroleum biomarkers, hopanes (b) and the sum of particle-phase-PAHs (c) measured in the PM2.5 sampled on 6-August 2002. Also shown is the pattern of vehicular flow calculated from the counts at the Baltimore Harbour Tunnel toll plaza for that day (a), and the wind direction/speed frequency plot for the day. 
The pattern of diurnal concentrations observed for the anthropogenic n-alkanes (C19-C25), n-alkylcyclohexanes (C19-C25), and n-alkanoic acids (C10-C20) are shown in Figure 4.17. Also included in this figure is the pattern of PM2.5 for this day. Throughout day 5-August the PM2.5 levels had built up to exceed $35 \mu \mathrm{g} / \mathrm{m}^{3}$ levels and decreased on 6-August, as shown in Figure 4.17 a. The pattern of n-alkanoic acids at the onset of the day follow a decreasing trend similar to that seen for the PM 2.5. On the other hand, the opposite trend is observed for the n-alkanes and n-alkylcyloalkanes.

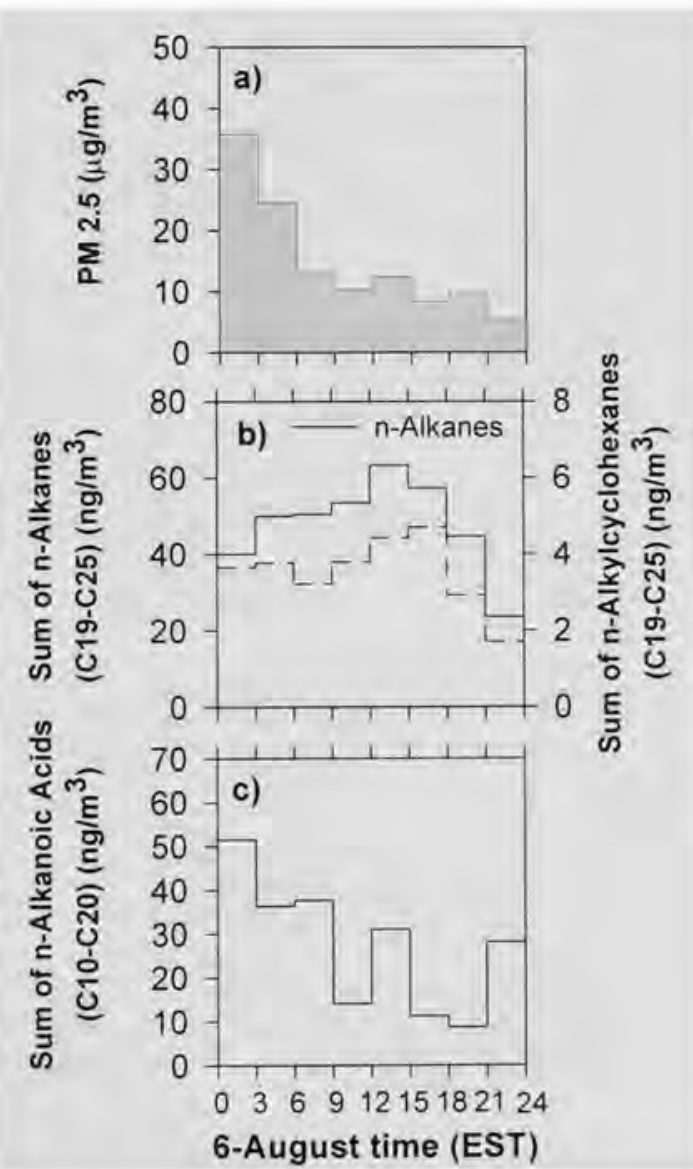

Figure 4.17: Three-hourly concentrations of anthropogenic n-alkanes (b) and n-alkanoic acids (c) measured in the PM2.5 sampled on 6-August 2002. Also shown, 3-hourly averages of PM 2.5 mass (a) averaged from 30 -min measurements for this day. 
The concentrations of aliphatic and aromatic dicarboxylic acids and of the secondary biogenic reaction products were at a minimum on 6-August in comparison to the rest of the summer campaign. However, understanding the dynamics associated to the patterns for a relatively tranquil day may provide useful information about the inputs and conditions necessary for secondary reaction products formation. The patterns observed for all these species on 6-August are presented together in Figure 4.18. Among the aliphatic homologues, azelaic acid is not observed, succinic is the least abundant, and

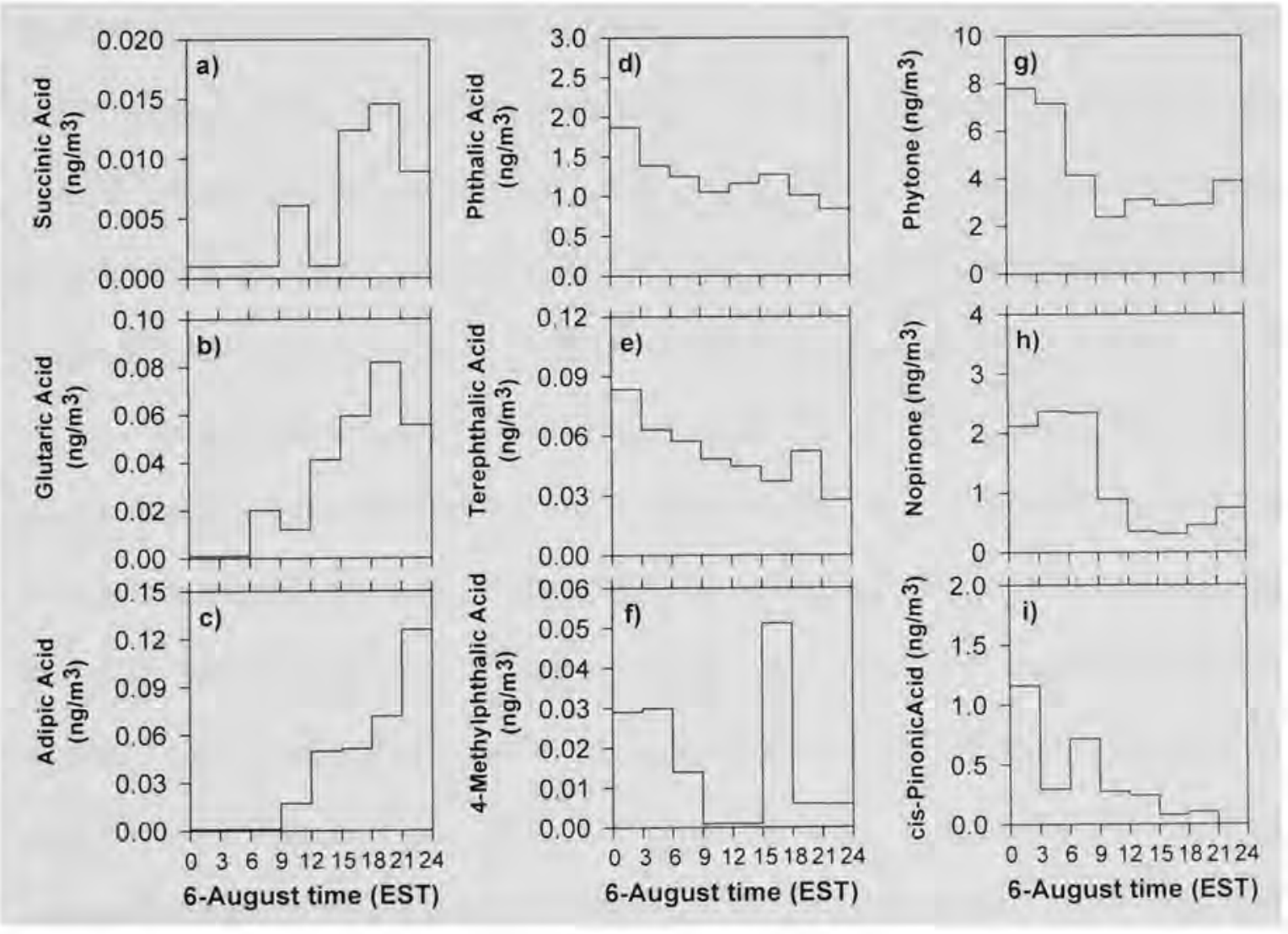

Figure 4.18: Three-hourly concentrations of aliphatic and aromatic dicarboxylic acids (butanedioic (succinic, a), pentanedioic (glutaric, b), hexanedioic (adipic, c), 1,2benzenedicarboxylic (phthalic, d), 1,4-benzenedicarboxylic (terephthalic, e), and 4methyl-1,2 benzenedicarboxylic (4-methylphthalic, f), and of secondary oxidation products measured in the PM2.5 sampled on 6-August 2002. 
adipic and glutaric are present in similar amounts; a level approximately one order of magnitude higher than succinic acid. These three species display similar patterns.

Important primary sources of aliphatic dicaboxylic acids are biomass burning and cooking operations; since their patterns bear no similarity to those of the major markers for those sources, respectively in Figure 4.13 and Figure 4.15, it follows that primary emission was not an important source on this day. Since biomass burning did not have an important impact on 6-August, the only direct conclusion than can be drawn so far is that cooking does not appear to be factor that determines the observed pattern. Obvious associations were not found between the measured concentrations and the meteorological and reactive chemical species, ozone and NOx. Under the conditions of this day, it can only be concluded that succinic is formed in the atmosphere. The ambient concentrations of these three species are seen rising from evening to night suggesting that they may be dependent on the ambient humidity, which follows the same trend (Figure $4.2 \mathrm{~b}$ ).

The aromatic dicarboxylic isophthalic acid was not detected on 6-August. A single mid-day peak is observed for 4-methylphthalic acid, and both phthalic and terephthalic acid display patterns that suggest a dominant background of continuum of emissions and/or production. Phthalic acid has been identified in the fine particles emitted by heavy-duty diesel trucks and high emitter gasoline vehicles while tested on dynamometers (Fujita et al., 2007). On the other hand, it is known that aromatic compounds have a large potential to form secondary organic aerosol (SOA) (Grosjean and Seinfeld, 1989), and that in urban areas the SOA formation potential of gasoline, for example, could be explained in terms of its aromatic fraction alone (Odum et al, 1997). It is thought that phthalic acid may be associated to oxidation of naphthalene and as such be 
a marker for anthropogenic SOA formation. The 4-methylphthalic acid has been identified in diurnal ambient samples from the Los Angeles area (Fine et al., 2004) and has been suggested as marker of secondary particle formation based on the correlation of the concentrations of phthalic and 4-methylphthalic acid found in that study. The diurnal pattern observed here support the idea that 4-methylphthalic acid is formed in the local atmosphere via a photochemical driven mechanism as indicated by a large midday peak, and it also suggests that the concentrations of this compound are dominated by this process. In contrast, no similar indication is noted for phthalic acid; and furthermore, for phthalic and terephthalic acid the largest concentrations are observed at the onset of the day suggesting that transported background levels were larger than specific local effects.

Lastly, the relatively low concentrations of nopinone and cis-pinonic acid suggest a low activity of the secondary biogenic reactions system under the northerly winds regime. The diurnal patterns suggest that night time production played an important role on the measured concentrations of these compounds on 6-August as per discussion in section 3.3.2.9.

\subsubsection{Wood Burning and Winter Nighttime Inversion: 24-25 November}

The Hysplit simulations indicate westerly influence for both days, and at least on the first day the local wind direction is mostly from the southwest. The lower temperatures were around $5^{\circ} \mathrm{C}$, and wind speeds were shallow $(0-2 \mathrm{~m} / \mathrm{s})$ on the evening of Sunday $24^{\text {th }}$ and through Monday $25^{\text {th }}$, somewhat increasing at the end of this day $(3-4$ $\mathrm{m} / \mathrm{s}$ through the sampling at 18:00 and 21:00). As presented in section 3.3.2.5, considering that surveys have found that wood burning is used in urban areas of the mid- 
Atlantic region for space heating during the winter, and that this was the coldest two weekend days of the November sampling campaign, residential wood burning activity is reasonably expected. Furthermore, the prevalent local atmospheric conditions of a still evening were favorable to develop a typical winter inversion layer.

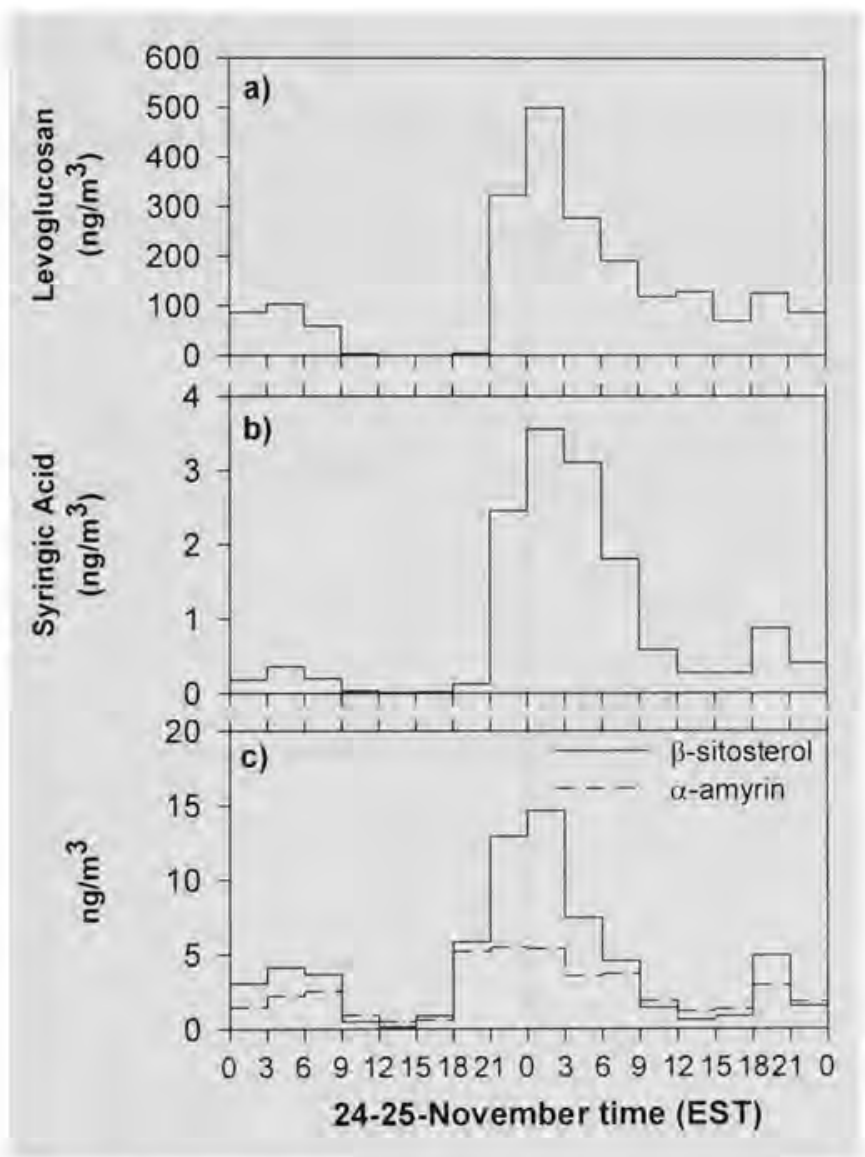

Figure 4.19: Three-hourly concentrations of wood burning markers levoglucosan (a) and syringaldehyde (b), the plant sterol $\beta$-sitosterol and the pentacyclic triterpenic terrestrial plant biomarker $\alpha$-amyrin (c), measured in the PM2.5 sampled on 24- and 25-November 2002.

Figure 4.19 shows the 3 -hourly concentrations of selected wood burning markers. On the night of 24-November the concentrations of levoglucosan were 2-4 times larger than any other measured during the winter campaign. Elevated concentrations of the 
same order were also observed for syringic acid, an indicator of hardwood burning (Simoneit et al., 2004a). In addition, elevated concentrations of $\beta$-sitosterol, $\alpha$-amyrin, and $\beta$-amyrin are also measured in those samples. The amyrins and $\beta$-sitosterol have been identified in the aerosol emitted from the fireplace combustion of hardwoods grown in the Northeastern U.S. (Fine et al., 2001). Amyrins are incorporated in the wood smoke by a process involving direct volatilization from the source (Elias et al., 1998). They are susceptible to photochemical and microbial degradation (Simoneit, 2004b); therefore, the concurrent $\alpha$-amyrin peak helps to confirm smoke from the burning of angiosperms (hardwood).

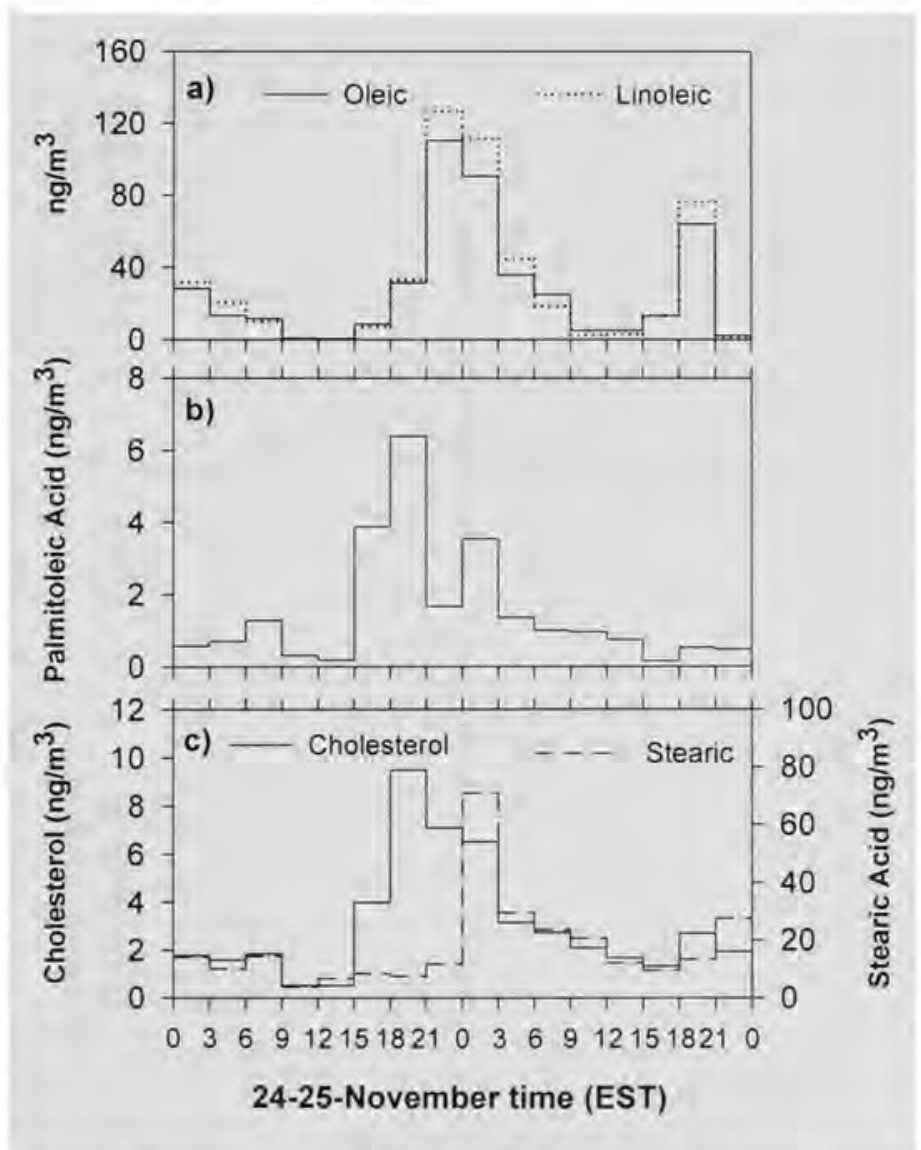

Figure 4.20: Three-hourly concentrations of unsaturated n-alkenoic acids (C16:1, C18:1, C18:2) and n-octadecanoic acid (stearic, c) measured in the PM2.5 sampled on 24- and 25-November 2002. 
Diurnal variations of the concentrations of the unsaturated n-alkenoic acids are displayed in Figure 4.20. The peak concentrations observed around the midnight line may in part reflect the slower dynamic of the unsaturated fatty acids, particularly oleic and linoleic acids; however, it is likely to also reflects poorer dispersion of particles due to prevalent local meteorological conditions that night; that is, pollutant concentrations build up.

Figure 4.21 show that all three fossil fuel markers, sum of n-alkanes (C19-C25), sum of n-alkylcyclohexanes (C19-C25) and hopanes follow the same trend. In addition,

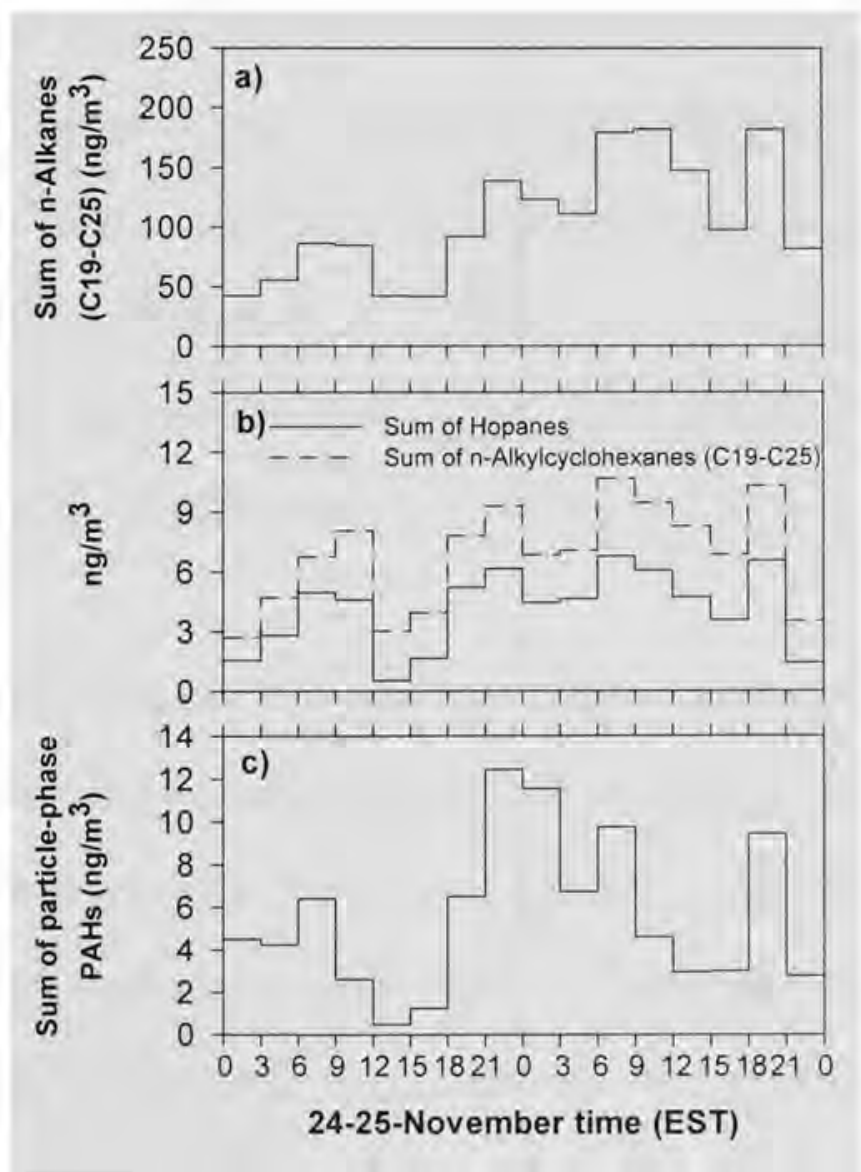

Figure 4.21: Three-hourly concentrations of selected markers of anthropogenic activity measured in the PM2.5 sampled on 24- and 25-November 2002. 
this trend is also found to be very similar to the one observed for EC. Inter-correlations among the 3-hourly concentrations of EC and the fossil fuel markers yield correlation factors in the range $0.99>R^{2}>0.90$. The fit is somewhat weaker with the particle-phase PAHs as these display a different pattern. The minimum of diurnal vehicular traffic flow takes place during the sampling period 00:00-03:00; accordingly, a drop is seen in the concentrations of hopanes and n-alkylcyclohexanes (Figure 4.21 b) on the other hand, PAHs concentrations continue rising during the night (Figure $4.21 \mathrm{c}$ ) and display a slower decay (midnight line) than the other three sets of markers. This suggests other net sources of PAHs during this night.

Figure 4.22 shows the 3-hourly sum of the concentrations of the low- and highmolecular weight n-alkanoic acids. The pattern of PAHs resembles more closely that of the high-molecualr weight. These are associated to contribution from wood burning; consequently, to test the hypothesis that the increase of concentration of the particlephase PAHs may be associated to wood burning, the correlation of the PAHs with the high molecular weight n-alkanoic acids on 24-25-November was compared to that for all other winter days.

In order to avoid the bias of comparing a different amount of data points, Figure 4.23 illustrates this relation by comparing the sets $8-9-$ November with $24-25$-November, respectively representing days with a low and a higher wood burning activity (Figure 4.23 a, association of levoglucosan vs particle-phase PAHs). For the two sets of days, the concentrations of the low-molecular weight acids are similar and the slopes of the two lines are also very similar (Figure 4.23 b); conversely, the proportion of the high molecular weight acids and the slope are larger for the 24-25-November set (Figure 4.23 
c). These results suggest that residential woodburning may be the source of significant amounts of particle-phase PAHs.

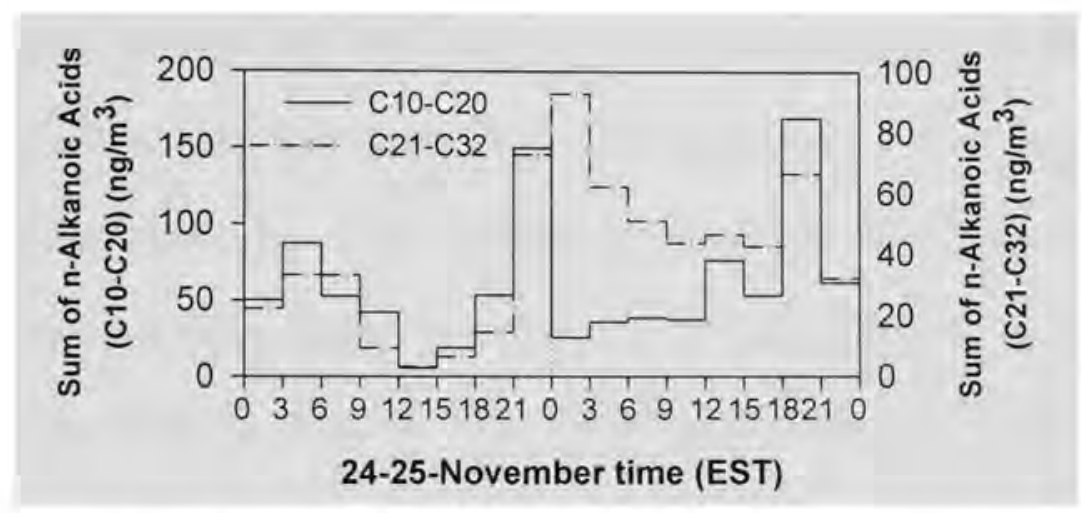

Figure 4.22: Three-hourly concentrations of n-alkanoic acids in the ranges $\mathrm{C} 10-\mathrm{C} 20$ and C21-C32 measured in the PM2.5 sampled on 24- and 25-November 2002.
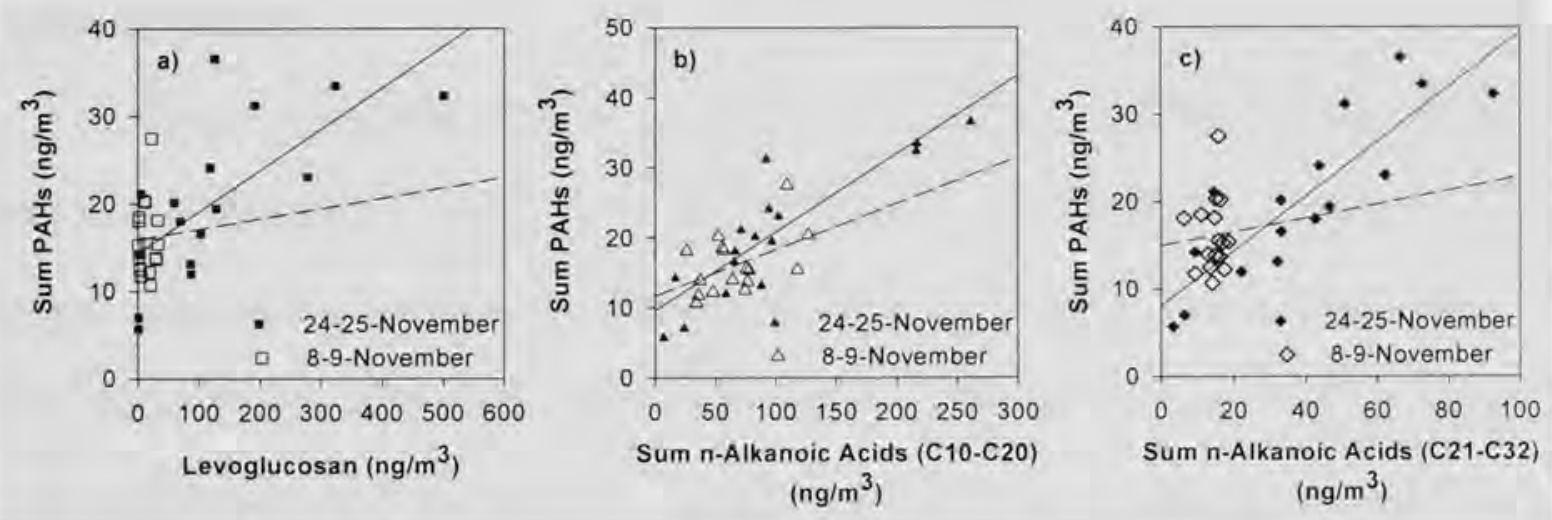

Figure 4.23: Scatter plots of the three-hourly concentrations of PAHs (Sum from benzo[b]fluoranthene to coronene) vs. (a) levoglucosan, (b) the low-molecular weight nalkanoic acids (C10-C20), (c) the high-molecular weight n-alkanoic acids (C21-32), measured in the PM2.5 sampled on 24- and 25-November 2002. 
Though we have seen that overall vehicular sources dominate the emissions of particle-phase PAHs, the findings accounted in this section are in agreement with the information from organic profiles of woodsmoke reported in the literature. According to published organic profiles for major urban sources of fine particles (Table 1.1), the emission rates of PAHs by non-catalyst equipped gasoline-powered vehicles or old and poorly maintained units is one order of magnitude or larger than it is for well operating vehicles (see Appendix B, Figure B.6). Otherwise, among the fuels typically used for space heating, i.e., fuel oil, natural gas and woodfuel, the emission factors of the PAHs up to $\mathrm{BaP}$ are of the same magnitude as those from vehicular emissions, and the heavier PAHs are identified only in woodsmoke and in appreciable amount in the smoke produced by burning plastic waste. Furthermore, we have estimated the contribution from natural gas burning (section 3.3.2.6) to be minor compared to that of wood burning (section 3.3.2.5).

Under the specific conditions of sources and meteorology described for this event, the diurnal variations observed for the aliphatic and aromatic dicarboxylic acids can be better understood in relation to the differences that are observed in the patterns for these two days in contrast to the other winter sampling days. The following two figures, Figure 4.24 and Figure 4.25 illustrate the 3-hourly time series of the concentrations of the aliphatic and aromatic dicarboxylic acids. As expressed previously in section 3.3.2.8, the importance of these acids rests primarily on the information that they can provide about the atmospheric dynamics. The time-series of the concentration of levoglucosan are included in both graphs to highlight since it is possible that the presence of particles of such nature may play a role in the dynamics observed. 
Significant features identified among the aliphatic acids (Figure 4.24) are those observed for adipic and azelaic acid; the observed patterns, i.e., transient peak concentration at midday, are consistent with photochemical formation. The pattern further suggests that photochemical formation is the prevalent mechanism influencing the ambient concentrations of azelaic acid. Among the aromatic dicarboxylic acids, a similar

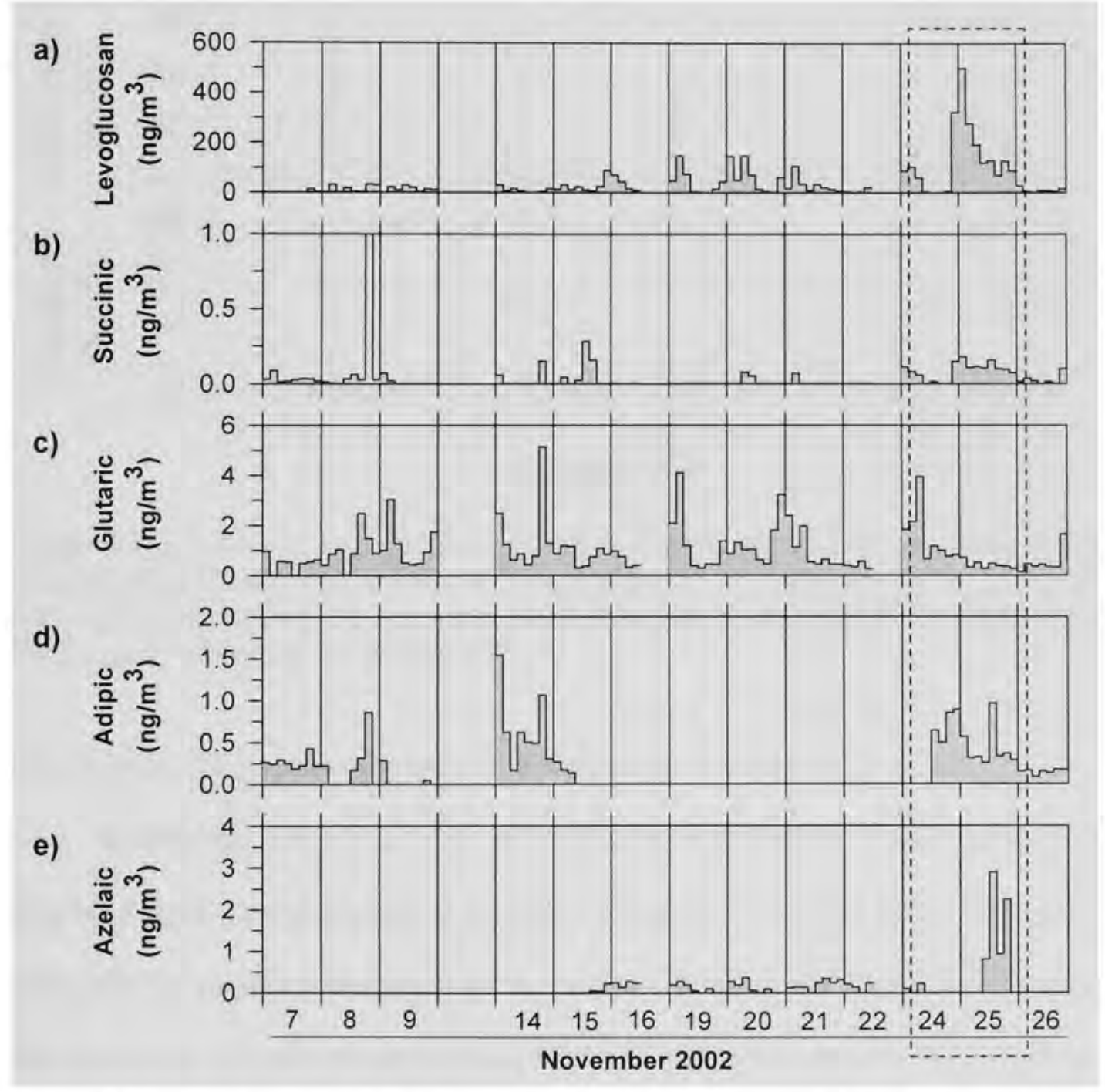

Figure 4.24: Time series of the three-hourly concentrations of levoglucosan (a) and the aliphatic dicarboxylic acids butanedioic (succinic, b), pentanedioic (glutaric, c), hexanedioic (adipic, d), and nonanedioic (azelaic, e) measured in the PM2.5 sampled during November 2002. 


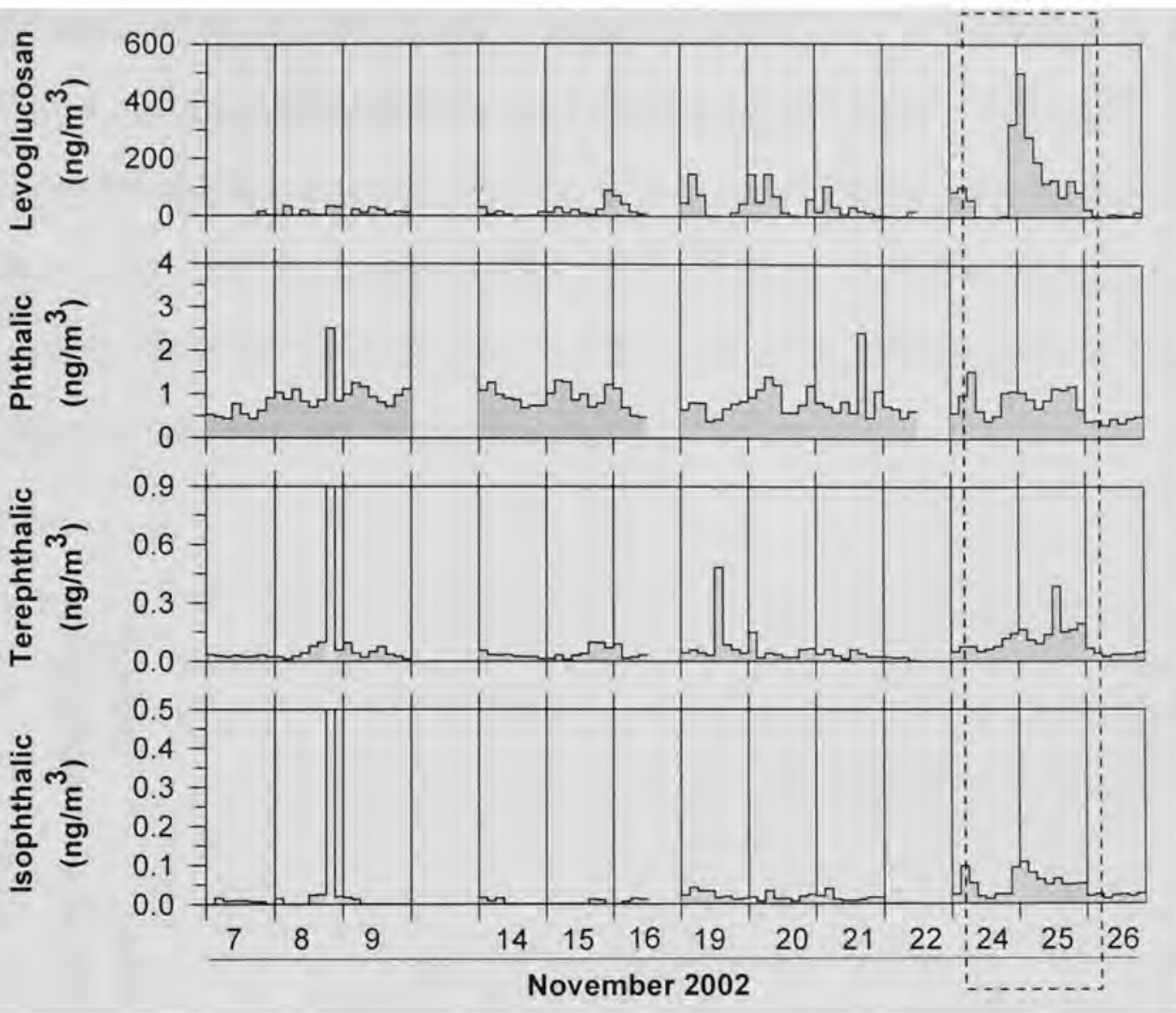

Figure 4.25: Time series of the three-hourly concentrations of levoglucosan (a) and the aromatic dicarboxylic acids acids 1,2-benzenedicarboxylic (phthalic, b), 1,4-benzenedicarboxylic (terephthalic, c), and 1,3-benzenedicarboxylic (isophthalic, d) measured in the PM2.5 sampled during November 2002.

trend is observed only for terephthalic acid as shown in Figure 4.25.

During this episode, all four secondary reaction products measured in this study displayed peak concentrations at midday, as shown in Figure 4.26. Summary plots presented in Chapter 3 (section 3.3.2.9, Figure 3.22) show that during the summer, peak concentrations of nopinone are always observed during the night or the early morning; during the winter, the peak and the maxima are typically observed at 06:00 instead of the usual 03:00 of the summer. According to information presented in Chapter 3, the 
association of the concentration of nopinone with $\mathrm{NO}_{2}$ (or $\mathrm{NOx}$ ) and with $\mathrm{O}_{3}$ is not different than that indicated by the trend (see Figure 3.23). Peak concentrations of cispinonic and norpinonic acid are observed at daytime and nighttime during the summer (Figure 3.24) and this pattern is also seen, at various concentration levels, in the preceding November sampling days; however, during the 24-25-November event the daytime maxima prevails as shown in Figure 4.26.

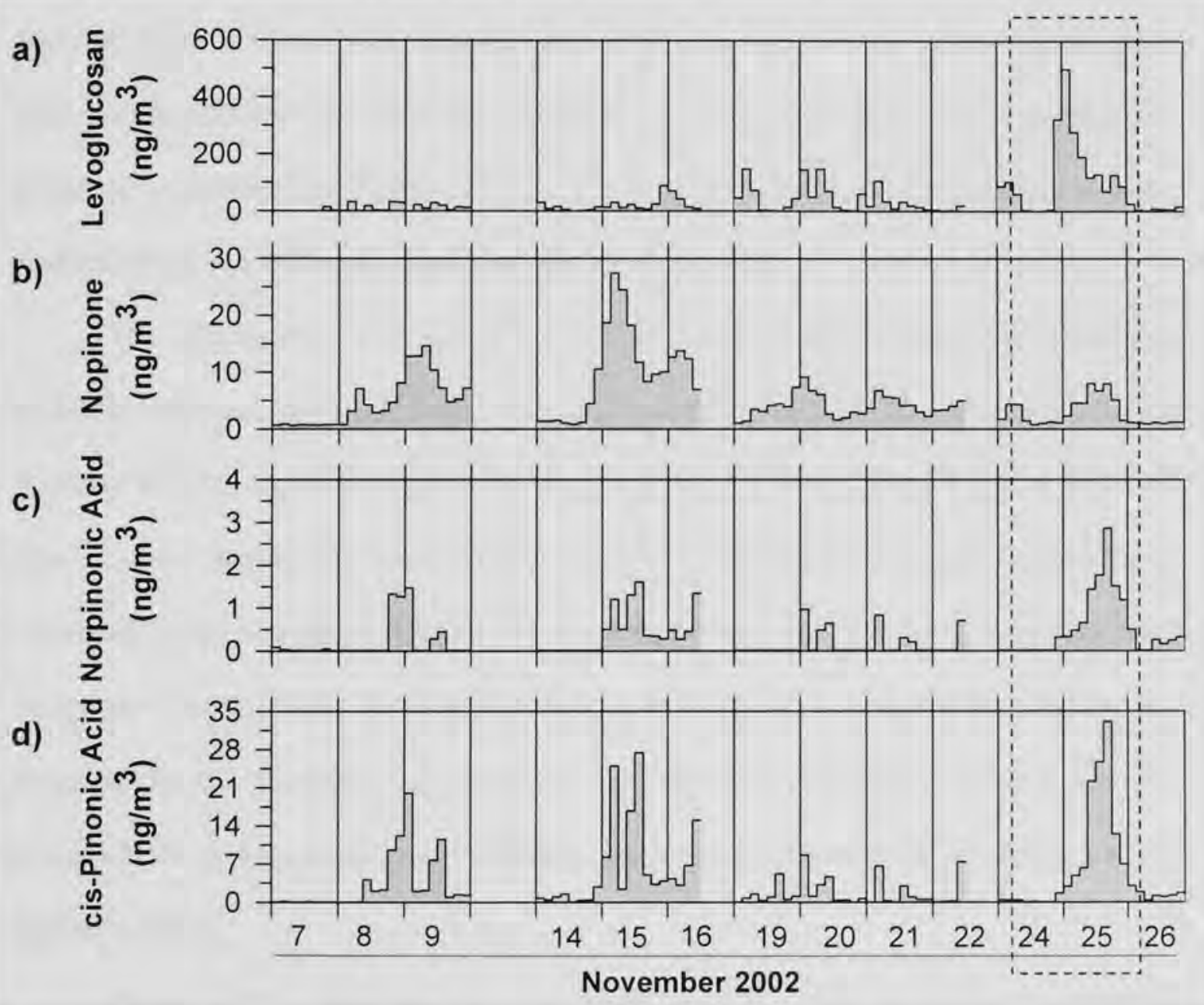

Figure 4.26: Time series of the three-hourly concentrations of levoglucosan (a) and the secondary biogenic reaction products nopinone (b), norpinonic acid (c), cis-pinonic acid (d) measured in the PM2.5 sampled during November 2002. 
Chamber experiments and SOA model predictions reported by Kamens and Jaoui (2001) have indicated that pinonic acid and norpinonic acid are specifically observed in the particle phase of the aerosol formed from the oxidation of $\alpha$-pinene in sunlight and in presence of NOx. The reaction with $\mathrm{O}_{3}$ is one of the dominant atmospheric loss mechanisms of $\alpha$-pinene during darkness (Kamens et al, 1999). This reaction also leads to the particle-phase products pinonic and norpinonic acids via the "pinacid" path. In their studies, the chamber experiment and model predictions indicated that products onset occurred about 7.5 hours after reaction with ozone. The reaction of $\alpha$-pinene in the dark with nitrate radicals has also been studied; however, according to the mechanism presented in Kamens and Jaoui (2001), in this case the final particle phase product from pinonaldehyde is a different compound, norpinonaldehyde.

The information that can be extracted from the Baltimore data about the secondary reaction products of the $\alpha$-pinene system is well illustrated in Figure 3.25 (Chaper 3). This figure indicates that the availability of NOx does not appear to be an issue; in both seasons, the production of cis-pinonic and norpinonic acid are positively correlated to the available NOx. On the other hand, reaction with $\mathrm{O}_{3}$ is only important during the summer when the levels of this gas are high. According to the mechanisms proposed in the literature, presented in the previous paragraph, reaction via the sunlight/NOx system should yield a daytime peak while reaction with $\mathrm{O}_{3}$ should yield a night-time peak.

Figure $4.27 \mathrm{f}$ indicates that the night and day peak sequence is observed throughout the summer and winter, except the period 6-9-August, and 7-November. According to the evaluated daily associations with gas data (section 3.3.2.9) it is possible 
a)

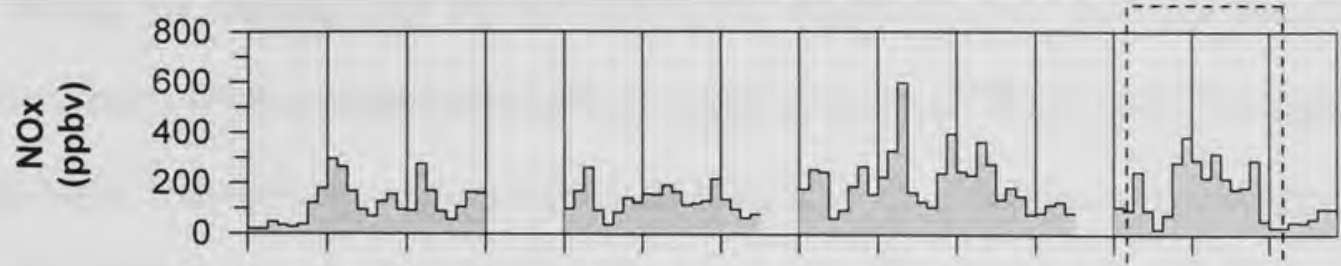

b)

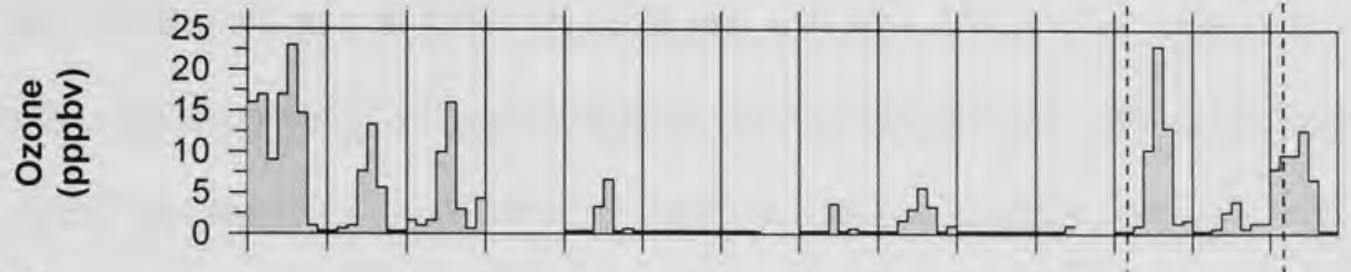

c)

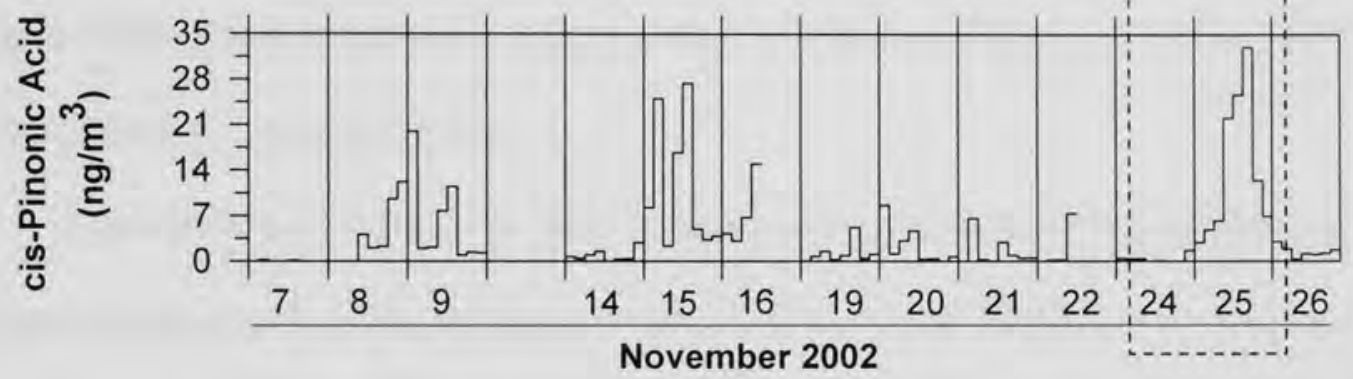

d)

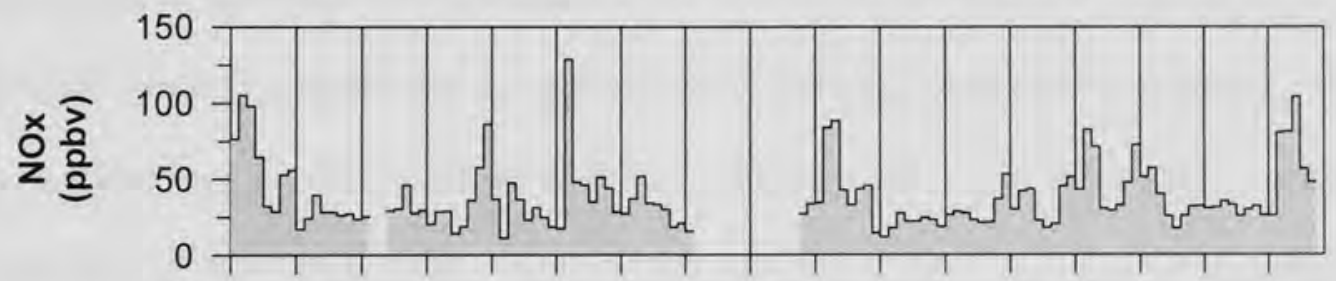

e)
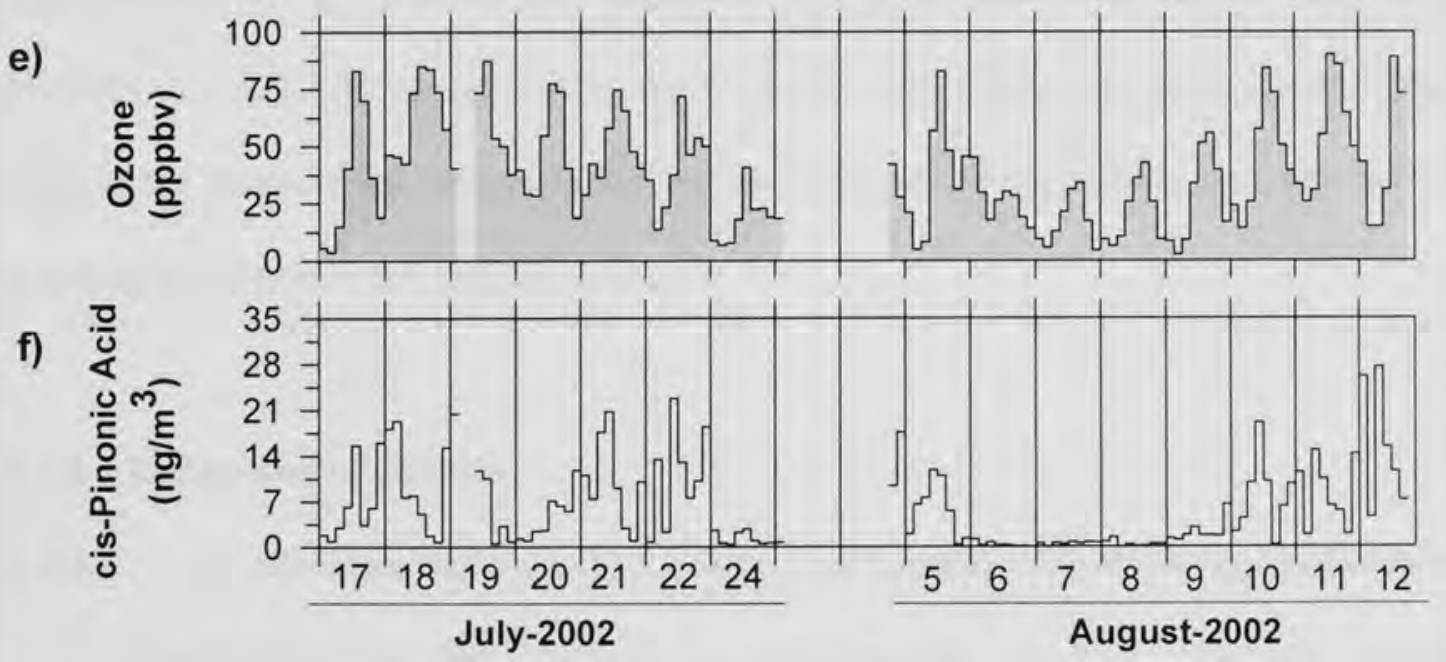

Figure 4.27: Time series of the three-hourly winter and summer concentrations of reactive gases nitrogen oxides (NOx: a, d) and ozone (b, e) and of the secondary biogenic reaction product cis-pinonic acid $(\mathrm{c}, \mathrm{f})$. 
that during the summer, but not the winter, the nighttime peak be associated to $\mathrm{O}_{3}$, Further details of these associations are presented in section 4.3.4.3. Here, regarding the 24-25-November episode it can be seen that in the presence of a large concentration of $\mathrm{O}_{3}$ on 24-November (Figure $4.27 \mathrm{~b}$ ), the nightime production of cis-pinonic acid is much lower than the daytime 25 -November (Figure $4.27 \mathrm{c}$ ). One of the possible implications of this result is that the production of these secondary reaction products via the sunlight/NOx system is enhanced in the presence of woodsmoke aerosol under conditions of photochemical smog production.

It can be concluded that the field measurements reported here lend support to the mechanisms proposed in the literature (Kamens et al., 1999, 2001) for the formation of particle-phase cis-pinonic and norpinonic, in that the diurnal variations observed for these compounds can be explained by a combination of the nighttime loss of $\alpha$-pinene via $\mathrm{O}_{3}$ and a daytime loss which involves NOx. Furthermore, the results also suggest possible enhancement of the yield of the sunlight/NOx system in the presence of woodsmoke particles. To our knowledge this is the first time that field data provides evidence to support the mechanisms proposed for the formation of particle-phase products from the $\alpha$-pinene oxidation in the real atmosphere.

\subsubsection{Long-range Episodes}

\subsubsection{Biomass Burning, 20-21 July, and Associated Long-range Influence}

The nature of this episode is distinguished by the relatively elevated concentrations of levoglucosan. As presented in section 3.3.2.5, the largest levels during the summer, observed on 20-21-July, are about the magnitude of the median observed 
during the winter. Levoglucosan is regarded as a source-specific and stable marker (Fraser et al., 2000), and its presence in aerosol is indicative of input from biomass burning. The sum of the eight 3-hourly concentrations for each day between 20-22-July is, respectively, $61.9 \mathrm{ng} / \mathrm{m}^{3}, 41.2 \mathrm{ng} / \mathrm{m}^{3}$ and $27.3 \mathrm{ng} / \mathrm{m}^{3}$. According to Yue et al., (2004), these levels are consistent with a low intensity fire or persistent regional influence from previous large scale fires.

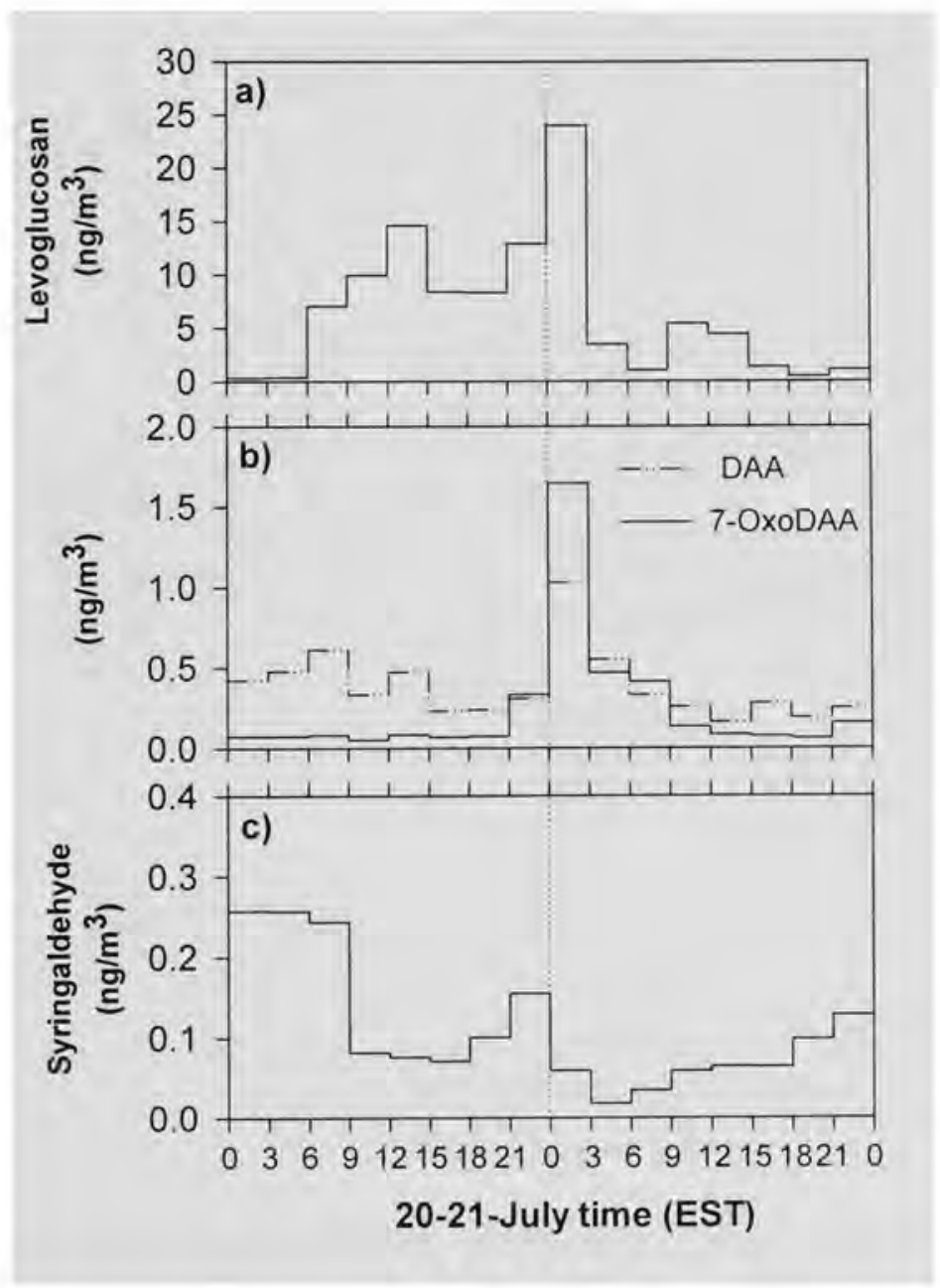

Figure 4.28: Three-hourly concentrations of organic markers of biomass burning measured in the PM2.5 sampled on 20- and 21-July 2002. 
As it can readily be grasped from Figure 4.28, there are no obvious associations amongst the variations of concentrations of the biomass burning markers during this episode. The implication of this is that the observed concentrations are not determined by a single source, or one of homogeneous characteristics emissions. In addition, the biogenic-derived fractions of $\mathrm{n}$-alkanes and $\mathrm{n}$-alkanoic acids indicate a disproportionately larger amount of the higher-molecular weight acids fraction as shown in Figure 4.29.

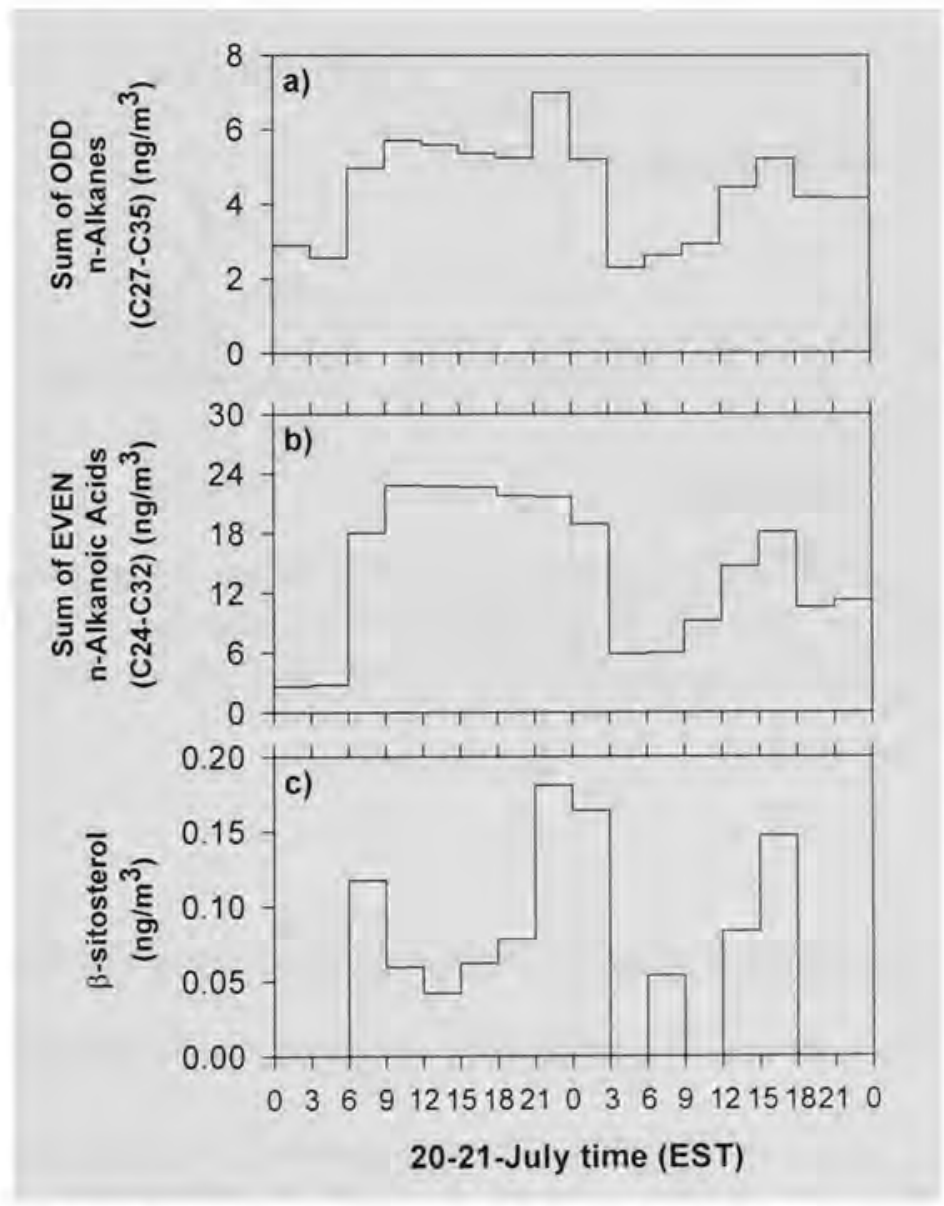

Figure 4.29: Three-hourly concentrations of biogenic-derived organic high molecular weight $n$-alkanes (a) and $n$-alkanoic acids (b), and plant steroid $\beta$-sitosterol (c) measured in the PM2.5 sampled on 20- and 21-July 2002. 
Figure 4.30 presents the time-series of the 3-hourly concentrations of levoglucosan, with an overlaid line showing the ratio of the biogenic-derived n-alkanoic acids to n-alkanes; i.e., the sum of the even homologues n-alkanoic acids in the range $\mathrm{C} 24$ to $\mathrm{C} 32$, divided by the sum of the odd homologes n-alkanes in the range C27-C33. This figure indicates that there is an association between the observations of levoglucosan and a higher ratio of the biogenic-derived high molecular n-alkanoic acids to n-alkanes.

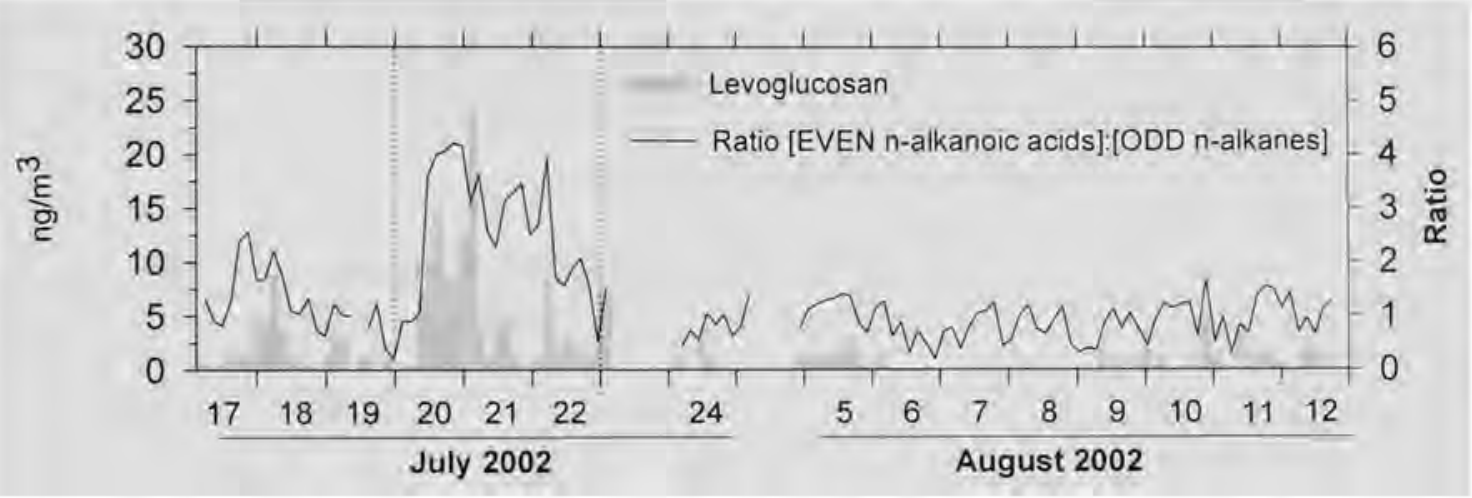

Figure 4.30: Time series of the three-hourly concentrations of the wood burning marker levoglucosan and of the fraction of even alkanoic acids to odd n-alkanes calculated as [Sum n-alkanoic acids (C24, C26, C28, C30, C32)]/[Sum n-alkanes (C27, C29, C31. $\mathrm{C} 33, \mathrm{C} 35)]$.

The fraction of the even-carbon number long-chain fatty acids homologues, C24 to $\mathrm{C} 32$, and the homologue displaying the maximum concentration in this group (Cmax) can assist in distinguishing the characteristics of the vegetative input. During the summer, the maximum is generally $\mathrm{C} 24$; however, two salient exceptions are noted: the periods from 00:00 17-July until 03:00 18-July and from 06:00 20-July until 21:00 22-July where $\mathrm{Cmax}=\mathrm{C} 22$, and from the beginning of 6-August until early morning of 7-August where 
$\mathrm{C} \max =\mathrm{C} 28$. In the episode analyzed in this section, an abrupt change in the distribution pattern of the n-alkanoic acids is observed in the sample 06:00 19-July.

a)

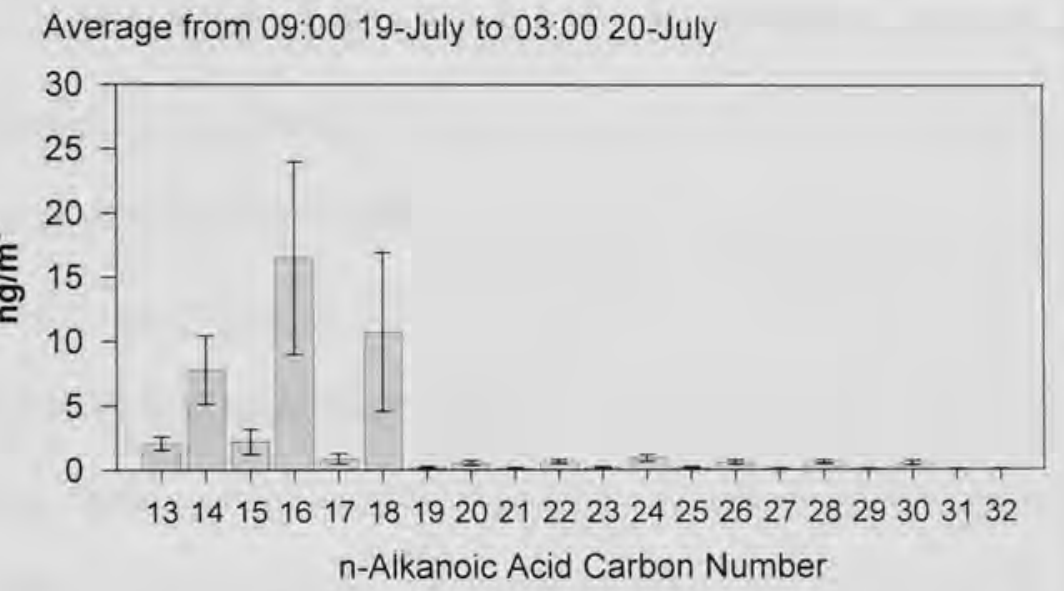

b) Average from 06:00 20-July to 21:00 22-July

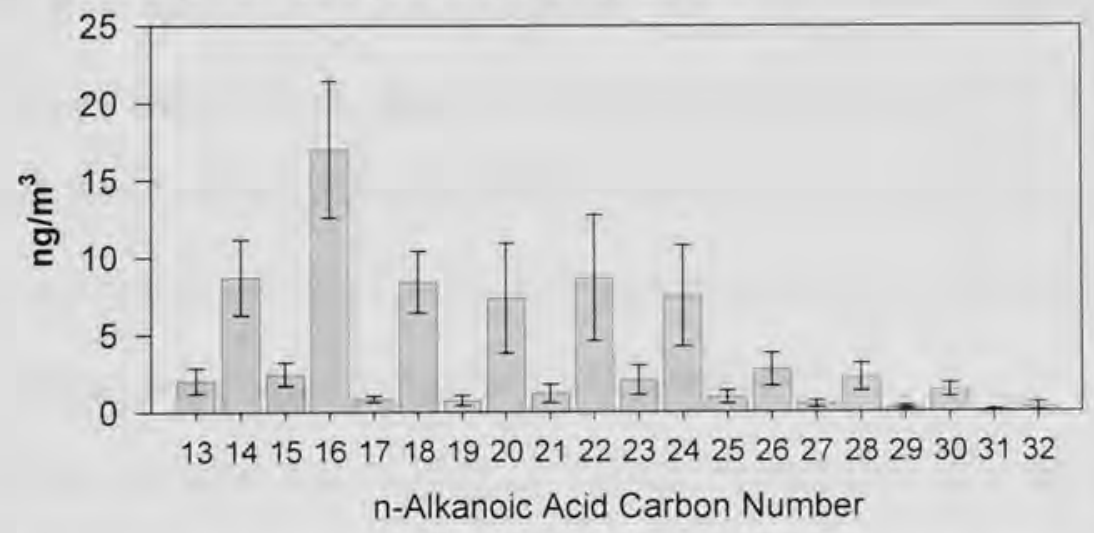

Figure 4.31: Concentration distributions patterns of n-Alkanoic acids (C13 to C32): a) most frequently observed pattern, shown as average of samples from 09:00 19-July to 03:00 20-July, and b) uncharacteristic pattern observed from 06:00 20-July until 21:00 22-July.

Figure 4.31 illustrates the average distribution of n-alkanoic acids observed for the seven samples previous to the onset of the episode (from 09:00 19-July to 03:00 20-July), and for the group of samples through which the unusual distribution pattern is observed (from 06:00 20-July to 21:00 22-July). This figure shows a pattern characterized by the 
surge of concentrations of the homologues $n-C 20, n-C 22, n-C 24$ and to a lesser extent of n-C26, and n-C28. A similar distribution pattern was observed by Yue et al., (2004) during a regional wood smoke episode at the TexAQS 2002 sampling site.

In order to investigate the possible origin in the Baltimore case, the distribution patterns of n-alkanoic acids published in the literature for a variety of open burning cases were compiled to examine the similarities with the observed patterns. Data from all published organic characterization studies of biomass under open burning conditions were considered including simulations of forest type burning (Hays et al. 2002; Oros et al., 2001a, 2001b, 2006), actual field measurements of a prescribed burning in Georgia (Lee et al., 2005), as ell as agricultural fields open burning simulations (Hays et al, 2005). Figure 4.32 displays relevant results of the comparison, indicating that the observed pattern is unlikely to be associated to agricultural burning, and showing some surprising similarities with the organic profiles of aerosols from the burning of forest tree species which are mostly abundant in the western portions of USA particularly western hemlock, ponderosa pine, lodgepole pine and montezuma pine.

There are two important features to consider in exploring the possible source region associated to this episode. The levoglucosan concentrations are large relative to the levels measured the remaining of the summer; however, they are not large enough to suggest that they are caused by an event happening nearby. Furthermore, it must also be considered that the signals of the organic species that characterize this episode surge abruptly and encompass a relatively large span of 2-3 days (up to last sample of the first summer sampling period, that is, 21:00 22-July). These features suggest that the event is likely to be associated to one or more changes in the influencing background air. 


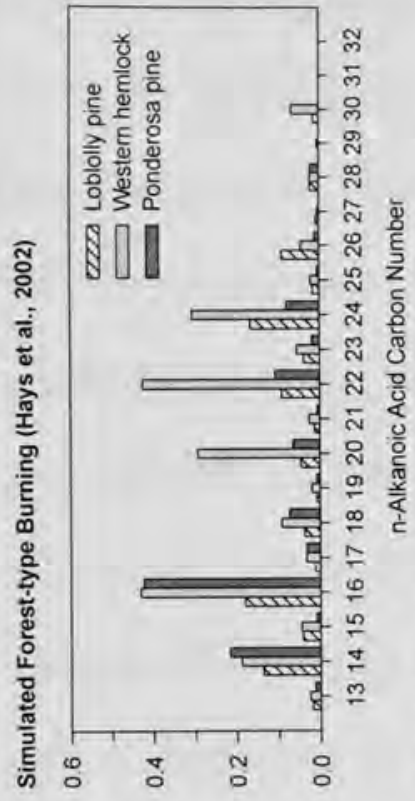

จ sseus giWd to \%

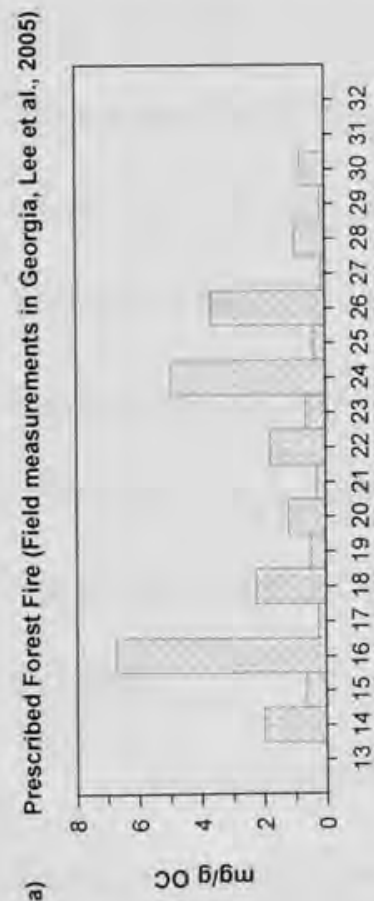

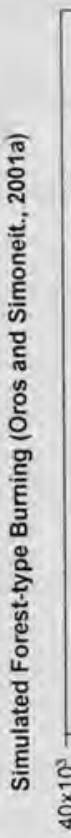

ฮิ

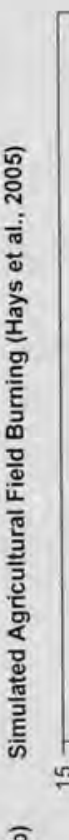

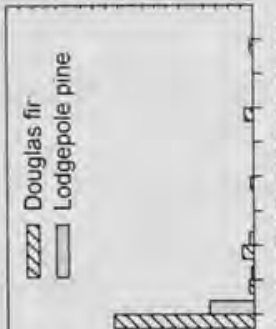

त)

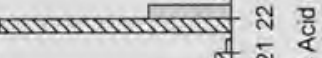

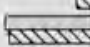

(2)

$\infty<$

I $=$

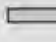

(114)

뗃ำ

मे

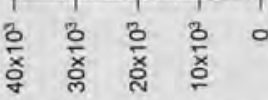

pəusnq әәมา fo $6 y / 6 u$

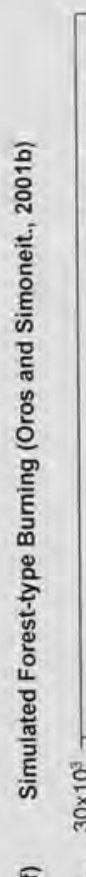

$=$

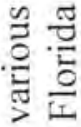

เิ

突

苞

$\stackrel{\Xi}{\Xi}:$

$\cong$

$\Xi$.

एृ

बालmयाम 2 \%

巳

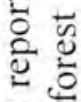

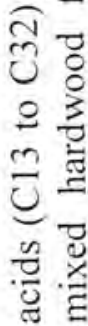

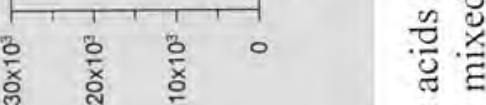

冚恶

$=$ iो

ธิ

芒 $\stackrel{\Xi}{0}$

胥苍

E of

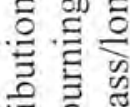

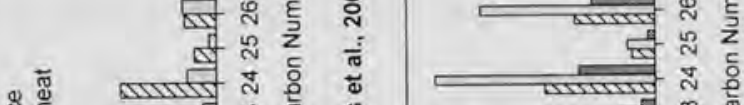

$\frac{\pi}{2}$ बान

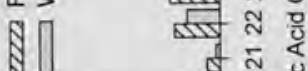
बत्यु aीt

aाय =

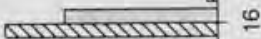
of $\frac{10}{-1}$

안다

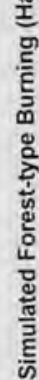

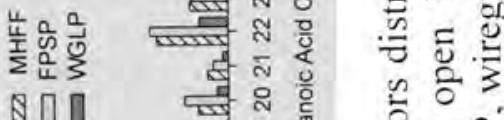

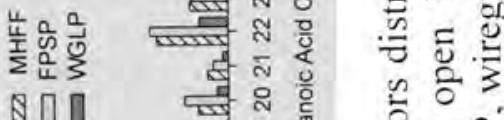

苟

뎅 a

E 3

灾芯芯

吉氞

ij

? ग क

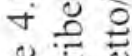

渮 
In general, the long-range air masses diagram shown in Figure 4.3 indicates that a northwestern component was ever present throughout the July sampling period together with other alternating regimes. In particular, Figure 4.33 shows one Hysplit trajectory map displaying the backtracked air masses trajectories ending at the sampling site on the $20^{\text {th }}$. The model shows that on that day a parcel originated from the northwest arrived at the sampling site very close to the time when the characteristic patterns emerge. There is also excellent agreement in the trajectory tracked from three independent runs (Figure 4.33 b); i.e., independently run trajectories ending on 19-, 20- and 21 -July. Wildfires and prescribed fires during the summertime are very common in all forest areas along the path of the northwesterly regime including, for example, Canada and Michigan, U.S. Prescribed fires can last for 2-3 days, and wildfires even longer. As an example, in each of the counties several thousands of fires burn over two million hectares every year. A large majority of the larger Canadian fires occur in the central provinces of Ontario and Manitoba (GFMC, 2002) in the large forest areas northwest of the Great Lakes. Therefore, this is a plausible explanation for part of the event. In addition, it must also be considered that part of the levoglucosan from 21-July is overlapped with one of a more "regional" origin, since as noted in Figure 4.3, on 21-22-July air parcels also came from the south, as did as well on 5-Agust and 10-12-August when the levoglucosan signal reemerges.

The diurnal variations of concentrations of the n-alkenoic acids and cholesterol for these two days are shown in Figure 4.34. In spite of very similar local wind direction from midday 20-July and throughout 21-22-July, the patterns are very different from day $20^{\text {th }}$ to $21^{\text {st }}$. The pattern of diurnal variation for these compounds is essentially erased 
through the $20^{\text {th }}$. Given the labile character of these species, this result suggests that the intrusion of the regional background during this episode has a prominent influence on the characteristics of the measured PM2.5 as proposed in section 4.3.3.2.

a) NOAA HYSPLIT MODEL

Backward trajectories ending at 11 UTC 20 Jul 02 EDAS Meteorological Data

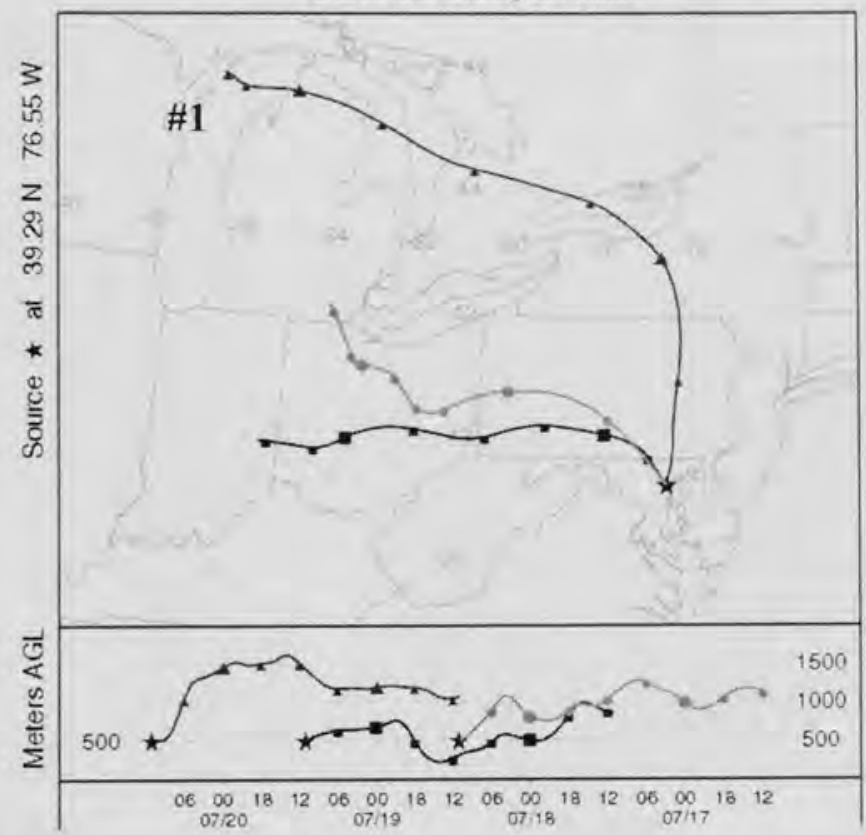

b)

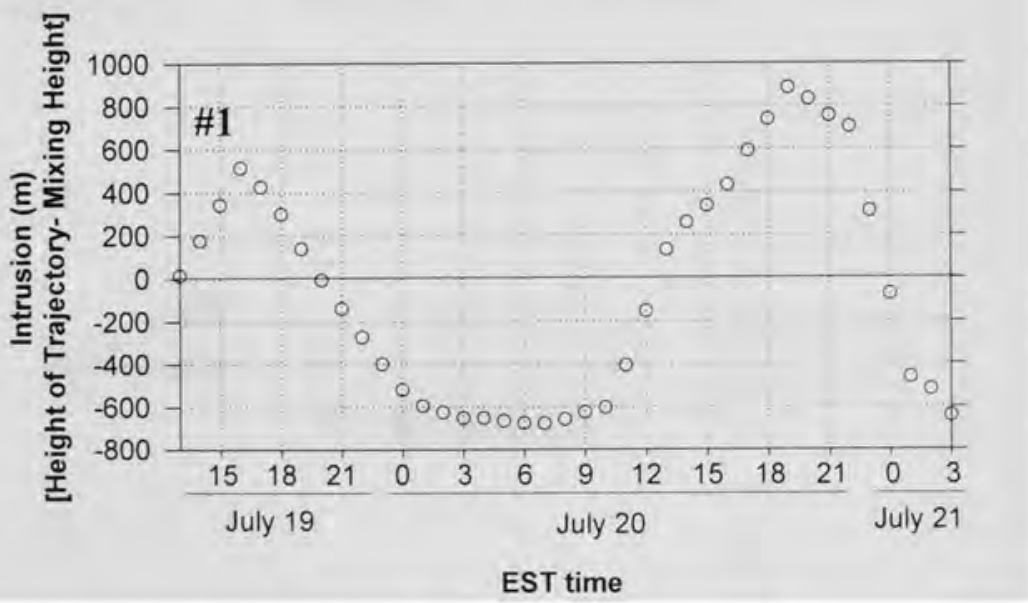

Figure 4.33: Hysplit trajectories map (a) and calculated intrusion diagram (b) (explained in section 4.3.1) of the trajectory labeled \#1 followed in the individual runs of four consecutive days (from 19 to 22 July). The standard deviation of each point is $\pm 10 \mathrm{~m}$. 


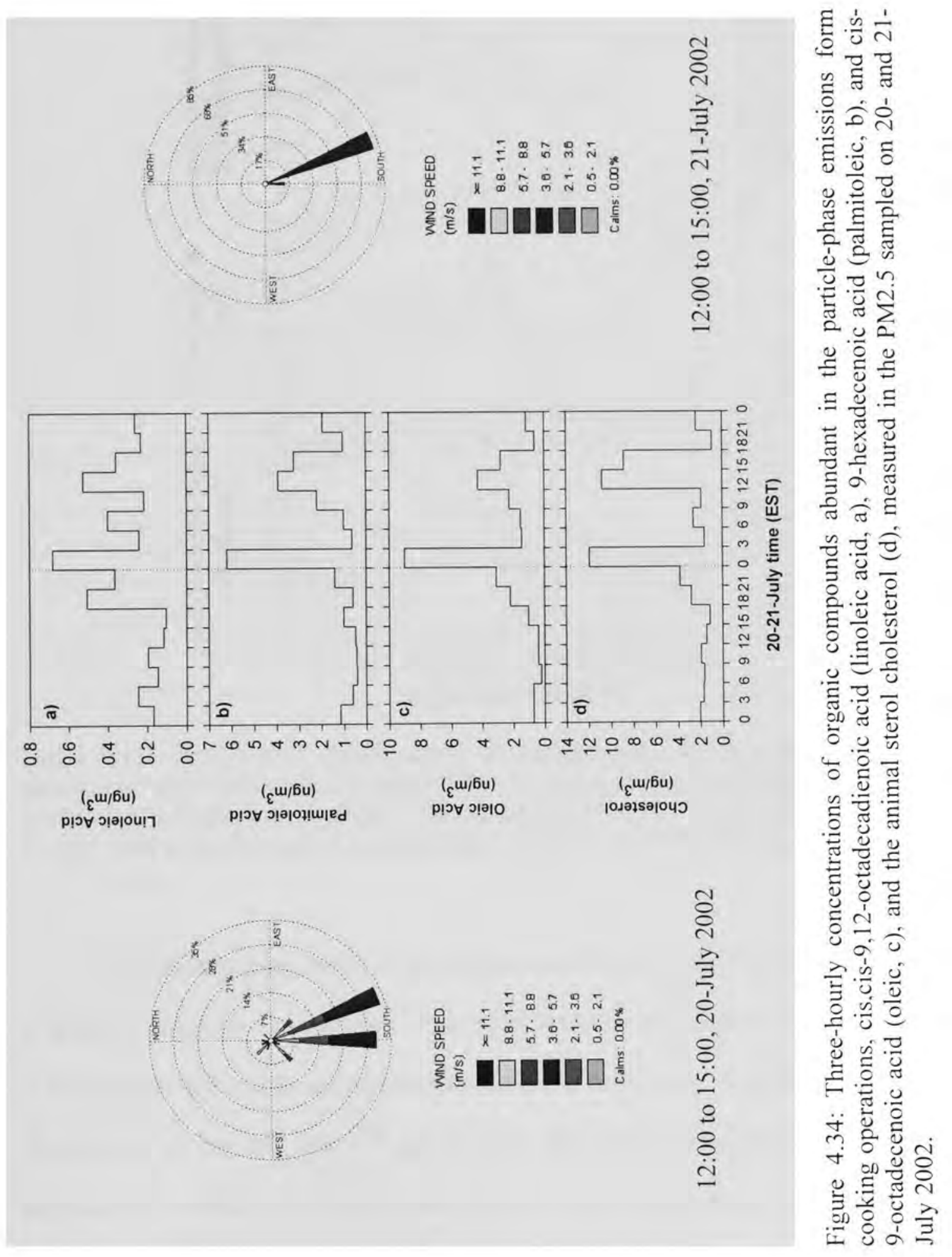




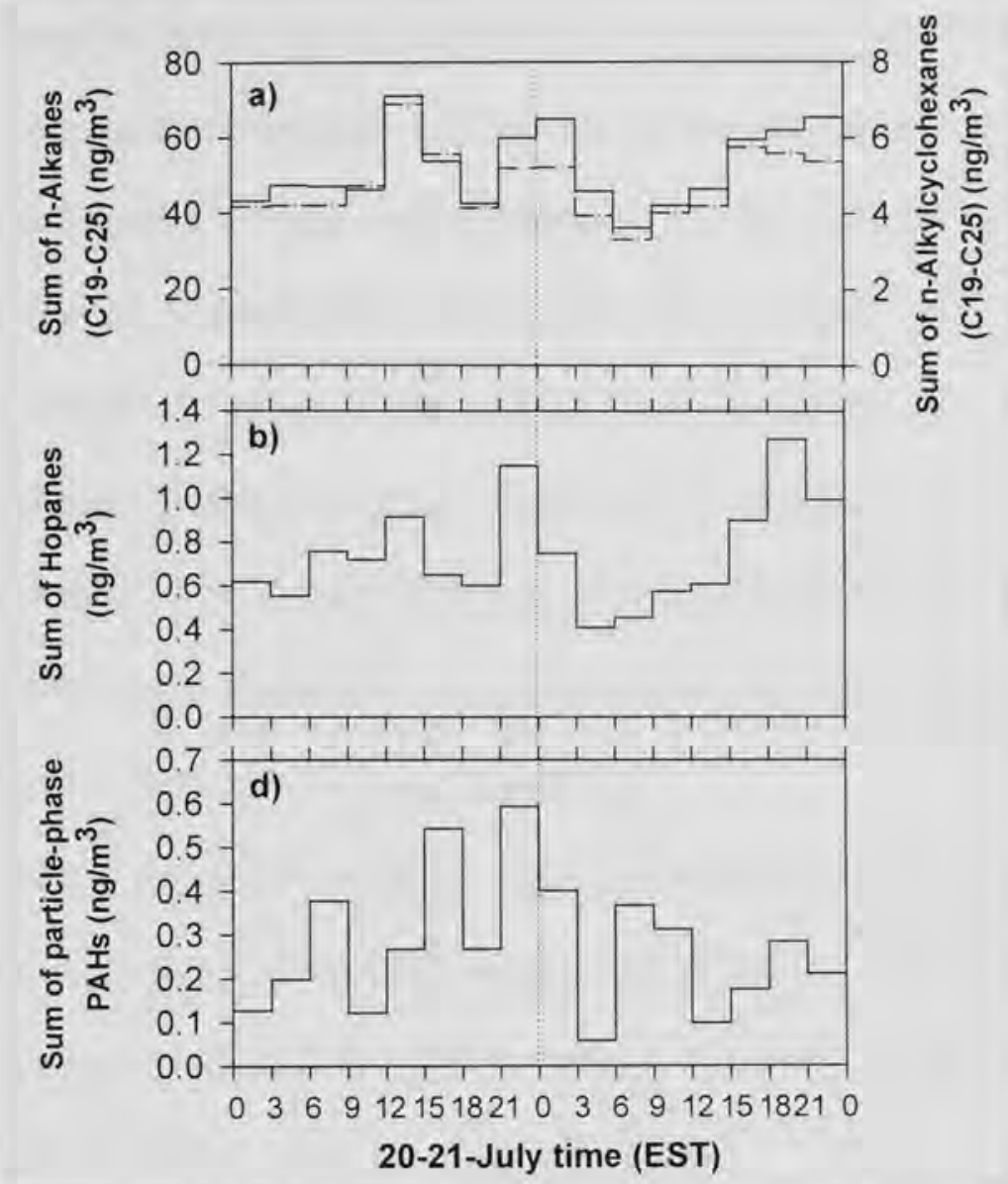

Figure 4.35: Three-hourly concentrations of select organic markers of fossil fuel, nalkanes (a), and n-alkylcyclohexanes (b), the petroleum biomarkers hopanes (c), and the combustion-derived particle-phase PAHs (d), measured in the PM2.5 sampled on 20- and 21-July 2002 at the Ponca Street site during the Baltimore PM-Supersite.

The concentration levels of the organic markers of fossil fuel derived products (Figure 4.35) are not very different from those observed on 6-August (Figures 4.16 and 4.17) suggesting that they are representative of local emissions. The differences between the patterns of day $20^{\text {th }}$ and $21^{\text {th }}$ and between these and those of 6-August could be explained by changes in the local wind direction and perhaps in part, also reflecting a weekend effect (Sa-20, Sun-21). 
Analogously to the 24-25-November event, the concentration levels and diurnal patterns of the aliphatic and aromatic dicarboxylic acids observed during the 20-21-July event are best understood in the context of the season's data as shown in Figures 4.36 and 4.37. Firstly, it is readily illustrated that the concentrations of these compounds are one to two orders of magnitude larger during this episode than on the rest of the summer sampling campaign. Secondly, for all species these maximum concentrations are observed as a transient 3-6 hours nighttime peak. Lastly, the peak concentrations of azelaic and adipic acids during this summer episode are very similar to the levels measured during the winter 24-25-November event.

Both azelaic and adipic acids have been measured as minor components in the aerosol emitted from wood burning and open biomass burning. For example, data from Hays et al. (2002) indicate that the open burning of the biomass emit azelaic acid in a proportion of $1 \%$ to $3 \%$ of the levoglucosan, and adipic acid in a proportion of less than $1 \%$ of the levoglucosan. In Baltimore, the fraction of azelaic acid relative to levoglucosan during the summer episode ranges between a minimum of $1 \%$ and a maximum of $36 \%$ with a median of $10 \%$, and the fraction of adipic acid from a minimum of $0.2 \%$ to a maximum of $5 \%$ with a median of $1.3 \%$. In fact, the median value of these fractions all through the summer set of samples is $21 \%$ and $4 \%$, respectively for azelaic and adipic acids. These results indicate that the atmospheric levels of these acids observed in Baltimore (Figure 4.36) are dominated by secondary formation; furthermore, the data suggests that during the summer and the winter there appears to be an association between higher levels of wood smoke burning (as recognized by levoglucosan) and greatly enhanced levels of azelaic and adipic acids. It is also noteworthy in Figure 4.36 
that two peaks are seen for these acids, a daytime (day $20^{\text {th }}$ ) consistent with local formation, and a nighttime much larger peak which could be explained as been associated with the arriving more "regional" (less old) parcel from the south and poorer atmospheric dispersion at night.

a)

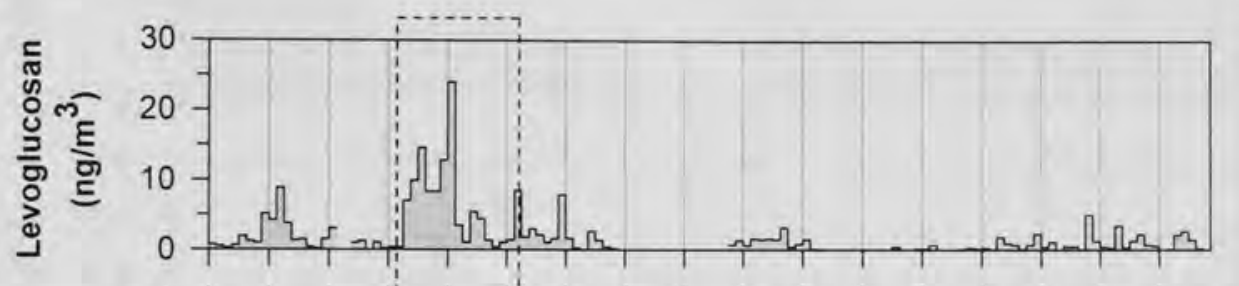

b)

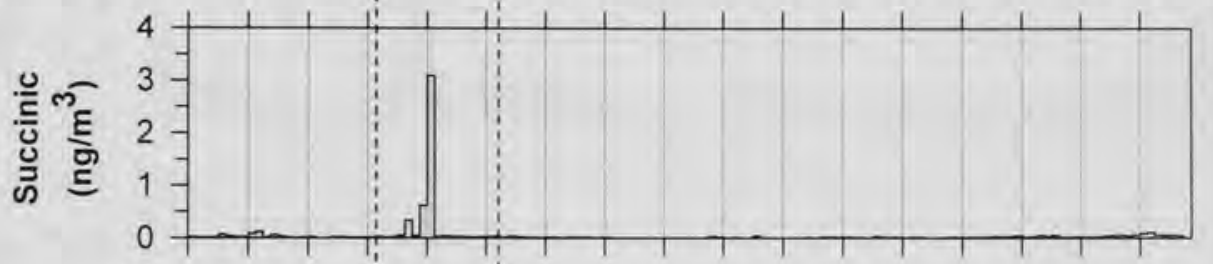

c)

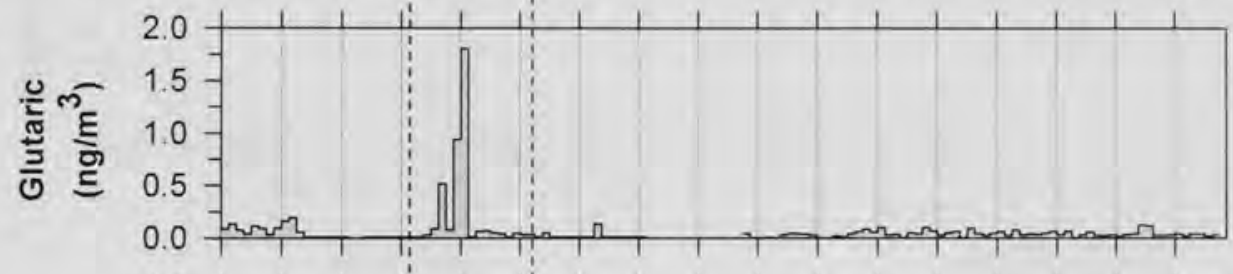

d)

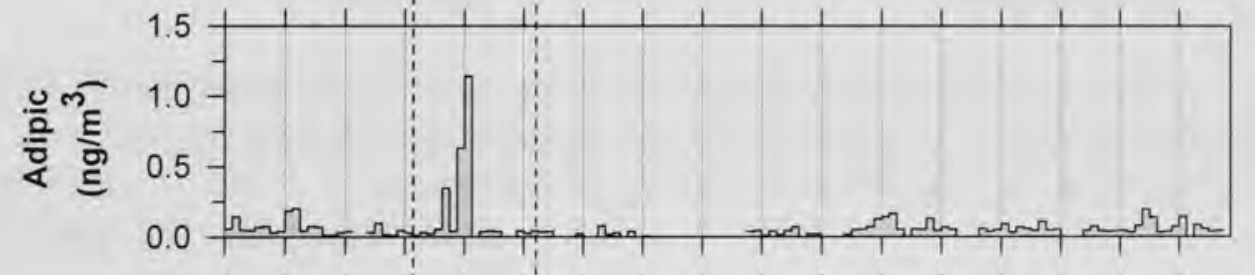

e)

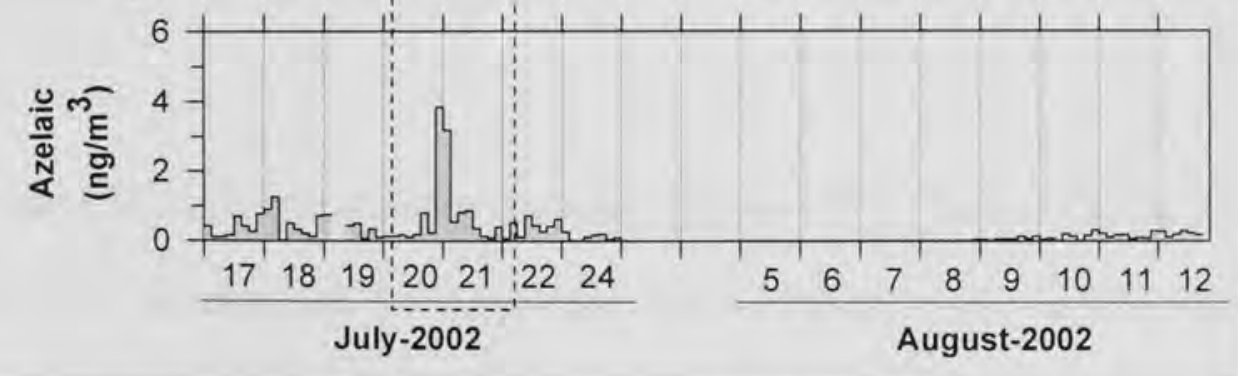

Figure 4.36: Time series of the three-hourly concentrations of levoglucosan (a) and the aliphatic dicarboxylic acids butanedioic (succinic, b), pentanedioic (glutaric, c), hexanedioic (adipic, d), and nonanedioic (azelaic, e) measured in the PM2.5 sampled during July and August 2002. 


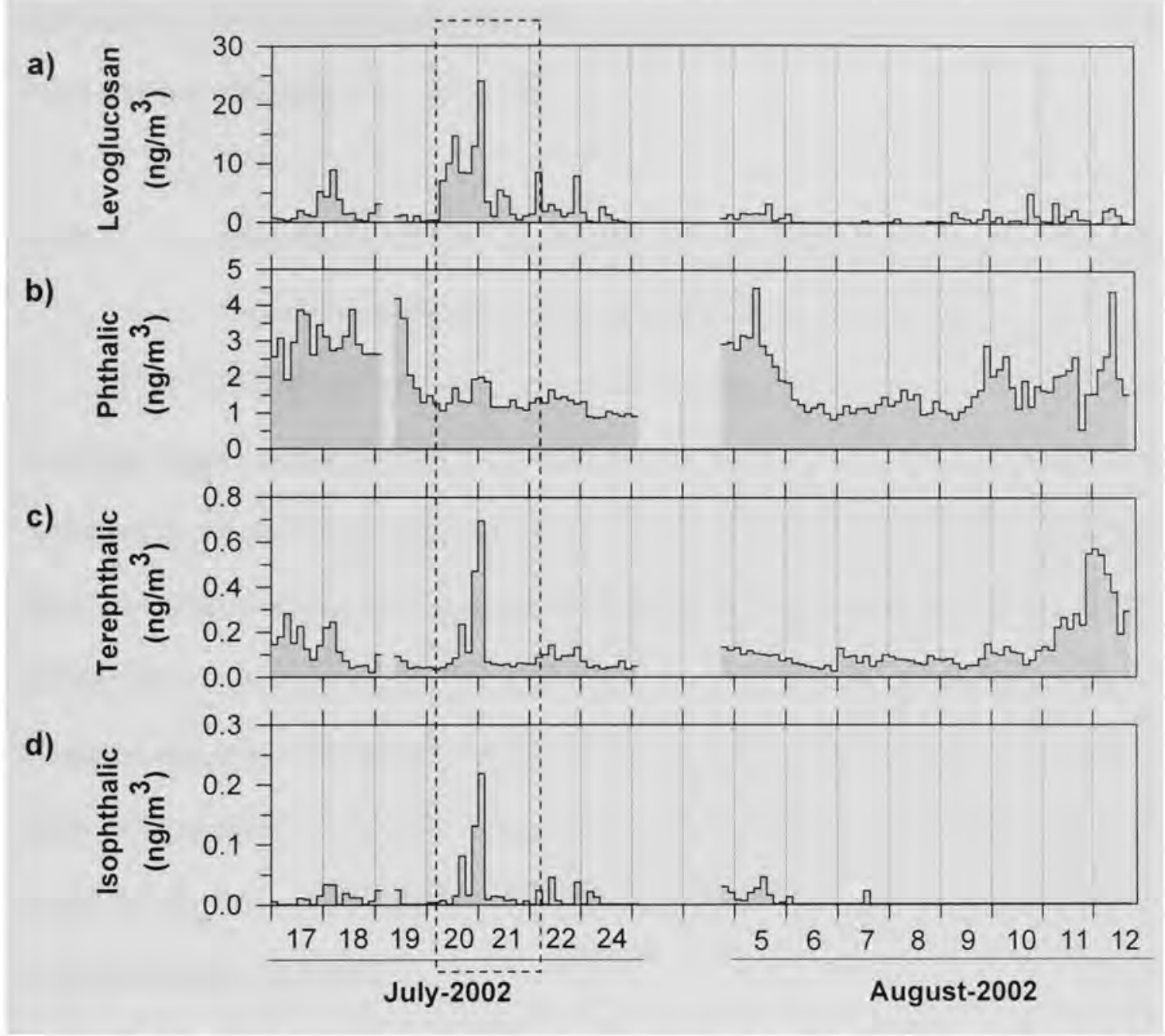

Figure 4.37: Time series of the three-hourly concentrations of levoglucosan (a) and the aromatic dicarboxylic acids 1,2-benzenedicarboxylic (phthalic, b), 1,4-benzenedicaboxylic (terephthalic, c), and 1,3-benzenedicarboxylic (isophthalic, d) measured in the PM2.5 sampled during July and August 2002.

Among the aromatic dicarboxylic acids (Figure 4.37), similar features as those described above are observed for terephthalic and isophthalic acids. In both cases, the large overnight concentrations could be explained as an effect of particles trapped into the nighttime mixing layer in the normal daily stability cycle and rapidly dissipating in the morning. In contrast, the levels of phtahlic acid during this episode were not 
appreciably affected, suggesting that their measured concentrations are controlled by other sources or factors.

\subsubsection{Association of the Variations in Minimum Daily Levels of Organic Compounds and the Origin of Transported Air Parcels}

Fine particles can stay suspended from a brief few minutes to several days. Acquiring eight samples of PM2.5 per day gives the unique opportunity to determine the variations in the minimum concentration of each of the organic compounds in sequential days. In order to account for atmospheric dilution, the minimum concentration of each compound was normalized by the corresponding 3-hourly OC concentration prior to assessing changes in the background levels. Let's call this minimum daily level the dailyMIN. If the observed daily-MIN would be determined only by sources nearby, then they would be similar in contiguous days provided that there is no major identifiable event or a significant amount of rain.

Evaluating the variations of the daily-MIN of each of the organic chemical species can help identify trends which may indicate the changing regimes of influencing background air. Comparing the trends of those variations with the diagram of the regimes of influx of background air throughout the sampling periods can help establish associations with the different areas. The results obtained for each individual compound are provided in simple bar plots in the Appendix C (Figures C.5 to C.13). Here, only relevant findings from the evaluation of the results will be presented.

A salient feature is the remarkable depletion of the n-alkanes homologues larger than $\mathrm{C} 25$ in the contiguous seven sampling days from July compared to August. This 
feature is particularly noticeable for n-pentacosane, exhibiting a minimum-maximum daily-MIN range of $0.10-0.43 \mathrm{ng} / \mu \mathrm{g} \mathrm{OC}$ in July and $0.42-2.19 \mathrm{ng} / \mu \mathrm{OC}$ in August. In addition, while the daily-MIN of $18(\alpha)$-22,29-30-trisnorneohopane and $17 \alpha(\mathrm{H})-22,29,30-$ trisnorhopane are very similar in July, August and the winter samples (0.02-0.06 ng/ $\mathrm{gg}$ $\mathrm{OC})$, that of the remaining hopanes show a trend of lower values in July (0.01-0.05 ng/ $\mathrm{gg}$ $\mathrm{OC})$ compared to August $(0.03-0.09 / \mu \mathrm{g} \mathrm{OC})$ and to the winter $(0.04-0.11 / \mu \mathrm{g} \mathrm{OC})$. The daily-MIN of the particle phase PAHs are also about 2-3 times larger in the winter days compared to August, and they are lower in July. For example, the daily-MIN ranges for

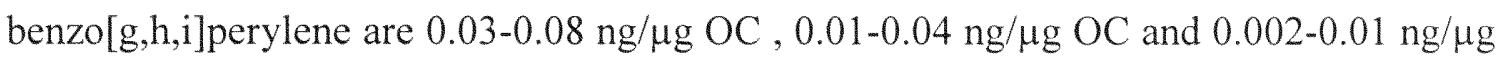
OC, respectively. These combined observations indicate that the overall characteristics of the aerosol during the July sampling period show a lower impact of fossil fuel burning compared to August.

The variations in the daily-MIN of the n-alkanoic acids are also informative. For example, the homologues with $\mathrm{C}>19$ display elevated values during 20-22-July. Among the lower molecular weight homologues distinctly larger daily-MIN of the homologues C9-C13 is noted on 18-19-July, a dip on day $20^{\text {th }}$ and rising again on 21-24-July but not to the point observed on the previous two-day period. Measurements reflect the overlapping prints of several inputs. Since we know that biomass burning had an influence during 20-22-July, it is possible that larger daily-MIN on these days are more associated to this specific episode. The levels suggest that local sources contributed by comparison less of the lower molecular weight homologues compared to the more ubiquitous $\mathrm{C} 16$ and $\mathrm{C} 18$, which daily-MIN remain approximately even. 


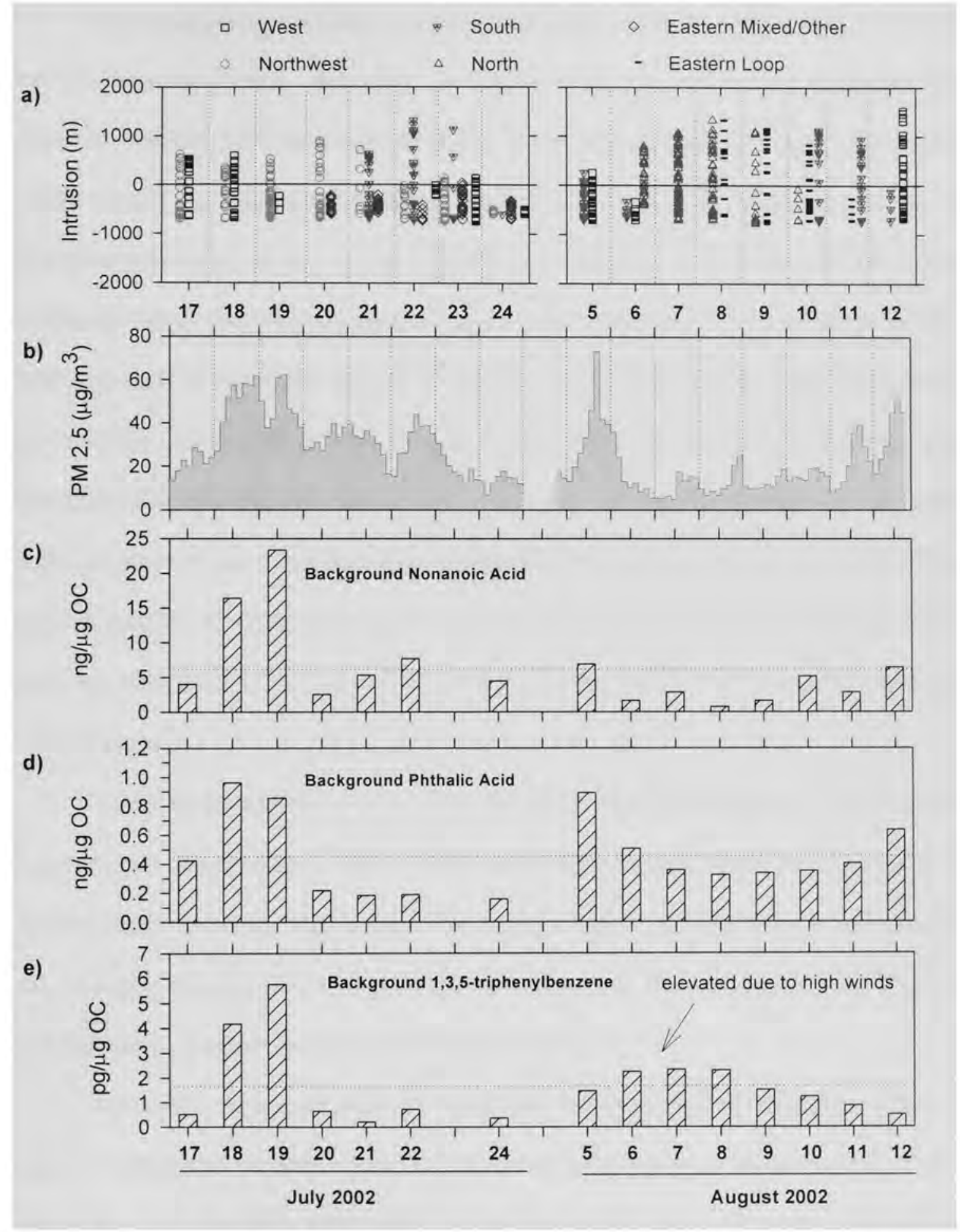

Figure 4.38: Diagram of the evolving geographical regimes of background air throughout the days of the summer sampling campaign (a), the 3-hourly concentrations of PM 2.5 mass (b), and the daily minimum concentration (background level) OC-basis of selected organic molecular markers (c-e). 
One surprising finding is the appreciably higher daily-MIN of 1,3,5triphenylbenzene during 18-19-July. In Figure 4.38, the results just described are displayed together with the diagrams of the intruding long-range air masses. During the summer sampling campaign, 3-hourly measurements of total PM2.5 mass at the sampling site were performed using the tapered-element oscillating microbalance (TEOM). The measured values exceeded the daily-standard on a continuous basis during 18-19-July and were close to exceeding during 20-21-July, 5-, and 11-12-August. Figure 4.38 shows the intrusion diagram for the summer, the 3-hourly time-series of the PM2.5 mass, and the daily-MIN of n-nonanoic acid, phthalic acid and 1,3,5-triphenylbenzene. This figure indicates that the days when excessive increases of the background concentrations of the organic species are observed coincide with the days of high PM2.5; furthermore, these days are associated to intrusion of the longer traveling air parcels originated from the western regions.

Many anthropogenic sources emit the low molecular weight n-alkanoic acids; however, the characteristic of the overall seven days in July have a lesser pyrogenic imprint compared to the August days. The days in July are influenced by air masses that are, in sequence, old (18-19-July), display an imprint of biomass burning (20-21-July), and successive southern and western flows until the $22^{\text {nd }}$.

Nonanoic and azelaic acids are commonly observed product of the heterogeneous ozonolysis/aging of particles containing oleic acid (review paper: Zahardis et al., 2006). Therefore, one reasonable explanation for the appreciably larger values of daily-MIN of n-nonanoic acid is that they are associated to the relativele more processed background air. Additional pieces of strong evidence are the relative apparent depletion of the high 
molecular weight n-alkylcyclohexanes larger than C28 (Figure C.10 and Figure C.18) and n-alkanes larger than C32 (Figure C.5 and Figure C.13).

Since the n-alkylcyclohexanes are derived from petroleum, their presence in urban aerosol is evidence of fossil fuel input. While the indications from the lower- and the mid-molecular weight homologues may be confusing in a situation where overlapping short- and long-range signals are present; the predominant source, if not the only, of the large molecular weight homologues with $\mathrm{C}>28$ is the re-suspension of road dust. Here, the backgrounds of those species are very similar in the winter and August, but they are much lower or below detection limit in July, as can be seen from the Appendix C figures.

Hostettler et al., (2002) have conducted studies to investigate the bacterial degradation of the aliphatic series of n-alkanes and n-alkylcyclohexanes and they have observed that both homologues series display a degradation sequence that starts at the high molecular weight end and displays a simultaneous enhancement of the concentrations of the lower-end homologues. While there are numerous biogenic and anthropogenic sources of $n$-alkanes that can difficult or mask finding evidence of such environmental degradation for this series, the n-alkylcyclohexanes measured in urban areas are exclusively derived from crude oil distillate fractions, particularly lubricating oils and diesel fuel; therefore, if the fraction of the high molecular weight nalkylcyclohexanes would be markedly lower in some days this would be an indication of a greater degree of weathering.

In order to avoid any temperature related bias in the comparison of data from both seasons, we take a ratio of compounds that we know are solely found in the filters in samples from the winter and the summer. Since the higher homologues C27 and C28 are 
not even found in more than half of the summer samples, we compute the ratio of the sum of the homologues C25 (n-nonadecylcyclohexane) and C26 (n-eicosylcyclohexane) divided by the sum of the homologues C23 (n-heptadecylcyclohexane) and C24 (noctadecylcyclohexane). As shown in Figure 4.39 during the winter, the 3-hourly samples display an average ratio of $0.61 \pm 0.10$; on the other hand, the summer samples display a much lower and more variable ratio. The 3-hourly samples from 6-12-August display an average ratio of $0.28 \pm 0.12$ for, and the average ratio is $0.10 \pm 0.05$ for the rest of the samples. This result supports the conclusion that, compared to August, the July sampling week was influenced by an appreciably older/aged aerosol.

a)

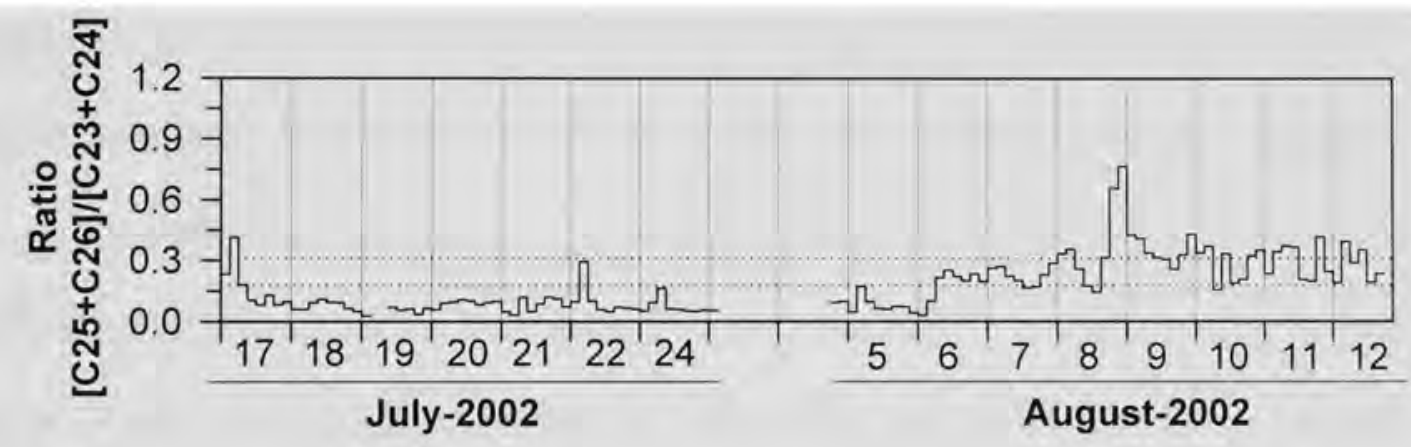

b)
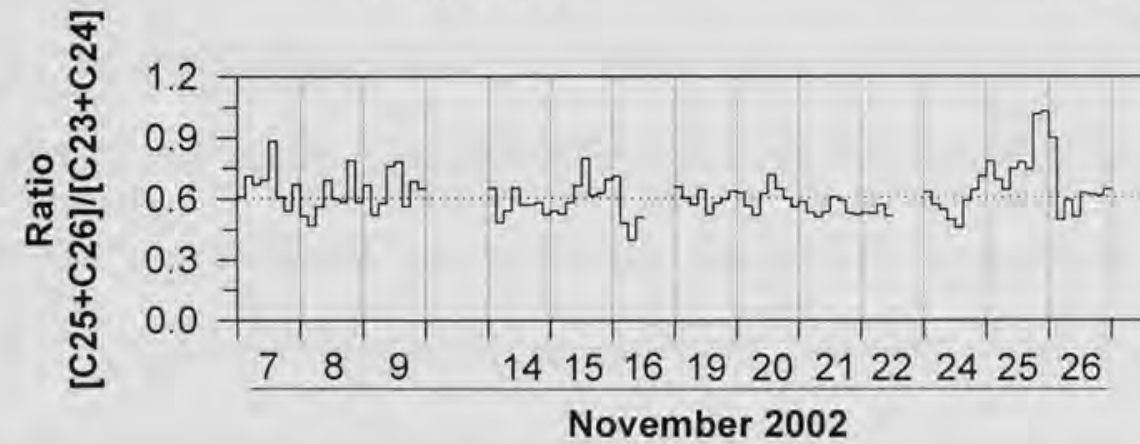
whe vish

Figure 4.39: Time-series of the three-hourly ratios of the n-alkylcyclohexanes ([nonadecylcyclohexane]+[eicosylcyclohexane])/([heptadecylcyclohexane] + [octadecylcyclohexane]) during summer (a) and winter (b). 
Lastly, a significant increase of the daily-MIN of the polyaromatic hydrocarbon 1,3,5-triphelbenzene (Figure 4.38 e), a marker for incineration activity (Tong et al.. 1984), can also be taken as an indication of transport. This compound is in the list of persistent organic pollutants and it has been associated with transport over thousand of kilometers from its source (for example, Primbs, et al, 2007). The local cycles of this compound are still well distinguishable (see Figure 4.7 a) over the elevated daily-MIN; however, even after accounting for dilution on a OC-basis, this level still appears to be significantly enhanced through 18-19-July.

Figure 4.40 shows the analogous sequence of diagram and compounds for the winter data set. It can be seen that the daily-MIN of n-nonanoic acid is at least one order of magnitude lower than the observed during the summer; that is, all values are below 1 $\mathrm{ng} / \mu \mathrm{g}$ OC compared to a median of $4.0 \mathrm{ng} / \mu \mathrm{g}$ OC in the summer. A steady increase is observed through 24-26-November; this is likely associated to the event examined in section 4.3.3.4. Phthalic acid also displays lower daily-MIN in the winter, but the difference is less pronounced, all values are below $0.15 \mathrm{ng} / \mu \mathrm{g}$ OC compared to a median of $0.35 \mathrm{ng} / \mu \mathrm{g}$ OC in the summer. The higher value on $26-$ November is likely associated to wood burning and the 7-November coincides with the period of most intrusion activity, from the west/northwest and southwest. Though the background levels of 1,3,5triphenylbenzene are mostly even throughout the sampling season, they are in average five times larger than the summer median value. Day $22^{\text {nd }}$ experienced appreciable higher wind speeds; however, a reason for the generally larger daily-MIN values for this compound is unknown. 
a)

$$
\text { ․ West South - Eastern Loop }
$$

- Northwest $\nabla$ Southwest $\circ$ Northern-mixed Ocean-short

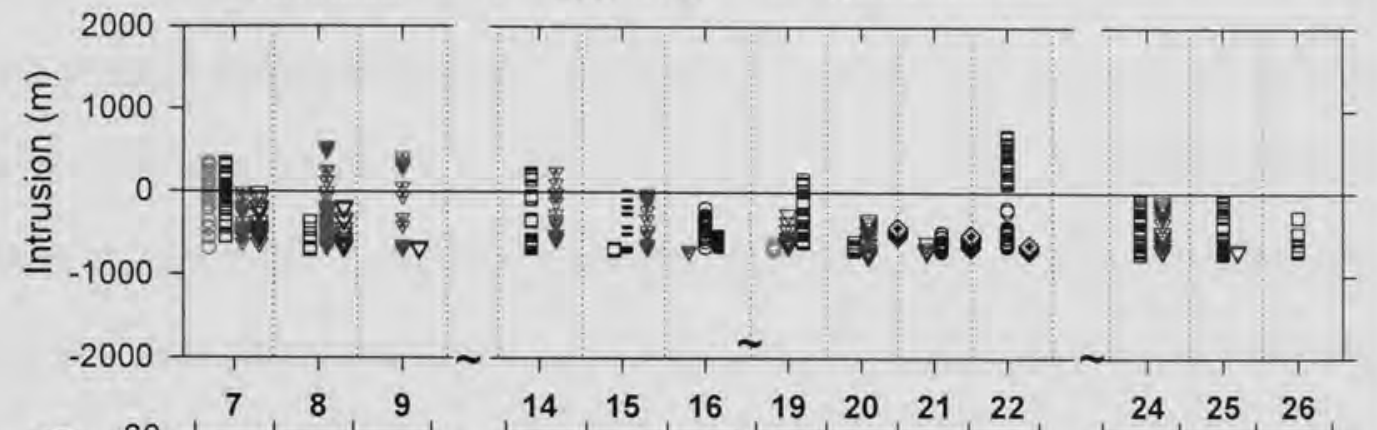

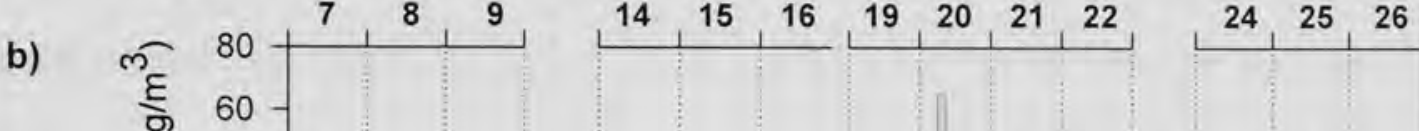

c)

d)
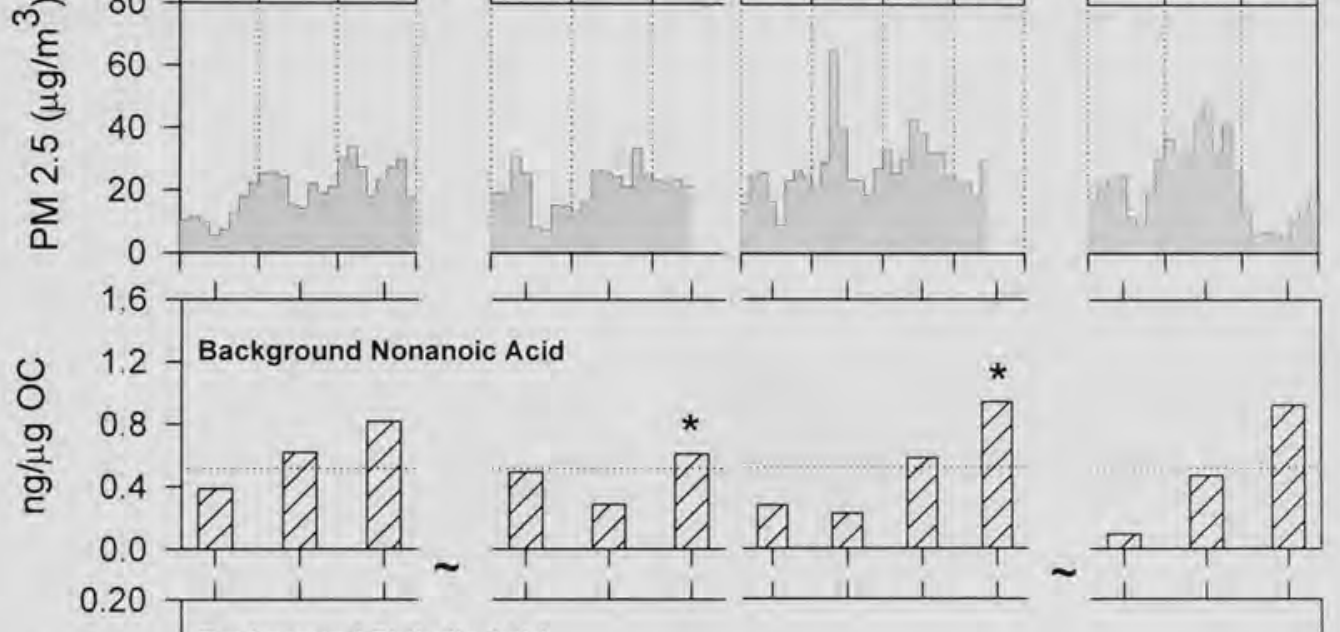

e)
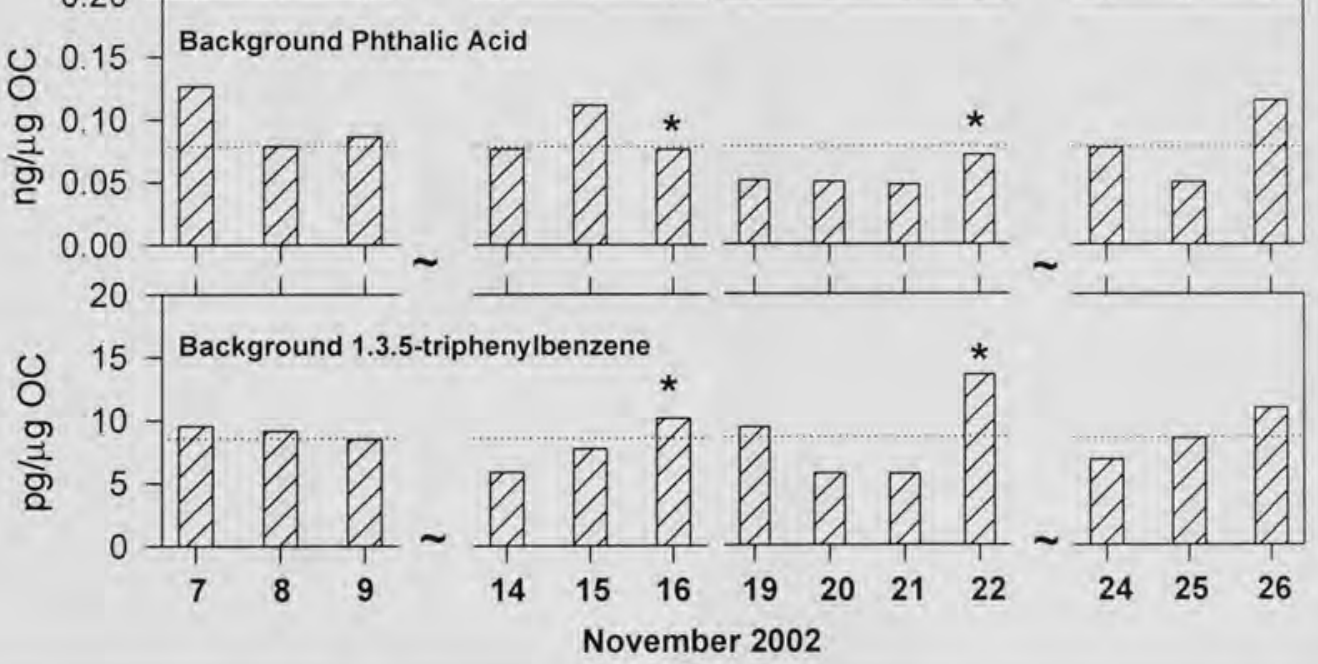

Figure 4.40: Diagram of the evolving geographical regimes of background air throughout the November sampling days (a), the 3-hourly concentrations of PM 2.5 mass (b), and the daily minimum concentration (background level) OC-basis of selected organic molecular markers (c-e). Marked with asterisk $(*)$ are the days for which the last sample was for the period starting at 09:00; i.e., not a complete day. 
Local wind speed pattern played a role on the rise of the daily-MIN values observed on 6-8-August, with distinct characteristics on day $6^{\text {th }}$. As explained in previous sections, during 6-9-August the local wind direction was from the north, aligned with the large-scale winds, while during the 9-12-August the local winds were mostly from the south (see Appendix B). The continuous influx from local sources from the north (6-9August) and from the south (9-12-August) elevates the background of the fossil fuel markers; this is illustrated in Figure 4.41. Yet, PM2.5 levels remained low until day $10^{\text {th }}$.

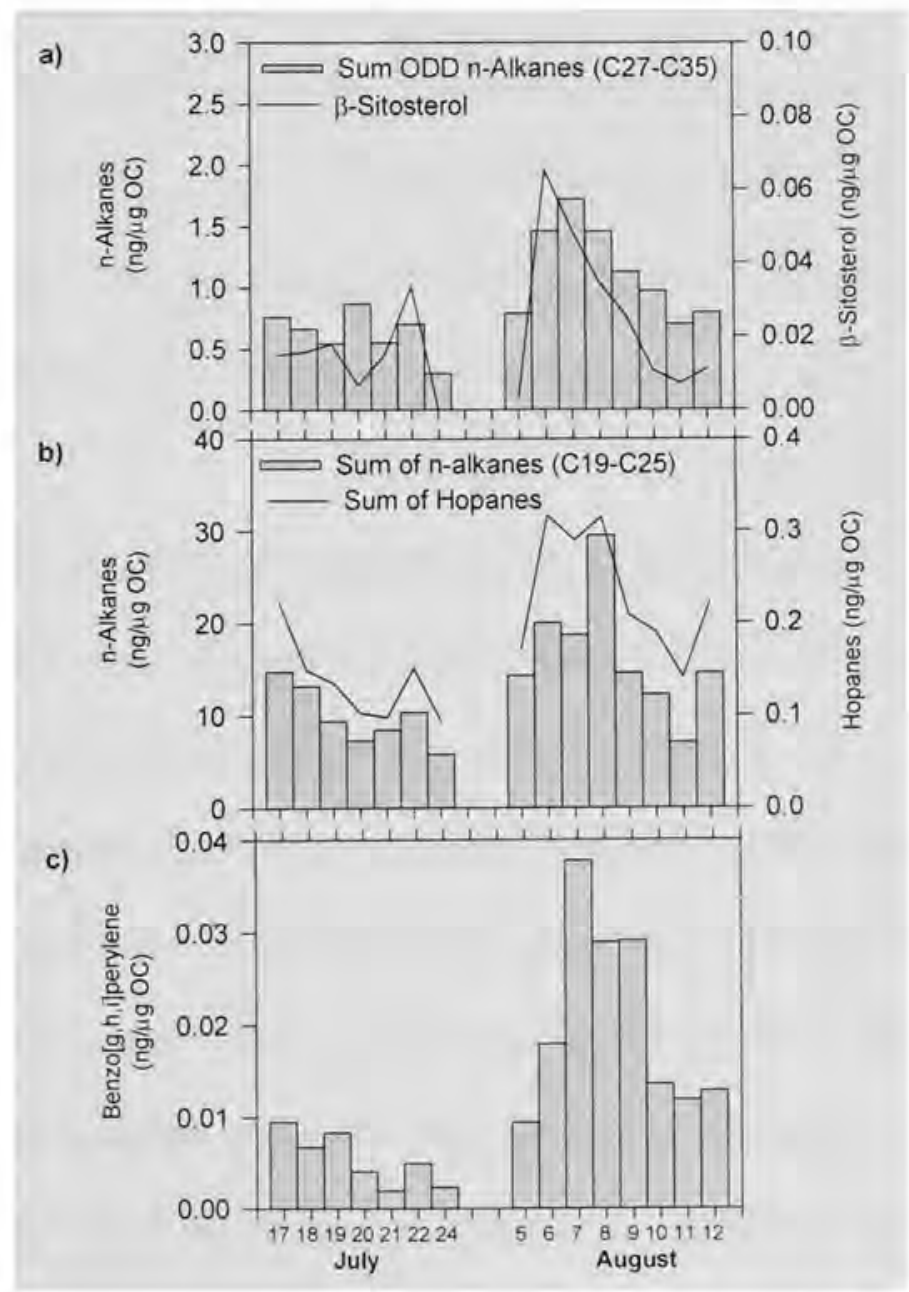

Figure 4.41: Daily minimum concentration on a OC-basis (daily-MIN) of selected biogenic (a) and anthropogenic (b, c) organic molecular markers during the summer 2002 sampling campaigns. 


\subsubsection{Association of the Variations in the Daily Cycles of Biogenic \\ Secondary Reaction Products and the Origin and Characteristics of the Background Air}

During the summer, the 3 -hourly concentrations of nopinone follow a trend very similar to that of humidity. This is illustrated in Figure 4.42. Due to their low vapor pressure $\left(0.402\right.$ torr, $8.5 \times 10-4$ torr and $1.9 \times 10-4$ torr at $25^{\circ} \mathrm{C}$ for nopinone, norpinonic acid and cis-pinonic acid, respectively) secondary organic aerosols form in the gas phase and partition onto pre-existing particles. The effect of temperature and ambient humidity on this partition equilibrium has been investigated (detailed in Review by Lee et al., 2006). More recently results from a chamber study (Stenby et al., 2007) have suggested that the yields of nopinone are determined more strongly by the effects of temperature and humidity on the chemical reaction itself than the vapor pressure dependencies of the products.

Here, we investigated the correlations between the 3-hourly concentrations of nopinone and the corresponding ambient relative humidity. In Table 4.1 the values of the linear correlation parameters for each day of the summer and the winter are given. Several important pieces of information can be gathered from this simple analysis. The correlation factors reaffirm what is illustrated in the time-series diplayed in Figure 4.42; that is; there is a consistently high correlation during the summer. Furthermore, it is also informative that the intercept is negative for each day as this suggests that the ambient humidity in fact determines the ambient concentration of particle-phase nopinone. On the other hand, during the winter, only on two days, 20-November and 26-November, humidity appears to play a role. 
A further evaluation of the daily 3 -hourly concentrations averages or sum indicate that the best association of nopinone and relative humidity is observed during August, coinciding with the period when a positive correlation is also seen between the daily concentrations of $\mathrm{O}_{3}$ and nopinone (Figure 3.23). Figure 4.43 illustrates the correlations of the daily averages of nopinone with both $\mathrm{O}_{3}$ and humidity during summer and winter. Thus far, it can be concluded that from 6-August to 12-August the production of particlephase nopinone could be explained by a mechanism involving $\mathrm{O}_{3}$ and dependent on the ambient humidity. In contrast, during the winter, the formation of nopinone appears more associated to NOx (see Figure 3.23) and a dependence on the relative humidity is not observed. Also, on 9-, and 15-16-November the concentrations of nopinone are twothree times larger than indicated by the trends derived from either the $\mathrm{O}_{3}$ or $\mathrm{NOx}$ systems.

Table 4.1: Correlation Parameters, $\mathrm{R}^{2}$, slope and intercept, for the Linear Fitting of the three-hourly Concentrations of Nopinone vs Relative Humidity for each summer and winter sampling day.

\begin{tabular}{lrrrlrrr}
\hline Date & $\mathrm{R}^{2}$ & Slope & Intercept & & $\mathrm{R}^{2}$ & Slope & Intercept \\
\hline 17-Jul-02 & $\mathbf{0 . 5 4}$ & $\mathbf{0 . 1 9}$ & $\mathbf{- 4 . 4 7}$ & 7-Nov-02 & 0.05 & 0.00 & 0.68 \\
18-Jul-02 & $\mathbf{0 . 5 8}$ & $\mathbf{0 . 1 4}$ & $\mathbf{- 4 . 6 7}$ & 8-Nov-02 & 0.02 & 0.02 & 2.74 \\
19-Jul-02 & 0.15 & 0.05 & -1.57 & 9-Nov-02 & 0.38 & 0.18 & -3.84 \\
20-Jul-02 & $\mathbf{0 . 8 7}$ & $\mathbf{0 . 1 1}$ & $\mathbf{- 3 . 8 2}$ & 14-Nov-02 & 0.00 & -0.01 & 3.28 \\
21-Jul-02 & $\mathbf{0 . 5 1}$ & $\mathbf{0 . 1 4}$ & $\mathbf{- 7 . 1 2}$ & 15-Nov-02 & 0.10 & -0.12 & 23.45 \\
22-Jul-02 & 0.47 & 0.13 & $\mathbf{- 5 . 6 7}$ & 16-Nov-02 & 0.12 & -0.20 & 30.41 \\
24-Jul-02 & 0.38 & 0.10 & -6.18 & 19-Nov-02 & 0.05 & -0.05 & 7.13 \\
5-Aug-02 & 0.39 & 0.27 & $\mathbf{- 1 2 . 0 5}$ & 20-Nov-02 & 0.64 & 0.13 & $\mathbf{- 5 . 2 3}$ \\
6-Aug-02 & $\mathbf{0 . 8 7}$ & $\mathbf{0 . 0 5}$ & $\mathbf{- 1 . 1 6}$ & 21-Nov-02 & 0.27 & 0.33 & -26.44 \\
7-Aug-02 & $\mathbf{0 . 5 9}$ & $\mathbf{0 . 0 6}$ & $\mathbf{- 1 . 8 1}$ & 24-Nov-02 & 0.17 & 0.05 & -0.58 \\
8-Aug-02 & $\mathbf{0 . 5 3}$ & $\mathbf{0 . 0 5}$ & $\mathbf{- 1 . 0 9}$ & 25-Nov-02 & 0.12 & -0.07 & 10.23 \\
9-Aug-02 & $\mathbf{0 . 9 1}$ & $\mathbf{0 . 0 8}$ & $\mathbf{- 1 . 7 7}$ & 26-Nov-02 & 0.66 & $\mathbf{0 . 0 2}$ & $\mathbf{- 0 . 3 2}$ \\
10-Aug-02 & $\mathbf{0 . 6 7}$ & $\mathbf{0 . 1 4}$ & $\mathbf{- 4 . 1 3}$ & 21-Feb-03 & 0.16 & -0.02 & 2.71 \\
11-Aug-02 & $\mathbf{0 . 8 9}$ & $\mathbf{0 . 1 2}$ & $\mathbf{- 3 . 7 9}$ & 23-Feb-03 & 0.00 & -0.00 & 1.36 \\
12-Aug-02 & $\mathbf{0 . 9 4}$ & $\mathbf{0 . 2 0}$ & $\mathbf{- 6 . 5 6}$ & & & & \\
& & & & & & & \\
Average & 0.68 & 0.11 & $\mathbf{- 3 . 5 6}$ & Average & 0.45 & -0.01 & 2.84 \\
Standard & & & & Standard & & & \\
Deviation & 0.12 & 0.06 & 2.19 & Deviation & 0.37 & 0.11 & 6.79 \\
\hline \hline
\end{tabular}




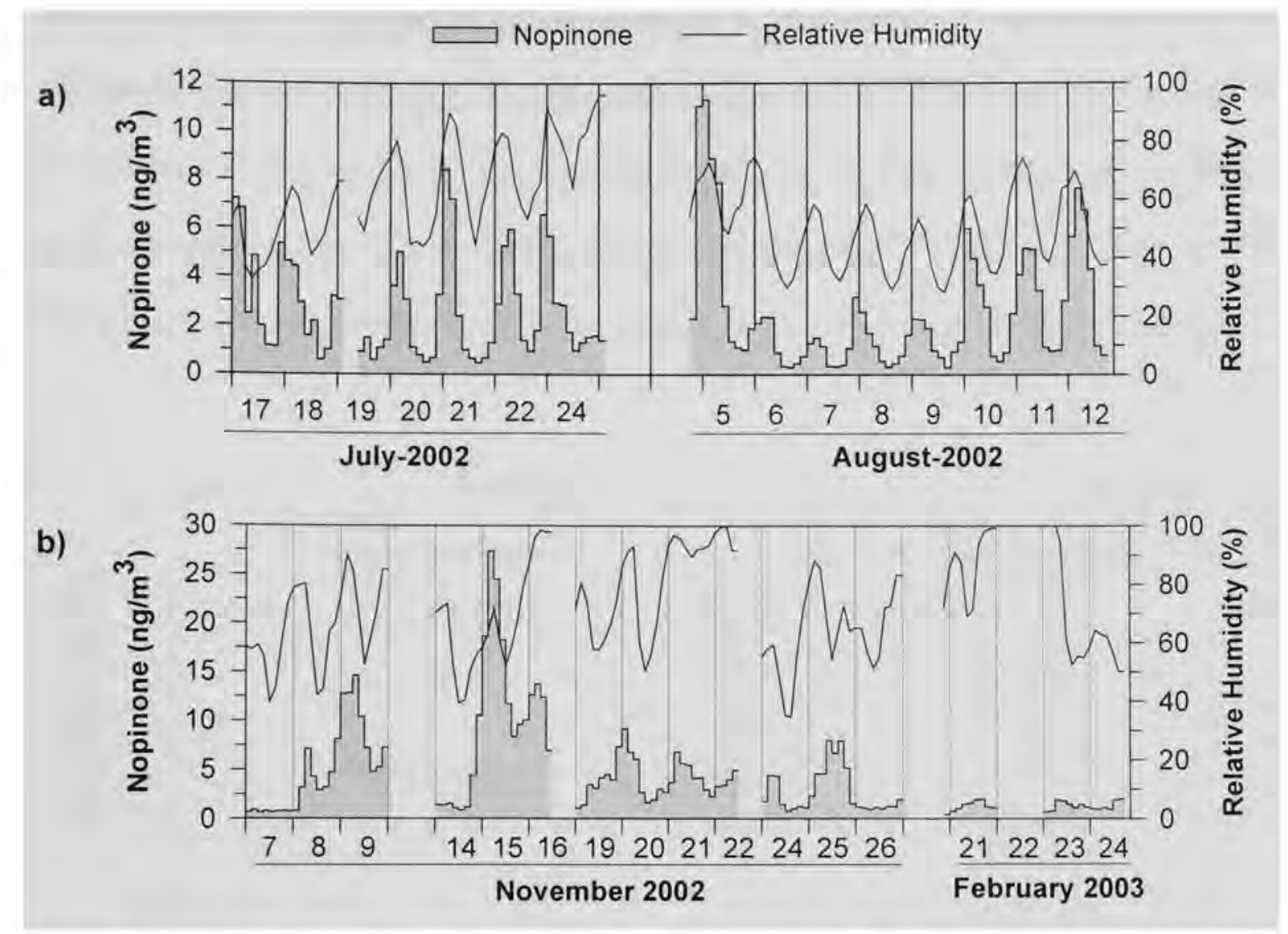

Figure 4.42: Time series of the three-hourly summer (a) and winter (b) concentrations of nopinone and relative humidity.

As presented in section 3.3.2.9, the progression of the 3-hourly concentrations of both nopinone and phytone suggests an "accumulation-like" curve, particularly strong during two separate two-day periods, 8-9-November, 15-16-November. This trend is also displayed here in Figure 4.42 for nopinone. It was also explained before, that during the summer, particularly during the August days, a correlation with $\mathrm{O}_{3}$ and dependent on humidity is found, and all peaks are observed at night. Because the concentration of $\mathrm{O}_{3}$ is low, it is unlikely that the nighttime peaks of 8 -November and most especially 14November be associated to $\mathrm{O}_{3}$. Furthermore, no nighttime peak is observed in association 
to the largest levels of winter $\mathrm{O}_{3}$ (7-November and 24-November). An additional piece of relevant information is given by the ratio benzo[a]pyrene $(\mathrm{BaP})$ to benzo[e]pyrene $(\mathrm{BeP})$; as explained in section 3.3.2.7 and illustrated in Figure 3.20, this ratio display a diurnal minimum at noon, due to photochemical degradation, everyday with the exception of 8November and 14-November when two minimum are observed, one of them at nighttime.
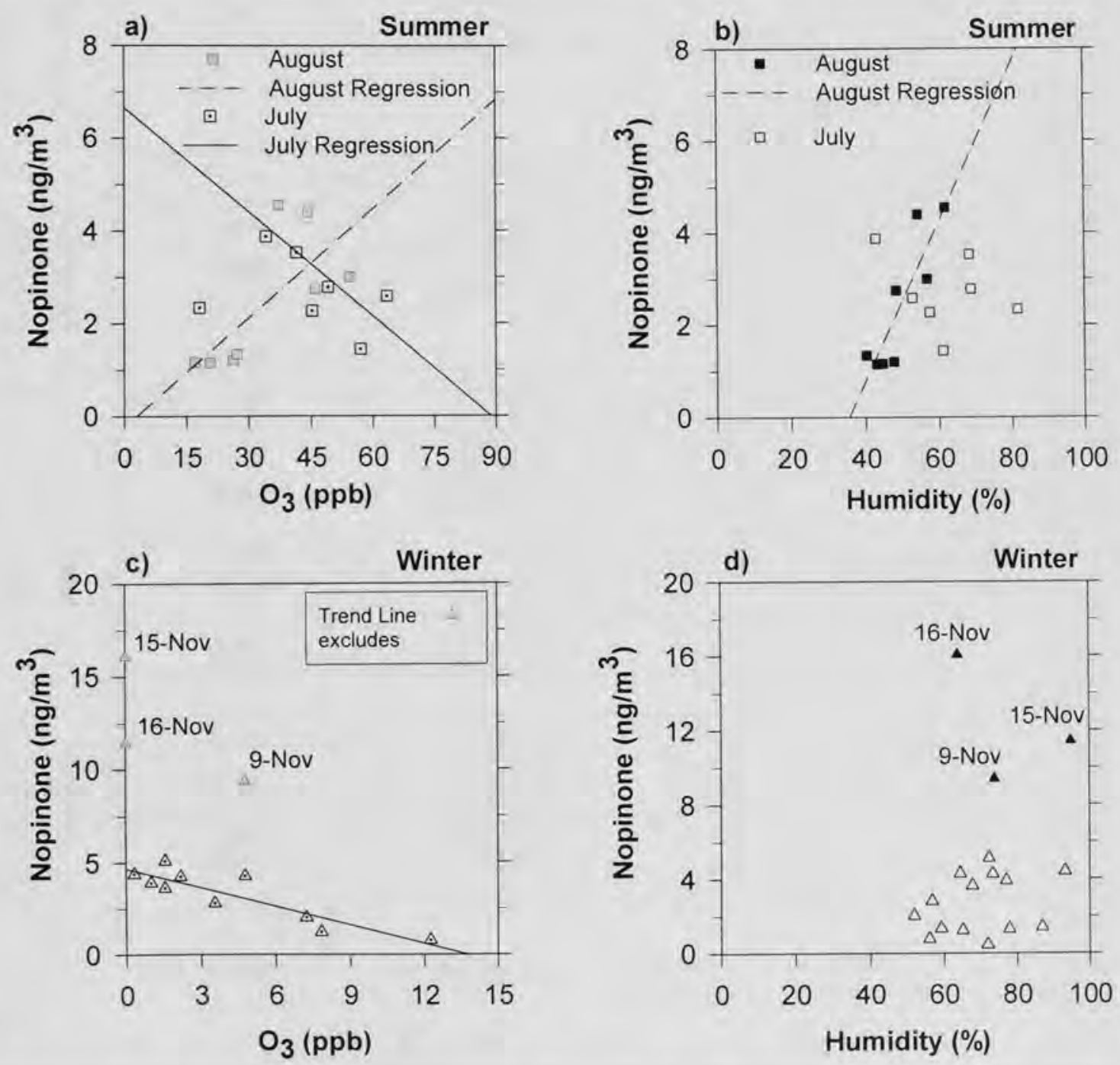

Figure 4.43: Scatter plots showing the associations of the daily averaged concentrations of nopinone vs. those of ozone $\left(\mathrm{O}_{3}\right)(\mathrm{a}, \mathrm{c})$ and the ambient relative humidity $(b, d)$ in summer and winter, respectively. 


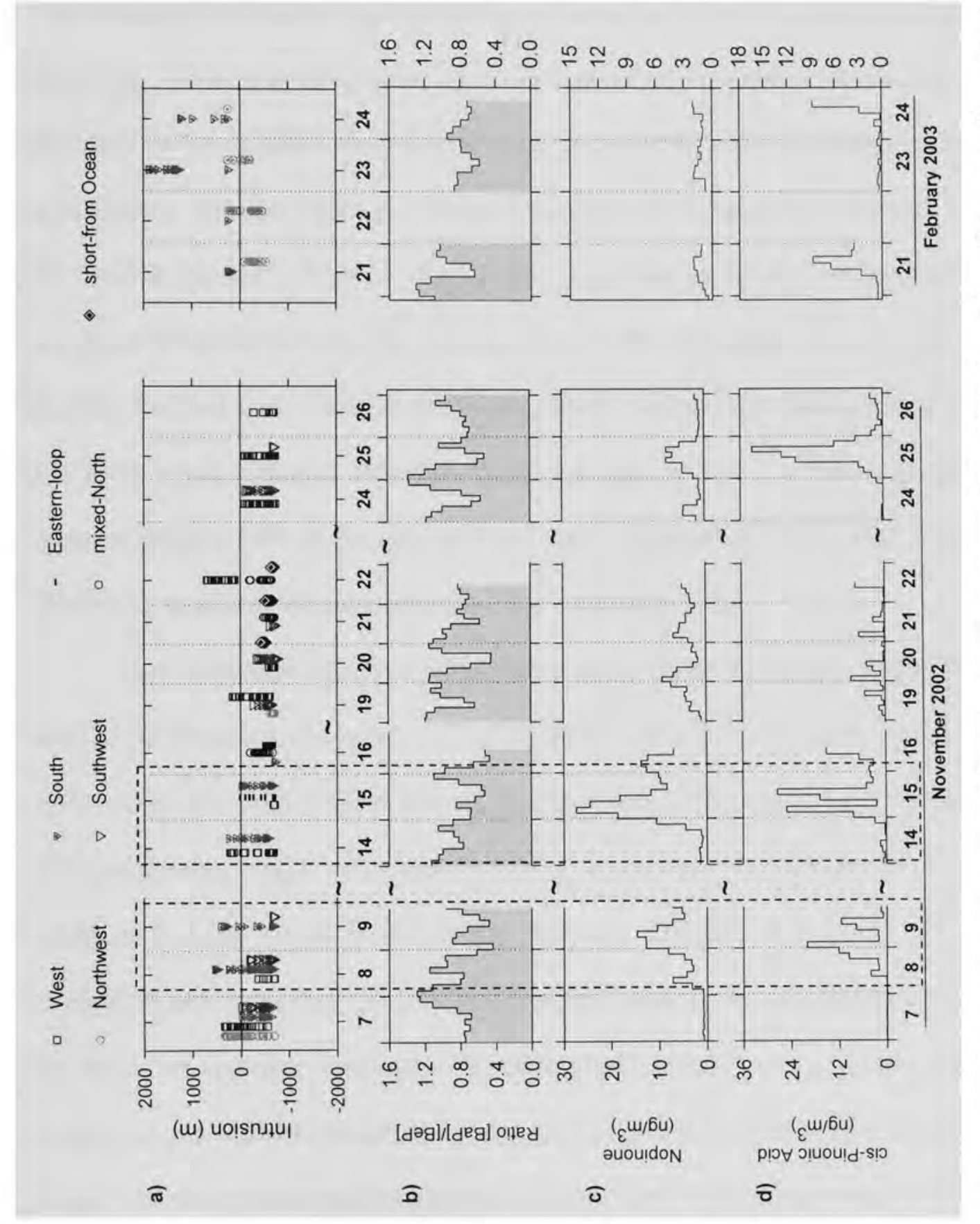

हี

of

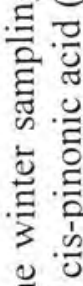

ङ

ङ0

อั

층

밀

N

呐

n

吉 元

은

ฮี

을

范

¿ $\frac{0}{0}$

कD 르

$\frac{0}{0}$

3 ㄴ.

르

$4 \frac{\pi}{0}$

콩

DD 
Figure 4.44 displays the winter intrusion diagram together with the ratio $\mathrm{BaP} / \mathrm{BeP}$ and the time-series of 3-hourly concentrations of nopinone and cis-pinonic acid. According to the diagram, such episodes are associated with long-range air parcels from the south. In the second episode, 14-15-November, and a trend of the steadily lowering $\mathrm{BaP} / \mathrm{BeP}$ values is noted. Recalling from section 4.3.2 that the near surface-wind pattern was aligned with the long-range winds throughout 7-15-November, the last 24 -hour of the Hysplit trajectory, shown in Figure 4.45, indicate that for days 8- and 14-November the parcel's trajectories traveled through areas of West Virginia and Virginia which are densely forested (U.S. Geological Survey, 2000). In contrast, during 19-22-November the local winds changed direction frequently and, as seen in the long-range winds diagram (Figure 4.44 a) the parcels travel short distances and come mixed from many directions; therefore, the measured PM2.5 is essentially local.

One additional significant observation from Figure 4.44 is the appreciably larger ratio of cis-pinonic to nopinone on days 25-November and 21-February. However, before undertaking this point, Figure 4.46 shows, by comparison to the winter, the associations between the long-range winds and the time-series of the concentrations of the secondary biogenic reaction products during the summer. During 6-9-August, the period of northerly winds influence, the secondary biogenic activity was at its minimum; however, the cycles of nopinone continue to be cyclical and mainly even in terms of day to day concentrations, with one major exception, on 5-August the concentrations are appreciably larger. The most prominent characteristic associated to the southern winds regime (dotted triangle-down, Figure 4.46 a) is the increased frequency of daytime cis-pinonic peaks and the concomitant increase in the ratio of cis-pinonic acid to nopinone. 


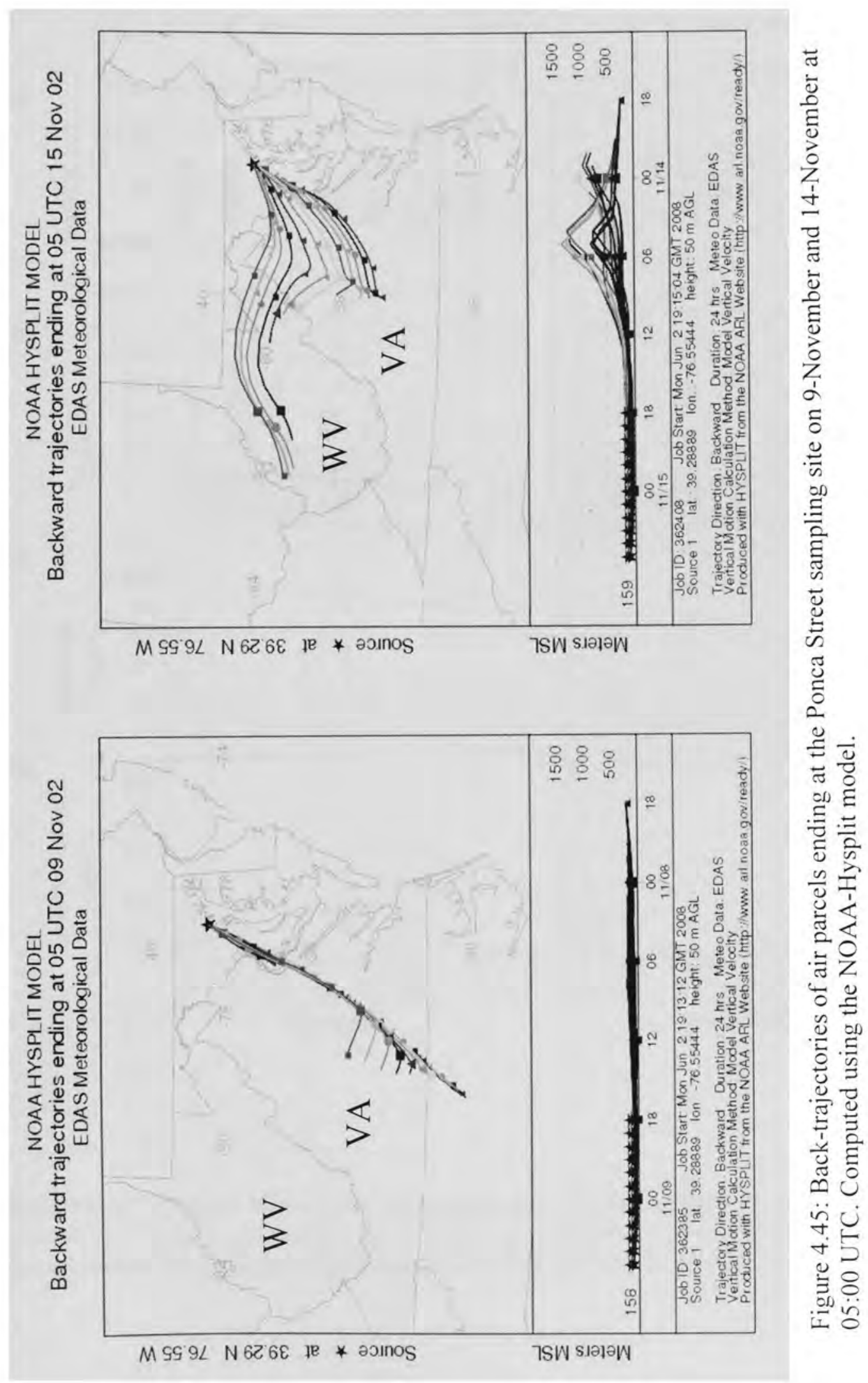


a)

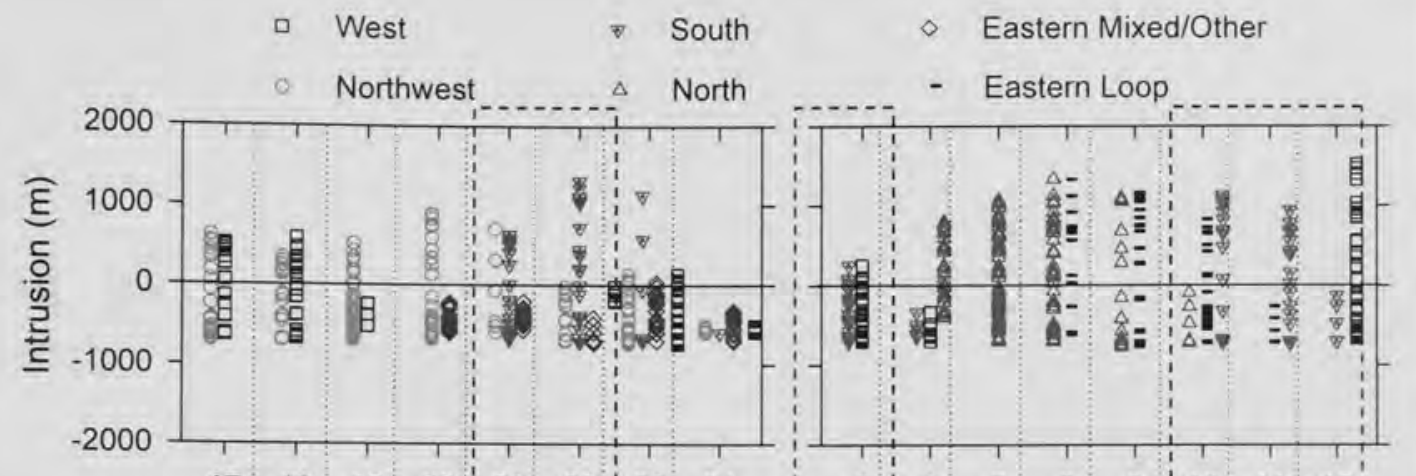

b)

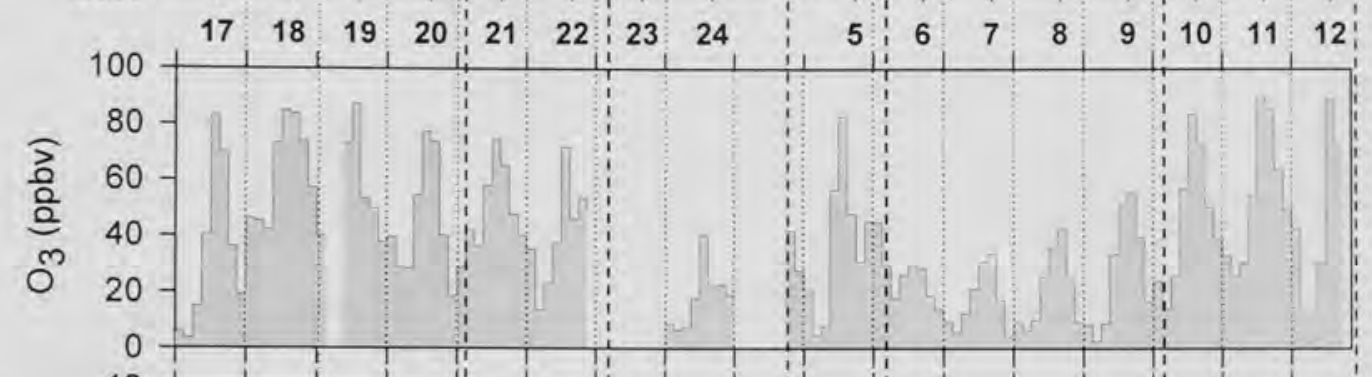

c)

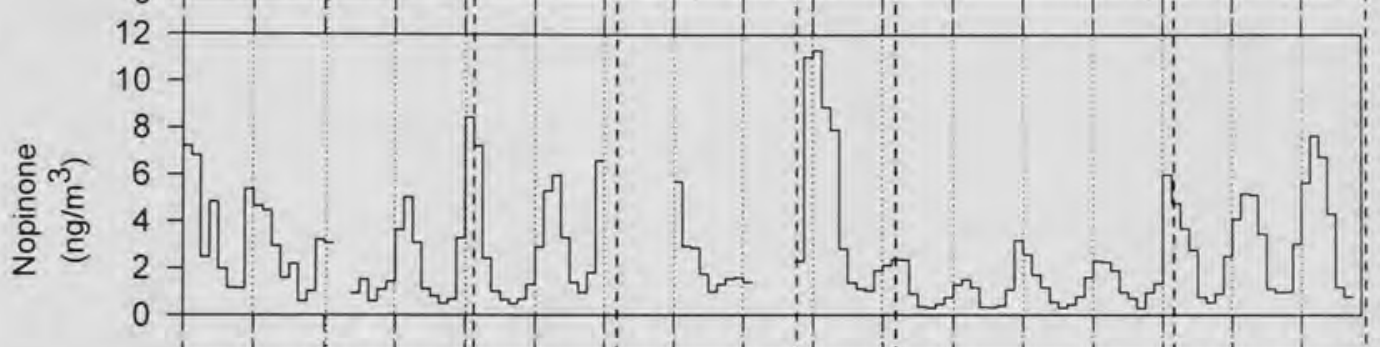

d)

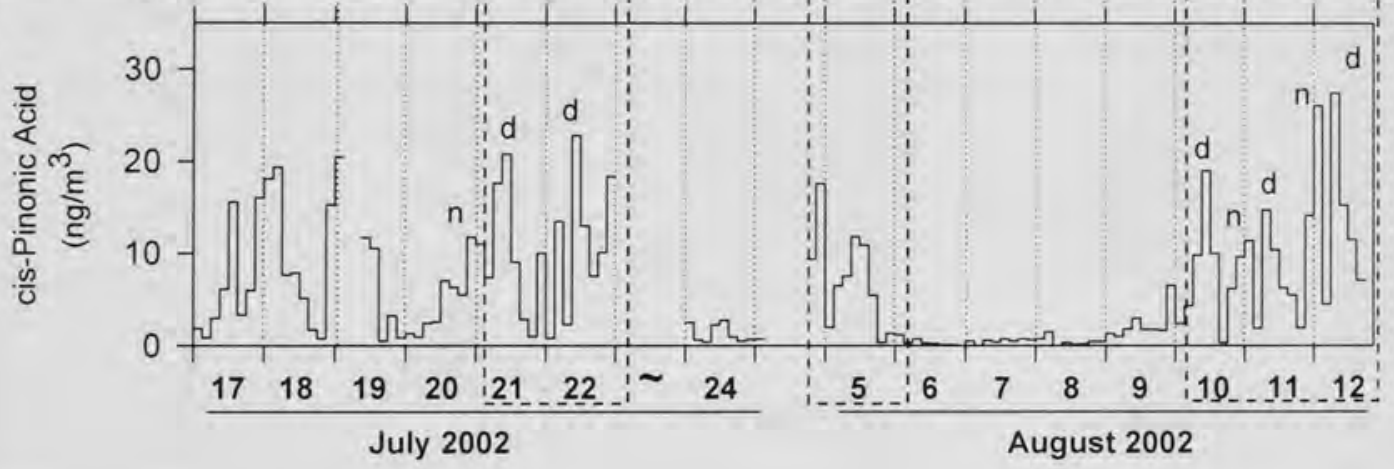

Figure 4.46: Diagram of the evolving geographical regimes of background air throughout the summer sampling campaign (a), the three-hourly concentrations of ozone $\left(\mathrm{O}_{3}, \mathrm{~b}\right)$, and the secondary biogenic reaction products nopinone (c) and cis-pinonic acid (d). 

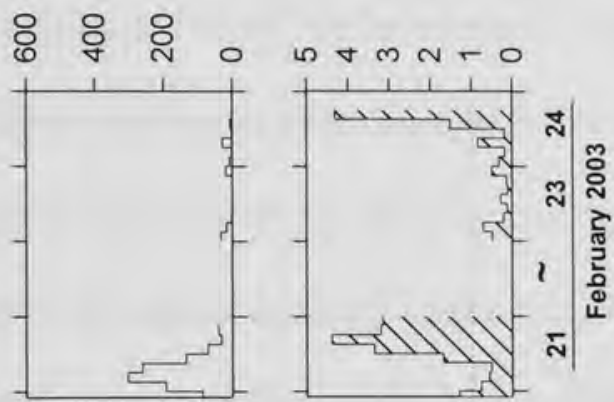

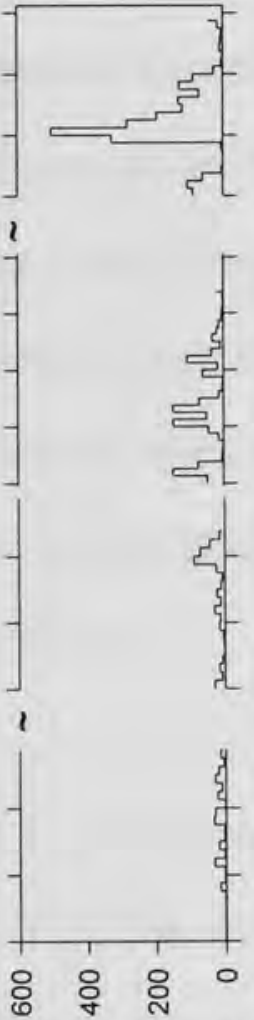

( $\left.{ }_{\varepsilon} w / 6 u\right)$ [ouou!ldoN]/[p! uesoวก|60กอา

สิ
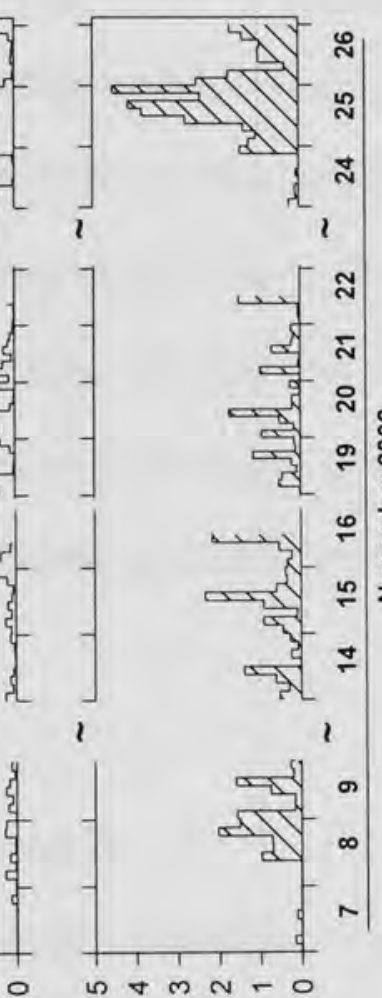

n $\rightarrow$ m olıey

อ

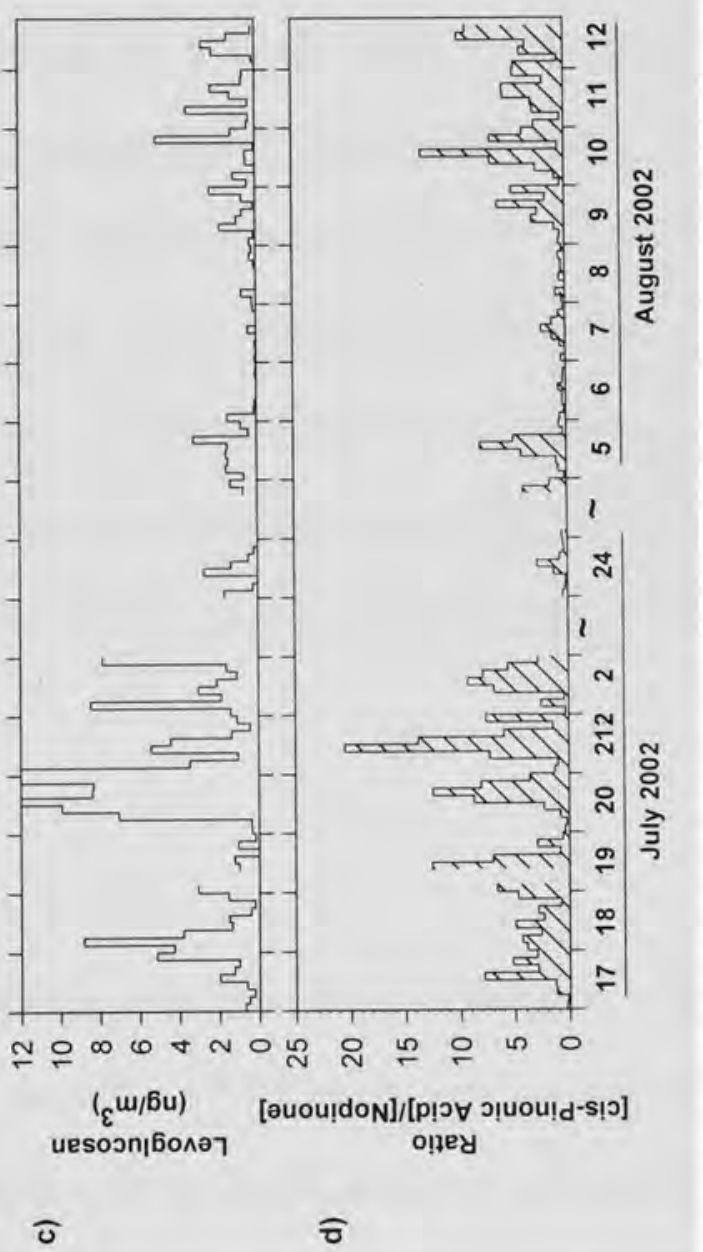



(3)

离

$3 \dot{0}$

可

()ํㅇ 
A change in the ratio of cis-pinonic acid to nopinone could be caused, for example, by a change in the feed composition of $\alpha$ - and $\beta$-pinene depending on the tree composition of a specific area were the secondary biogenic reaction products were formed, or it could be associated to a change in the dynamics of formation or depletion of the secondary reaction products. However, the cleavage between the night and the day peaks of cis-pinonic acid is an indication that the daytime peak of cis-pinonic acid corresponds to material formed in the local atmosphere, not transported. Examining the time series of the 3-hourly concentrations of cis-pinonic acid to nopinone for both seasons, presented in Figure 4.46, indicate that higher ratios, during both summer and winter, are associated to the presence of wood/biomass smoke particles as discernible by the levoglucosan signal. These observations are consistent with results from chamber studies which have indicated that wood soot increase the yields of secondary biogenic reaction products of the $\alpha$-pinene/NOx system in presence of sunlight to levels much higher that what are predicted from theoretical gas-particle partitioning only (Jang et al., 2002).

\subsection{Conclusions}

This chapter examined the relationships of the observed continuous variations of the concentrations of organic markers as well as PM2.5 mass and the reactive species Ozone $\left(\mathrm{O}_{3}\right)$ and nitrous oxides $\left(\mathrm{NO}_{2}, \mathrm{NOx}\right)$ with the on-site meteorological measurements conducted parallel to the PM2.5 sampling and the synoptic patterns of weather and wind conditions. 
Measurements encompass two distinct influencing meteorological scenarios. Days during which a local sea breeze circulation is observed in the diurnal wind direction data, and others during which the local wind direction experiences no diurnal change. The latter, concur with periods during which the prevalent direction of the long-range winds is from the west, northwest, north or south, and the local wind is persistently aligned with that direction for periods of one to three days.

The periods identified as being under a strong west/northwesterly influence are 09:00 17-July to 09:00 19-July, 5-August and 7-November, under northerly 00:00 6August to 06:00 9-August, and under southerly 09:00 21-July to 21:00 22-July, 10-12August, 8-9-November, and 12:00 14-November to 12:00 15-November.

This study shows that, during the summer, under conditions of pervasive westerly/northwesterly influence the data displays a number of characteristics consistent with the PM2.5 being strongly influenced by the aged/processed nature of the background air masses. These characteristic include larger concentrations and percent proportions of the lower-molecular weight n-alkanoic acids, particularly n-nonanoic acid, dicarboxylic acids particularly azelaic and phthalic acid, as well as a significant disruption of both the percent proportions of hopanes and the relationship of hopanes to n-alkylcyclohexanes typical of vehicular emissions, even though the sampling site was located within less than one kilometer from a major highway.

The study conducted here permits to make several important conclusions as it regards to the dynamics of formation of the secondary biogenic reaction species in the real atmosphere. The prevalent regime of influence during the November portion of the winter sampling campaign was from the south and this regime is observed to be 
associated with appreciably larger concentrations of the secondary biogenic reaction products nopinone, cis-pinonic acid and norpinonic acid. During the summer, the southerly influence is seen more associated with the transport of fine particles from biomass burning and during this influence an appreciable enhancement of the measured concentrations of daytime cis-pinonic acid is observed. Because a similar enhancement is observed in two cases during the winter (24-25-Novembera bd 21-February, 2003) which can specifically be isolated to be influenced by local emissions and with large contribution from wood burning (approximately $30 \%$ of the OC) it can be concluded that it is possible that such enhancement be associated to the presence of wood soot, as has been hypothesized from chamber experiment reported in the research literature.

The major implications from the above results are two fold: During the summer, long-range transport can be important under the influence of the long-range westerly regimes. During the winter, intrusions from more "regional" air masses are more important. Specific evidence of transport under the southerly regimes is given by the presence of secondary biogenic reaction products. This is supported by the knowledge that areas from West Virginia and Virginia are densely forested.

Investigations of the origin of an unusual pattern of $n$-alkanes displaying a strong even-to-odd predominance in some of the summer and winter ambient samples indicates that there is an association between this pattern and the presence of tris(2,4-ditertbutylphenyl) phosphate (tbPO4), an oxidation product of the anti-oxidant Irgafos 168 (tris(2,4-di-tert-butylphenyl)phosphite) specifically used in the production of plastic and rubber materials. Based on previous knowledge from the literature, it can be concluded that this association provides evidence of frequently occurring local events of open 
burning including polyethylene plastic materials. In addition the presence of 1,3,5triphenylbenzene (TPB) exhibiting highly regular diurnal variations of concentrations is an indication of the regular input from the exhaust of local incinerators burning plastic materials.

Early morning strong transient regular events identified as vehicular emissions were observed from the organic data. These events were also confirmed from the concurrence with the measurements of NOx and NO conducted parallel to the PM2.5 sampling by a different research group. These events were recognized as being originated from either a bus depot operated by the Maryland Transportation Authority located southwest from the sampling site or a strong influence from the nearby highway, observed under specific meteorological conditions. 


\section{References}

Chen, B.G. Doddridge, Dickerson, R.R., Chow, J.C., Henry, R.C., 2002. Origins of fine aerosol mass in the Baltimore-Washington corridor: implications from observation, factor analysis, and ensemble air parcel back trajectories, Atmospheric Environment 36 (28), 4541-4554.

Cheng, Y., Li, S.-M., Leithead, A., Brickell, P.C., Leaitch, W.R, 2004. Characterizations of cis-pinonic acid and $n$-fatty acids on fine aerosols in the Lower Fraser Valley during Pacific 2001 Air Quality Study. Atmospheric Environment 38 (34), 5789 5800 .

Cheng, Y., Li, S.-M., Leithead, A., Brook, J.R., 2006. Spatial and diurnal distributions of n-alkanes and n-alkan-2-ones on PM2.5 aerosols in the Lower Fraser Valley, Canada. Atmospheric Environment 40 (15), 2706-2720.

Draxler R.R., 1994. Hybrid Single-Particles Lagrangian Integrated Trajectories. Webbased Version 4.0, NOAA-ARL.

Echalar, F., Gaudichet, A., Cachier, H., Artaxo, P., 1995. Aerosol emissions by tropical forest and savanna biomass burning: Characteristic trace elements and fluxes. Geophysical Research Letters 22, 3039-3042.

Elias, V.O., Simoneit, B.R.T., Pereira, A.S., Cardoso, J.N., 1998. High Temperature Gas Chromatography with a Glass Capillary Column for the Analysis of High Molecular Weight Tracers in Smoke Samples from Biomass Burning 21 (2), 8793.

Fine, P. M., Chakrabarti B, Krudysz, Schauer J, Sioutas C., 2004. Diurnal variations of individual organic compound constituents of ultrafine and accumulation mode particulate matter in the Los Angeles basin. Environmental Science and Technology 38 (5), 1296-1304.

Font, R., Aracil, I., Fullana, A., Conesa, J.A., 2004. Semivolatile and volatile compounds combustion of polyethylene. Chemosphere 57 (7), 615-627.

Fraser, M.P., Lakshmanan, K. 2000. Using Levoglucosan as a Molecular Marker for the Long-Range Transport of Biomass Combustion Aerosols. Environmental Science and Technology, 34 (21), $4560-4564$.

Fujita, E. M., Zielinska, B., Campbell, D., Arnott, W. P., Sagebiel, J. C., Mazzoleni, L., Chow, J. C., Crews, W., Snow, R., Clark, N., Wayne W. S., Lawson, D.R., 2007. Variations in speciated emissions from spark-ignition and compression-ignition motor vehicles in California's South Coast Air Basin. Journal of the Air and Waste Management Association, 57, 705-720. 
GFMC, Global Fire Monitoring Center, 2002. Reports of forest fires in the U.S. and Canada. Online at: http://www.fire.uni-freiburg.de/

Grosjean, D., Seinfeld, J.H., 1989. Parameterization of the formation potential of secondary organic aerosols. Atmospheric Environment 23 (8), 1733-1747.

Hays, M. D., Geron, C. D., Linna, K. J., Smith, N. D., Schauer, J. J., 2002. Speciation of gas-phase and fine particle emissions from burning of foliar fuels. Environmental Science and Technology $36(11), 2281-2295$.

Hays, M. D., Fine, P. B., Geron, C. D., Kleeman, M. J., Gullett, B. K., 2005. Open burning of agricultural biomass: Physical and chemical properties of particlephase emissions. Atmospheric Environment 39 (36), 6747-6764.

Hostettler, F.D., Kvenvolden, K.A., 2002. Alkylcyclohexanes in environmental geochemistry. Environmental Forensic 3(3-4), 293-301.

Jang, M., Czoschke, N.M., Lee, S., Kamens, R. M., 2002. Heterogeneous atmospheric organic aerosol production by inorganic acid-catalyzed particle-phase reactions, Science 298, 814-817.

Kamens, R., Jang, M., Chien, C.-J., Leach, K., 1999. Aerosol formation from the reaction of $\alpha$-Pinene and ozone using a gas-phase kinetics-aerosol partitioning model. Environmental Science and Technology 33(9), 1430-1438.

Kamens, R. M., Jaoui, M., 2001. Modeling aerosol formation from $\alpha$-Pinene + NOx in the presence of natural sunlight using gas-phase kinetics and gas-particle partitioning theory. Environmental Science and Technology 35(7), 1394-1405

Kawamura, K., Ikushima, K., 1993. Seasonal changes in the distribution of dicarboxylic acids in the urban atmosphere. Environmental Science and Technoogy 27(10), 2227-2235.

Kleiman, G., Prinn, R. G., 2000, Measurement and deduction of emissions of trichloroethene, tetrachloroethene, and trichlorinated-methane (chloroform) in northeastern United States and southeastern Canada. Journal of Geophysical Research 105, 28,875-28,893.

Kleiman, G., Marin, A. 2002. Trajectory Analysis of Potential Source Regions Affecting Class I Areas in the MANE-VU Region. Prepared by Northeast States for Coordinated Air Use Management (NESCAUM) for the MANE-VU Regional Planning Organization. 
Lee, S., Baumann, K., Schauer, J.J., Sheesley, R.J., Naeher, L.P., Meinardi, S., Blake, D.R., Edgerton, E.S., Russell, A.G., Clements M., 2005. Gaseous and particulate emissions from prescribed burning in Georgia, Environmental Science and Technology 39 (23), 9049-9056.

Lee, A., Goldstein, A.H., Keywood, M.D., Gao, S., Varutbangkul, V., Bahreini, R., Ng, N. L, Flagan, R. C., Seinfeld, J. H.., 2006. Gas-phase products and secondary aerosol yields from the ozonolysis of ten different terpenes. Journal of Geophysical Research-Atmospheres 111 (D7), D07302.

Lemieux, P.M., Lutes, C.C., Santoianni, D.A., 2004. Emissions of organic air toxics from open burning: a comprehensive review. Progress in Energy and Combustion Science $30(1), 1-32$.

Ning, Z., Geller, M.D., Moore, K.F., Sheesley, R., Schauer, J.J., Sioutas, C., 2007. Daily variation in chemical characteristics of urban ultrafine aerosols and inference of their sources. Environmental Science and Technology 41 (17), 6000-6006.

NOAA, National Oceanic and Atmospheric Administration. Central Library U.S. Daily Weather Maps Project, online at:

http://docs.lib.noaa.gov/rescue/dwm/data_rescue_daily weather_maps.html

Nolte, C. G., Schauer, J. J., Cass, G. R., Simoneit, B. R. T,. 1999. Highly polar organic compounds present in meat smoke. Environmental Science and Technology 33 (19), 3313-3316.

Odum, J. R., Jungkamp, T. P. W., Griffin, R. J., Flagan, R. C., Seinfeld J. H., 1997. The atmospheric aerosol-forming potential of whole gasoline vapor, Science 276 (5309), 96-99.

Ondov, J.M., Buckley, T.J., Hopke, P.K., Ogulei, D., Parlanged, M.B.,Rogge, W.F., Squibb, K.S., Johnston, M.V., Wexler, A.S., 2006. Baltimore Supersite: Highly time- and size-resolved concentrations of urban PM2.5 and its constituents for resolution of sources and immune responses. Atmospheric Environment 40, S224-S237.

Park, S.S., Ondov, J.M., Harrison, D., Nair, N.P., 2005. Seasonal and shorter-term variations in particulate atmospheric nitrate in Baltimore. Atmospheric Environment 39 (11), 2011-2020.

Primbs, T., Simonich, S., Schmedding, D., Wilson, G., Jaffe, D., Takami, Shungo Kato, A., Hatakeyama, S., Kajii, Y., 2007. Atmospheric Outflow of Anthropogenic Semivolatile Organic Compounds from East Asia in Spring 2004, Environmental Science and Technology 41 (10), $3551-3558$, 
Ryan, W.F., Doddridge, B.G., Dickerson, R.R., Morales, R.M., Hallock, K.A., Roberts, P.T., Blumenthal, D.L., Anderson, J.A., Civerolo, K.., 1998. Pollutant transport during a regional $\mathrm{O}_{3}$ episode in the mid-Atlantic states. Journal of the Air and Waste Management Association 48(9), 786-797.

Schauer, J. J., Kleeman, M. J., Cass, G. R., Simoneit, B. R. T., 1999a. Measurement of emissions from air pollution sources. 1. C-1 through C-29 organic compounds from meat charbroiling. Environmental Science and Technology 33 (10), 15661577.

Schauer, J. J., Kleeman, M. J., Cass, G. R., Simoneit, B. R. T., 2002b. Measurement of emissions from air pollution sources. 4. C-1-C-27 organic compounds from cooking with seed oils. Environmental Science and Technology 36 (4), 567-575.

Simoneit, B.R.T., Kobayashi, M., Mochida, M., Tsubonuma, N., Kawamura, K., Lee, M., Komazaki, N., 2004a. Composition and major sources of organic compounds of aerosol particulate matter sampled during the ACE-Asia campaign. Journal of Geophysical Research 109, D19S10.

Simoneit, B.R.T., 2004b. A review of current applications of mass spectrometry for biomarker/molecular tracer elucidations. Mass Spectrometry Reviews 94 (5), 619 675 .

Simoneit, B.R.T., Medeiros, P.M., Didyk, B.M., 2005. Combustion Products of Plastics as Indicators for Refuse Burning in the Atmosphere. Environmental Science and Technology 39 (18), $6961-6970$.

Stenby, C., Pöschi, U., von Hessberg, P., Bilde, M., Nielsen, O. J., Moortgat, G.K., 2007. Temperature and humidity dependence of secondary organic aerosol yield from the ozonolysis of $\beta$-pinene. Atmospheric Chemistry and Physics Discussion 6, S7399-S7406.

Tong HY, Shore DL, Karasek FW, Helland P. Jellum E., 1984. Identification of organic compounds obtained from incineration of municipal waste by HPLCFractionation and GC-MS. Journal of Chromatography 285, 423-441.

U.S. Geological Survey, 2000. Forest Cover Types of the U.S.A. Available from Nationalatlas.gov

Wright, S.J., Dale, M.J., Langridge-Smith, P.R.R., Zhan, Q., Zenobi, R., 1996. Selective in Situ Detection of Polymer Additives Using Laser Mass Spectrometry, Analytical Chemistry 68, 20, 3585-3564.

Yue, Z. W., Fraser, M.P., 2004. Polar organic compounds measured in fine particulate matter during TexAQS 2000. Atmospheric Environment 38 (20), 3253-3261. 
Zahardis J, Petrucci GA, 2007. The oleic acid-ozone heterogeneous reaction system: products, kinetics, secondary chemistry, and atmospheric implications of a model system - a review. Atmospheric Chemistry and Physics 7, 1237-1274. 
Appendix A

Table of the emission factors of organic compounds in individual samples from the Squirrel Hill Tunnel, Pittsburgh, PA analyzed as part of the Sources Characterization Program of the Pittsgurgh Air Quality Study (PAQS). Supporting table for Chapter 2. 
Table A.1: Emission Factors of Organic Compounds in Individual Samples ( $\mu \mathrm{g} / \mathrm{kg}$ fuel)

\begin{tabular}{|c|c|c|c|c|c|c|c|}
\hline Compounds ${ }^{1}$ & EM1 & EM2 & RHI & RH2 & RH3 & MD & $\begin{array}{c}\text { Compound } \\
\text { ID }^{2}\end{array}$ \\
\hline \multicolumn{8}{|l|}{ n-Alkanes } \\
\hline n-Nonadecane & 777 & 768 & 407 & 366 & 385 & 726 & a \\
\hline n-Eicosane & 554 & 533 & 272 & 268 & 276 & 454 & a \\
\hline n-Heneicosane & 415 & 382 & 193 & 210 & 213 & 283 & $\mathrm{a}$ \\
\hline n-Docosane & 298 & 286 & 147 & 161 & 171 & 192 & a \\
\hline n-Tricosane & 226 & 210 & 117 & 115 & 139 & 146 & a \\
\hline n-Tetracosane & 124 & 120 & 69.3 & 67.7 & 76.6 & 81.0 & a \\
\hline n-Pentacosane & 86.0 & 76.6 & 59.7 & 50.1 & 54.7 & 64.4 & a \\
\hline n-Hexacosane & 47.9 & 49.7 & 26.8 & 32.2 & 31.1 & 31.9 & a \\
\hline n-Heptacosane & 25.1 & 23.7 & 14.0 & 7.42 & 11.1 & 17.5 & a \\
\hline n-Octacosane & 16.3 & 18.6 & 6.72 & 9.16 & 9.28 & 14.4 & a \\
\hline n-Nonacosane & 12.7 & 13.7 & 5.41 & 9.39 & 8.04 & 7.55 & a \\
\hline \multirow[t]{2}{*}{ n-Triacontane } & 5.95 & 9.60 & 1.87 & 5.50 & 5.65 & 7.93 & a \\
\hline & 2,587 & 2,491 & 1,319 & 1,301 & 1,381 & 2,025 & \\
\hline \multicolumn{8}{|l|}{ n-Alkylcyclohexanes } \\
\hline n-Undecylcyclohexane & 75.0 & 93.1 & 46.2 & 40.0 & 37.8 & 80.3 & $\mathrm{~b}$ \\
\hline n-Dodecylcyclohexane & 40.1 & 45.5 & 22.1 & 20.3 & 21.0 & 45.5 & a \\
\hline n-Tridecylcyclohexane & 28.0 & 32.1 & 16.2 & 14.9 & 14.2 & 32.0 & $b$ \\
\hline n-Tetradecylcyclohexane & 24.1 & 23.6 & 14.1 & 13.7 & 13.7 & 24.2 & $\mathrm{~b}$ \\
\hline n-Pentadecylcyclohexane & 31.0 & 31.3 & 18.2 & 20.5 & 18.7 & 25.7 & $b$ \\
\hline n-Hexadecylcyclohexane & 30.8 & 31.1 & 20.0 & 22.6 & 21.0 & 24.7 & $\mathrm{a}$ \\
\hline n-Heptadecylcyclohexane & 34.7 & 34.3 & 23.4 & 28.2 & 23.5 & 27.4 & a \\
\hline n-Octadecylcyclohexane & 30.8 & 26.5 & 18.9 & 23.0 & 19.4 & 21.3 & $b$ \\
\hline n-Nonadecylcyclohexane & 21.5 & 20.5 & 12.6 & 15.3 & 14.2 & 15.3 & a \\
\hline n-Eicosylcyclohexane & 15.6 & 13.4 & 8.84 & 7.84 & 8.77 & 7.93 & $\mathrm{~b}$ \\
\hline n-Heneicosylcyclohexane & 8.38 & 4.93 & 4.53 & 4.50 & 2.93 & 4.51 & b \\
\hline \multirow[t]{2}{*}{ n-Docosylcyclohexane } & 3.02 & 2.28 & 2.06 & 1.51 & 1.06 & 2.58 & $b$ \\
\hline & 343 & 359 & 207 & 212 & 196 & 311 & \\
\hline \multicolumn{8}{|l|}{ Hopanes } \\
\hline $17 \alpha(\mathrm{H})-22,29,30$-trisnorhopane & 12.6 & 14.5 & 9.4 & 10.0 & 11.0 & 10.9 & a \\
\hline $17 \alpha(\mathrm{H}), 21 \mathrm{~b}(\mathrm{H})-29$-norhopane & 54.6 & 67.1 & 37.3 & 41.7 & 43.9 & 41.7 & $b$ \\
\hline $17 \alpha(\mathrm{H}), 21 \beta(\mathrm{H})$-hopane & 29.7 & 35.6 & 20.0 & 20.6 & 22.3 & 23.3 & $\mathrm{a}$ \\
\hline $\begin{array}{l}22-\mathrm{S}, 17 \alpha(\mathrm{H}), 21 \beta(\mathrm{H})-30- \\
\text { homohopane }\end{array}$ & 16.1 & 17.8 & 9.70 & 10.6 & 11.2 & 11.4 & c \\
\hline $\begin{array}{l}22-\mathrm{R}, 17 \alpha(\mathrm{H}), 21 \beta(\mathrm{H})-30- \\
\text { homohopane }\end{array}$ & 10.9 & 12.8 & 7.26 & 7.97 & 8.15 & 8.30 & c \\
\hline $\begin{array}{l}22-\mathrm{S}, 17 \alpha(\mathrm{H}), 21 \beta(\mathrm{H})-30- \\
\text { bishomohopane }\end{array}$ & 8.71 & 9.86 & 5.14 & 6.18 & 6.11 & 6.46 & c \\
\hline \multirow[t]{2}{*}{$\begin{array}{l}22-\mathrm{R}, 17 \alpha(\mathrm{H}), 21 \beta(\mathrm{H})-30- \\
\text { bishomohopane }\end{array}$} & 6.00 & 6.82 & 3.55 & 4.31 & 4.75 & 4.53 & c \\
\hline & 139 & 164 & 92.4 & 101 & 107 & 107 & \\
\hline
\end{tabular}

Table continues in next page 
Table A.1...continuation

\begin{tabular}{|c|c|c|c|c|c|c|c|}
\hline Compounds ${ }^{1}$ & EM1 & $\mathrm{EM} 2$ & RHI & $\mathrm{RH} 2$ & RH3 & MD & $\begin{array}{c}\text { Compound } \\
\mathrm{ID}^{2}\end{array}$ \\
\hline \multicolumn{8}{|l|}{ Steranes } \\
\hline $\begin{array}{l}20 \mathrm{R}-5 \alpha(\mathrm{H}), 14 \beta(\mathrm{H}), 17 \beta(\mathrm{H})- \\
\text { Cholestane }\end{array}$ & 13.2 & 13.6 & 9.81 & 9.74 & 10.0 & 10.2 & a \\
\hline $\begin{array}{l}20 \mathrm{~S}-5 \alpha(\mathrm{H}), 14 \beta(\mathrm{H}), 17 \beta(\mathrm{H})- \\
\text { Cholestane }\end{array}$ & 9.89 & 10.6 & 6.42 & 7.10 & 7.85 & 7.31 & b \\
\hline $\begin{array}{l}20 \mathrm{R}-5 \alpha(\mathrm{H}), 14 \beta(\mathrm{H}), 17 \beta(\mathrm{H})- \\
\text { Ergostane }\end{array}$ & 12.3 & 12.7 & 7.80 & 8.27 & 8.43 & 9.47 & $b$ \\
\hline $\begin{array}{l}20 \mathrm{~S}-5 \alpha(\mathrm{H}), 14 \beta(\mathrm{H}), 17 \beta(\mathrm{H})- \\
\text { Ergostane }\end{array}$ & 7.22 & 7.80 & 5.26 & 5.58 & 5.50 & 6.34 & $\mathrm{~b}$ \\
\hline $\begin{array}{l}20 \mathrm{R}-5 \alpha(\mathrm{H}), 14 \beta(\mathrm{H}), 17 \beta(\mathrm{H})- \\
\text { Sitostane }\end{array}$ & 18.8 & 22.0 & 12.7 & 14.5 & 14.5 & 15.0 & $b$ \\
\hline \multirow[t]{2}{*}{ Sitostane } & 17.0 & 21.2 & 11.1 & 12.1 & 12.4 & 13.3 & $b$ \\
\hline & 78.5 & 87.8 & 53.1 & 57.3 & 58.7 & 61.6 & \\
\hline PAHs & & & & & & & \\
\hline Phenanthrene (Phen) & 633 & 759 & 390 & 350 & 395 & 618 & a \\
\hline Anthracene (Anth) & 113 & 112 & 60.2 & 56 & 64 & 103 & $\mathrm{a}$ \\
\hline $\begin{array}{l}\text { Cyclopentaphenanthrene } \\
\text { (Cyphen) }\end{array}$ & 25.9 & 26.6 & 14.7 & 12.5 & 17.2 & 19.1 & a \\
\hline Fluoranthene (Fluo) & 140 & 155 & 78 & 75 & 108 & 116 & a \\
\hline Pyrene (Pyre) & 160 & 172 & 96 & 95 & 94 & 124 & $\mathrm{a}$ \\
\hline Benzo[a]anthracene (BaA) & 23.5 & 19.2 & 13.1 & 15.4 & 51.9 & 20.8 & a \\
\hline Chrysene/Triphenylene $(\mathrm{Ch} / \mathrm{Tr})$ & 22.9 & 19.5 & 13.5 & 15.5 & 45.9 & 21.6 & a \\
\hline Benzo[b]fluoranthene $(\mathrm{BbF})$ & 21.2 & 13.9 & 12.2 & 13.8 & 37.8 & 17.6 & $\mathrm{a}$ \\
\hline Benzo[k]fluoranthene $(\mathrm{BkF})$ & 4.56 & 5.37 & 6.15 & 5.77 & 20.44 & 4.6 & a \\
\hline Benzo[j]fluoranthene (BjF) & 4.91 & 3.86 & 2.6 & 3.10 & 7.45 & 3.80 & a \\
\hline Benzo[e]pyrene (BeP) & 15.0 & 11.8 & 10.4 & 11.3 & 21.1 & 13.0 & a \\
\hline Benzo[a]pyrene (BaP) & 14.4 & 10.3 & 9.9 & 10.6 & 29.4 & 12.8 & a \\
\hline Perylene (Pery) & 1.99 & 1.8 & 1.71 & 1.8 & 10.79 & 3.4 & a \\
\hline Indeno[1,2,3-cd]pyrene (IcdP) & 7.12 & 4.50 & 7.22 & 7.31 & 38.3 & 10.7 & a \\
\hline Benzo[g,h,i]perylene (BghiP) & 16.7 & 13.3 & 18.2 & 16.3 & 96.0 & 17.7 & a \\
\hline Dibenzo[a,h]anthracene (DahA) & 0.30 & 0.39 & 0.58 & 0.48 & 8.40 & 1.07 & a \\
\hline \multirow[t]{2}{*}{ Coronene (Coro) } & 3.77 & 3.86 & 10.2 & 6.61 & 53.11 & 4.45 & a \\
\hline & 1,208 & 1,331 & 745 & 696 & 1,099 & 1,112 & \\
\hline $\begin{array}{l}\text { oxy-PAHs } \\
\text { 9-Fluorenone (9-Fluo) }\end{array}$ & 147 & 180.7 & 98.3 & 97.6 & 82.4 & 155.8 & a \\
\hline $\begin{array}{l}9,10 \text {-Anthracenedione } \\
(9,10-\text { Anth })\end{array}$ & 61.1 & 71.3 & 36.2 & 37.2 & 33.8 & 59.6 & a \\
\hline $\begin{array}{l}\text { 7H-Benz[de]anthracen-7-one } \\
\text { (7H-BdeA) }\end{array}$ & 16.5 & 15.4 & 8.9 & 10.8 & 11.5 & 13.2 & a \\
\hline $\begin{array}{l}\text { Benz[a]anthracen-7,12-dione } \\
(\mathrm{BaA}-7,12 \mathrm{O})\end{array}$ & 225 & 267 & 143 & 146 & 128 & 229 & $\mathrm{a}$ \\
\hline
\end{tabular}

Table continues in next page 
Table A.1...continuation

\begin{tabular}{|c|c|c|c|c|c|c|c|}
\hline Compounds ${ }^{1}$ & EM11 & $\mathrm{EM} 2$ & RHI & $\mathrm{RH} 2$ & $\mathrm{RH} 3$ & $\mathrm{MD}$ & $\begin{array}{c}\text { Compound } \\
\mathrm{ID}^{2}\end{array}$ \\
\hline \multicolumn{8}{|l|}{ n-Alkanoic acids } \\
\hline n-Decanoic Acid & 35.4 & 58.6 & 33.4 & 22.3 & 19.2 & 26.8 & a \\
\hline n-Undecanoic Acid & 47.9 & 52.4 & 37.0 & 31.4 & 31.7 & 32.9 & a \\
\hline n-Dodecanoic Acid & 78.5 & 74.7 & 22.9 & 18.2 & 35.4 & 117 & a \\
\hline n-Tridecanoic Acid & 12.8 & 14.9 & 9.64 & 8.52 & 8.30 & 17.2 & a \\
\hline n-Tetradecanoic Acid & 57.3 & 55.3 & 13.6 & 13.1 & 20.5 & 73.7 & a \\
\hline n-Pentadecanoic Acid & 16.3 & 20.7 & 7.11 & 6.32 & 7.05 & 14.3 & a \\
\hline n-Hexadecanoic Acid & 143 & 222 & 57.4 & 49.1 & 23 & 127 & a \\
\hline n-Heptadecanoic Acid & 10.1 & 15.8 & 5.51 & 4.75 & 3.93 & 7.45 & a \\
\hline n-Octadecanoic Acid & 61.5 & 154 & 40.5 & 26.6 & 30.4 & 54.8 & a \\
\hline n-Nonadecanoic Acid & 3.75 & 6.60 & 1.80 & 1.76 & 1.78 & 2.29 & a \\
\hline n-Eicosanoic Acid & 5.99 & 15.5 & 2.97 & 1.74 & 2.39 & 4.89 & a \\
\hline \multirow[t]{2}{*}{ n-Heneicosanoic Acid } & 2.45 & 9.43 & 0.941 & 0.416 & 1.36 & 0.980 & a \\
\hline & 475 & 699 & 233 & 184 & 185 & 480 & \\
\hline \multicolumn{8}{|l|}{ Dicarboxylic acids } \\
\hline $\begin{array}{l}\text { 1,3-benzenedicarboxylic acid - } \\
\text { Isophthalic- }\end{array}$ & 3.74 & 3.24 & 2.53 & 1.80 & 1.51 & 1.88 & a \\
\hline \multicolumn{8}{|l|}{ Organic sulfur compounds } \\
\hline Dibenzothiophene & 43.7 & 48.9 & 27.7 & 26.5 & 34.1 & 54.2 & a \\
\hline 4-methyldibenzothiophene & 25.9 & 31.3 & 16.9 & 15.5 & 15.8 & 33.2 & b \\
\hline 4,6-dimethyldibenzothiophene & 15.6 & 17.3 & 9.06 & 7.97 & 8.07 & 17.9 & b \\
\hline $\begin{array}{l}\text { Benzo[b]naphtho[2,1-d] } \\
\text { thiophene }\end{array}$ & 0.67 & 1.16 & 1.80 & 1.38 & 12.2 & 4.35 & $\mathrm{~b}$ \\
\hline \multicolumn{8}{|l|}{ Other } \\
\hline Benzothiazole & 157 & 247 & 678 & 420 & 325 & 255 & a \\
\hline
\end{tabular}

\footnotetext{
${ }^{1}$ Abbreviations given in parenthesis

${ }^{2}$ Compound identification:

a, authentic standard verification and quantification;
b, MS-spectrum verification and quantified using authentic standard with similar structure, polarity, and volatility;

c, NIST sample-spectrum verification and quantified using authentic standard with similar structure.
} 
Appendix B

Supplemental figures for Chapter 3 


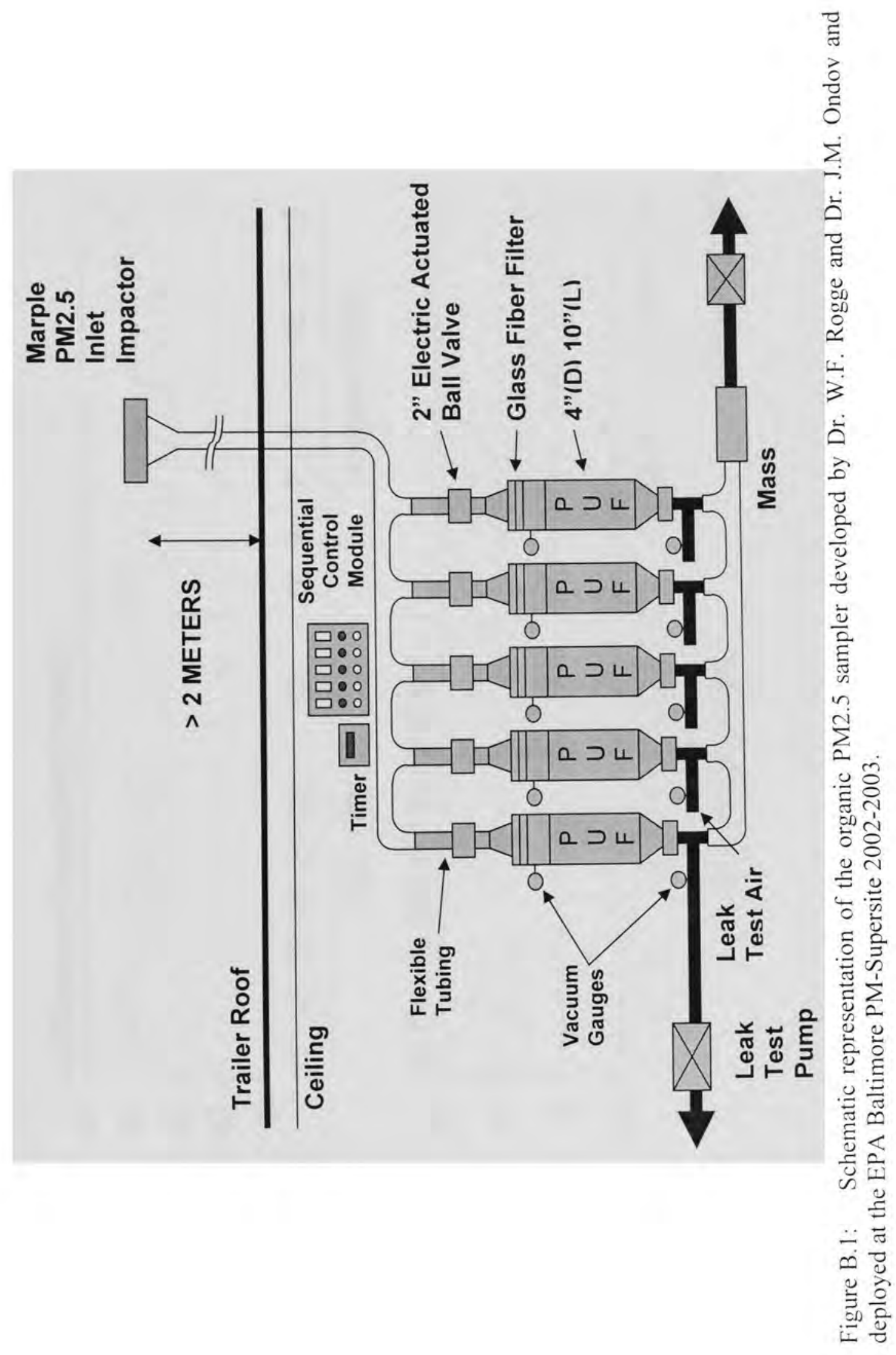



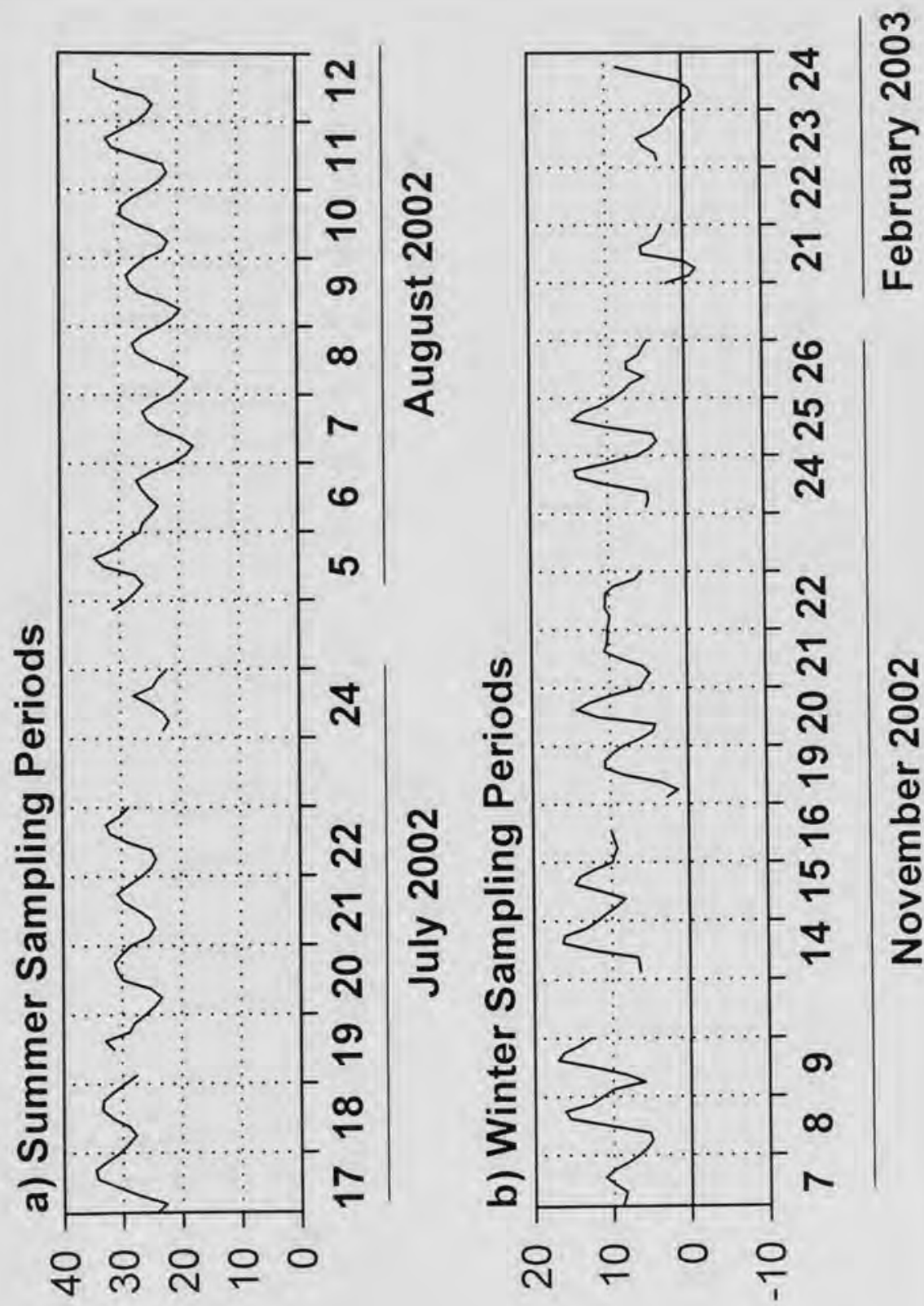

ว。

ว。

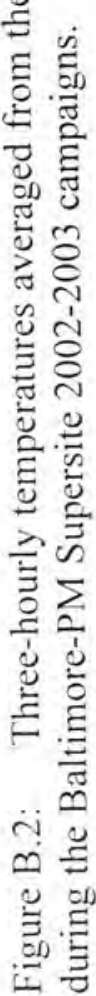



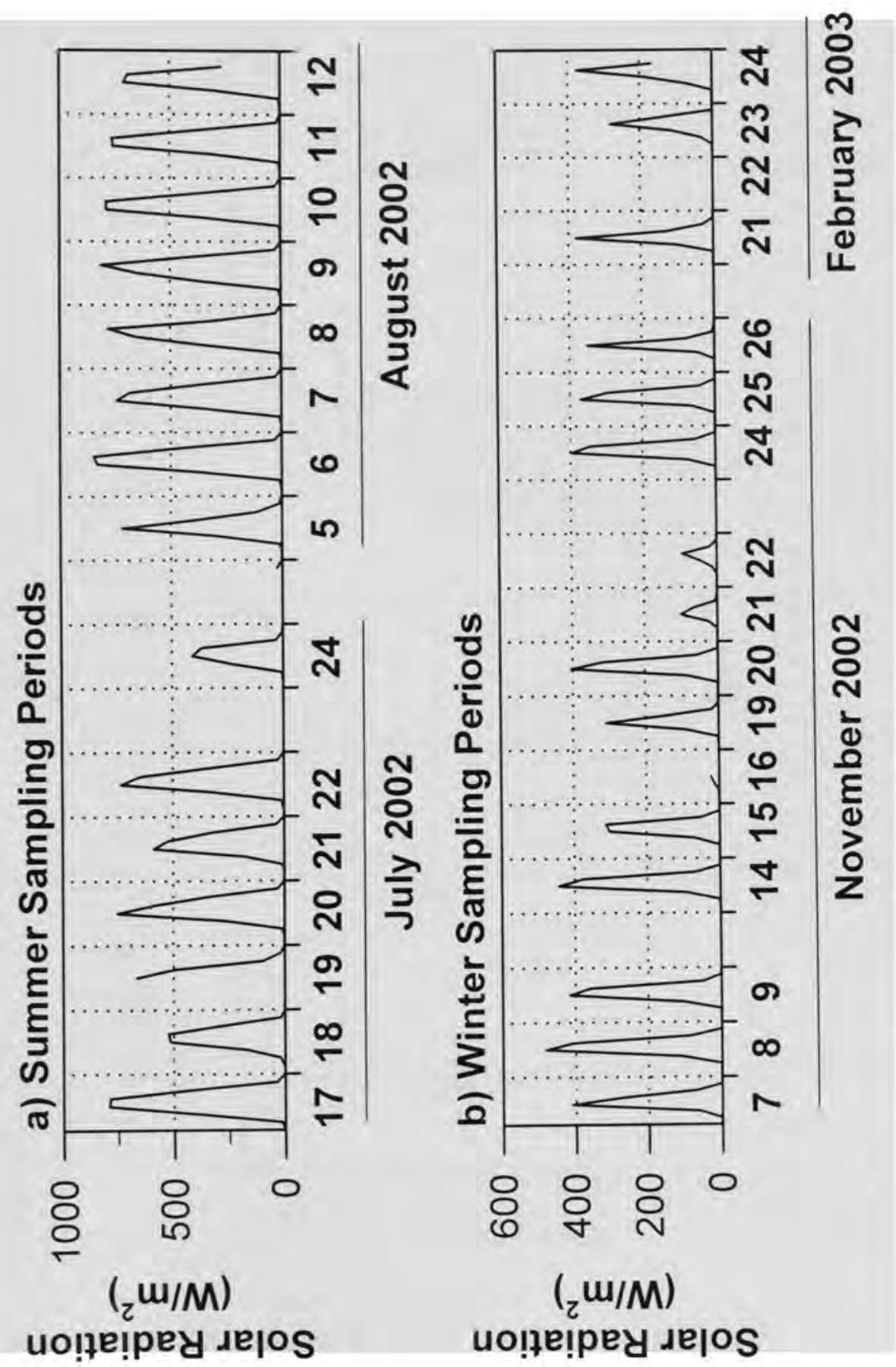
a)

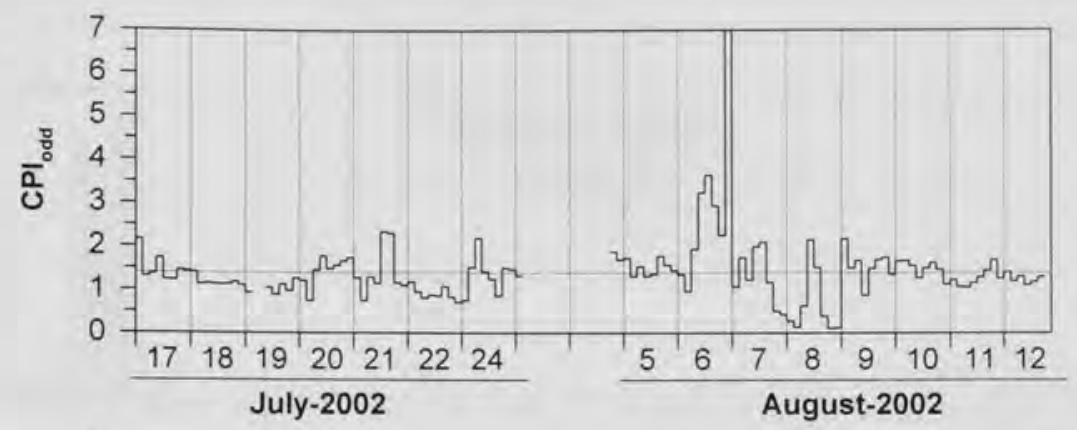

b)

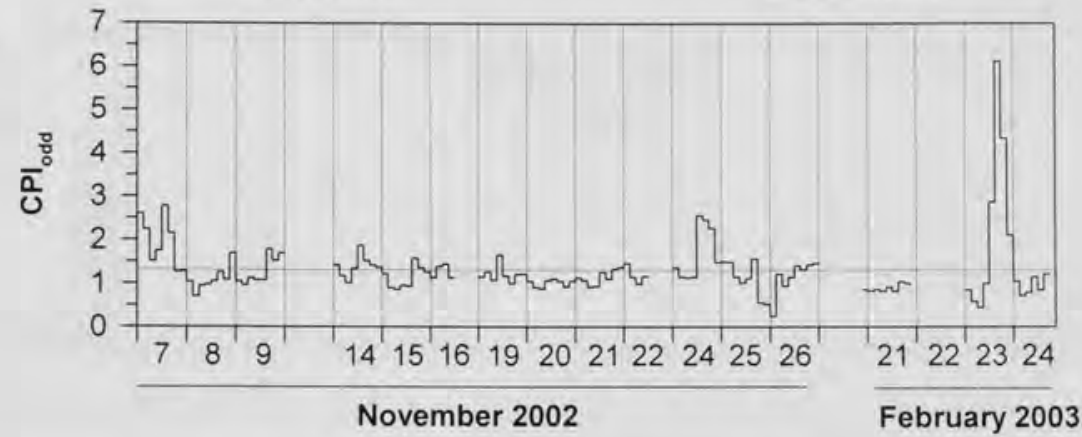

c)

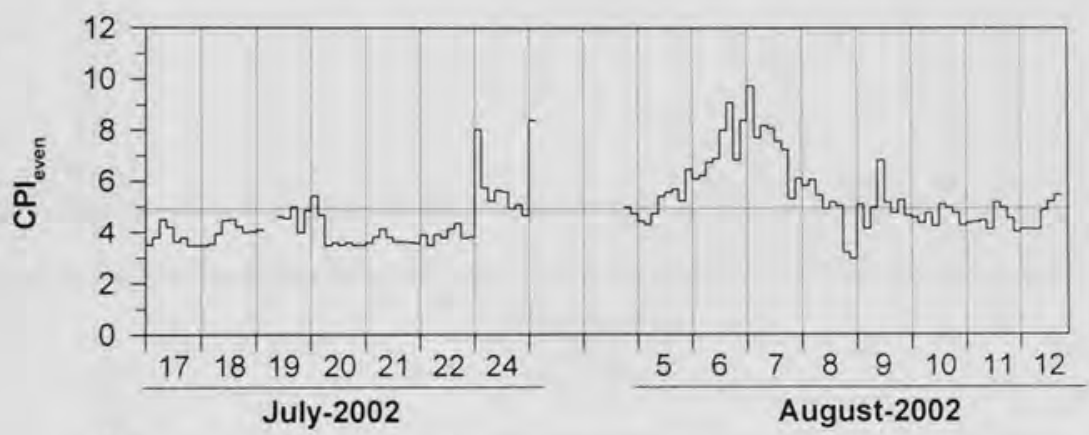

d)

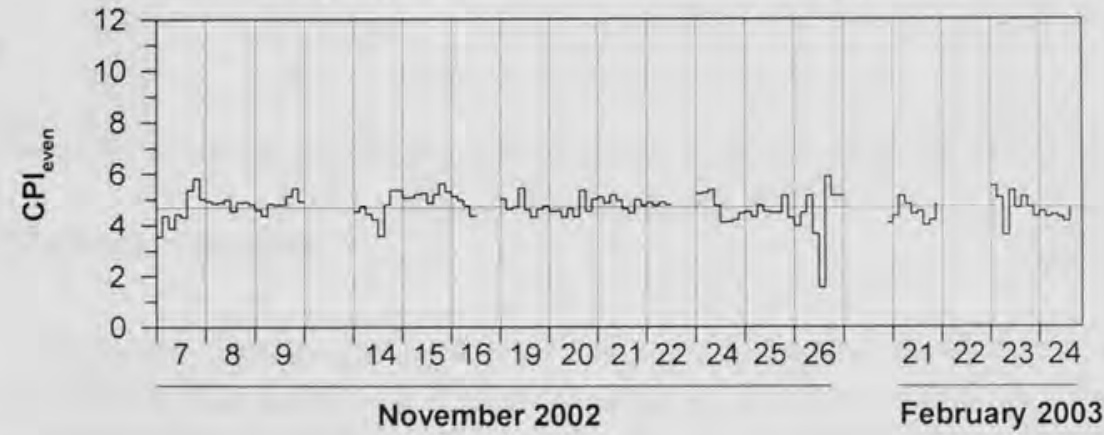

Figure B.4: Time-series of the three-hourly values of $\mathrm{CPI}_{\text {odd }}$ and $\mathrm{CPI}_{\text {even }}$ for summer 2002 and winter 2002/2003 Baltimore PM-Supersite sampling campaigns.

CPI: n-alkanes $=\sum$ Odd $[$ C25-C33]/ 2 Even $[$ C24-C32];

n-alkanoic acids $=\sum$ Even [C24-C32]/Odd[C23-C31]; Ref: Simoneit, 1982 


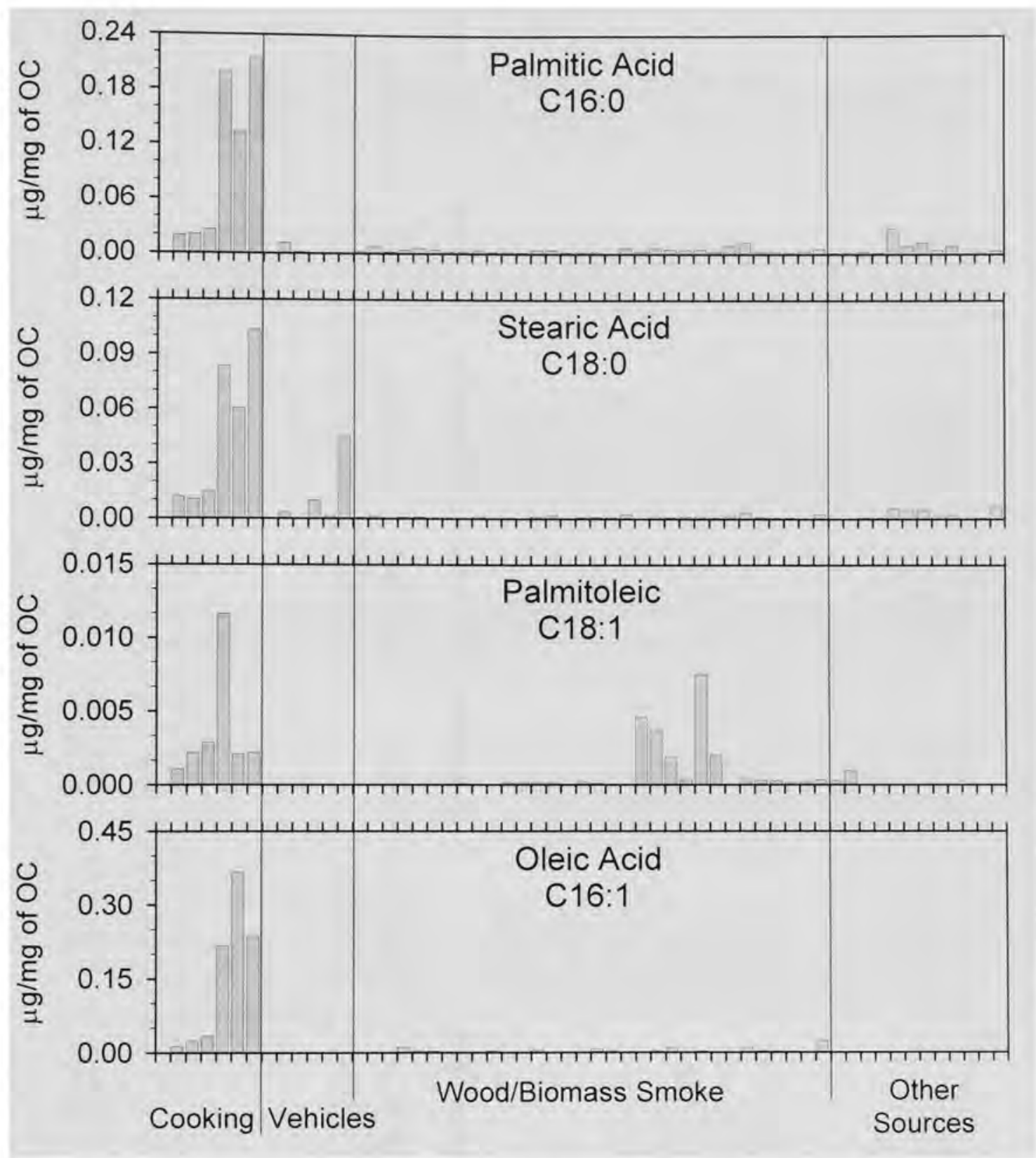

Figure B.5: Emission factors (in $\mu \mathrm{g} / \mathrm{mg}$ of $\mathrm{OC}$ ) of selected saturated and unsaturated fatty acids reported in the following literature sources profiles: Cooking (Rogge et al., 1991; Schauer et al., 1999a, 2002b), vehicles (Rogge et al., 1993b; Schauer et al., 1999b, 2002), wood/biomass smoke (Rogge et al., 1998, Schauer et al., 2002a; Fine et al., 2001; Fine et al., 2002; Lee et al., 2005; Hays et al., 2002, 2005; Fine et al, 2004b), other sources (leaves' waxes: Rogge et al., 1993d ; cigarette smoke: Rogge et al., 1994; urban road dust: Rogge et al., 1993c; fuel oil: Rogge et al., 1997b; natural gas: Rogge et al., 1993e; plastic burning: Simoneit et al., 2005). 


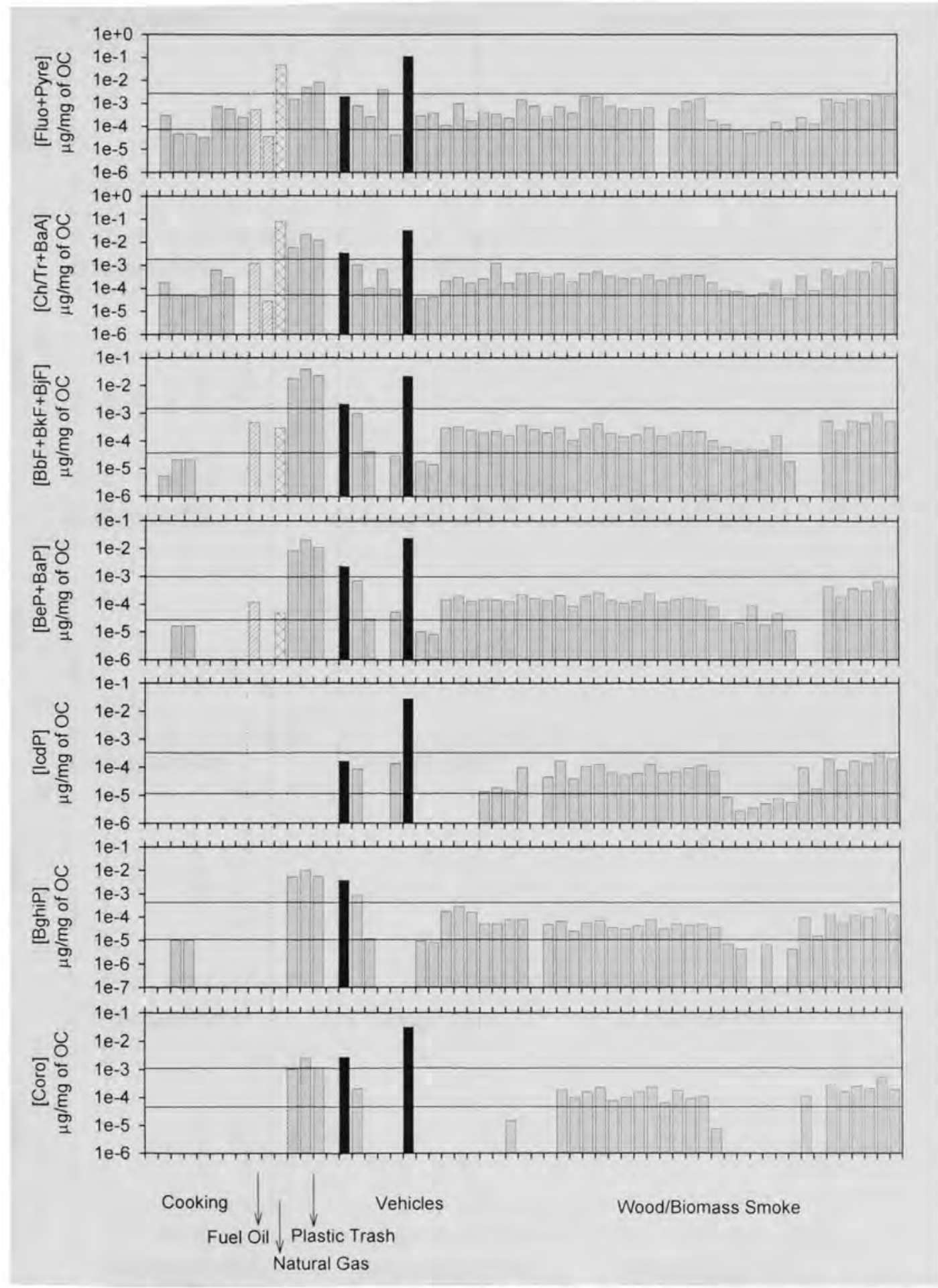

Figure B.6: Emission factors (in $\mu \mathrm{g} / \mathrm{mg}$ of $\mathrm{OC}$ ) of selected polyaromatic hydrocarbons (PAHs) reported in the sources profiles listed in Figure B.5. Black bars: vehicles not equipped with afterburner catalyst (Rogge et al., 1993b; Schauer et al., 2002c). PAHs abbreviations as given in Table A.1. 


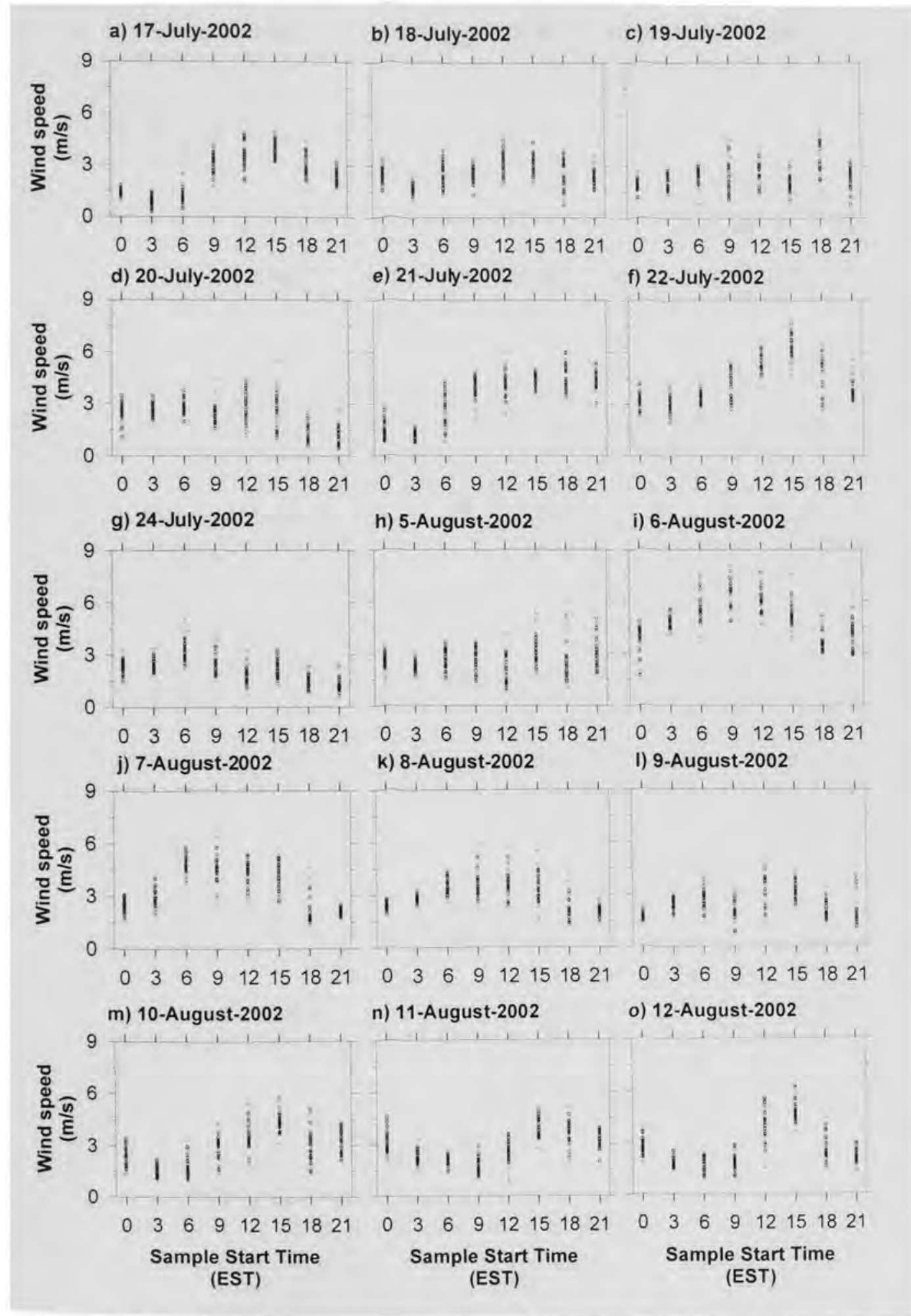

Figure B.7: Measurements of wind speed at $10 \mathrm{~m}$ height, conducted at the Ponca Street sampling site during the Baltimore PM-Supersite summer 2002 campaign. Graphs show 5-min data for each three-hourly interval. 


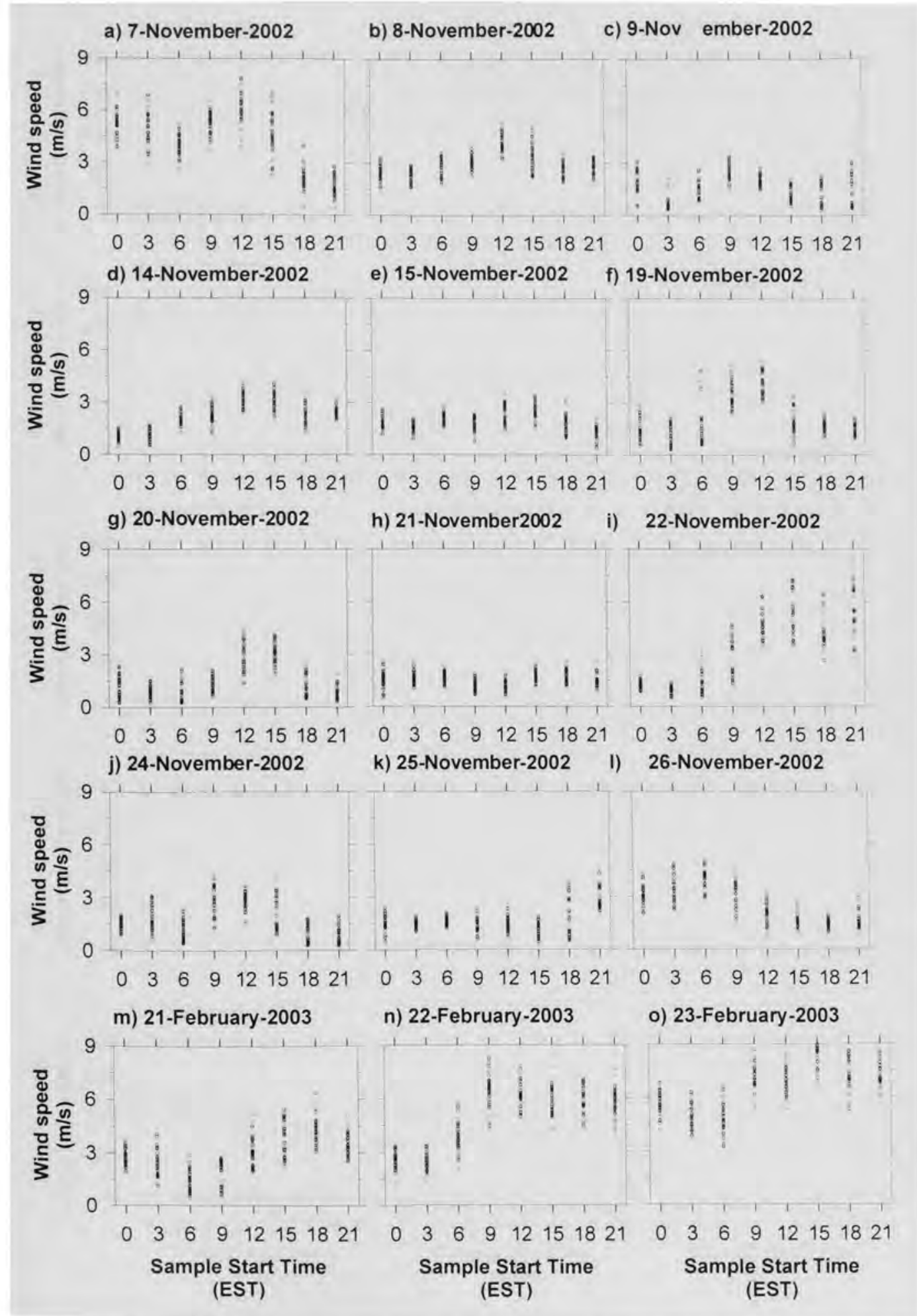

Figure B.8: Measurements of wind speed at $10 \mathrm{~m}$ height, conducted at the Ponca Street sampling site during the Baltimore PM-Supersite winter 2002-2003 campaign. Graphs show 5-min data for each three-hourly interval. 


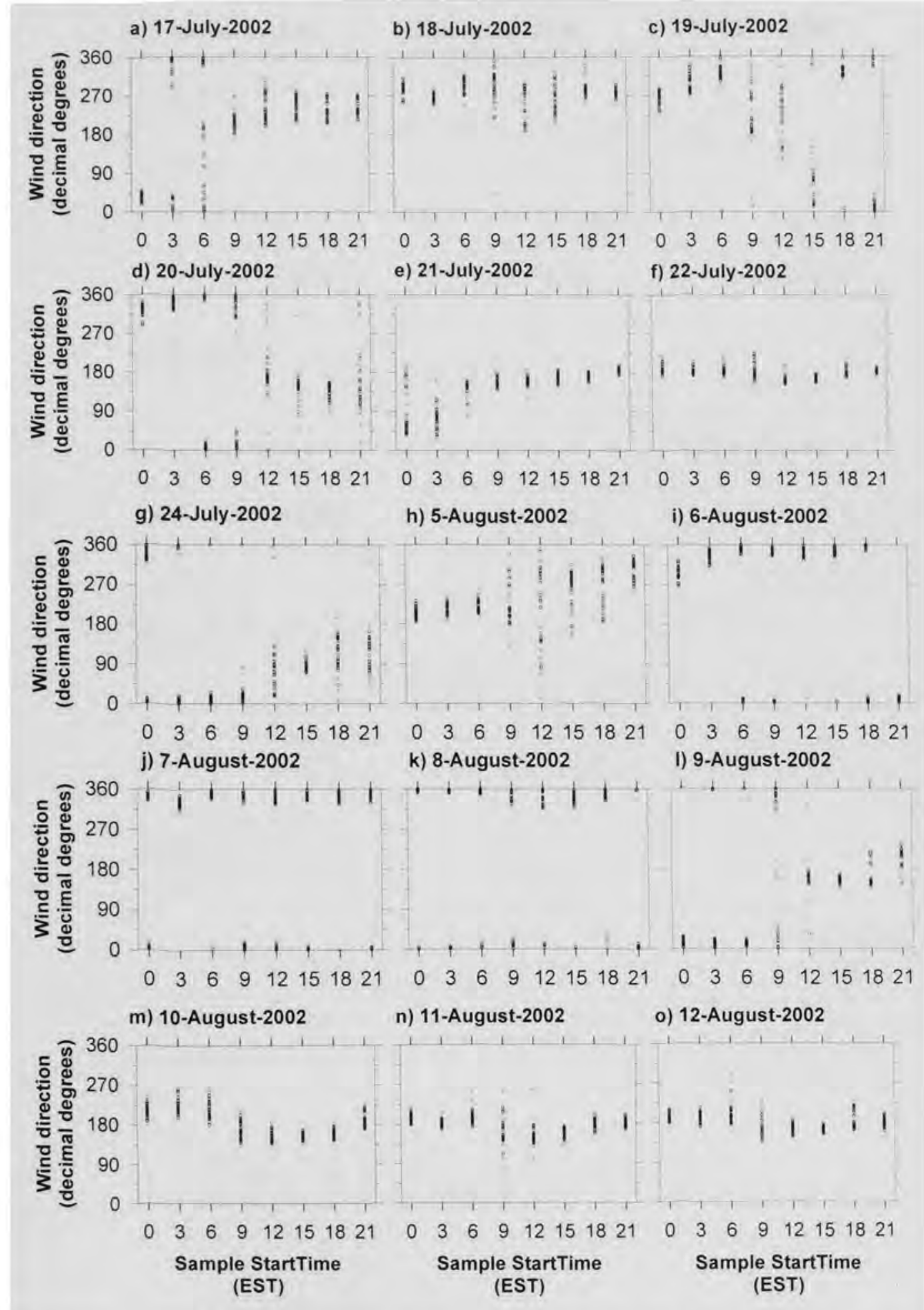

Figure B.9: Measurements of wind direction, conducted at the Ponca Street sampling site during the Baltimore PM-Supersite summer 2002 campaign. Graphs show 5-min data for each three-hourly interval. 


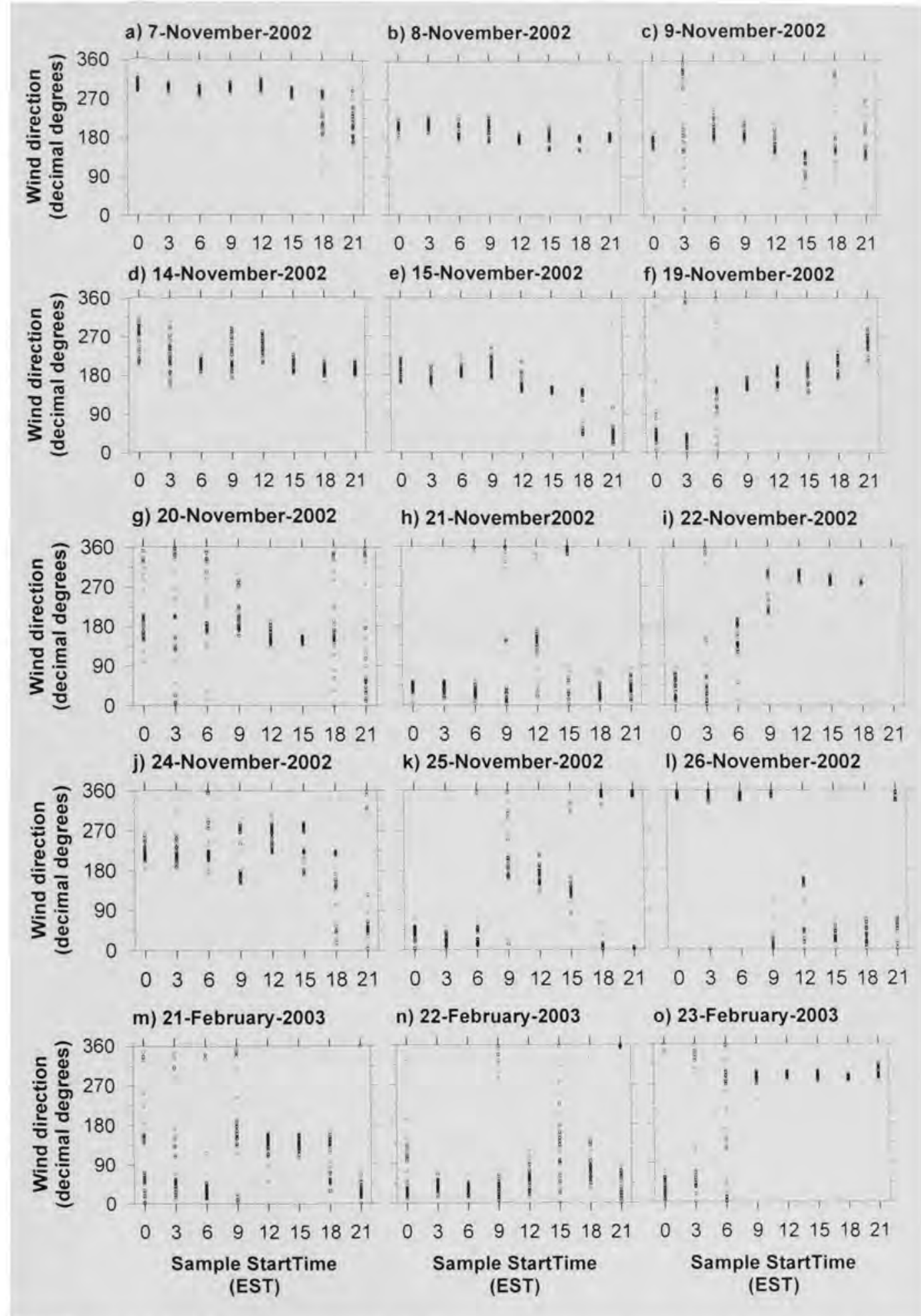

Figure B.10: Measurements of wind direction, conducted at the Ponca Street sampling site during the Baltimore PM-Supersite winter 2002-2003 campaign. Graphs show 5-min data for each three-hourly interval. 
Appendix C

Supplemental figures for Chapter 4 

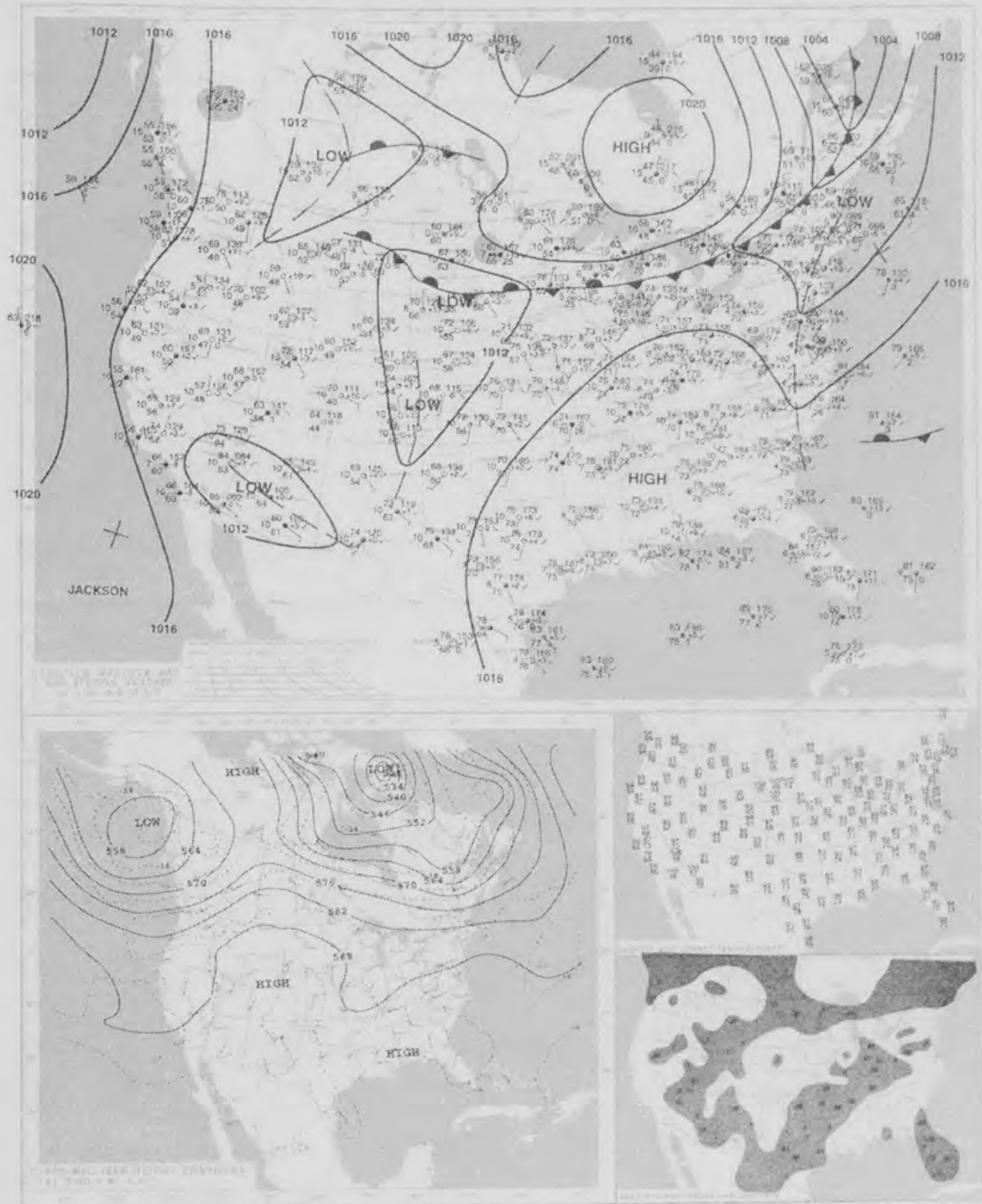

Figure C1: Weather map for July 18, 2002. The meaning of basic symbols is given in Figure $\mathrm{C} 4$. 

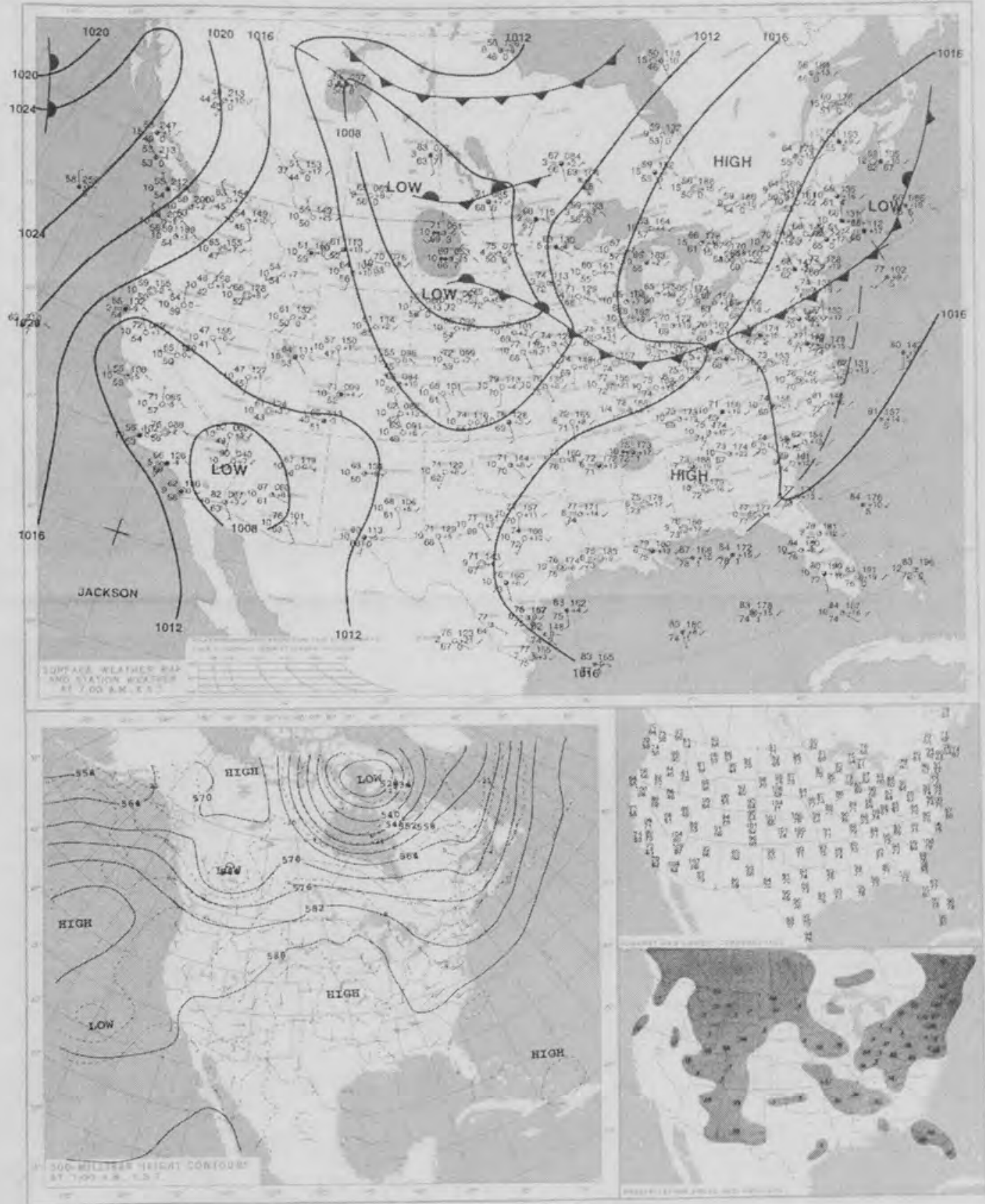

Figure C2: Weather map for July 20, 2002. The meaning of basic symbols is given in Figure $\mathrm{C} 4$. 


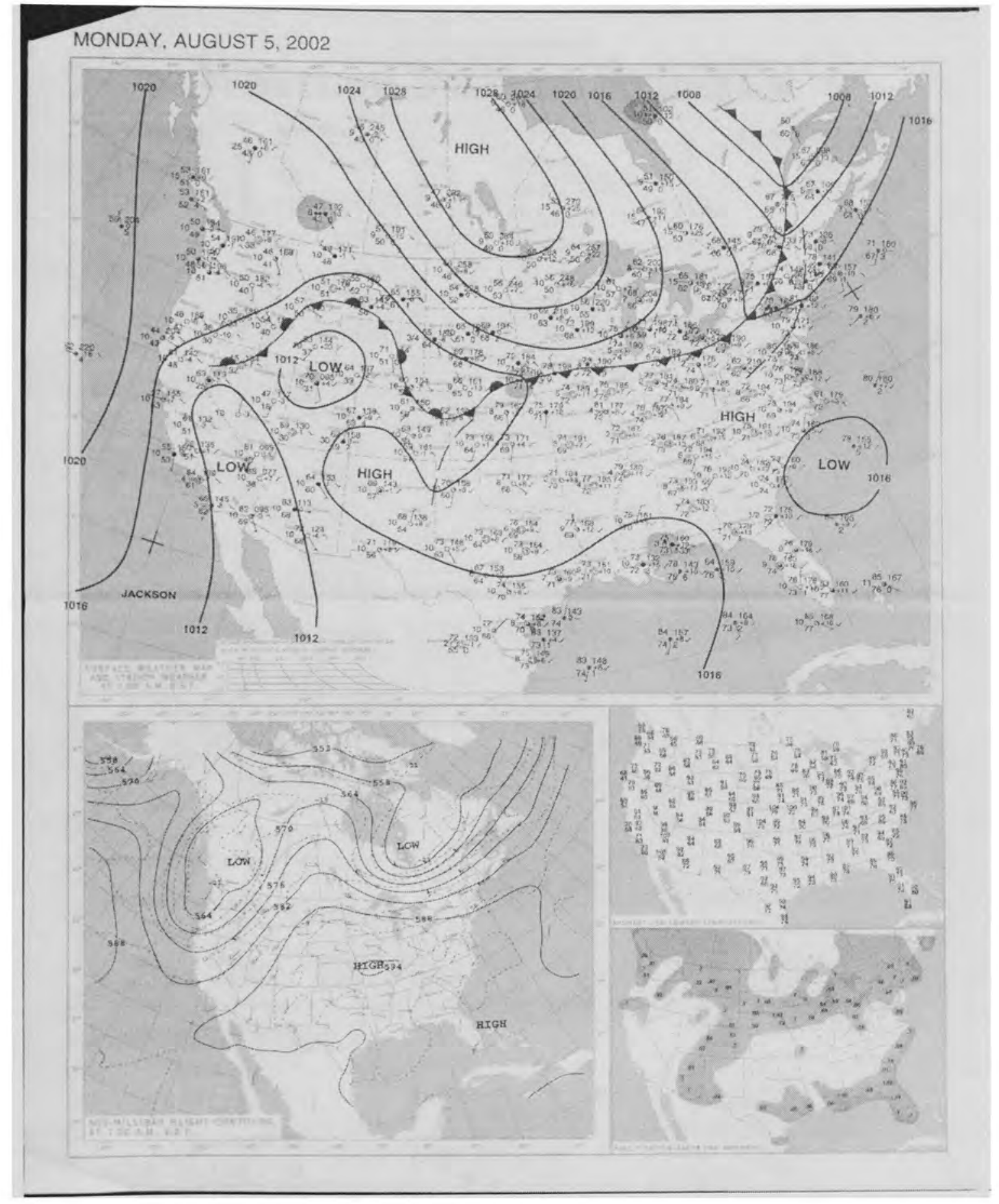

Figure C3: Weather map for August 5, 2002. The meaning of basic symbols is given in Figure $\mathrm{C} 4$. 


\section{Feather Station Symbols it}

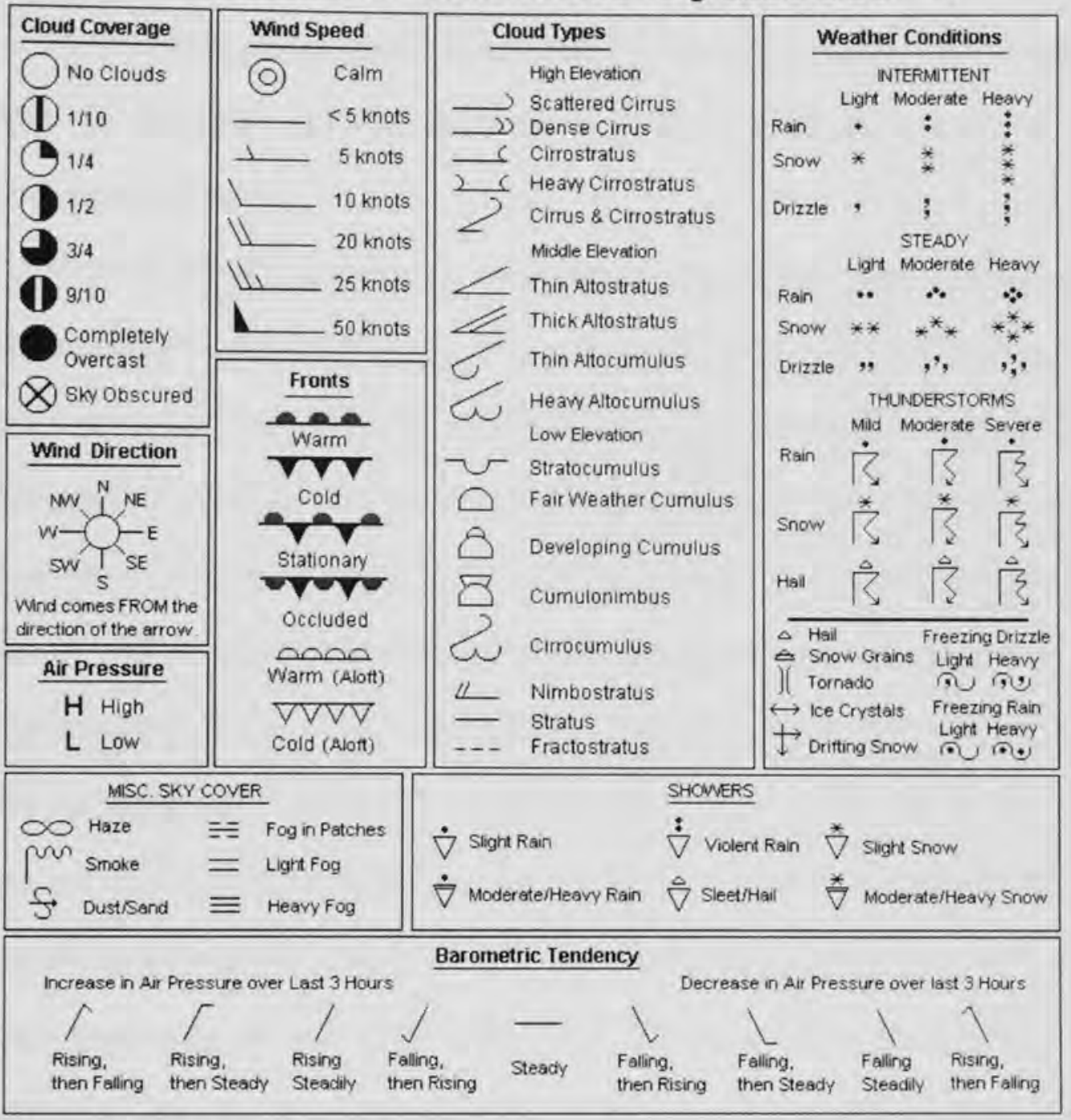

Weather Station Model Demo

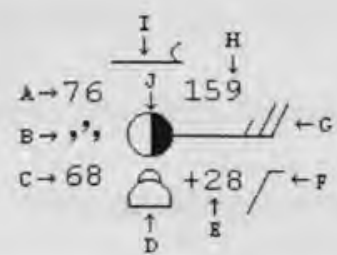

$$
\begin{aligned}
& \text { A- Temperature } \\
& \text { B - Present Ueather } \\
& \text { C - Dew Point } \\
& \text { D - Low Cloud Type } \\
& \text { E - Pressure Change }
\end{aligned}
$$

F-Pressure Tendency

G- Wind Speed \& Direction

H - Barowetric Pressure

I - High Cloud TYpe

$\mathrm{J}$ - Cloud Coverage

Figure C4: Description of symbols used in weather maps. Taken from the New Jersey Dept of Environmental Protection's "Print Me!" pages: http://www.state.nj.us/dep/seeds/wssym.htm 


\section{Procedure for Building Intrusion Diagrams}

The following procedure describes the steps followed to categorize the trajectories predicted by HYSPLIT for the month of July. Similar procedures were used for November and February.

All three HYSPLIT trajectories predicted for day 17-July were identical; these showed air masses which had originated in the northern Great Lakes area, and had been traveling on a consistent path from the northwest, through Michigan and the middle of Pennsylvania for three-four days prior to reaching the sampling site. Therefore, for the purpose of processing the end-points data these three trajectories were labeled "northwest" and every time that a similar central path appeared in the consecutive days was also labeled in the same way. On day 18-July, two of the three trajectories are shown to have the "northwest" path and one is shown to be a west regime along the line from Indiana and through Ohio and southwest tip of Pennsylvania; consequently, the first two are labeled "July-northwest" and the latter "west". The process was repeated with each of the three trajectories of each of day. The other two paths that were identified in the trajectories of July are: a) a path generally originating in New Hampshire and looping over the ocean and reaching Baltimore from the south, labeled "mixed/other", and b) a path traveling from the south through coastal North Carolina and Virginia ("south").

The northwesterly flow regime was not observed during the month of August. The prevalent influence for this month were trajectories originated straight due north (especially 6-9-August, north) as far back as Canada. The August-west regime was observed at the beginning and at the end of the August sampling period; the first time, 4- 
5-August, some of the trajectories predict a similar path to the one observed in July except somewhat more to the north, while others show it having a shorter reach (east Ohio-Pittsburgh-Maryland). On day $5^{\text {th }}$ HYSPLIT predicts the western mass arriving but not intruding

During November, trajectories originating in the northwest and the west predominated. These followed a similar path to those observed in July, (northwest, west); however, the level of intrusion is predicted to have been smaller than in the summer due to a less deep mixing layer in the former. Intrusions are negative only for the first sampling day, 7-November (northwest), and for 21-22-November. The latter influencing parcel originates in the southwest and follows a trajectory from Mississippi and through Tennessee, Kentucky and West Virginia (southwest). The nort/mixed regime originates in Ontario, similarly to the north observed in August; however it travels through the western portion of Pennsylvania. 

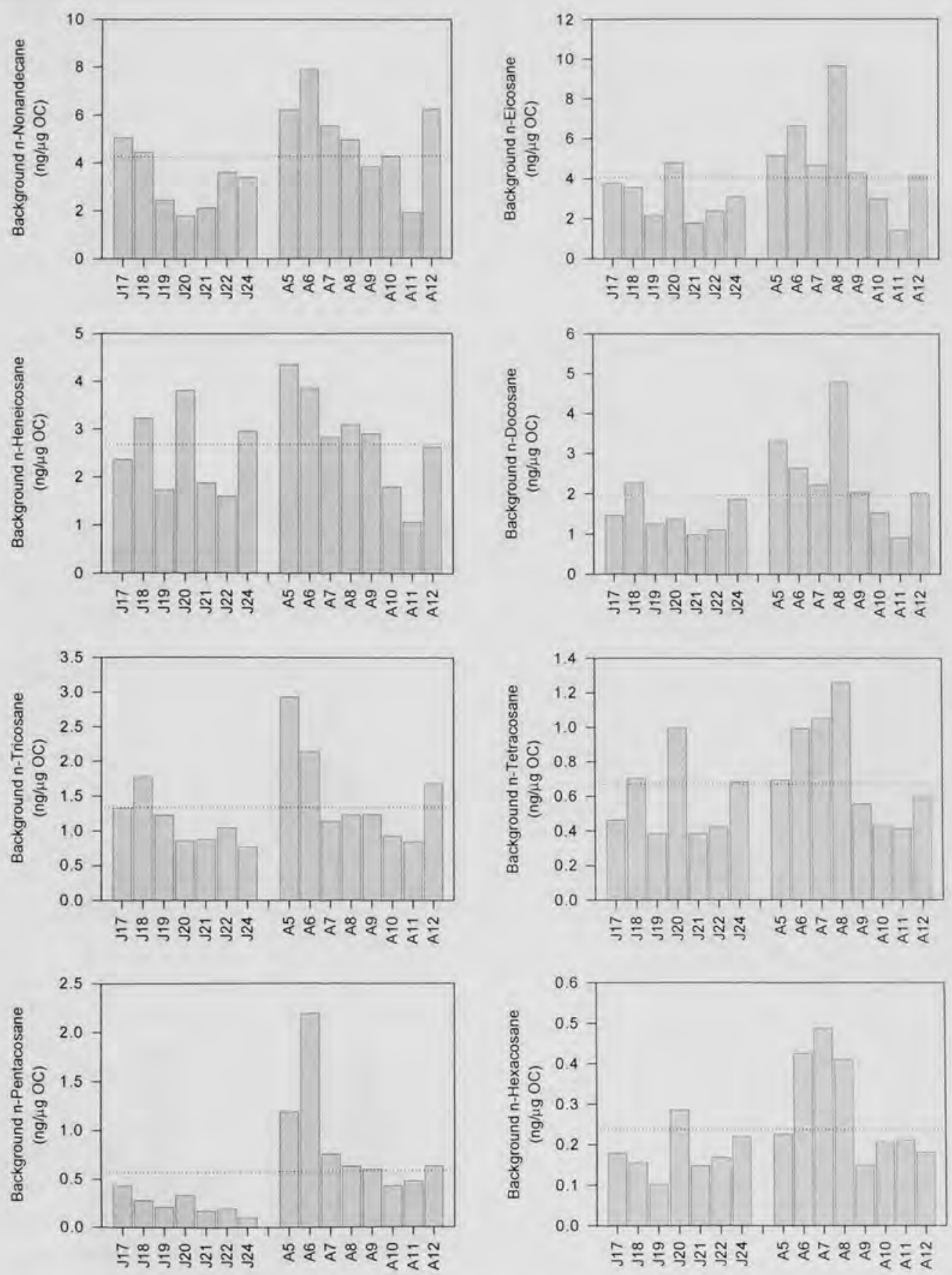

Figure C.5 part-i of ii: Bar graphs showing the OC-normalized background concentration of individual n-alkanes. That is, the minimum concentration observed of the compound in the given day, divided by the OC concentration measured concurrently. J=July, $\mathrm{A}=$ August days of 2002. Dotted line indicates the average. (Figure continues in next page) 

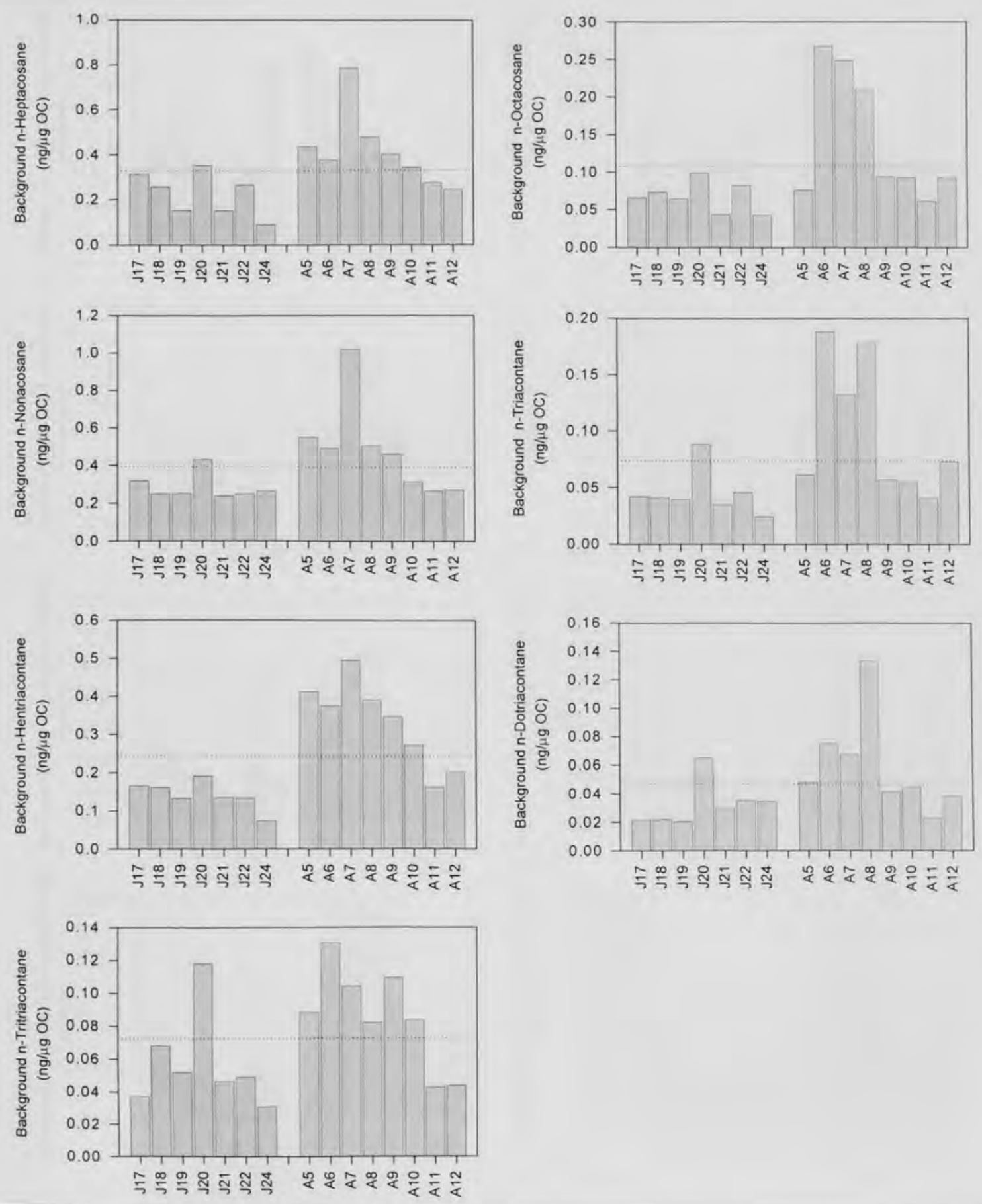

Figure C.5-part ii of ii: Bar graphs showing the OC-normalized background concentration of individual n-alkanes. That is, the minimum concentration observed of the compound in the given day, divided by the OC concentration measured concurrently. J=July, $\mathrm{A}=$ August days of 2002. Dotted line indicates the average. 

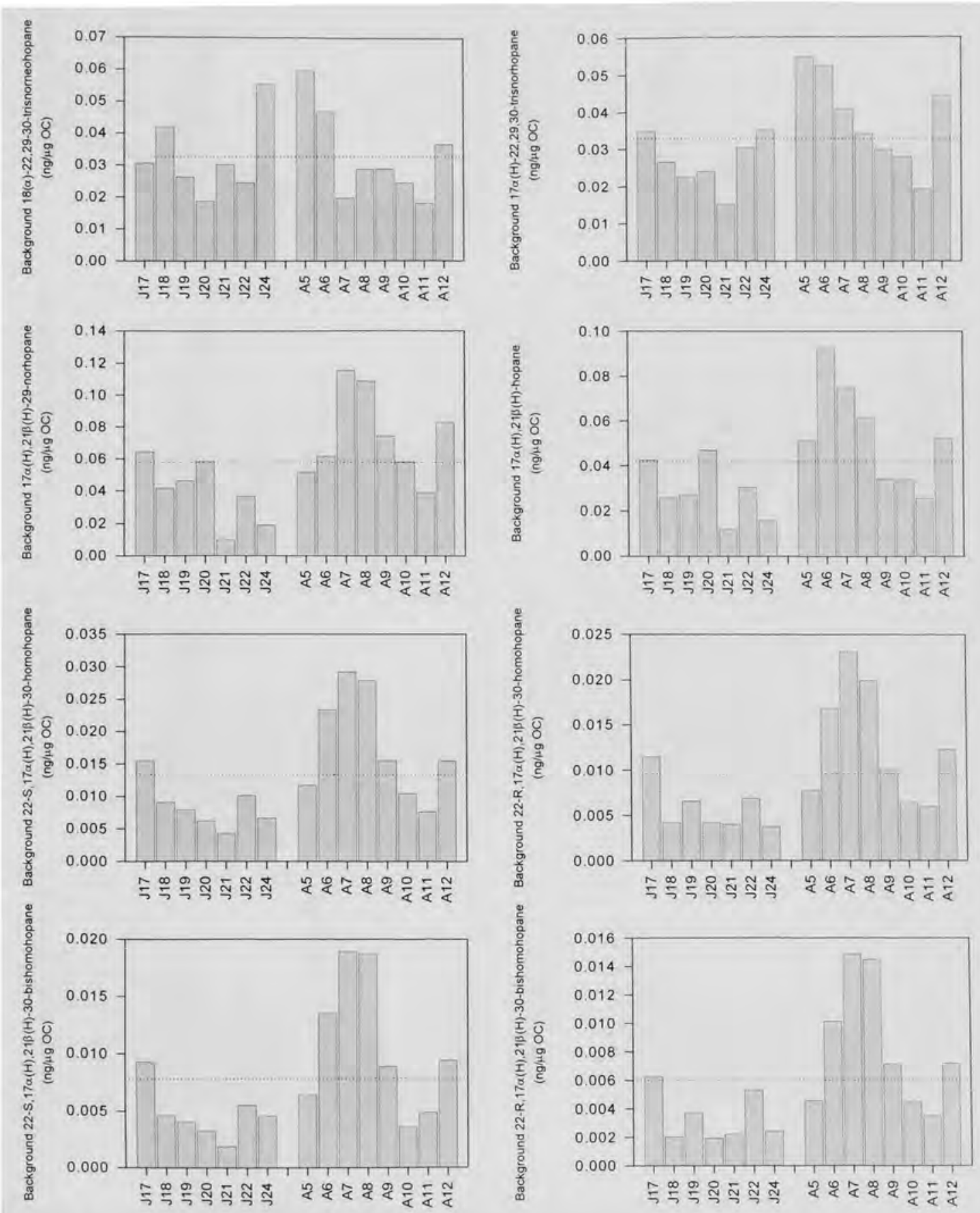

Figure C.6: Bar graphs showing the OC-normalized background concentration of individual hopanes. That is, the minimum concentration observed of the compound in the given day, divided by the $\mathrm{OC}$ concentration measured concurrently. $\mathrm{J}=\mathrm{July}, \mathrm{A}=$ August days of 2002. Dotted line indicates the average. 

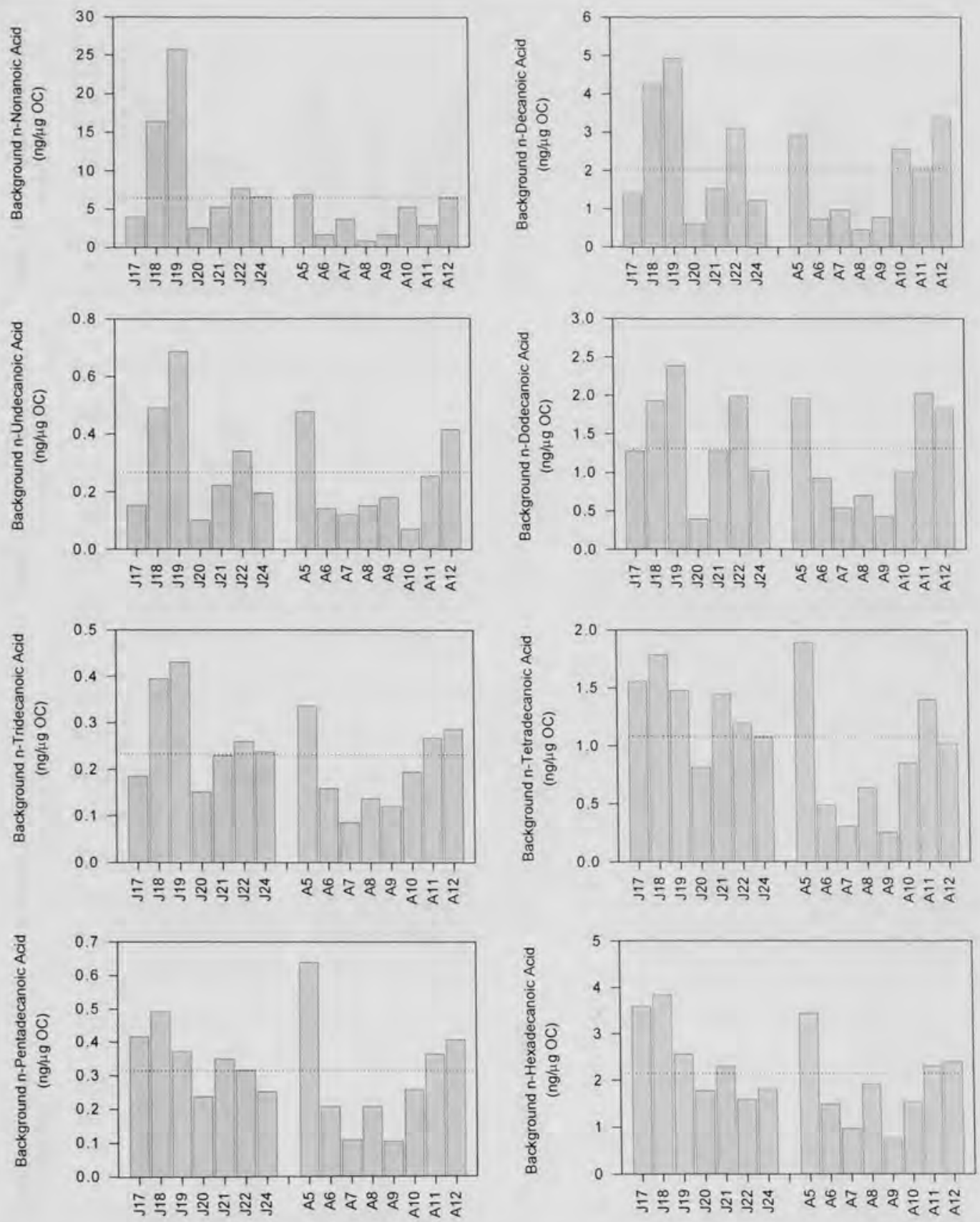

Figure C.7-part i of ii: Bar graphs showing the OC-normalized background concentration of individual $\mathrm{n}$-alkanoic acid. That is, the minimum concentration observed of the compound in the given day, divided by the OC concentration measured concurrently. $\mathrm{J}=\mathrm{July}, \mathrm{A}=$ August days of 2002. Dotted line indicates the average. (Figure continues in next page) 

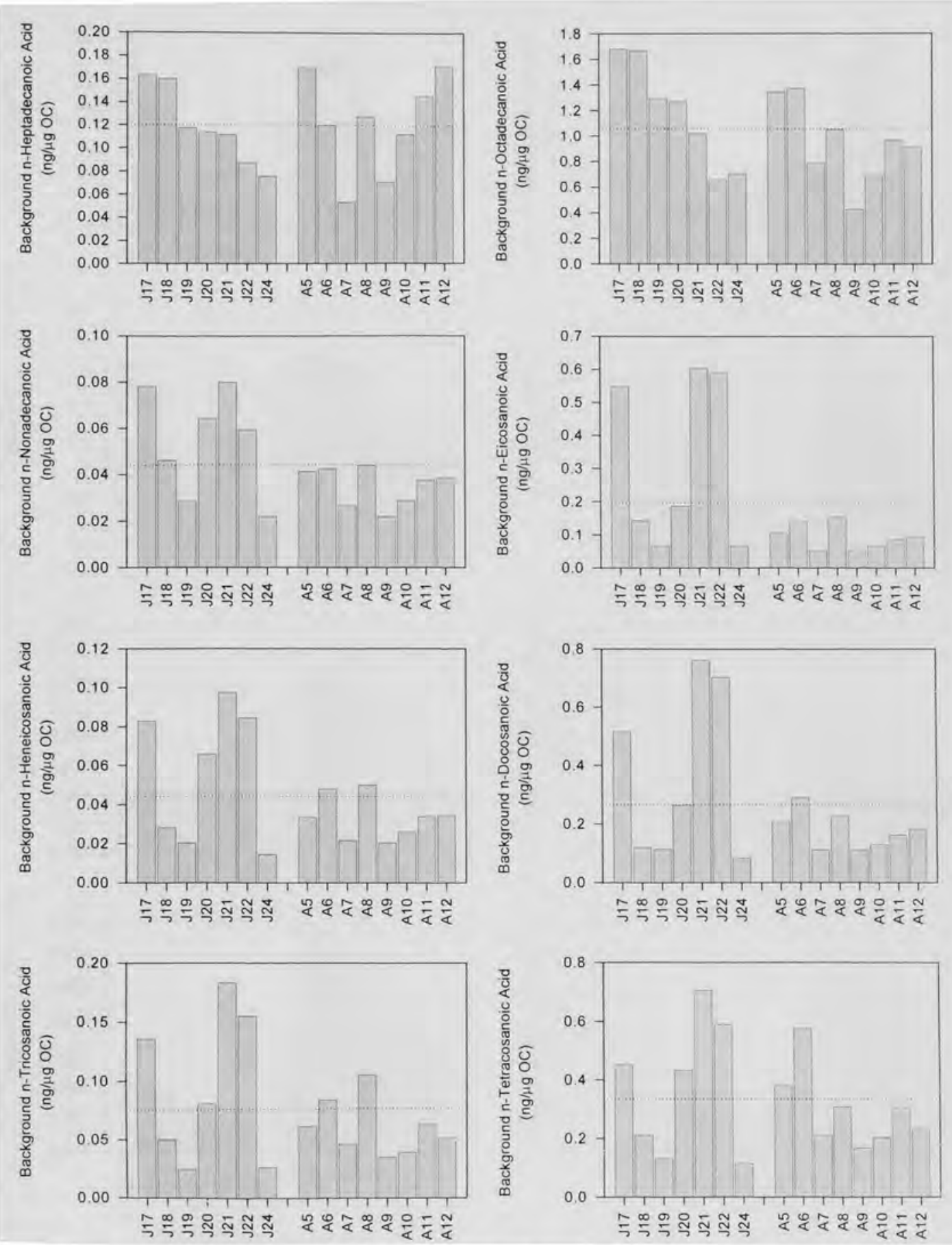

Figure C.7-part ii of ii: Bar graphs showing the OC-normalized background concentration of individual n-alkanoic acid. That is, the minimum concentration observed of the compound in the given day, divided by the $\mathrm{OC}$ concentration measured concurrently. $\mathrm{J}=\mathrm{July}, \mathrm{A}=$ August days of 2002. Dotted line indicates the average. 

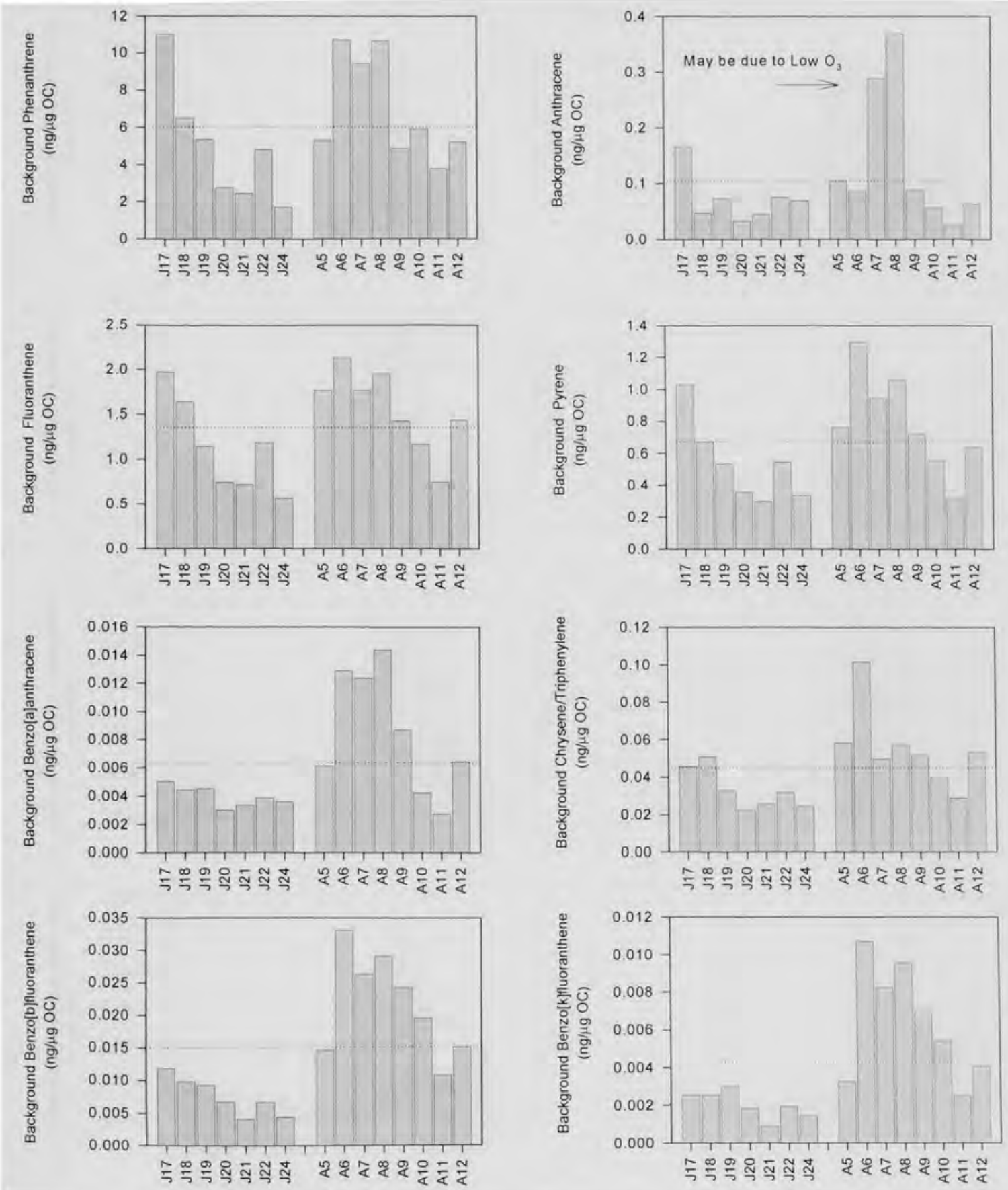

Figure C.8-part i of ii: Bar graphs showing the OC-normalized background concentration of individual polycyclic aromatic hydrocarbon (PAHs). That is, the minimum concentration observed of the compound in the given day, divided by the OC concentration measured concurrently. $\mathrm{J}=\mathrm{July}, \mathrm{A}=$ August days of 2002. Dotted line indicates the average. (Figure continues in next page) 

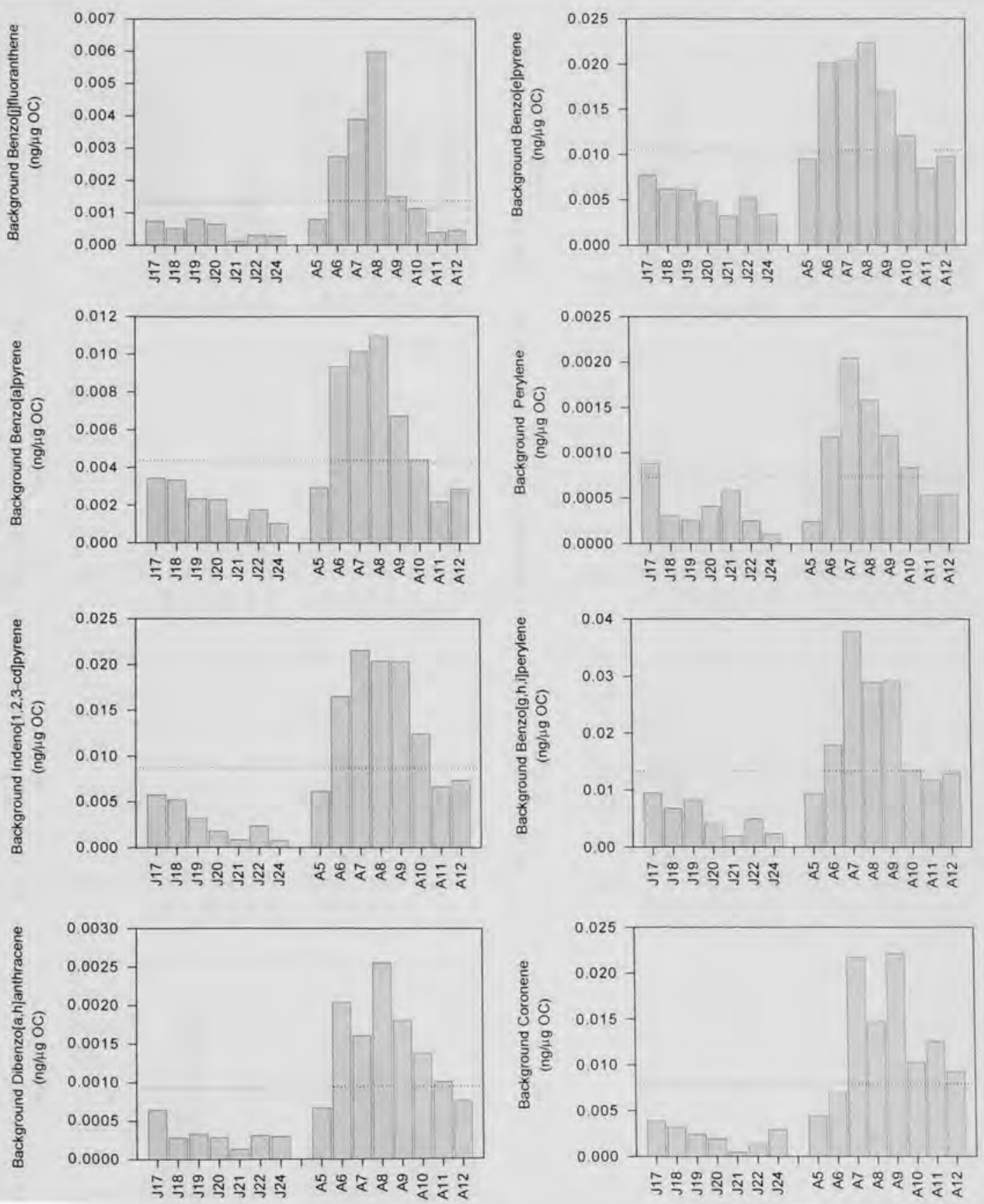

Figure C.8-part ii of ii: Bar graphs showing the OC-normalized background concentration of individual polycyclic aromatic hydrocarbon (PAHs). That is, the minimum concentration observed of the compound in the given day, divided by the OC concentration measured concurrently. $\mathrm{J}=\mathrm{July}, \mathrm{A}=$ August days of 2002. Dotted line indicates the average. (Figure continues in next page) 


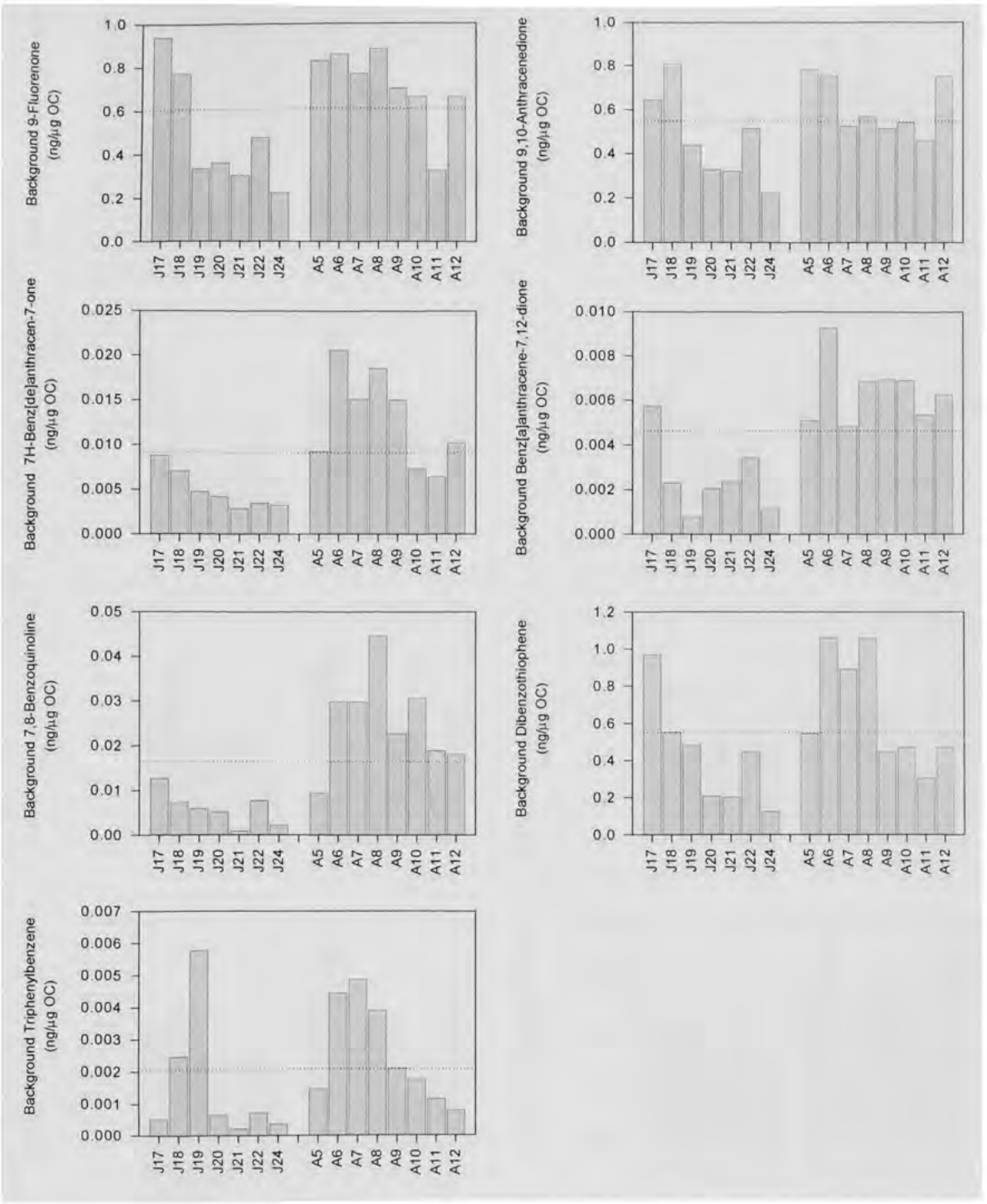

Figure C.9: Bar graphs showing the OC-normalized background concentration of individual hetero-polycyclic aromatic hydrocarbon (hetero-PAHs), and triphenylbenzene (TPB). That is, the minimum concentration observed of the compound in the given day, divided by the OC concentration measured concurrently. J=July, A=August days of 2002. Dotted line indicates the average. 

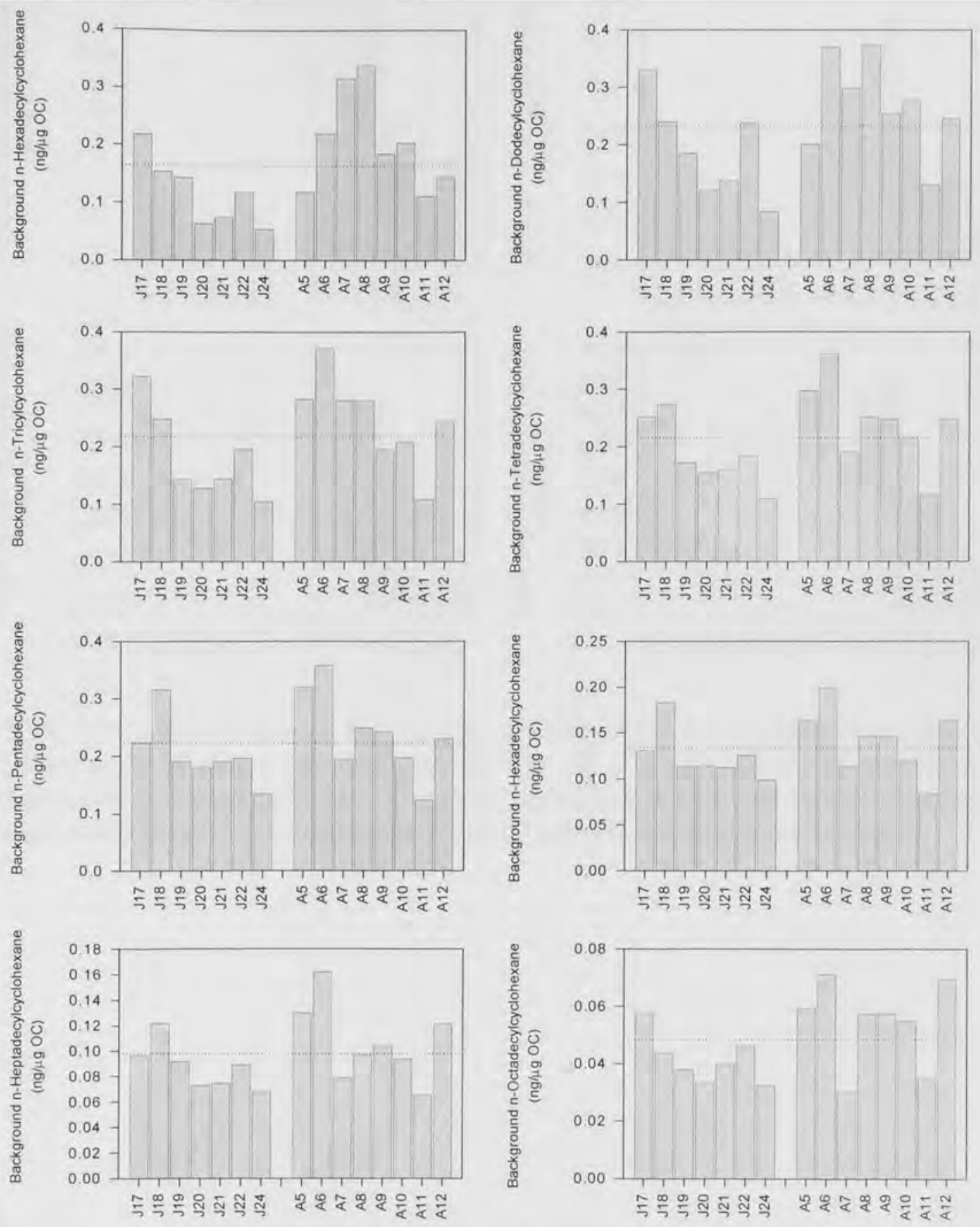

Figure C.10-part i of ii: Bar graphs showing the OC-normalized background concentration of individual n-alkylcyclohexane. That is, the minimum concentration observed of the compound in the given day, divided by the $\mathrm{OC}$ concentration measured concurrently. $\mathrm{J}=\mathrm{July}, \mathrm{A}=$ August days of 2002. Dotted line indicates the average. (Figure continues in next page) 


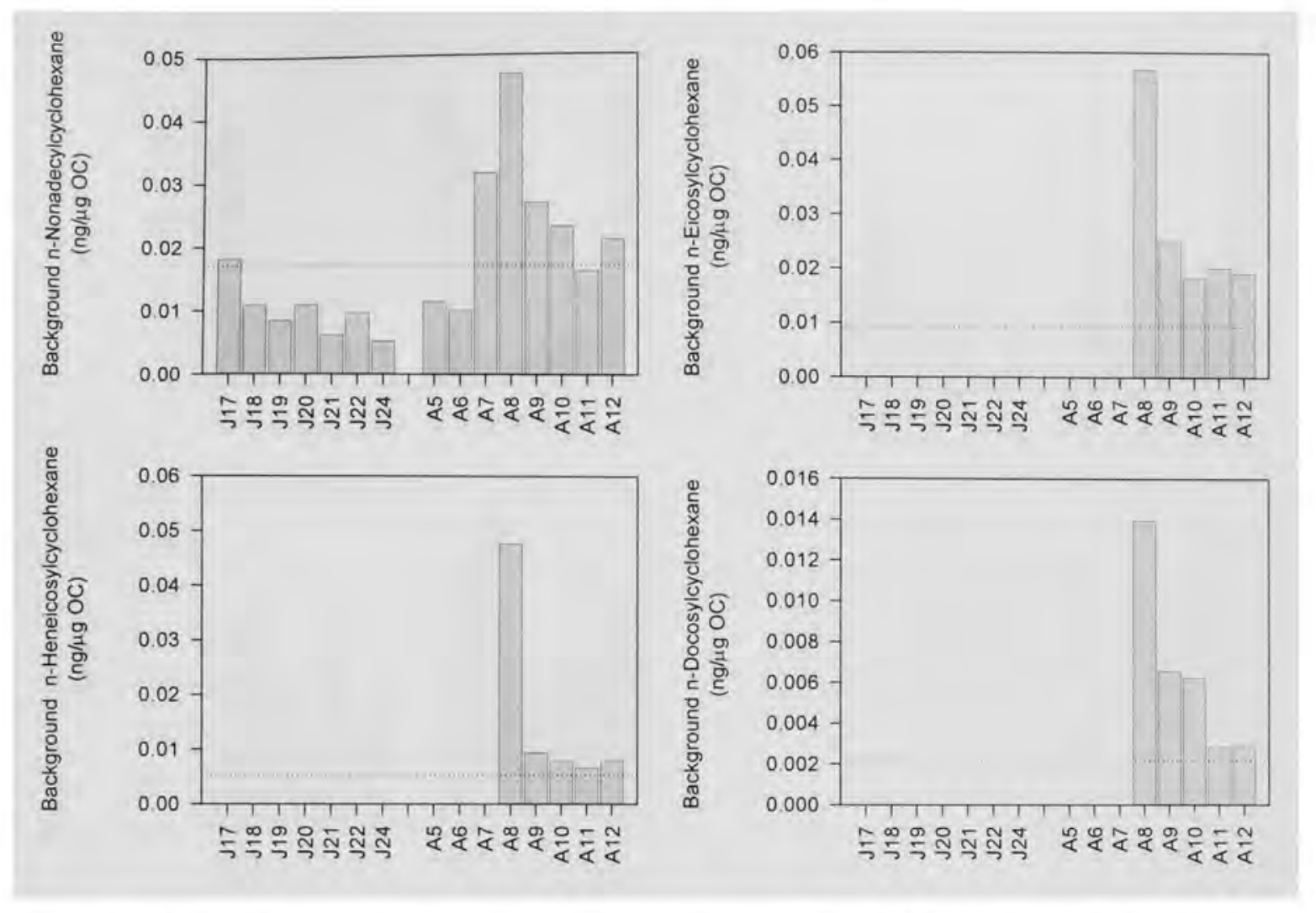

Figure C.10-part ii of ii: Bar graphs showing the OC-normalized background concentration of individual n-alkylcyclohexane. That is, the minimum concentration observed of the compound in the given day, divided by the OC concentration measured concurrently. $\mathrm{J}=\mathrm{July}, \mathrm{A}=$ August days of 2002. Dotted line indicates the average. 

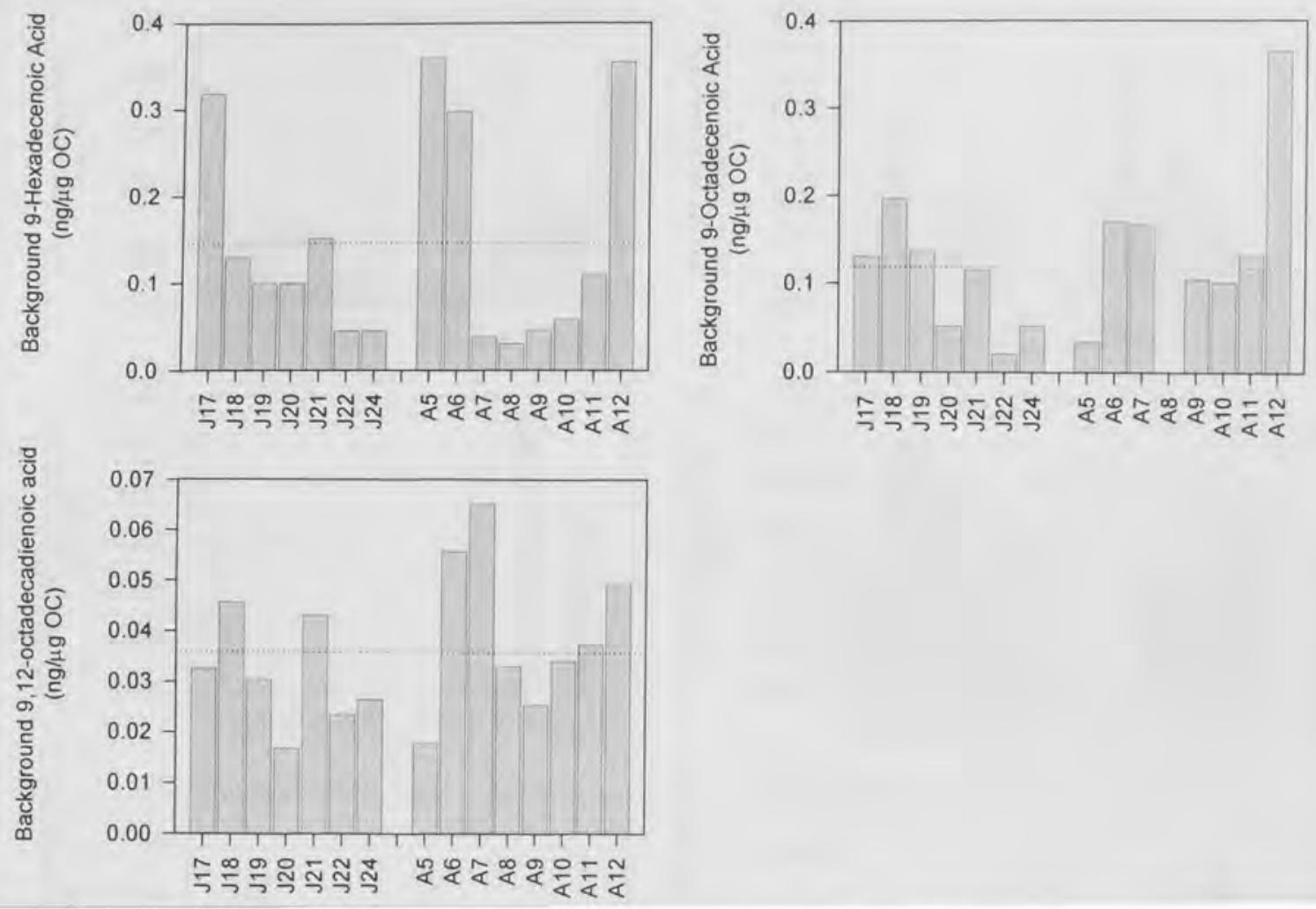

Figure C.11: Bar graphs showing the OC-normalized background concentration of individual n-alkenoic acid. That is, the minimum concentration observed of the compound in the given day, divided by the $\mathrm{OC}$ concentration measured concurrently. $\mathrm{J}=\mathrm{July}, \mathrm{A}=$ August days of 2002. Dotted line indicates the average. 

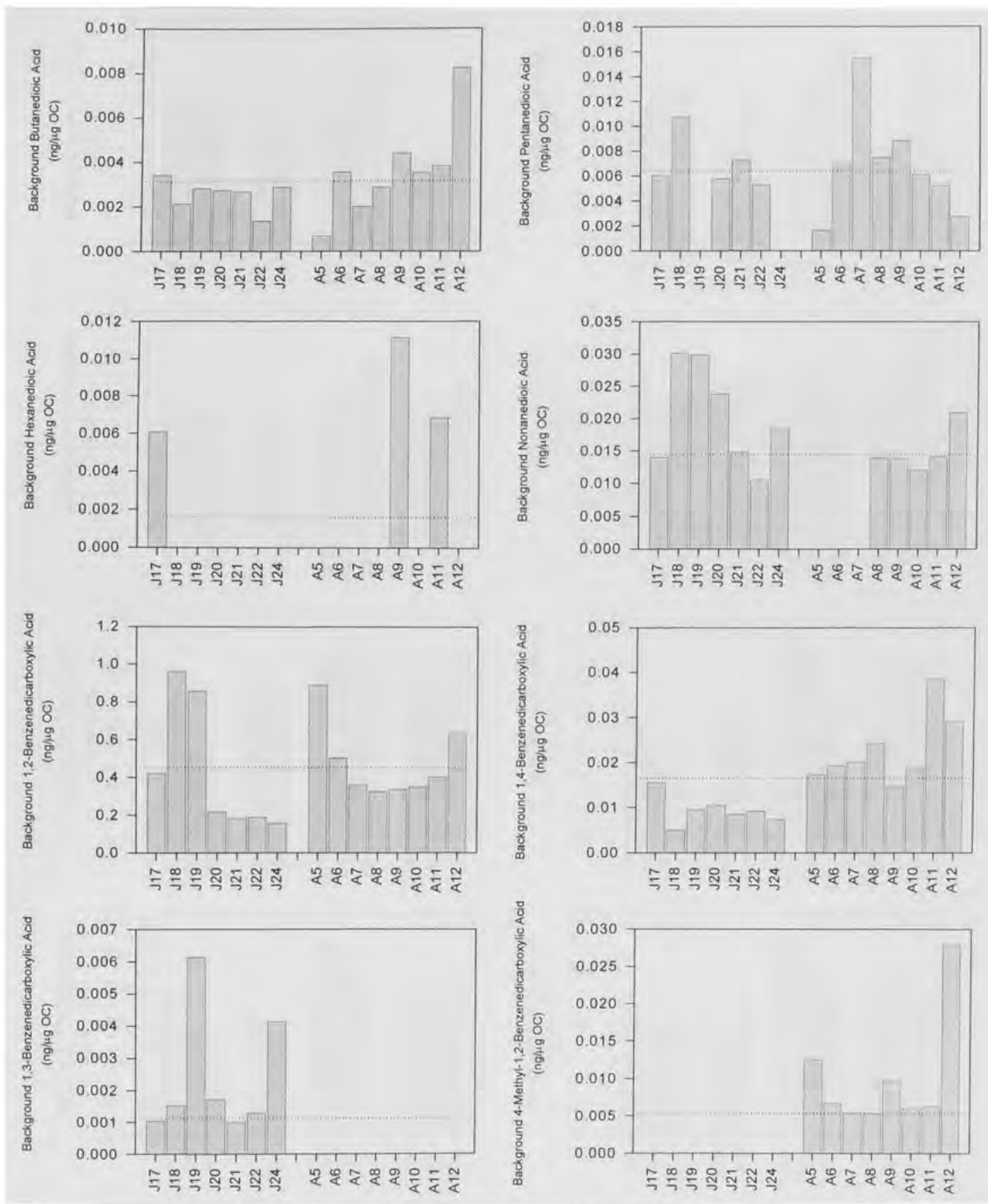

Figure C.12: Bar graphs showing the OC-normalized background concentration of individual aliphatic and aromatic dicarboxylic acid. That is, the minimum concentration observed of the compound in the given day, divided by the OC concentration measured concurrently. $\mathrm{J}=\mathrm{July}, \mathrm{A}=$ August days of 2002. Dotted line indicates the average. 

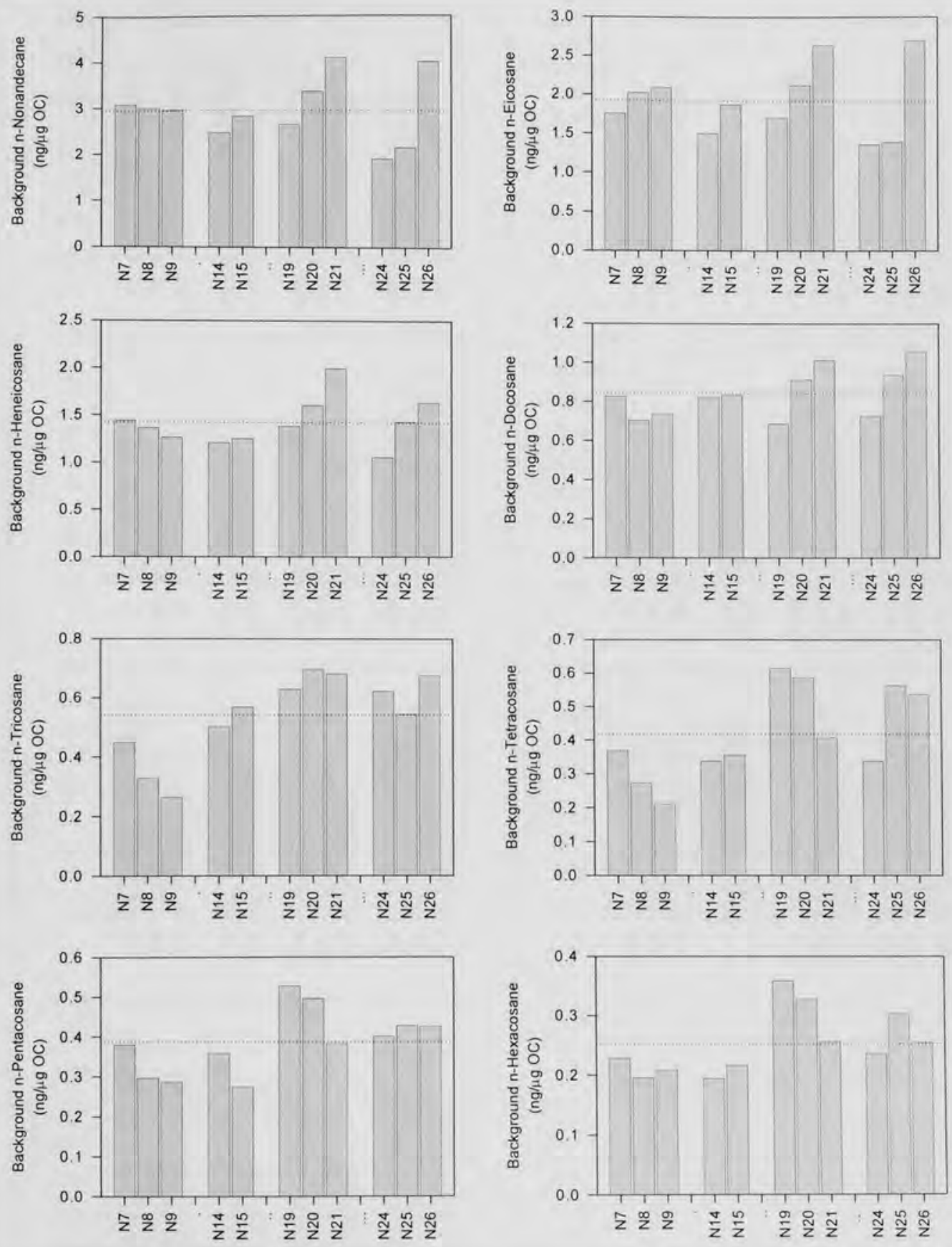

Figure C.13-part $\mathrm{i}$ of ii: Bar graphs showing the OC-normalized background concentration of individual n-alkanes. That is, the minimum concentration observed of the compound in the given day, divided by the OC concentration measured concurrently. $\mathrm{N}=$ November days of 2002. Dotted line indicates the average. (Figure continues in next page) 

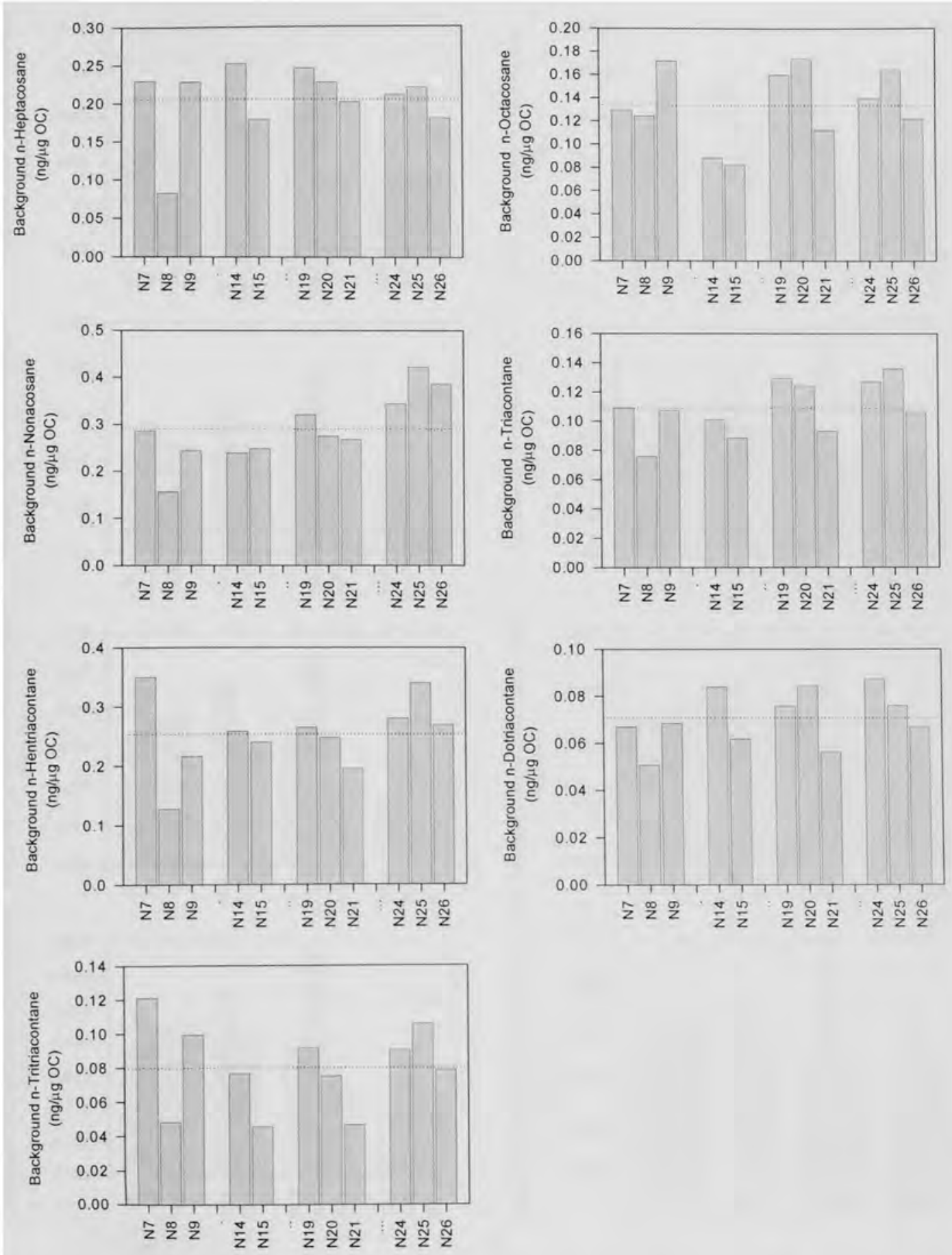

Figure C.13-part ii of ii: Bar graphs showing the OC-normalized background concentration of individual n-alkanes. That is, the minimum concentration observed of the compound in the given day, divided by the OC concentration measured concurrently. $\mathrm{N}=$ November days of 2002 . Dotted line indicates the average. 

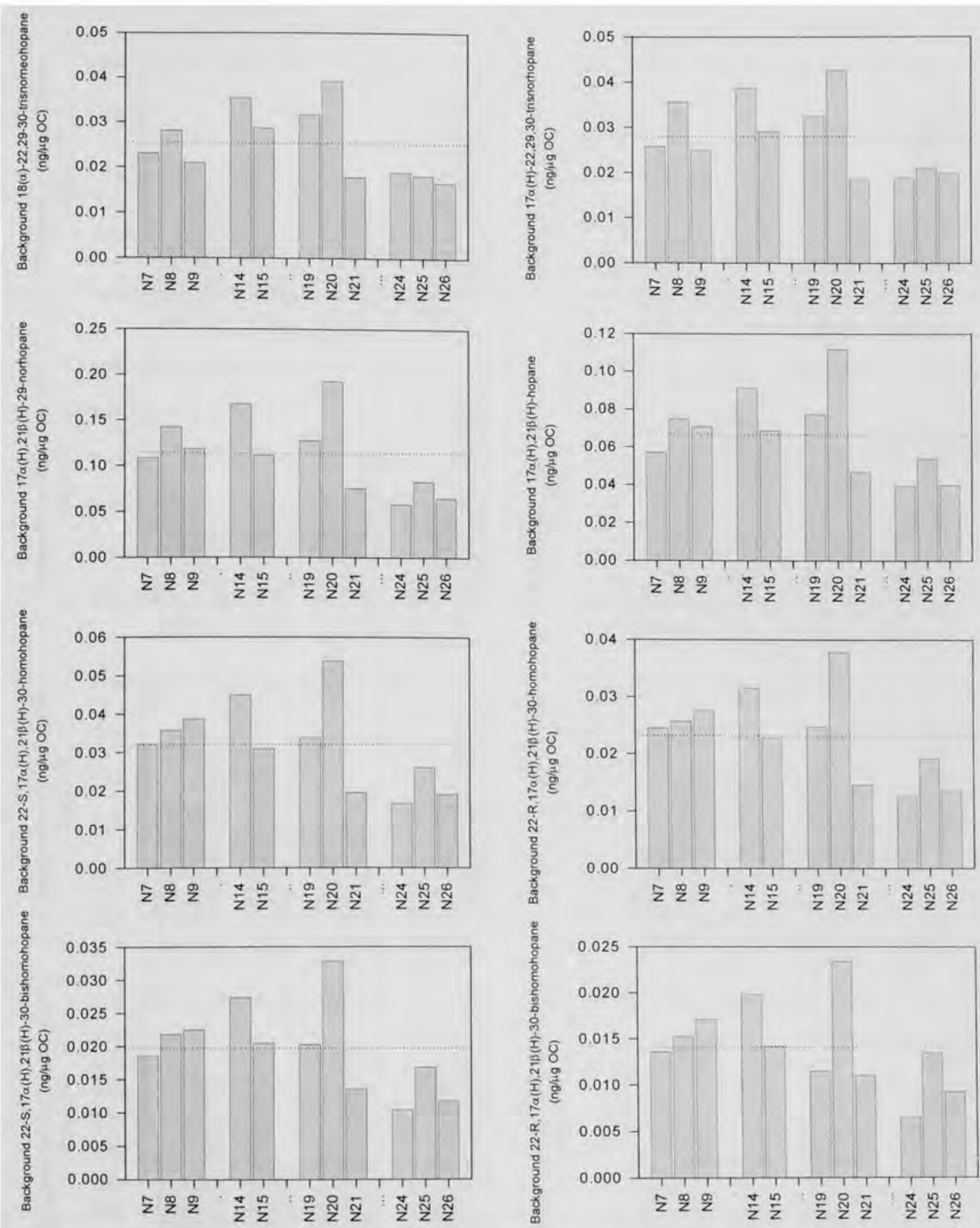

Figure C.14: Bar graphs showing the OC-normalized background concentration of individual hopanes. That is, the minimum concentration observed of the compound in the given day, divided by the $\mathrm{OC}$ concentration measured concurrently. $\mathrm{N}=\mathrm{November}$ days of 2002. Dotted line indicates the average. 

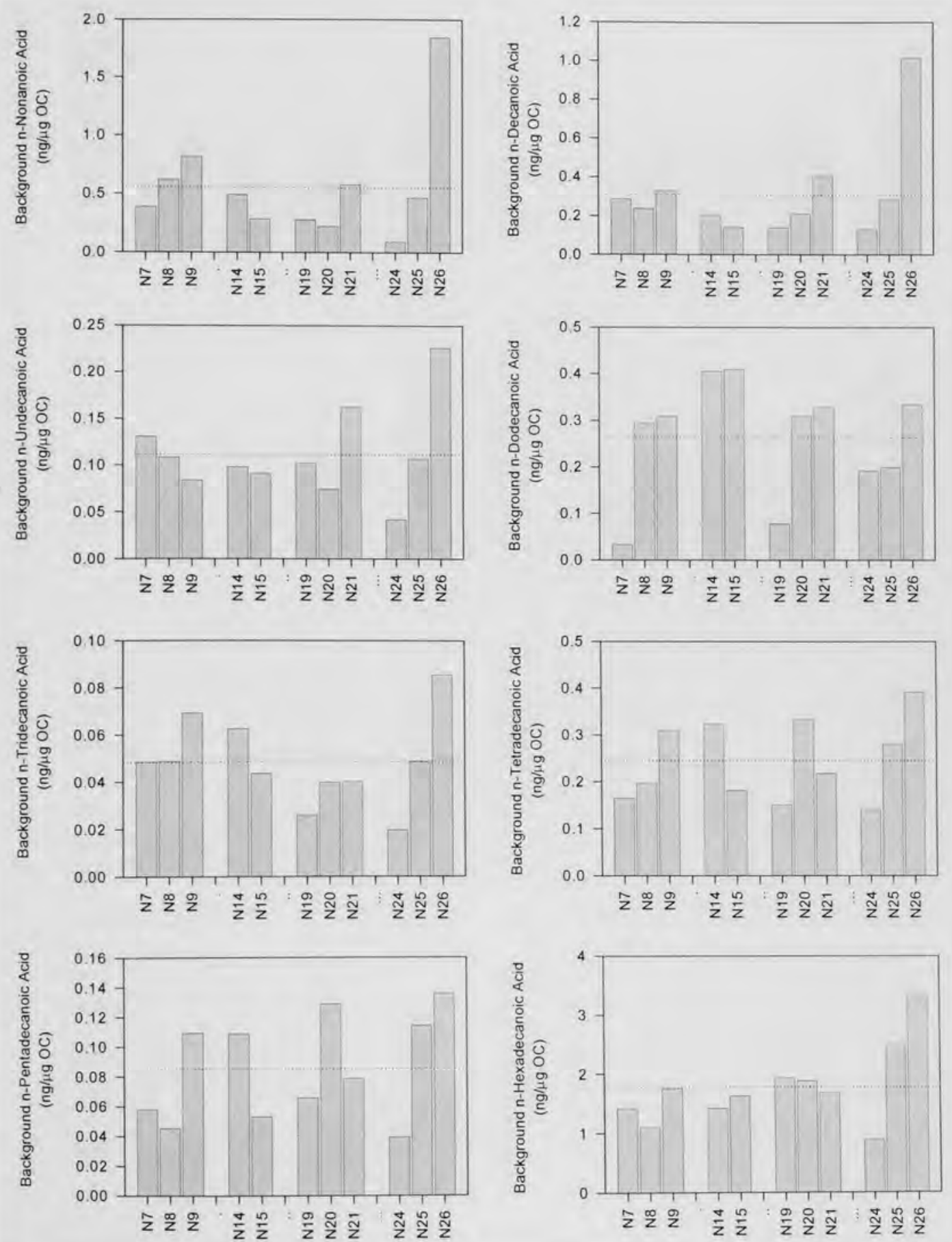

Figure C.15-part $\mathrm{i}$ of ii: Bar graphs showing the OC-normalized background concentration of individual n-alkanoic acid. That is, the minimum concentration observed of the compound in the given day, divided by the OC concentration measured concurrently. $\mathrm{N}=$ November days of 2002. Dotted line indicates the average. (Figure continues in next page) 

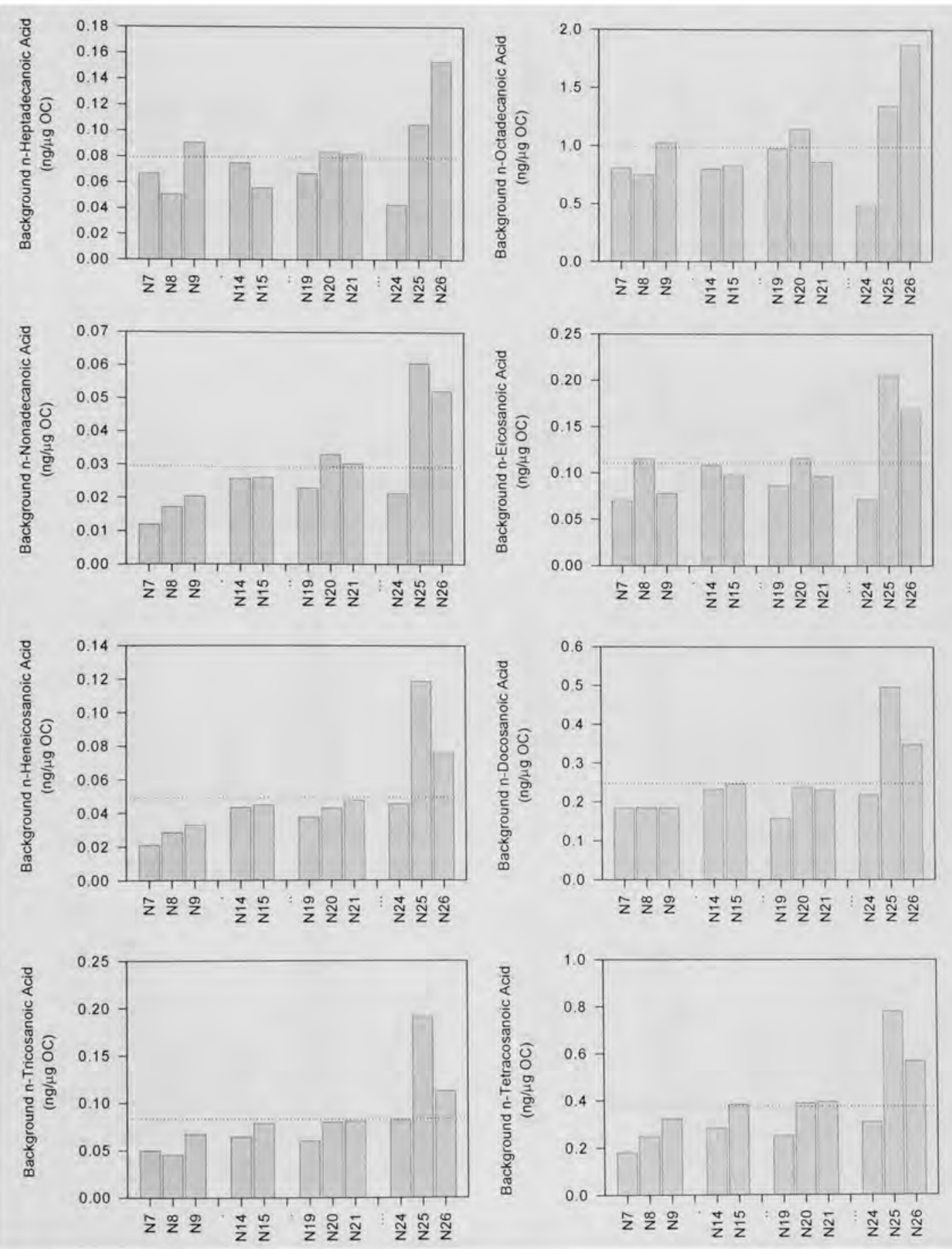

Figure C.15-part ii of ii: Bar graphs showing the OC-normalized background concentration of individual n-alkanoic acid. That is, the minimum concentration observed of the compound in the given day, divided by the OC concentration measured concurrently. $\mathrm{N}=$ November days of 2002 . Dotted line indicates the average. 

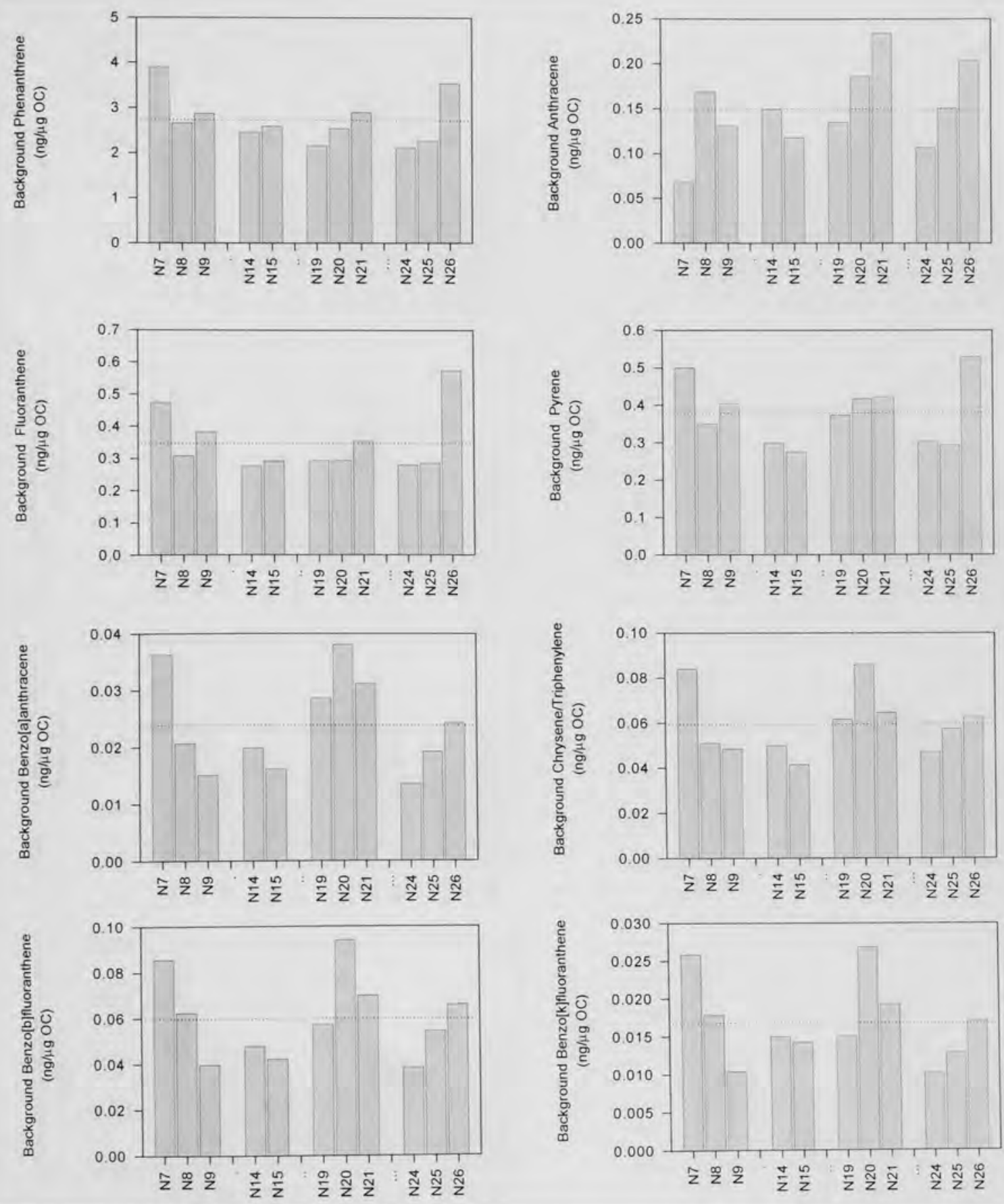

Figure C.16-part $\mathrm{i}$ of ii: Bar graphs showing the OC-normalized background concentration of individual polycyclic aromatic hydrocarbon (PAHs). That is, the minimum concentration observed of the compound in the given day, divided by the OC concentration measured concurrently. N=November days of 2002. Dotted line indicates the average. (Figure continues in next page) 

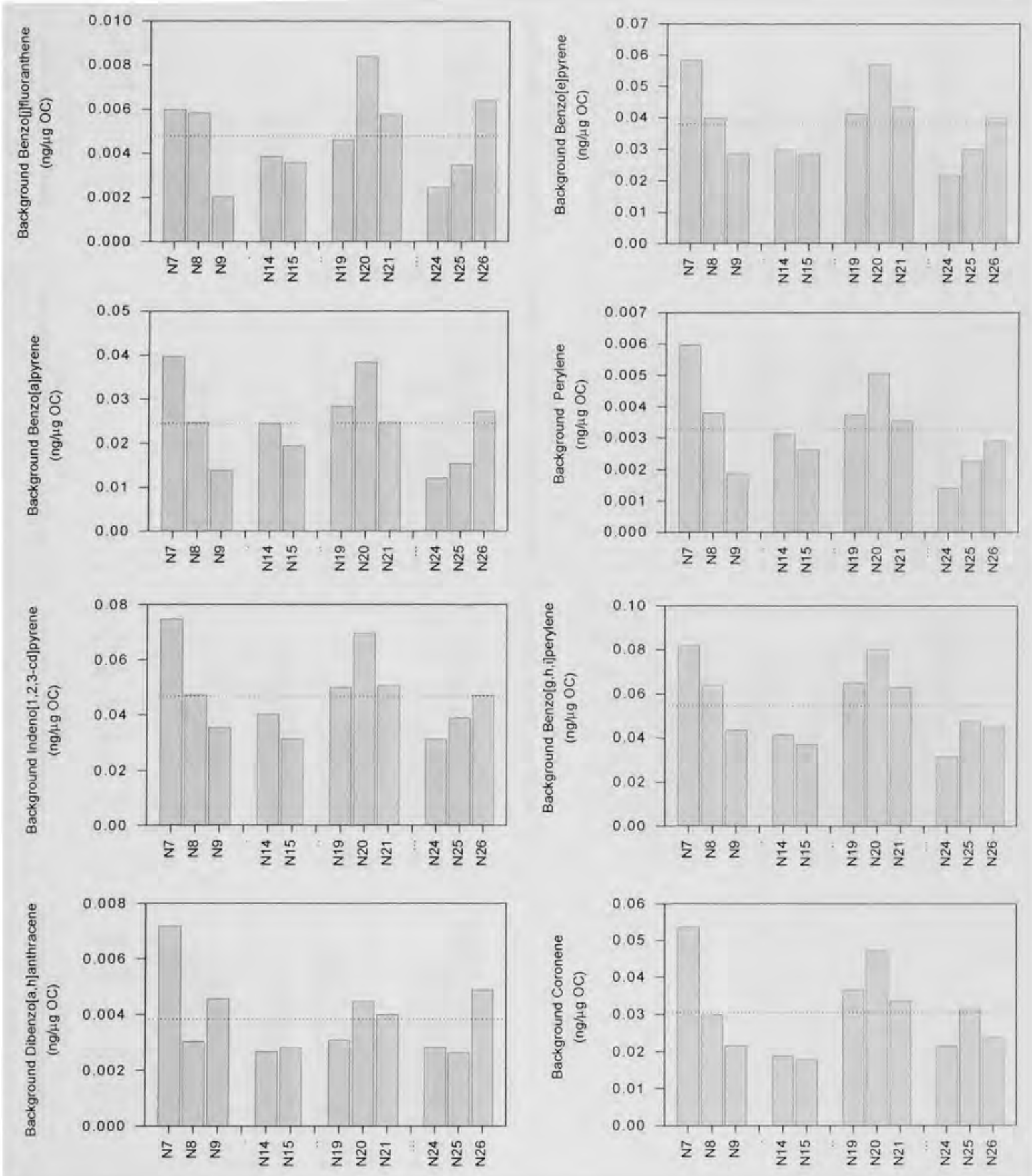

Figure C.16-part ii of ii: Bar graphs showing the OC-normalized background concentration of individual polycyclic aromatic hydrocarbon (PAHs). That is, the minimum concentration observed of the compound in the given day, divided by the OC concentration measured concurrently. $\mathrm{N}=$ November days of 2002. Dotted line indicates the average. 

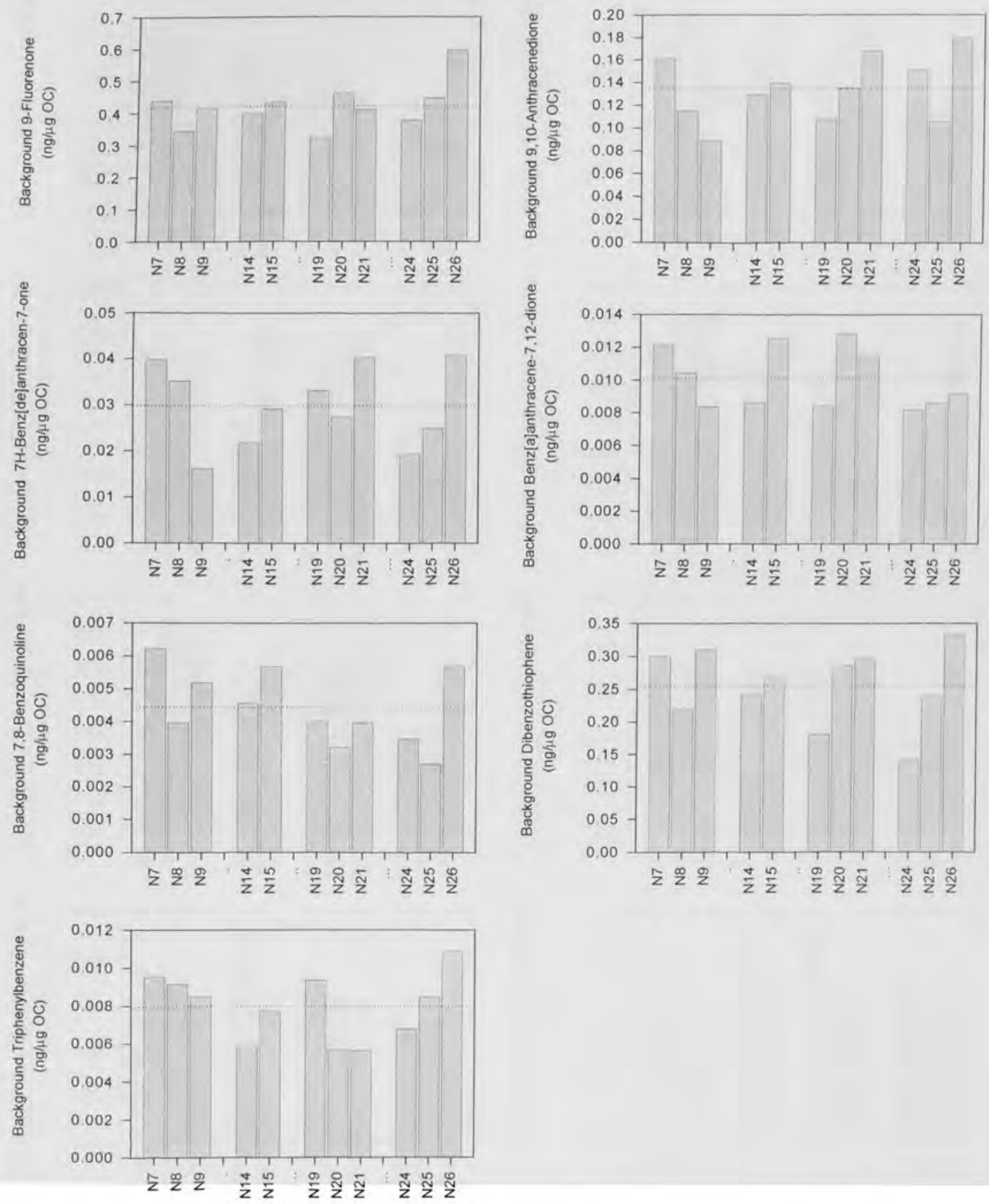

Figure C.17: Bar graphs showing the OC-normalized background concentration of individual hetero-polycyclic aromatic hydrocarbon (hetero-PAHs), and triphenylbenzene (TPB). That is, the minimum concentration observed of the compound in the given day, divided by the OC concentration measured concurrently. N=November days of 2002. Dotted line indicates the average. 


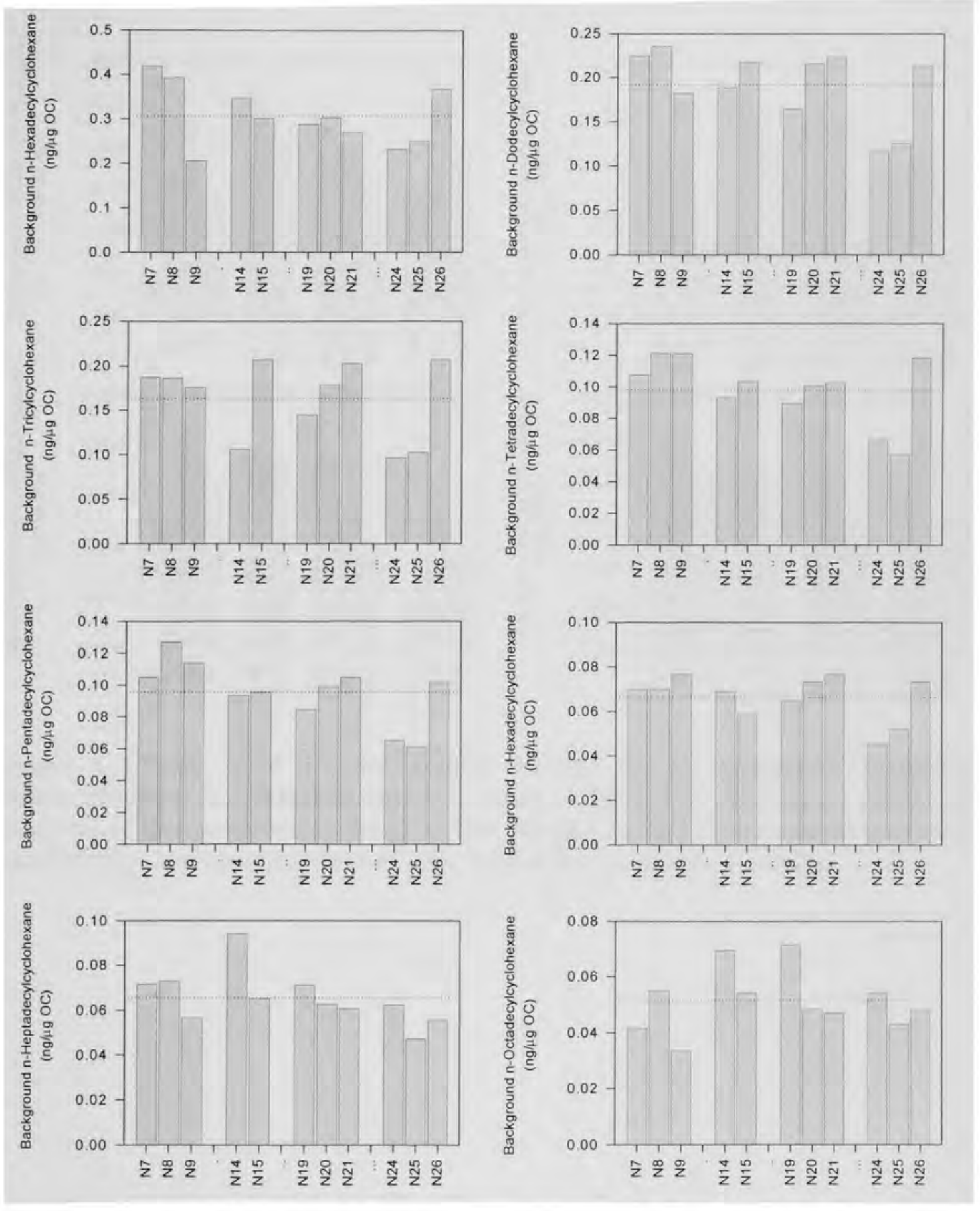

Figure C.18-part $\mathrm{i}$ of ii: Bar graphs showing the OC-normalized background concentration of individual $\mathrm{n}$-alkylcyclohexane. That is, the minimum concentration observed of the compound in the given day, divided by the OC concentration measured concurrently. N=November days of 2002. Dotted line indicates the average. (Figure continues in next page) 


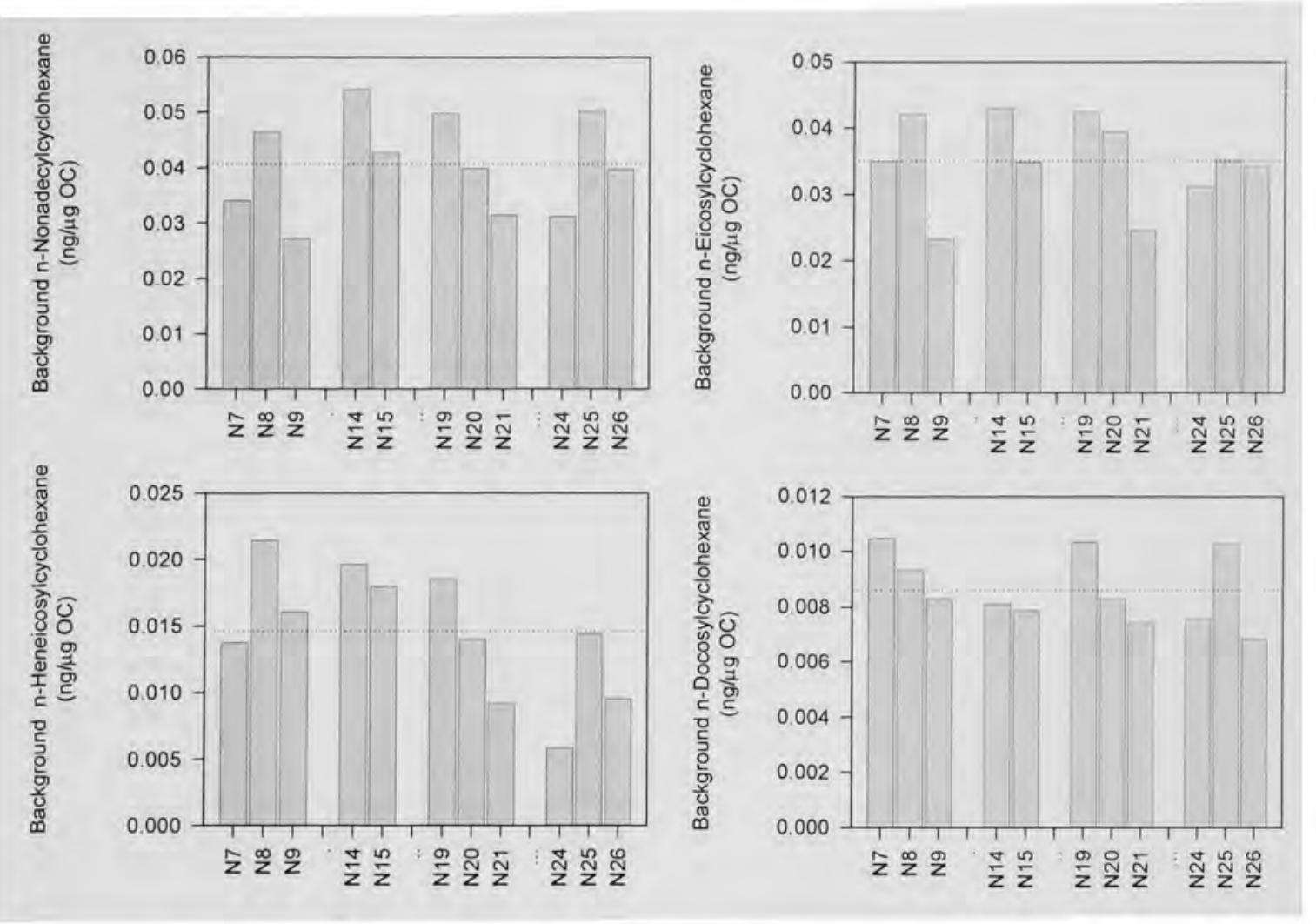

Figure C.18-part ii of ii: Bar graphs showing the OC-normalized background concentration of individual n-alkylcyclohexane. That is, the minimum concentration observed of the compound in the given day, divided by the $\mathrm{OC}$ concentration measured concurrently. $\mathrm{N}=$ November days of 2002 . Dotted line indicates the average. 


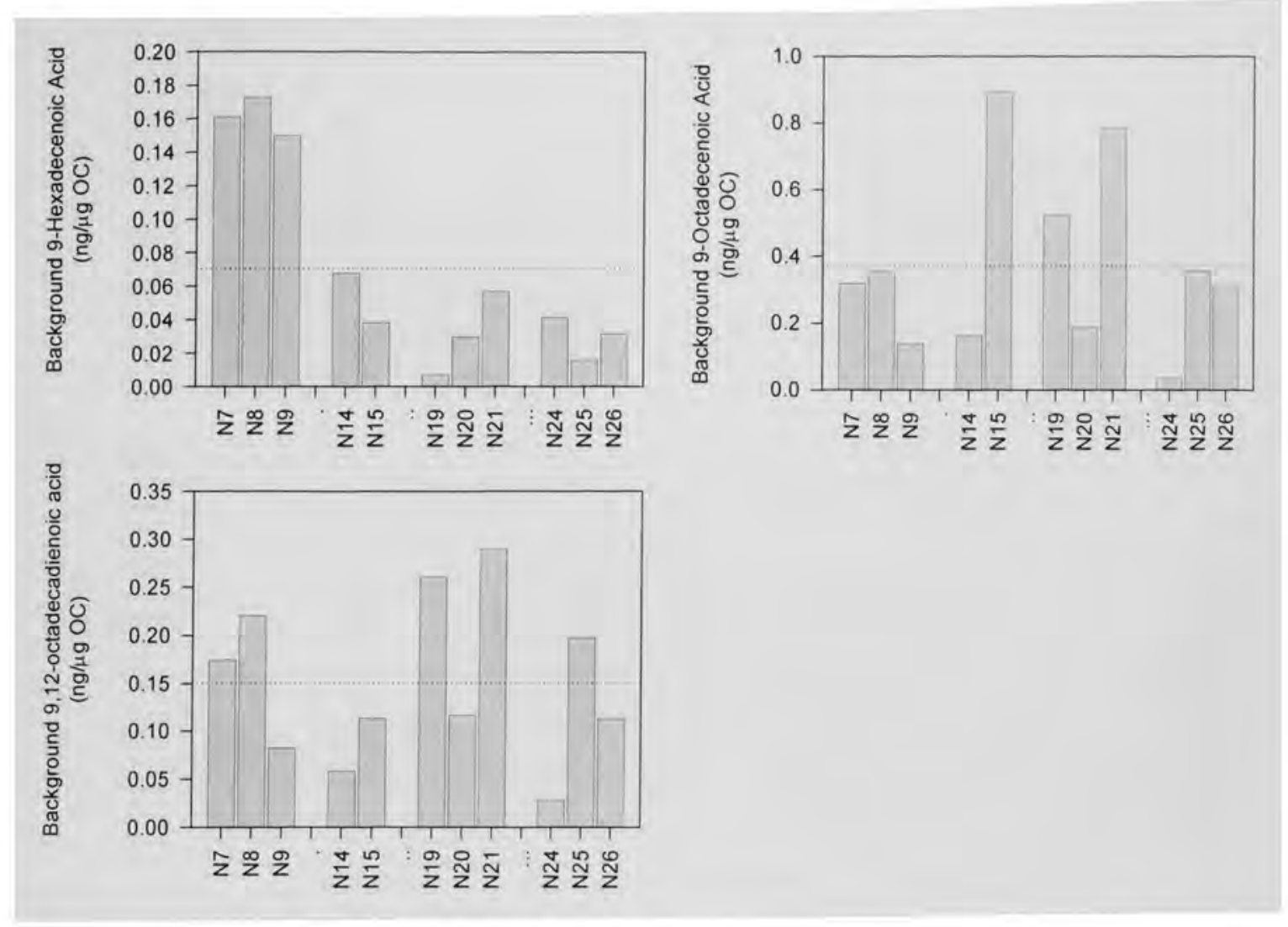

Figure C.19: Bar graphs showing the OC-normalized background concentration of individual n-alkenoic acid. That is, the minimum concentration observed of the compound in the given day, divided by the OC concentration measured concurrently. $\mathrm{N}=$ November days of 2002. Dotted line indicates the average. 


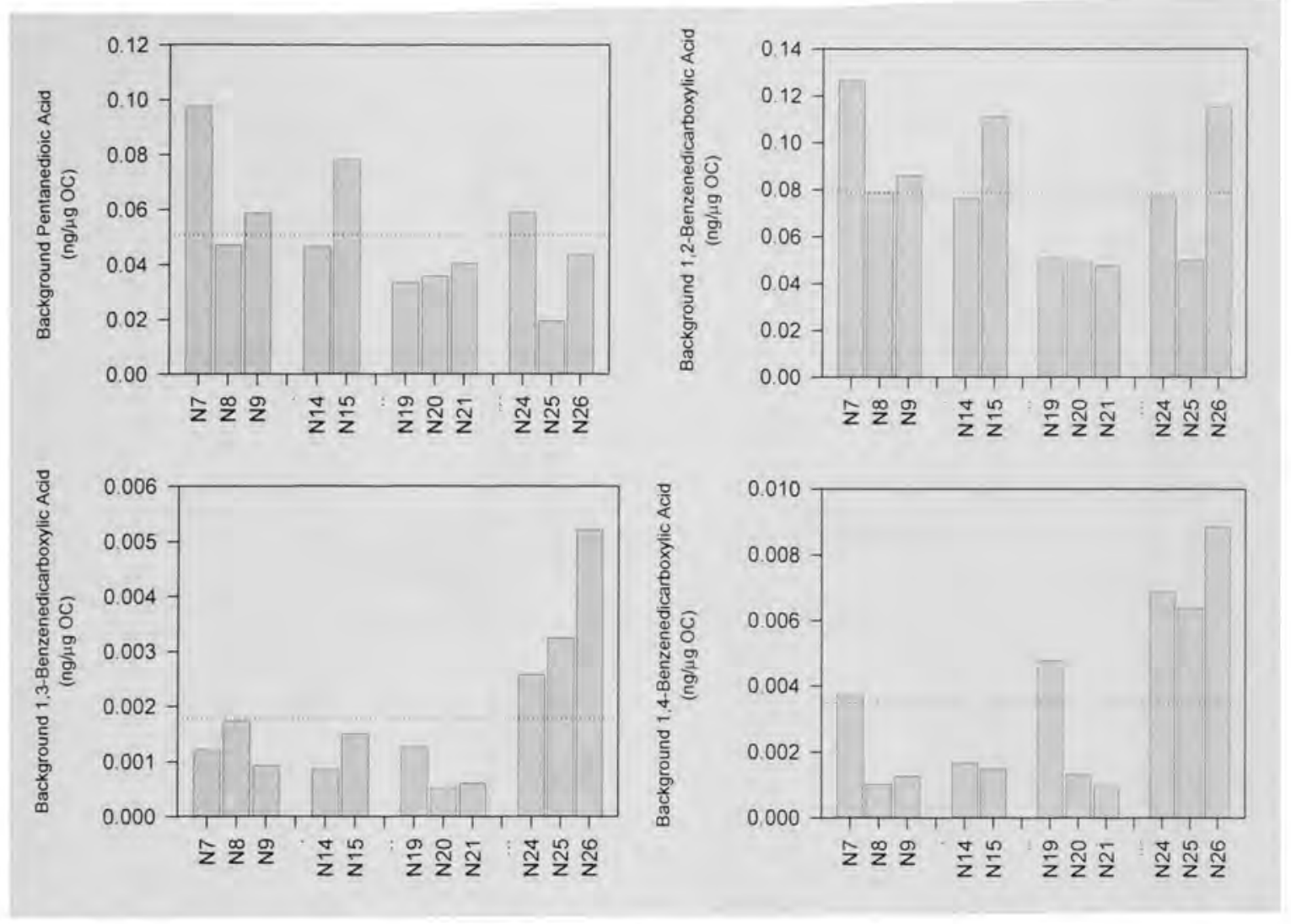

Figure C.20: Bar graphs showing the OC-normalized background concentration of individual aliphatic and aromatic dicarboxylic acid. That is, the minimum concentration observed of the compound in the given day, divided by the OC concentration measured concurrently. $\mathrm{N}=$ November days of 2002 . Dotted line indicates the average. 


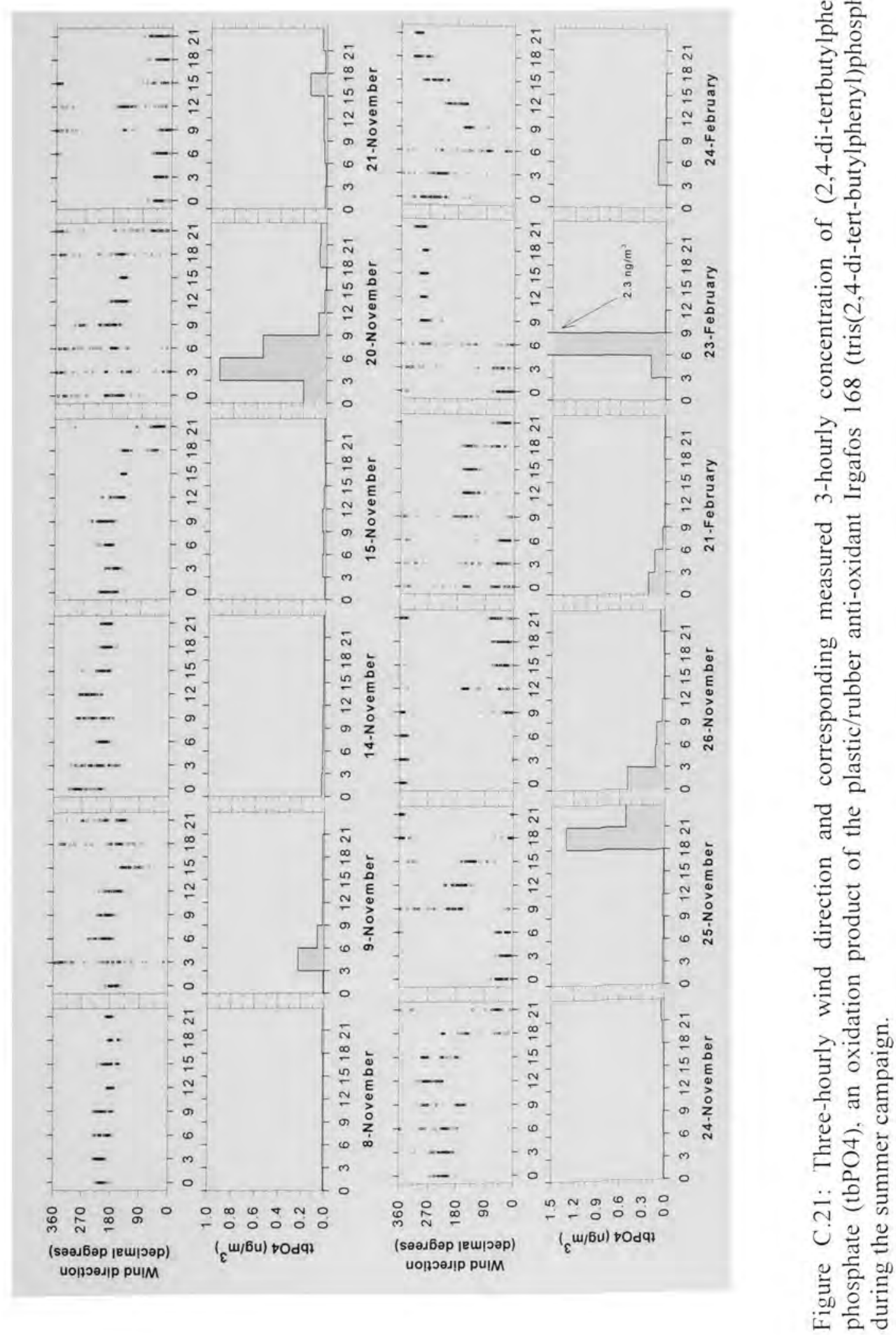




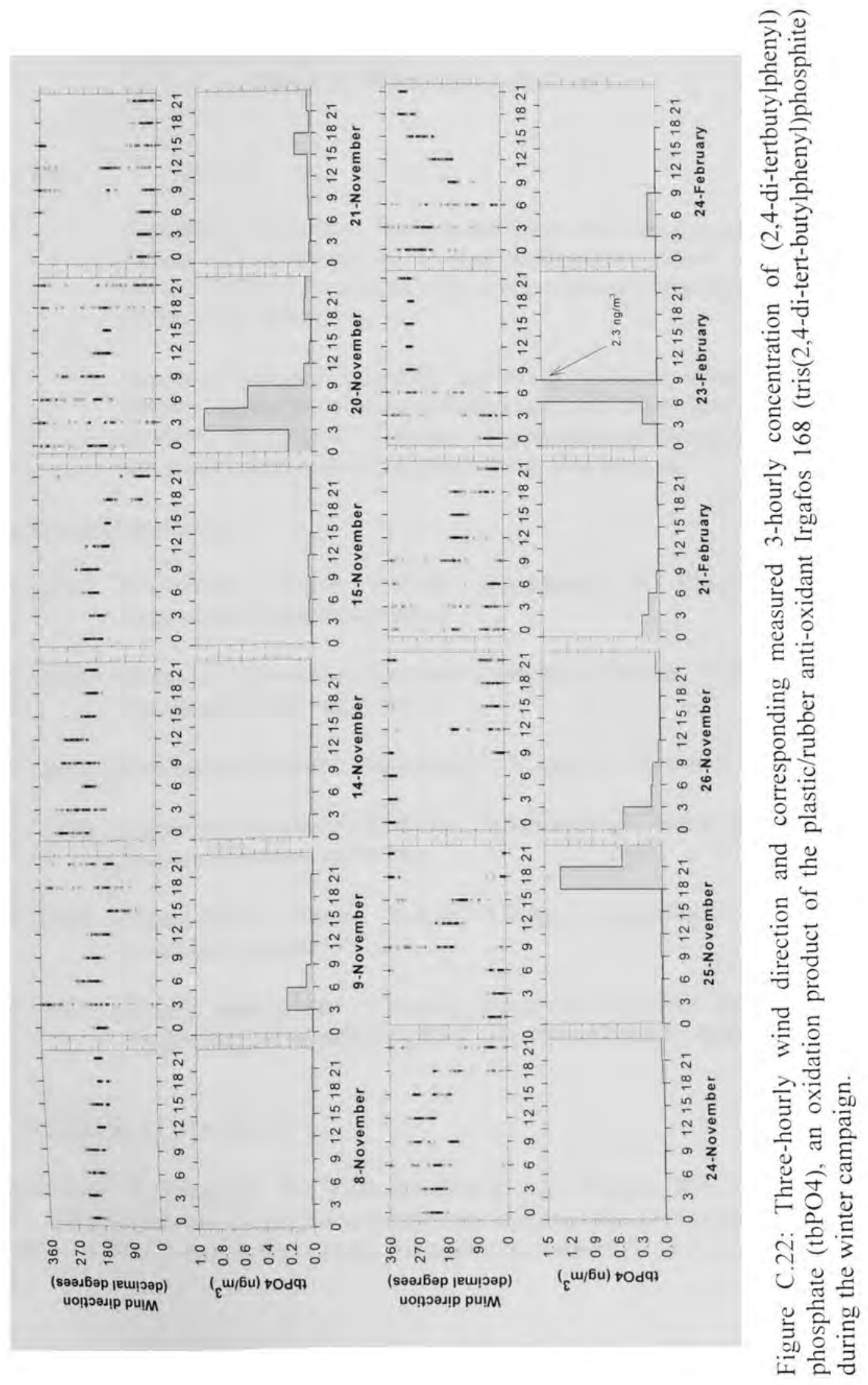


Education

1987 Licenciate (Chemistry), Universidad Simon Bolivar, Caracas, Venezuela Thesis: "Development of a high performance liquid chromatography (HPLC) method to elucidate the composition of commercial antioxidant packages for lubricating oils"

1993

Master of Science (Chemistry), University of Miami, Miami, FL, USA Thesis: "Cyclobis(paraquat-p-phenylene), and calix[6]arene derivatives as synthetic receptors for electron-rich aromatic compounds: electrochemical and spectroscopic studies of neurotransmitter binding"

Professional Experience

1983-1987 Universidad Simon Bolivar, Department of Chemistry, Caracas, Venezuela: Research Assistant.

1987 - 1989 Maraven, Venezuelan Petroleum Company Affiliate, Venezuela: Products Specifications Development.

1989 - 1993 University of Miami, Department of Chemistry: Research Assistant.

1993 - 1996 University of Miami, RSMAS, Department of Marine and Atmospheric Science: Research Associate.

1997 - 2003 Miami-Dade College, Kendall Campus, Department of Community Education: Adjunct Faculty.

2002 - 2007 Florida International University, Department of Civil and Environmental Engineering: Research Associate, Nontenure Faculty, Instructor.

\section{SELECTED PUBLICATIONS}

Subramanian, R., Donahue, N., Bernardo-Bricker, A., Rogge, W.F., Robinson, A.L., 2007. Insights into the primary-secondary and regional-local contributions to organic aerosol and PM2.5 mass in Pittsburgh, Pennsylvania, Atmospheric Environment 41 (35), 7414-7433. 
Robinson, A.L., Subramanian, R., Donahue, N., Bernardo-Bricker, A., Rogge, W.F., 2006. Source apportionment of molecular markers and organic aerosol - 1. Polycyclic aromatic hydrocarbons and methodology for data visualization. Environmental Science and Technology 40(24), 7803-7810.

Robinson, A.L., Subramanian, R., Donahue, N., Bernardo-Bricker, A., Rogge, W.F., 2006. Source apportionment of molecular markers and organic aerosol - 2. Biomass smoke. Environmental Science and Technology 40(24), 7811-7819.

Robinson, A.L., Subramanian, R., Donahue, N., Bernardo-Bricker, A., Rogge, W.F., 2006. Source apportionment of molecular markers and organic aerosol - 3. Food cooking emissions. Environmental Science and Technology 40(24), 7820-7827.

Bernardo-Bricker, A., Rogge, W.F., Robinson, A.L., Subramanian, R., Donahue, N.M., Source Profiles for Organic PM2.5 from Diesel Trucks and Gasoline Vehicles determined for the Squirrel Hill Tunnel in Pittsburgh, PA, in preparation.

Bernardo, A., Farmer, C., Milne, P., Riemer, D., Zika, R., Stoneking, C., Validation of speciated nonmethane hydrocarbon compounds data collected during the 1992 Atlanta intensive as part of the Southern Oxidants Study (SOS). Journal of the Air and Waste Management Association 1995, 45, 591-603.

Bernardo, A.R., Lu, T., Cordova, E., Zhang, L., Gokel, G.W., Kaifer, A.E., 1994. Hostguest complexation at the electrode/solution interface: the inclusion of an amphiphilic viologen guest by an amphiphilic calix[6]arene host. Journal of Chemical SocietyChemical Communications, 529-530.

Bernardo, A.R., Stoddart, J.F., Kaifer, A.E., 1992. Cyclobis(paraquat-p-phenylene) as a synthetic receptor for electron-rich aromatic compounds: electrochemical and spectroscopic studies of neurotransmitter binding, Journal of the American Chemical Society, 114, 10, 624-631.

Bernardo P., A., Zapata A.J,, deOteiza deGuerrero, M., 1988. Development of a method for the characterization of antioxidant packages for lubricants using HPLC. Revista Técnica de Intevep, 8(1), 59-68.

Awards

2007 Dissertation Year Fellowship. Florida International University

1989 - 1993 Full-Tuition Scholarship. Department of Chemistry. University of Miami

$1982-1988$ Scholarship. Association of University Women (VAAUW)

1987 - 1988 Scholarship. Intevep (Venezuelan Petroleum Research Institute) 